\title{
Energy Savings and Economics of Advanced Control Strategies for Packaged Air-Conditioning Units with Gas Heat
}

W Wang

S Katipamula
Y Huang

MR Brambley

December 2011

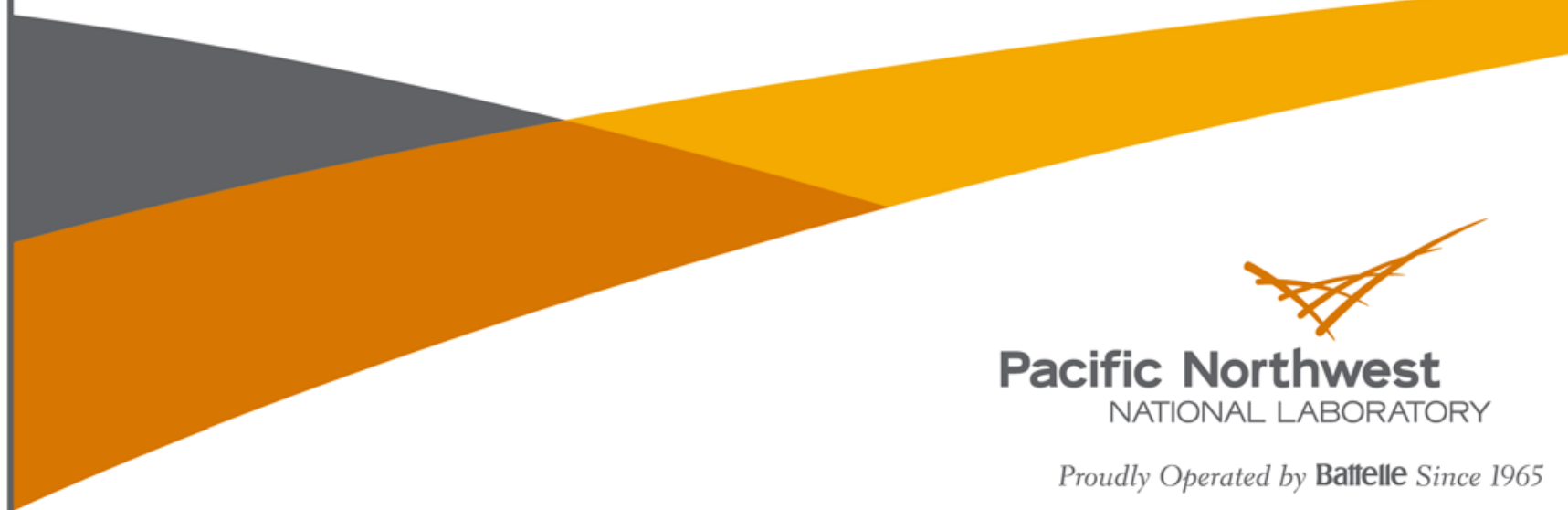




\title{
DISCLAIMER
}

This report was prepared as an account of work sponsored by an agency of the United States Government. Neither the United States Government nor any agency thereof, nor Battelle Memorial Institute, nor any of their employees, makes any warranty, express or implied, or assumes any legal liability or responsibility for the accuracy, completeness, or usefulness of any information, apparatus, product, or process disclosed, or represents that its use would not infringe privately owned rights. Reference herein to any specific commercial product, process, or service by trade name, trademark, manufacturer, or otherwise does not necessarily constitute or imply its endorsement, recommendation, or favoring by the United States Government or any agency thereof, or Battelle Memorial Institute. The views and opinions of authors expressed herein do not necessarily state or reflect those of the United States Government or any agency thereof.

\author{
PACIFIC NORTHWEST NATIONAL LABORATORY \\ operated by \\ BATTELLE \\ for the \\ UNITED STATES DEPARTMENT OF ENERGY \\ under Contract DE-AC05-76RL01830
}

Printed in the United States of America

Available to DOE and DOE contractors from the

Office of Scientific and Technical Information,

P.O. Box 62, Oak Ridge, TN 37831-0062;

ph: (865) 576-8401

fax: (865) 576-5728

email: reports@adonis.osti.gov

Available to the public from the National Technical Information Service, U.S. Department of Commerce, 5285 Port Royal Rd., Springfield, VA 22161 ph: (800) 553-6847 fax: (703) 605-6900

email: orders@ntis.fedworld.gov

online ordering: http://www.ntis.gov/ordering.htm

This document was printed on recycled paper. 
PNNL-20955

\title{
Energy Savings and Economics of Advanced Control Strategies for Packaged Air-Conditioning Units with Gas Heat
}

\author{
W Wang Y Huang \\ S Katipamula $\quad$ MR Brambley
}

December 2011

Prepared for

U.S. Department of Energy

under Contract DE-AC05-76RL01830

Pacific Northwest National Laboratory

Richland, Washington 99352 



\begin{abstract}
Packaged air-conditioners and heat pumps serve over $60 \%$ of the commercial building floor space in the U.S., contributing to about 230 trillion Btus of energy consumption annually. Therefore, even a small increase in operational efficiency of these units can lead to significant reductions in energy use and carbon emissions. Pacific Northwest National Laboratory, with funding from the U.S. Department of Energy’s (DOE’s) Building Technologies Program, evaluated a number of control strategies that can be implemented in a controller, which can be retrofit into an existing unit, to improve the operational efficiency of packaged heating, ventilation and air-conditioning (HVAC) equipment.
\end{abstract}

The results from detailed simulation analysis show significant energy (24\% to 35\%) and cost savings (38\%) from fan, cooling and heating energy consumption when packaged units are retrofitted with advanced control packages. The major findings include:

- Retrofitting packaged HVAC units with the most energy-efficient package controls option considered (integrated differential enthalpy economizer, multi-speed supply fan, two-stage capacity control and demand-controlled ventilation [DCV]) relative to a base case with no economizer and a constant speed supply fan, results in average HVAC energy savings (electricity for cooling and fan and gas for heating) across 16 locations in 15 climate zones of about 35\% for three building types (small office, stand-alone retail, strip mall) and 24\% for supermarkets.

- For the most energy efficient controls package considered, average HVAC cost savings are $46 \%, 43 \%$, 35\%, and 24\%, respectively, for the small office, retail, strip mall and supermarket buildings.

- $\quad$ Retrofitting packaged HVAC units with a modified (less aggressive) energy efficient controls package option (integrated differential dry-bulb economizer, multi-speed supply fan, singlestage capacity control and DCV) relative to modified base case with integrated differential dry-bulb economizer, constant speed supply fan and single-stage capacity control, results in average HVAC energy savings of about $28 \%$ for the small office building, $32 \%$ for the standalone retail and strip mall buildings, and $24 \%$ for the supermarket.

- For the modified packaged control option, average HVAC energy cost savings are 38\% for all four building types.

- The maximum controller cost that will provide payback periods of no more than 3 years for all U.S. locations under current utility rates are \$2103 per controller for stand-alone retail, strip mall and supermarket buildings and between \$540 and \$1350 for small office buildings. The precise value depends on the number of square feet of floor space per controller (1100 and $2750 \mathrm{ft}^{2}$, respectively, for the small office building costs given).

- Individual control strategies have different degrees of impact on energy and cost savings. The simulation results indicate that multi-speed fan control and DCV are the two control strategies contributing most of the savings. In many cases, multi-speed fan control dominates the impact in hot and mild climates (e.g., Miami and Los Angeles), while DCV dominates the impact in climates with significant heating and cooling loads (e.g., Baltimore) and cold climates (e.g., Seattle, Chicago and Duluth). 
Even if one-half of the packaged HVAC units are retrofitted with the modified control package option, it will result in annual savings of approximately 55 trillion Btus (assuming the percent savings are $30 \%$ ). The energy savings are equivalent to removing over 16 coal-powered (200 MW each) power plants. 


\section{Executive Summary}

Packaged cooling equipment is used in $46 \%$ of all commercial buildings, serving over $60 \%$ of the commercial building floor space in the U.S. (EIA 2003). The site cooling energy consumption associated with packaged cooling equipment is about 160 trillion Btus annually (EIA 2003). Packaged heat pumps account for an additional 70 trillion Btus annually (EIA 2003). Therefore, even a small increase in the efficiency of part-load operation of these units can lead to significant reductions in energy use and carbon emissions. Pacific Northwest National Laboratory (PNNL), with funding from the U.S. Department of Energy's (DOE's) Building Technologies Program (BTP), evaluated a number of control strategies that can be implemented in a controller, which can be retrofit into existing units, to improve the operational efficiency of packaged air conditioning units.

The two primary objectives of this research project are to: 1) determine the magnitude of energy and cost savings achievable by retrofitting existing packaged air-conditioning units with advanced control strategies not ordinarily used for packaged units and 2) estimate the maximum installed cost of a replacement controller with the desired features in various regions of the U.S. to provide acceptable payback periods to owners.

Many local building codes require that the supply fan on packaged units operates continuously while a building is occupied to meet the ventilation needs, irrespective of whether the unit is providing cooling or heating. A significant portion of the packaged units in the field (over 90\%) have constant speed supply fans. Because the fan is on continuously (and the compressor only intermittently under most conditions), in many locations in the U.S., the fan energy consumption can be greater than the compressor energy consumption). It is not uncommon to see packaged units in ventilation mode for $40 \%$ to $60 \%$ of the time in any climate.

Packaged equipment with a constant speed supply fan is designed to provide ventilation at the design ventilation rate at all times when the fan is operating. Although there are a number of hours during the day when a building may not be fully occupied or the need for ventilation is lower than designed, the ventilation rate cannot be adjusted easily with a constant speed fan. Studies have shown that demand-based ventilation control can save significant energy in climates that are not favorable for economizing. Traditional demand controlled ventilation (DCV) strategies modulate the outdoor-air damper to reduce the rate at which outdoor air enters the unit and the associated energy needed to condition that air (Brandemuel and Braun 1999; Roth et. al. 2003; Stanke 2006). This strategy reduces cooling or heating energy use, but the supply fan still runs at full speed even in the ventilation mode.

When the unit is in ventilation mode, the role of the supply fan is to provide fresh air to maintain proper indoor-air quality in the spaces that it serves. Therefore, modulating the supply-fan speed in conjunction with DCV not only reduces the cooling and heating energy requirements but also reduces the fan energy use.

\section{Analytic Approach}

As noted earlier, the two main objectives for this study are to estimate energy and cost savings from use of advanced controls on packaged units and to estimate the maximum installed cost of the controller that will yield generally acceptable payback periods based on the energy savings and prices of electricity and gas. Only packaged rooftop air conditioners with direct expansion 
cooling and gas furnace heating are considered in this study. The analysis approach used is as follows: specify advanced control options, create packages of advanced control options, select representative buildings that predominately use packaged units, simulate the energy performance of the selected buildings in U.S. climate zones, determine energy savings associated with changing from initial control packages to more advanced controls, and conduct the economic analysis. Although the control options selected apply equally to both air conditioners and heat pumps, the results presented in this report are limited to packaged air conditioners with gas heating.

The energy savings are estimated based on detailed EnergyPlus (DOE 2010) simulations. Twenty-two combinations of advanced control strategies are simulated in each of 4 building types in 16 climate zones.

\section{Control Sequence of Operation for Packaged Air Conditioners with Gas Heating}

There are a number of control options that can be added to packaged units including: air-side economizer, supply-fan speed control, cooling-capacity control, and demand-controlled ventilation. For this study, all four control options are evaluated in terms of their impact on energy and cost savings for packaged single-zone air-conditioning systems with gas heating as compared to a base case. These base case the control options are analyzed individually as well as in combinations of one or more options.

\section{Building Prototypes}

For this study, four prototype buildings that predominately use packaged heating and cooling units are chosen from the DOE's post-1980 commercial reference building models (Deru et al. 2011): small office, stand-alone retail, strip mall, and supermarket. The post-1980 reference building models are developed to represent existing buildings constructed in or after 1980. They are widely used for DOE commercial building research to assess new technologies. Significant changes were made to the reference models to simulate the various control strategies that were evaluated using the EnergyPlus energy management controls module.

\section{Methodology}

To estimate the energy consumption of a prototype building with the baseline rooftop control option and a modified prototype with advanced packaged unit control options, a detailed simulation model is needed. An EnergyPlus model with energy management feature was used to simulate the buildings and the various control options for the package units in four different prototype buildings resulting in 1,408 simulation runs.

For each simulation, EnergyPlus provides estimates of fan electricity energy consumption, cooling electricity energy consumption, heating gas energy consumption and total energy consumption. The total energy consumption is the sum of all three end-uses in consistent units. Energy cost is simply calculated as a product of the utility rates and the annual energy consumption. The total energy cost is the sum of the both gas and electricity costs.

\section{Energy Savings Results for Various Control Combinations}

Only heating, ventilation and air-conditioning (HVAC) energy uses are considered in estimating the energy and cost savings, because the investigated control strategies do not affect the energy 
use for lighting, plug loads and service hot water. The total annual HVAC energy consumption, which is simply the sum of the gas energy use for heating and the electrical energy use for cooling and fan operation, lies between 90 and 420 million Btus/y per building for the small office building, 640 and 5,610 million Btus/y for the stand-alone retail building, 700 and 5,590 million Btus/y for the strip mall, and 1,310 and 13,920 million Btus/y for the supermarket building. After normalization with the building area, the HVAC energy use intensity for the four building types is in the following ranges: 17 through $82 \mathrm{kBtu} / \mathrm{ft}^{2} / \mathrm{yr}$ for the small office building, 26 through $227 \mathrm{kBtu} / \mathrm{ft}^{2} / \mathrm{yr}$ for the stand-alone retail building, 31 through $248 \mathrm{kBtu} / \mathrm{ft}^{2} / \mathrm{yr}$ for the strip mall, and 29 through $287 \mathrm{kBtu} / \mathrm{ft}^{2} / \mathrm{yr}$ for the supermarket.

For the baseline case (no economizer, constant speed supply fan and single-stage compressor), when the air conditioning unit with gas furnace is on, it operates in one of the three operating modes: ventilation mode, cooling mode or heating mode. The simulation results indicate that packaged single-zone rooftop units operate in the ventilation mode for more than $50 \%$ of their run time. The units in the hot climates have the lowest percentage of time in the ventilation mode, while the mild climates such as Los Angeles and San Francisco have the highest percentage of time in the ventilation mode. The percentage of time the unit is in the cooling mode ranges between $4 \%$ and $40 \%$. The percentage of time the unit is in the heating mode lies in the range from less than $1 \%$ to about $12 \%$ for the small office building. For other building types it is about $20 \%$.

The most energy efficient combination of control strategies investigated includes a multi-speed supply fan control, demand-controlled ventilation, two-stage compressor control and integrated differential enthalpy economizer control. Figure ES 1 depicts the percentage reductions of HVAC energy use (gas for heating and electricity for cooling and fan) for the most energy efficient control option considered by climate zone and location, while Table ES 1 summarizes the energy savings including maximum, minimum and average savings. The key findings include:

1. The range of energy savings, by building type, is between $22 \%$ and $56 \%$ for the small office building, $25 \%$ and $47 \%$ for the stand-alone retail building, $24 \%$ and $46 \%$ for the strip mall, and $16 \%$ and $47 \%$ for the supermarket.

2. The average of the HVAC energy savings across the 16 locations is about $35 \%$ for the small office building, the stand-alone retail building, and the strip mall, and $24 \%$ for the supermarket.

3. The maximum HVAC energy savings as a percentage of the pre-retrofit HVAC energy use occurs in Los Angeles for the small office, retail and strip mall building types, while it occurs in Miami for the supermarket.

4. The minimum percentage savings occurs in Fairbanks for all four building types. 


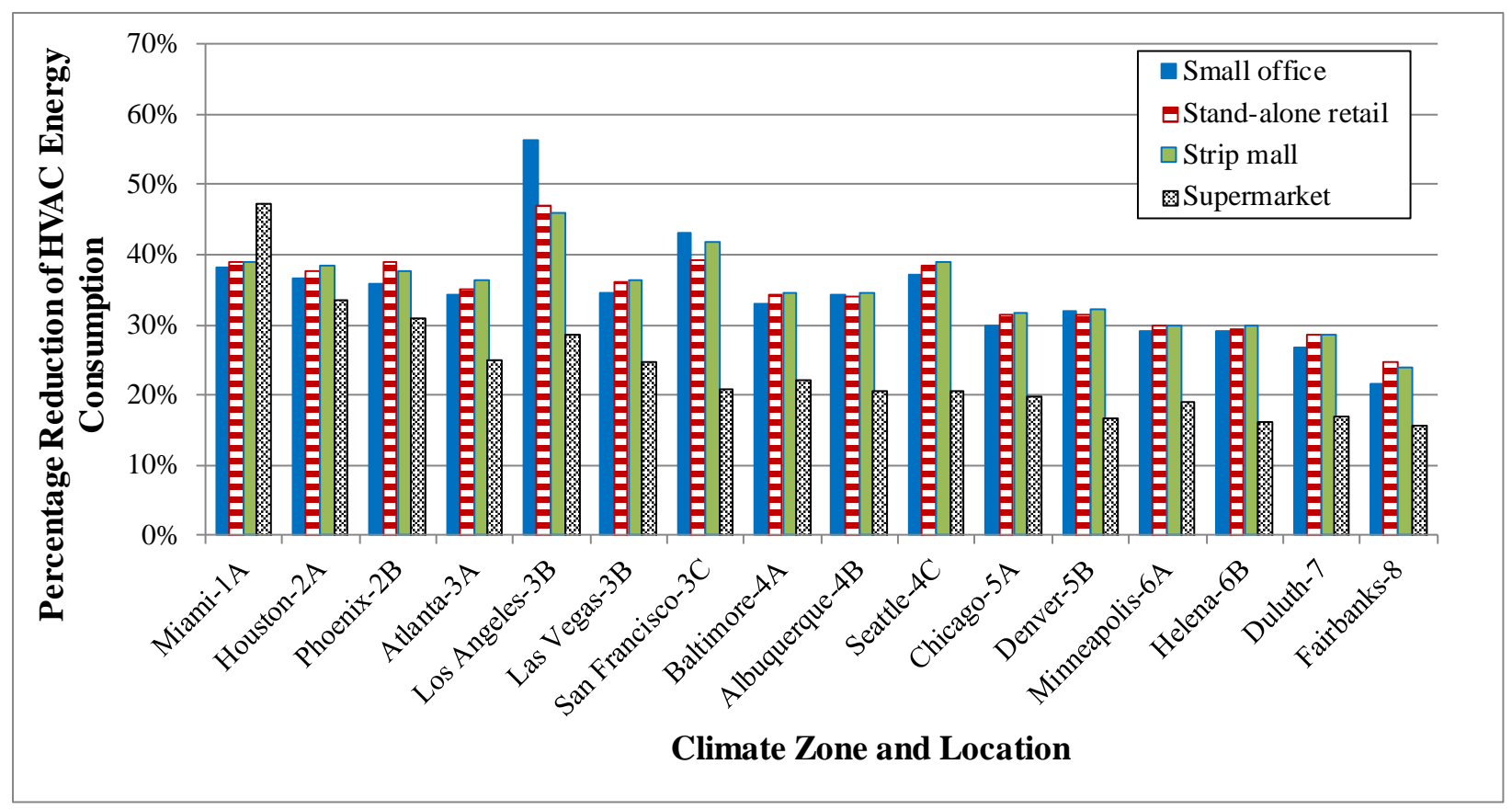

Figure ES 1: HVAC Energy Savings from Retrofit Installation of the Most Energy Efficient Control Package Considered (integrated differential enthalpy economizer, multi-speed supply fan, two-stage capacity control, and DCV) relative to and as a percentage of the HVAC Energy Use of the Base Case (no economizer and constant speed supply fan) for Four Building Types at all Locations Examined 
Table ES 1: Summary of HVAC Energy Savings for from Replacing Controllers with No Economizers or Other Advanced Controls with the Most Energy Efficient Control Package Considered Having Integrated Dry-bulb Economizers, Multi-speed Supply-Fan Controls, Two-stage Capacity Controls and DCV

\begin{tabular}{|l|c|c|c|c|}
\hline 8 & \multicolumn{5}{|c|}{ Building Type } \\
\hline $\begin{array}{l}\text { Monstruction area (ft') } \\
\text { Maximum percentage }\end{array}$ & 5500 & 25000 & 22500 & 45000 \\
\hline $\begin{array}{l}\text { Lovings } \\
\text { percention for maximum savings }\end{array}$ & Los Angeles & Los Angeles & Los Angeles & Miami \\
\hline $\begin{array}{l}\text { Minimum percentage } \\
\text { savings }\end{array}$ & $22 \%$ & $25 \%$ & $24 \%$ & $16 \%$ \\
\hline $\begin{array}{l}\text { Location for minimum } \\
\text { percentage savings }\end{array}$ & Fairbanks & Fairbanks & Fairbanks & Fairbanks \\
\hline $\begin{array}{l}\text { Average percentage } \\
\text { savings }\end{array}$ & $35 \%$ & $35 \%$ & $35 \%$ & $24 \%$ \\
\hline $\begin{array}{l}\text { Maximum absolute } \\
\text { savings (MMBtu/yr) }\end{array}$ & 97 & 1388 & 1333 & 2029 \\
\hline $\begin{array}{l}\text { Location for maximum } \\
\text { absolute savings }\end{array}$ & Fairbanks & Fairbanks & Fairbanks & Fairbanks \\
\hline $\begin{array}{l}\text { Minimum absolute } \\
\text { savings (MMBtu/yr) }\end{array}$ & 40 & 300 & 324 & 582 \\
\hline $\begin{array}{l}\text { Location for minimum } \\
\text { absolute savings }\end{array}$ & $\begin{array}{c}\text { San } \\
\text { Francisco }\end{array}$ & Los Angeles & Los Angeles & Los Angeles \\
\hline $\begin{array}{l}\text { Average absolute } \\
\text { savings (MMBtu/yr) }\end{array}$ & 59 & 609 & 608 & 1010 \\
\hline
\end{tabular}

Another possible controls combination is use of a multi-speed supply fan, demand-controlled ventilation, single-stage compressor control and integrated differential dry-bulb economizer control. It is less expensive to convert a supply fan to multi-speed or variable-speed than to convert the compressor to a multi-speed or variable-speed compression. Because many of the existing units may have economizer controls, a more common advanced controls retrofit would likely be conversion of a unit with constant-speed supply fan, single-stage compressor and an integrated dry-bulb economizer to multi-speed supply-fan control and demand control ventilation, keeping single-stage compressor and integrated dry-bulb economizer controls.

Figure ES 2 depicts the percentage reductions of HVAC energy use (gas for heating and electricity for cooling and fan) for the modified control package option by climate zone and location, while Table ES 2 summarizes the energy savings including maximum, minimum and average savings. 
1. The range of HVAC energy savings, by building type, is between $20 \%$ and $42 \%$ for the small office building, $23 \%$ and $40 \%$ for the stand-alone retail building, $21 \%$ and $40 \%$ for the strip mall, and $14 \%$ and $41 \%$ for the supermarket.

2. The average HVAC energy savings across 16 locations is about $28 \%$ for the small office building, 32\% for the stand-alone retail and strip mall buildings, and $24 \%$ for the supermarket.

3. The maximum HVAC energy saving as a percentage of the pre-retrofit energy consumption occurs in Los Angeles for the small office building and the retail building, in San Francisco for the strip mall, and in Miami for the supermarket.

4. The minimum percentage savings occur in Fairbanks for all four building types.

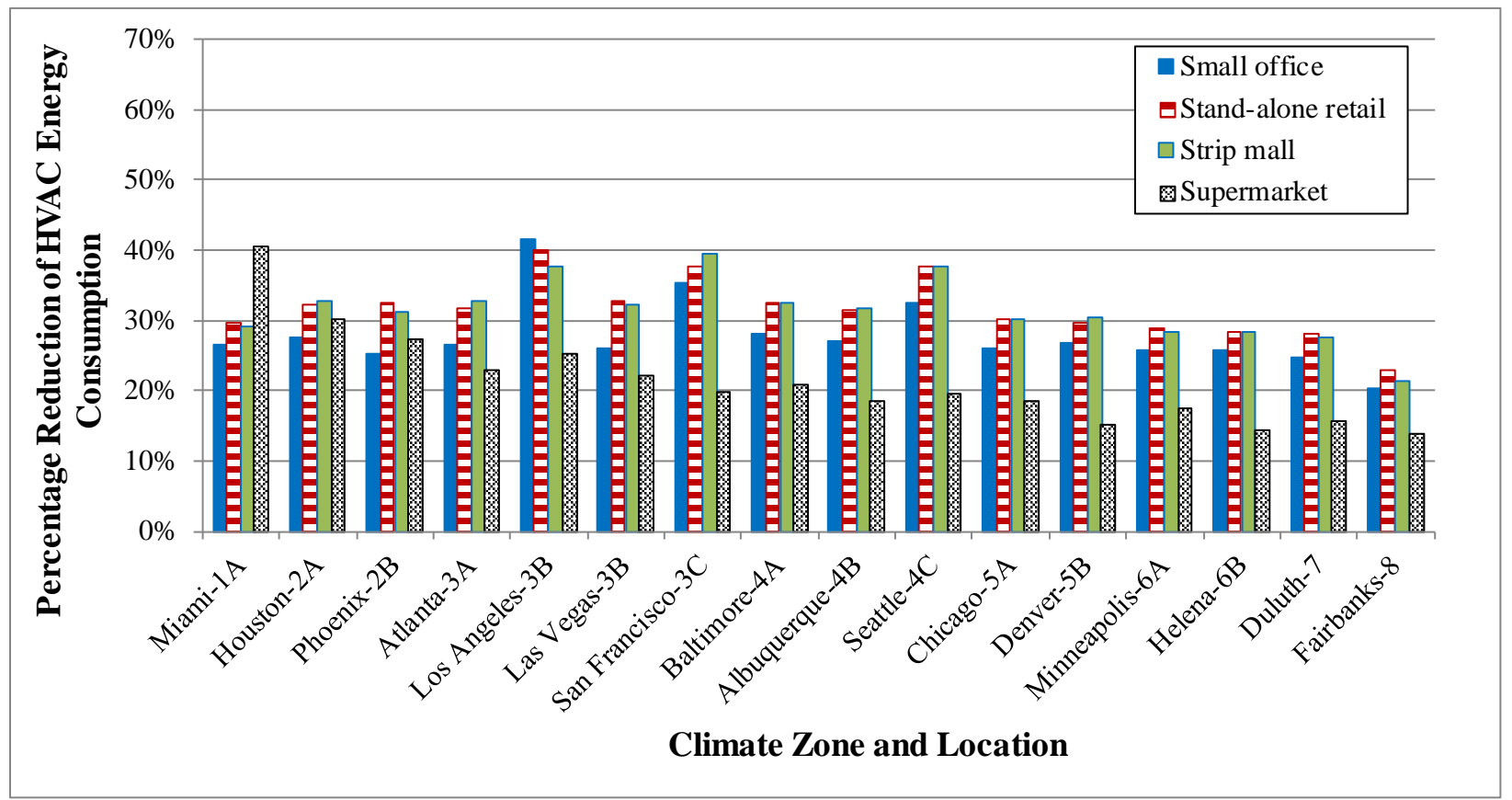

Figure ES 2: HVAC Energy Savings from Retrofit Installation of the Control Package using an Integrated Dry-bulb Economizer, Multi-Speed Supply Fan, Single-stage Capacity Control, and DCV relative to and as a percentage of the HVAC Energy Use of the Modified Base Case, which has an Integrated Dry-bulb Economizer, Constant-speed Supply Fan and Single-stage Capacity Control for Four Building Types at all Locations Examined 
Table ES 2: Summary of HVAC Energy Savings from Replacing Modified Base Case Control Packages Having Integrated Dry-bulb Economizers, Constant-speed Supply-Fan Controls and Single-stage Capacity Controls with Controllers Having Integrated Dry-bulb Economizers, Multi-speed Supply-Fan Controls, Single-stage Capacity Controls and DCV

\begin{tabular}{|c|c|c|c|c|}
\hline 88888888888888 & & Building & Гуре & \\
\hline 80808008080808008 & Small office & Stand-alone retail & Strip mall & Supermarket \\
\hline Construction area $\left(\mathrm{ft}^{2}\right)$ & 5500 & 25000 & 22500 & 45000 \\
\hline $\begin{array}{l}\text { Maximum percentage } \\
\text { savings }\end{array}$ & $42 \%$ & $40 \%$ & $40 \%$ & $41 \%$ \\
\hline $\begin{array}{l}\text { Location for maximum } \\
\text { percentage savings }\end{array}$ & Los Angeles & Los Angeles & $\begin{array}{c}\text { San } \\
\text { Francisco }\end{array}$ & Miami \\
\hline $\begin{array}{l}\text { Minimum percentage } \\
\text { savings }\end{array}$ & $20 \%$ & $23 \%$ & $21 \%$ & $14 \%$ \\
\hline $\begin{array}{l}\text { Location for minimum } \\
\text { percentage savings }\end{array}$ & Fairbanks & Fairbanks & Fairbanks & Fairbanks \\
\hline $\begin{array}{l}\text { Average percentage } \\
\text { savings }\end{array}$ & $28 \%$ & $32 \%$ & $32 \%$ & $22 \%$ \\
\hline $\begin{array}{l}\text { Maximum absolute } \\
\text { savings (MMBtu/yr) }\end{array}$ & 91 & 1268 & 1165 & 1770 \\
\hline $\begin{array}{l}\text { Location for maximum } \\
\text { absolute savings }\end{array}$ & Fairbanks & Fairbanks & Fairbanks & Fairbanks \\
\hline $\begin{array}{l}\text { Minimum absolute } \\
\text { savings (MMBtu/yr) }\end{array}$ & 29 & 232 & 237 & 500 \\
\hline $\begin{array}{l}\text { Location for minimum } \\
\text { absolute savings }\end{array}$ & $\begin{array}{c}\text { San } \\
\text { Francisco }\end{array}$ & Los Angeles & Los Angeles & Los Angeles \\
\hline $\begin{array}{l}\text { Average absolute } \\
\text { savings (MMBtu/yr) }\end{array}$ & 46 & 560 & 547 & 906 \\
\hline
\end{tabular}

In addition to the most energy efficient control package considered, the impacts of the control strategies individually and in combinations were evaluated. Some of the result highlights include:

- Use of the air-side economizer potentially saves more energy in warm and dry climates than in other climates, and the savings vary with building types, with the small office building having the highest percent savings.

- The percentage HVAC energy savings from the use of an air-side economizer decreases if the fan speed control changes from constant speed to multiple speed.

- Switching from nonintegrated economizer controls to integrated economizer controls provide small incremental energy savings.

- Use of multi-speed fan control leads to about 15\% reduction in HVAC energy in Miami and Los Angeles, which are representative of hot-humid and warm-dry climates. 
However, the multi-speed fan control usually increases HVAC energy consumption in Chicago and Duluth, which are representative of cold climates. Although there is a reduction in fan energy consumption, which decreases the heat gains from the fan, the heating energy consumption increases in cold climates to compensate for the reduced fan heat gains. Despite this increase in heating energy consumption for cold climates, multispeed fan control leads to a cost savings even in the cold climates because electricity prices are generally higher than gas prices.

- The impact of multi-speed fan control on energy consumption varies with building type. In Miami, the supermarket has the largest percentage (27\%) energy savings while the other three building types show between 15\% and 20\% HVAC energy savings relative to the base case. In Los Angeles, the percentage HVAC energy savings from multi-speed fan control decreases in the sequence of small office building (35\%), stand-alone retail building (17\%), strip mall (16\%), and supermarket (5\%).

- DCV contributes to more than $10 \%$ of HVAC energy savings in all cases except for the small office building in Miami and Los Angeles. The largest percentage (35\%) energy savings occurs in Seattle for the stand-alone retail building and the strip mall. DCV is more effective in heating-dominated climates.

- Changing the unit from single-stage to two-stage compressor controls can yield about 9\% savings in hot climates, primarily from a reduction in cooling energy consumption.

- Multi-speed fan control and DCV are the two control strategies that dominate the impact on HVAC energy savings. Specifically, multi-speed fan control dominates the impact in hot climates (e.g., Miami) while DCV dominates the impact in cold climates (Seattle, Chicago, and Duluth).

- Adding an air-side economizer after adding multi-speed fan control does not have a large impact on HVAC energy savings except for a few cases, such as the small office building in Los Angeles.

- Both multi-speed supply fan control and air-side economizers have noticeable contributions to annual cooling energy savings. In particular, their combinations lead to more than $80 \%$ cooling energy savings in Los Angeles, Seattle, and Duluth.

\section{Economic Analysis}

In addition to the energy savings, PNNL estimated the energy cost savings from different combinations of control strategies. Furthermore, using the energy cost savings, the maximum installed cost for the add-on controller to achieve specific simple payback periods is determined for selected utility rates.

The energy cost savings for the most energy efficient control package option considered are shown in Figure ES 3 and Table ES 3. The key findings include:

1. The HVAC energy cost savings as a percentage of the base case energy consumption, which corresponds to a unit with no economizer or other advanced control features, from adding the most energy efficient control combination considered (having an integrated differential enthalpy economizer, multi-speed supply fan control, two-speed compressor control, and DCV) lies between 38\% and 67\% for the small office building, 36\% and 
$60 \%$ for the stand-alone retail building, 36\% and 59\% for the strip mall, and $28 \%$ and $55 \%$ for the supermarket.

2. The average HVAC energy cost savings are $46 \%, 43 \%, 35 \%$, and $24 \%$, respectively, for the small office, retail, strip mall and supermarket buildings.

3. The maximum percentage HVAC energy cost savings occur in San Francisco for the small office building and in Los Angeles for the other three building types.

The minimum percentage of savings occurs in Miami for the small office building, in Fairbanks for the two retail buildings, and in Seattle for the supermarket.

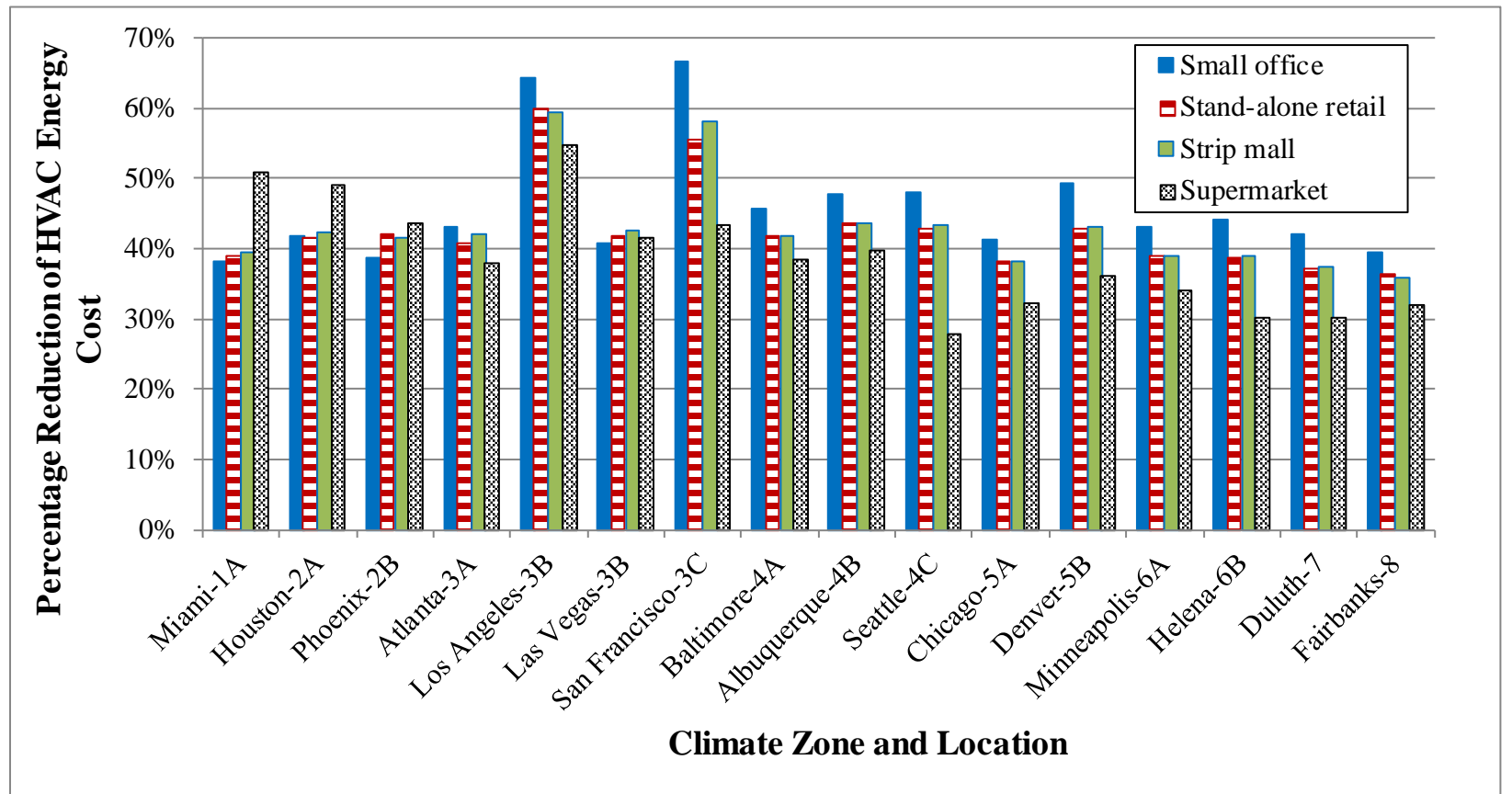

Figure ES 3: HVAC Energy Cost Savings from use of the Most Energy Efficient Control Package Considered (integrated differential enthalpy economizer, multi-speed supply-fan control, two-stage capacity [compressor-motor speed] control and DCV) relative to and as a percentage of the Base Case (no economizer and constant speed supply fan) HVAC energy use for Four Building Types at All Locations Examined 
Table ES 3: Summary of Energy Cost Savings from Replacing Controllers with No Economizers or Other Advanced Controls with the Most Energy Efficient Control Package Considered Having Integrated Dry-bulb Economizers, Multi-speed Supply-Fan Controls, Two-stage Capacity Controls and DCV

\begin{tabular}{|c|c|c|c|c|}
\hline 80880808808808808 & & Buildi & Туре & \\
\hline 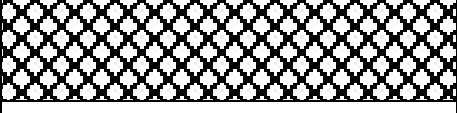 & Small Office & $\begin{array}{l}\text { Stand-alone } \\
\text { Retail }\end{array}$ & Strip Mall & Supermarket \\
\hline Construction area $\left(\mathrm{ft}^{2}\right)$ & 5500 & 25000 & 22500 & 45000 \\
\hline Maximum savings & $67 \%$ & $60 \%$ & $59 \%$ & $55 \%$ \\
\hline $\begin{array}{l}\text { Location for maximum } \\
\text { savings }\end{array}$ & San Francisco & Los Angeles & Los Angeles & Los Angeles \\
\hline Minimum savings & $38 \%$ & $36 \%$ & $36 \%$ & $28 \%$ \\
\hline $\begin{array}{l}\text { Location for minimum } \\
\text { savings }\end{array}$ & Miami & Fairbanks & Fairbanks & Seattle \\
\hline Average savings & $46 \%$ & $43 \%$ & $43 \%$ & $39 \%$ \\
\hline $\begin{array}{l}\text { Maximum absolute } \\
\text { savings }(\$ / y r)\end{array}$ & 2393 & 23779 & 23414 & 52217 \\
\hline $\begin{array}{l}\text { Location for maximum } \\
\text { absolute savings }\end{array}$ & Fairbanks & Fairbanks & Fairbanks & Fairbanks \\
\hline $\begin{array}{l}\text { Minimum absolute } \\
\text { savings }(\$ / y r)\end{array}$ & 923 & 7,864 & 7,633 & 16,087 \\
\hline $\begin{array}{l}\text { Location for minimum } \\
\text { absolute savings }\end{array}$ & Seattle & Albuquerque & Albuquerque & Seattle \\
\hline $\begin{array}{l}\text { Average absolute } \\
\text { savings }(\$ / y r)\end{array}$ & 1,496 & 10,820 & 11,000 & 24,200 \\
\hline
\end{tabular}

The energy cost savings for the modified base case control package option, which has an integrated dry-bulb economizer, constant-speed supply fan and single-stage capacity control (i.e., a constant single-speed compressor motor), with an advanced controller having an integrated dry-bulb economizer, multi-speed supply-fan control, single-stage capacity control, and DCV are shown in Figure ES 4 and Table ES 4. The key findings include:

1. The HVAC energy cost savings as a percentage of the modified base case energy cost lies between $27 \%$ and $59 \%$ for the small office building, 30\% and 53\% for the stand-alone retail building, 29\% and 54\% for the strip mall, and 27\% and 50\% for the supermarket.

2. The average HVAC energy cost savings across all 16 locations is about $38 \%$ for all four building types.

3. The maximum HVAC energy cost savings as a percentage of the modified base case energy cost occurs in Los Angeles for the supermarket building and in San Francisco for the other three building types. 
The minimum percentage savings occurs in Seattle for the supermarket building and in Miami for the other three building types.

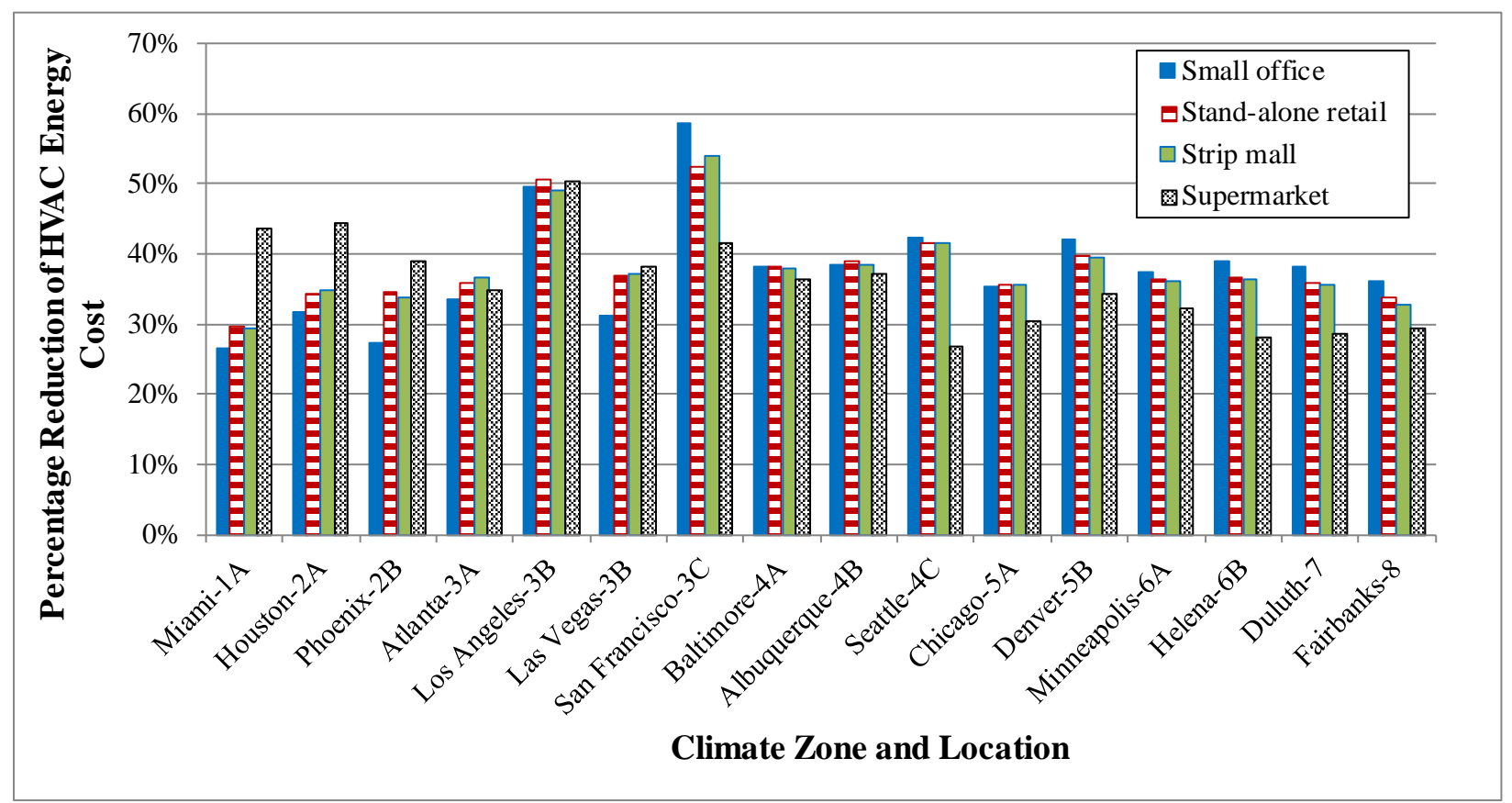

Figure ES 4: HVAC Energy Cost Savings from use of a Control Option with an integrated dry-bulb economizer, multi-speed supply fan control, single-stage capacity control and DCV) relative to and as a percentage of the Modified Base Case (with an integrated drybulb economizer, constant speed supply-fan control and single-stage capacity control) HVAC energy use for Four Building Types at all Locations Examined

The advanced control features affect electricity and gas cost savings differently. The percentage of the total cost savings attributable to electricity is usually more than $50 \%$ in the warmer climates (1A through 4B), while the gas cost savings dominate in the other climates (4C through 8). Both most energy efficient control package and modified control package have smaller percentages of the total energy cost associated with electricity than base case and a modified base case. This is primarily because the DCV and multi-speed fan controls, which are added in both the most energy efficient control package and modified control package, decrease electricity use considerably, and the price of electricity is greater than the price of natural gas, thus decreasing the fraction of the total cost attributable to electricity use.

Other highlights of the economic analysis results include:

- The percentage cost savings relative to the baseline are largest for Los Angeles. Using advanced controls in packaged roof top units can reduce HVAC energy consumption cost by more than $60 \%$ in Los Angeles.

- Relative to the baseline, energy cost savings are positive for all cases except for one (no economizer, constant speed supply fan, single-stage cooling and DCV) in Los Angeles for the small office building. 
- Just like for the energy savings, multi-speed fan control and DCV are the two control strategies that dominate the impact on energy cost savings. Multi-speed fan control dominates the impact in hot and mild climates (Miami and Seattle), while DCV dominates the impact in mixed and cold climates (Seattle, Chicago, and Duluth).

Table ES 4: Summary of Energy Cost Savings from Replacing Modified Base Case Control Packages Having Integrated Dry-bulb Economizers, Constant-speed Supply-Fan Controls and Single-stage Capacity Controls with Controllers Having Integrated Dry-bulb Economizers, Multi-speed Supply-Fan Controls, Single-stage Capacity Controls and DCV

\begin{tabular}{|c|c|c|c|c|}
\hline \multirow{2}{*}{ 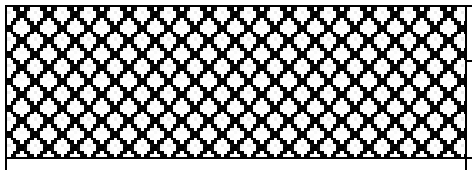 } & \multicolumn{4}{|c|}{ Building Type } \\
\hline & Small Office & $\begin{array}{l}\text { Stand-alone } \\
\text { Retail }\end{array}$ & Strip Mall & Supermarket \\
\hline Construction area $\left(\mathrm{ft}^{2}\right)$ & 5500 & 25000 & 22500 & 45000 \\
\hline Maximum savings & $59 \%$ & $53 \%$ & $54 \%$ & $50 \%$ \\
\hline $\begin{array}{l}\text { Location for maximum } \\
\text { savings }\end{array}$ & San Francisco & San Francisco & San Francisco & Los Angeles \\
\hline Minimum savings & $27 \%$ & $30 \%$ & $29 \%$ & $27 \%$ \\
\hline $\begin{array}{l}\text { Location for minimum } \\
\text { savings }\end{array}$ & Miami & Miami & Miami & Seattle \\
\hline Average savings & $38 \%$ & $38 \%$ & $38 \%$ & $36 \%$ \\
\hline $\begin{array}{l}\text { Maximum absolute } \\
\text { savings (\$/yr) }\end{array}$ & 2,108 & 21,383 & 20,370 & 46,605 \\
\hline $\begin{array}{l}\text { Location for maximum } \\
\text { absolute savings }\end{array}$ & Fairbanks & Fairbanks & Fairbanks & Fairbanks \\
\hline $\begin{array}{l}\text { Minimum absolute } \\
\text { savings (\$/yr) }\end{array}$ & 752 & 6,868 & 6,556 & 15,046 \\
\hline $\begin{array}{l}\text { Location for minimum } \\
\text { absolute savings }\end{array}$ & Seattle & Albuquerque & Albuquerque & Miami \\
\hline $\begin{array}{l}\text { Average absolute } \\
\text { savings (\$/yr) }\end{array}$ & 1,134 & 9,481 & 9,390 & 21,960 \\
\hline
\end{tabular}

In contrast with the incremental impact on energy savings, cost savings are affected more by multi-speed fan control. This is because the price of electricity per unit of energy is greater than the price of natural gas, and the use of multi-speed fan control significantly reduces electricity consumption for all locations.

\section{Controller Cost}

The maximum installed cost of advanced controllers that will yield a specific simple payback period is important for potential users to evaluate the financial merits of installing advanced controllers but also for vendors and developers in pricing their advanced control products. 
Because an add-on controller is usually associated with each rooftop unit, the total energy cost savings for a whole building needs to be normalized before calculating the maximum acceptable controller installed cost.

Controllers with different combinations of advanced control capabilities are likely to have different manufacturing and installation costs. Controllers with greater functionality will likely cost more. On the other hand, the examined control strategies have different degrees of impact on energy cost savings. Controllers with greater functionality (actually, the best combination of functionality) provide greater energy and cost savings. Therefore, analysis of the savings provided by a controller relative to its cost is important. We examine this by determining the maximum total installed cost per controller that yields a 3-year simple payback for controllers with different combinations of control functionality. A total of four scenarios are considered:

- Scenario 1: the advanced controller with only multi-speed supply-fan control is retrofit to an existing packaged unit having a base case controller with no advanced control capabilities (including no economizer).

- Scenario 2: the advanced controller with only DCV is retrofit to an existing packaged unit having a base case controller with no advanced control capabilities (including no economizer)

- Scenario 3: the advanced controller with integrated differential dry-bulb economizer, multi-speed fan control and DCV is retrofit to an existing packaged unit with a controller having an integrated differential dry-bulb economizer, single-speed fan control, one-stage cooling, and no DCV.

- Scenario 4: the advanced controller with an integrated dry-blub differential economizer control, multi-speed supply fan control, two-stage compressor control and DCV is retrofit to existing packaged units having a base case controller with no advanced control capabilities (including no economizer).

The results show that the maximum total installed controller cost per packaged unit providing a 3-year payback period varies with the four scenarios. For all four building types, controllers discussed in Scenarios 3 and 4 can bear the largest maximum cost per controller for all 16 locations because the control options in those two scenarios produce the maximum cost savings. Also, because the initial packaged unit controllers before retrofit in Scenarios 3 and 4 differ only in that the one in Scenario 3 has an air-side dry-bulb temperature based economizer control, the differences between their maximum controller costs largely depends on the impacts of the airside economizer control and the electricity prices.

The maximum acceptable total installed controller cost is larger in locations where the air-side economizer control contributes significant cooling energy savings and the electricity price is high (such as Los Angeles, San Francisco, and Fairbanks). The relationship between the maximum controller costs for Scenarios 1 and 2 depends on both location and building type. For the small office building, Scenario 1 with multi-speed fan control achieves a higher maximum controller cost than Scenario 2 with DCV for all 16 locations. For the two retail buildings, Scenario 1 usually has a higher maximum controller cost than Scenario 2 in hot (e.g., Miami, Houston, Phoenix) and warm climates (e.g., Los Angeles, Las Vegas, and San Francisco), while the reverse is true in cold climates (e.g., Chicago, Helena, and Duluth). For the supermarket 
building, Scenario 2 has a higher maximum controller cost than Scenario 1 only in four locations, Seattle, Chicago, Helena, and Duluth.

For a specific scenario and location, the maximum acceptable installed cost is highest for the supermarket, then progressively lower for stand-alone retail building, strip mall, and small office building. For example, for Scenario 4, the calculated maximum acceptable controller cost lies in the approximate range between:

1. $\$ 8,000$ and $\$ 26,000$ for the supermarket building,

2. $\$ 5,900$ and $\$ 17,800$ for the stand-alone retail building,

3. $\$ 2,300$ and $\$ 7,000$ for the strip mall building, and

4. $\$ 550$ and $\$ 1,400$ for the small office building.

The reasons for the differences are explained in more detailed in the main body of the report.

For purposes of vendors setting prices for advanced controllers the smallest value of the maximum total installed cost that provides sufficient return to building owners in the geographic regions targeted for sales is an important input. This cost is determined for two scenarios considered common opportunities for packaged unit controller retrofits in the commercial sector: 1) retrofit of a unit having differential dry-bulb temperature-based integrated economizer, singlespeed fan, and single-stage compressor control (and no DCV) with an advanced controller that adds multi-speed fan and DCV control (Scenario A) and 2) retrofit of a unit having no advanced controls with an advanced controller having integrated enthalpy-based economizer, multi-speed fan, two-stage (speed) compressor control, and DCV (Scenario B). When the entire U.S. represents the targeted market, the minimum of the maximum total installed cost for stand-alone retail, strip mall and supermarket buildings is $\$ 2,103$ per controller, which is found for Albuquerque to achieve a 3-year payback period and \$3,505 for a 5-year payback period (see Table ES 5). For small office buildings, the maximum cost is smaller at $\$ 451$ per controller for a building with 1 packaged unit per 1,100 sf of conditioned floor space and \$1,128 per controller for 1 packaged unit per 2,750 sf of floor space.

Vendors may choose to target selected building types or geographic regions for sales of advanced controllers. In this case, the minimum value of maximum total installed cost for the selected building types and geographic regions is used. For example, the most favorable building-type market for advanced controller sales across the U.S. is supermarkets for which the maximum total cost per advanced controller is $\$ 7,523$ for a 3-year payback period and $\$ 12,539$ for a 5-year payback period. The report provides data that enables determination of the appropriate maximum cost per controller for many different selections of target building types and geographic region. 
Table ES 5: Maximum values of the installed cost for advanced controllers that provide simple payback periods of 3 and 5 years across the U.S. and the specific locations and climate zones to which these values correspond

\begin{tabular}{|c|c|c|c|c|c|}
\hline & Scenario* & Small Office & Standalone Retail & Strip mall & Supermarket \\
\hline \multirow{2}{*}{$\begin{array}{c}\text { 3-year } \\
\text { payback }\end{array}$} & Scenario A & $\begin{array}{c}451 \\
\text { [Seattle-4C] }\end{array}$ & $\begin{array}{c}5,151 \\
\text { [Albuquerque-4B] }\end{array}$ & $\begin{array}{c}1,967 \\
\text { [Albuquerque-4B] }\end{array}$ & $\begin{array}{c}\text { 7,523 } \\
{[\text { Miami-1A] }}\end{array}$ \\
\hline & Scenario B & $\begin{array}{c}554 \\
\text { [Seattle-4C] }\end{array}$ & $\begin{array}{c}5,898 \\
\text { [Albuquerque-4B] }\end{array}$ & $\begin{array}{c}2,290 \\
\text { [Albuquerque-4B] }\end{array}$ & $\begin{array}{c}8044 \\
\text { [Seattle-4C] }\end{array}$ \\
\hline \multirow{2}{*}{$\begin{array}{c}\text { 5-year } \\
\text { payback }\end{array}$} & Scenario A & $\begin{array}{c}752 \\
\text { [Seattle-4C] }\end{array}$ & $\begin{array}{c}\text { 8,585 } \\
\text { [Albuquerque-4B] }\end{array}$ & $\begin{array}{c}\text { 3,278 } \\
\text { [Albuquerque-4B] }\end{array}$ & $\begin{array}{c}12,539 \\
{[\text { Miami-1A] }}\end{array}$ \\
\hline & Scenario B & $\begin{array}{c}923 \\
\text { [Seattle-4C] }\end{array}$ & $\begin{array}{c}9,830 \\
\text { [Albuquerque-4B] }\end{array}$ & $\begin{array}{c}\text { 3,817 } \\
\text { [Albuquerque-4B] }\end{array}$ & $\begin{array}{c}13,406 \\
\text { [Seattle-4C] }\end{array}$ \\
\hline
\end{tabular}

* Scenario A: retrofit of a unit having differential dry-bulb temperature-based integrated economizer, single-speed fan, and single-stage compressor control (and no DCV) with an advanced controller that adds multi-speed fan and DCV control; Scenario B: retrofit of a unit having no advanced controls with an advanced controller having integrated enthalpy-based economizer, multi-speed fan, two-stage (speed) compressor control, and DCV

\section{Conclusion}

Individual control strategies have different degrees of impact on energy and cost savings. The simulation results indicate that multi-speed fan control and DCV are the two control strategies contributing the most to energy and cost savings for packaged units. In many cases, multi-speed fan control dominates the impact in hot and mild climates (e.g., Miami and Los Angeles), while DCV dominates the impact in climate that have significant cooling and heating load and cold climates (e.g., Seattle, Chicago and Duluth). Applying multi-speed fan control only may lead to increased overall HVAC energy consumption in cold climates but still show energy cost reductions. The air-side economizing is a powerful strategy to reduce cooling, but it usually has a very small contribution to the overall HVAC energy and energy cost savings, except for locations with mild climates, such as Los Angeles.

With the fullest set of advanced control strategies (most energy efficient package considered), the annual absolute energy cost savings relative to the base case lies the approximate ranges between:

1. $\$ 900$ and $\$ 2,400$ for the small office building,

2. $\$ 8,000$ and $\$ 24,000$ for the stand-alone retail building,

3. $\$ 7,600$ and $\$ 23,000$ for the strip mall, and

4. $\$ 16,000$ and $\$ 52,000$ for the supermarket.

The maximum absolute cost savings relative to the base case all occur for Fairbanks. The average absolute cost savings (not normalized for differences in building floor area) across the 16 locations are about $\$ 1,500$ for the small office building, $\$ 11,000$ for the two retail buildings, and $\$ 24,200$ for the supermarket building. 


\section{Future Work}

Bringing retrofitable advanced control packages rapidly to the mass market to realize the large energy and cost savings potential found in this study will likely require additional information and further development of the technology. Some key needs identified by the project team include the following.

- The energy savings estimated with simulations in this study should be validated with field tests of retrofitable controllers for packaged units that are beginning to enter the marketplace. Testing can be used to validate overall energy savings as well as savings from individual control strategies and specific combinations of control strategies.

- As this study considered packaged rooftop air conditioners with direct expansion cooling and gas furnace heating, similar analyses of packaged air source heat pumps and air conditioners with electric resistive heating would prove valuable.

- The small office building model is a single-story building with just less than $5000 \mathrm{ft}^{2}$ floor area. The small size, together with its somewhat atypical attic roof construction, makes it not representative of most office buildings served by packaged rooftop units. Therefore, results may be improved by using an office building model that corresponds closer to the size and construction of the median office building that uses packaged rooftop units, such as the DOE reference building model for a medium office building, which has a conditioned floor area of about 50,000 $\mathrm{ft}^{2}$.

- If the cost of advanced controllers on the market exceeds the maximum cost for a payback period commonly found acceptable by building owners, additional technological innovation may be required to lower the cost of advanced controllers to acceptable levels. This technology development may be best performed in government-industry collaborations (e.g., national laboratories with building controller manufacturers).

- Development of a guide or software tool for building owners and managers to assist them in making decisions to install advanced controllers may be important to accelerate the market penetration of advanced controllers, which based on this study can save considerable energy (approximately 25\% to 60\% of the energy consumption of rooftop units over a broad range of U.S. climates).

- In addition to the measures considered (air-side economizer, multiple supply-fan speed control, DCV and staged direct expansion cooling using multi-speed control of compressor motors), other advanced control technologies applicable to packaged rooftop units should be evaluated. Such technologies include optimal start times, closing outdoorair dampers during morning warm up or cool down periods, and fully variable-speed control of the supply fan, condenser fan and compressor.

- The analysis in this report assumes that all sensors are accurate. However, sensors are rarely perfectly accurate and control precise in practice. For this reason, it is important to consider the uncertainty of sensor measurements. The impacts of uncertainty on energy savings, cost savings, and the maximum economical total cost of the control retrofits should be investigated.

- The impact assessment was made for a single set of predefined values for the key control parameters. Because these values are likely to vary in field applications, it is worthwhile 
to investigate the impact on energy and cost savings of using different parameter values. The control parameters could even be optimized.

- The EnergyPlus program and DOE reference building models were used in the current work to evaluate the energy saving potential of advanced rooftop unit control strategies. The impact of compressor cycling on cooling efficiency was not considered in this analysis. Because ignoring cycling losses underestimates the savings potential from staged cooling, the simulation of control needs to be improved to incorporate compressor cycling. 


\section{Acknowledgement}

The authors would like to acknowledge the Buildings Technologies Program of the U.S.

Department of Energy Office of Energy Efficiency and Renewable Energy for supporting the research and development effort. The authors would also like to thank Alan Schroeder, Technology Development Manager, George Hernandez (PNNL) for technical guidance, Ron Underhill and Anne Wagner for providing the technical review, Andrew Nicholls (Program Manager at PNNL) for thoughtful comments and insights, Sue Arey for editorial support and Loren Ruiz for help in preparing this document. 


\section{Contents}

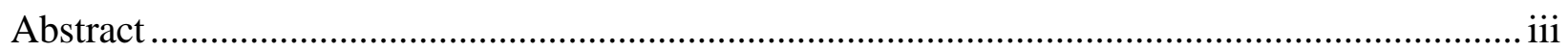

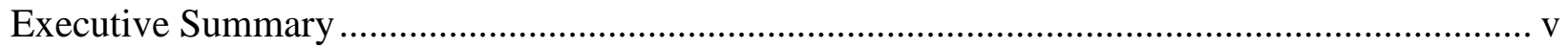

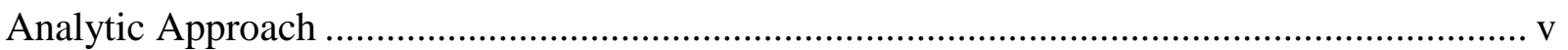

Control Sequence of Operation for Packaged Air Conditioners with Gas Heating .................... vi

Building Prototypes ................................................................................................................... vi

Methodology …………............................................................................................. vi

Energy Savings Results for Various Control Combinations ...................................................... vi

Economic Analysis.................................................................................................................. xii

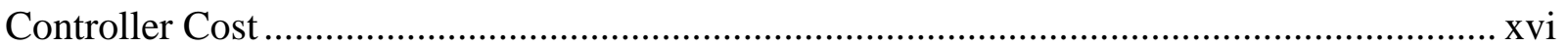

Conclusion............................................................................................................... xix

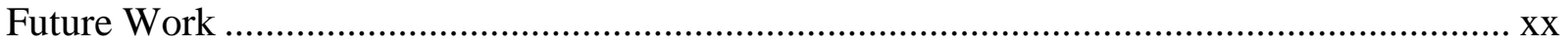

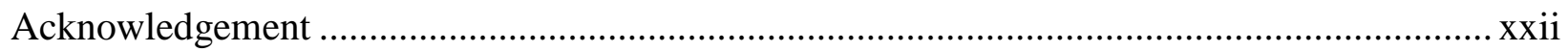

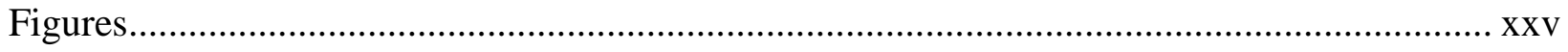

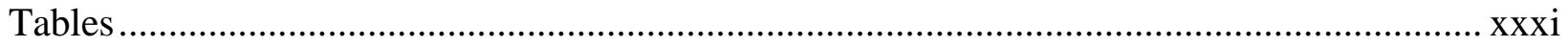

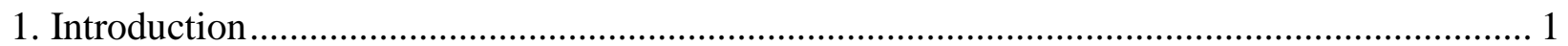

2. Control Sequence of Operation for Packaged Rooftop Units with Gas Heating......................... 3

2.1 Conventional Control Options for Packaged Rooftop Units..................................................... 3

2.2 Advanced Control Options for Packaged Rooftop Units ......................................................... 4

2.3 Sequences of Operation...................................................................................................... 7

3. Representative Buildings, Climates and Locations .................................................................. 10

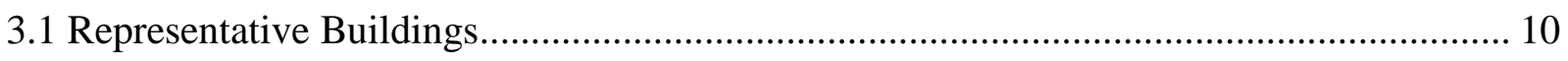

3.2 Climates and Locations .............................................................................................. 13

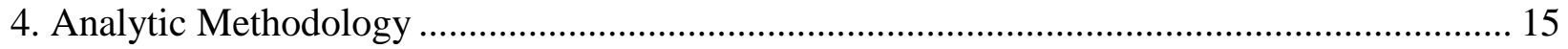

4.1 Energy Use Estimation Methodology …………………............................................. 15

4.2 Economic Analysis Methodology ………………….................................................... 20

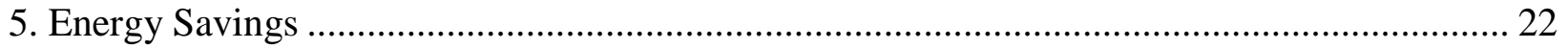

5.1 Baseline HVAC Energy Use and Distribution of Operation Modes..................................... 22

5.2 Impact Assessment of Individual Control Strategies on HVAC Energy Uses .................... 27

5.3 Incremental Impact of Selected Advanced Control Strategies on HVAC Energy Uses..... 36

5.4 Comparison of Energy Consumption between Case 18 and Case 4 .................................... 47 
5.5 Comparison of Energy Consumption between Case 22 and the Base Case (Case 1) ......... 51

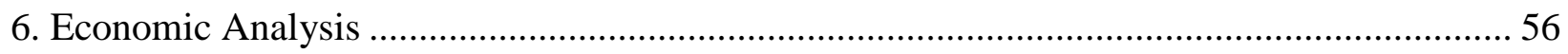

6.1 Impact Assessment of Individual Control Strategies on HVAC Energy Cost................... 56

6.2 Incremental Impact of Selected Control Strategies on HVAC Energy Cost....................... 61

6.3 HVAC Energy Cost Comparison between Case 18 and Case 4 ..................................... 70

6.4 HVAC Energy Cost Comparison between Case 22 and the Base Case (Case 1) .............. 74

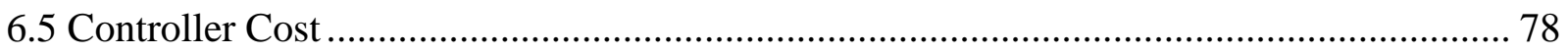

7. Conclusions and Future Planned Work............................................................................. 88

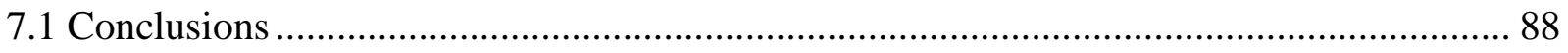

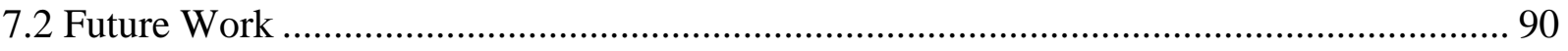

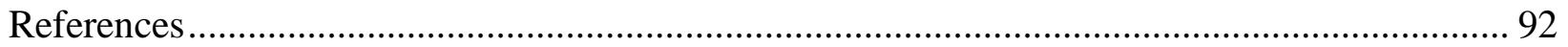

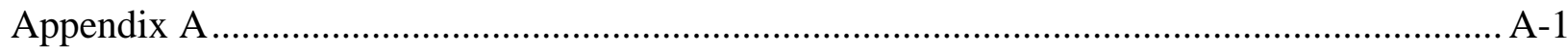

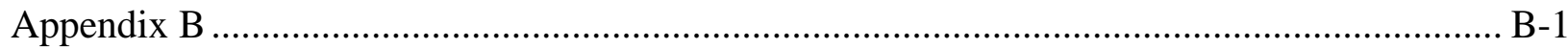

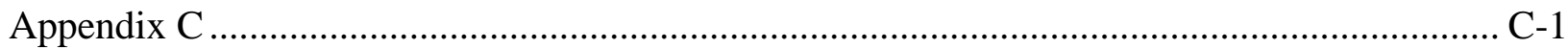

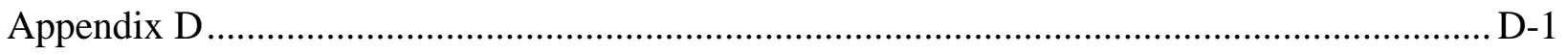




\section{Figures}

Figure ES 1: HVAC Energy Savings from Retrofit Installation of the Most Energy Efficient Control Package Considered (integrated differential enthalpy economizer, multispeed supply fan, two-stage capacity control, and DCV) relative to and as a percentage of the HVAC Energy Use of the Base Case (no economizer and constant speed supply fan) for Four Building Types at all Locations Examined viii

Figure ES 2: HVAC Energy Savings from Retrofit Installation of the Control Package using an Integrated Dry-bulb Economizer, Multi-Speed Supply Fan, Single-stage Capacity Control, and DCV relative to and as a percentage of the HVAC Energy Use of the Modified Base Case, which has an Integrated Dry-bulb Economizer, Constant-speed Supply Fan and Single-stage Capacity Control for Four Building Types at all Locations Examined. $\mathrm{X}$

Figure ES 3: HVAC Energy Cost Savings from use of the Most Energy Efficient Control

Package Considered (integrated differential enthalpy economizer, multi-speed supplyfan control, two-stage capacity [compressor-motor speed] control and DCV) relative to and as a percentage of the Base Case (no economizer and constant speed supply fan) HVAC energy use for Four Building Types at All Locations Examined xiii

Figure ES 4: HVAC Energy Cost Savings from use of a Control Option with an integrated drybulb economizer, multi-speed supply fan control, single-stage capacity control and DCV) relative to and as a percentage of the Modified Base Case (with an integrated dry-bulb economizer, constant speed supply-fan control and single-stage capacity control) HVAC energy use for Four Building Types at all Locations Examined ...... XV

Figure 1: Illustration of the Typical Control Sequence for Rooftop Units in Single-Zone HVAC

System 8

Figure 2: Axonometric View of Small Office Building ......................................................... 11

Figure 3: Axonometric View of Stand-alone Retail Building ............................................... 11

Figure 4: Axonometric View of Strip Mall........................................................................ 12

Figure 5: Axonometric View of Supermarket ..................................................................... 12

Figure 6: Annual HVAC Energy Use for Base Case Control (Case 1) of the Small Office

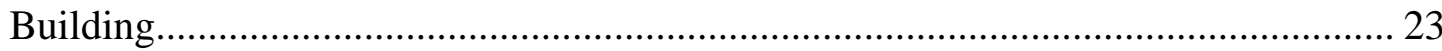

Figure 7: Annual HVAC Energy Use for Base Case Control (Case 1) of the Stand-alone Retail

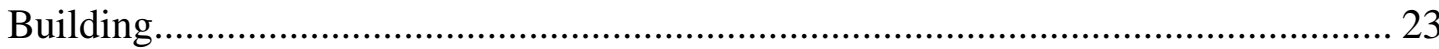

Figure 8: Annual HVAC Energy Use for Base Case Control (Case 1) of the Strip Mall Building

Figure 9: Annual HVAC Energy Use for Base Case Control (Case 1) of the Supermarket Building. 24

Figure 10: Percentage of Time in Each of the Operational Modes for the Small Office Building for all 16 Locations 25 
Figure 11: Percentage of Time in Each of the Operational Modes for the Stand-alone Retail Building for all 16 Locations ............................................................................ 26

Figure 12: Percentage of Time in Each of the Operational Modes for the Strip Mall Building for all 16 Locations.............................................................................................. 26

Figure 13: Percentage of Time in Each of the Operational Modes for the Supermarket Building for all 16 Locations ............................................................................................ 27

Figure 14: HVAC Energy Savings from the Use of Nonintegrated Air-Side Differential DryBulb Economizer Controls (Case 2) Compared to the Base Case without Air-Side

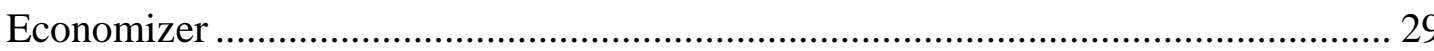

Figure 15: HVAC Energy Savings from use of a Nonintegrated Air-Side Differential Enthalpy Economizer in place of a Nonintegrated Differential Dry-Bulb Economizer for Four Building Types.............................................................................................. 30

Figure 16: HVAC Energy Savings from the Use of Multi-speed Supply-Fan Control (Case 6) Compared to the Base Case with Constant-Speed Fan Control................................. 32

Figure 17: HVAC Energy Savings from the Use of Demand Controlled Ventilation (Case 14) Compared to the Base Case with Constant Outdoor-Air Supply............................... 33

Figure 18: Weekday Occupancy Schedules for the Four Building Types................................. 34

Figure 19: HVAC Energy Savings from the Use of Two-Stage Cooling (Case 11) Compared to Single-Stage Cooling (Case 6) ........................................................................... 36

Figure 20: HVAC Energy Savings Resulting from Incremental Addition of Advanced Control Strategies for the Small Office Building............................................................ 38

Figure 21: HVAC Energy Savings Resulting from Incremental Addition of Advanced Control Strategies for the Stand-alone Retail Building...................................................... 38

Figure 22: HVAC Energy Savings Resulting from Incremental Addition of Advanced Control Strategies for the Strip Mall Building 39

Figure 23: HVAC Energy Savings Resulting from Incremental Addition of Advanced Control Strategies for the Supermarket Building 39

Figure 24 Annual Fan Energy Savings Resulting from Incremental Addition of Advanced Control Strategies for the Small Office Building ................................................ 40

Figure 25: Annual Fan Energy Savings Resulting from Incremental Addition of Advanced Control Strategies for the Stand-alone Retail Building

Figure 26: Annual Fan Energy Savings Resulting from Incremental Addition of Advanced Control Strategies for the Strip Mall Building.....

Figure 27: Annual Fan Energy Savings Resulting from Incremental Addition of Advanced Control Strategies for the Supermarket.

Figure 28: Annual Cooling Energy Savings Resulting from Incremental Addition of Advanced Control Strategies for the Small Office Building 43

Figure 29: Annual Cooling Energy Savings Resulting from Incremental Addition of Advanced Control Strategies for the Stand-alone Retail Building ..... 
Figure 30: Annual Cooling Energy Savings Resulting from Incremental Addition of Advanced Control Strategies for the Strip Mall Building.

Figure 31: Annual Cooling Energy Savings Resulting from Incremental Addition of Advanced Control Strategies for the Supermarket Building 44

Figure 32: Annual Heating Energy Savings Resulting from Incremental Addition of Advanced Control Strategies for the Small Office Building .... 45

Figure 33: Annual Heating Energy Savings Resulting from Incremental Addition of Advanced Control Strategies for the Stand-alone Retail Building.

Figure 34: Annual Heating Energy Savings Resulting from Incremental Addition of Advanced Control Strategies for the Strip Mall.

Figure 35: Annual Heating Energy Savings Resulting from Incremental Addition of Advanced Control Strategies for the Supermarket.

Figure 36: Comparison of HVAC Energy Consumption between Case 4 (left bar for each location) and Case 18 (right bar for each location) for the Small Office Building. Percent Difference in the Total Energy Consumption between Case 4 and Case 18 is also shown for Each Location

Figure 37: Comparison of HVAC Energy Consumption between Case 4 (left bar for each location) and Case 18 (right bar for each location) for the Stand-alone Retail Building. Percent Difference in the Total Energy Consumption between Case 4 and Case 18 is also shown for Each Location.

Figure 38: Comparison of HVAC Energy Consumption between Case 4 (left bar for each location) and Case 18 (right bar for each location) for the Strip Mall Building. Percent Difference in the Total Energy Consumption between Case 4 and Case 18 is also shown for Each Location.

Figure 39: Comparison of HVAC Energy Consumption between Case 4 (left bar for each location) and Case 18 (right bar for each location) for the Supermarket Building. Percent Difference in the Total Energy Consumption between Case 4 and Case 18 is also shown for Each Location.

Figure 40: Comparison of HVAC Energy Consumption between the Baseline (Case 1; left bar for each location) and Case 22 (right bar for each location) for the Small Office Building. Percent Difference in the Total Energy Consumption between Case 1 and Case 22 is also shown for Each Location.

Figure 41: Comparison of HVAC Energy Consumption between the Baseline (Case 1; left bar for each location) and Case 22 (right bar for each location) for the Stand-alone Retail Building. Percent Difference in the Total Energy Consumption between Case 1 and Case 22 is also shown for Each Location.

Figure 42: Comparison of HVAC Energy Consumption between the Baseline (Case 1; left bar for each location) and Case 22 (right bar for each location) the Strip Mall Building. Percent Difference in the Total Energy Consumption between Case 1 and Case 22 is also shown for Each Location. 
Figure 43: Comparison of HVAC Energy Consumption between the Baseline (Case 1; left bar for each location) and Case 22 (right bar for each location) for the Supermarket Building. Percent Difference in the Total Energy Consumption between Case 1 and Case 22 is also shown for Each Location.

Figure 44: HVAC Energy Cost Savings from the Use of an Integrated Air-Side Differential Dry-Bulb Economizer (Case 4) Compared to the Base Case without an Air-Side Economizer ....

Figure 45: HVAC Energy Cost Savings from the Use of Multi-speed Supply-Fan Control (Case

6) Compared to the Base Case with Constant-Speed Fan Control 59

Figure 46: HVAC Energy Cost Savings from the Use of Demand Controlled Ventilation (Case

14) Compared to the Base Case with Constant Outdoor-Air Supply 60

Figure 47: HVAC Energy Cost Savings from the Use of Two-Stage Cooling (Case 11) Compared to Single-Stage Cooling (Case 6) 61

Figure 48: Total Energy Cost Savings Resulting from Incremental Addition of Advanced Control Strategies for the Small Office Building.... 63

Figure 49: Total Energy Cost Savings Resulting from Incremental Addition of Advanced Control Strategies for the Stand-alone Retail Building..... 63

Figure 50: Total Energy Cost Savings Resulting from Incremental Addition of Advanced Control Strategies for the Strip Mall Building..... 64

Figure 51: Total Energy Cost Savings Resulting from Incremental Addition of Advanced Control

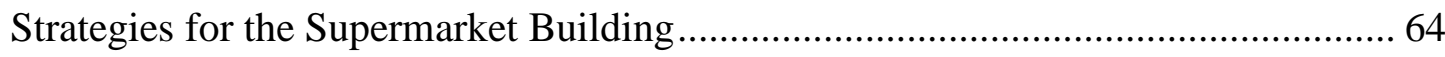

Figure 52: Electricity Cost Savings Resulting from Incremental Addition of Advanced Control Strategies for the Small Office Building.

Figure 53: Electricity Cost Savings Resulting from Incremental Addition of Advanced Control Strategies for the Stand-alone Retail Building. 66

Figure 54: Electricity Cost Savings Resulting from Incremental Addition of Advanced Control Strategies for the Strip Mall Building. 66

Figure 55: Electricity Cost Savings Resulting from Incremental Addition of Advanced Control Strategies for the Supermarket Building

Figure 56: Gas Cost Savings Resulting from Incremental Addition of Advanced Control Strategies for the Small Office Building

Figure 57: Gas Cost Savings Resulting from Incremental Addition of Advanced Control Strategies for the Stand-alone Retail Building. 68

Figure 58: Gas Cost Savings Resulting from Incremental Addition of Advanced Control Strategies for the Strip Mall Building.

Figure 59: Gas Cost Savings Resulting from Incremental Addition of Advanced Control Strategies for the Supermarket Building....

Figure 60: Comparison of HVAC Energy Cost between Case 4 (left bar for each location) and Case 18 (right bar for each location) for the Small Office Building. Percent 
Difference in the Total Energy Cost between Case 4 and Case 18 is also shown for Each Location.

Figure 61: Comparison of HVAC Energy Cost between Case 4 (left bar for each location) and Case 18 (right bar for each location) for the Stand-alone Retail Building. Percent Difference in the Total Energy Cost between Case 4 and Case 18 is also shown for Each Location.

Figure 62: Comparison of HVAC Energy Cost between Case 4 (left bar for each location) and Case 18 (right bar for each location) for the Strip Mall Building. Percent Difference in the Total Energy Cost between Case 4 and Case 18 is also shown for Each Location.

Figure 63: Comparison of HVAC Energy Cost between Case 4 (left bar for each location) and Case 18 (right bar for each location) for the Supermarket Building. Percent Difference in the Total Energy Cost between Case 4 and Case 18 is also shown for Each Location.

Figure 64: Comparison of HVAC Energy Cost between Case 1(left bar for each location) and Case 22 (right bar for each location) for the Small Office Building. Percent Difference in the Total Energy Cost between Case 1 and Case 22 is also shown for Each Location.

Figure 65: Comparison of HVAC Energy Cost between Case 1(left bar for each location) and Case 22 (right bar for each location) for the Stand-alone Retail Building. Percent Difference in the Total Energy Cost between Case 1 and Case 22 is also shown for Each Location.

Figure 66: Comparison of HVAC Energy Cost between Case 1 (left bar for each location) and Case 22 (right bar for each location) for the Strip Mall Building. Percent Difference in the Total Energy Cost between Case 1 and Case 22 is also shown for Each Location. 76

Figure 67: Comparison of HVAC Energy Cost between Case 1(left bar for each location) and Case 22 (right bar for each location) for the Supermarket Building. Percent Difference in the Total Energy Cost between Case 1 and Case 22 is also shown for Each Location.

Figure 68: Maximum Total Installed Cost per Controller Unit to Achieve a Payback Period of 3 Years for the Small Office Building with Different Control Capabilities Added to an Existing Packaged Unit That Has Integrated Dry-Bulb Economizer for Scenario 3 but No Advanced Control in the Other Three Scenarios

Figure 69: Maximum Total Installed Cost per Controller Unit to Achieve a Payback Period of 3 Years for the Stand-alone Retail Building with Different Control Capabilities Added to an Existing Packaged Unit That Has Integrated Dry-Bulb Economizer for Scenario 3 but No Advanced Control in the Other Three Scenarios 81

Figure 70: Maximum Total Installed Cost per Controller Unit to Achieve a Payback Period of 3 Years for the Strip Mall Building with Different Control Capabilities Added to an 
Existing Packaged Unit That Has Integrated Dry-Bulb Economizer for Scenario 3 but No Advanced Control in the Other Three Scenarios

Figure 71: Maximum Total Installed Cost per Controller Unit to Achieve a Payback Period of 3 Years for the Supermarket Building with Different Control Capabilities Added to an Existing Packaged Unit That Has Integrated Dry-Bulb Economizer for Scenario 3 but No Advanced Control in the Other Three Scenarios 82

Figure 72: Maximum Total Installed Cost per Controller that Provides a Payback of 5 Years for the Small Office Building with Different Control Capabilities Added to an Existing Packaged Unit that has Integrated Differential Dry-Bulb Economizer for Scenario 3 but no Advanced Control in the Other 3 Scenarios

Figure 73: Maximum Total Installed Cost per Controller that Provides a Payback of 5 Years for the Stand-alone Retail Building with Different Control Capabilities Added to an Existing Packaged Unit that has Integrated Differential Dry-Bulb Economizer for Scenario 3 but no Advanced Control in the Other 3 Scenarios

Figure 74: Maximum Total Installed Cost per Controller Unit that Provides a Payback of 5 Years for the Strip Mall Building with Different Control Capabilities Added to an Existing Packaged Unit that has Integrated Differential Dry-Bulb Economizer for Scenario 3 but no Advanced Control in the Other 3 Scenarios 84

Figure 75: Maximum Total Installed Cost per Controller Unit that Provides a Payback of 5 Years for the Supermarket Building with Different Control Capabilities Added to an Existing Packaged Unit That has Integrated Differential Dry-Bulb Economizer for Scenario 3 but no Advanced Control in the Other 3 Scenarios

Figure 76: Maximum Total Installed Cost per Controller Unit that Provide Simple Payback of 3 Years for the Small Office Building with Different Control Capabilities and the Number of Packaged Units is reduced from 5 to 2 


\section{Tables}

Table ES 1: Summary of HVAC Energy Savings for from Replacing Controllers with No

Economizers or Other Advanced Controls with the Most Energy Efficient Control Package Considered Having Integrated Dry-bulb Economizers, Multi-speed Supply-

Fan Controls, Two-stage Capacity Controls and DCV... ix

Table ES 2: Summary of HVAC Energy Savings from Replacing Modified Base Case Control

Packages Having Integrated Dry-bulb Economizers, Constant-speed Supply-Fan Controls and Single-stage Capacity Controls with Controllers Having Integrated Drybulb Economizers, Multi-speed Supply-Fan Controls, Single-stage Capacity Controls and DCV xi

Table ES 3: Summary of Energy Cost Savings from Replacing Controllers with No Economizers or Other Advanced Controls with the Most Energy Efficient Control Package Considered Having Integrated Dry-bulb Economizers, Multi-speed Supply-Fan Controls, Two-stage Capacity Controls and DCV xiv

Table ES 4: Summary of Energy Cost Savings from Replacing Modified Base Case Control Packages Having Integrated Dry-bulb Economizers, Constant-speed Supply-Fan Controls and Single-stage Capacity Controls with Controllers Having Integrated Drybulb Economizers, Multi-speed Supply-Fan Controls, Single-stage Capacity Controls and DCV xvi

Table ES 5: Maximum values of the installed cost for advanced controllers that provide simple payback periods of 3 and 5 years across the U.S. and the specific locations and climate zones to which these values correspond. xix

Table 1: Advanced Control Options Considered for this Study ................................................ 6

Table 2: Building Types Studied ......................................................................................... 13

Table 3: Selected Climates and Corresponding Representative Locations for Saving Analysis.. 14 Table 4: Combinations of Control Options (or Control Packages) Considered for Each Building

Type in all 16 Locations ............................................................................... 17

Table 5: Efficiency of Cooling, Heating and Fan Systems..................................................... 18

Table 6: Default Values of the Key Control Parameters ....................................................... 19

Table 7: Electricity and Gas Prices by Location in the Year of 2010 (EIA 2011) ..................... 21

Table 8: Summary of HVAC Energy Savings for Case 18 Relative to Case 4 .......................... 51

Table 9: Summary of HVAC Energy Savings for Case 22 Relative to the Base Case (Case 1) .. 55

Table 10: Summary of Energy Cost Savings for Case 18 Relative to Case 4 ............................ 73

Table 11: Summary of Energy Cost Savings for Case 22 Relative to the Base Case (Case 1) .... 78 Table 12: Maximum Values of the Installed Cost for Advanced Controllers that Provide Simple Payback Periods of 3 and 5 Years across the U.S. and the Specific Locations and Climate Zones to which these Values Correspond ................................................ 86 
Table A-1: Key Geometric, Envelope, HVAC, Water Heating and Internal Load Characteristics for the Small Office Building Prototype.

Table A-2: Key Geometric, Envelope, HVAC, Water Heating and Internal Load Characteristics for the Stand-alone Retail Building Prototype A-3

Table A-3: Key Geometric, Envelope, HVAC, Water Heating, and Internal Load Characteristics for the Strip Mall Building Prototype A-4

Table A-4: Key Geometric, Envelope, HVAC, Water Heating, and Internal Load Characteristics for the Supermarket Building Prototype ....................................................... A-5

Table B-1: HVAC Energy Uses for the Small Office Building in Climate Zones 1A and 2A . B-2 Table B-2: HVAC Energy Uses for the Small Office Building in Climate Zones 2B and 3A.. B-3 Table B-3: HVAC Energy Uses for the Small Office Building in Climate Zone 3B .............. B-4 Table B-4: HVAC Energy Uses for the Small Office Building in Climate Zones 3C and 4A.. B-5 Table B-5: HVAC Energy Uses for the Small Office Building in Climate Zones 4B and 4C.. B-6 Table B-6: HVAC Energy Uses for the Small Office Building in Climate Zones 5A and 5B.. B-7 Table B-7: HVAC Energy Uses for the Small Office Building in Climate Zones 6A and 6B.. B-8 Table B-8: HVAC Energy Uses for the Small Office Building in Climate Zones 7 and 8 ....... B-9 Table B-9: HVAC Energy Uses for the Stand-alone Retail Building in Climate Zones 1A and

Table B-10: HVAC Energy Uses for the Stand-alone Retail Building in Climate Zones 2B and 3A. B-11

Table B-11: HVAC Energy Uses for the Stand-alone Retail Building in Climate Zone 3B... B-12 Table B-12: HVAC Energy Uses for the Stand-alone Retail Building in Climate Zones 3C and $4 \mathrm{~A}$. B-13

Table B-13: HVAC Energy Uses for the Stand-alone Retail Building in Climate Zones 4B and $4 \mathrm{C}$ B-14

Table B-14: HVAC Energy Uses for the Stand-alone Retail Building in Climate Zones 5A and $5 B$. B-15

Table B-15: HVAC Energy Uses for the Stand-alone Retail Building in Climate Zones 6A and 6B. B-16

Table B-16: HVAC Energy Uses for the Stand-alone Retail Building in Climate Zones 7 and 8 B-17

Table B-17: HVAC Energy Uses for the Strip Mall Building in Climate Zones 1A and 2A.. B-18 Table B-18: HVAC Energy Uses for the Strip Mall Building in Climate Zones 2B and 3A.. B-19 Table B-19: HVAC Energy Uses for the Strip Mall Building in Climate Zone 3B ............... B-20 Table B-20: HVAC Energy Uses for the Strip Mall Building in Climate Zones 3C and 4A.. B-21 Table B-21: HVAC Energy Uses for the Strip Mall Building in Climate Zones 4B and 4C .. B-22 Table B-22: HVAC Energy Uses for the Strip Mall Building in Climate Zones 5A and 5B.. B-23 Table B-23: HVAC Energy Uses for the Strip Mall Building in Climate Zones 6A and 6B.. B-24 Table B-24: HVAC Energy Uses for the Strip Mall Building in Climate Zones 7 and 8 ....... B-25 
Table B-25: HVAC Energy Uses for the Supermarket Building in Climate Zones 1A and 2A.. B26

Table B-26: HVAC Energy Uses for the Supermarket Building in Climate Zones 2B and 3A.. B27

Table B-27: HVAC Energy Uses for the Supermarket Building in Climate Zone 3B B-28

Table B-28: HVAC Energy Uses for the Supermarket Building in Climate Zones 3C and 4A.. B29

Table B-29: HVAC Energy Uses for the Supermarket Building in Climate Zones 4B and 4C .. B30

Table B-30: HVAC Energy Uses for the Supermarket Building in Climate Zones 5A and 5B.. B31

Table B-31: HVAC Energy Uses for the Supermarket Building in Climate Zones 6A and 6B.. B32

Table B-32: HVAC Energy Uses for the Supermarket Building in Climate Zones 7 and 8 ... B-33

Table C-1: HVAC Energy Savings Compared to Case 1 for the Small Office Building in

Climate Zones 1, 2 and 3A C-2

Table C-2: HVAC Energy Savings Compared to Case 1 for the Small Office Building in Climate Zones 3B, 3C and 4A. C-3

Table C-3: HVAC Energy Savings Compared to Case 1 for the Small Office Building in Climate Zones 4B, 4C, 5A and 5B C-4

Table C-4: HVAC Energy Savings Compared to Case 1 for the Small Office Building in Climate Zones 6, 7 and 8 C-5

Table C-5: HVAC Energy Savings Compared to Case 1 for the Stand-alone Retail Building in Climate Zones 1, 2 and 3A C-6

Table C-6: HVAC Energy Savings Compared to Case 1 for the Stand-alone Retail Building in Climate Zones 3B, 3C and 4A. C-7

Table C-7: HVAC Energy Savings Compared to Case 1 for the Stand-alone Retail Building in Climate Zones 4B, 4C, 5A and 5B C-8

Table C-8: HVAC Energy Savings Compared to Case 1 for the Stand-alone Retail Building in Climate Zones 6, 7 and 8 C-9

Table C-9: HVAC Energy Savings Compared to Case 1 for the Strip Mall Retail Building in Climate Zones 1, 2 and 3A C-10

Table C-10: HVAC Energy Savings Compared to Case 1 for the Strip Mall Retail Building in Climate Zones 3B, 3C and 4A. C-11

Table C-11: HVAC Energy Savings Compared to Case 1 for the Strip Mall Retail Building in Climate Zones 4B, 4C, 5A and 5B C-12

Table C-12: HVAC Energy Savings Compared to Case 1 for the Strip Mall Retail Building in Climate Zones 6, 7 and 8 C-13

Table C-13: HVAC Energy Savings Compared to Case 1 for the Supermarket Building in Climate Zones 1, 2 and 3A C-14 
Table C-14: HVAC Energy Savings Compared to Case 1 for the Supermarket Building in Climate Zones 3B, 3C and 4A ........................................................................ C-15

Table C-15: HVAC Energy Savings Compared to Case 1 for the Supermarket Building in Climate Zones 4B, 4C, 5A and 5B ................................................................. C-16

Table C-16: HVAC Energy Savings Compared to Case 1 for the Supermarket Building in Climate Zones 6, 7 and 8 .............................................................................. C-17

Table C-17: Electricity Savings Compared to Case 1 for the Small Office Building in Climate

Zones 1,2 and $3 \mathrm{~A}$ C-18

Table C-18: Electricity Savings Compared to Case 1 for the Small Office Building in Climate

Zones 3B, 3C and 4A.................................................................................... C-19

Table C-19: Electricity Savings Compared to Case 1 for the Small Office Building in Climate

Zones 4B, 4C, 5A and 5B

Table C-20: Electricity Savings Compared to Case 1 for the Small Office Building in Climate

Zones 6, 7 and 8 C-21

Table C-21: Electricity Savings Compared to Case 1 for the Stand-alone Retail Building in

Climate Zones 1, 2 and 3A

Table C-22: Electricity Savings Compared to Case 1 for the Stand-alone Retail Building in

Climate Zones 3B, 3C and 4A.

Table C-23: Electricity Savings Compared to Case 1 for the Stand-alone Retail Building in

Climate Zones 4B, 4C, 5A and 5B

Table C-24: Electricity Savings Compared to Case 1 for the Stand-alone Retail Building in

Climate Zones 6, 7 and 8 C-25

Table C-25: Electricity Savings Compared to Case 1 for the Strip Mall Building in Climate Zones 1,2 and $3 \mathrm{~A}$. C-26

Table C-26: Electricity Savings Compared to Case 1 for the Strip Mall Building in Climate Zones 3B, 3C and 4A. $\mathrm{C}-27$

Table C-27: Electricity Savings Compared to Case 1 for the Strip Mall Building in Climate Zones 4B, 4C, 5A and 5B C-28

Table C-28: Electricity Savings Compared to Case 1 for the Strip Mall Building in Climate Zones 6, 7 and 8 C-29

Table C-29: Electricity Savings Compared to Case 1 for the Supermarket Building in Climate

Zones 1,2 and $3 \mathrm{~A}$ C-30

Table C-30: Electricity Savings Compared to Case 1 for the Supermarket Building in Climate

Zones 3B, 3C and 4A...... C-31

Table C-31: Electricity Savings Compared to Case 1 for the Supermarket Building in Climate

Zones 4B, 4C, 5A and 5B C-32

Table C-32: Electricity Savings Compared to Case 1 for the Supermarket Building in Climate

Zones 6, 7 and 8 C-33

Table C-33: Gas Savings Compared to Case 1 for the Small Office Building in Climate Zones 1,

2 and $3 \mathrm{~A}$ C-34 
Table C-34: Gas Savings Compared to Case 1 for the Small Office Building in Climate Zones

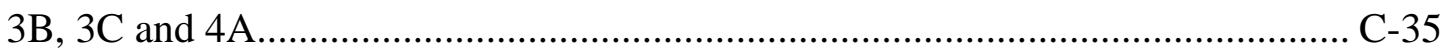

Table C-35: Gas Savings Compared to Case 1 for the Small Office Building in Climate Zones

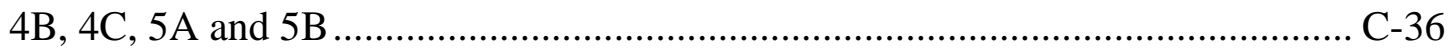

Table C-36: Gas Savings Compared to Case 1 for the Small Office Building in Climate Zones 6,

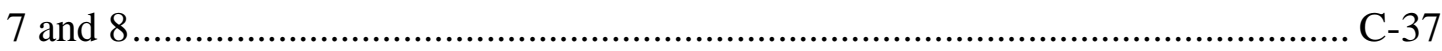

Table C-37: Gas Savings Compared to Case 1 for the Stand-alone Retail Building in Climate

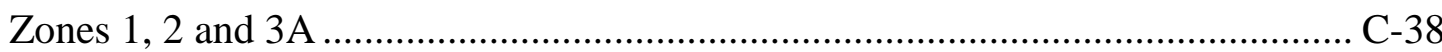

Table C-38: Gas Savings Compared to Case 1 for the Stand-alone Retail Building in Climate

Zones 3B, 3C and 4A......................................................................................

Table C-39: Gas Savings Compared to Case 1 for the Stand-alone Retail Building in Climate

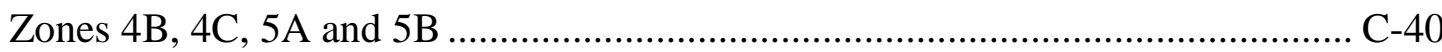

Table C-40: Gas Savings Compared to Case 1 for the Stand-alone Retail Building in Climate

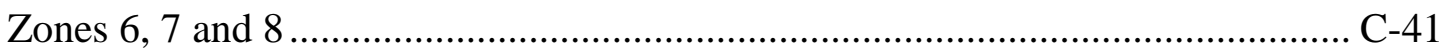

Table C-41: Gas Savings Compared to Case 1 for the Strip Mall Building in Climate Zones 1, 2

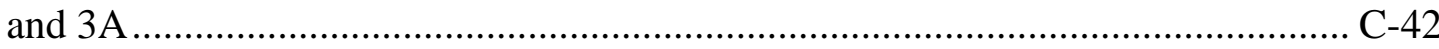

Table C-42: Gas Savings Compared to Case 1 for the Strip Mall Building in Climate Zones 3B,

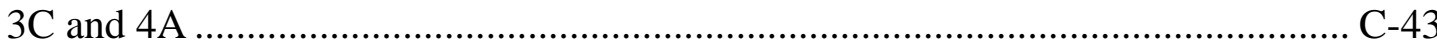

Table C-43: Gas Savings Compared to Case 1 for the Strip Mall Building in Climate Zones 4B,

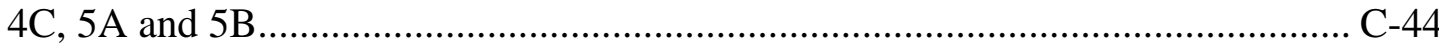

Table C-44: Gas Savings Compared to Case 1 for the Strip Mall Building in Climate Zones 6, 7

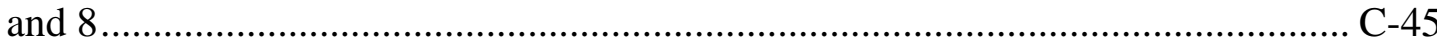

Table C-45: Gas Savings Compared to Case 1 for the Supermarket Building in Climate Zones 1,

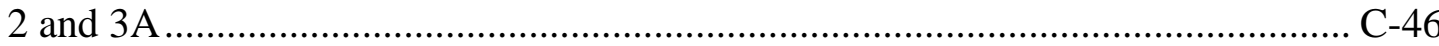

Table C-46: Gas Savings Compared to Case 1 for the Supermarket Building in Climate Zones

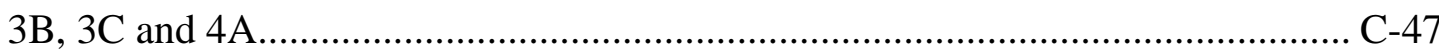

Table C-47: Gas Savings Compared to Case 1 for the Supermarket Building in Climate Zones

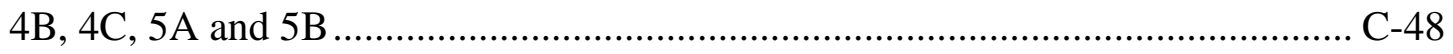

Table C-48: Gas Savings Compared to Case 1 for the Supermarket Building in Climate Zones 6,

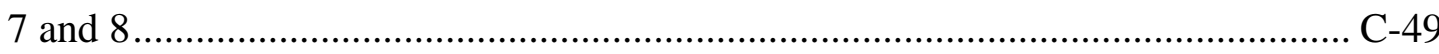

Table D-1: HVAC Energy Cost Savings Compared to Case 1 for the Small Office Building in Climate Zones 1, 2 and 3A ....................................................................... D-2

Table D-2: HVAC Energy Cost Savings Compared to Case 1 for the Small Office Building in Climate Zone 3B, 3C and 4A..................................................................... D-3

Table D-3: HVAC Energy Cost Savings Compared to Case 1 for the Small Office Building in Climate Zones 4B, 4C and 5 ...................................................................... D-4

Table D-4: HVAC Energy Cost Savings Compared to Case 1 for the Small Office Building in Climate Zones 6, 7 and 8 D-5

Table D-5: HVAC Energy Cost Savings Compared to Case 1 for the Stand-alone Retail Building in Climate Zones 1, 2 and 3A D-6 
Table D-6: HVAC Energy Cost Savings Compared to Case 1 for the Stand-alone Retail

Building in Climate Zone 3B, 3C and 4A...................................................... D-7

Table D-7: HVAC Energy Cost Savings Compared to Case 1 for the Stand-alone Retail

Building in Climate Zones 4B, 4C and 5..................................................... D-8

Table D-8: HVAC Energy Cost Savings Compared to Case 1 for the Stand-alone Retail

Building in Climate Zones 6, 7 and 8 .............................................................. D-9

Table D-9: HVAC Energy Cost Savings Compared to Case 1 for the Strip Mall Building in

Climate Zones 1, 2 and 3A ....................................................................... D-10

Table D-10: HVAC Energy Cost Savings Compared to Case 1 for the Strip Mall Building in

Climate Zone 3B, 3C and 4A.................................................................... D-11

Table D-11: HVAC Energy Cost Savings Compared to Case 1 for the Strip Mall Building in

Climate Zones 4 and 4B, 4C and 5 ............................................................. D-12

Table D-12: HVAC Energy Cost Savings Compared to Case 1 for the Strip Mall Building in

Climate Zones 6, 7 and 8 D-13

Table D-13: HVAC Energy Cost Savings Compared to Case 1 for the Supermarket Building in

Climate Zones 1, 2 and 3A D-14

Table D-14: HVAC Energy Cost Savings Compared to Case 1 for the Supermarket Building in

Climate Zone 3B, 3C and 4A..................................................................... D-15

Table D-15: HVAC Energy Cost Savings Compared to Case 1 for the Supermarket Building in

Climate Zones 4B, 4C and 5.................................................................. D-16

Table D-16: HVAC Energy Cost Savings Compared to Case 1 for the Supermarket Building in

Climate Zones 6, 7 and 8

Table D-17: Electricity Cost Savings Compared to Case 1 for the Small Office Building in

Climate Zones 1, 2 and 3A ......................................................................... D-18

Table D-18: Electricity Cost Savings Compared to Case 1 for the Small Office Building in

Climate Zones 3B, 3C and 4A .................................................................... D-19

Table D-19: Electricity Cost Savings Compared to Case 1 for the Small Office Building in

Climate Zones 4B, 4C, and 5 ..................................................................... D-20

Table D-20: Electricity Cost Savings Compared to Case 1 for the Small Office Building in

Climate Zones 6, 7 and 8 ........................................................................ D-21

Table D-21: Electricity Cost Savings Compared to Case 1 for the Stand-alone Retail Building in

Climate Zones 1, 2 and 3A ....................................................................... D-22

Table D-22: Electricity Cost Savings Compared to Case 1 for the Stand-alone Retail Building in

Climate Zones 3B, 3C and 4A .................................................................. D-23

Table D-23: Electricity Cost Savings Compared to Case 1 for the Stand-alone Retail Building in

Climate Zones 4B, 4C and 5..................................................................... D-24

Table D-24: Electricity Cost Savings Compared to Case 1 for the Stand-alone Retail Building in

Climate Zones 6, 7 and 8 ...................................................................... D-25

Table D-25: Electricity Cost Savings Compared to Case 1 for the Strip Mall Building in Climate

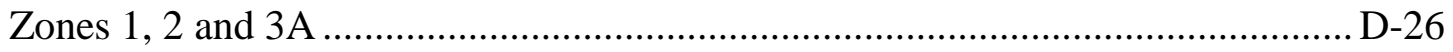


Table D-26: Electricity Cost Savings Compared to Case 1 for the Strip Mall Building in Climate Zones 3B, 3C and 4A. D-27

Table D-27: Electricity Cost Savings Compared to Case 1 for the Strip Mall Building in Climate Zones 4B, 4C, 5A and 5B D-28

Table D-28: Electricity Cost Savings Compared to Case 1 for the Strip Mall Building in Climate Zones 6, 7 and 8 D-29

Table D-29: Electricity Cost Savings Compared to Case 1 for the Supermarket Building in

Climate Zones 1, 2 and 3A D-30

Table D-30: Electricity Cost Savings Compared to Case 1 for the Supermarket Building in

Climate Zones 3B, 3C and 4A. D-31

Table D-31: Electricity Cost Savings Compared to Case 1 for the Supermarket Building in

Climate Zones 4B, 4C, 5A and 5B D-32

Table D-32: Electricity Cost Savings Compared to Case 1 for the Supermarket Building in

Climate Zones 6, 7 and 8

Table D-33: Gas Cost Savings Compared to Case 1 for the Small Office Building in Climate

Zones 1, 2 and 3A

Table D-34: Gas Cost Savings Compared to Case 1 for the Small Office Building in Climate

Zones 3B, 3C and 4A D-35

Table D-35: Gas Cost Savings Compared to Case 1 for the Small Office Building in Climate

Zones 4B, 4C, 5A and 5B D-36

Table D-36: Gas Cost Savings Compared to Case 1 for the Small Office Building in Climate

Zones 6, 7 and 8 D-37

Table D-37: Gas Cost Savings Compared to Case 1 for the Stand-alone Retail Building in

Climate Zones 1, 2 and 3A D-38

Table D-38: Gas Cost Savings Compared to Case 1 for the Stand-alone Retail Building in

Climate Zones 3B, 3C and 4A. D-39

Table D-39: Gas Cost Savings Compared to Case 1 for the Stand-alone Retail Building in

Climate Zones 4B, 4C, 5A and 5B D-40

Table D-40: Gas Cost Savings Compared to Case 1 for the Stand-alone Retail Building in Climate Zones 6, 7 and 8 D-41

Table D-41: Gas Cost Savings Compared to Case 1 for the Strip Mall Building in Climate Zones 1,2 and $3 \mathrm{~A}$ D-42

Table D-42: Gas Cost Savings Compared to Case 1 for the Strip Mall Building in Climate Zones 3B, 3C and 4A. D-43

Table D-43: Gas Cost Savings Compared to Case 1 for the Strip Mall Building in Climate Zones 4B, 4C, 5A and 5B D-44

Table D-44: Gas Cost Savings Compared to Case 1 for the Strip Mall Building in Climate Zones 6, 7 and 8. D-45

Table D-45: Gas Cost Savings Compared to Case 1 for the Supermarket Building in Climate Zones 1, 2 and $3 \mathrm{~A}$ D-46 
Table D-46: Gas Cost Savings Compared to Case 1 for the Supermarket Building in Climate Zones 3B, 3C and 4A

Table D-47: Gas Cost Savings Compared to Case 1 for the Supermarket Building in Climate Zones 4B, 4C, 5A and 5B D-48

Table D-48: Gas Cost Savings Compared to Case 1 for the Supermarket Building in Climate Zones 6, 7 and 8 D-49

Table D-49: Maximum Controller Installed Cost per Unit Supporting Different Retrofits for the Small Office Building Based on the Payback Period of 3 Years and the Original Utility Rates

Table D-50: Maximum Controller Installed Cost per Unit Supporting Different Retrofits for the Stand-alone Retail Building Based on the Payback Period of 3 Years and the Original Utility Rates

Table D-51: Maximum Controller Installed Cost per Unit Supporting Different Retrofits for the Strip Mall Building Based on the Payback Period of 3 Years and the Original Utility Rates. D-52

Table D-52: Maximum Controller Installed Cost per Unit Supporting Different Retrofits for the Supermarket Building Based on the Payback Period of 3 Years and the Original Utility Rates

Table D-53: Maximum Installed Cost per Controller Unit Supporting the Retrofit from Case 4 to Case 18 to Achieve Payback Periods of 1, 3 and 5 Years as Functions of Different Utility Rates in Climate Zones 1A, 2A, 2B, and 3A. D-54

Table D-54: Maximum Installed Cost per Controller Unit Supporting the Retrofit from Case 4 to Case 18 to Achieve Payback Periods of 1, 3 and 5 Years as Functions of Different

Utility Rates in Climate Zones 3B, 3C, and 4A. D-55

Table D-55: Maximum Installed Cost per Controller Unit Supporting the Retrofit from Case 4 to Case 18 to Achieve Payback Periods of 1, 3 and 5 Years as Functions of Different Utility Rates in Climate Zones 4B, 4C, 5A, and 5B. D-56

Table D-56: Maximum Installed Cost per Controller Unit Supporting the Retrofit from Case 4 to Case 18 to Achieve Payback Periods of 1, 3 and 5 Years as Functions of Different Utility Rates in Climate Zones 6A, 6B, 7 and 8 D-57

Table D-57: Maximum Installed Cost per Controller Unit Supporting the Retrofit from Case 1 to Case 22 to Achieve Payback Periods of 1, 3 and 5 Years as Functions of Different

Utility Rates in Climate Zones 1A, 2A, 2B, and 3A......................................... D-58

Table D-58: Maximum Installed Cost per Controller Unit Supporting the Retrofit from Case 1 to Case 22 to Achieve Payback Periods of 1, 3 and 5 Years as Functions of Different Utility Rates in Climate Zones 3B, 3C and 4A D-59

Table D-59: Maximum Installed Cost per Controller Unit Supporting the Retrofit from Case 1 to Case 22 to Achieve Payback Periods of 1, 3 and 5 Years as Functions of Different Utility Rates in Climate Zones 4B, 4C, 5A, and 5B. D-60 
Table D-60: Maximum Installed Cost per Controller Unit Supporting the Retrofit from Case 1 to Case 22 to Achieve Payback Periods of 1, 3 and 5 Years as Functions of Different Utility Rates in Climate Zones 6A, 6B, 7 and 8 D-61 


\section{Introduction}

Efforts to increase the energy efficiency in commercial buildings have focused mainly on improving the efficiency of heating, ventilation and air conditioning (HVAC) equipment along with improvements to lighting, windows and other envelope measures. Because the efforts directed at improving the efficiency of HVAC equipment primarily focus on the rated (or design) efficiency, they are usually not applicable to building retrofits without equipment replacement. In addition, focusing on improving the rated efficiency may not yield significant energy savings because systems tend to operate at off-design or part-load conditions for most of their lives. In contrast, approaches that address the improvement in the part-load performance can lead to significant increases in the operating efficiency of equipment and buildings. More importantly, measures that address the operational efficiency apply to both existing and new buildings.

The objective of this research and development project is to determine the magnitude of energy savings achievable by retrofitting existing packaged rooftop air conditioners with advanced control strategies not ordinarily used for packaged units.

Packaged cooling equipment is used in $46 \%$ (2.1 million) of all commercial buildings, serving over $60 \%$ (39 billion square feet) of the commercial building floor space in the U.S. (EIA 2003). The site cooling energy consumption associated with packaged cooling equipment is about 160 trillion Btus annually. Packaged heat pumps account for an additional 70 trillion Btus annually. Therefore, even a small improvement in part-load operation of these units can lead to significant reductions of energy use and carbon emissions.

Building codes require that when a building is occupied, the supply fan on packaged units operates continuously to meet the ventilation needs, irrespective of whether the unit is providing cooling or heating. A significant portion of the packaged units in the field (over 90\%) have constant speed supply fans. Because the fan is on continuously, the fan energy consumption can be greater than the compressor energy consumption in many locations in the U.S. This implies that there exists a big potential to achieve energy savings from fan speed control.

Packaged equipment with constant speed supply fans is designed to provide ventilation at the design rate at all times when the fan is operating. Although there are a number of hours during the day when a building may not be fully occupied or the need for ventilation is lower than designed, the ventilation rate cannot be adjusted easily with a constant speed fan. Studies have shown that demand-based ventilation control can save significant energy in climates that are not favorable for economizing (Brandemuehl and Braun 1999; Roth et al. 2003). Traditional demand controlled ventilation (DCV) strategies modulate the outdoor-air damper to reduce the rate at which outdoor air enters and the associated energy needed to condition that air. This strategy reduces cooling energy, but the supply fan still runs at full speed.

Supply-fan energy savings can be achieved by modulating the supply-fan speed during the ventilation mode. When the unit is in ventilation mode, the role of the supply fan is to provide fresh air to maintain proper indoor air quality in the spaces that it is serving. Therefore, modulating the supply fan in conjunction with DCV will not only reduce the coil energy but also reduce the fan energy. The total savings (fan and coil) will depend on a number of factors including control strategy, thermostat set point and characteristics (throttling range and deadband), oversizing of the packaged unit, the efficiency of the packaged unit, and the thermal load profiles. 
To estimate the potential energy and the associated cost savings from widespread use of advanced control strategies with packaged rooftop units, the U.S. Department of Energy's (US DOE's) Building Technologies Program (BTP) has sponsored this study. In this study, the savings are estimated based on detailed EnergyPlus (DOE 2010) simulation. Although it is possible to simulate buildings with various combinations of the influencing parameters, the size of simulation runs will become large and unmanageable. Therefore, for this study, only a selected combination of influencing parameters is used to estimate the savings from use of advanced control strategies. The parameters that will be varied include building type (4), building location (16), and various control strategies (22).

The various control strategies and how they differ from conventional controls is summarized in Section 2. Four buildings types that predominantly use packaged units are considered: small office, stand-alone retail, strip mall, and supermarket. Detailed descriptions of the building types, the climate zones and representative locations used for the analysis are described in Section 3. The methodologies used in estimating the energy consumption, energy cost and maximum total cost of the control technology are described in Section 4. Sections 5 and 6 provide results for the energy and cost savings for the various combinations of control strategies by building type and location. Conclusions and discussion of potential future work are provided in Section 7. 


\section{Control Sequence of Operation for Packaged Rooftop Units with Gas Heating}

Packaged rooftop air conditioners are factory-made, self-contained units comprising a number of off-the-shelf components available in standard design and cooling capacities. Typically, a packaged rooftop unit consists of a fan and filter section, a mechanical cooling section, and a heating section. In the fan and filter section, outdoor air enters the rooftop unit through a damper and is mixed with the air returned from the space. The mixed air then passes through filters to protect downstream components from dirt accumulation. A relief fan may also be used to exhaust some return air to the outdoors through a damper. The mechanical cooling section provides cooling through a vapor compression cycle, which usually consists of a reciprocating or scroll compressor, an air-cooled condenser, a direct expansion (DX) evaporator and a thermal expansion valve. The supply air is cooled by heat exchange with the cooler refrigerant passing through the evaporator coil, and an air condenser fan passes air through the condenser coil to dissipate refrigerant heat to the outdoors. The heating section provides heating to the supply air stream by a gas furnace, electrical resistance heating element, or a reverse vapor compression cycle (in heat pumps).

According to its cooling capacity, packaged equipment is divided into three categories: residential with cooling capacities less than $65,000 \mathrm{Btu} / \mathrm{h}$, light commercial with capacities up to 135,000 Btu/h, and commercial with capacities of 135,000 Btu/h or greater (ASHRAE 2008). The cooling efficiency is normally measured in terms of energy efficiency ratio (EER) and integrated energy efficiency ratio (IEER) at standard rated conditions for commercial units. Although high efficiency equipment contributes to saving energy, it is not always possible to improve the efficiency of packaged rooftop units because of technical and economic constraints. This is especially true for existing building retrofits when the replacement of rooftop units is not a viable consideration. On the other hand, a number of technologies are commercially available to improve the operational efficiency of packaged rooftop units. Representative technologies include economizer controls, supply-fan speed controls, optimal start and stop controls, and demand-controlled ventilation. Many of these advanced control options could be added if they are not used in existing rooftop units. This study investigates the energy and cost savings associated with some of these advanced control options for packaged rooftop units individually and in various combinations. The savings are estimated by comparing annual estimated energy consumption of the unit when using an advanced control option with the energy use for the base case controls. The base case control options and the advanced control options are discussed in this section, together with the sequences of operations considered for this work.

\subsection{Conventional Control Options for Packaged Rooftop Units}

In most packaged units, a thermostat controls the operation of the compressor or the gas furnace, depending on whether the zone is calling for cooling or heating. In conventional control (base case), the compressor or the furnace is turned on or off to maintain the required zone set point. Although the compressor and furnace are cycled, the supply fan runs continuously when the building is occupied. Even though some packaged units might have air-side economizer controls and staged cooling and heating, the base case scenario used for this study assumes that the package unit has single-stage cooling and heating with no economizer controls. Therefore, the base case controls use the zone thermostat to cycle the compressor and the furnace, with the supply fan operating continuously when the building is occupied to provide ventilation. 


\subsection{Advanced Control Options for Packaged Rooftop Units}

There are a number of additional control options that can be added to rooftop units including: air-side economizers, supply-fan speed controls, cooling capacity controls, and demand-controlled ventilation. For this study, the energy savings impacts of all four control options were evaluated for packaged single-zone systems compared to the base case. ${ }^{1}$ The control options were analyzed individually as well as in combinations of multiple control options. These four control options are discussed next.

\section{$\underline{\text { Air-side economizer controls }}$}

Air-side economizers use cool outdoor air (OA) to reduce energy use for mechanical cooling. When the space served requires cooling and the outdoor conditions are favorable for economizing (as determined by the economizer controls), an air-side economizer brings in outdoor air at a rate greater than the minimum required for ventilation through damper modulation. This displaces the need for some or all mechanical cooling and reduces energy consumption of the unit. Several commonly used economizer control strategies include fixed (high-limit) dry-bulb temperature, fixed (high-limit) enthalpy, differential dry-bulb temperature, and differential enthalpy.

With a fixed dry-bulb or enthalpy high limit controller, the outdoor air property used for control (i.e., dry-bulb temperature or enthalpy) is measured and compared to a fixed set point. If the value of the outdoor air property is less than the set point, outdoor air is used to meet all or part of the cooling demand; otherwise, the air-side economizer is not used (outdoor air dampers are positioned at the minimum position to meet ventilation needs). Depending on the climate and whether the economizer is integrated with mechanical cooling, the fixed dry-bulb set point is usually set between $55^{\circ} \mathrm{F}$ and $75^{\circ} \mathrm{F}$, whereas the fixed enthalpy set point is set around $28 \mathrm{Btu} / \mathrm{lb}$ (Brandemuel and Braun 1999; Taylor and Cheng 2010).

With a differential dry-bulb temperature or differential enthalpy economizer control, the outdoorair condition is measured and compared with the return-air condition. If the value of the outdoorair condition (dry-bulb temperature or enthalpy) is less than the condition for the return air, outdoor air is used to meet all or part of the cooling demand; otherwise, the air-side economizer is not used.

In addition to these strategies, air-side economizers can either work in concert with the mechanical cooling or not. These modes of economizer operation are respectively referred to as integrated and nonintegrated. An integrated economizer, as its name implies, is fully integrated with the mechanical cooling system such that it can use $100 \%$ outdoor air to provide as much cooling as possible and mechanical cooling is engaged to make up the cooling load not met by use of outdoor air alone. On the other hand, a nonintegrated economizer does not operate simultaneously with the mechanical cooling system. When the outdoor-air condition is favorable, the economizer provides all necessary cooling. However, when the outdoor-air conditions are not sufficiently favorable to meet all the cooling demand, the outdoor-air damper returns to its

\footnotetext{
${ }^{1}$ Savings achieved by changing between any two control options can be determined by taking the difference between the tabulated energy savings relative to the base case for the two operations considered.
} 
minimum position without the use of economizing, and the mechanical system provides all necessary cooling.

\section{$\underline{\text { Fan-Speed Control }}$}

Generally, a packaged rooftop unit serving a single zone has three fan control options: constant- speed control, multi-speed control, and variable -speed control.

- With a constant fan -speed control, the supply fan runs at its design speed as long as the packaged rooftop unit is on or as long as the building is occupied. This is the base case option.

- With a multi-speed fan control, the supply fan runs at different speeds depending on the space load and the rooftop unit operation mode. For example, the fan may run at a reduced speed when neither cooling nor heating is requested (ventilation mode), or with a multi -stage unit, the fan speed can also be discretely changed at different stages of cooling or heating. Modulating the fan to a lower speed can reduce fan energy consumption and improve humidification control in the space. Many advanced control scenarios simulated for this study use the multiple supply-fan speed option.

- With a variable-speed fan control, the supply fan speed is modulated in proportion to the difference between the actual space temperature and the temperature set point. Meanwhile, the heating or cooling output is adjusted through staging or capacity modulation to satisfy the discharge air temperature set point. This option is not evaluated in this study.

\section{Cooling Capacity Control}

Packaged rooftop units are usually sized to handle the system load at peak design conditions, which are expressed in terms of the weather and the internal loads of the space served. However, because the majority of actual operating hours occur at off-peak conditions, the packaged unit must have some capacity reduction mechanisms to deal with part-load conditions. Three cooling capacity control methods commonly used in packaged rooftop units are:

- Simple on-off control (base case option). For this case, the compressor is switched on and off as necessary to meet the load requirements. Once the compressor is on, it operates at full capacity, and the packaged unit provides cool air to the space. When the space temperature drops below the zone set point temperature, the compressor is turned off. This simple on-off control is normally used in package units with capacities less than 90,000 Btu/h.

- Staged cooling. Staged cooling is often accomplished by using two or more separate refrigeration circuits, which allows independent operation of the individual circuits. The magnitude of the cooling load (indicated by the deviation of the zone temperature from zone set point temperature) determines whether the unit operates at its full capacity or a lower capacity. At part-load conditions, using part of the unit's cooling capacity can reduce the compressor's excessive on-off cycling and contribute to better indoor temperature and humidity control.

- Capacity modulation. Cooling capacity can be modulated through compressor cylinder unloading, multi- or variable-speed compressors, and hot-gas bypass control (ASHRAE 
2008). Cooling capacity modulation is usually used in packaged rooftop units serving variable-air-volume systems, but not single-zone constant-air-volume systems. This control option was not evaluated in this study.

\section{Ventilation Control}

Depending on whether the outdoor-air intake flow rate is dynamically reset based on the ventilation needs, the following two ventilation control strategies can be considered in a packaged rooftop unit:

- The first strategy maintains a fixed minimum outdoor-air intake rate during system operation. The fixed rate at which outdoor air is brought in is based on the design occupancy of the space served, which is usually larger than the actual occupancy during many operating hours. Therefore, excess outdoor air is supplied to the space whenever the space is partially occupied. This is the base case option.

- The second strategy, referred to as demand-controlled ventilation (DCV), adjusts the amount of outdoor air based on the number of occupants and the corresponding ventilation demand. Although a number of options such as direct people counting, timeof-day schedule tracking, and measuring $\mathrm{CO}_{2}$ concentration are available to estimate the actual occupancy of spaces, $\mathrm{CO}_{2}$-based DCV is by far the most commonly implemented measure when outdoor-air ventilation is dynamically reset (Stanke 2006). $\mathrm{CO}_{2}$-based DCV relies on sensed $\mathrm{CO}_{2}$ concentrations in the space (usually measured in the return air) to regulate the ventilation rate. Assuming that the $\mathrm{CO}_{2}$ generation rate is proportional to the number of occupants, the minimum required outdoor-air flow rate for single-zone systems can be calculated from the space $\mathrm{CO}_{2}$ concentration set point and the difference between indoor and outdoor $\mathrm{CO}_{2}$ concentrations (ASHRAE 2010a). By reducing outdoor-air intake, DCV has the potential to reduce the energy associated with conditioning the outdoor air.

Table 1 summarizes the control options for each control technology applied to rooftop units for this study.

\section{Table 1: Advanced Control Options Considered for this Study}

\begin{tabular}{|l|l|}
\hline Technology & Considered control options \\
\hline Air economizer & $\begin{array}{l}\text { No economizer (base control option) } \\
\text { Differential dry-bulb, nonintegrated } \\
\text { Differential dry-bulb, integrated } \\
\text { Differential enthalpy, nonintegrated } \\
\text { Differential enthalpy, integrated }\end{array}$ \\
\hline Fan-speed control & $\begin{array}{l}\text { Constant speed (base control option) } \\
\text { Multiple speed }\end{array}$ \\
\hline Cooling capacity control & $\begin{array}{l}\text { Single stage (base control option) } \\
\text { Two stages }\end{array}$ \\
\hline Ventilation control & $\begin{array}{l}\text { Constant outdoor-air supply (base control } \\
\text { option) } \\
\text { Demand-controlled ventilation }\end{array}$ \\
\hline
\end{tabular}




\subsection{Sequences of Operation}

The sequence of operation for packaged rooftop units varies with the control options selected. Figure 1 illustrates the typical control sequence for rooftop units in single-zone HVAC systems. Some details such as the control limits for safe equipment operations are not shown. Based on the sensed space temperature $T$, the rooftop unit has four basic operation modes: idle, ventilation, heating, and cooling.

Idle mode. The rooftop unit is in the idle mode if 1 ) the sensed space temperature lies between the heating and cooling set points, that is, $T_{\text {Heass }} \leq T \leq T_{\text {CoolsP }}$ and 2) the space is unoccupied. In the idle mode, the fan, the heating and the cooling are all off. Note that the heating and cooling set points during occupied and unoccupied modes may be different.

Ventilation mode. The rooftop unit operates in the ventilation mode if 1 ) the sensed space temperature lies between the heating and cooling set points, that is, $T_{\text {HeatsP }} \leq T \leq T_{\text {CoolsP }}$ and 2) the space is occupied. In the ventilation mode, the fan runs at the speed of $F a_{\text {Ven }}$ but both the heating and the cooling are off. In this study, the supply fan runs at $100 \%$ of the design speed $\left(\mathrm{Fan}_{\mathrm{Ven}}=100 \%\right)$ in the ventilation mode for the control option with a constant fan speed, while it runs at $40 \%$ of the design speed ( $\mathrm{Fan}_{\mathrm{Ven}}=40 \%$ ) for the control option with multiple fan speeds.

Heating mode. The rooftop unit operates in the heating mode if the sensed space temperature is less than the heating set point $\left(T<T_{\text {Heass }}\right)$. Once heating is initiated, it continues until the space temperature rises above the heating set point plus a differential, $T>T_{\text {Heass }}+\delta$, where $\delta$ is the differential. In the heating mode, the fan runs at the speed $\mathrm{Fan}_{\text {Heat }}$, which takes the value of $100 \%$ for the two considered options of fan-speed control.

Cooling mode. The rooftop unit operates in the cooling mode if the sensed space temperature is greater than the cooling set point $\left(T>T_{\text {Coolsp }}\right)$. Depending on the economizer and mechanical cooling stage control status, the rooftop unit may work in two different sub modes: economizing or mechanical cooling.

- Economizing (OA cooling) mode. Right after the cooling mode is initiated, the system controller determines whether the outdoor air is suitable for free cooling. If the outdoor air is favorable for cooling, the OA damper is modulated to maintain the supply-air temperature at the economizer supply-air set point, i.e., $T_{\text {Supply }}=T_{E c o S P}$. The economizing mode is used as long as the space temperature lies between the cooling set point and the cooling set point minus the differential, i.e., $T_{\text {CoolsP }}-\delta \leq T \leq T_{\text {CoolsP }}$. Otherwise, if $T<T_{\text {CoolsP }}-\delta$, the economizer is off and the outdoor-air damper returns to the ventilation-only position. The controller initiates mechanical cooling if the time in economizing mode, $\Delta t_{E c o}$, exceeds the interstage delay time limit, $\Delta t_{\text {Limit }}$ (i.e., $\Delta t_{E c o}>\Delta t_{\text {Limit }}$ ) and the supply-air temperature is greater than the threshold of changeover from OA cooling to mechanical cooling $\left(T_{\text {Supply }}>T_{E c o-D X}\right)$. In the economizing mode, the mechanical cooling is off and the supply fan operates at the speed $F_{E a n_{E c}}$, which takes the value of $100 \%$ for the constant fan-speed control and $75 \%$ for the control option with 


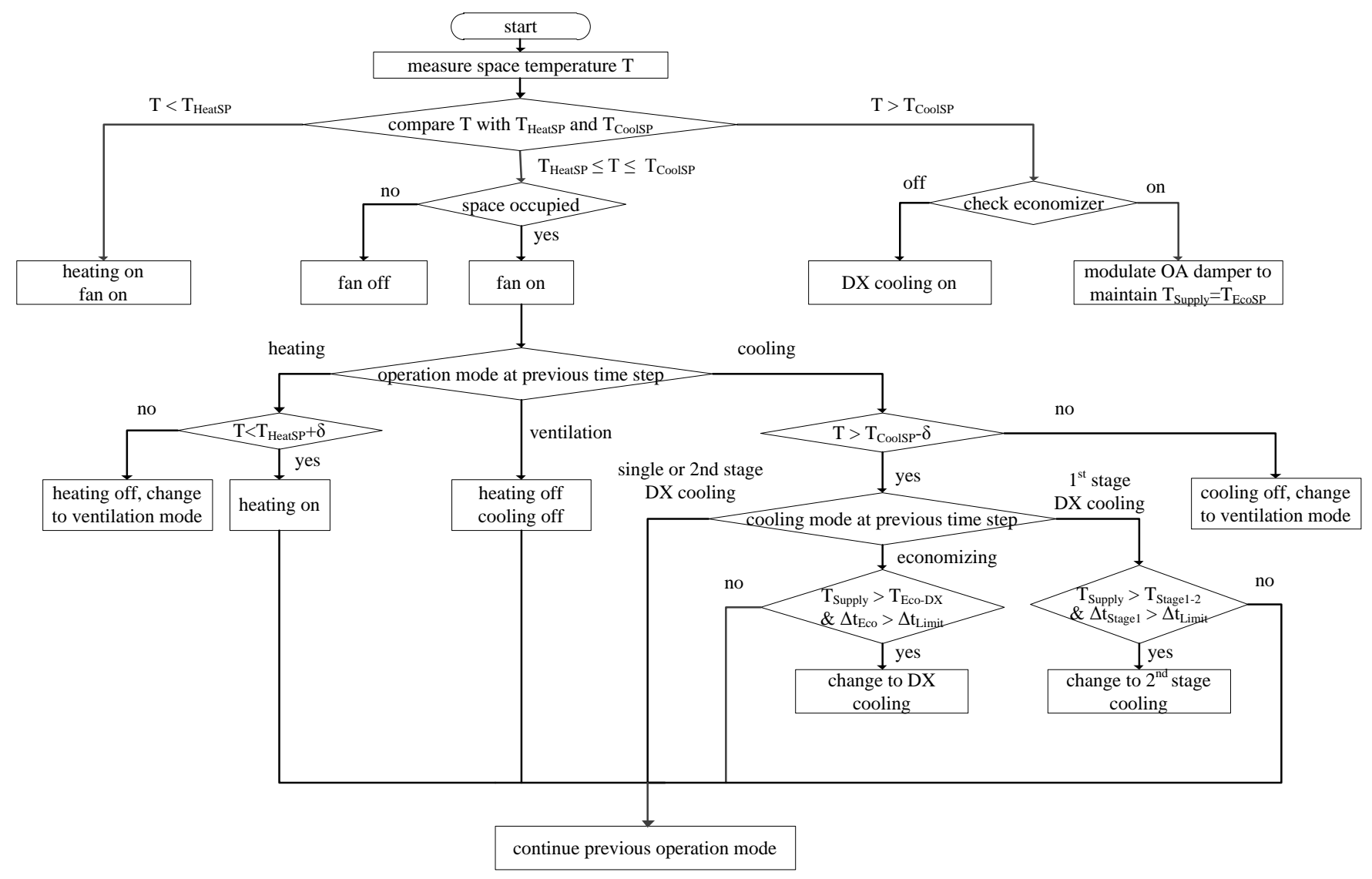

Figure 1: Illustration of the Typical Control Sequence for Rooftop Units in Single-Zone HVAC System

multiple fan speeds. The economizing mode occurs only if an air-side economizer is available.

- Mechanical cooling mode. For single-stage cooling, the rooftop unit runs at its full cooling capacity until the space is cooled down to a temperature below the difference of the cooling set point and the differential (i.e., $T<T_{\text {CoolsP }}-\delta$ ). For two-stage cooling, the unit runs stage-one cooling first. Cooling continues with only the first stage operating as long as the space temperature lies between the cooling set point and the cooling set point minus the differential, i.e., $T_{\text {CoolsP }}-\delta \leq T \leq T_{\text {CoolsP }}$. Otherwise, the mechanical cooling is discontinued when $T<T_{\text {CoolsP }}-\delta$. The rooftop unit triggers the second stage mechanical cooling if the time in stage-one cooling mode exceeds the interstage delay time limit (i.e., $\Delta t_{\text {Stage } 1}>\Delta t_{\text {Limit }}$ ) and the supply-air temperature is greater than the threshold of changeover between cooling stages $\left(T_{\text {Supply }}>T_{\text {Stage1-2 }}\right.$ ). After the rooftop unit initiates the second stage of cooling, both stages are on until the space is cooled to a temperature below $T_{\text {CoolsP }}-\delta$. In the mechanical cooling mode, if an integrated economizer is used and the OA condition is favorable for cooling, the control system fully opens the OA damper; otherwise, the controls keep the OA damper at the minimum position required by ventilation. The supply fan runs at the speed of $F a n_{\text {Stage } 1}$ and $F a n_{\text {Stage } 2}$, respectively 
for first stage and second stage cooling ( $\mathrm{Fan}_{\text {Stagez }}$ applies if there is a single-stage cooling). Fan Stage1 $_{\text {and }}$ Fan $n_{\text {Stage } 2}$ are set to $75 \%$ and $100 \%$ of the design speed in this study for the control option with multiple fan speeds.

If DCV control is available, the OA damper can be modulated depending on the sensed $\mathrm{CO}_{2}$ concentration $\left(C_{\mathrm{CO} 2, S_{5}}\right)$ in the return air. The OA damper is modulated further toward fully closed if $C_{C O 2, S}$ is less than the space $\mathrm{CO}_{2}$ set point ( $C_{\mathrm{CO} 2, S P}$ ), while it is opened further if $C_{\mathrm{CO} 2, S}$ is greater than $C_{\mathrm{CO}, S P}$. An absolute lower limit for OA ventilation is usually applied to ensure adequate ventilation to dilute air contaminants from non-occupant-related sources, such as building materials, furnishings, and finishes. This lower limit is reflected by the OA rate per area as indicated in ASHRAE Standard 62.1-2010 (ASHRAE 2010a). For example, in office spaces, the $\mathrm{OA}$ rate per space area is required to be $0.06 \mathrm{cfm} / \mathrm{ft}^{2}$. It needs to be noted that when both air-side economizer and DCV controls are active, the economizer control takes precedence over DCV control. 


\section{Representative Buildings, Climates and Locations}

To estimate the energy savings potential of advanced control packages across the U.S., the energy use for a number of prototypical buildings, which predominantly use packaged units for heating and cooling, needs to be simulated in different climates. The representative building types, locations, and climates are discussed in this section.

\subsection{Representative Buildings}

The U.S. DOE has developed 16 reference building prototypes to represent most of the commercial buildings in the U.S. (Deru et al. 2011). These reference building prototypes cover about $70 \%$ of the commercial building stock, including office buildings, restaurants, retail buildings, schools, healthcare buildings, supermarkets, lodging, and warehouses. For each reference building prototype, the associated model has three versions with different vintages: new construction, post-1980 construction, and pre-1980 construction. The models with different vintages differ with respect to envelope insulation levels, lighting power densities, and HVAC equipment types and efficiencies. Because significant efforts were taken to have the reference building models represent realistic building characteristics and construction practices, the reference models are usually used as the starting point for energy efficiency research (Field et al. 2010; Fumo et al. 2010).

Four building prototypes including small office, stand-alone retail, strip mall, and supermarket are chosen for analysis in this study. The post-1980 construction reference models corresponding to the four building types were used because they predominantly use packaged equipment for which the advanced controls being evaluated apply. The four building prototypes are discussed briefly below.

\section{Small Office Building}

The small office building model shown in Figure 2 has a single above-ground floor with a total floor area of 5,500 $\mathrm{ft}^{2}$. The building has a rectangular shape with aspect ratio of 1.5. The total window-to-wall ratio is about $20 \%$. Five packaged units with gas heating and DX-coil cooling serve four perimeter zones and one core zone. Key building characteristics of the small office building are listed in Table A1 in Appendix A. 


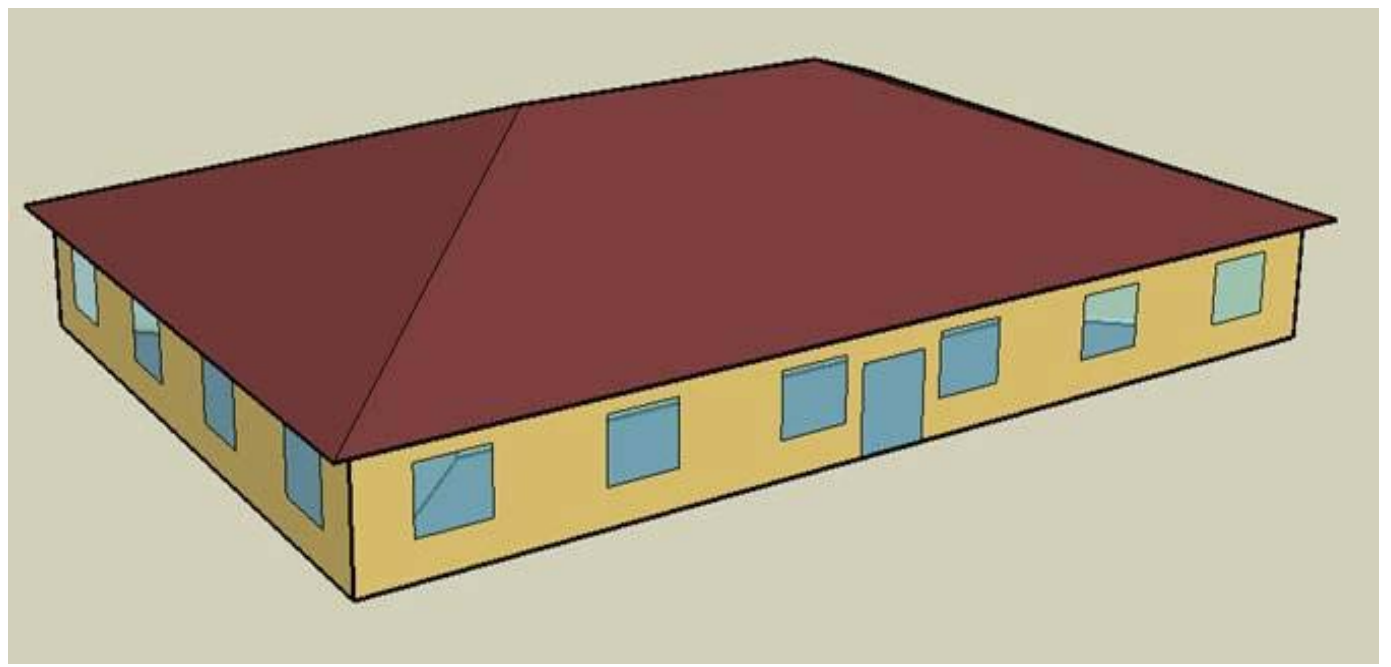

Figure 2: Axonometric View of Small Office Building

\section{Stand-alone Retail Building}

The stand-alone retail prototype shown in Figure 3 represents a retail box store with a total floor area of about 25,000 $\mathrm{ft}^{2}$. Based on the space usage and the location, the store is divided into five areas: front entry (0.5\%), storage space (16.5\%), core retail (70\%), front retail (6.5\%), and cashier area (6.5\%), where the number in parenthesis indicates the percentage of that space area. Each space area is regarded as one thermal zone. Except for the front entry served by a unit heater, the other thermal zones are equipped with a packaged unit with DX cooling and gas furnace heating. Key building characteristics of the stand-alone building are shown in Table A2 in Appendix A.

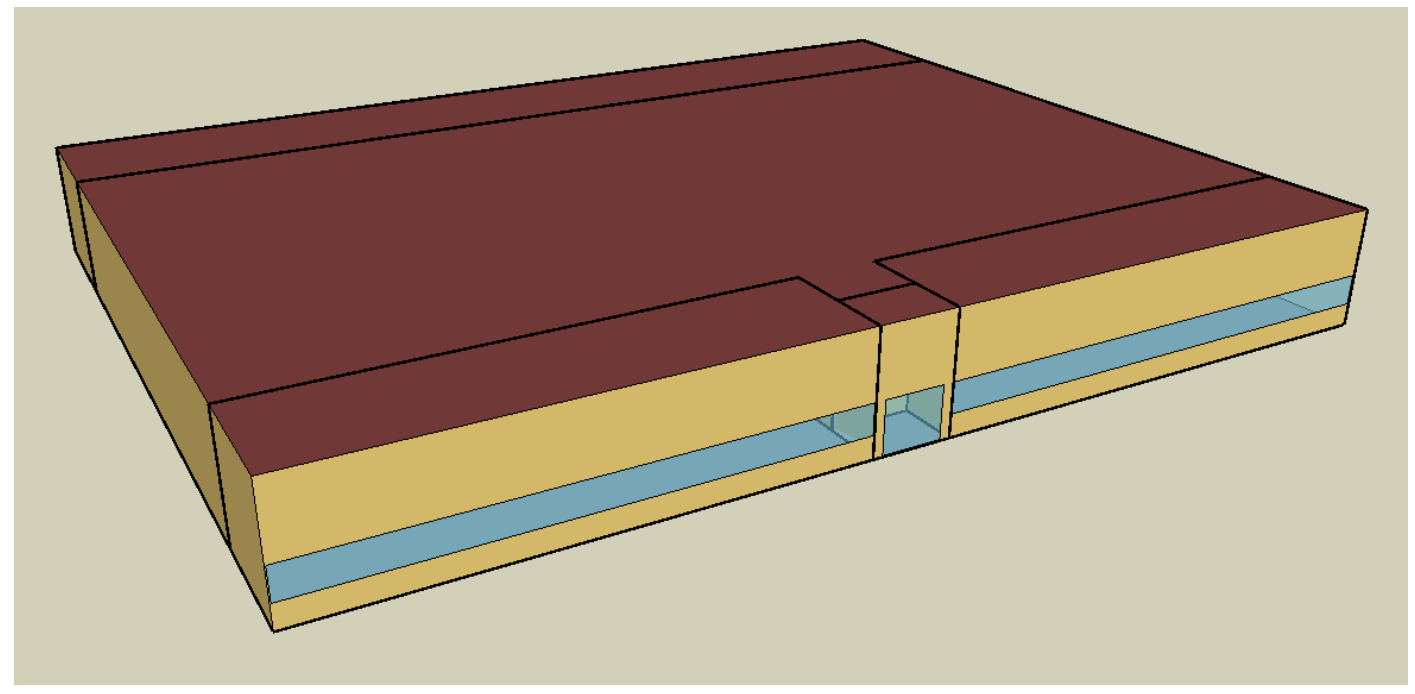

Figure 3: Axonometric View of Stand-alone Retail Building

\section{$\underline{\text { Strip Mall }}$}

The strip mall retail prototype building (Figure 4) has a total floor area of 22,500 $\mathrm{ft}^{2}$. It consists of two large stores and eight small stores. The large store has an area of $3,750 \mathrm{ft}^{2}$ and the small 
store has an area of $1,875 \mathrm{ft}^{2}$. All glazing is on the south façade, and the overall window-to-wall ratio is $10.5 \%$ for the whole building. Each store is served by a packaged single-zone unit with gas furnace heating and DX cooling. Major building characteristics of the strip mall are given in Table A3 in Appendix A.

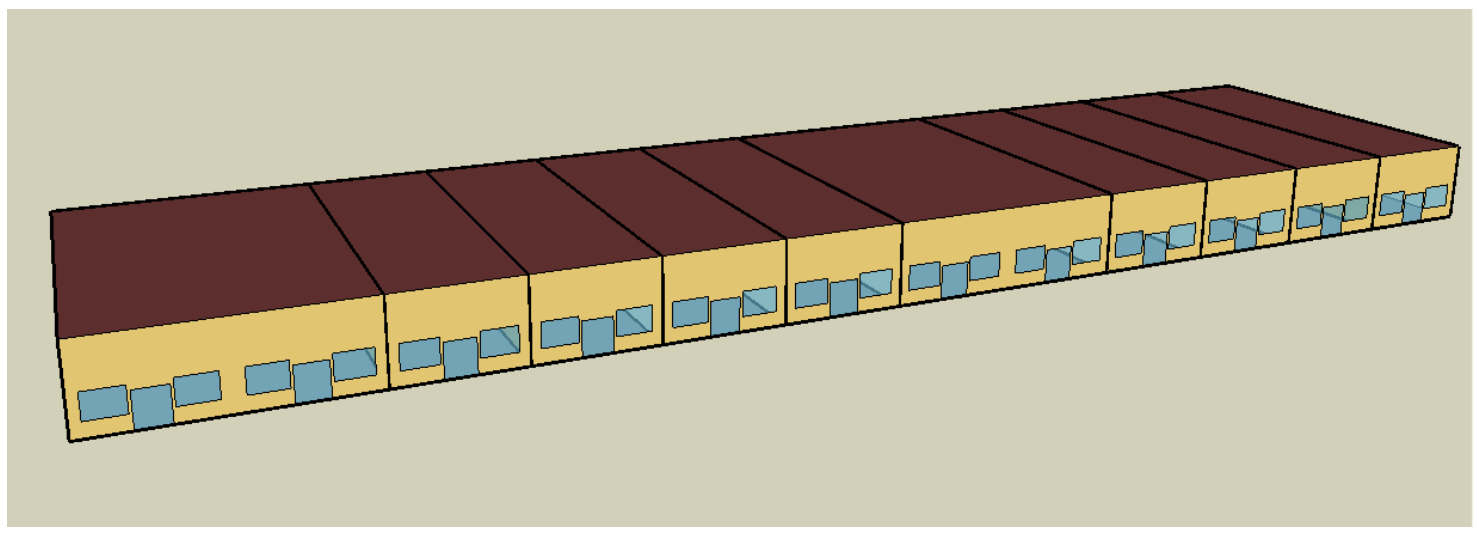

\section{Figure 4: Axonometric View of Strip Mall}

\section{$\underline{\text { Supermarket }}$}

The supermarket prototype building (Figure 5) has a total floor area of $45,000 \mathrm{ft}^{2}$. There is glazing only on the south façade. The overall window-to-wall ratio for the whole building is $10.5 \%$. This single-floor store is divided into six different functional spaces: main sales (56\%), produce (17\%), bakery (5\%), deli (5\%), office (2\%) and dry storage (15\%), where the number in parenthesis indicated the percentage of area for each space. Each functional space is dealt as a thermal zone served by a packaged air conditioner with gas furnace heating and DX cooling. The basic characteristics of the supermarket building are listed in Table A4 in Appendix A.

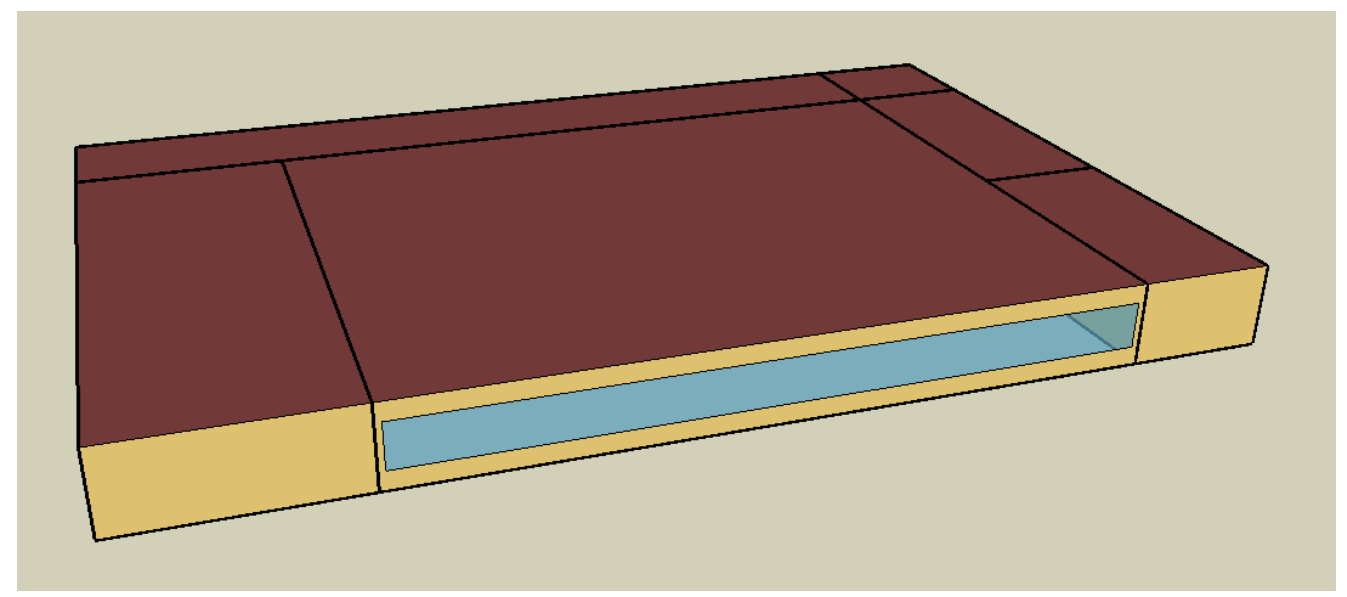

\section{Figure 5: Axonometric View of Supermarket}

Table 2 summarizes the floor area, number of packaged systems, system operation hours and ventilation requirement for all four building types. Because these building are modeled as post1980 construction, the ventilation requirements for different spaces are set according to ASHRAE Standard 62.1-1999 (ASHRAE 1999). 
Table 2: Building Types Studied

\begin{tabular}{|c|c|c|c|c|}
\hline Building Type & $\begin{array}{c}\text { Floor } \\
\text { Area (ft }{ }^{2} \text { ) }\end{array}$ & $\begin{array}{c}\text { Number } \\
\text { of } \\
\text { Packaged } \\
\text { Systems }\end{array}$ & $\begin{array}{c}\text { System } \\
\text { Operation } \\
\text { Hours per } \\
\text { Week (Hours) }\end{array}$ & Ventilation \\
\hline Small Office & 5,500 & 5 & 92 & $20 \mathrm{cfm} /$ person \\
\hline $\begin{array}{c}\text { Stand-alone } \\
\text { Retail }\end{array}$ & 25,000 & 4 & 91 & $\begin{array}{c}0.15 \mathrm{cfm} / \mathrm{sf} \text { (storage) } \\
0.3 \mathrm{cfm} / \mathrm{sf}(\mathrm{sales})\end{array}$ \\
\hline Strip Mall & 22,500 & 10 & 91 & $0.3 \mathrm{cfm} / \mathrm{sf}$ \\
\hline Supermarket & 45,000 & 6 & 168 & $\begin{array}{c}20 \mathrm{cfm} / \text { person } \\
\text { (office) } \\
0.15 \mathrm{cfm} / \mathrm{sf} \text { (storage) } \\
0.3 \mathrm{cfm} / \mathrm{sf} \text { (sales) }\end{array}$ \\
\hline
\end{tabular}

\subsection{Climates and Locations}

The energy saving potential from adding advanced controls to packaged rooftop units usually varies with climate conditions. Hence, it is desirable to simulate the same building model in different climate conditions. ASHRAE Standard 90.1 (ASHRAE 2010b) provides a classification of climate zones according to the heating- and cooling-degree-days and the atmospheric moisture. This classification covers eight major climate zones from 1 to 8 with increasing heating-degree-days and decreasing cooling-degree-days. A major climate zone may be further divided into humid, dry, and marine climate types, which are labeled as A, B and C, respectively. For example, climate zone 3 is characterized as warm climate, and it has three subcategories: $3 \mathrm{~A}$ for humid climate; 3B for dry climate and 3C for marine climate. Following the DOE reference building models (Deru et al. 2011), a total of 16 populous cities were selected to represent all climate zones in the U.S. (Table 3). Two locations were selected for climate zone 3B because of the large variations of the regional weather conditions within that zone (Deru et al. 2011). 
Table 3: Selected Climates and Corresponding Representative Locations for Saving Analysis

\begin{tabular}{|c|c|c|c|}
\hline $\begin{array}{l}\text { Climate } \\
\text { Zone }\end{array}$ & Climate Type & Representative City & Thermal Criteria \\
\hline $1 \mathrm{~A}$ & Very hot, humid & Miami, FL & $5000<\mathrm{CDD} 50^{\circ} \mathrm{F}$ \\
\hline $2 \mathrm{~A}$ & Hot, humid & Houston, TX & $3500<\mathrm{CDD} 50{ }^{\circ} \mathrm{F} \leq 5000$ \\
\hline $2 \mathrm{~B}$ & Hot, dry & Phoenix, AZ & $3500<\mathrm{CDD} 50{ }^{\circ} \mathrm{F} \leq 5000$ \\
\hline $3 \mathrm{~A}$ & Warm, humid & Atlanta, GA & $2500<\mathrm{CDD} 50{ }^{\circ} \mathrm{F} \leq 3500$ \\
\hline $3 \mathrm{~B}$ & Warm, coastal & Los Angeles, CA & $2500<\mathrm{CDD} 50{ }^{\circ} \mathrm{F} \leq 3500$ \\
\hline $3 B$ & Warm, dry & Las Vegas, NV & $2500<\mathrm{CDD} 50{ }^{\circ} \mathrm{F} \leq 3500$ \\
\hline $3 C$ & Warm, marine & San Francisco, CA & HDD $65^{\circ} \mathrm{F} \leq 2000$ \\
\hline $4 \mathrm{~A}$ & Mixed, humid & Baltimore, MD & $\begin{array}{l}\mathrm{CDD} 50^{\circ} \mathrm{F} \leq 2500 \\
\mathrm{HDD} 65^{\circ} \mathrm{F} \leq 3000\end{array}$ \\
\hline $4 \mathrm{~B}$ & Mixed, dry & Albuquerque, NM & $\begin{array}{l}\mathrm{CDD} 50^{\circ} \mathrm{F} \leq 2500 \\
\mathrm{HDD} 65^{\circ} \mathrm{F} \leq 3000\end{array}$ \\
\hline $4 \mathrm{C}$ & Mixed, marine & Seattle, WA & $2000<\mathrm{HDD} 65^{\circ} \mathrm{F} \leq 3000$ \\
\hline $5 \mathrm{~A}$ & Cool, humid & Chicago, IL & $3000<\mathrm{HDD} 65^{\circ} \mathrm{F} \leq 4000$ \\
\hline $5 B$ & Cool, dry & Denver, CO & $3000<\mathrm{HDD} 65^{\circ} \mathrm{F} \leq 4000$ \\
\hline $6 \mathrm{~A}$ & Cold, humid & Minneapolis, MN & $4000<\mathrm{HDD} 65^{\circ} \mathrm{F} \leq 5000$ \\
\hline $6 \mathrm{~B}$ & Cold, dry & Helena, MT & $4000<\mathrm{HDD} 65^{\circ} \mathrm{F} \leq 5000$ \\
\hline 7 & Very cold & Duluth, MN & $5000<\mathrm{HDD} 65^{\circ} \mathrm{F} \leq 7000$ \\
\hline 8 & Subarctic & Fairbanks, AK & $7000<\mathrm{HDD} 65^{\circ} \mathrm{F}$ \\
\hline
\end{tabular}

CDD: cooling-degree-days; HDD: heating-degree-days 


\section{Analytic Methodology}

The energy usage impacts (savings or potential penalties) associated with changing from the baseline control for packaged units to one of the advanced control packages is determined using simulation of the representative prototype buildings with the EnergyPlus software. By taking the difference in energy use of the packaged units between the base case control and the advanced control package, the impact of using the advanced control package can be determined.

Electricity and gas consumption are separated to obtain the impacts by energy source. Savings on energy costs are estimated by multiplying the change in use of each of the energy sources by the corresponding energy price. Blended rates that essentially combine demand charges with usage charges are used for electricity. The energy cost impacts are then used to calculate the breakeven non-energy costs (capital plus installation) that would yield selected values of the simple payback period. The analyses are performed for the four building types identified in Section 3, at least one location in each primary U.S. climate zone, and many selected combinations of advanced control options (i.e., control packages). The results provide insight into how impacts vary with location (and climate), building type and energy prices, and perspective on the total of the capital and installations costs that yield a range of payback periods likely to be acceptable to building owners. Greater detail on the methodology is provided in the sections that follow.

\subsection{Energy Use Estimation Methodology}

To estimate the energy consumption of a prototype building using packaged rooftop units with various control options, detailed EnergyPlus simulation models are used. Specifically, the EnergyPlus software with the energy management system feature (DOE 2010) is used to simulate energy usage over a typical climatological year for each location. Simulations were performed for:

- 4 building types,

- 16 locations (in 15 climate zones), and

- 22 control options (base case + 21 different combinations of advanced control options).

Combinations of these characteristics resulted in 1,408 cases (and corresponding EnergyPlus runs). In this section, the various packages of advanced control strategies are described. All combinations of control strategies are listed in Table 4. The strategies include economizer control, supply-fan-speed control, single- and two-stage cooling, and demand-control ventilation (DCV) control. In Table 4:

- The case name and number are used as identifiers and are used while discussing the results. The case name consists of four to five dot-separated parts identifying the control strategies associated with each case. The following abbreviations are used to designate the control features in each case: nonintegrated economizer (NIEcon), integrated economizer (IEcon), no economizer (NoEcon), differential dry-bulb economizer control (DB), differential enthalpy economizer control (EH), single-speed fan (SSFan), multispeed fan (MSFan), single-cooling stage (CS1), two-cooling stages (CS2), DCV control (DCV1), and no DCV control (DCV0).

- The baseline case has a constant speed supply fan, single-stage cooling, no air-side economizer and no DCV. This baseline is assumed to be typical for many existing light commercial rooftop units. Although in many locations some form of economizer control 
is required, for this study the base case building has no economizer controls. This definition of the base case is not critical because any case (e.g., Case 2 or 3, which include economizer control), can be considered as the base case for determining the incremental impacts of adding more control options. Thus, by comparing energy consumption of the base case with other cases, the energy and cost savings from retrofitting existing packaged units with advanced control packages can be estimated. For other initial control capabilities, the energy use with the appropriate initial control package can be compared to the energy use with other control packages to investigate the benefits from adding other advanced control features to those initially present.

- Not all possible combinations of different control strategies are investigated for the purpose of simplification. For example, the nonintegrated economizer is considered in only four cases (Cases 2, 3, 7 and 8) in the context of single-stage cooling and no DCV, although many more cases could be created by combining it with two-stage cooling and DCV.

Simulations were performed for all 22 control cases for the four building types in each of the 15 climates and 16 locations, leading to 1408 simulations.

Following the original DOE commercial building reference models (Deru et al. 2011), both gas furnace and DX cooling are sized automatically by EnergyPlus. The weather conditions for HVAC equipment sizing are selected as: the dry-bulb temperature corresponding to the $99.6 \%$ annual cumulative frequency of occurrence for the heating-design-day condition and the drybulb temperature corresponding to the $1 \%$ annual cumulative frequency of occurrence and the corresponding wet-bulb temperature for the cooling-design-day condition. The internal loads including occupancy, lights, and plug loads are specified as zero on the heating design day and as the peak values (Table A1 thru A4 in Appendix A) on the cooling design day.

For packaged rooftop units serving single-zone systems, EnergyPlus sizes the supply-fan air flow and the capacities of DX cooling and gas furnace in a number of steps. The space heating and cooling loads are calculated for each predefined time step (e.g., 15 minutes) for each design day. Based on the system-design supply-air temperature, the zone supply-air flow rates needed to meet the zone design loads are calculated using the heat balance method (ASHRAE 2009). The sub-hourly zone loads are summed and averaged across a wide time window (e.g., 1 hour) to prevent unrealistically large flow rates caused by space warm up or cool down when an abrupt change of thermostat set points occurs. The maximum heating and cooling air flow rate is then regarded as the supply-fan design flow rate. This design flow rate is used together with the design minimum outdoor-air flow rate to obtain the mixed-air conditions, based on which heating and cooling coil loads can be calculated. The maximum heating coil load is then assigned as the gas furnace capacity. Because the coil inlet-air and outdoor-air conditions at the peak cooling coil load may differ from the rating conditions for packaged DX cooling, the maximum cooling load needs to be processed further by accounting for the capacity change with operating conditions to obtain the rated DX cooling capacity (DOE 2010). An oversize factor of 1.2 is applied to the resulting capacities to size the equipment consistently with general design practice.

As shown in Table 5, the packaged cooling equipment at different capacities and the gas furnace efficiencies were selected as those used in the DOE reference buildings (Deru et al. 2011). Post1980 vintage buildings were selected to represent control strategies commonly used for packaged units on existing buildings. 
Table 4: Combinations of Control Options (or Control Packages) Considered for Each Building Type in all 16 Locations

\begin{tabular}{|c|c|c|c|c|c|c|}
\hline $\begin{array}{c}\text { Case } \\
\text { No }\end{array}$ & Case Name & $\begin{array}{c}\text { Economizer } \\
\text { Control } \\
\end{array}$ & $\begin{array}{c}\text { Integrated } \\
\text { Economizer }\end{array}$ & $\begin{array}{c}\text { Fan Speed } \\
\text { Control } \\
\end{array}$ & $\begin{array}{c}\text { DX Cooling } \\
\text { Stages }\end{array}$ & DCV \\
\hline 1 & Baseline & No economizer & - & Constant & One & No \\
\hline 2 & NIEcon.DB.SSFan.CS1.DCV0 & Differential dry bulb & No & Constant & One & No \\
\hline 3 & NIEcon.EH.SSFan.CS1.DCV0 & Differential enthalpy & No & Constant & One & No \\
\hline 4 & IEcon.DB.SSFan.CS1.DCV0 & Differential dry bulb & Yes & Constant & One & No \\
\hline 5 & IEcon.EH.SSFan.CS1.DCV0 & Differential enthalpy & Yes & Constant & One & No \\
\hline 6 & NoEcon.MSFan.CS1.DCV0 & No economizer & - & Multiple & One & No \\
\hline 7 & NIEcon.DB.MSFan.CS1.DCV0 & Differential dry bulb & No & Multiple & One & No \\
\hline 8 & NIEcon.EH.MSFan.CS1.DCV0 & Differential enthalpy & No & Multiple & One & No \\
\hline 9 & IEcon.DB.MSFan.CS1.DCV0 & Differential dry bulb & Yes & Multiple & One & No \\
\hline 10 & IEcon.EH.MSFan.CS1.DCV0 & Differential enthalpy & Yes & Multiple & One & No \\
\hline 11 & NoEcon.MSFan.CS2.DCV0 & No economizer & - & Multiple & Two & No \\
\hline 12 & IEcon.DB.MSFan.CS2.DCV0 & Differential dry bulb & Yes & Multiple & Two & No \\
\hline 13 & IEcon.EH.MSFan.CS2.DCV0 & Differential enthalpy & Yes & Multiple & Two & No \\
\hline 14 & NoEcon.SSFan.CS1.DCV1 & No economizer & - & Constant & One & Yes \\
\hline 15 & IEcon.DB.SSFan.CS1.DCV1 & Differential dry bulb & Yes & Constant & One & Yes \\
\hline 16 & IEcon.EH.SSFan.CS1.DCV1 & Differential enthalpy & Yes & Constant & One & Yes \\
\hline 17 & NoEcon.MSFan.CS1.DCV1 & No economizer & - & Multiple & One & Yes \\
\hline 18 & IEcon.DB.MSFan.CS1.DCV1 & Differential dry bulb & Yes & Multiple & One & Yes \\
\hline 19 & IEcon.EH.MSFan.CS1.DCV1 & Differential enthalpy & Yes & Multiple & One & Yes \\
\hline 20 & NoEcon.MSFan.CS2.DCV1 & No economizer & - & Multiple & Two & Yes \\
\hline 21 & IEcon.DB.MSFan.CS2.DCV1 & Differential dry bulb & Yes & Multiple & Two & Yes \\
\hline 22 & IEcon.EH.MSFan.CS2.DCV1 & Differential enthalpy & Yes & Multiple & Two & Yes \\
\hline
\end{tabular}


Table 5: Efficiency of Cooling, Heating and Fan Systems

\begin{tabular}{|c|c|c|c|}
\hline Equipment & Capacity & Performance Metric & Value \\
\hline \multirow{5}{*}{$\begin{array}{l}\text { Packaged DX } \\
\text { cooling }\end{array}$} & $<65 \mathrm{kBtu} / \mathrm{h}$ & SEER & 11.06 \\
\hline & $\begin{array}{c}\geq 65 \mathrm{kBtu} / \mathrm{h} \text { and }<135 \\
\mathrm{kBtu} / \mathrm{h}\end{array}$ & EER & 9.63 \\
\hline & $\begin{array}{c}\geq 135 \mathrm{kBtu} / \mathrm{h} \text { and }<240 \\
\mathrm{kBtu} / \mathrm{h}\end{array}$ & EER & 9.28 \\
\hline & $\begin{array}{c}\geq 240 \mathrm{kBtu} / \mathrm{h} \text { and }<760 \\
\mathrm{kBtu} / \mathrm{h}\end{array}$ & EER & 8.92 \\
\hline & $>760 \mathrm{kBtu} / \mathrm{h}$ & EER & 8.63 \\
\hline Gas furnace & all & $\begin{array}{l}\text { Combustion } \\
\text { efficiency }\end{array}$ & 0.8 \\
\hline \multirow{6}{*}{ Fan } & \multirow{2}{*}{$<7,487 \mathrm{cfm}$} & Pressure rise & 2.5 in. w.c. \\
\hline & & Mechanical efficiency & $65 \%$ \\
\hline & \multirow{2}{*}{$\begin{array}{l}\geq 7,487 \mathrm{cfm} \text { and }<20,000 \\
\mathrm{cfm}\end{array}$} & Pressure rise & 4.46 in. w.c. \\
\hline & & Mechanical efficiency & $65 \%$ \\
\hline & \multirow{2}{*}{$>20,000 \mathrm{cfm}$} & Pressure rise & 4.09 in. w.c. \\
\hline & & Mechanical efficiency & $65 \%$ \\
\hline
\end{tabular}

The sequence of rooftop unit operation considered in this work requires specialized control of packaged single-zone systems. The traditional controls built into EnergyPlus are not capable of modeling many control options, for example, the temperature set point differential and variation of fan speed with operation modes. To address the challenge, the energy management system (EMS) feature in EnergyPlus (DOE 2010) is used to provide the ability to customize controls. The EMS provides a variety of sensors and actuators much like actual building automation systems. The sequences of operations embedded in the EnergyPlus input files are used to override the traditional control and to add the desired control functionality into the simulation.

Several significant considerations in use of the EMS feature of EnergyPlus are discussed below.

- A number of control parameters need to be defined for the EMS control. Table 6 lists the parameters that are independent of climate, location, and building type. The table shows that the constant speed fan runs at its design speed, and the multi-speed fan runs at different speeds in different operation modes: $40 \%$ of the design speed in ventilation mode, $75 \%$ of the design speed in economizing mode, $75 \%$ and $100 \%$ of the design speed in first and second stage cooling modes, respectively, when two-stage cooling applies. The fan runs at $100 \%$ of the design speed when single-stage DX cooling is used. 
Table 6: Default Values of the Key Control Parameters

\begin{tabular}{|c|c|}
\hline Parameter & Value \\
\hline Heating and cooling set point differential $(\delta)$ & $1.8^{\circ} \mathrm{F}$ \\
\hline Economizer supply-air temperature set point $\left(\mathrm{T}_{\mathrm{EcoSP}}\right)$ & $55^{\circ} \mathrm{F}$ \\
\hline Interstage delay time limit $\left(\Delta t_{\text {Limit }}\right)$ & $9 \mathrm{~min}$ \\
\hline $\begin{array}{l}\text { Temperature threshold for changeover from OA } \\
\text { economizer cooling to DX cooling }\left(\mathrm{T}_{\text {Eco-DX }}\right)\end{array}$ & $58^{\circ} \mathrm{F}$ \\
\hline $\begin{array}{l}\text { Temperature threshold for changeover from first to } \\
\text { second stage } \mathrm{DX} \text { cooling }\left(\mathrm{T}_{\mathrm{DX} \_ \text {Stage }}\right)\end{array}$ & $58^{\circ} \mathrm{F}$ \\
\hline Fan speed in ventilation mode $\left(\right.$ Fan $\left._{\text {Ven }}\right)$ & $\begin{array}{l}\text { 100\% (constant speed) } \\
40 \% \text { (multi-speed) }\end{array}$ \\
\hline Fan speed in heating mode $\left(\right.$ Fan $\left._{\text {Heat }}\right)$ & $100 \%$ \\
\hline Fan speed in economizing mode (Fan Eco $)$ & $\begin{array}{l}\text { 100\% (constant speed) } \\
\text { 75\% (multi-speed) }\end{array}$ \\
\hline Fan speed in first stage cooling $\left(\right.$ Fan $\left._{\text {Stage1 }}\right)$ & $\begin{array}{l}\text { 100\% (constant speed) } \\
75 \% \text { (multi-speed) }\end{array}$ \\
\hline $\begin{array}{l}\text { Fan speed in single-stage cooling or second stage of } \\
\text { two stage cooling }\left(\operatorname{Fan}_{\text {stage } 2}\right)\end{array}$ & $100 \%$ \\
\hline Ambient $\mathrm{CO}_{2}$ concentration & 400 ppm (ASHRAE 2010a) \\
\hline Space $\mathrm{CO}_{2}$ concentration set point $\left(C_{C O 2, S P}\right)$ & 1000 ppm (ASHRAE 2010a) \\
\hline $\mathrm{CO}_{2}$ generation rate from people & $0.0084 \mathrm{cfm} / \mathrm{met}$ (ASHRAE 2010a) \\
\hline
\end{tabular}

- The fan power consumption is calculated based on the design pressure rise, the air flow rate, and the fan efficiency. For the ideal situation of no power loss on fan drive and motor, the power is proportional to the cube of the fan speed. Chan (2004) and Ford (2011) have shown that to approximately account for these losses, the fan power can be expressed as proportional to fan speed, to a power of between 2.0 and 3.0. Therefore, we express the fan power at any fraction of full speed by the relation:

$$
\begin{aligned}
P_{\text {Fan }, x} & =P_{\text {Fan }, 100} *\left(\frac{x}{100}\right)^{2.5} \\
& =\frac{Q_{\text {design }} \Delta P}{6350 \eta_{\text {total }}} *\left(\frac{x}{100}\right)^{2.5}
\end{aligned}
$$

where $P_{\text {Fan }}$ is the fan power in hp; $Q_{\text {design }}$ is the design air flow rate of the fan in cfm; $\Delta P$ is the design pressure rise in in. w.c. across the fan; $\eta_{\text {total }}$ is the fan total efficiency including fan mechanical efficiency, drive efficiency and motor efficiency; and the subscripts $\mathrm{x}$ and 100 designate the fraction fan speed to which the variable corresponds.

- For cases with two-stage cooling, it is assumed that the two stages have the same cooling capacity under the same operating conditions. The decrease in efficiency caused by compressor cycling is not considered in this work. 
- For the ventilation control, the EMS works directly on the outdoor air flow rate instead of through OA-damper modulation as usually found in practice. Thus, for the cases with no DCV control, the OA flow rate is maintained at the design ventilation level unless an air economizer is activated. For the cases with DCV control, the minimum OA flow rate is set at $25 \%$ of the design ventilation level to dilute contaminates from non-occupants (i.e., even if the space $\mathrm{CO}_{2}$ concentration is less than $1000 \mathrm{ppm}, 25 \%$ of the design ventilation air is provided).

\subsection{Economic Analysis Methodology}

For each simulation, EnergyPlus provides estimates of fan electricity consumption, cooling electricity consumption, gas consumption for heating, and total (electricity plus gas) energy consumption. The total energy consumption is the sum of all four end-uses in consistent units. Annual energy cost is simply calculated from the utility rates and the annual energy consumption using the equation:

$$
\begin{aligned}
A E C & =G C+E C \\
& =r_{\text {gas }} * Q_{\text {gas }}+r_{\text {elec }} * Q_{\text {elec }}
\end{aligned}
$$

where $A E C, G C$ and $E C$, respectively, represent annual energy cost, annual gas cost, and annual electricity cost; $r_{\text {gas }}$ and $r_{\text {elec }}$ are the utility rates (i.e., prices) for natural gas and electricity, respectively; $Q_{g a s}$ is the annual natural gas consumption in Therms; and $Q_{\text {elec }}$ is the annual electricity consumption in $\mathrm{kWh}$.

Average blended gas and electricity prices from EIA (2011) are used for the analysis. EIA provides the historical data on monthly utility rates in all states back to the 1970s. For each location, the corresponding state average price in the year of 2010 is used as the applicable price for a whole year.

Table 7 lists the electricity and gas prices for all 16 locations, each located in a different climate zone (except for Las Vegas and Los Angeles).

The maximum total initial (non-energy) cost of retrofitting an advanced control package on an existing rooftop unit equals the breakeven initial total cost that can be supported by the energy savings from adding the advanced control package. This initial cost, which is the sum of the initial capital cost of the advanced controller equipment and the cost of installation, is a function of the simple payback period desired by the purchaser (ordinarily the building owner). Having the annual energy cost for a given advanced control package in case i, the maximum acceptable initial cost can be calculated as:

$$
\begin{aligned}
I C_{i, \max } & =\left(I C_{i, \text { capital }}+I C_{i, \text { installation }}\right)_{\max } \\
& =\left(A E C_{i}-A E C_{\text {base }}\right)^{*} N_{s p p}
\end{aligned}
$$


where, $I C_{i, \max }$ is the maximum acceptable initial total installed cost of the advanced controller with case i for a building in $\$$; $I C_{i, \text { capital }}$ is the corresponding capital cost of the controller; $I C_{i, \text { nstallation }}$ is the installation cost; $N_{\text {spp }}$ is the simple payback period in years; and the subscripts $i$ and base refer to the $i$-th case and the baseline case, respectively. Note that IC is the total installed cost for a building. Therefore, if the building has a number of units, then per unit cost can be estimated by dividing IC by the number of units to obtain the maximum acceptable total initial cost for a single advanced controller.

The conventional approach of assuming a total initial cost $\left(I C_{i}\right)$ of the advanced controller for a building could, of course, be assumed. In this situation, the payback period for the controller could be estimated as:

$$
N_{\text {spp }}=\frac{I C_{i}}{A E C_{i}-A E C_{\text {base }}}
$$

Table 7: Electricity and Gas Prices by Location in the Year of 2010 (EIA 2011)

\begin{tabular}{|c|c|c|c|c|}
\hline Climate Zone & City & State & $\begin{array}{c}\text { Electricity } \\
\mathbf{( \$ / k W h )}\end{array}$ & $\begin{array}{c}\text { Natual Gas } \\
\mathbf{( \$ / T h e r m})\end{array}$ \\
\hline 1A & Miami & FL & 0.098 & 1.052 \\
\hline 2A & Houston & TX & 0.092 & 0.806 \\
\hline 2B & Phoenix & AZ & 0.094 & 1.073 \\
\hline 3A & Atlanta & GA & 0.091 & 1.137 \\
\hline 3B & Los Angeles & CA & 0.138 & 0.830 \\
\hline 3B & Las Vegas & NV & 0.099 & 0.977 \\
\hline 3C & San Francisco & CA & 0.138 & 0.830 \\
\hline 4A & Baltimore & MD & 0.116 & 1.006 \\
\hline 4B & Albuquerque & NM & 0.086 & 0.755 \\
\hline 4C & Seattle & WA & 0.073 & 1.072 \\
\hline 5A & Chicago & IL & 0.088 & 0.983 \\
\hline 5B & Denver & CO & 0.090 & 0.775 \\
\hline 6A & Minneapolis & MN & 0.083 & 0.736 \\
\hline 6B & Helena & MT & 0.085 & 0.895 \\
\hline 7 & Duluth & MN & 0.083 & 0.736 \\
\hline 8 & Fairbanks & AK & 0.141 & 0.863 \\
\hline
\end{tabular}




\section{Energy Savings}

The energy savings from different packaged rooftop unit control strategies are presented and discussed in this section. The baseline HVAC energy use and the distribution of time in different operating modes are presented first. Then, in Section 5.2, the impact of each individual control strategy on HVAC energy savings is investigated. Section 5.3 shows the incremental impact of several advanced control strategies. Two pairs of control combinations are selected, and they are compared in Sections 5.4 and 5.5 to understand the potential of energy savings from different control combinations.

\subsection{Baseline HVAC Energy Use and Distribution of Operation Modes}

It is important to have a clear picture of the baseline energy use before investigating the potential of energy savings with various control combinations. Because the investigated control strategies do not affect the energy use for lighting, plug loads and service hot water, only HVAC energy uses (i.e., ventilation, cooling, and heating) are considered. Figure 6 through Figure 9 show the annual HVAC energy use and its split between heating, cooling and fan consumption across all 16 locations for the four building types. For the horizontal axis, the number and letter after the location name indicates the climate zone that the location belongs to. In these figures, the gas energy for heating and the electrical energy for cooling and fan operation are simply summed without distinction of the fuel types to obtain the total energy use. These figures lead to the following observations:

- The annual HVAC energy consumption lies in between 90 and $420 \mathrm{MMBtu}$ for the small office building, 640 and 5,610 MMBtu for the stand-alone retail building, 700 and 5,590 MMBtu for the strip mall, and 1310 and 13,920 MMBtu for the supermarket building. After normalization with the building area (Table 2), the HVAC energy use intensities for the four building types are in the following ranges: 17 through $82 \mathrm{kBtu} / \mathrm{ft}^{2} / \mathrm{yr}$ for the small office building, 26 through $227 \mathrm{kBtu} / \mathrm{ft}^{2} / \mathrm{yr}$ for the stand-alone retail building, 31 through $248 \mathrm{kBtu} / \mathrm{ft}^{2} / \mathrm{yr}$ for the strip mall, and 29 through $287 \mathrm{kBtu} / \mathrm{ft}^{2} / \mathrm{yr}$ for the supermarket.

- Except for the supermarket, all building types have the lowest energy consumption in mild climates, such as Los Angeles and San Francisco. Because of the additional energy required to compensate for the heating load from refrigeration cases, the supermarket building has the lowest energy consumption in Miami. As expected, all four building types have the largest energy consumption in the extremely cold climates, i.e., Fairbanks.

- Of the three HVAC end uses, fans consume about $10 \%$ to $40 \%$ of the total HVAC energy, the precise fraction depending on the climate. Fan energy use accounts for larger fractions in mild climates and smaller fractions in cold climates. Cooling and heating, in contrast, account for $1 \%$ to $70 \%$ and $1 \%$ to $90 \%$ of the total HVAC energy use, respectively.

For ease of reference, the annual HVAC energy uses for the base case and all other 21 advanced control cases are also tabulated in Appendix B for the four building types. 


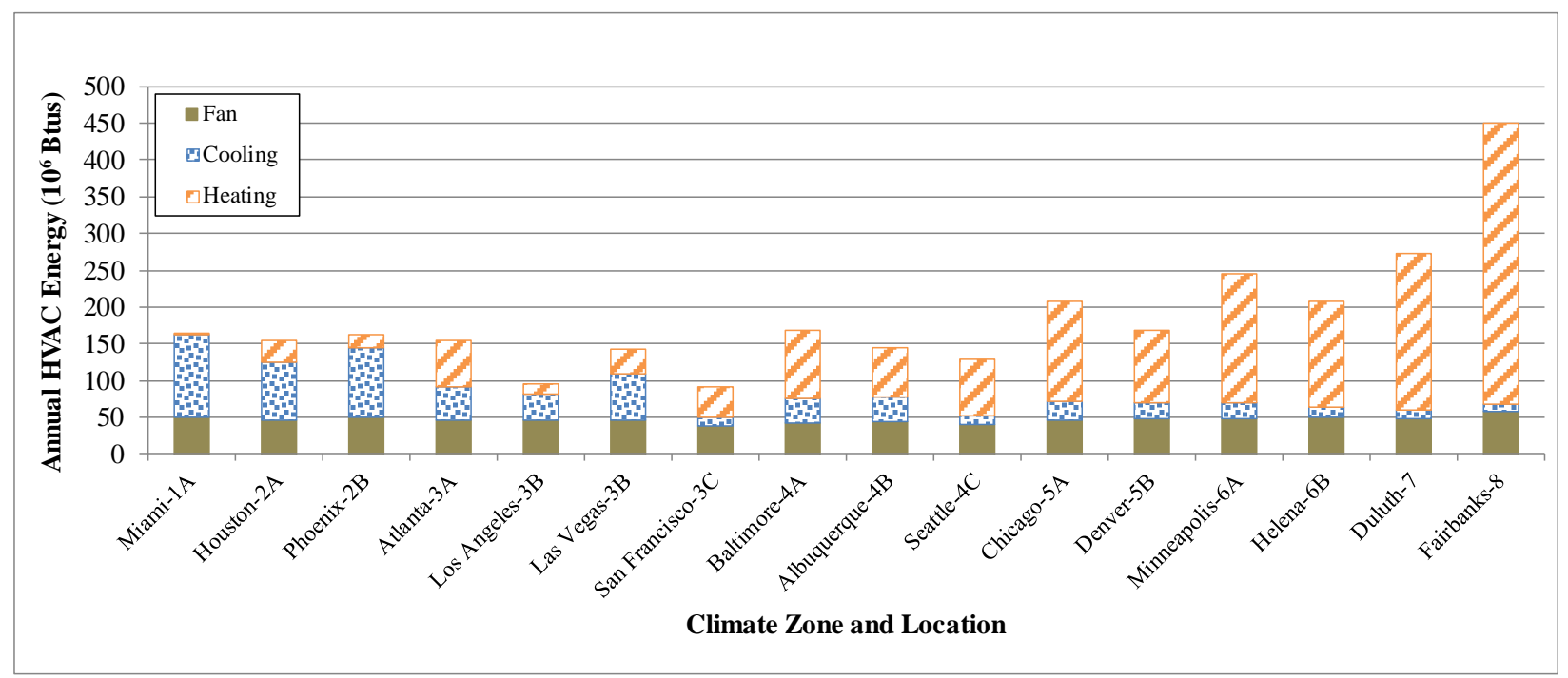

Figure 6: Annual HVAC Energy Use for Base Case Control (Case 1) of the Small Office Building

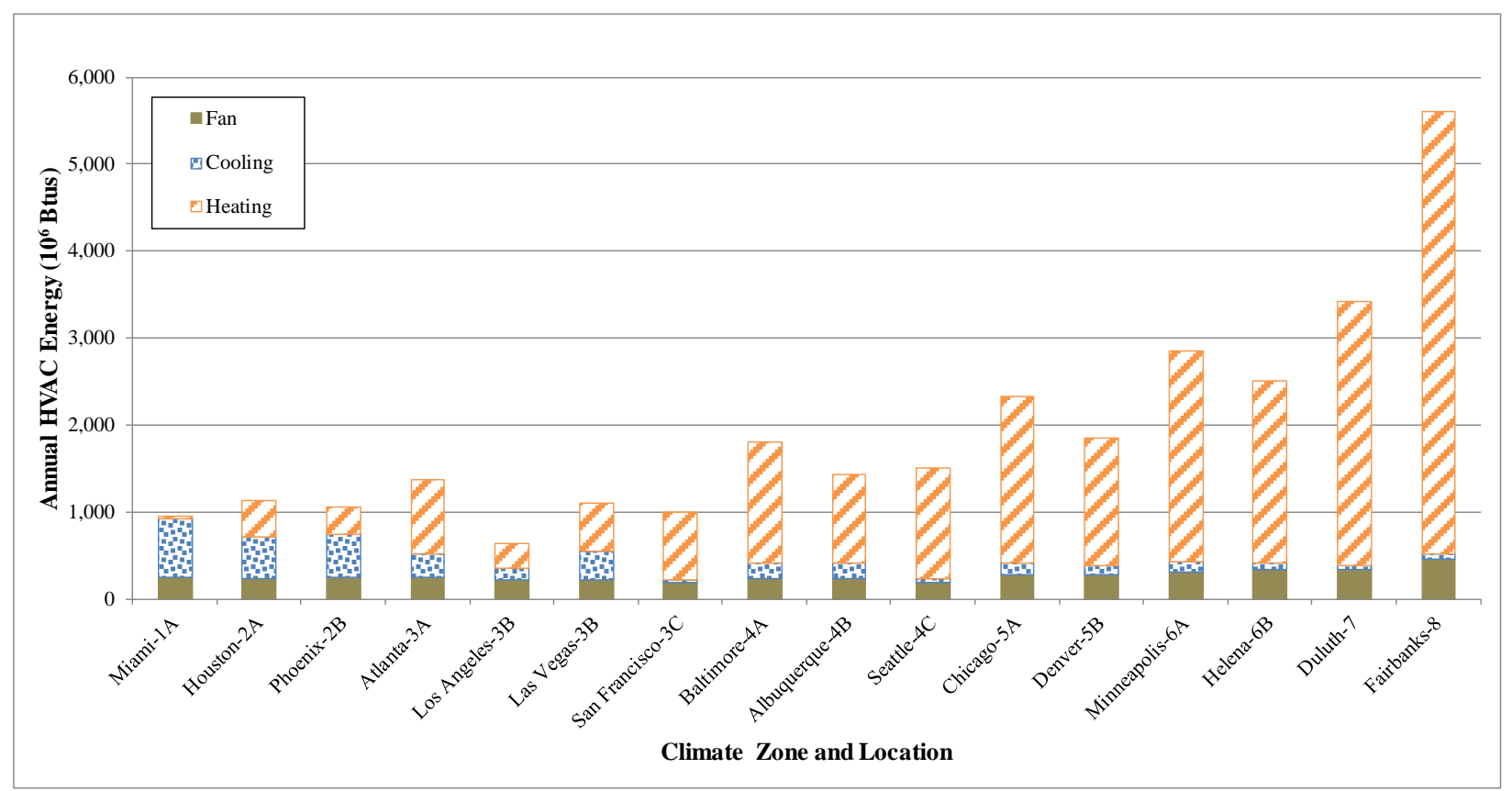

Figure 7: Annual HVAC Energy Use for Base Case Control (Case 1) of the Stand-alone Retail Building 


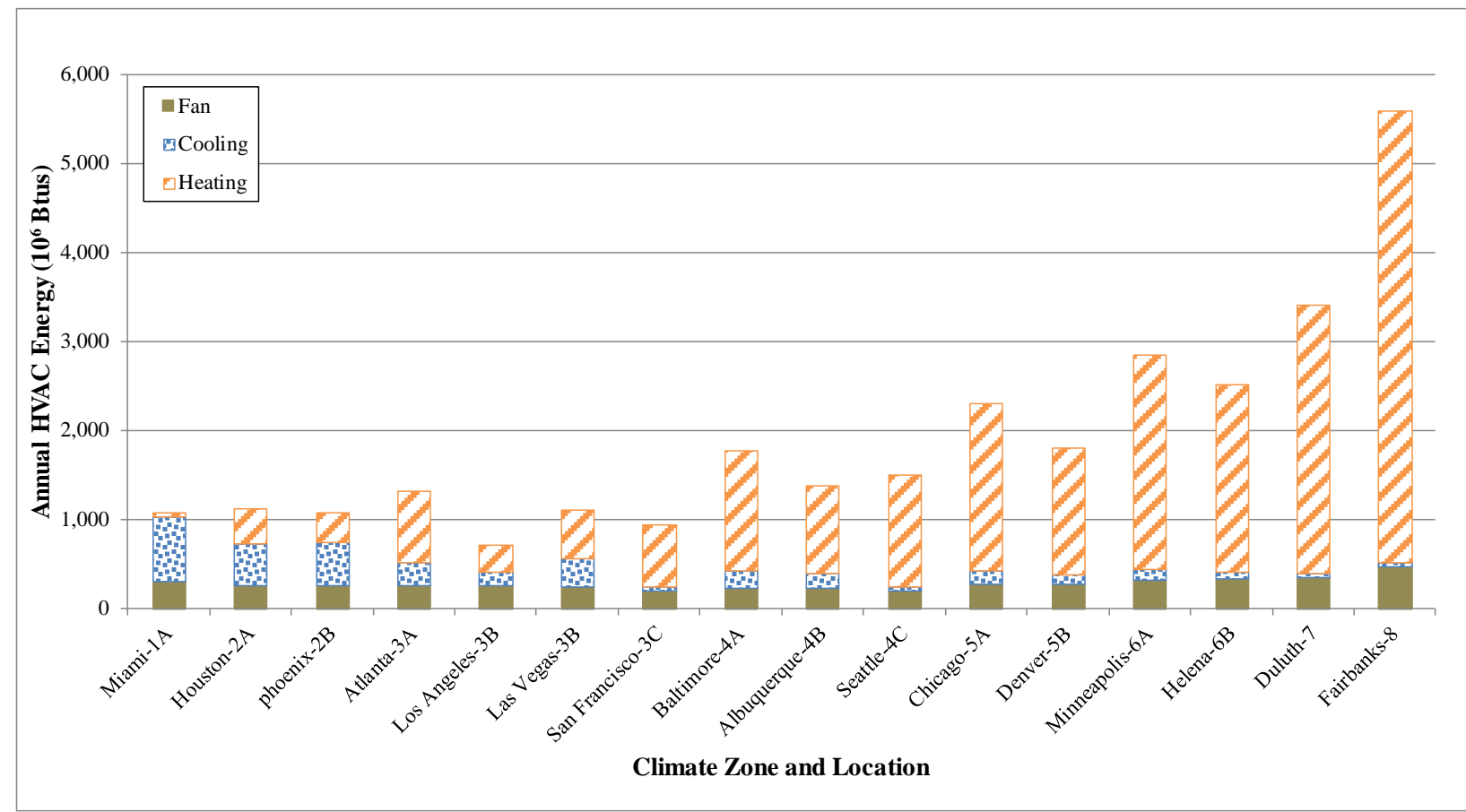

Figure 8: Annual HVAC Energy Use for Base Case Control (Case 1) of the Strip Mall Building

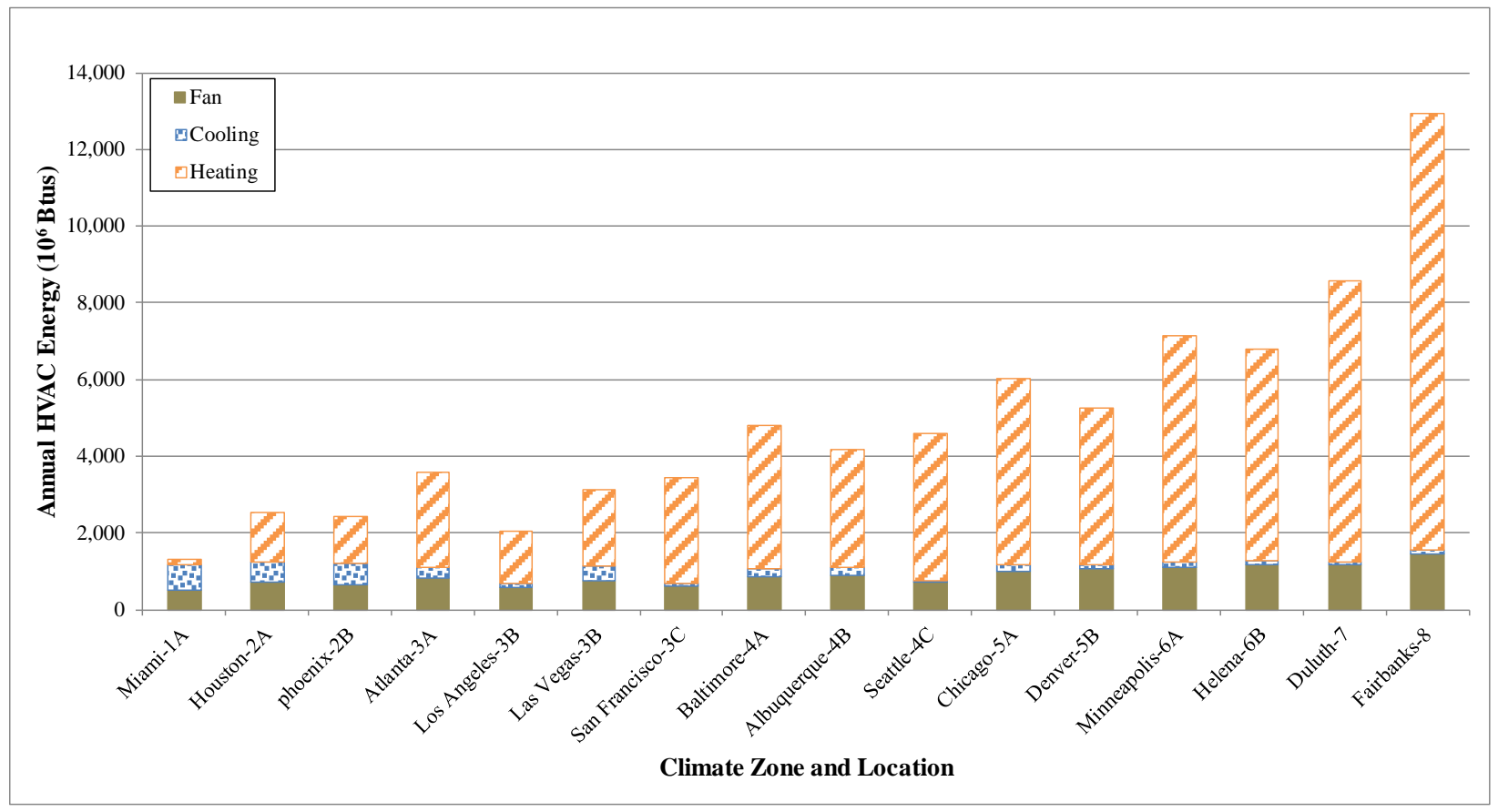

Figure 9: Annual HVAC Energy Use for Base Case Control (Case 1) of the Supermarket Building 
For the base case, when the packaged rooftop unit is on, it operates in one of the three operating modes: ventilation mode, cooling mode or heating mode. Figure 10 through Figure 13 show the distribution of the operation modes as a percentage of the total operating time in each location for the four building types. These results indicate that:

- Packaged single-zone rooftop units operate in the ventilation mode for more than $50 \%$ of their run time. This is observed for all examined building types and locations. The units in the hot climates have the lowest percentage of their operating time in the ventilation mode, while the units in the mild climates (such as Los Angeles and San Francisco) have the highest percentage of time in the ventilation mode.

- The percentage of time in the cooling mode ranges from about $4 \%$ to $40 \%$. As expected, the percentage of time in the cooling mode is generally greater for hot than for cold climates.

- The percentage of time in the heating mode lies in the range from less than $1 \%$ to about $12 \%$ for the small office building and to about $20 \%$ for the other three building types. In comparison with the other three building types, the small office building has a relatively small percentage of time in the heating mode. This is likely caused by the small office building having an attic roof, which acts as a buffer between the outdoors and the indoors, reducing the heat loss through the ceiling and thus the total heating load. As expected, the percentage of time in the heating mode increases as the climate becomes colder.

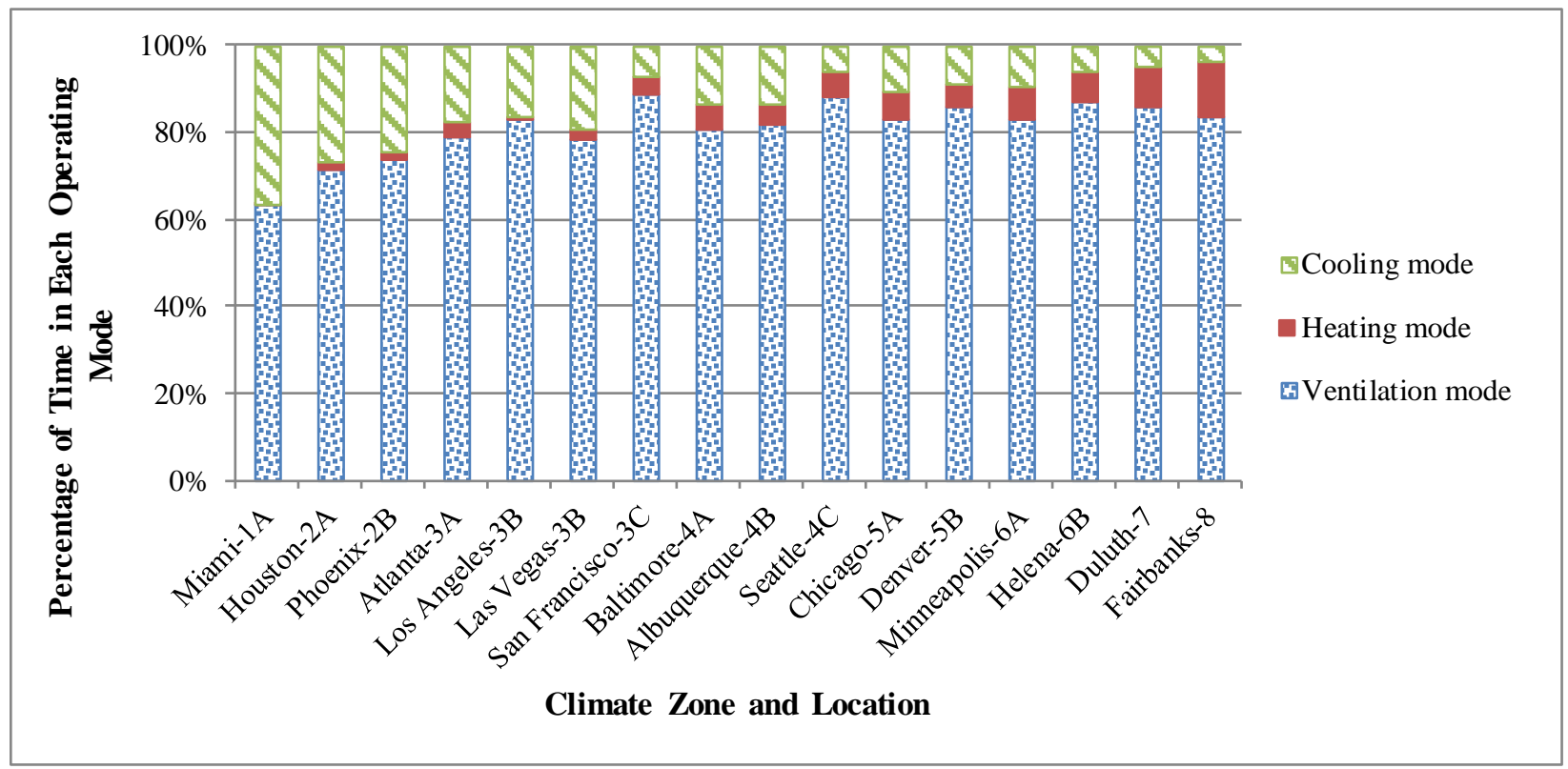

Figure 10: Percentage of Time in Each of the Operational Modes for the Small Office Building for all 16 Locations 


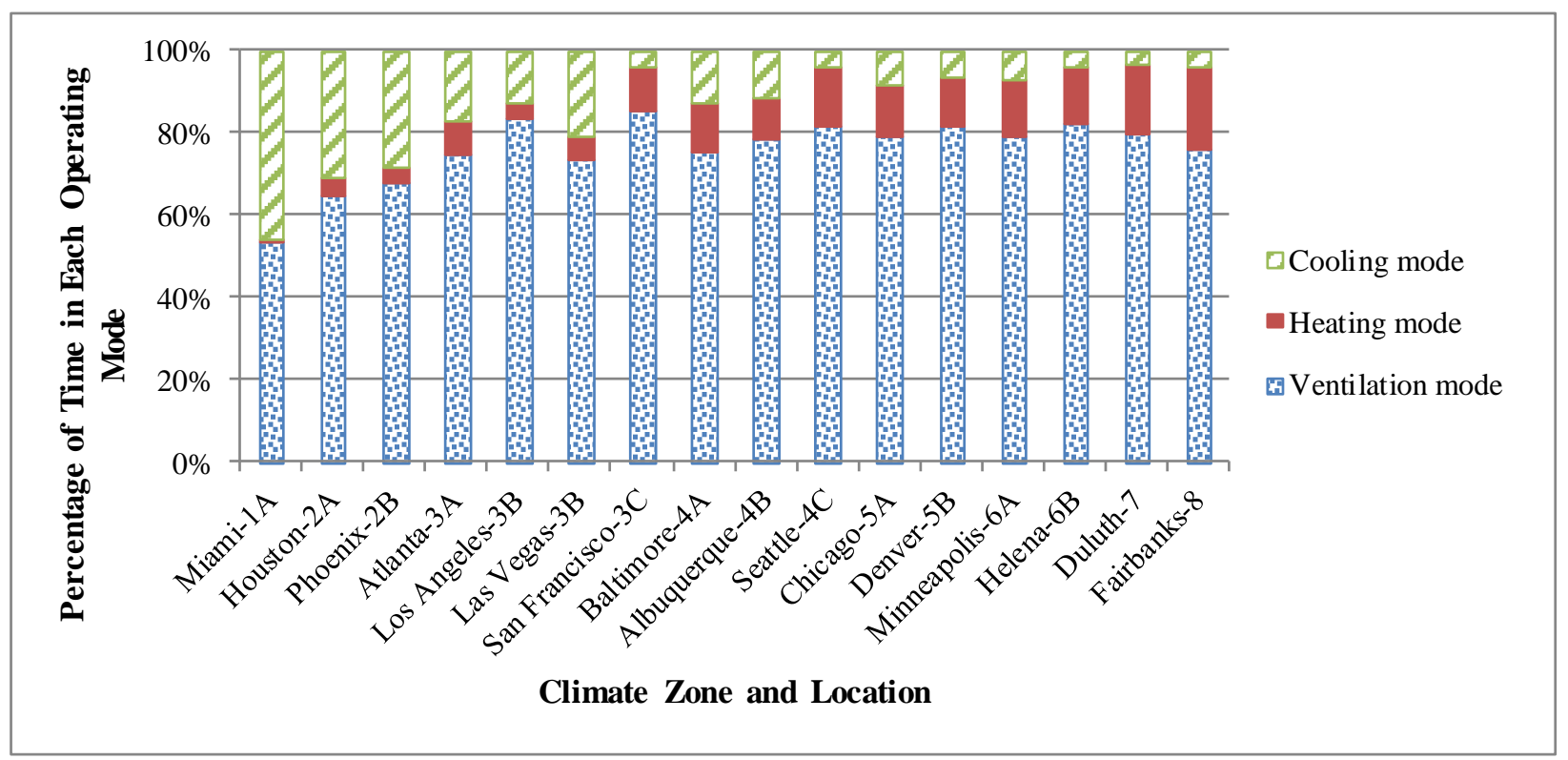

Figure 11: Percentage of Time in Each of the Operational Modes for the Stand-alone Retail Building for all 16 Locations

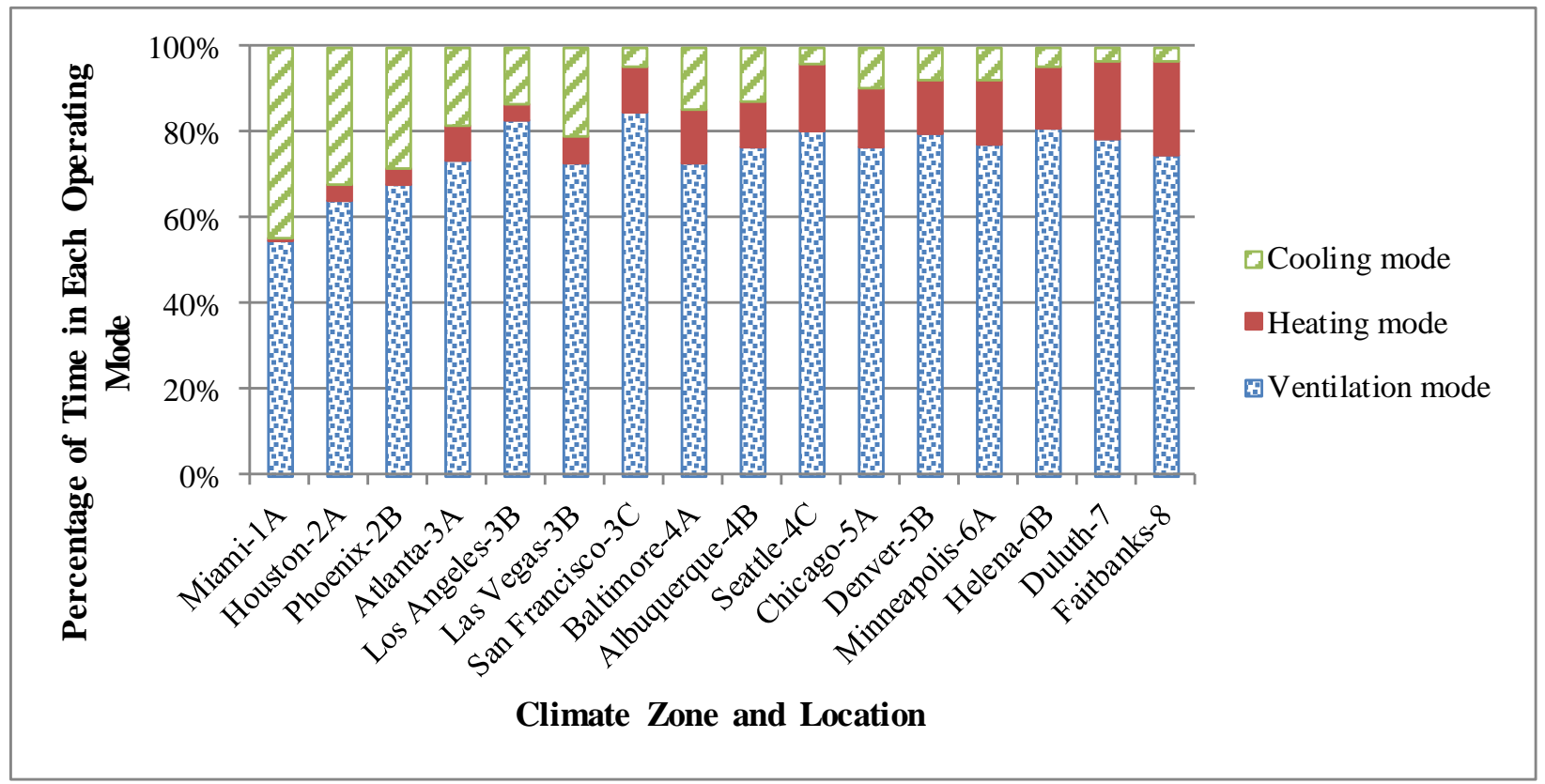

Figure 12: Percentage of Time in Each of the Operational Modes for the Strip Mall Building for all 16 Locations 


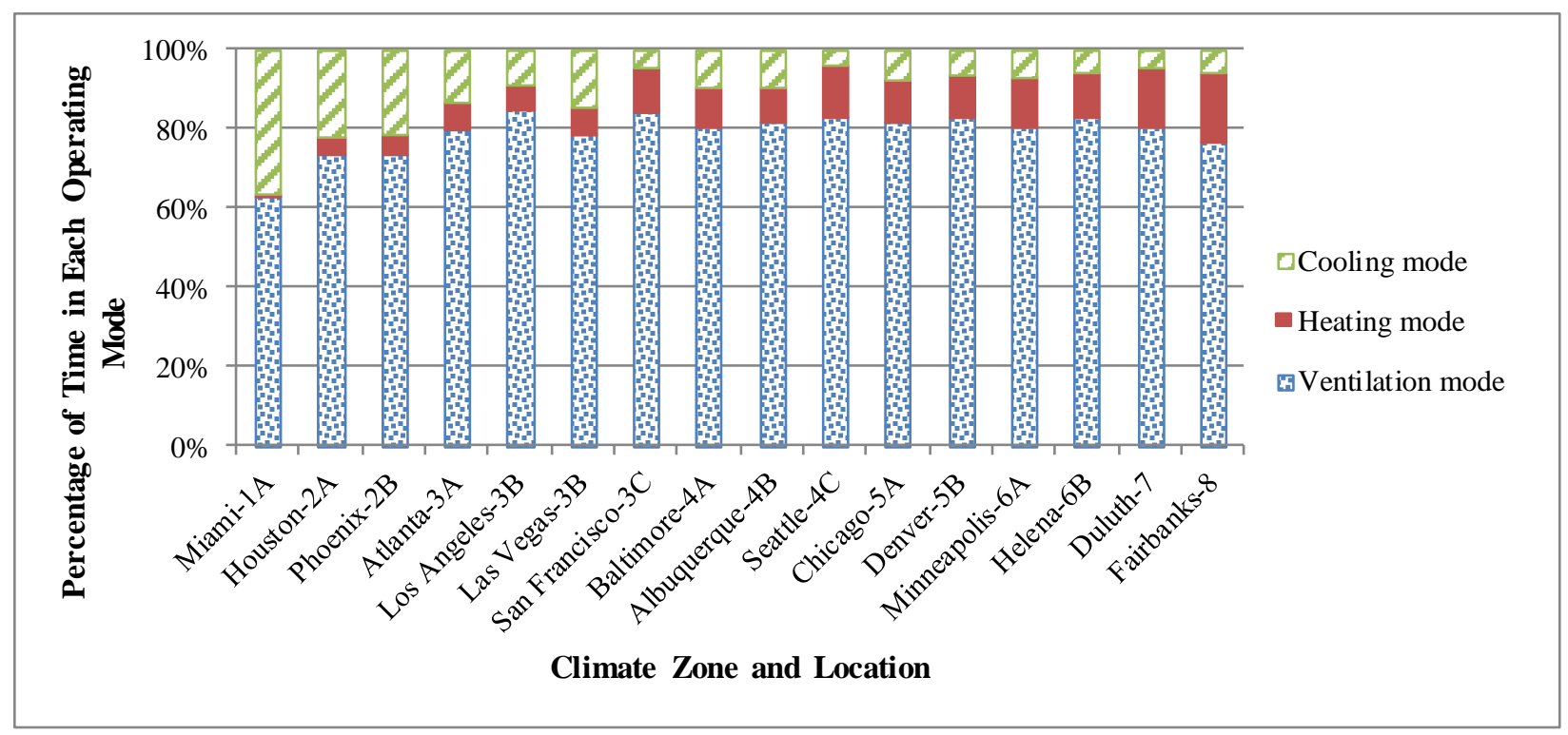

Figure 13: Percentage of Time in Each of the Operational Modes for the Supermarket Building for all 16 Locations

\subsection{Impact Assessment of Individual Control Strategies on HVAC Energy Uses}

With the HVAC energy uses for all 22 cases, the annual HVAC energy savings for each of the 21 advanced control combinations (cases) can be easily calculated as the difference between energy consumption for the base case and an advanced case for a given building type. The results are provided in Appendix C. To provide insights into the impact of advanced control combinations on the savings of different fuel sources, the results are presented for the total energy savings (Table C1 through C16), the electricity savings (Table C17 through C32), and the gas savings (Table C33 through C48). In all tables, the energy savings are shown as both absolute values and the percentages of the base case (Case 1) annual energy consumption. The difference between the tabulated energy savings for any two cases for a specific building type and location provides the average annual HVAC energy savings (i.e., consumption change) when changing from one combination of packaged-unit control strategies to another. Based on these results, the impact of air-side economizer, multi-speed fan control, DCV, and staged cooling is evaluated individually below.

The impact of an air-side economizer based on differential dry-bulb temperature is investigated in two steps: 1) the nonintegrated economizer control compared to the base case control is studied first, and 2) the results for the integrated economizer are then compared with the energy savings for the nonintegrated economizer control to obtain the additional benefits from integrating the air-side economizer with the mechanical cooling system. The integrated economizer option allows use of mechanical cooling to meet any cooling load that is not met by the economizer when outdoor conditions are suitable for economizing (compared to a packaged unit with a nonintegrated economizer that does not operate the economizer and mechanical cooling simultaneously), thus providing additional savings.

Comparing the energy consumption of Case 2 with the baseline (Case 1) provides the energy savings attributable to the nonintegrated air-side economizer using differential dry-bulb temperature as the control variable. In terms of the percentage savings (the upper part in Figure 
14), the nonintegrated air-side economizer has much greater energy savings potential in warm climates (Los Angeles and San Francisco) than it has in other climates. In Los Angeles, for example, energy savings of more than $20 \%$ of the Case 1 energy consumption are achieved for the small office building. In contrast, much smaller (less than 5\% of the Case 1 HVAC energy consumption) HVAC energy savings are observed for the locations with hot (e.g., Miami and Houston) or cold climates (e.g., Minneapolis and Duluth).

The percentage savings also vary with the building type. The small office building mostly has a higher percentage of energy savings than the other three building types. However, in terms of the absolute energy savings, the supermarket mostly has higher energy savings than other building types, which is simply because it has the largest floor area among the four building types.

The percentage savings from use of a nonintegrated economizer are greatest for the office building because the energy use for cooling, as a fraction of the total HVAC energy use, is greatest for the small office building compared to the other types of buildings. Furthermore, because economizing displaces mechanical cooling with "free" cooling with outdoor air, when cooling represents a greater fraction of the HVAC energy use (as with the small office building), the energy savings as a percentage of total HVAC energy use are also greater. It needs to be noted that the energy savings impacts of air-side economizer shown in Figure 14 correspond to a packaged unit having a single-speed fan, single-stage cooling, and no DCV. The results vary slightly with changes in the other advanced controls present on the packaged unit. For example, the percentage HVAC energy saving from the use of an air-side economizer decreases if the unit has multi-speed fan control rather than a constant fan speed, as can be found by comparing Cases 7 and 6.

For packaged single-zone rooftop units, switching from a nonintegrated economizer to an integrated economizer yields little energy savings. In hot-humid climates such as Miami, the use of integrated dry-bulb economizers may even increase the cooling energy consumption, as can be found by comparing Case 2 and Case 4 in Appendix B. This energy increase can occur because 1) the control logic based on differential dry-bulb temperature may causes the OA damper to fully open when the outdoor-air condition is cool but sufficiently humid to make the enthalpy of the outdoor air greater than the enthalpy of the return air (Taylor and Cheng 2010), and 2) the use of an integrated economizer increases the frequency at which this incorrect control decision occurs. 


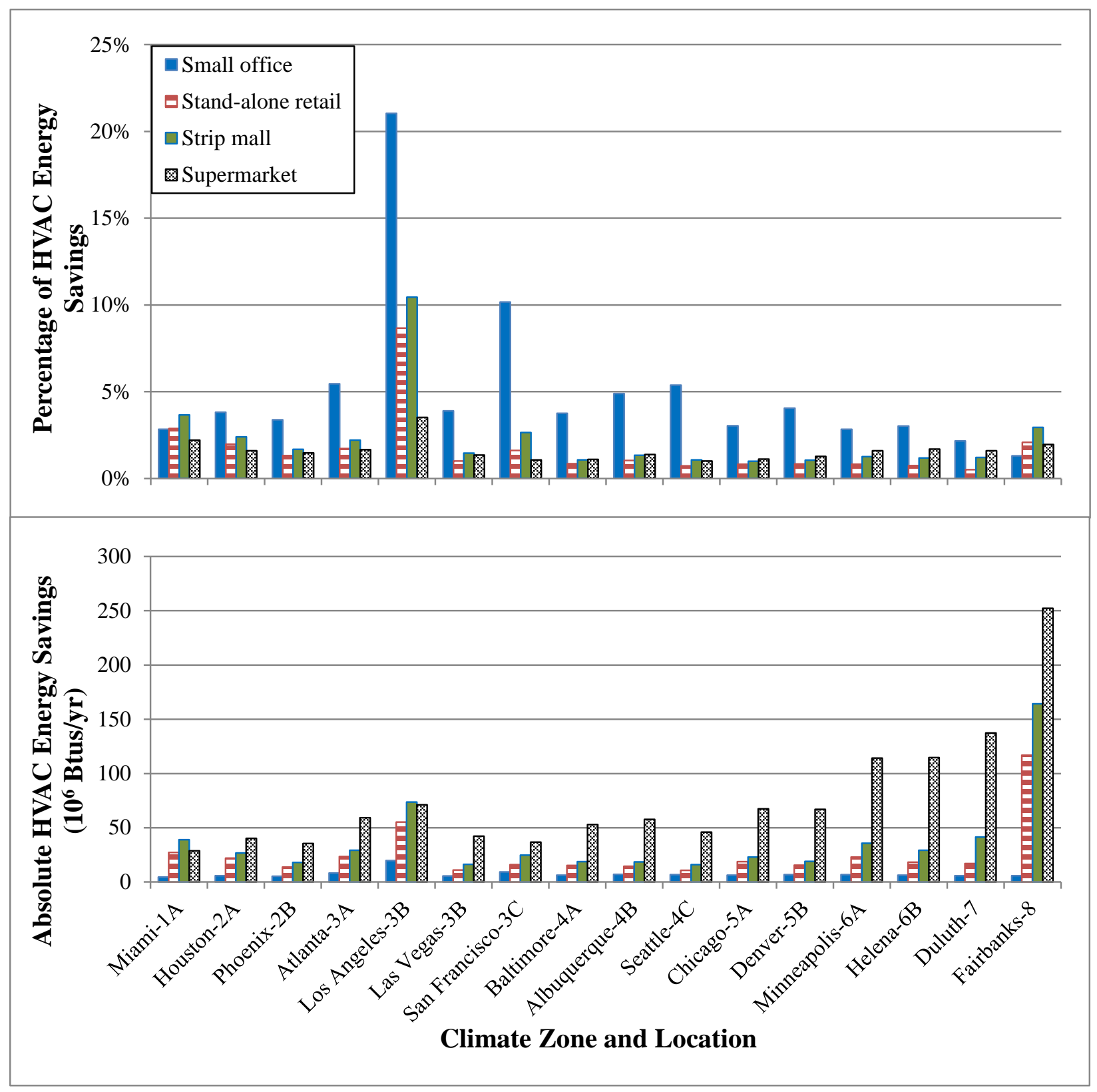

Figure 14: HVAC Energy Savings from the Use of Nonintegrated Air-Side Differential Dry-Bulb Economizer Controls (Case 2) Compared to the Base Case without Air-Side Economizer

Figure 15 shows the change of HVAC energy consumption from replacing nonintegrated differential dry-bulb economizing (Case 2) with nonintegrated differential enthalpy economizer control (Case 3). The upper part of the figure shows the energy savings as percentages of Case 2 HVAC energy consumption, whereas the lower part shows the energy savings as absolute values. Because a constant-speed fan is used for both cases, the fan energy consumption is identical. Therefore, the difference in HVAC energy consumption shown in Figure 15 results from changes in the energy required for cooling only. The negative values show that the differential enthalpybased economizer control saves no cooling energy. In fact, it increases the energy consumption. This result is expected for dry climates such as Los Angeles and Duluth. However, it is 
somewhat unexpected in humid climates such as Miami and Chicago, where differential enthalpy-based economizer control would intuitively be expected to perform more effectively than differential dry-bulb temperature-based economizer control. This phenomenon needs to be further investigated for possible explanations.

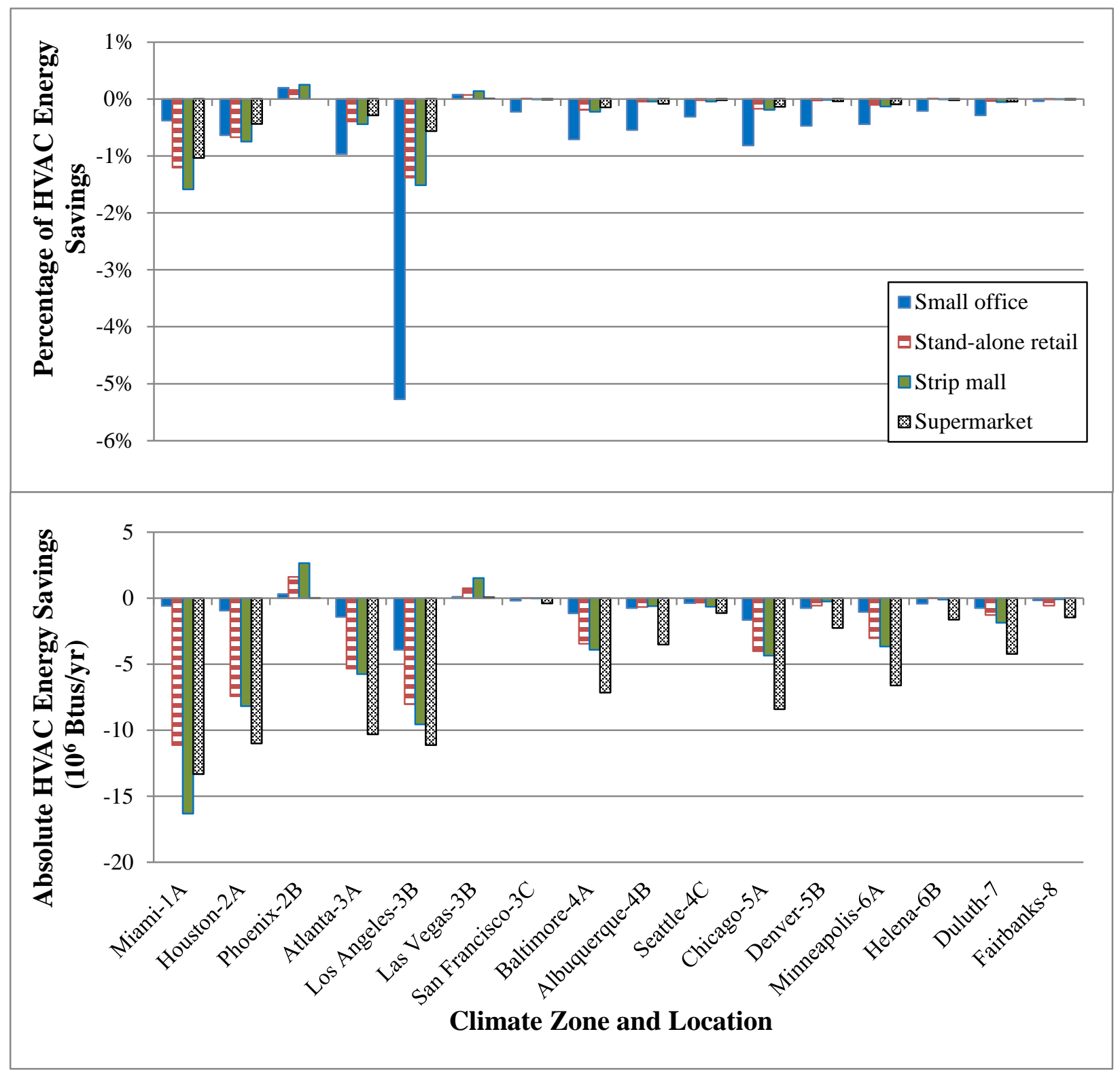

Figure 15: HVAC Energy Savings from use of a Nonintegrated Air-Side Differential Enthalpy Economizer in place of a Nonintegrated Differential Dry-Bulb Economizer for Four Building Types

The impact of supply-fan control on HVAC energy consumption can be investigated by comparing two cases, one using single-speed fan control and the other using multi-speed fan control. Figure 16 shows the change of HVAC energy consumption between the base case and Case 6, which uses multi-speed supply fan control. The upper part of the figure shows the energy 
savings as percentages of the base case HVAC energy consumption whereas the lower part shows the energy savings as absolute values. From Figure 16, the following observations are made:

- For all 4 building types, replacement of constant-speed fan control with multi-speed fan control yields energy savings of about $10 \%$ or more of the baseline HVAC energy consumption in hot climates (climate zones 1 and 2). However, the multi-speed fan option increases the HVAC energy consumption in cold climates (climate zones 6, 7 and 8). This observation can be explained by the impact of supply-fan control on energy end uses. The use of multi-speed fan control can significantly reduce fan energy use as a result of the fan speed reduction in a large fraction of the total fan operation time. Because fan power use is proportional to approximately the cubic power of the air flow rate, the significant decrease in fan speed provides substantial energy savings for fan operation. The fan energy reduction also contributes to reduction in cooling energy use because heat gains from the supply-fan motor also decrease. Therefore, multi-speed fan control can achieve significant energy savings in hot climates, where fans and mechanical cooling often account for more than 60\% of the total HVAC energy use. In contrast, in cold climates with large heating loads, heating dominates the total HVAC energy consumption, and the increased heating energy required to compensate for the substantial decrease in heat loss from the supply-fan motor usually exceeds the decrease in cooling and fan energy use while the unit operates in cooling mode, resulting from the change from constant-speed to multi-speed fan control. As a result, the overall annual HVAC energy consumption increases in cold climates. Although not shown in Figure 16, savings on energy costs result even in heating-dominated climates because the decrease in the cost for highly priced electricity is greater than the cost increase for lower-priced gas used for heating.

- The impact of multi-speed fan control on energy consumption varies with building type. In terms of the percentage energy saving relative to the base case (Case 1) energy consumption, the office building and the supermarket building have higher savings than the two retail buildings in three locations, including Miami (climate zone 1A), Houston (climate zone 2A), and Phoenix (climate zone 2B). The small office building maintains its highest percentage savings (or lowest percentage of energy increases) for all examined locations in climate zones 3 through 8 . The supermarket building shows an energy increase in many locations belonging to climate zones 4 through 8 . In terms of the absolute values of energy consumption changes, the use of multi-speed fan control has the largest impact on the supermarket building, while it has the smallest impact on the small office building. This difference in absolute energy savings among the building types is mainly caused by the difference in building size.

Certainly, the energy saving potential from multi-speed supply-fan control depends on the advanced control strategies already present on a packaged unit when multi-speed fan control is added. In addition to the comparison between Case 6 and the baseline, the impact of supply-fan control on energy savings can be investigated also by comparing a pair of other cases with multispeed supply-fan control as the only difference. Several examples of such case pairs are Case 7 vs. Case 2, Case 9 vs. Case 4, Case 18 vs. Case 15 and Case 19 vs. Case 16. 


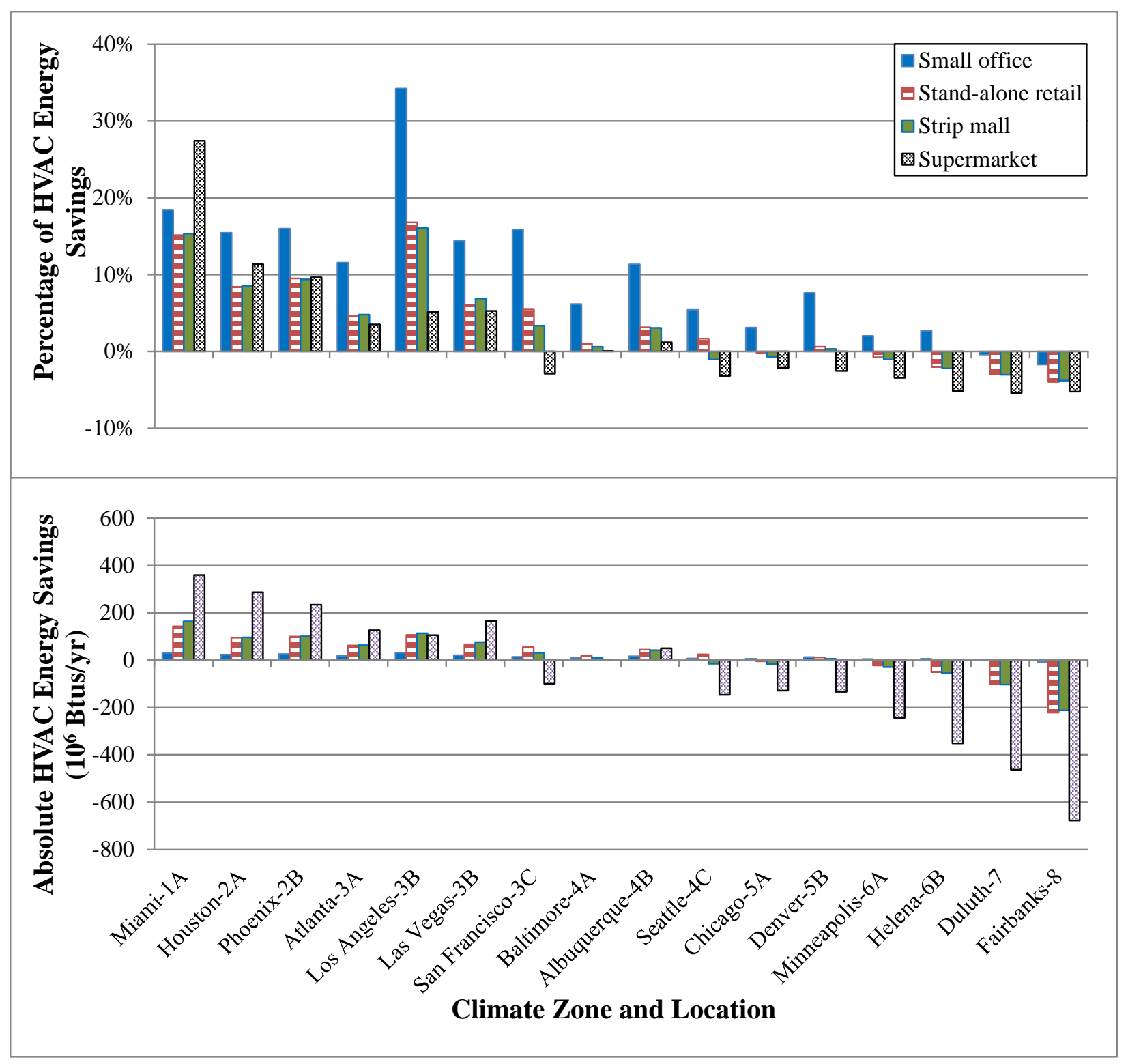

Figure 16: HVAC Energy Savings from the Use of Multi-speed Supply-Fan Control (Case 6) Compared to the Base Case with Constant-Speed Fan Control

The impact of demand controlled ventilation (DCV) on HVAC energy consumption can be investigated by comparing two cases, one using DCV and the other not using it. Figure 17 shows the change of HVAC energy consumption between the base case and Case 14, which differs from the base case only by the presence of DCV. The upper part of the figure shows the energy savings as percentages of the base case HVAC energy consumption whereas the lower part shows the energy savings as absolute values. 

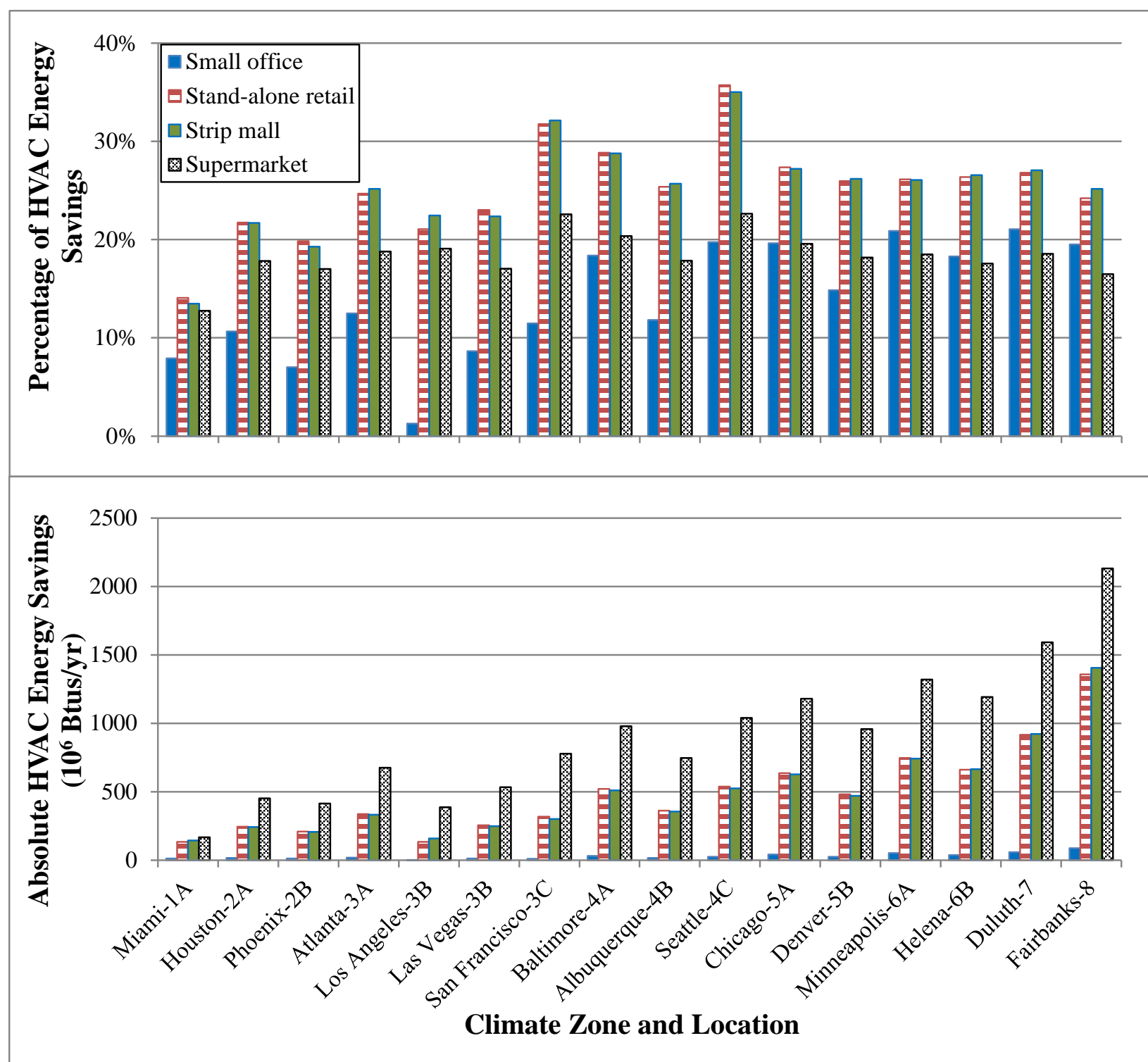

Figure 17: HVAC Energy Savings from the Use of Demand Controlled Ventilation (Case 14) Compared to the Base Case with Constant Outdoor-Air Supply

From Figure 17, the following can be observed:

- DCV provides HVAC energy savings of more than $10 \%$ of the base case energy consumption in all cases except for the small office building in Miami, Phoenix, Los Angeles, and Las Vegas. The largest percentage (approximately 35\%) energy savings occurs in Seattle for the stand-alone retail and the strip mall buildings.

- DCV achieves a smaller percentage HVAC energy savings for the small office building than it does for the other building types (except in the very cold climate of Duluth and Fairbanks). The difference in savings between building types can be attributed to some extent to their different occupancy profiles. Figure 18 shows the weekday occupancy profiles where the stand-alone retail building and the strip mall have the same occupancy 
schedule. For most occupied hours, the small office building has a more constant and higher occupancy ratio than the other three building types. A stable ventilation requirement close to the peak design limits the potential of energy savings from DCV.

- $\quad$ DCV seems to be more effective in the climates that have cold winters (climate zones 4 through 8). DCV is less effective in mild climates for two reasons. First, in mild climates, the outdoor-air temperature is close to the return-air temperature during much of the occupied period. Therefore, the amount of outdoor air exceeding ventilation requirements brought in by the packaged unit has less impact on energy consumption in mild climates than it has in harsher climates. Second, Case 14 and the base case have no air-side economizers. If DCV is used without an air-side economizer, reducing the OA flow rate may increase energy consumption when the system is in cooling mode and the outdoorair condition is favorable for economizing. This situation is expected to occur more often in mild climates.

Again, the energy savings potential from DCV depends on the other control strategies already used by the packaged unit. In addition to the comparison between Case 14 and the baseline, the impact of DCV on energy savings can also be investigated by comparing other case pairs such as Case 15 vs. Case 4 and Case 17 vs. Case 6. For example, comparing Case 17 and Case 6 leads to the impact of DCV when the packaged units have already used the multi-speed supply-fan control.

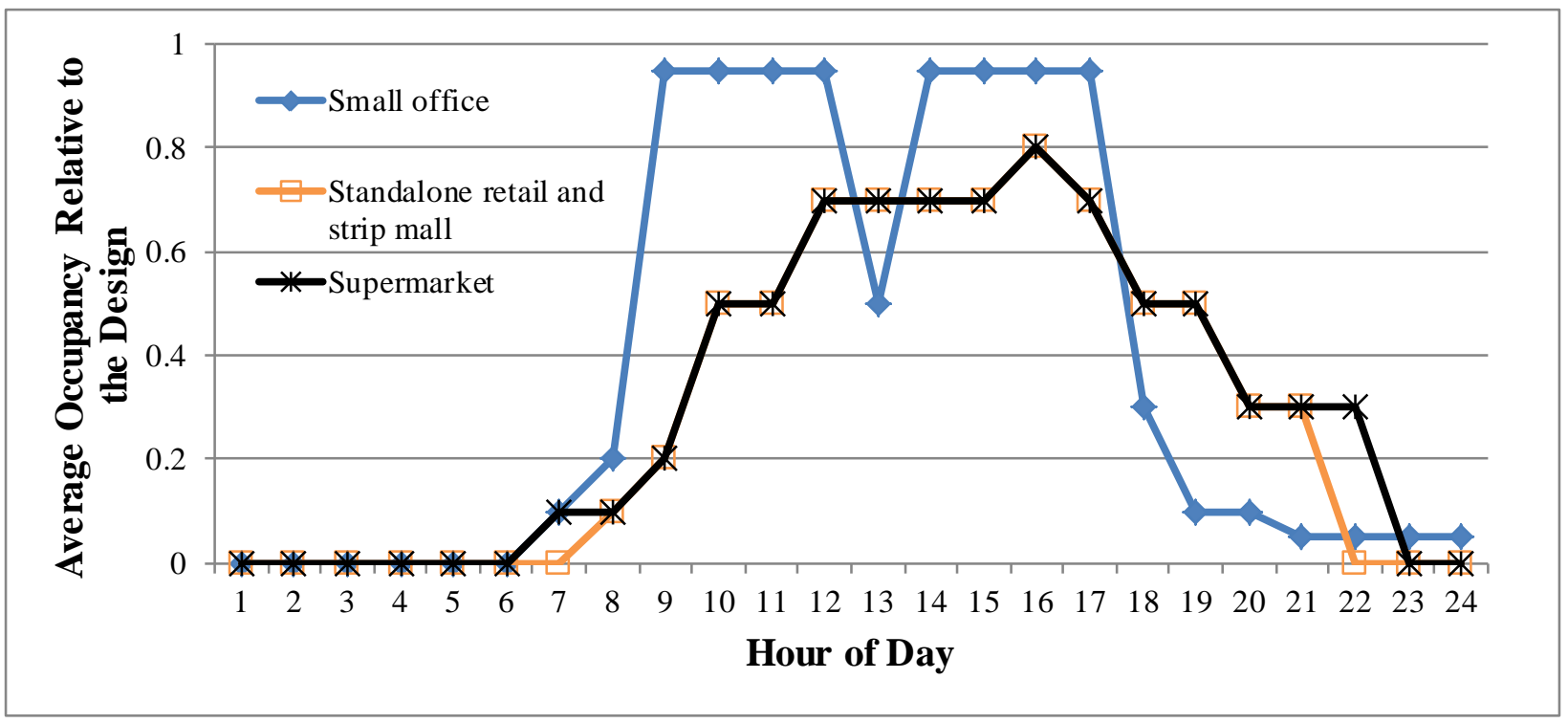

Figure 18: Weekday Occupancy Schedules for the Four Building Types 
Retrofit devices are available on the market to vary the speed of compressor in existing rooftop units (Criscione 2011). Therefore, it is technically feasible to upgrade from one-stage cooling to multi-stage cooling without changing the whole compressor. The impact of two-stage cooling on HVAC energy consumption can be investigated by comparing two cases, one using two-stage cooling and the other using single-stage cooling. Figure 19 shows the change in total HVAC energy consumption in changing from single-stage cooling (Case 6) to two-stage cooling (Case 11). As shown, two-stage cooling is more effective in hot climates. It can save as much as $12 \%$ of the total HVAC energy use. Recall that for two-stage cooling, the supply fan runs at $75 \%$ and $100 \%$ of its full design speed, respectively, in the first and second stage, while it runs at the full speed in the cooling mode when there is only single-stage cooling. Because the cooling efficiency does not vary with cooling stages, the energy savings associated with staged cooling result mostly from the reduced supply-fan energy. The decrease in fan energy use also leads to a decrease in energy use for mechanical cooling because less heat is rejected by the supply fan to the supply air stream. Since staged cooling reduces energy consumption for fan operation and cooling, it is more effective in hot climates where cooling requirements are greater. Similarly, because the energy used for fan operation and mechanical cooling in the small office building represents a larger fraction of the total HVAC energy use than it does in the other building types, staged cooling achieves a higher percentage of energy savings for the small office building.

Similar results for the impact of staged cooling can be obtained by comparing other pairs of cases such as Case 13 vs. Case 10 and Case 21 vs. Case 18. In addition, it needs to be noted that one major advantage of staged cooling is to reduce the frequency of compressor on-off cycles. Because the simulation model does not consider the efficiency reduction caused by compressor cycling, the energy saving results shown in Figure 19 are likely somewhat underestimated. 


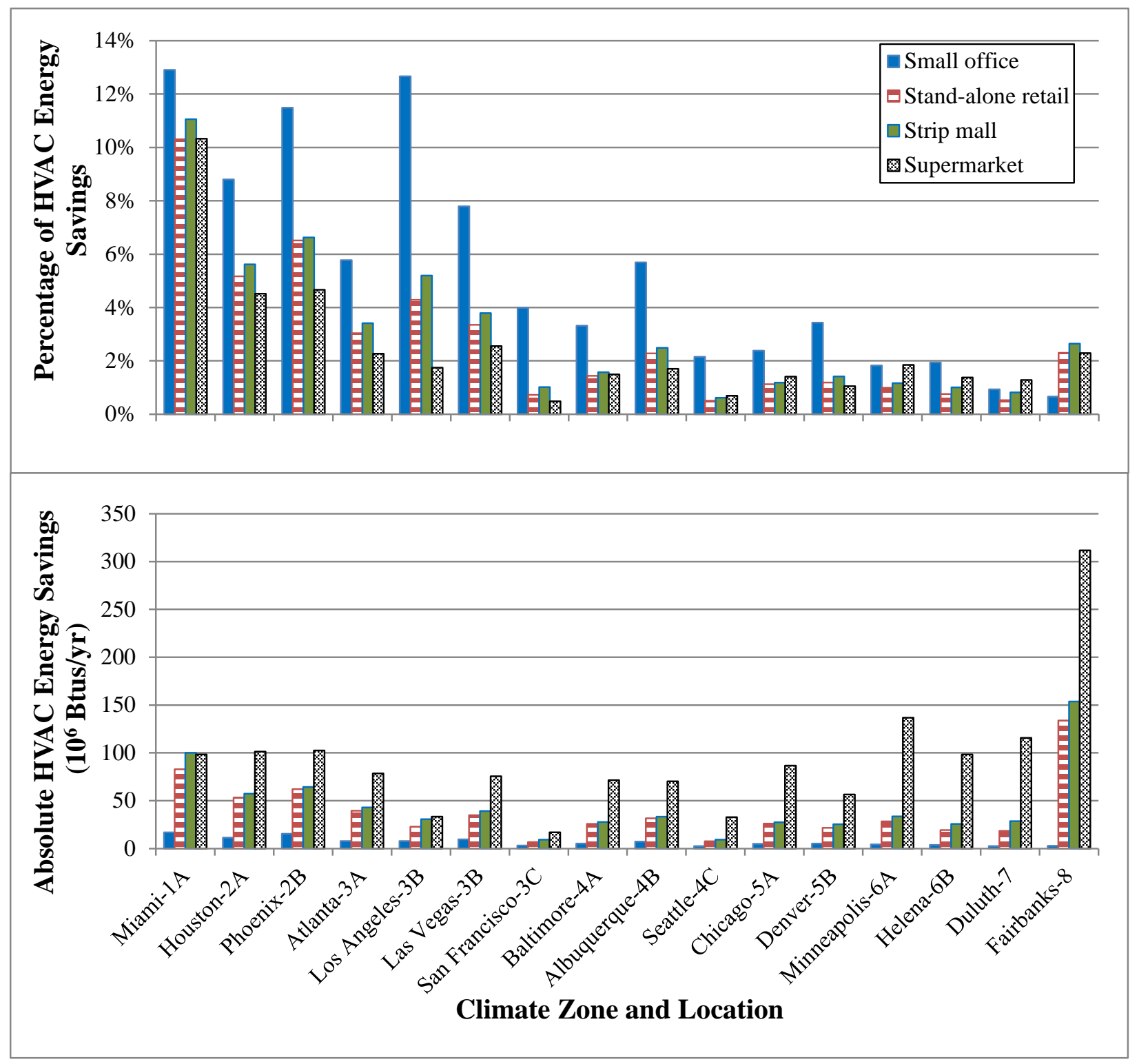

Figure 19: HVAC Energy Savings from the Use of Two-Stage Cooling (Case 11) Compared to Single-Stage Cooling (Case 6)

\subsection{Incremental Impact of Selected Advanced Control Strategies on HVAC Energy Uses}

The results presented in Section 5.2 have focused on the impact of individual control strategies with Case 1 mostly selected as the common base case. It is worthwhile to investigate the incremental impact on HVAC energy savings of adding control strategies gradually (one at a time). In addition, in this section, the HVAC energy savings are broken down into the fan energy savings, the cooling energy savings, and the heating energy savings to better characterize how each control strategy affects the primary components of HVAC energy use.

Five cases (Cases 1, 6, 7, 9 and 18) from Table 4 are selected to illustrate the impact on energy savings of incrementally adding control strategies. The sequence of incrementally adding control strategies is: 
- Starting with a packaged unit with none of the advanced control features, add supply-fan multispeed control (Case 1 to Case 6)

- Add a nonintegrated air-side economizer based on differential dry-bulb temperature control to the unit having multiple-speed supply-fan control as the only advanced control feature (Case 6 to Case 7)

- Change the economizer control from nonintegrated to integrated (Case 7 to Case 9)

- $\quad$ Add DCV to Case 9 (Case 9 to Case 18).

Figure 20 through Figure 23 show the incremental total HVAC energy savings for all 16 locations. The incremental energy savings may be negative if adding a control strategy leads to an increase in HVAC energy consumption. The sum of these incremental energy savings (both positive and negative) equals the total savings for Case 18 (compared to the base case, Case 1). It can be seen from these figures that:

- Multi-speed fan control and DCV are the two control strategies that contribute most to the HVAC energy savings. Specifically, multi-speed fan control dominates the impact in a small number of cases, including all four building types in Miami and the small office building in Houston, Phoenix and Los Angeles. DCV dominates the impact for all other cases. The multi-speed fan contribution to savings can be negative in cold climates (e.g, Duluth and Fairbanks for all building types).

- Adding an air-side economizer after multi-speed fan control does not have a large impact on HVAC energy savings except for a few cases, such as the small office building in Los Angeles. In comparison with a nonintegrated economizer, the integrating economizer has negligible impact on HVAC energy savings.

All of these findings are consistent with those for the individual control strategies. 


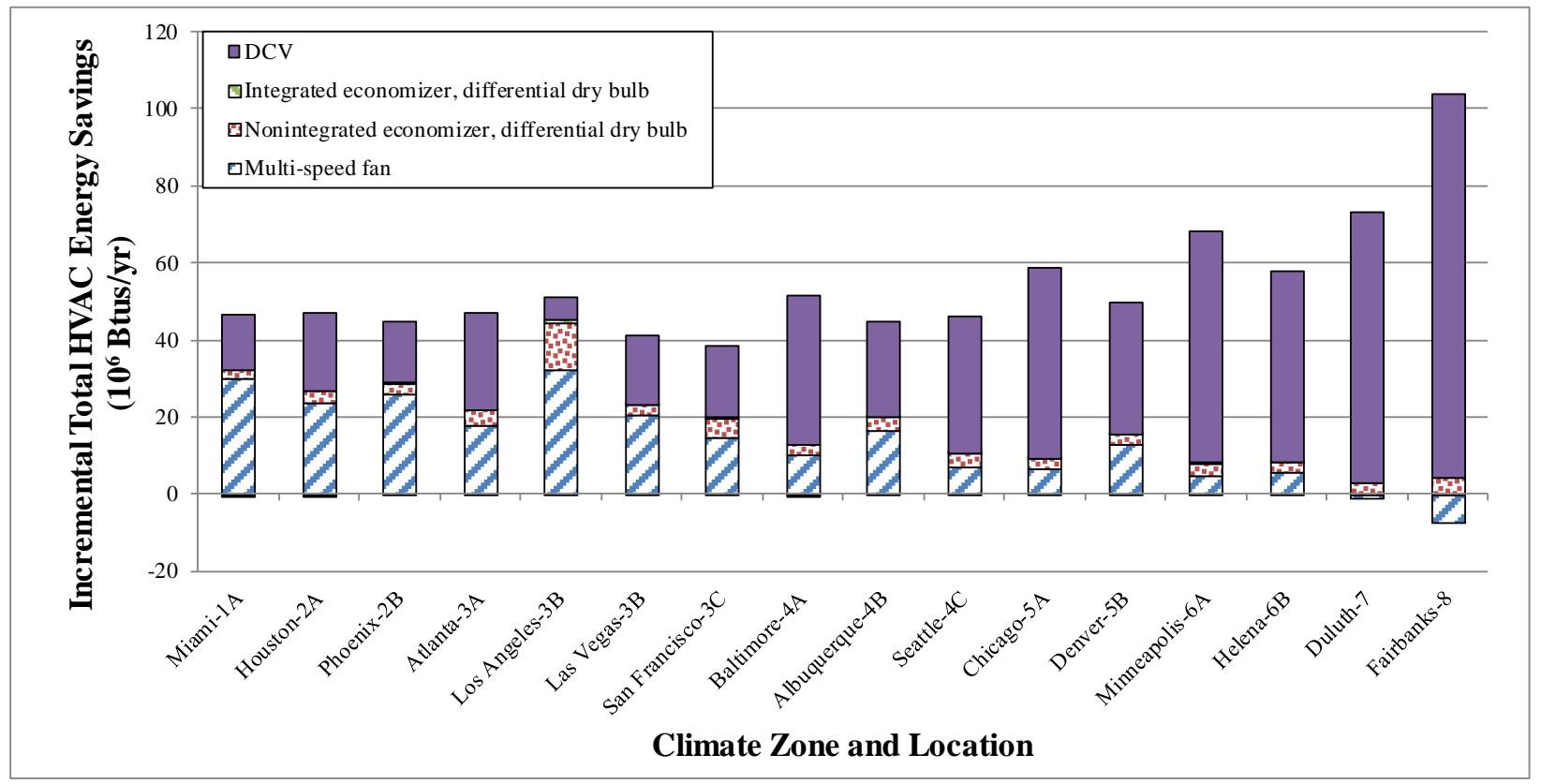

Figure 20: HVAC Energy Savings Resulting from Incremental Addition of Advanced Control Strategies for the Small Office Building

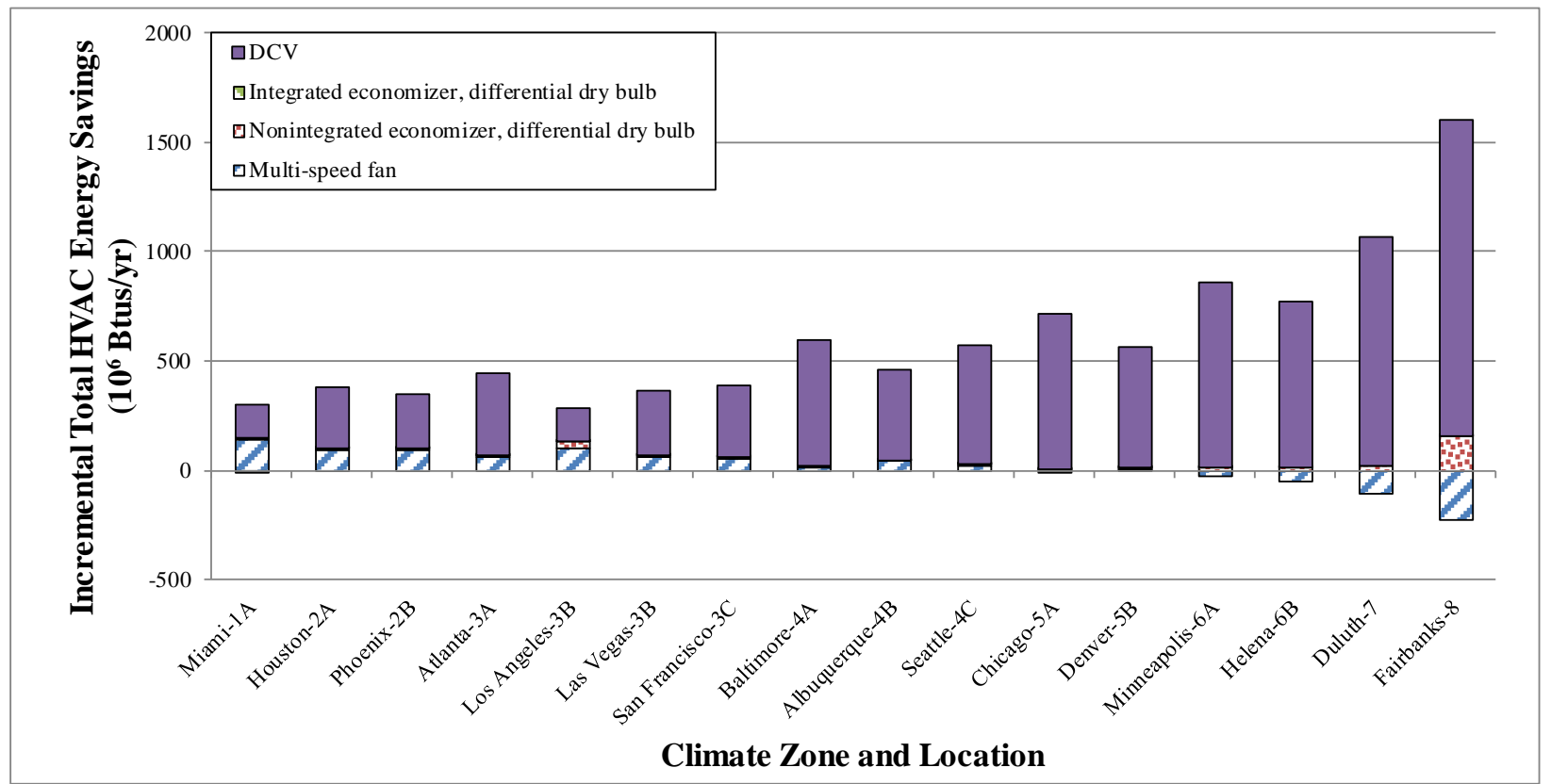

Figure 21: HVAC Energy Savings Resulting from Incremental Addition of Advanced Control Strategies for the Stand-alone Retail Building 


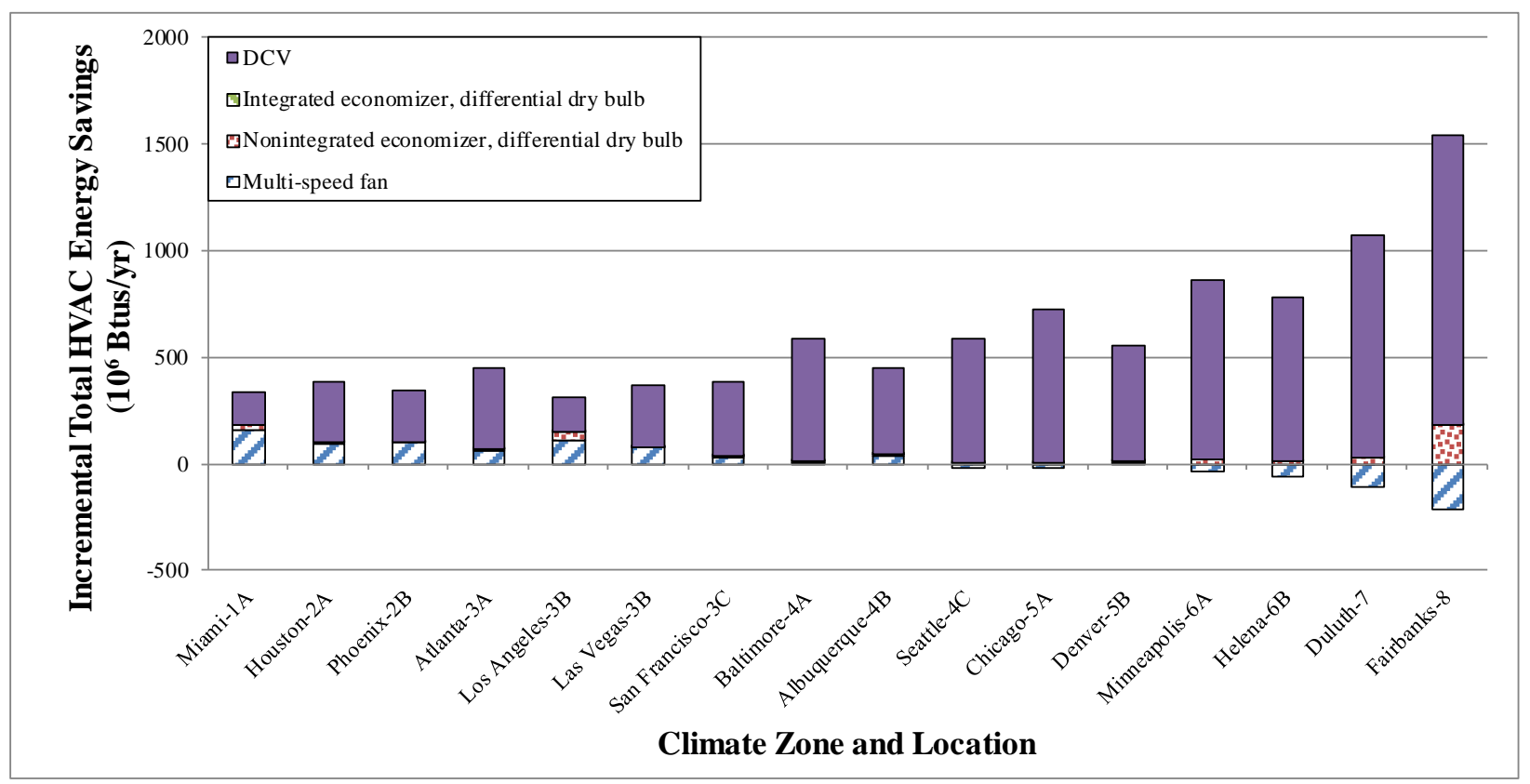

Figure 22: HVAC Energy Savings Resulting from Incremental Addition of Advanced Control Strategies for the Strip Mall Building

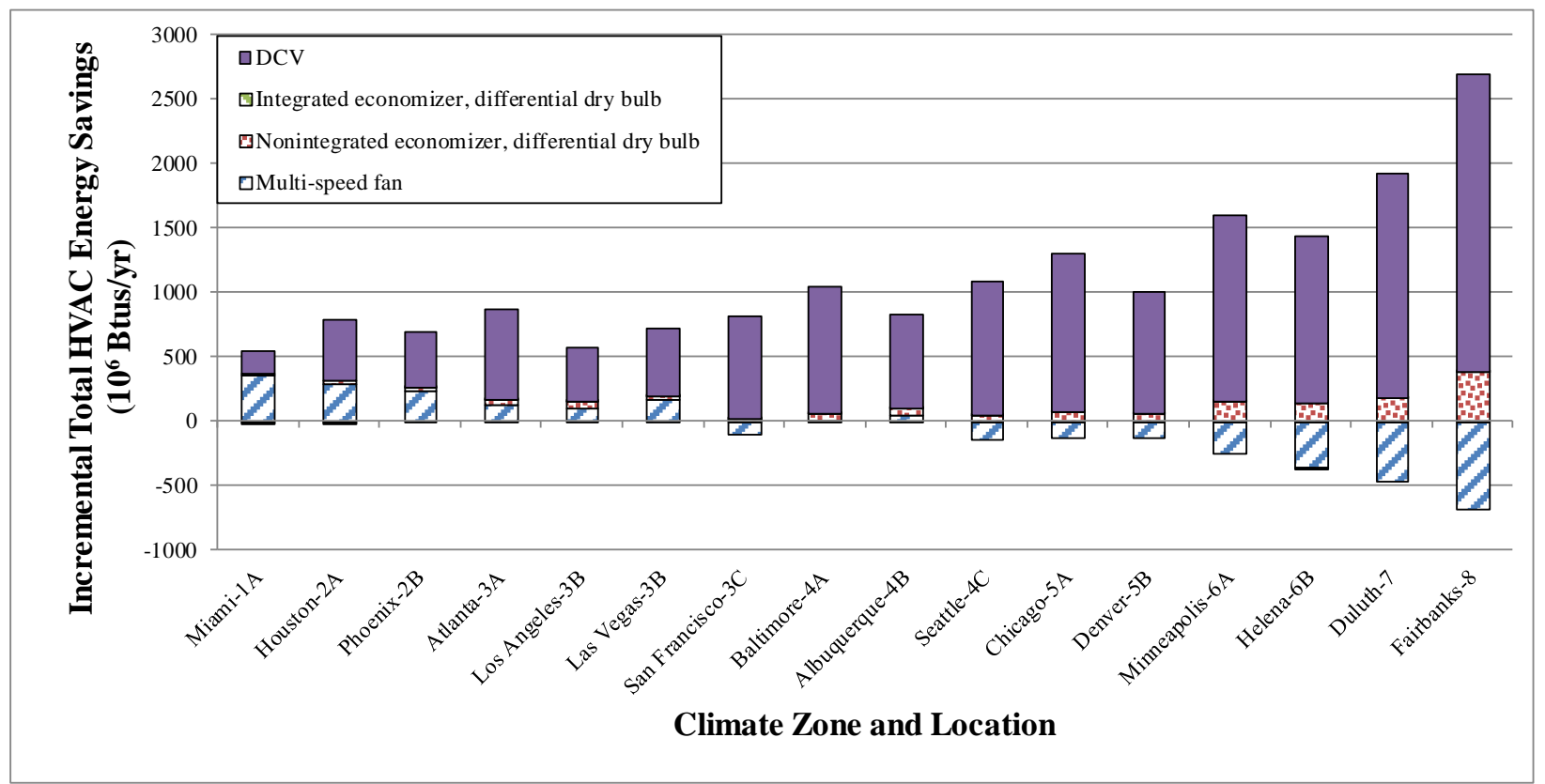

Figure 23: HVAC Energy Savings Resulting from Incremental Addition of Advanced Control Strategies for the Supermarket Building

Figure 24 through Figure 27 show the incremental contributions of the sequential addition of advanced control strategies to annual fan energy savings for all 16 locations and 4 building types. These figures show the following: 
- Multi-speed fan control contributes more than 95\% of the annual fan energy savings for all investigated building types and locations.

- Applying an air economizer after multi-speed fan control may cause a small increase in fan energy use. This increase can be explained by two factors. First, with an economizer, the packaged unit operates in the economizing mode for some time and thereby decreasing the time in the ventilation-only mode. Second, the supply fan runs at $40 \%$ of its full design speed in the ventilation mode, while at $75 \%$ speed in the economizing mode. For example, for the stand-alone retail building in Los Angeles, the operation mode statistics show that about $84 \%$ of all system running time lies in the ventilation mode for Case 6, but the percentage decreases to 68\% in Case 7 after applying an air-side economizer.

- Adding DCV after multi-speed fan control usually contributes an additional small amount (around 5\%) to fan energy savings. Because DCV leads to a decrease in conditioning load from the outdoor-air intake, it may cause a small increase in the time when packaged single-zone systems operate in the ventilation-only mode, thus decreasing fan energy use.

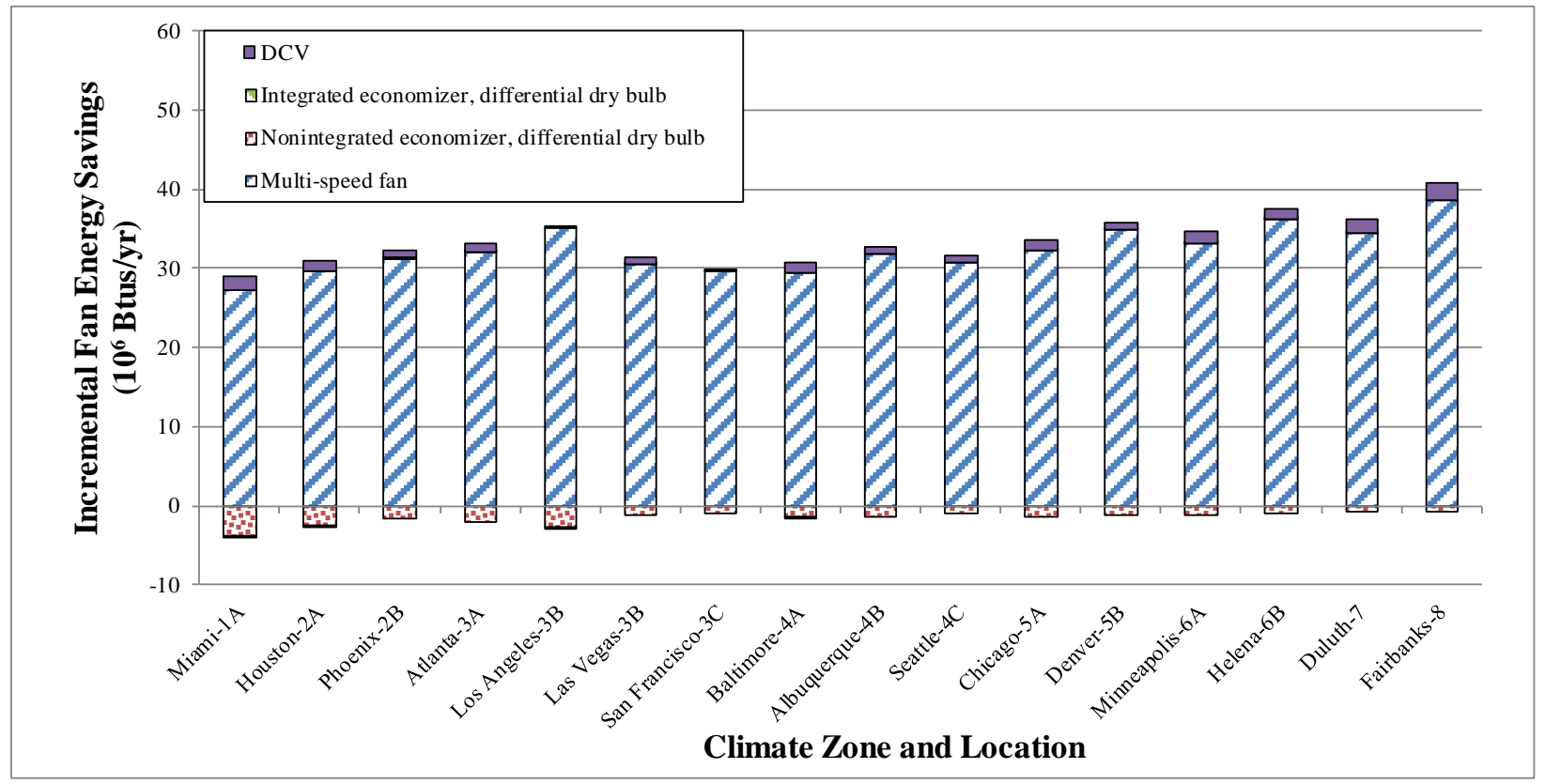

Figure 24 Annual Fan Energy Savings Resulting from Incremental Addition of Advanced Control Strategies for the Small Office Building 


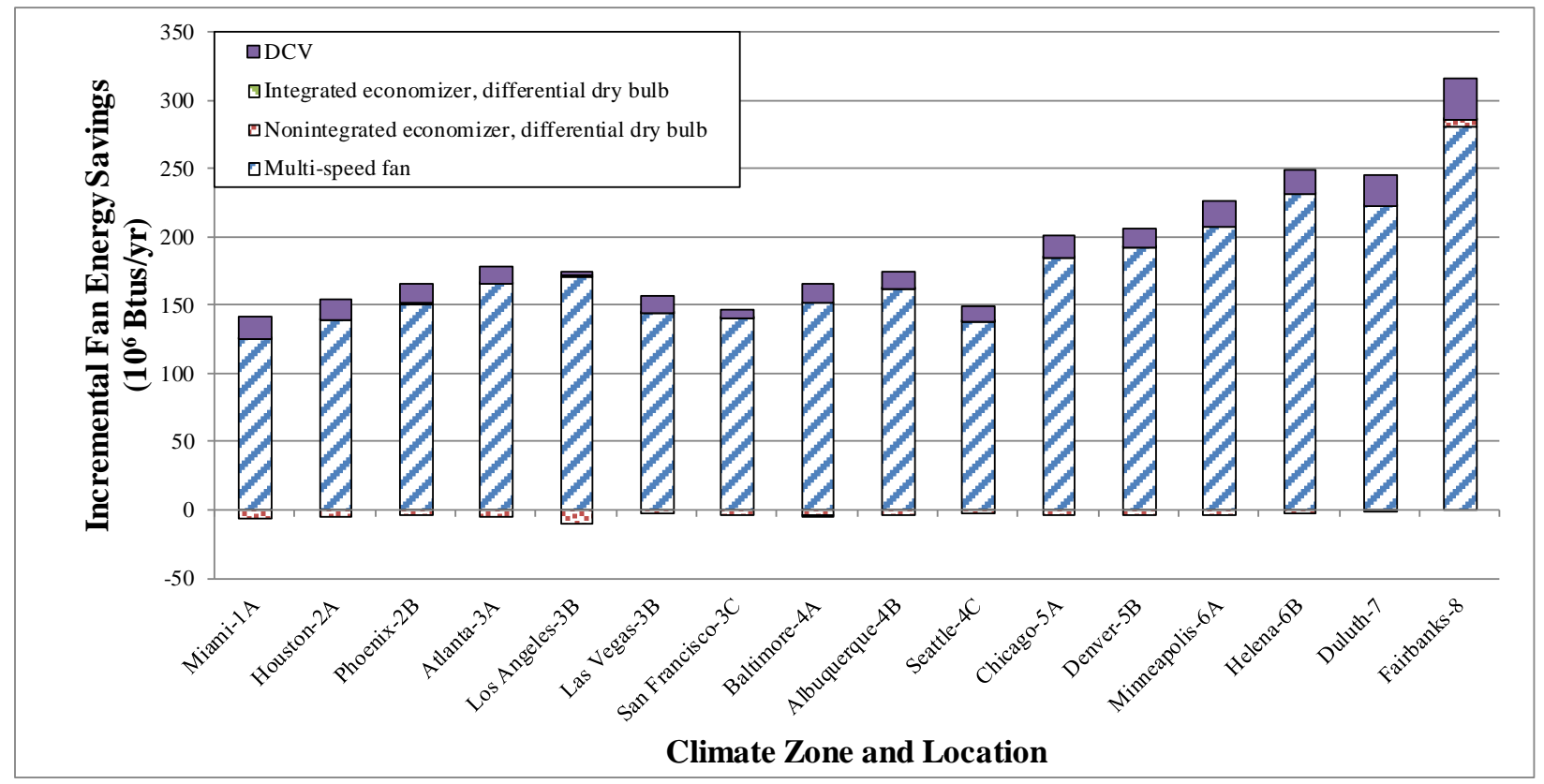

Figure 25: Annual Fan Energy Savings Resulting from Incremental Addition of Advanced Control Strategies for the Stand-alone Retail Building

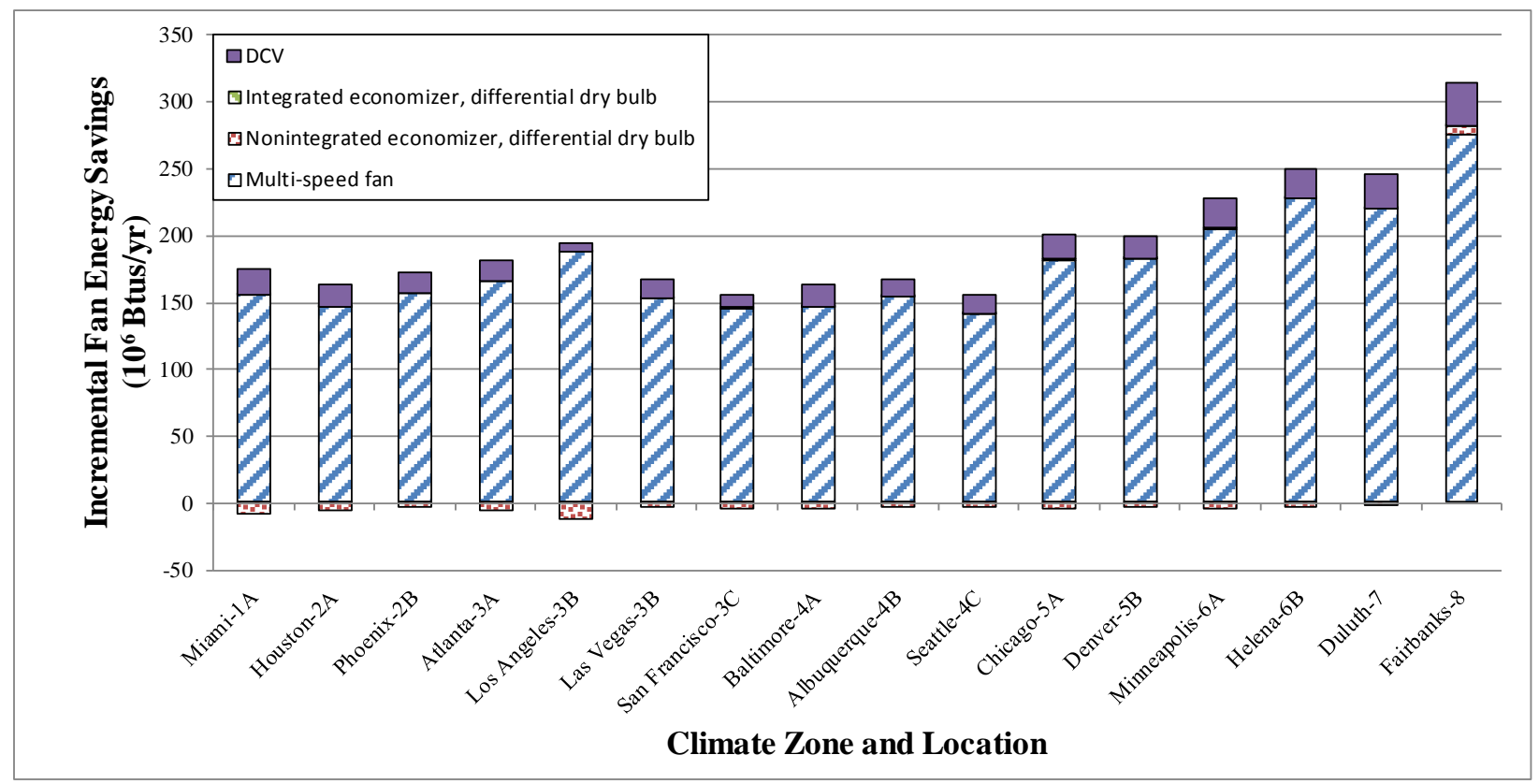

Figure 26: Annual Fan Energy Savings Resulting from Incremental Addition of Advanced Control Strategies for the Strip Mall Building 


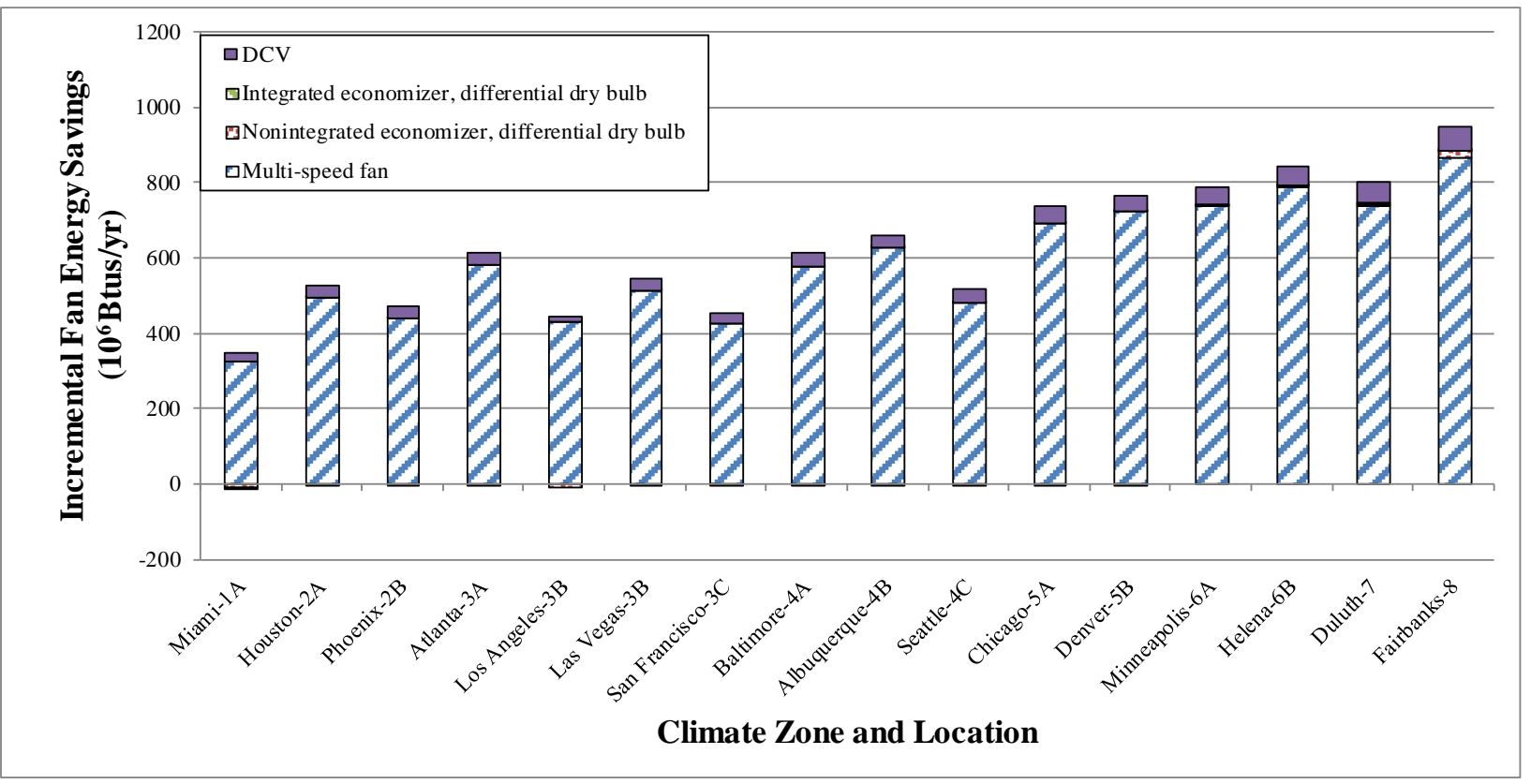

Figure 27: Annual Fan Energy Savings Resulting from Incremental Addition of Advanced Control Strategies for the Supermarket

Figure 28 through Figure 31 show the annual cooling energy savings resulting from the incremental addition of advanced control strategies for all 16 locations and 4 building types. These figures show the following:

- Both multi-speed supply-fan control and the air-side economizer make noticeable contributions to annual cooling energy savings. In particular, for all four building types, the combination of those two control strategies leads to savings of more than $80 \%$ of the total cooling energy in Los Angeles, San Francisco, Seattle, and Helena, Duluth and Fairbanks.

- The air-side economizer dominates the cooling energy savings in Los Angeles and Fairbanks. However, as shown from the incremental change from Case 7 to Case 9, integrating air economizer with DX cooling has little impact on cooling energy consumption. These observations are consistent with those found previously in Section 5.2.

- DCV has significant impact on cooling energy savings in Miami, Houston, Phoenix, Las Vegas, Atlanta, and Baltimore. DCV may contribute more than $70 \%$ of the total cooling energy savings in some cases, such as the two retail buildings in Miami, Houston, Phoenix, and Las Vegas. 


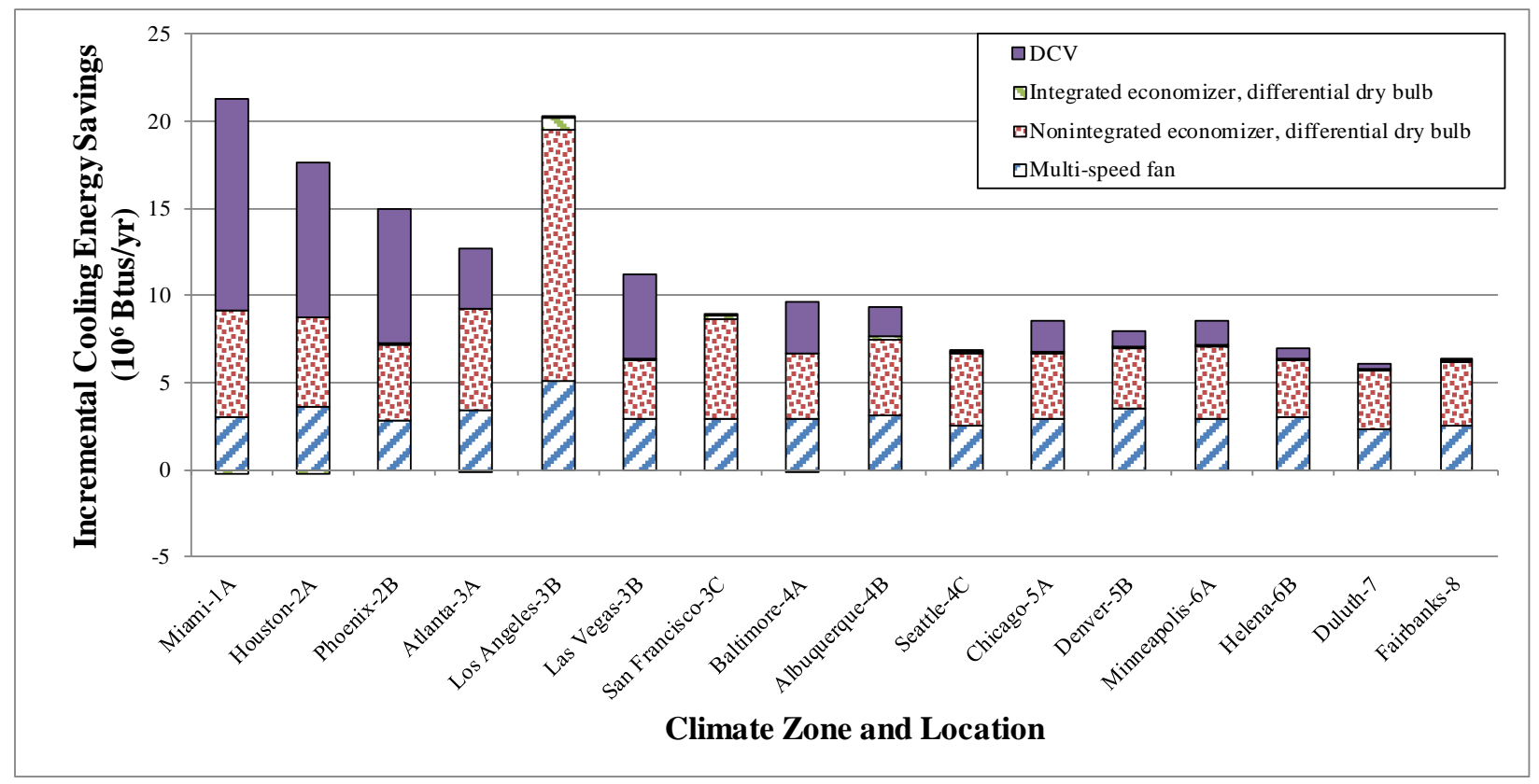

Figure 28: Annual Cooling Energy Savings Resulting from Incremental Addition of Advanced Control Strategies for the Small Office Building

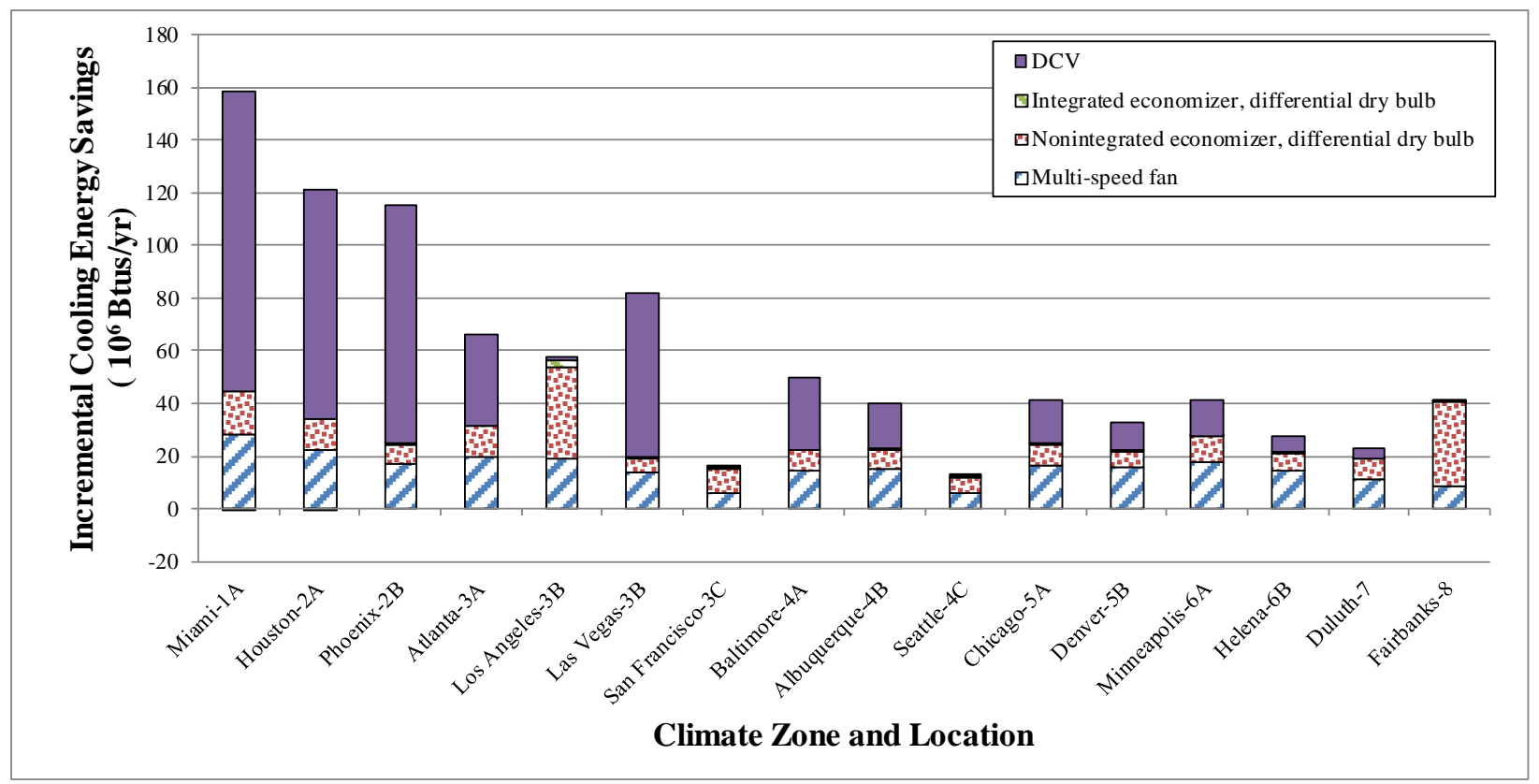

Figure 29: Annual Cooling Energy Savings Resulting from Incremental Addition of Advanced Control Strategies for the Stand-alone Retail Building 


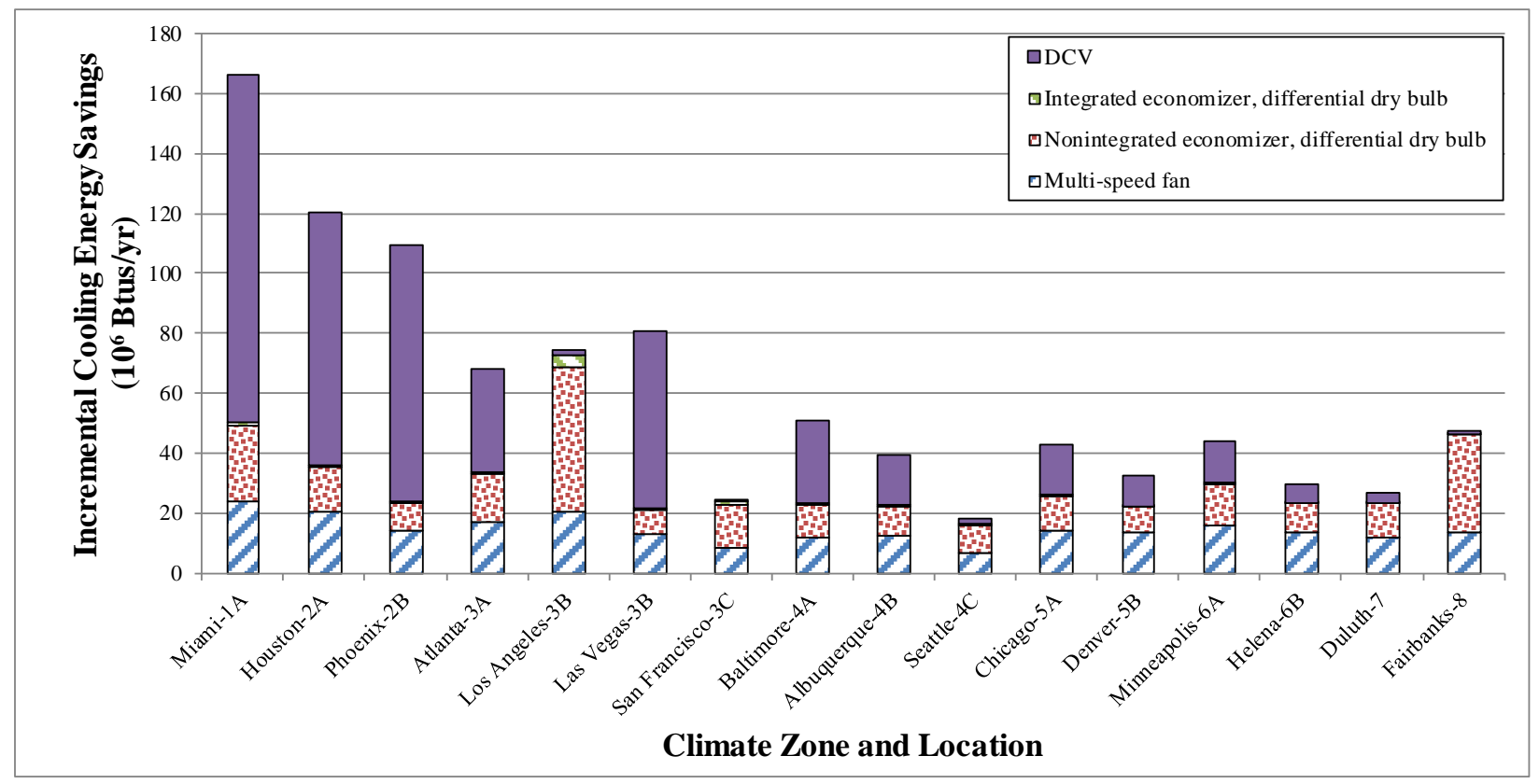

Figure 30: Annual Cooling Energy Savings Resulting from Incremental Addition of Advanced Control Strategies for the Strip Mall Building

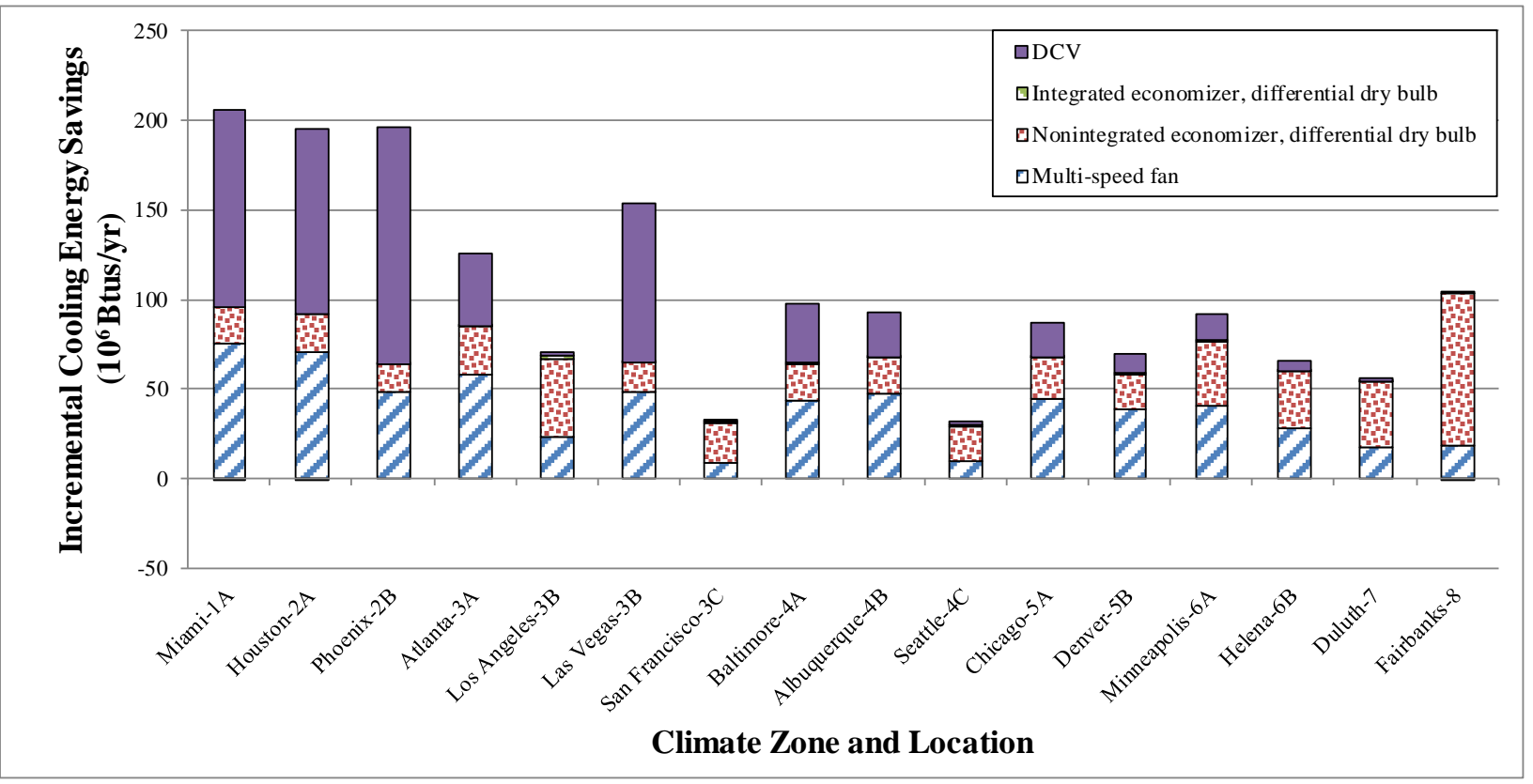

Figure 31: Annual Cooling Energy Savings Resulting from Incremental Addition of Advanced Control Strategies for the Supermarket Building

Figure 32 through Figure 35 show the annual heating energy savings across all 16 locations resulting from the incremental addition of advanced control strategies. These figures show the following:

- Multi-speed fan control increases heating energy consumption in all cases. By lowering the fan speed, multi-speed fan control decreases the heat loss from the fan motor to the 
supply-air stream. During heating mode operation, this decrease in heat gain from the supply fan must be compensated by an increase in heating energy.

- DCV contributes almost all the heating energy savings because it decreases outdoor air intake.

- The impact of multi-speed fan control and DCV on heating energy consumption (either savings or penalties) generally increases from hot to cold climates. Because Miami has negligible heating loads, the impact of control strategies on heating can be ignored there.

Theoretically, adding air-side economizer control should not impact heating energy consumption. However, a small amount of gas saving is observed in Fairbanks for the two retail buildings and in a couple of additional cold climates for supermarket. The EnergyPlus programs sometimes can oversize equipment, especially in extreme cold or hot climates. The oversized equipment capacity may cause the space to overcool if the time step is small, say 3 minutes used for the current work. Use of the energy management system control can avoid heating immediately after cooling by tracking the operation mode in previous time steps. If the packaged unit is in cooling mode in the previous steps, heating can be curtailed even if the space temperature is below the heating set point. For the current analysis heating was curtailed if there was any cooling in the two previous time steps. For extreme cold climates, like Fairbanks, use of two time steps was not sufficient. Thus, space heating sometimes was turned on shortly after cooling. Because the overcooling problem never occurs in the economizing mode, small gas savings from the use of air-side economizer may be observed in a few cases ${ }^{2}$.

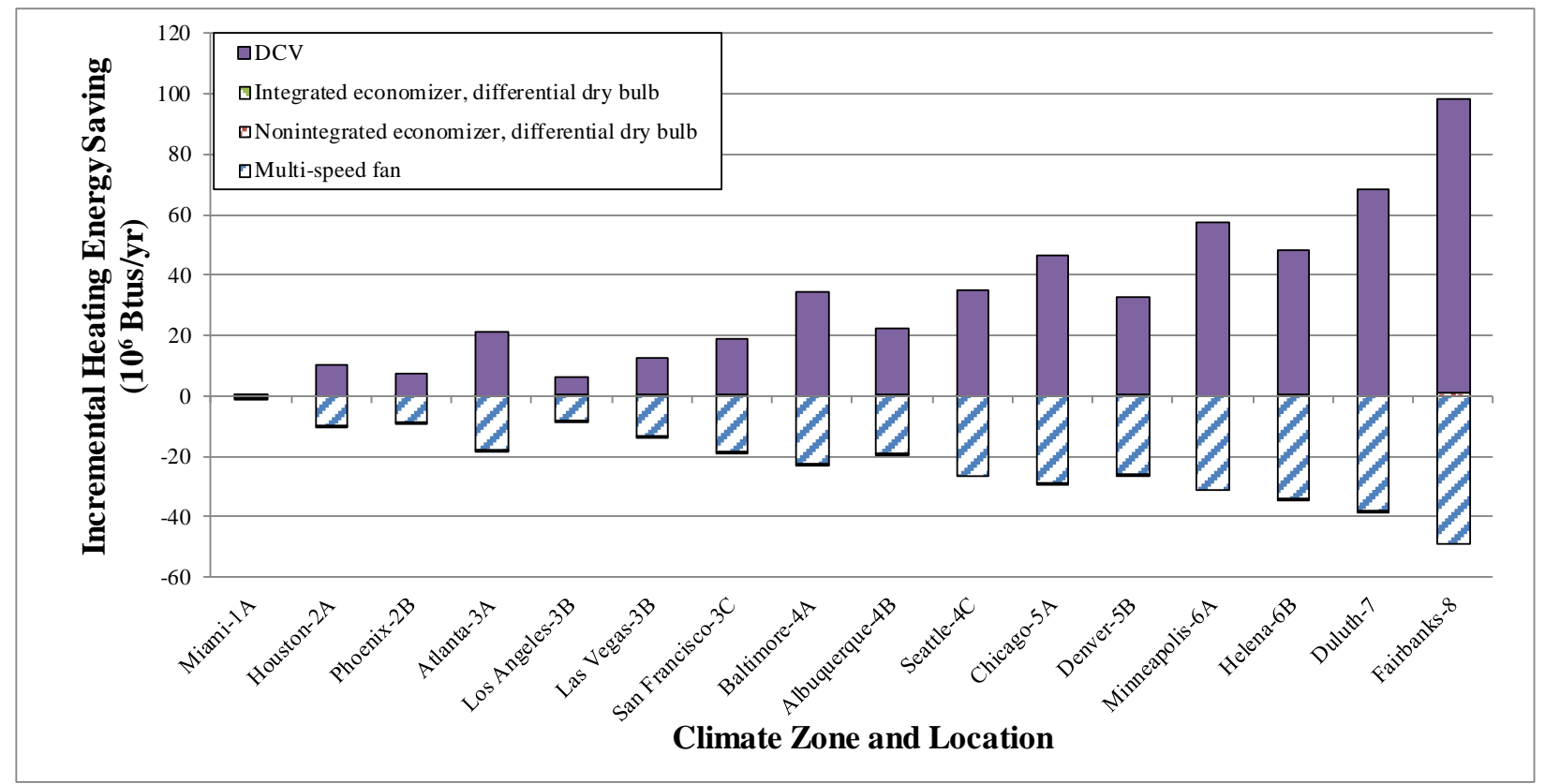

Figure 32: Annual Heating Energy Savings Resulting from Incremental Addition of Advanced Control Strategies for the Small Office Building

\footnotetext{
${ }^{2}$ We tested the stand-alone retail model and found use of four previous time steps would avoid the issue of space heating shortly after cooling. This minor impact does not affect the conclusions made in this report.
} 


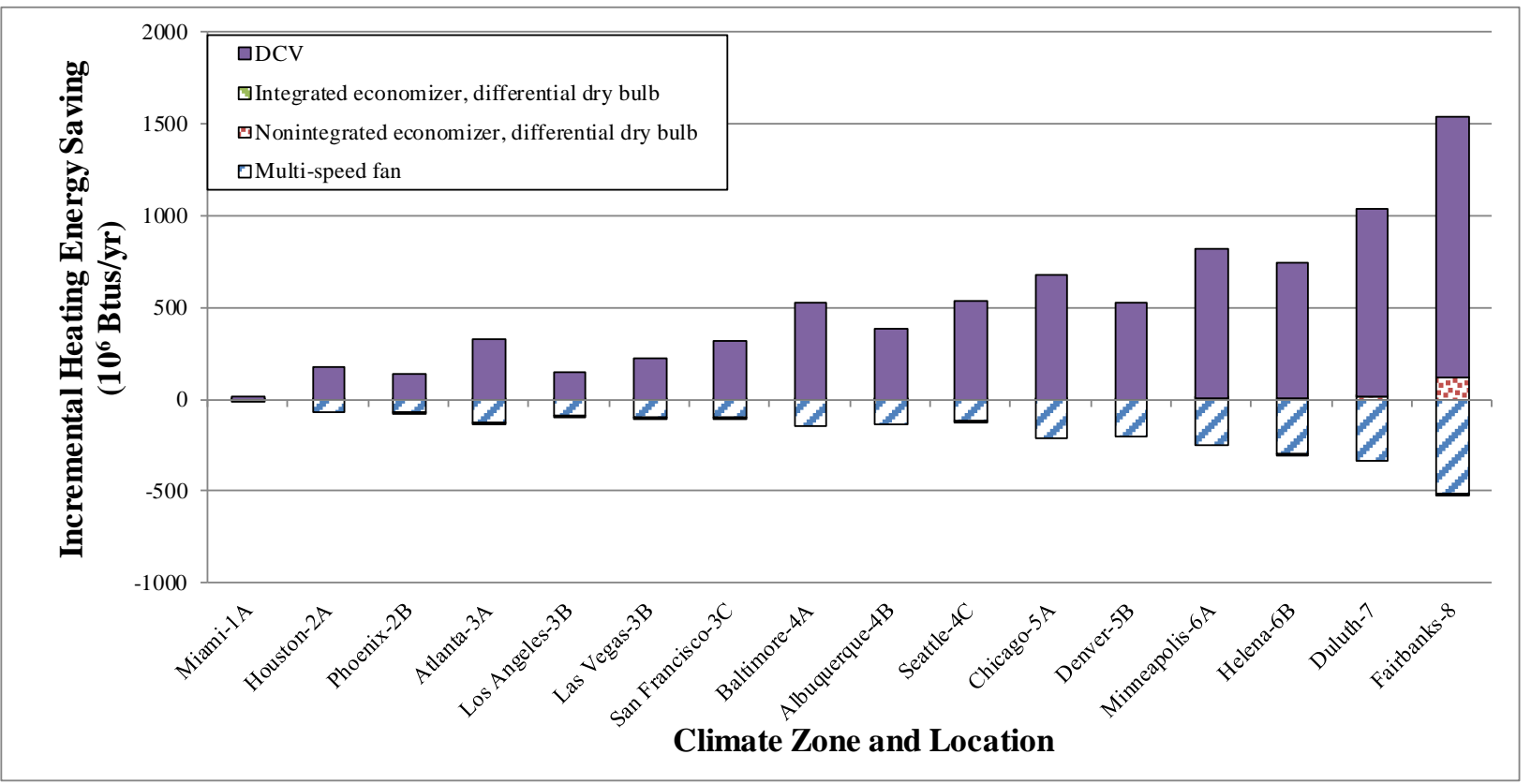

Figure 33: Annual Heating Energy Savings Resulting from Incremental Addition of Advanced Control Strategies for the Stand-alone Retail Building

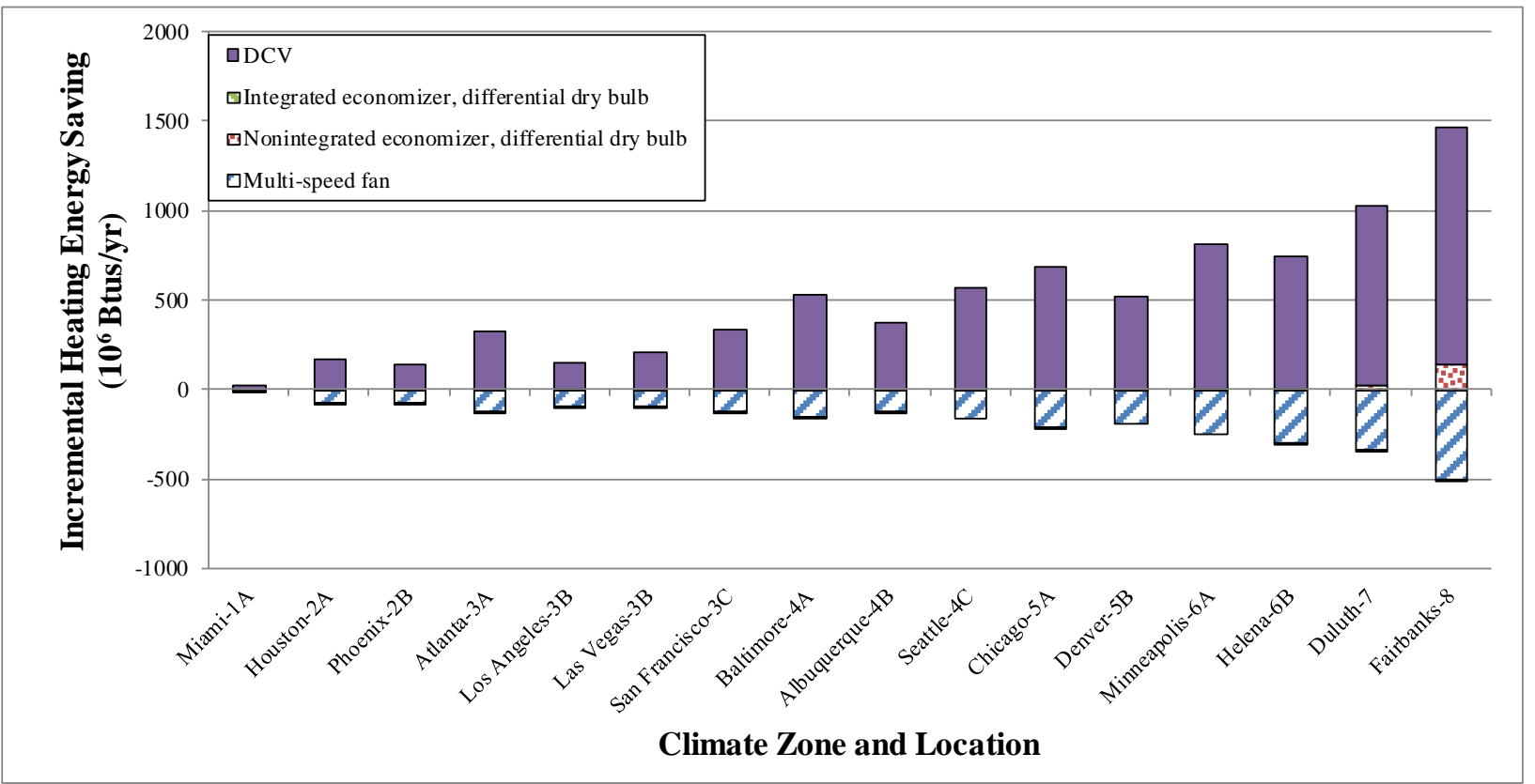

Figure 34: Annual Heating Energy Savings Resulting from Incremental Addition of Advanced Control Strategies for the Strip Mall 


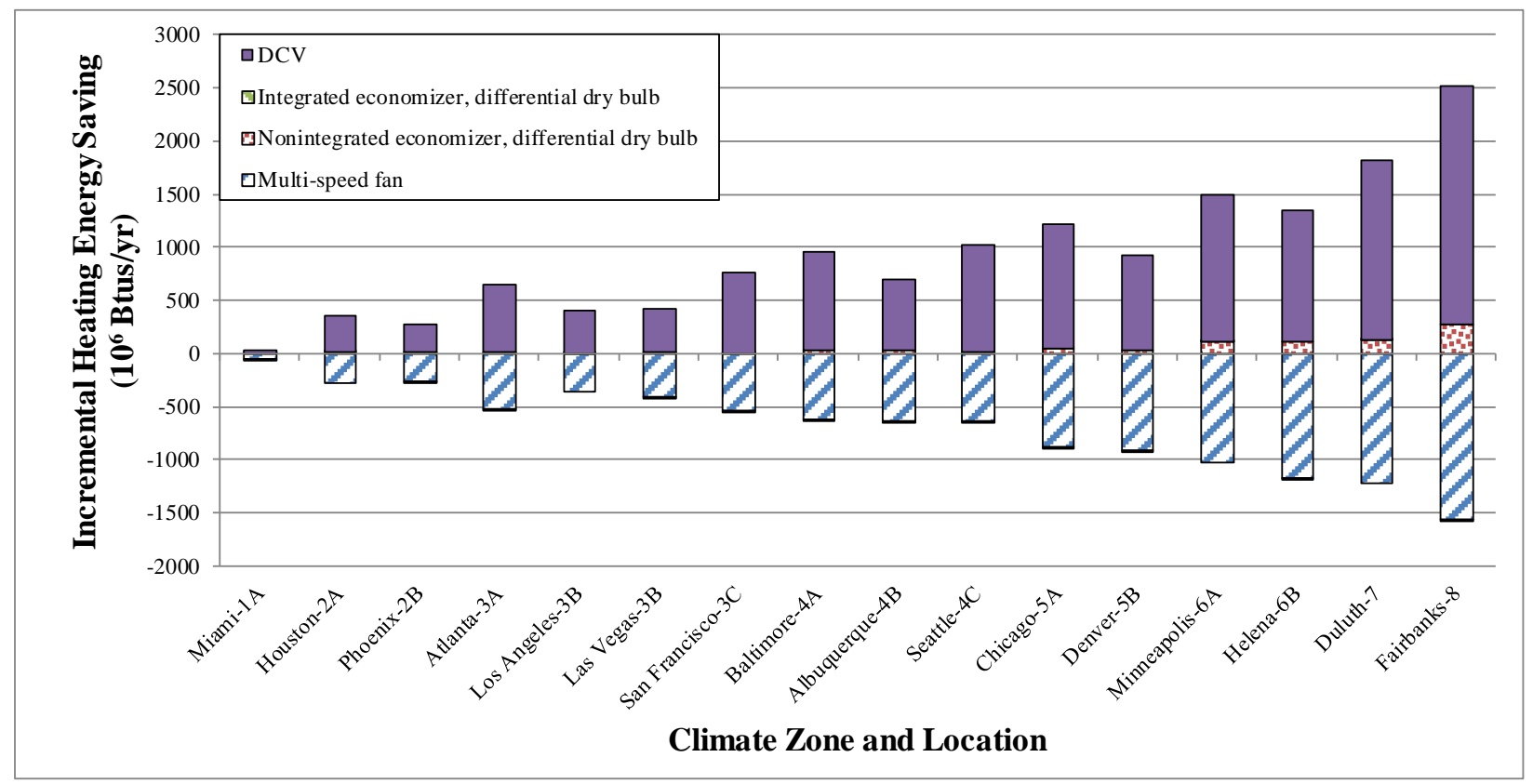

Figure 35: Annual Heating Energy Savings Resulting from Incremental Addition of Advanced Control Strategies for the Supermarket

\subsection{Comparison of Energy Consumption between Case 18 and Case 4}

Many existing packaged units may only have single-stage cooling and also may have an air-side economizer control. For these units, multi-speed fan control and DCV are the two strategies that can be easily added, which can result in significant energy savings. Hence, comparing a case with only air-side economizer and another case with multi-speed fan control and DCV added provides insights into a typical scenario for existing buildings. Case 4 (single-stage cooling with integrated differential dry-bulb economizer) and Case 18 (single-stage cooling, integrated differential dry-bulb economizer, multi-speed fan controls and DCV) are selected for comparison. For the four building types, Figure 36 through Figure 39 show the HVAC energy consumption (fan and cooling electricity and gas heating) of Case 18 and Case 4 for all 16 locations. The HVAC energy saving as a percentage of the energy consumption for Case 4 is also shown for each location (above the bars of the histograms). The following findings can be drawn from these figures:

- The largest absolute energy savings are obtained for Fairbanks for all building types, simply because Fairbanks has the largest HVAC loads by far. The annual absolute savings are about $91 \mathrm{MMBtu}$ for the small office building, 1,268 MMBtu for the standalone retail building, 1,165 MMBtu for the strip mall, and 1,770 MMBtu for the supermarket. The differences in these savings among the building types attributable to both differences in the size of the buildings and also the impact of multi-speed fan and DCV on the different types of buildings.

- The smallest absolute energy savings per year are obtained for San Francisco for the small office buildings (29 MMBtu), and Los Angeles for the other three building types (232 MMBtu for stand-alone retail building, 237 MMBtu for the strip mall, and 500 MMBtu for the supermarket). 
- The changes in total HVAC energy savings as a percentage of the energy consumption for Case 4 have similar variations with location (and climate) for the small office, standalone retail, and strip mall buildings. The percentage generally decreases from mild (Los Angeles, San Francisco and Seattle) to hot and then from hot to cold climates. Such trends can be explained by a couple of factors. First, the energy use intensity (EUI) for Case 4 (baseline in this comparison) is greater in cold climates but small in mild climates, and therefore, the same absolute energy savings corresponds to a smaller percentage of the baseline energy use for locations with larger values of the baseline energy consumption (or EUI). Second, as reported in Section 5.3, multi-speed fan control contributes significantly to the decrease in energy use for cooling. On the other hand, when fan energy use decreases, more heating energy is needed during heating mode to compensate for lower heat gains from the supply-fan motor. Because the space heating energy consumption is low in hot and mild climates, the overall impact of a multi-speed fan is more favorable in hot and mild climates.

- The results for the supermarket building in Figure 39 show variations with location different than those for the other three building types. The percentage of energy savings generally decreases from the hot and humid climate (Miami-Zone 1A) to the extreme cold climate (Fairbanks - Zone 8). For this trend, similar explanations can be given as those for the other three building types. First, the annual energy use of the supermarket generally increases from hot to cold climates because cooling provided by refrigerated cases and freezers contributes to cooling the store under hot outdoor conditions but also contributes to the need for heat during cold outdoor conditions. Second, because supermarket heating needs are more significant than for the other building types, reduced heat gains from multi-speed fans increase the heating energy consumption in the supermarket building.

- The percentage of HVAC energy savings lies in the range between $20 \%$ and $42 \%$ for the small office building, $23 \%$ and $40 \%$ for the stand-alone retail building, $21 \%$ and $40 \%$ for the strip mall, and $14 \%$ and $41 \%$ for the supermarket. The maximum HVAC energy saving as a percentage of the energy consumption for Case 4 occurs in Los Angeles for the small office building and the retail building, in San Francisco for the strip mall, while it occurs in Miami for the supermarket. The minimum percentage savings occurs in Fairbanks for all four building types. For all 16 locations (15 climates), Case 18 has an average HVAC energy savings of about $28 \%$ for small office, $32 \%$ for the stand-alone retail and strip mall buildings, and $24 \%$ for the supermarket. A summary of these savings is provided in Table 8. 


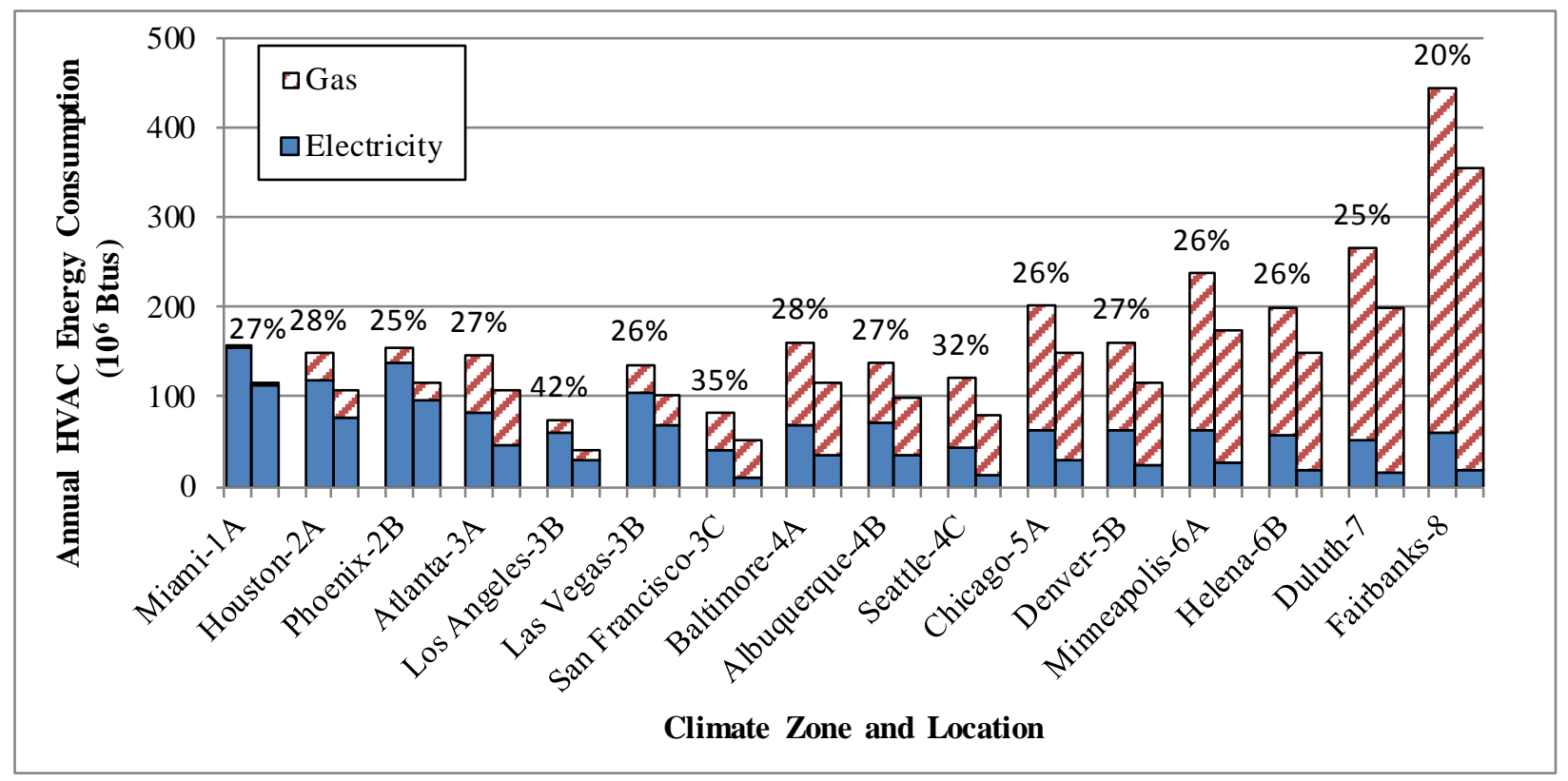

Figure 36: Comparison of HVAC Energy Consumption between Case 4 (left bar for each location) and Case 18 (right bar for each location) for the Small Office Building. Percent Difference in the Total Energy Consumption between Case 4 and Case 18 is also shown for Each Location.

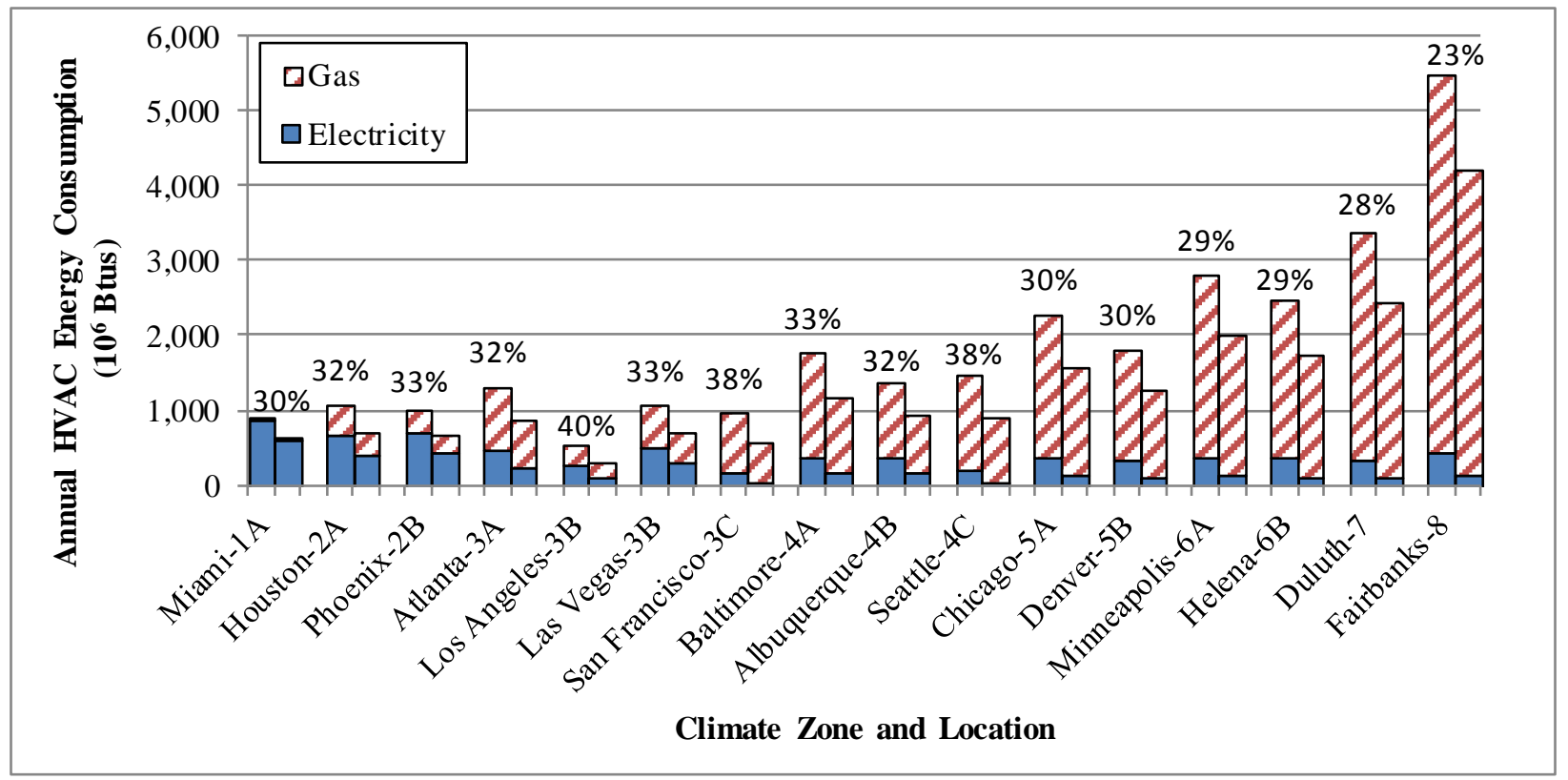

Figure 37: Comparison of HVAC Energy Consumption between Case 4 (left bar for each location) and Case 18 (right bar for each location) for the Stand-alone Retail Building. Percent Difference in the Total Energy Consumption between Case 4 and Case 18 is also shown for Each Location. 


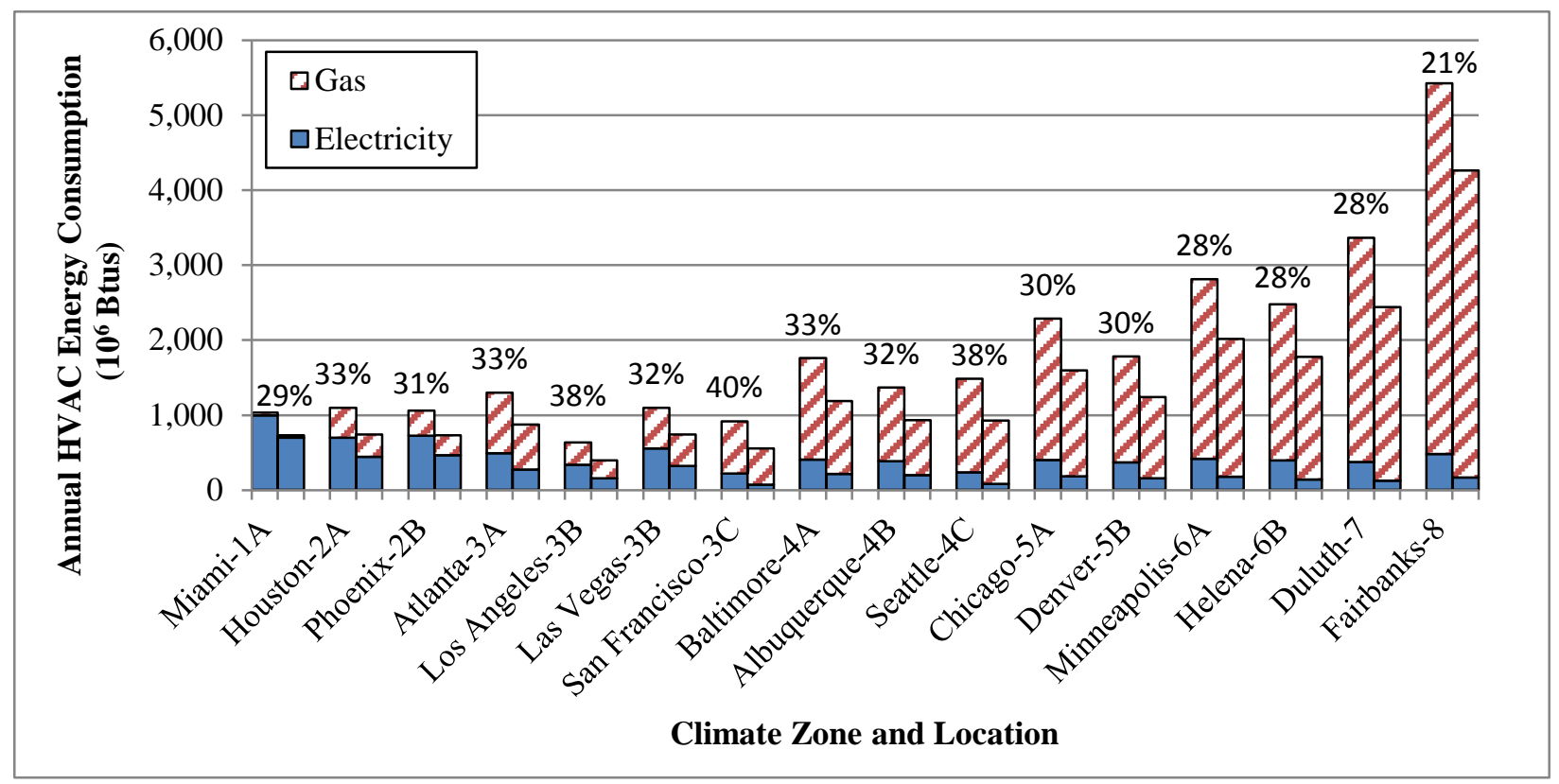

Figure 38: Comparison of HVAC Energy Consumption between Case 4 (left bar for each location) and Case 18 (right bar for each location) for the Strip Mall Building. Percent Difference in the Total Energy Consumption between Case 4 and Case 18 is also shown for Each Location.

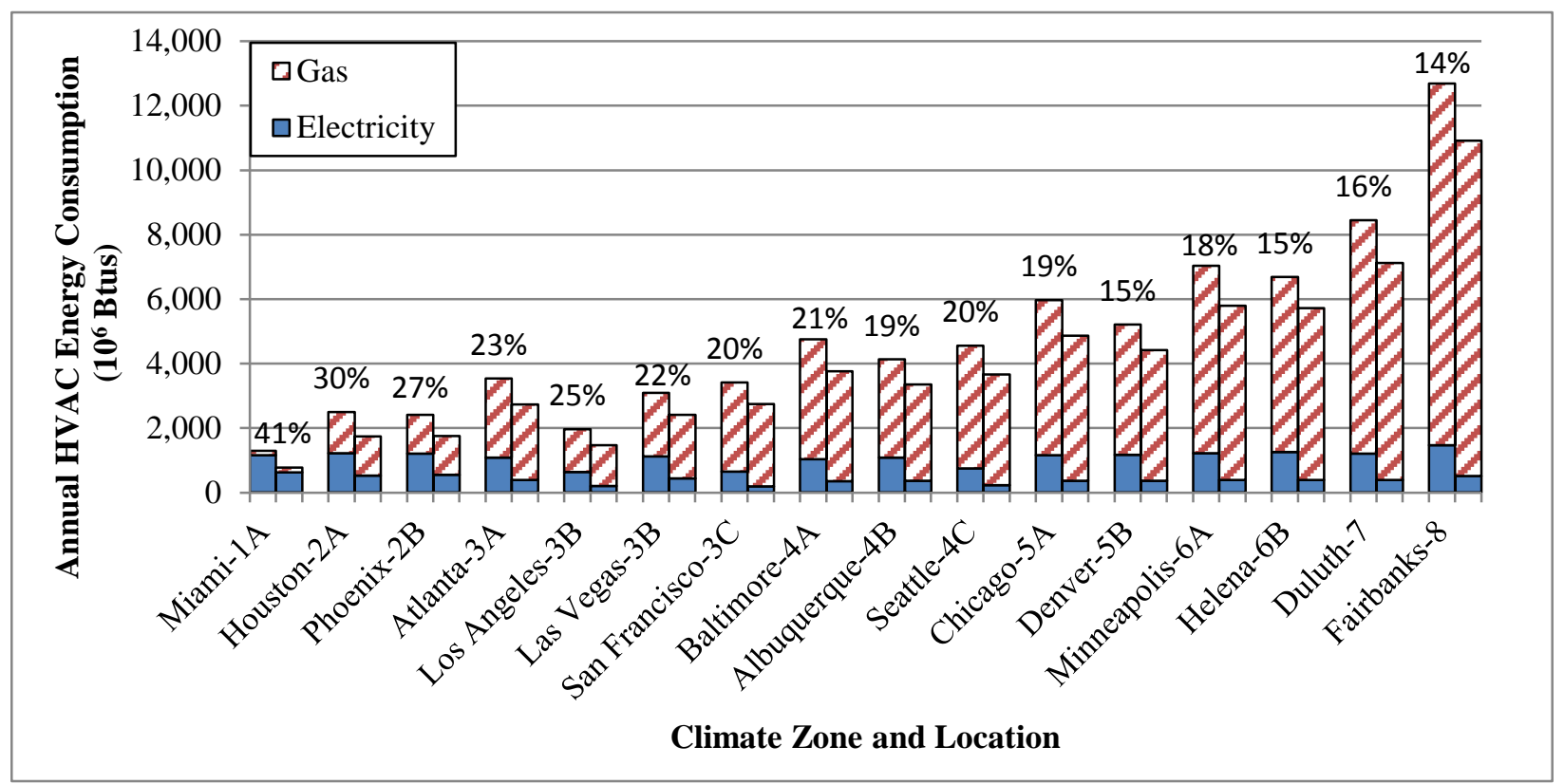

Figure 39: Comparison of HVAC Energy Consumption between Case 4 (left bar for each location) and Case 18 (right bar for each location) for the Supermarket Building. Percent Difference in the Total Energy Consumption between Case 4 and Case 18 is also shown for Each Location. 
Table 8: Summary of HVAC Energy Savings for Case 18 Relative to Case 4

\begin{tabular}{|c|c|c|c|c|}
\hline \multirow{2}{*}{ 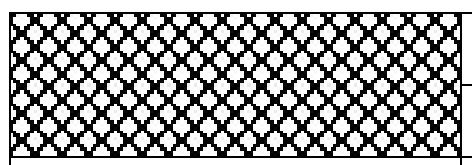 } & \multicolumn{4}{|c|}{ Building Type } \\
\hline & Small office & Stand-alone retail & Strip mall & Supermarket \\
\hline $\begin{array}{l}\text { Maximum percentage } \\
\text { savings }\end{array}$ & $42 \%$ & $40 \%$ & $40 \%$ & $41 \%$ \\
\hline $\begin{array}{l}\text { Location for maximum } \\
\text { percentage savings }\end{array}$ & Los Angeles & Los Angeles & $\begin{array}{c}\text { San } \\
\text { Francisco }\end{array}$ & Miami \\
\hline $\begin{array}{l}\text { Minimum percentage } \\
\text { savings }\end{array}$ & $20 \%$ & $23 \%$ & $21 \%$ & $14 \%$ \\
\hline $\begin{array}{l}\text { Location for minimum } \\
\text { percentage savings }\end{array}$ & Fairbanks & Fairbanks & Fairbanks & Fairbanks \\
\hline $\begin{array}{l}\text { Average percentage } \\
\text { savings }\end{array}$ & $28 \%$ & $32 \%$ & $32 \%$ & $22 \%$ \\
\hline $\begin{array}{l}\text { Maximum absolute } \\
\text { savings (MMBtu/yr) }\end{array}$ & 91 & 1268 & 1165 & 1770 \\
\hline $\begin{array}{l}\text { Location for maximum } \\
\text { absolute savings }\end{array}$ & Fairbanks & Fairbanks & Fairbanks & Fairbanks \\
\hline $\begin{array}{l}\text { Minimum absolute } \\
\text { savings (MMBtu/yr) }\end{array}$ & 29 & 232 & 237 & 500 \\
\hline $\begin{array}{l}\text { Location for minimum } \\
\text { absolute savings }\end{array}$ & $\begin{array}{c}\text { San } \\
\text { Francisco }\end{array}$ & Los Angeles & Los Angeles & Los Angeles \\
\hline $\begin{array}{l}\text { Average absolute } \\
\text { savings (MMBtu/yr) }\end{array}$ & 46 & 560 & 547 & 906 \\
\hline
\end{tabular}

\subsection{Comparison of Energy Consumption between Case 22 and the Base Case (Case 1)}

Of all control combinations listed in Table 4, Case 22 combines the most advanced control strategies. It includes multi-speed supply-fan control, demand controlled ventilation, two-stage compressor control, and integrated differential enthalpy economizer control. In contrast, the base case (Case 1) does not include any advanced control strategies. Therefore, comparing the two extreme cases provides the maximum energy savings that can be achieved with the most advanced control strategies of all examined cases. For the four building types, Figure 40 through Figure 43 show the HVAC energy consumption (fan and cooling electricity and gas heating) of Case 22 and the base case for all 16 locations. The HVAC energy saving as a percentage of the base case energy consumption is also shown for each location. The following findings can be drawn from these figures:

- The largest absolute energy savings are obtained for Fairbanks for all building types, which is the same as observed from the comparison between Case 18 and Case 4 . The annual absolute savings are about $97 \mathrm{MMBtu}$ for the small office building, 1,388 MMBtu for the stand-alone retail building, 1,333 MMBtu for the strip mall, and 2,029 MMBtu for the supermarket. The differences in these savings among the building types are 
attributable to both differences in the size of the buildings and also the impact of the advanced control strategies on the different types of buildings.

- The smallest absolute energy savings per year are obtained for San Francisco for the small office buildings (40 MMBtu), and Los Angeles for the other three building types (300 MMBtu for stand-alone retail building, 324 MMBtu for the strip mall, and 582 MMBtu for the supermarket).

- The changes in energy savings as a percentage of the base case energy consumption follow the same patterns as those found when comparing Case 18 and Case 4 in Section 5.4. For the small office, stand-alone retail, and strip mall buildings, the percentage of energy savings generally decreases from mild (Los Angeles, San Francisco and Seattle) to hot and then from hot to cold climates. For the supermarket building (Figure 43), the percentage generally decreases from the hot and humid climate (Miami-Zone 1A) to the extreme cold climate (Fairbanks - Zone 8). Such trends can be explained the same as given in Section 5.4.

- The percentage of HVAC energy savings lies in the range between $22 \%$ and $56 \%$ for the small office building, $25 \%$ and $47 \%$ for the stand-alone retail building, $24 \%$ and $46 \%$ for the strip mall, and $16 \%$ and $47 \%$ for the supermarket. The maximum HVAC energy saving as a percentage of the base case energy consumption (Case 1 without advanced control options) occurs in Los Angeles for the small office building, the retail building and the strip mall, while it occurs in Miami for the supermarket. The minimum percentage savings occurs in Fairbanks for all four building types. For all 16 locations (15 climates), Case 22 has an average HVAC energy savings of about 35\% for small office, stand-alone retail and strip mall buildings and $24 \%$ for the supermarket. A summary of these savings is provided in Table 9. 


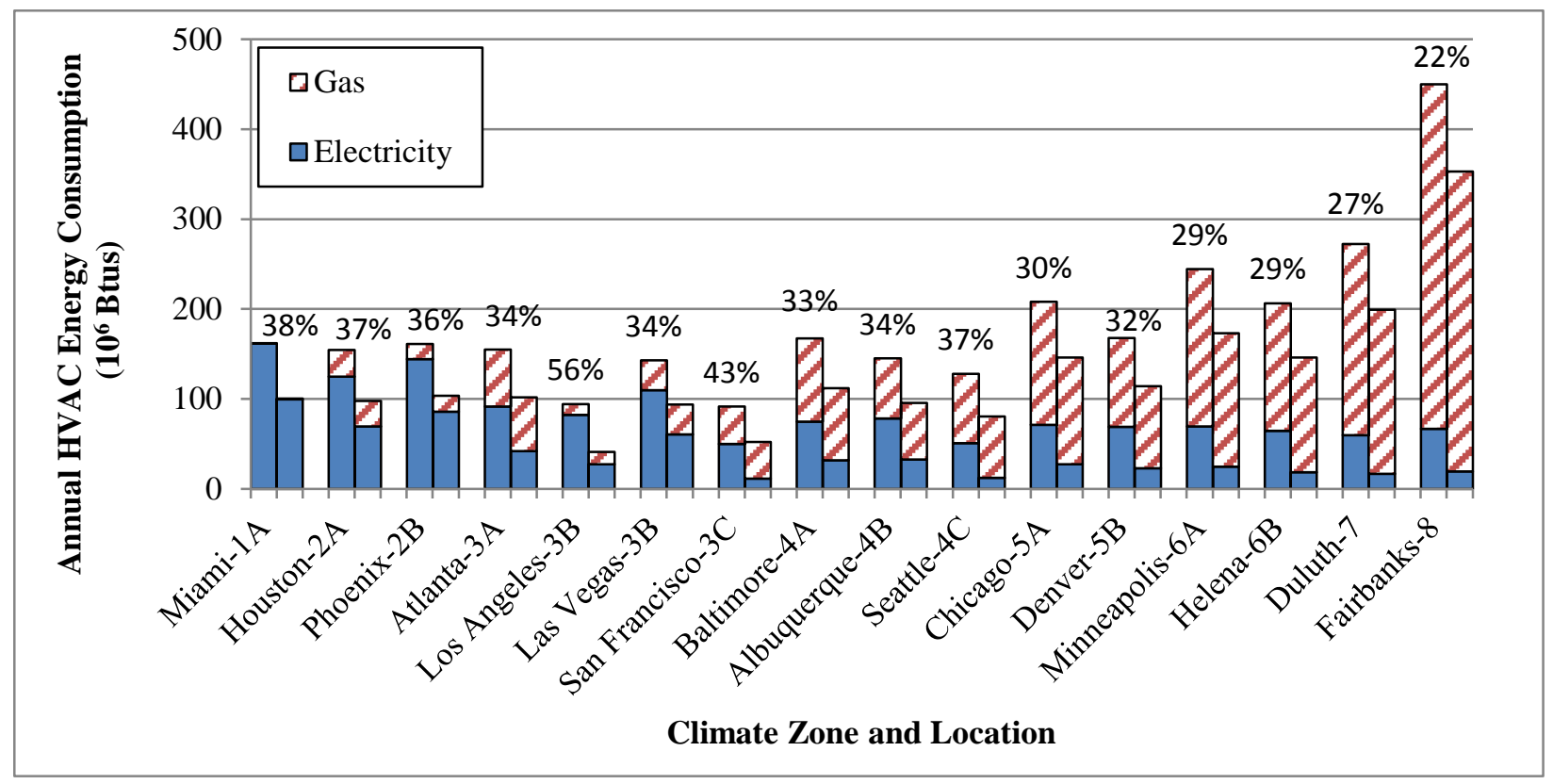

Figure 40: Comparison of HVAC Energy Consumption between the Baseline (Case 1; left bar for each location) and Case 22 (right bar for each location) for the Small Office Building. Percent Difference in the Total Energy Consumption between Case 1 and Case 22 is also shown for Each Location.

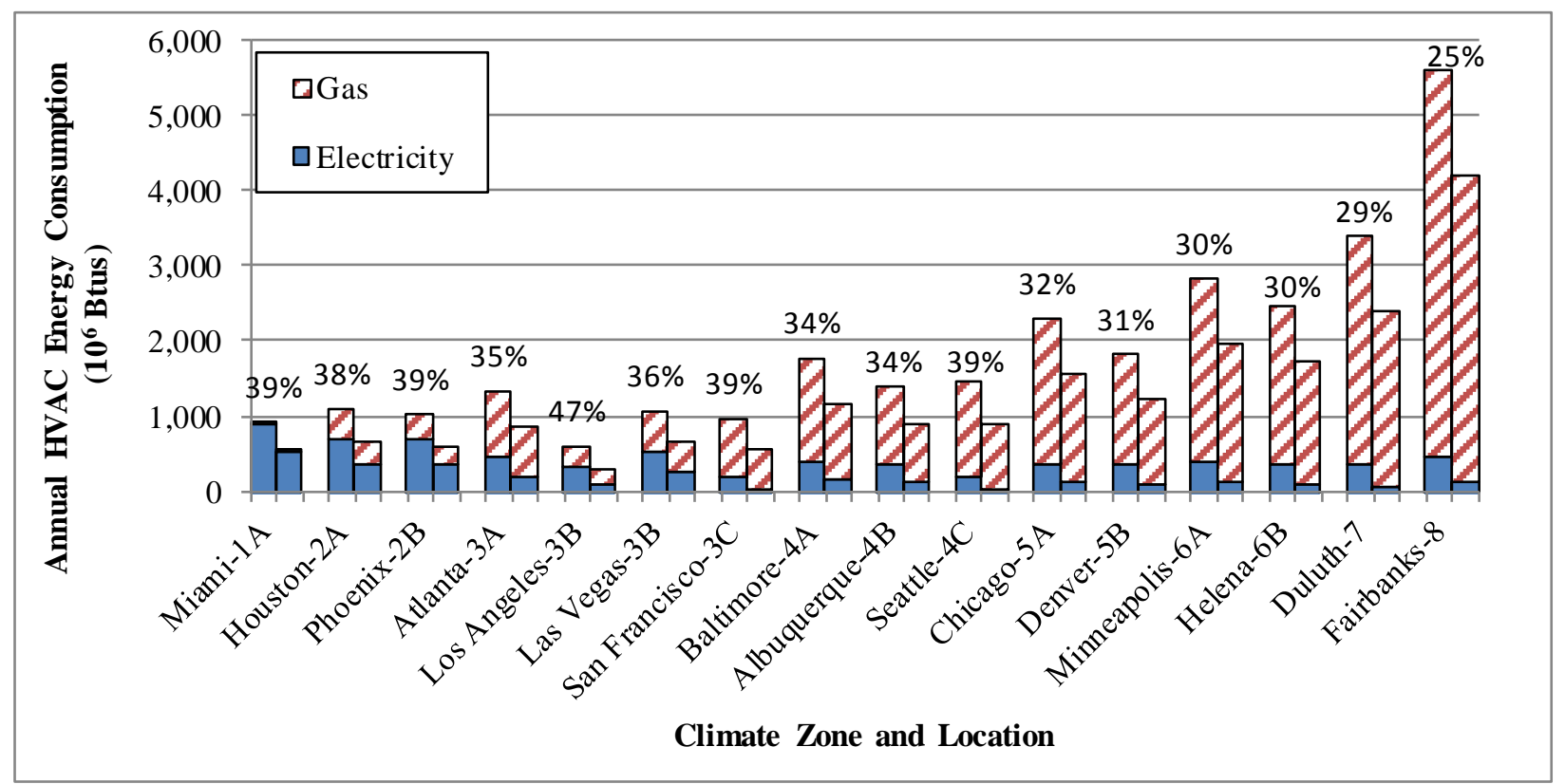

Figure 41: Comparison of HVAC Energy Consumption between the Baseline (Case 1; left bar for each location) and Case 22 (right bar for each location) for the Stand-alone Retail Building. Percent Difference in the Total Energy Consumption between Case 1 and Case 22 is also shown for Each Location. 


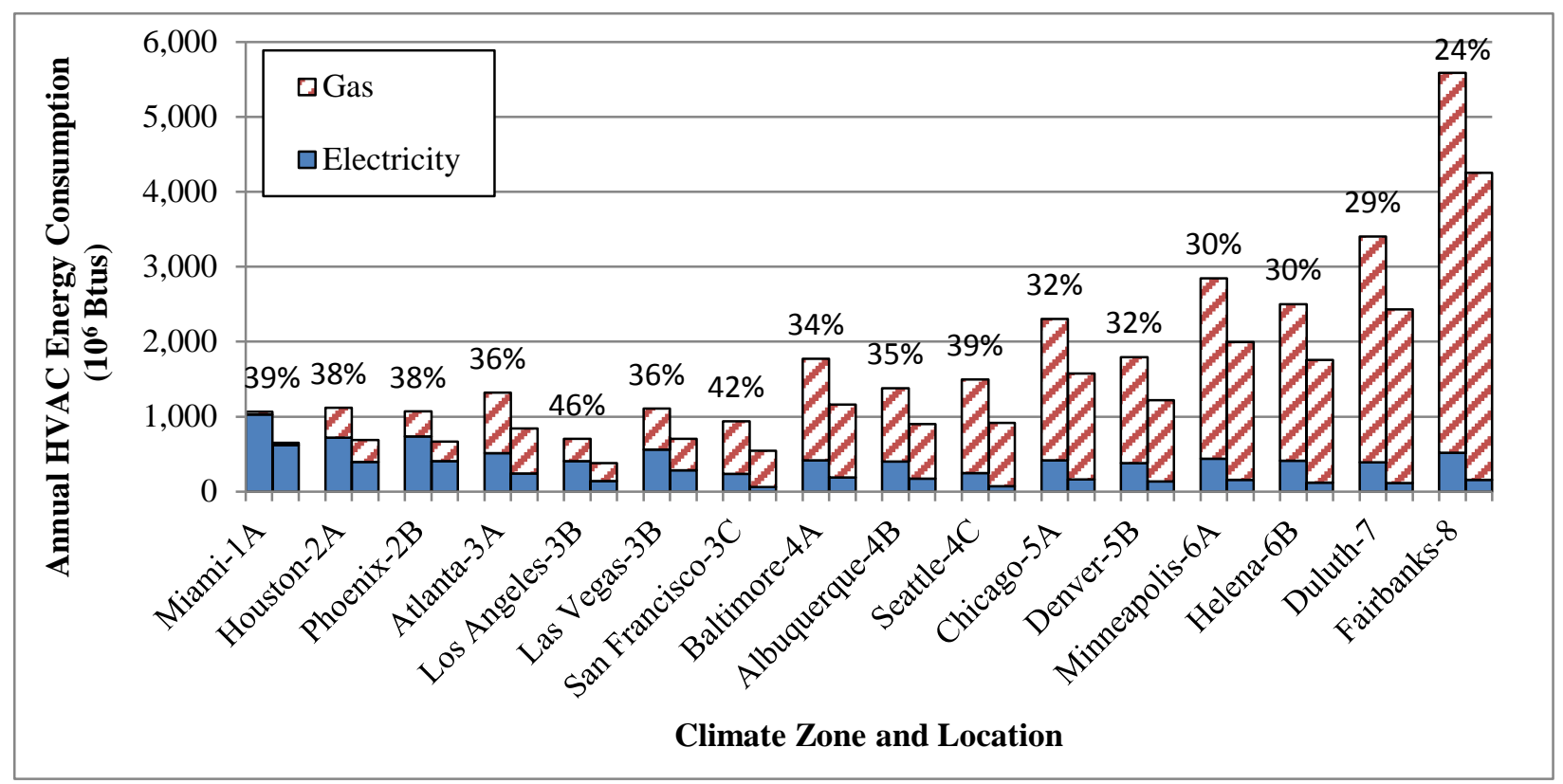

Figure 42: Comparison of HVAC Energy Consumption between the Baseline (Case 1; left bar for each location) and Case 22 (right bar for each location) the Strip Mall Building. Percent Difference in the Total Energy Consumption between Case 1 and Case 22 is also shown for Each Location.

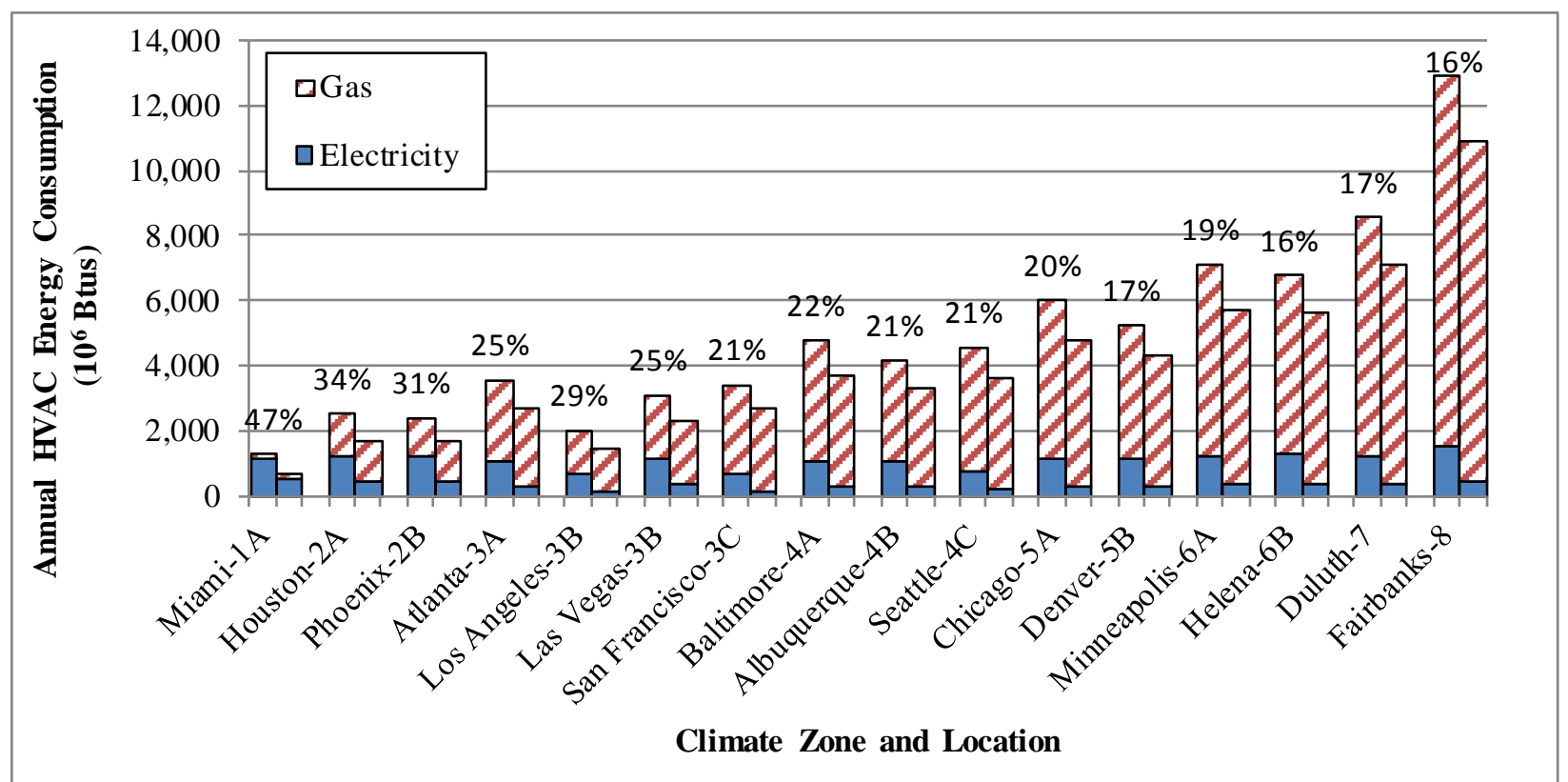

Figure 43: Comparison of HVAC Energy Consumption between the Baseline (Case 1; left bar for each location) and Case 22 (right bar for each location) for the Supermarket Building. Percent Difference in the Total Energy Consumption between Case 1 and Case 22 is also shown for Each Location. 
Table 9: Summary of HVAC Energy Savings for Case 22 Relative to the Base Case (Case 1)

\begin{tabular}{|c|c|c|c|c|}
\hline 8888888888888888 & & Building & уре & \\
\hline 8080808080808080 & Small office & Stand-alone retail & Strip mall & Supermarket \\
\hline $\begin{array}{l}\text { Maximum percentage } \\
\text { savings }\end{array}$ & $56 \%$ & $47 \%$ & $46 \%$ & $47 \%$ \\
\hline $\begin{array}{l}\text { Location for maximum } \\
\text { percentage savings }\end{array}$ & Los Angeles & Los Angeles & Los Angeles & Miami \\
\hline $\begin{array}{l}\text { Minimum percentage } \\
\text { savings }\end{array}$ & $22 \%$ & $25 \%$ & $24 \%$ & $16 \%$ \\
\hline $\begin{array}{l}\text { Location for minimum } \\
\text { percentage savings }\end{array}$ & Fairbanks & Fairbanks & Fairbanks & Fairbanks \\
\hline $\begin{array}{l}\text { Average percentage } \\
\text { savings }\end{array}$ & $35 \%$ & $35 \%$ & $35 \%$ & $24 \%$ \\
\hline $\begin{array}{l}\text { Maximum absolute } \\
\text { savings (MMBtu/yr) }\end{array}$ & 97 & 1388 & 1333 & 2029 \\
\hline $\begin{array}{l}\text { Location for maximum } \\
\text { absolute savings }\end{array}$ & Fairbanks & Fairbanks & Fairbanks & Fairbanks \\
\hline $\begin{array}{l}\text { Minimum absolute } \\
\text { savings (MMBtu/yr) }\end{array}$ & 40 & 300 & 324 & 582 \\
\hline $\begin{array}{l}\text { Location for minimum } \\
\text { absolute savings }\end{array}$ & $\begin{array}{c}\text { San } \\
\text { Francisco }\end{array}$ & Los Angeles & Los Angeles & Los Angeles \\
\hline $\begin{array}{l}\text { Average absolute } \\
\text { savings (MMBtu/yr) }\end{array}$ & 59 & 609 & 608 & 1010 \\
\hline
\end{tabular}




\section{Economic Analysis}

This section presents and discusses the energy cost saving results from different combinations of packaged rooftop unit control strategies. Based on the energy cost saving, the maximum total installed cost for the add-on controller to achieve a specific simple payback period is determined for several combinations of advanced control strategies.

\subsection{Impact Assessment of Individual Control Strategies on HVAC Energy Cost}

The annual HVAC energy cost is estimated using the methodology presented in Section 4. With the HVAC energy costs for all 22 cases, the annual energy cost savings for each of the 21 advanced control combinations (cases) can be easily calculated as the difference of energy cost between the base case and an advanced case for a given building type. The results are provided in Appendix D. To provide insights into the impact of advanced control combinations on the savings of different fuel costs, the results are presented for the total energy cost savings (Table D1 through D16), the electricity cost savings (Table D17 through D32), and the gas cost savings (Table D33 through D48). In all tables, the cost savings are shown as both absolute values and the percentages of the base case (Case 1) annual energy cost. The difference between the tabulated cost savings for any two cases for a specific building type and location provides the average annual HVAC energy cost savings when changing from one combination of packagedunit control strategies to another. Based on these results, the impact of air-side economizer, multi-speed fan control, DCV, and staged cooling is evaluated individually below.

The impact of air-side economizer on energy savings made in Section 5.2 has shown that there is negligible difference between examined economizer control options, including nonintegrated vs. integrated and differential dry-bulb vs. differential enthalpy. Therefore, the impact of air-side economizers on energy cost is investigated for only one economizer control option: the integrated air-side economizer using differential dry-bulb as the control variable. This impact assessment can be made by comparing the energy cost of Case 4 with the baseline (Case 1). As shown in Figure 44, the following observations can be made:

- In terms of the percentage savings (the upper part in Figure 44), the integrated air-side economizer has much greater energy cost savings potential in warm climates (Los Angeles and San Francisco) than it has in other climates. In Los Angeles, for example, energy cost savings of about $25 \%$ of the Case 1 energy cost are achieved for the small office building. In contrast, much smaller (less than 5\% of the Case 1 HVAC energy cost) energy cost savings are observed for the locations with hot (e.g., Miami and Houston) or cold climates (e.g., Minneapolis and Duluth).

- The percentage savings also vary with the building type. The small office building almost always has a higher percentage of energy cost saving than the other three building types. The energy cost for cooling as a fraction of the total HVAC energy cost is greatest for the small office building compared to the other types of buildings. When cooling represents a greater fraction of the total HVAC energy cost, as with the small office building, the impact of the economizer on percentage cost savings is also greater. 
- In terms of the absolute energy cost savings, the supermarket almost always has higher energy cost savings than other building types, which is simply because it has the largest floor area among the four building types.

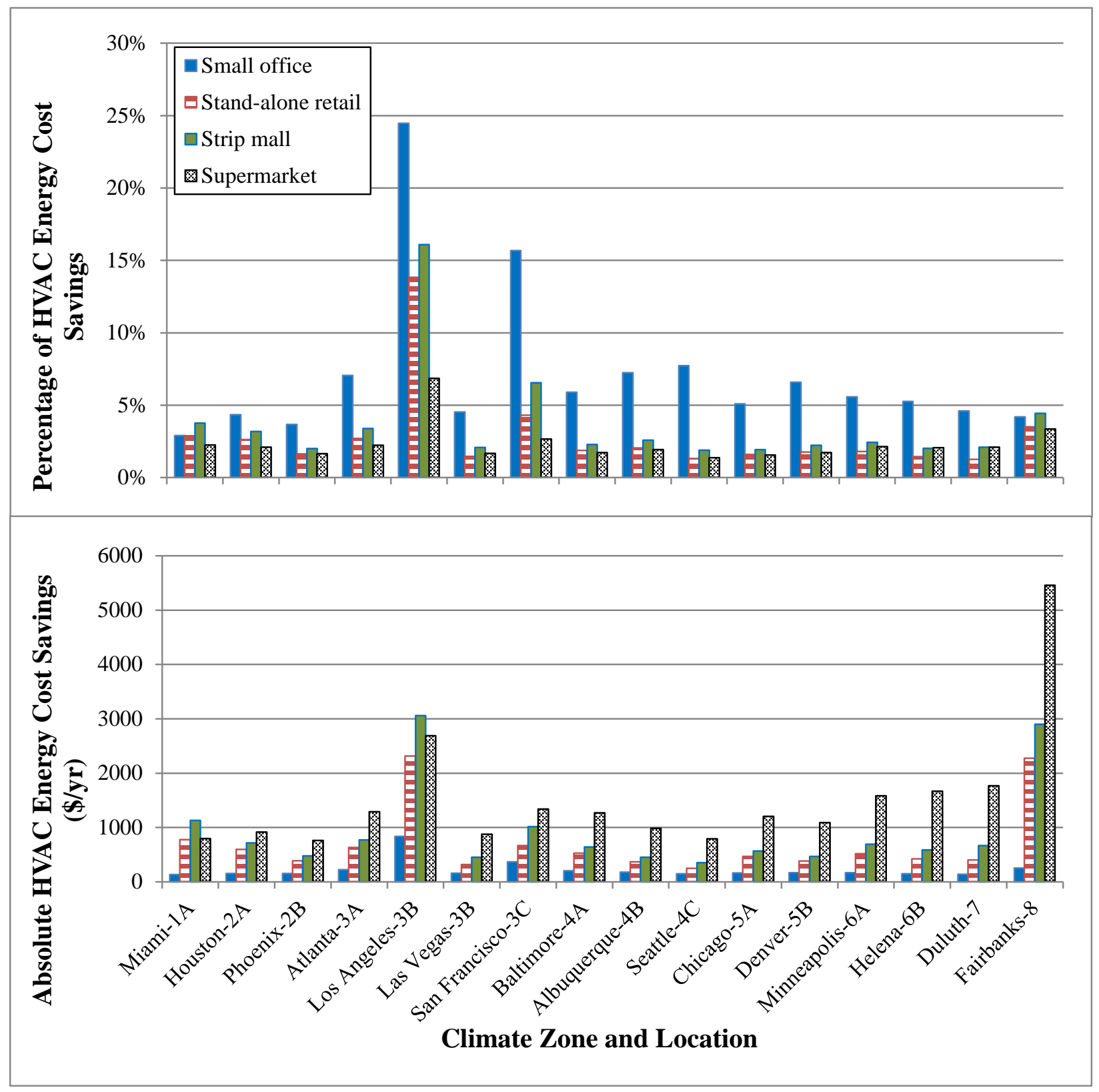

Figure 44: HVAC Energy Cost Savings from the Use of an Integrated Air-Side Differential Dry-Bulb Economizer (Case 4) Compared to the Base Case without an Air-Side Economizer

The impact of supply-fan control on HVAC energy cost can be investigated by comparing two cases, one using single-speed fan control and the other using multi-speed fan control. Following the approach used to study the impact of multi-speed fan control on energy consumption (Section 5.2), the same two cases, Case 6 and the base case, are compared to evaluate the supply-fan control in terms of energy cost. The upper part of Figure 45 shows the energy cost savings as 
percentages of the base case HVAC energy cost, whereas the lower part shows the energy cost savings as absolute values. From Figure 45, the following observations are made:

- For all four building types, replacement of constant-speed fan control with multi-speed fan control yields energy cost savings for all 16 locations. This observation differs from that found for energy savings in Section 5.2, where there was an increase of HVAC energy consumption in cold climates. The phenomenon of having energy penalties but cost savings in cold climates can be explained from the impact of multi-speed fan control on different energy end uses and different fuel prices. The use of multi-speed fan control decreases fan energy but increases heating energy. Although overall annual HVAC energy consumption increases in cold climates, the decrease in the cost for highly priced electricity used for fan operation is greater than the cost increase for lower-priced gas used for heating. Hence, positive energy cost savings are observed even in cold climates.

- For all four building types, using multi-speed fan control has about $18 \%$ or more cost savings for the locations in climate zones 1 to $4 \mathrm{~B}$. The percentage cost savings become smaller in cold climates, but around 10\% savings are still observed in most cases. The percentage savings in Seattle (zone 4C) is small because it has the lowest electricity price among all examined locations.

- The impact of multi-speed fan control on energy cost varies with building type. In terms of the percentage energy saving relative to the base case (Case 1) energy cost, the office building has the highest savings for the locations in climate zone 3 through 8 , while the supermarket building has the highest percentage savings in climate zone 1 and 2. In terms of the absolute values of energy cost changes, the use of multi-speed fan control has the largest impact on the supermarket building, while it has the smallest impact on the small office building. This difference in absolute energy cost savings among the building types is mainly caused by the difference in building size. 


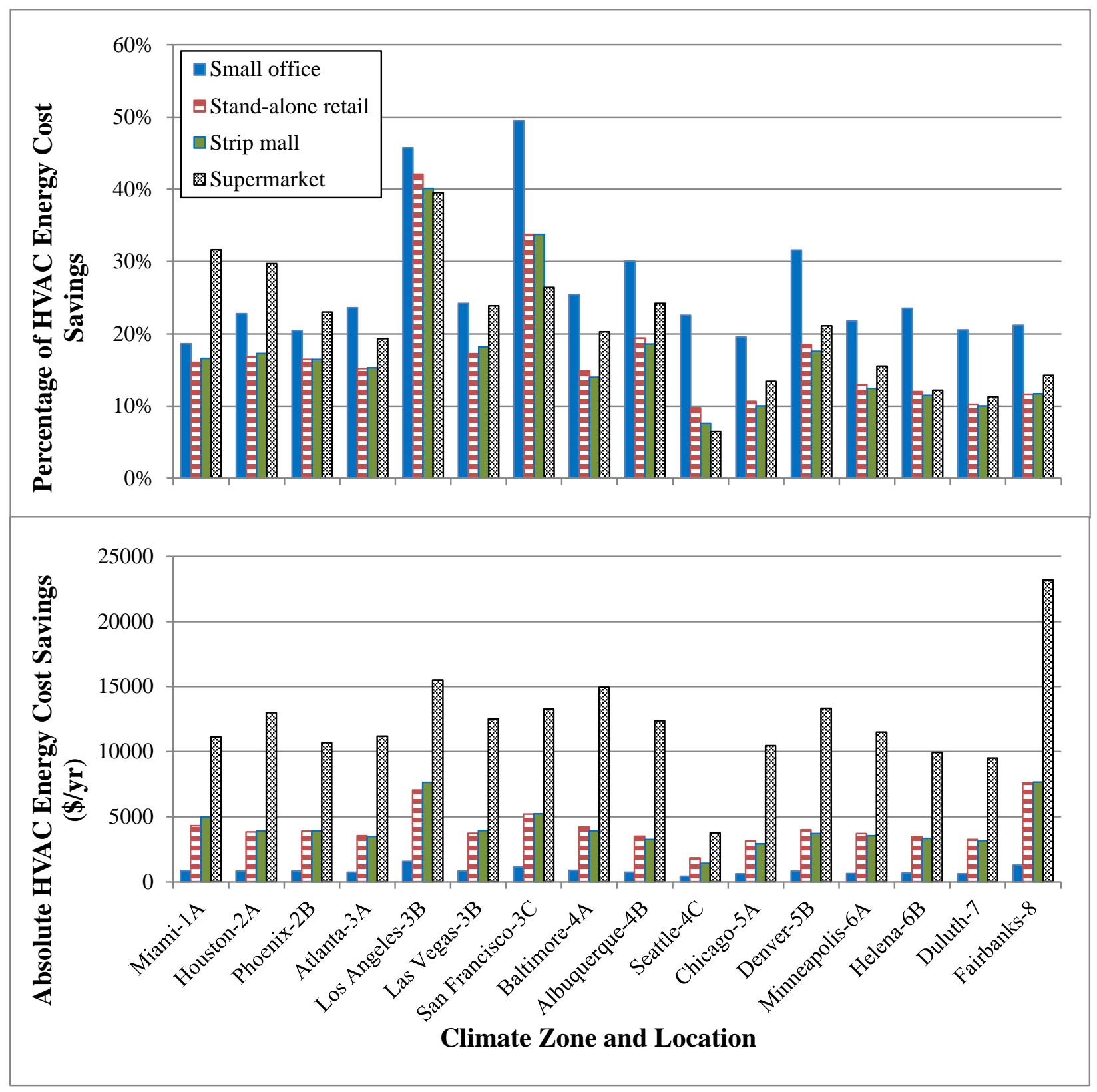

Figure 45: HVAC Energy Cost Savings from the Use of Multi-speed Supply-Fan Control (Case 6) Compared to the Base Case with Constant-Speed Fan Control

Following the approach used to study the impact of DCV on energy consumption (Section 5.2), Case 14 and the base case are compared to investigate the impact of DCV on HVAC energy cost. Case 14 differs from the base case only by the presence of DCV. The upper part of Figure 46 shows the energy cost savings as percentages of the base case HVAC energy cost, whereas the lower part shows the energy cost savings as absolute values. It can be seen from Figure 46 that the two retail buildings have a larger percentage cost savings resulting from DCV than the other two building types. Around 15\% cost savings are observed in the two retail buildings for most locations. The small office building has the smallest percentage cost savings in all locations except Fairbanks. A small increase in energy cost is even observed in Los Angeles and San 
Francisco for the small office building, although positive energy savings are observed in these two locations (see Section 5.2). This can be explained from the combined impact of DCV on HVAC energy end uses and different fuel prices. For example, for the small office building in Los Angeles, applying DCV (in Case 14) shows an increase in electricity consumption by 1.8 MMBtu and decrease in gas consumption by $3 \mathrm{MMBtu}$. The overall energy cost increases because the electricity price $(0.138 \$ / \mathrm{kWh}=\$ 40.4 / \mathrm{MMBtu})$ is much higher than the gas price (\$8.30 MMBtu) in Los Angeles.

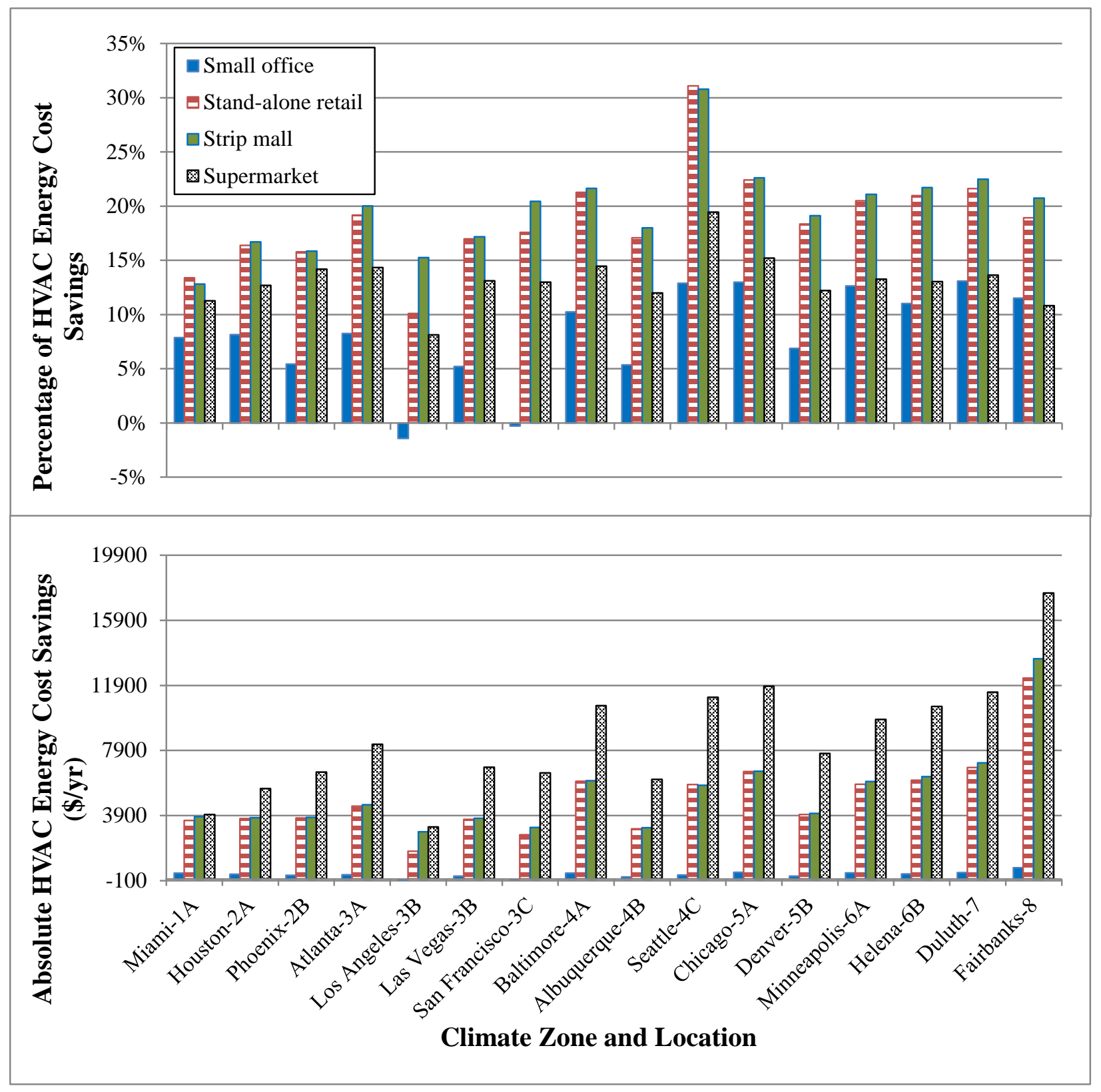

Figure 46: HVAC Energy Cost Savings from the Use of Demand Controlled Ventilation (Case 14) Compared to the Base Case with Constant Outdoor-Air Supply

Figure 47 shows the change in total HVAC energy cost by upgrading from single-stage cooling (Case 6) to two-stage cooling (Case 11). As shown, two-stage cooling is more effective in hot 
climates. It can save up to approximately $16 \%$ of the total HVAC energy cost for the small office building in Los Angeles. In comparison with the energy savings shown in Figure 19, the percentage cost savings is much greater than the percentage energy savings because staged cooling reduces cooling electricity and the electricity price is higher than the gas price.

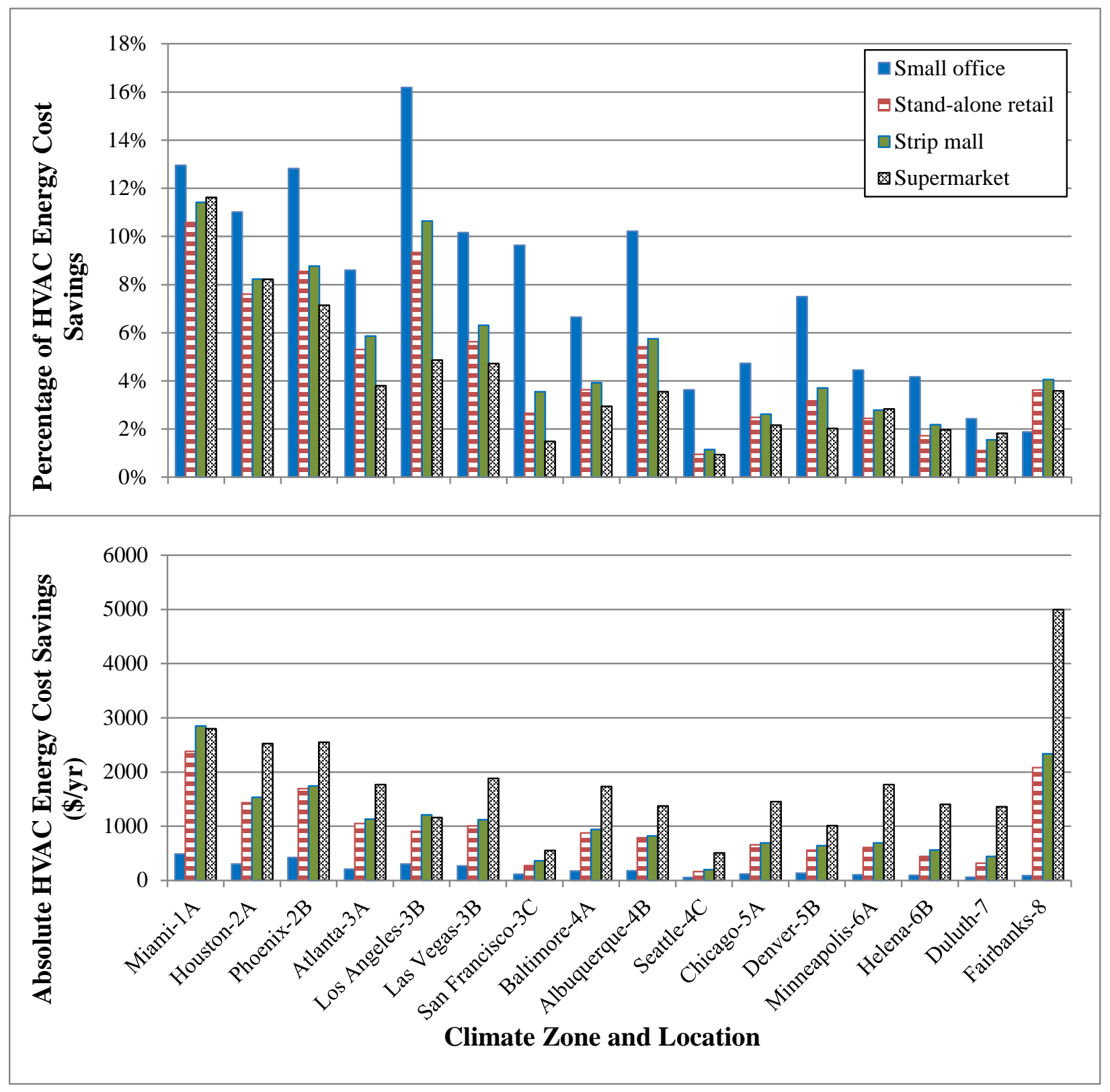

Figure 47: HVAC Energy Cost Savings from the Use of Two-Stage Cooling (Case 11) Compared to Single-Stage Cooling (Case 6)

\subsection{Incremental Impact of Selected Control Strategies on HVAC Energy Cost}

Following the approach used to study the incremental impact on energy savings in Section 5.4, the same five cases (Case 1, 6, 7, 9 and 18) are used in this section to illustrate the incremental impact of control strategies on energy cost savings. Sequentially comparing these cases reveals 
the incremental impact from adding the following control strategies in the order listed: supply fan with multiple speed control (from Case 1 to Case 6), nonintegrated air-side economizer based on differential dry-bulb temperature control (from Case 6 to Case 7), integrated economizer control (from Case 7 to Case 9), and DCV (from Case 9 to Case 18). The energy cost savings are broken down by fuel type (electricity and gas) to better characterize how each control strategy affects each fuel type.

Figure 48 through Figure 51 show the incremental total energy cost savings for all 16 locations. The incremental energy cost savings may be negative if adding a control strategy increases energy cost. The sum of these incremental savings (both positive and negative) on energy cost equals to the total energy cost savings. The following observations can be made from these figures:

- Multi-speed fan control and DCV are the two control strategies that dominate the impact on energy cost savings for almost all cases. The only two exceptions occur for the small office building in Los Angeles and San Francisco, where air-side economizer control contributes to more energy cost savings than DCV.

- Of all four control strategies used in this incremental impact analysis, the multi-speed fan control strategy usually contributes the most energy cost savings in hot and warm climates (e.g., Miami, Houston, and Los Angeles), while DCV contributes most in cold climates (e.g., Chicago and Duluth).

- Adding an air-side economizer after multi-speed fan control does not have a large impact on HVAC energy cost savings except for a few cases, like Los Angeles. Furthermore, in comparison with the nonintegrated air-side economizer, the integrated air-side economizer has a small impact on energy cost savings.

- In contrast with the incremental impact on energy savings (Figure 20 through Figure 23), multi-speed fan control plays a more important role in cost savings. Because electricity prices are generally higher than natural gas prices (per equivalent amount of energy), the use of multi-speed fan control significantly reduces electricity consumption for all locations, leading to significant cost impacts. 


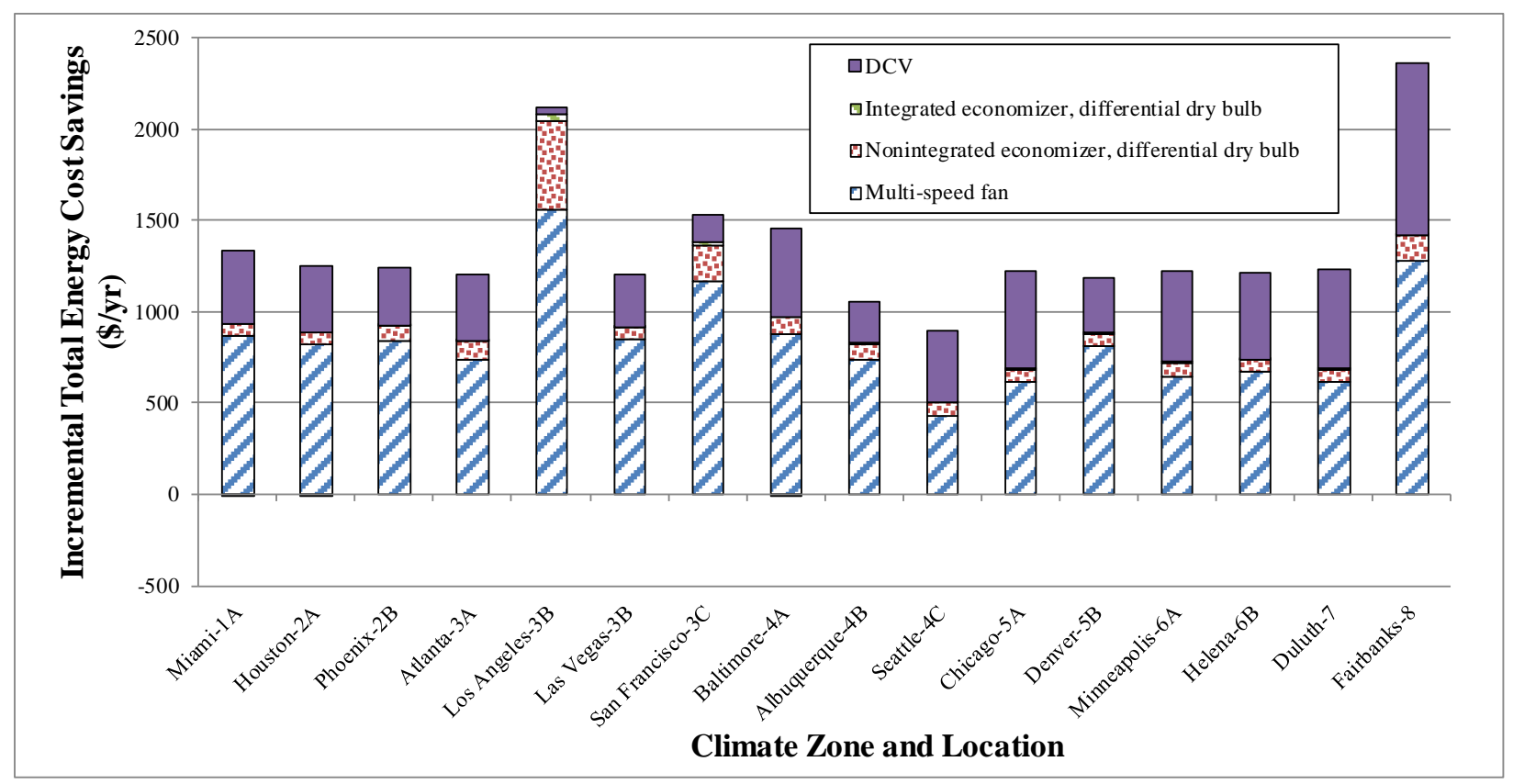

Figure 48: Total Energy Cost Savings Resulting from Incremental Addition of Advanced Control Strategies for the Small Office Building

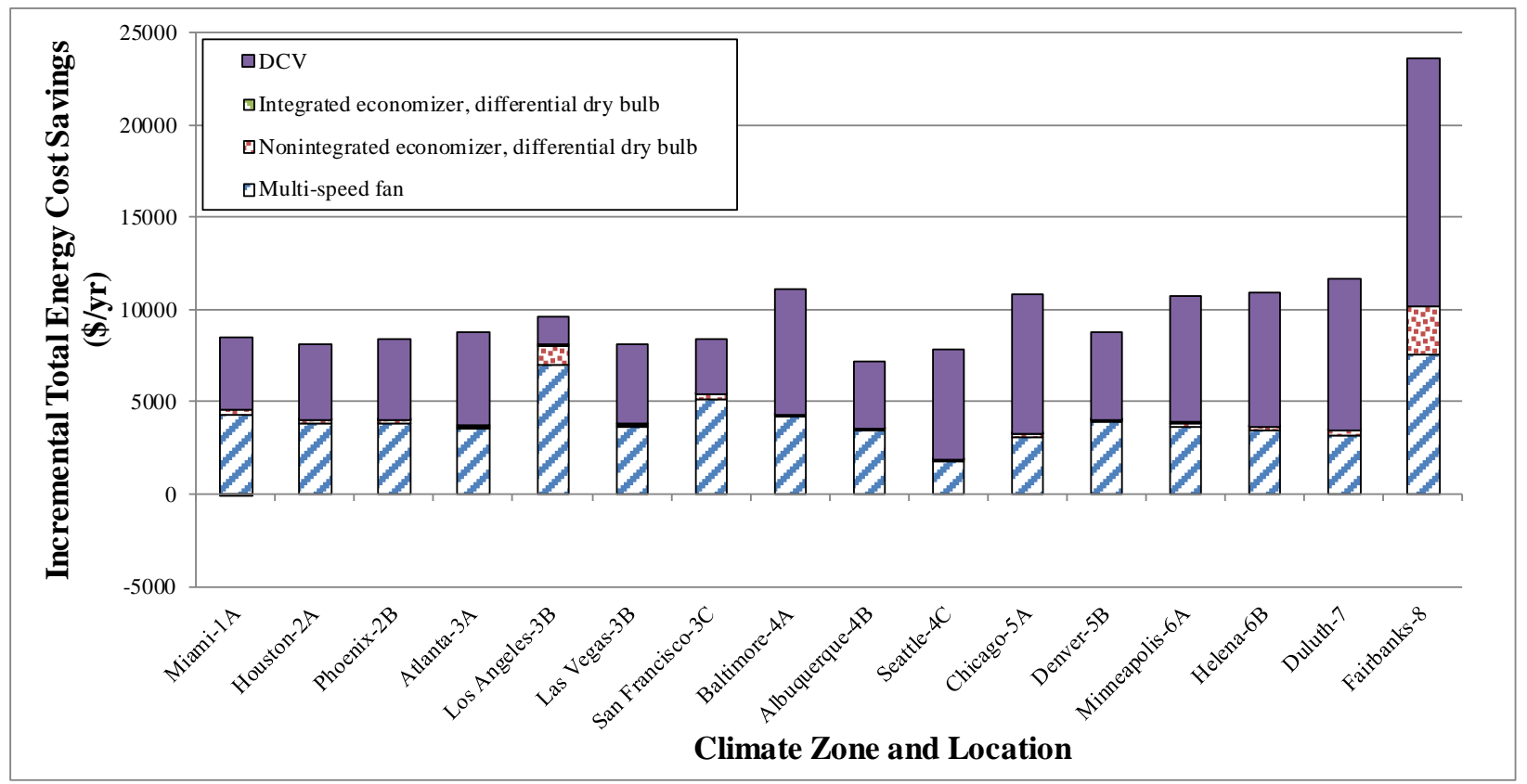

Figure 49: Total Energy Cost Savings Resulting from Incremental Addition of Advanced Control Strategies for the Stand-alone Retail Building 


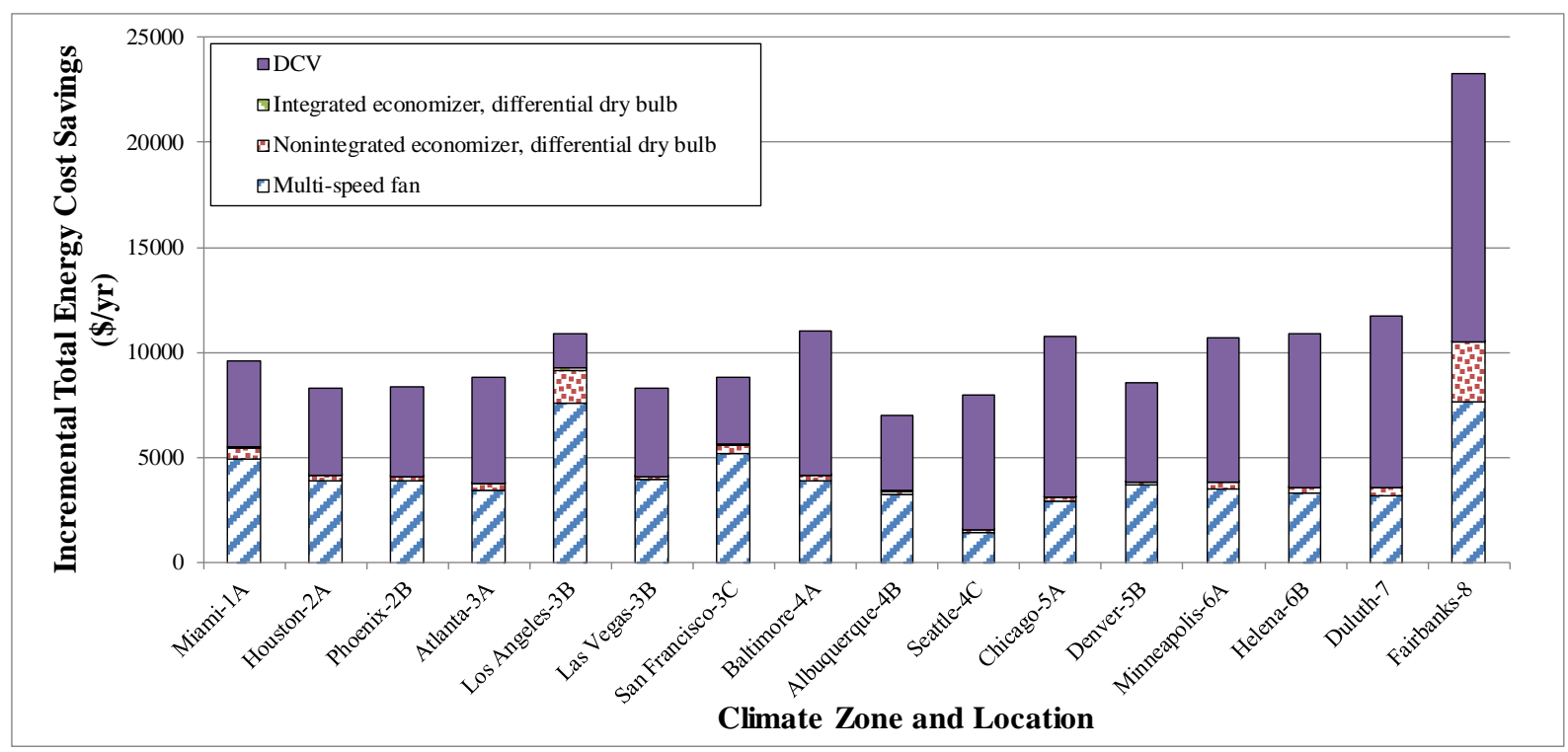

Figure 50: Total Energy Cost Savings Resulting from Incremental Addition of Advanced Control Strategies for the Strip Mall Building

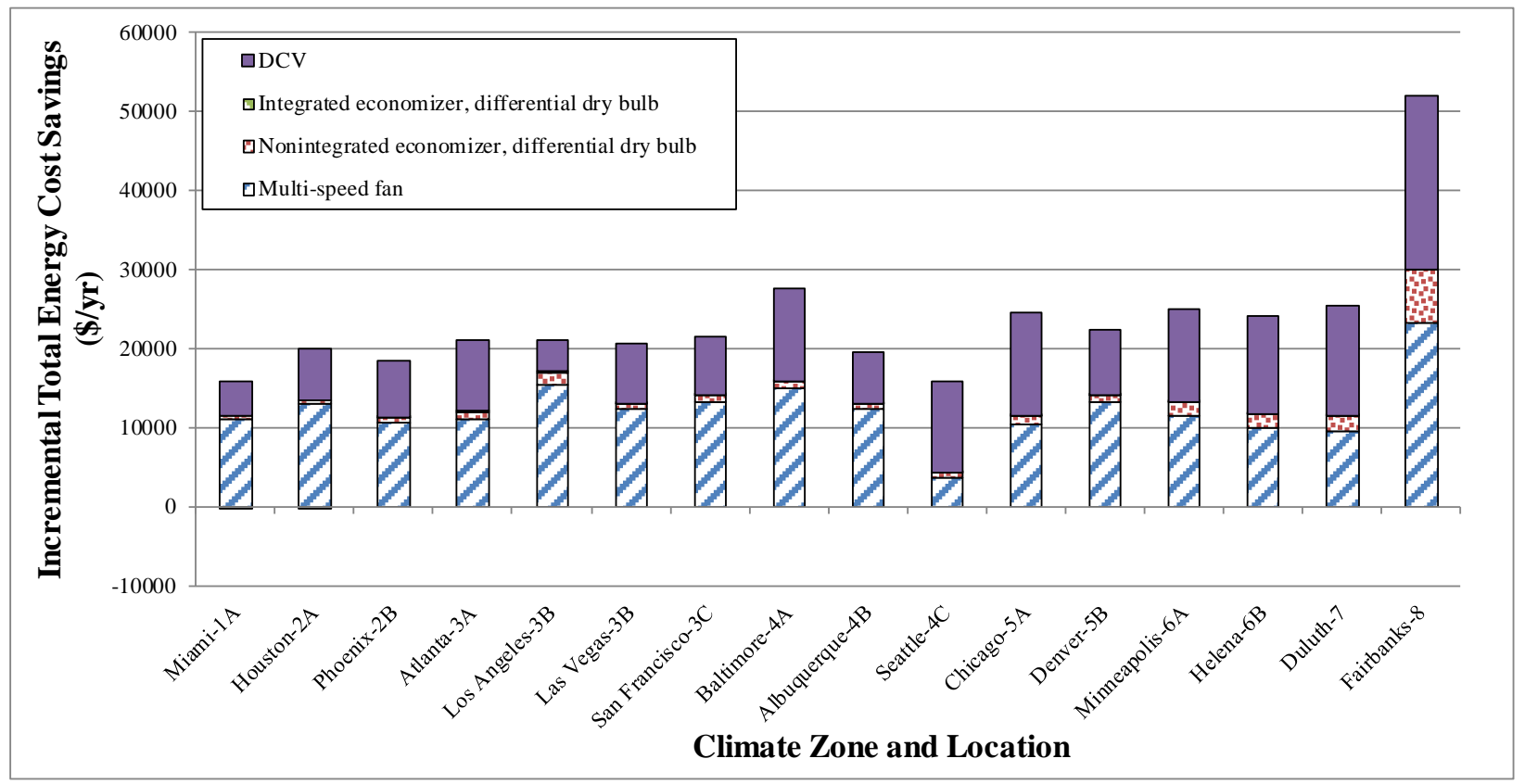

Figure 51: Total Energy Cost Savings Resulting from Incremental Addition of Advanced Control Strategies for the Supermarket Building

Figure 52 through Figure 55 show the annual savings of electricity cost resulting from the incremental addition of advanced control strategies for all 16 locations and 4 building types. These figures show the following:

- Multi-speed fan control dominates the impact on electricity cost savings in all 16 locations for the four building types. It contributes to more than $80 \%$ of the total electricity savings in the following locations: San Francisco in climate zone $3 \mathrm{~B}$ and all examined locations in climate zones 4B through 8. 
- In most climates, DCV has a secondary but noticeable impact on electricity savings. For all four building types, DCV contributes to between $15 \%$ and $40 \%$ of the total electricity savings in Miami, Houston, Phoenix and Las Vegas.

- Adding an air-side economizer after multi-speed fan control does not have a large impact on electricity cost savings except for a few cases, such as all four building types in Los Angeles and Fairbanks. Furthermore, in comparison with the nonintegrated air-side economizer, the integrated air-side economizer has a small impact on electricity cost savings.

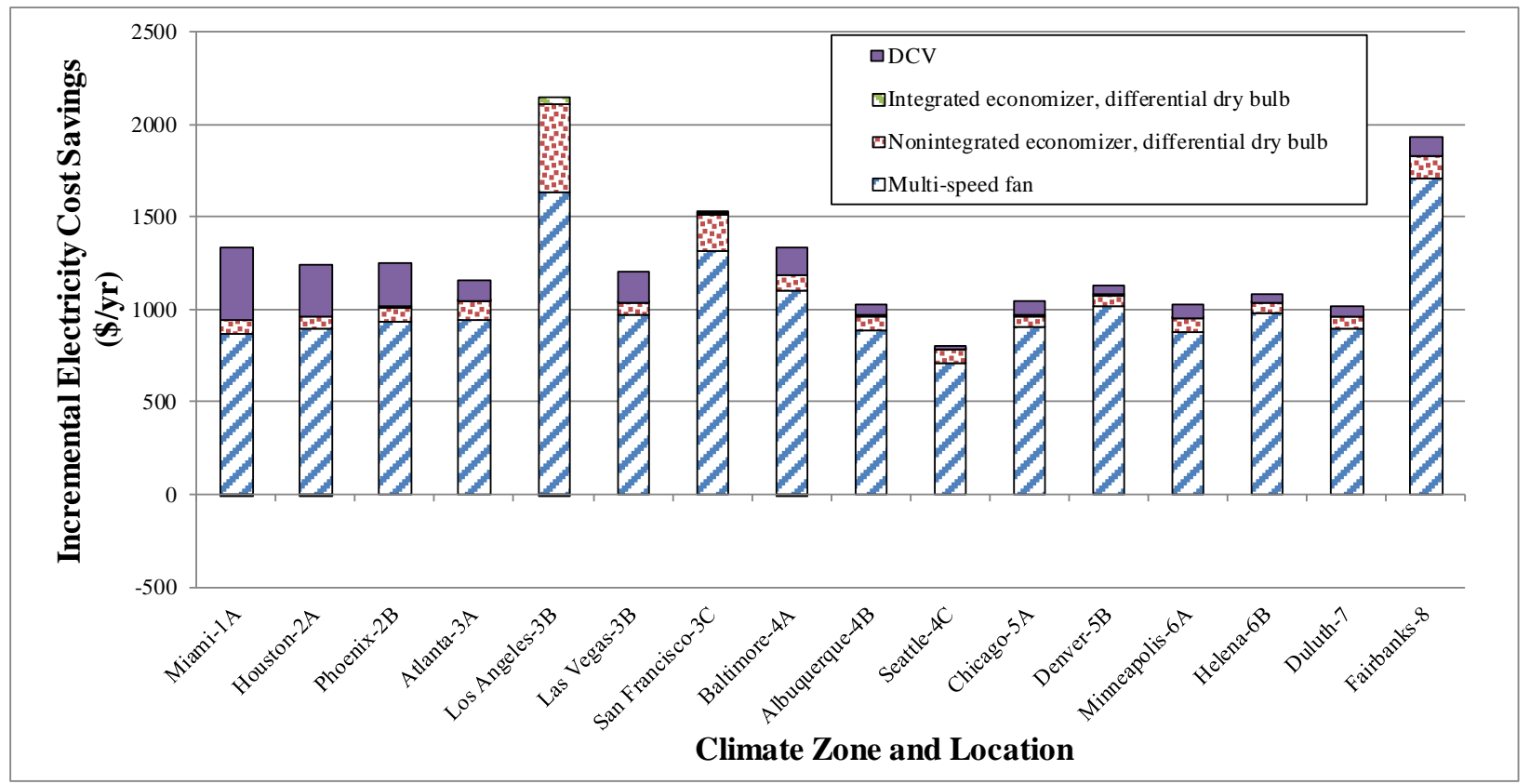

Figure 52: Electricity Cost Savings Resulting from Incremental Addition of Advanced Control Strategies for the Small Office Building 


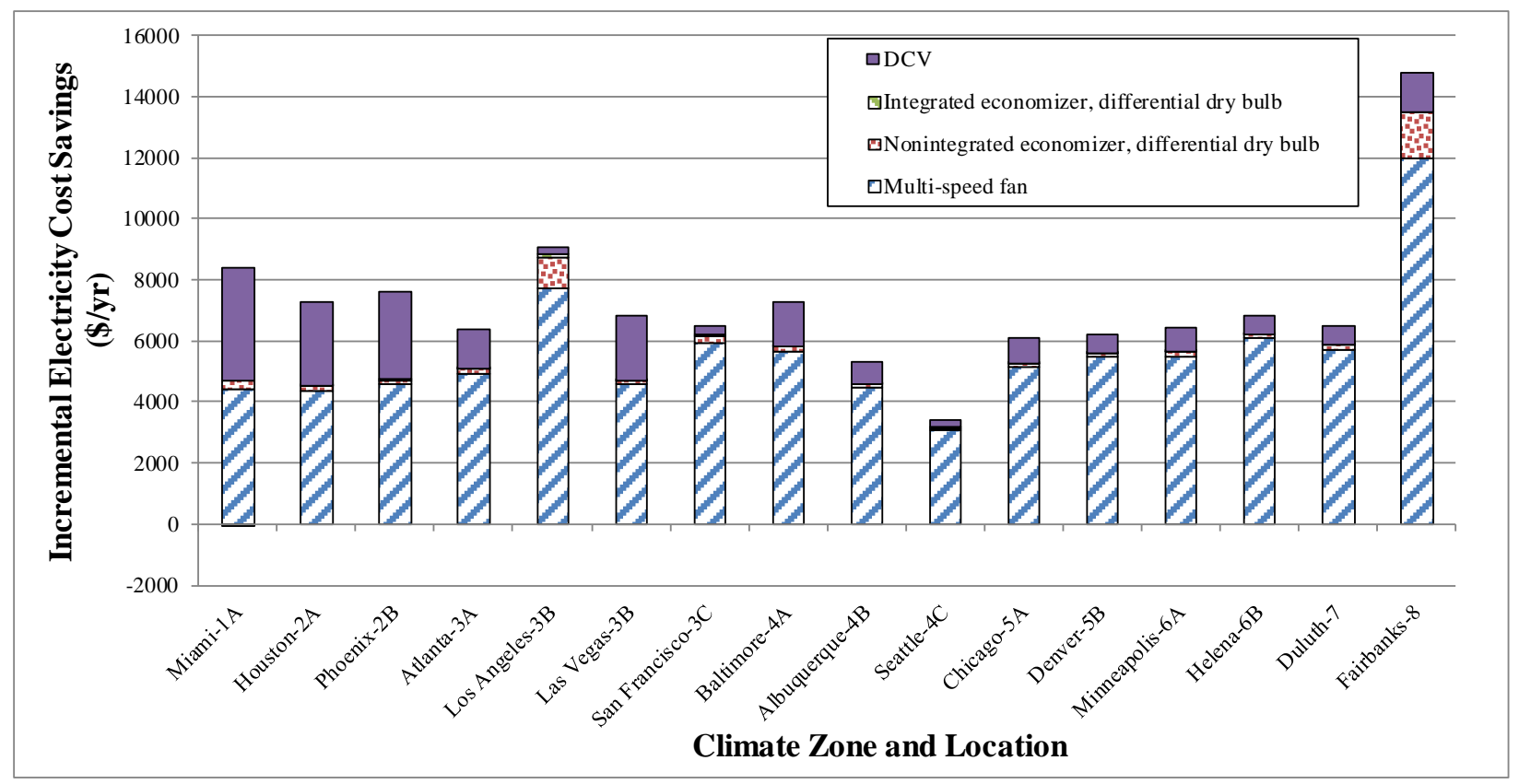

Figure 53: Electricity Cost Savings Resulting from Incremental Addition of Advanced Control Strategies for the Stand-alone Retail Building

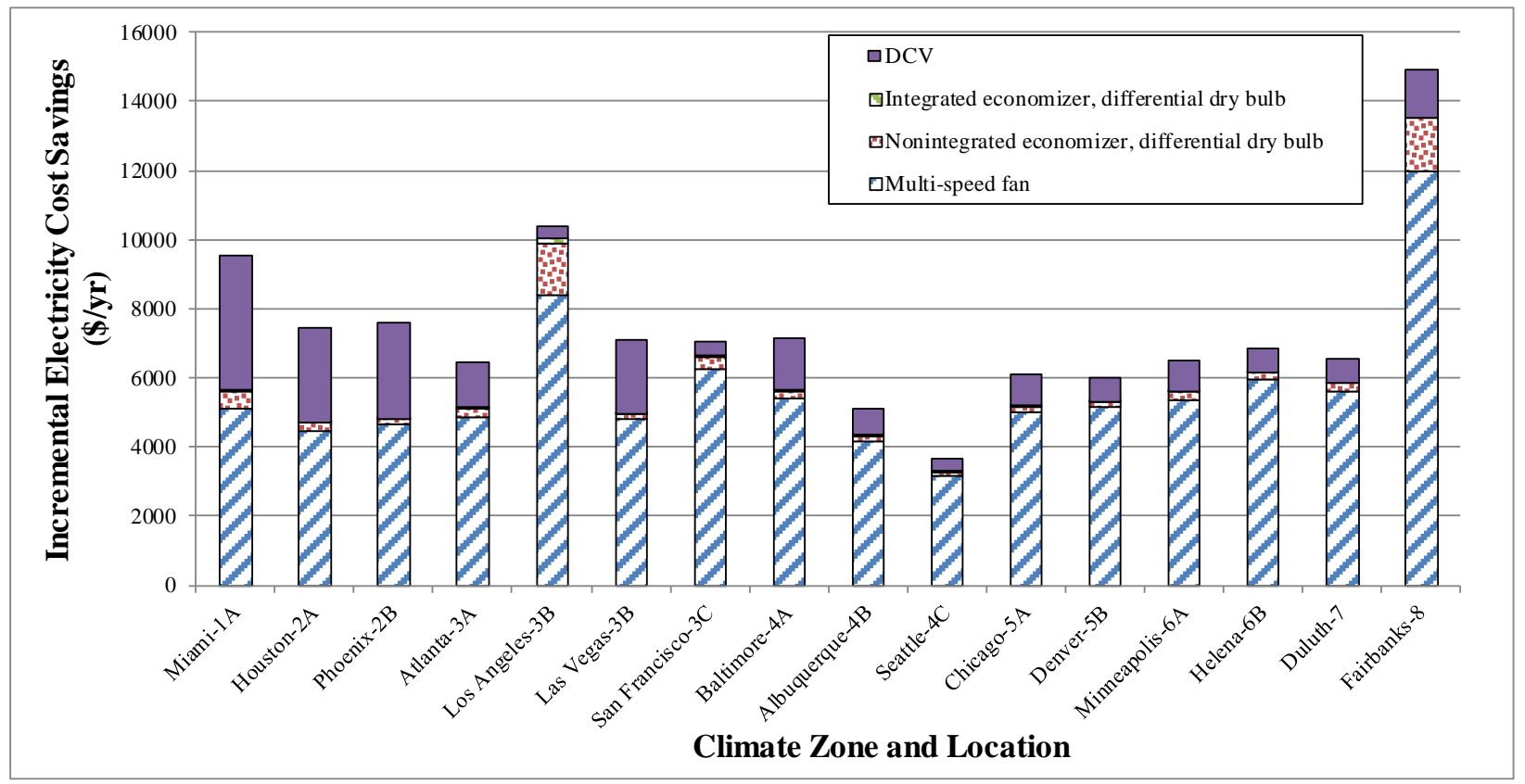

Figure 54: Electricity Cost Savings Resulting from Incremental Addition of Advanced Control Strategies for the Strip Mall Building 


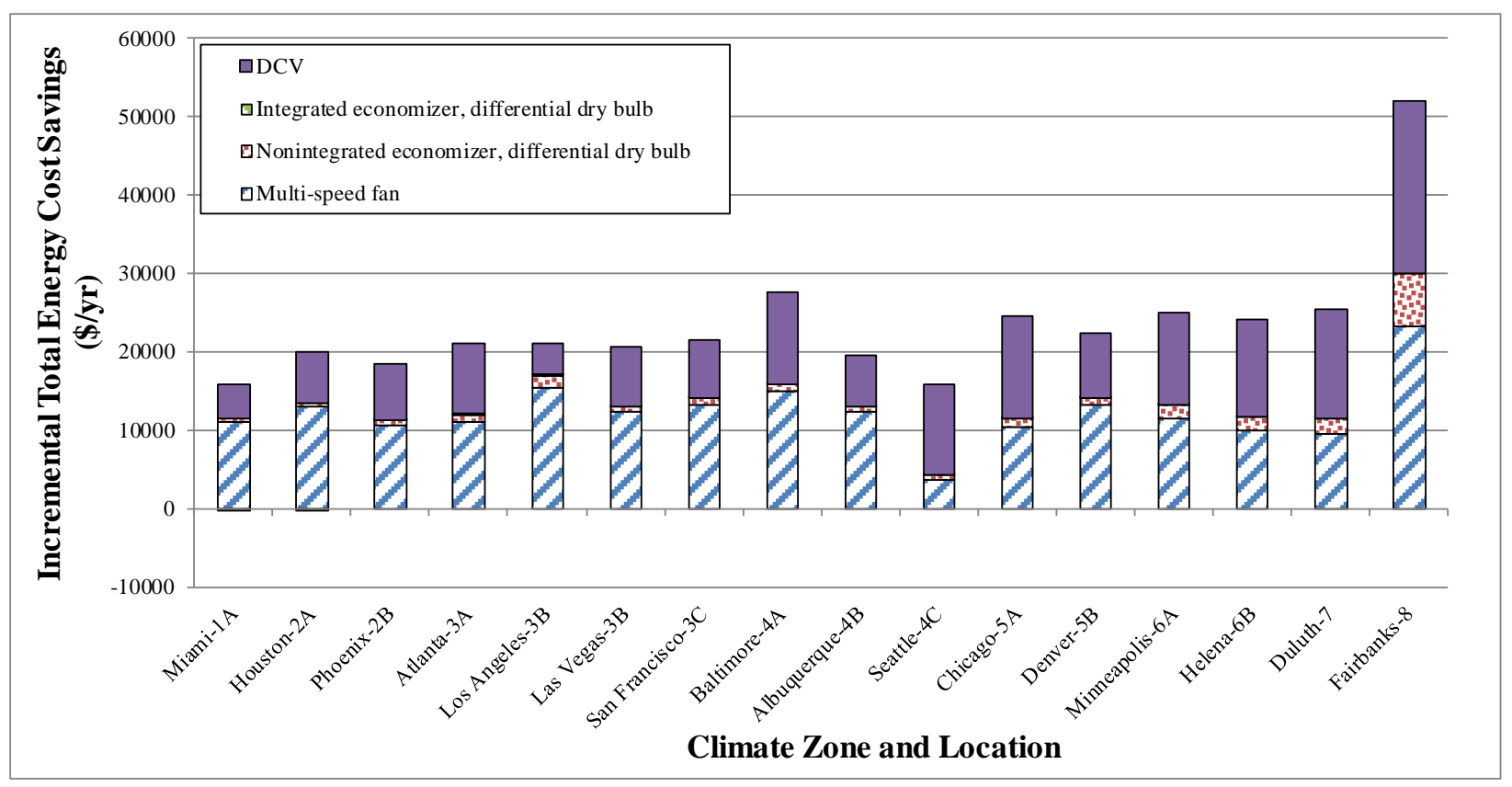

\section{Figure 55: Electricity Cost Savings Resulting from Incremental Addition of Advanced Control Strategies for the Supermarket Building}

Figure 56 through Figure 59 show the annual savings of gas cost resulting from the incremental addition of advanced control strategies for all 16 locations and 4 building types. These figures show the following:

- Multi-speed fan control increases gas cost in all 16 locations for the four building types. This can be simply explained by the heating energy increase resulting from the multispeed fan control, as discussed previously in Section 5.3. Similarly, DCV contributes almost all gas cost savings because it can significantly reduce heating energy consumption, as discussed in Sections 5.2 and 5.3.

- The impact of multi-speed fan control and DCV on gas cost (either savings or penalties) generally increases from hot to cold climates. However, because of the variation of gas prices, the sequence may not necessarily follow that found for heating energy savings. For example, in Figure 32 through Figure 35, the use of multi-speed fan control increases less heating energy in Helena than it has in Duluth. Because Helena has a higher gas price (\$0.895/Therm) than Duluth (\$0.736/Therm), there is more gas cost increase in Helena resulting from multi-speed fan control. 


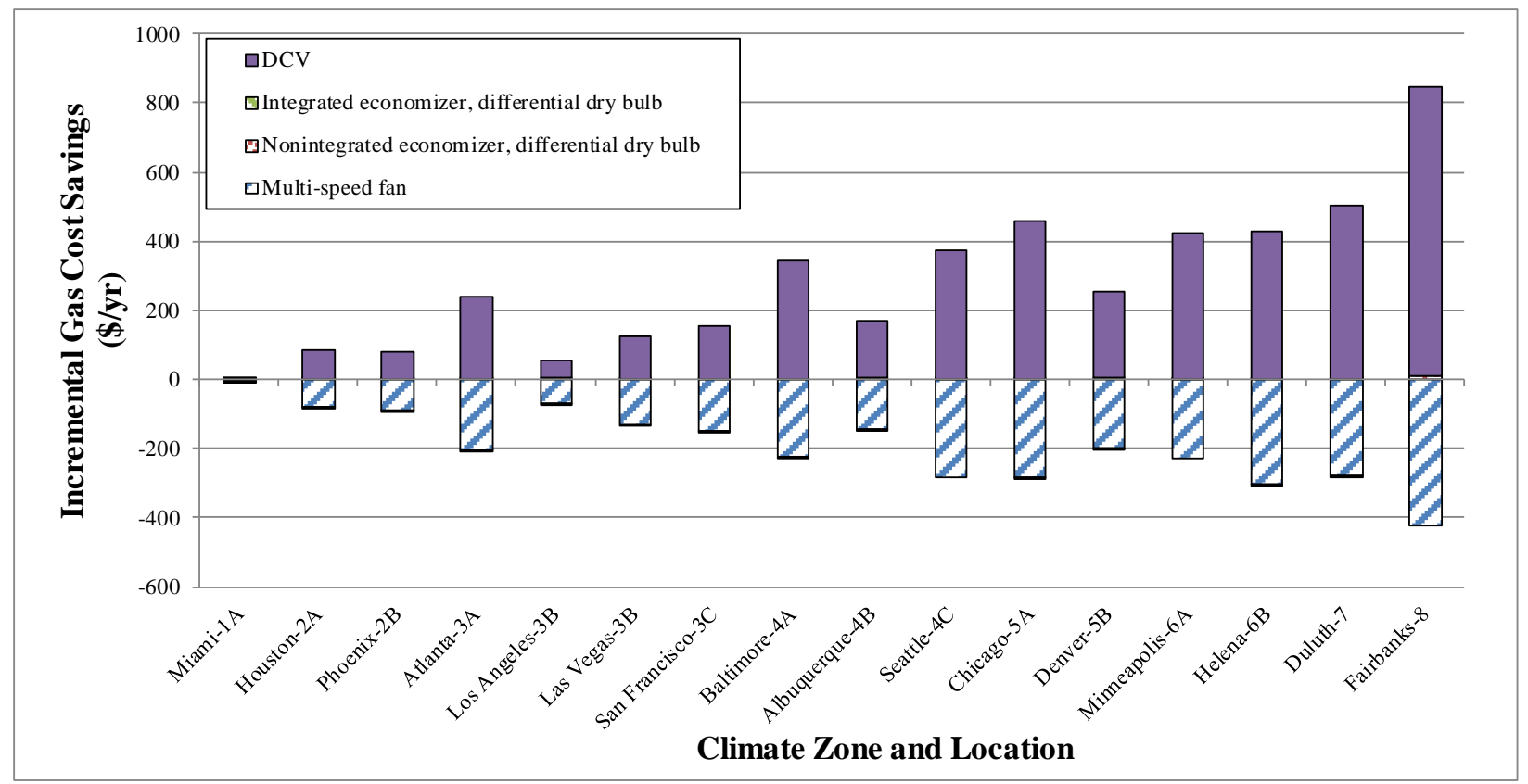

Figure 56: Gas Cost Savings Resulting from Incremental Addition of Advanced Control Strategies for the Small Office Building

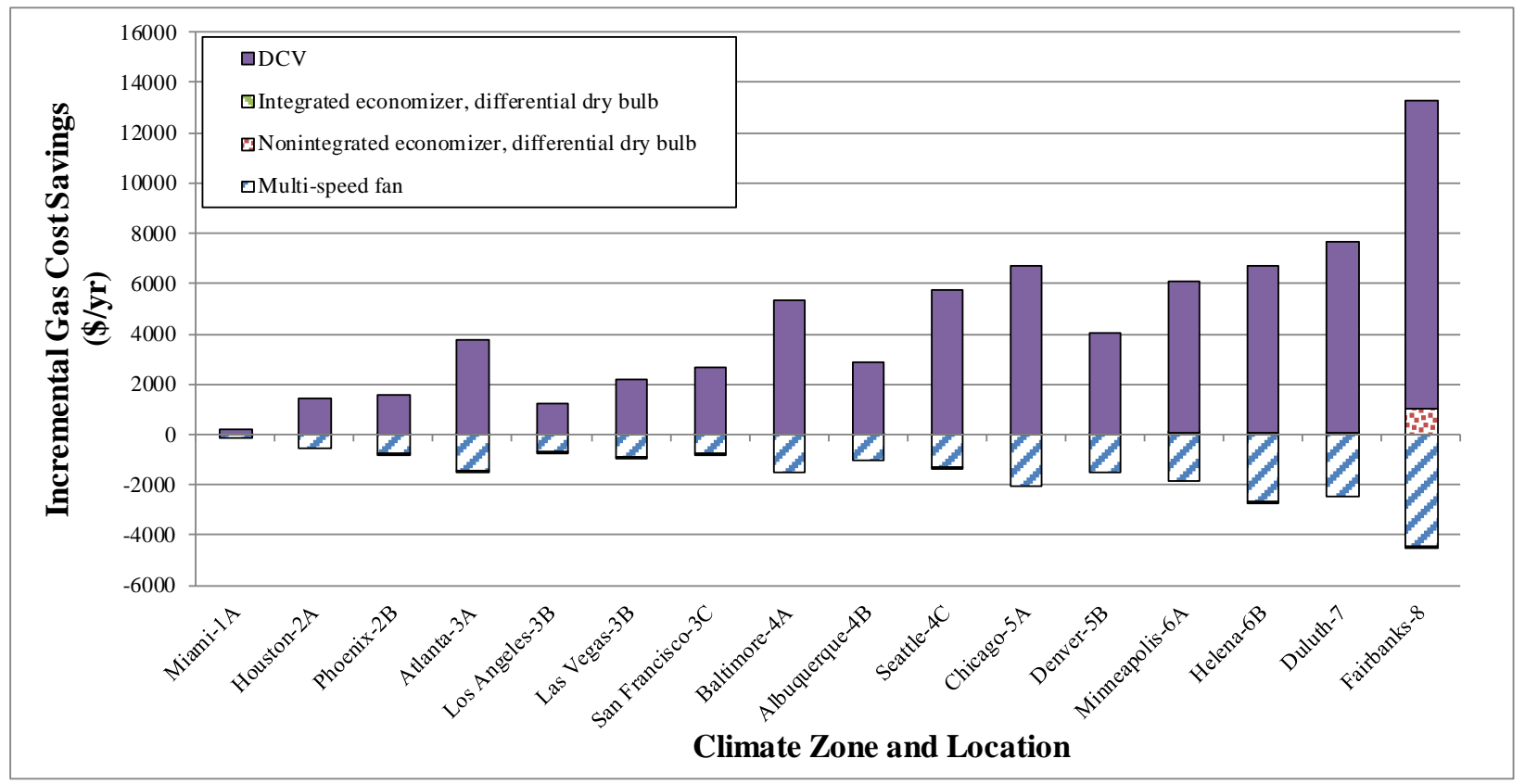

Figure 57: Gas Cost Savings Resulting from Incremental Addition of Advanced Control Strategies for the Stand-alone Retail Building 


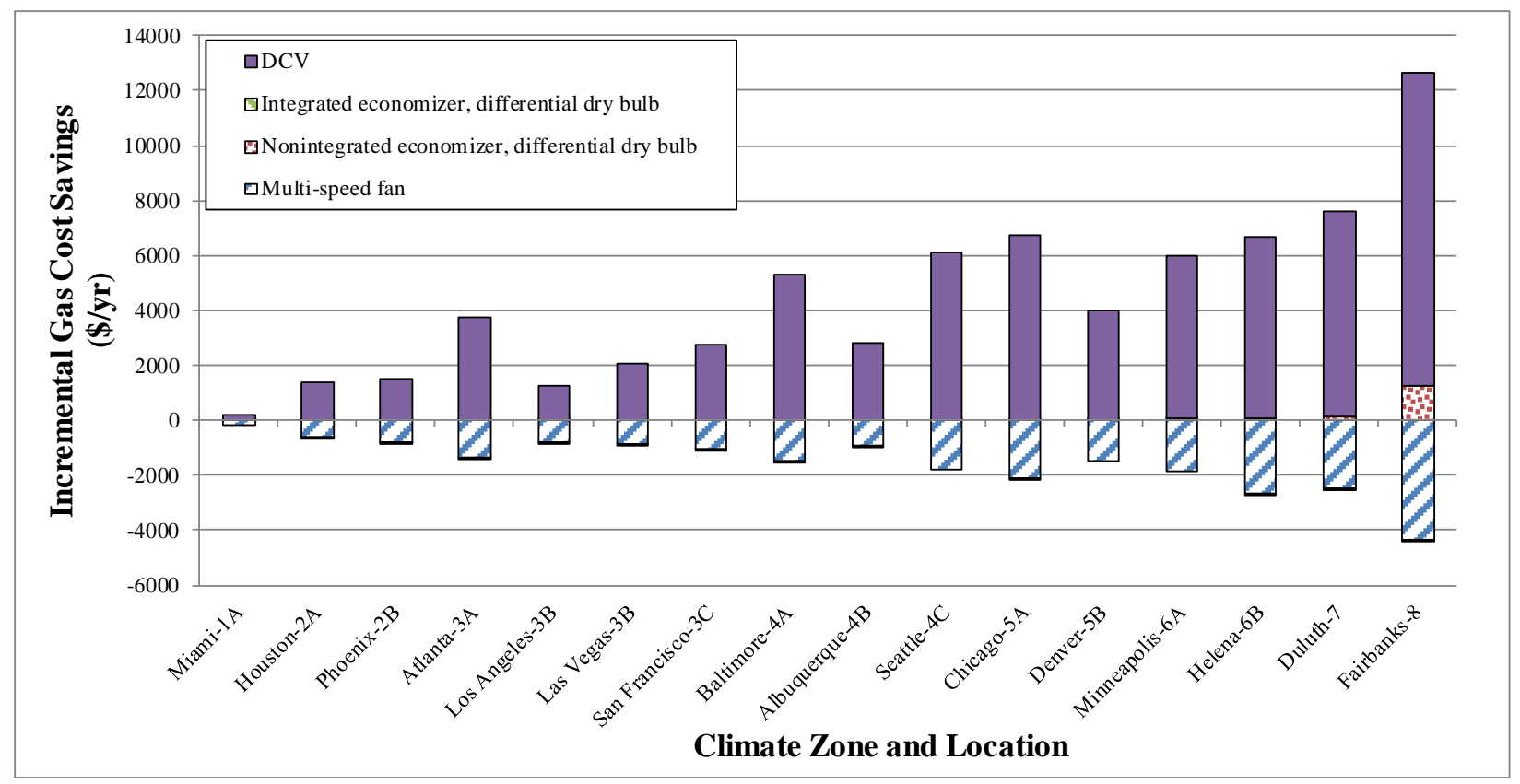

Figure 58: Gas Cost Savings Resulting from Incremental Addition of Advanced Control Strategies for the Strip Mall Building

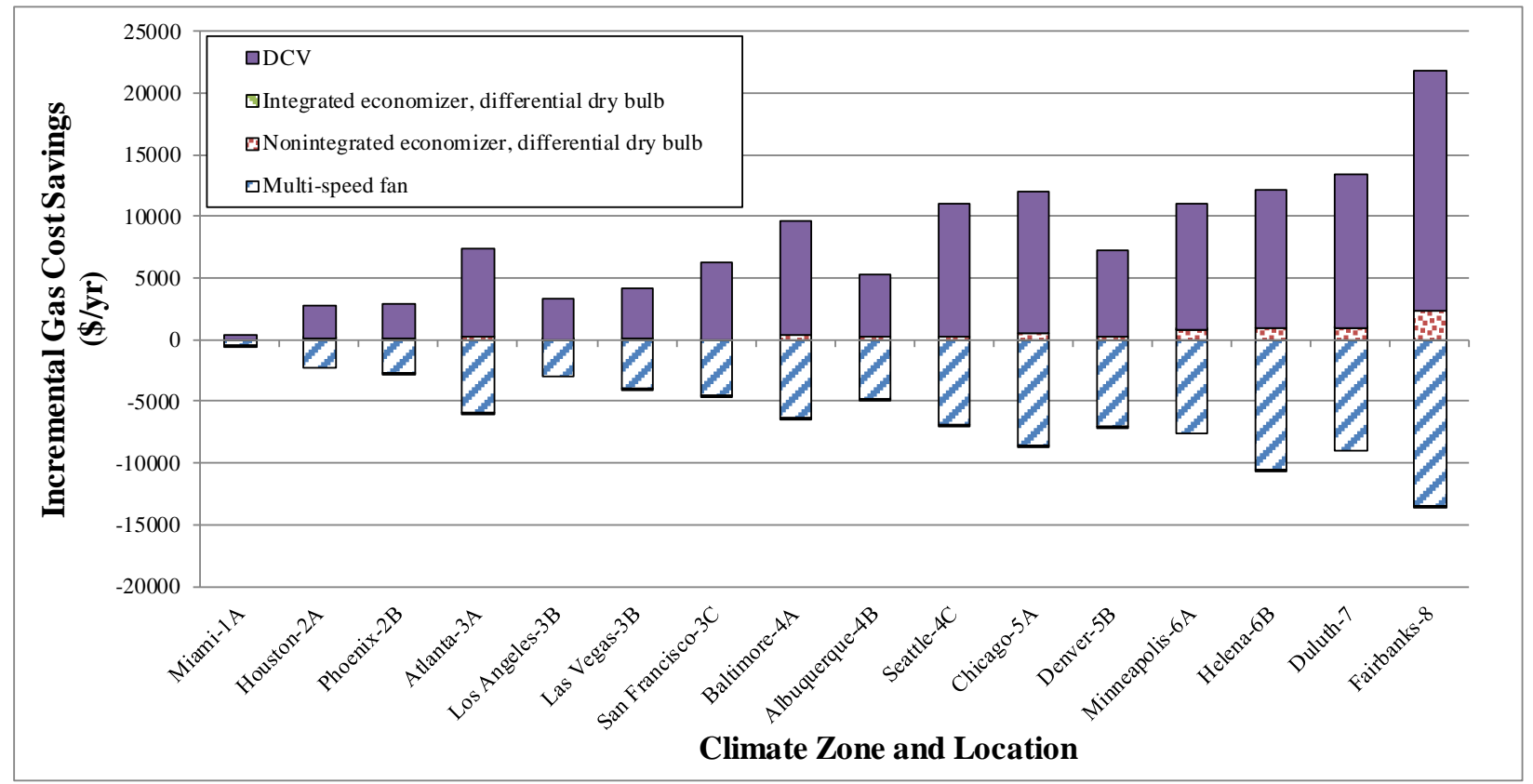

Figure 59: Gas Cost Savings Resulting from Incremental Addition of Advanced Control Strategies for the Supermarket Building 


\subsection{HVAC Energy Cost Comparison between Case 18 and Case 4}

As explained in Section 5.4, comparing a case with only air-side economizers and another case with multi-speed fan control and DCV added provides insights into a typical scenario for existing buildings. Therefore, Case 4 and Case 18 are selected to compare their HVAC energy costs. Case 4 has integrated differential dry-bulb economizer control, single-stage cooling, constantspeed fan and no DCV. Case 18 differs from Case 4 only by the presence of multi-speed fan control and DCV. For the four building types, Figure 60 through Figure 63 show the HVAC energy costs (both electricity and gas costs) of Case 18 and Case 4 for all 16 locations. The energy cost saving as a percentage of the energy cost for Case 4 is also shown for each location. These figures show two bars for each location. The left bar corresponds to Case 4 and the right one to Case 22. These figures lead to the following observations:

- The lowest annual energy costs for all building types except the supermarket occur for either Los Angeles or San Francisco, which also have the lowest EUI, or for Seattle, which has the lowest electricity price. This is reasonable because energy cost depends on both energy consumption and the prices of energy. The supermarket building has its lowest energy cost for Miami, which also has the lowest EUI (Figure 9). As expected, all four building types have the largest energy cost in the coldest climate examined (i.e., Fairbanks) primarily from gas heating.

- For all four building types, the largest absolute energy cost savings are obtained in Fairbanks. This is simply because Fairbanks has the largest absolute energy savings, as presented in Section 5.4. The annual absolute savings are \$2,108 for the small office building, $\$ 21,383$ for the stand-alone retail building, $\$ 20,370$ for the strip mall, and $\$ 46,605$ for the supermarket. The differences in these savings among the building types area attributable to both differences in the size of the buildings and also the impact of the advanced control strategies on the different types of buildings.

- The smallest absolute energy cost savings per year are obtained for Seattle for the supermarket $(\$ 15,046)$ and Miami for the other three building types (\$752 for the small office building, $\$ 6,868$ for the stand-alone retail and $\$ 6,556$ for the strip mall). Recall from Section 5.4 that the smallest energy savings are obtained in either Los Angeles or San Francisco. These two locations do not have the smallest energy cost savings because their high electricity prices make the cost savings more pronounced than the energy savings.

- The HVAC energy cost savings as a percentage of the base case energy cost lies in the range between $27 \%$ and 59\% for the small office building, 30\% and 53\% for the stand-alone retail building, 29\% and 54\% for the strip mall, and $27 \%$ and $50 \%$ for the supermarket (see Table 10). The maximum HVAC energy cost savings as a percentage of Case 4 energy cost occurs in Los Angeles for the supermarket building and in San Francisco for the other three building types. The minimum percentage savings occurs in Seattle for the supermarket building and in Miami for the other three building types. For all 16 locations, Case 18 has average HVAC energy cost savings of about 38\% for all four building types. A summary of these statistics is given in Table 10.

- For Case 4, the electricity cost usually takes a large portion (more than 50\%) of the total utility cost in the warmer climates (1A through 4B), while the gas cost is larger in most 
cold climates with predominated heating loads and in Seattle with the lowest electricity price. Case 18 has a smaller percentage of the total energy cost associated with electricity than Case 4 . This is primarily because the DCV and multi-speed fan controls, which are added in Case 18, decrease electricity use considerably, and the price of electricity is greater than the price of natural gas, thus decreasing the fraction of the total cost attributable to electricity use. Except for the two retail buildings in Seattle, most cost savings come from electricity savings.

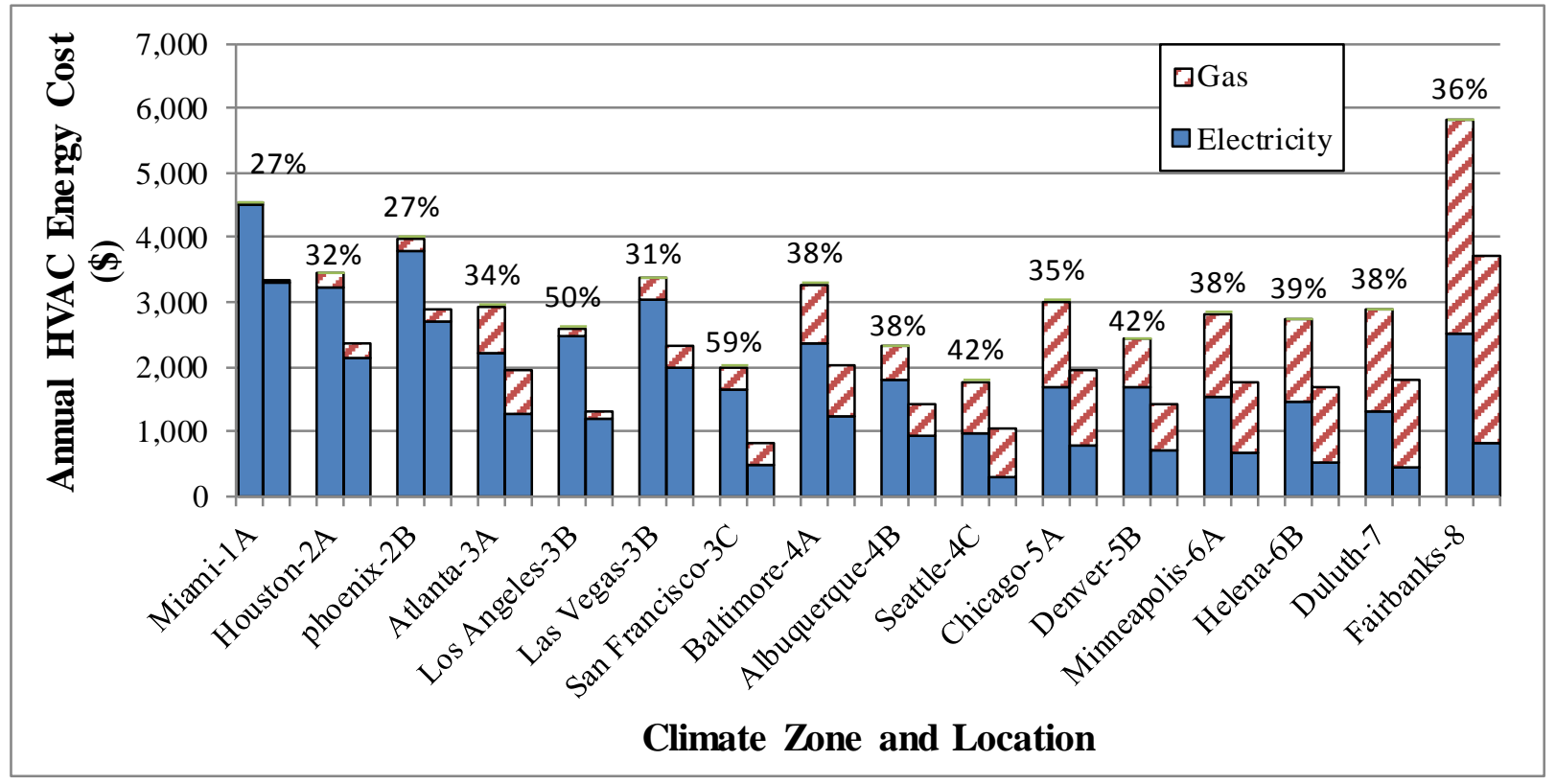

Figure 60: Comparison of HVAC Energy Cost between Case 4 (left bar for each location) and Case 18 (right bar for each location) for the Small Office Building. Percent Difference in the Total Energy Cost between Case 4 and Case 18 is also shown for Each Location. 


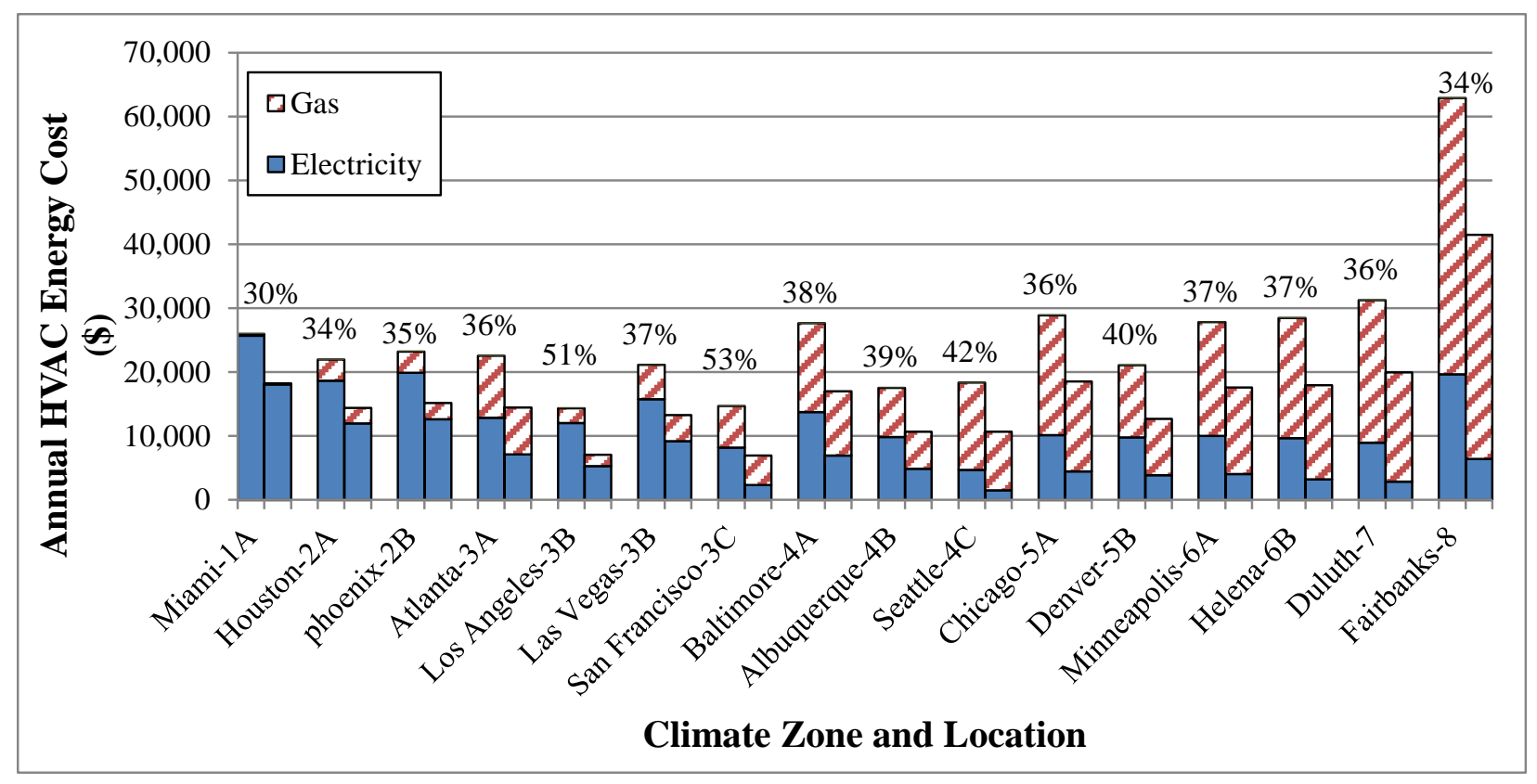

Figure 61: Comparison of HVAC Energy Cost between Case 4 (left bar for each location) and Case 18 (right bar for each location) for the Stand-alone Retail Building. Percent Difference in the Total Energy Cost between Case 4 and Case 18 is also shown for Each Location.

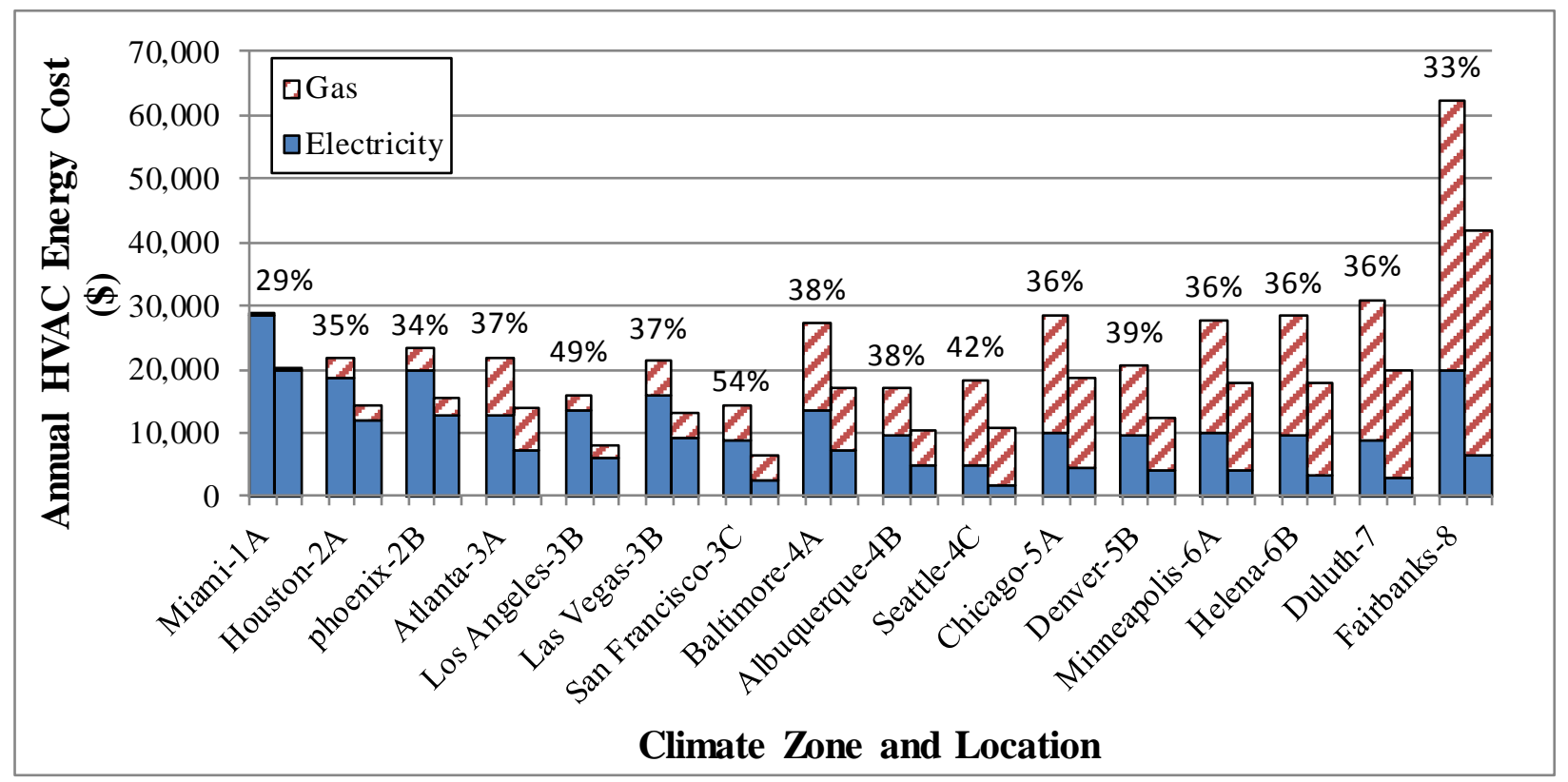

Figure 62: Comparison of HVAC Energy Cost between Case 4 (left bar for each location) and Case 18 (right bar for each location) for the Strip Mall Building. Percent Difference in the Total Energy Cost between Case 4 and Case 18 is also shown for Each Location. 


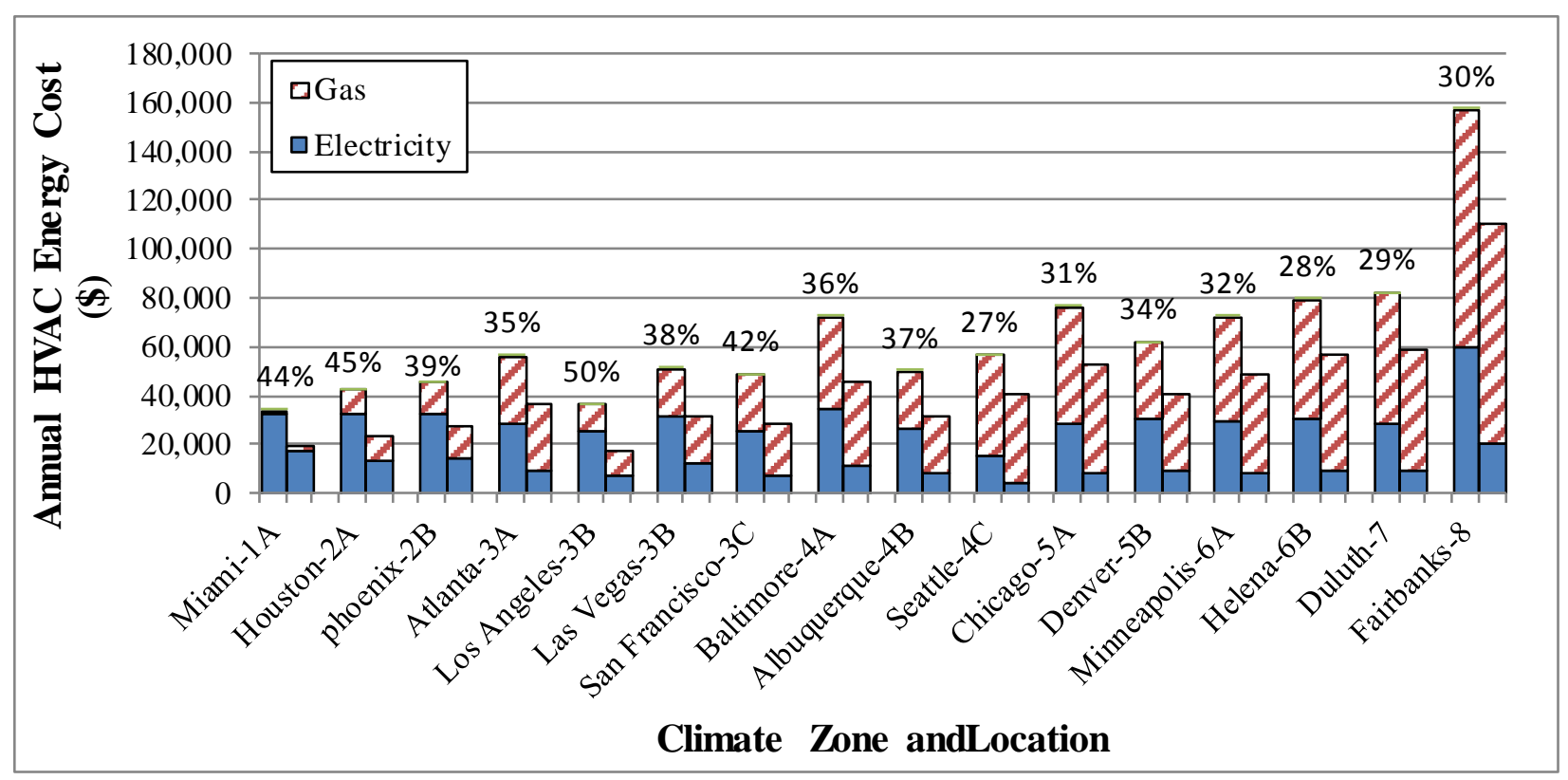

Figure 63: Comparison of HVAC Energy Cost between Case 4 (left bar for each location) and Case 18 (right bar for each location) for the Supermarket Building. Percent Difference in the Total Energy Cost between Case 4 and Case 18 is also shown for Each Location.

Table 10: Summary of Energy Cost Savings for Case 18 Relative to Case 4

\begin{tabular}{|c|c|c|c|c|}
\hline \multirow{2}{*}{ 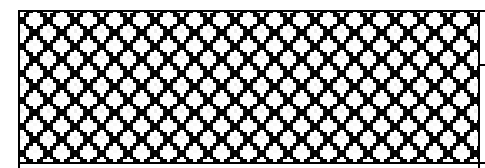 } & \multicolumn{4}{|c|}{ Building Type } \\
\hline & Small Office & $\begin{array}{l}\text { Stand-alone } \\
\text { Retail }\end{array}$ & Strip Mall & Supermarket \\
\hline Maximum savings & $59 \%$ & $53 \%$ & $54 \%$ & $50 \%$ \\
\hline $\begin{array}{l}\text { Location for maximum } \\
\text { savings }\end{array}$ & San Francisco & San Francisco & San Francisco & Los Angeles \\
\hline Minimum savings & $27 \%$ & $30 \%$ & $29 \%$ & $27 \%$ \\
\hline $\begin{array}{l}\text { Location for minimum } \\
\text { savings }\end{array}$ & Miami & Miami & Miami & Seattle \\
\hline Average savings & $38 \%$ & $38 \%$ & $38 \%$ & $36 \%$ \\
\hline $\begin{array}{l}\text { Maximum absolute } \\
\text { savings }(\$ / y r)\end{array}$ & 2,108 & 21,383 & 20,370 & 46,605 \\
\hline $\begin{array}{l}\text { Location for maximum } \\
\text { absolute savings }\end{array}$ & Fairbanks & Fairbanks & Fairbanks & Fairbanks \\
\hline $\begin{array}{l}\text { Minimum absolute } \\
\text { savings }(\$ / y r)\end{array}$ & 752 & 6,868 & 6,556 & 15,046 \\
\hline $\begin{array}{l}\text { Location for minimum } \\
\text { absolute savings }\end{array}$ & Seattle & Albuquerque & Albuquerque & Miami \\
\hline $\begin{array}{l}\text { Average absolute } \\
\text { savings }(\$ / y r)\end{array}$ & 1,134 & 9,481 & 9,390 & 21,960 \\
\hline
\end{tabular}




\subsection{HVAC Energy Cost Comparison between Case 22 and the Base Case (Case 1)}

Following the same approach used in Section 5.5, the two extreme cases, Case 1 and Case 22, are compared to provide the maximum energy savings that can be achieved with the most advanced control strategies of all examined cases. For the four building types, Figure 64 through Figure 67 show the HVAC energy costs (both electricity and gas costs) of Case 1 and Case 22 for all 16 locations. The energy cost saving as a percentage of the baseline energy cost is also shown for each location. These figures show two bars for each location. The left bar corresponds to the baseline (Case 1) and the right one to Case 22. The following findings can be drawn from these figures:

- For the base case, the electricity cost usually takes a large portion (more than 50\%) of the total utility cost in the warmer climates (1A through 4B), while the gas cost dominates in most cold climates with significant heating loads and in Seattle where the electricity price is the lowest among the examined locations. Case 22 has a smaller percentage of the total energy cost associated with electricity than the base case. This is primarily because the DCV and multi-speed fan controls, which are added in Case 22, decrease electricity use considerably, and the price of electricity is greater than the price of natural gas, thus decreasing the fraction of the total cost attributable to electricity use. Except for the two retail buildings in Seattle, most cost savings come from electricity savings.

- The largest absolute energy cost savings are obtained for Fairbanks for all building types, simply because Fairbanks has the largest HVAC loads by far. The annual absolute savings are $\$ 2,393$ for the small office building, $\$ 23,779$ for the stand-alone retail building, $\$ 23,414$ for the strip mall, and $\$ 52,217$ for the supermarket. The differences in these savings among the building types are attributable to both differences in the size of the buildings and also the impact of the advanced control strategies on the different types of buildings.

- The smallest annual absolute energy cost savings are obtained for Seattle for the small office buildings (\$923), Albuquerque for the stand-alone retail building $(\$ 7,864)$, Albuquerque for the strip mall building $(\$ 7,633)$, and Seattle for the supermarket $(\$ 16,087)$. Because of differences in fuel prices, the above locations with the smallest cost savings are not the same as those with the smallest energy savings.

- The HVAC energy cost savings as a percentage of the base case energy cost lies in the range between $38 \%$ and $67 \%$ for the small office building, $36 \%$ and $60 \%$ for the standalone retail building, $36 \%$ and $59 \%$ for the strip mall, and $28 \%$ and 55\% for the supermarket (see 
Table 11). The maximum HVAC energy cost savings as a percentage of the base case energy cost occurs in San Francisco for the small office building and in Los Angeles for the other three building types. The minimum percentage savings occurs in Miami for the small office, in Fairbanks for the two retail buildings, and in Seattle for the supermarket. For all 16 locations, Case 22 has average HVAC energy cost savings of about 46\%, 43\%, $43 \%$, and $39 \%$, respectively, for the small office building, retail building, strip mall, and supermarket. A summary of these statistics is given in Table 11.

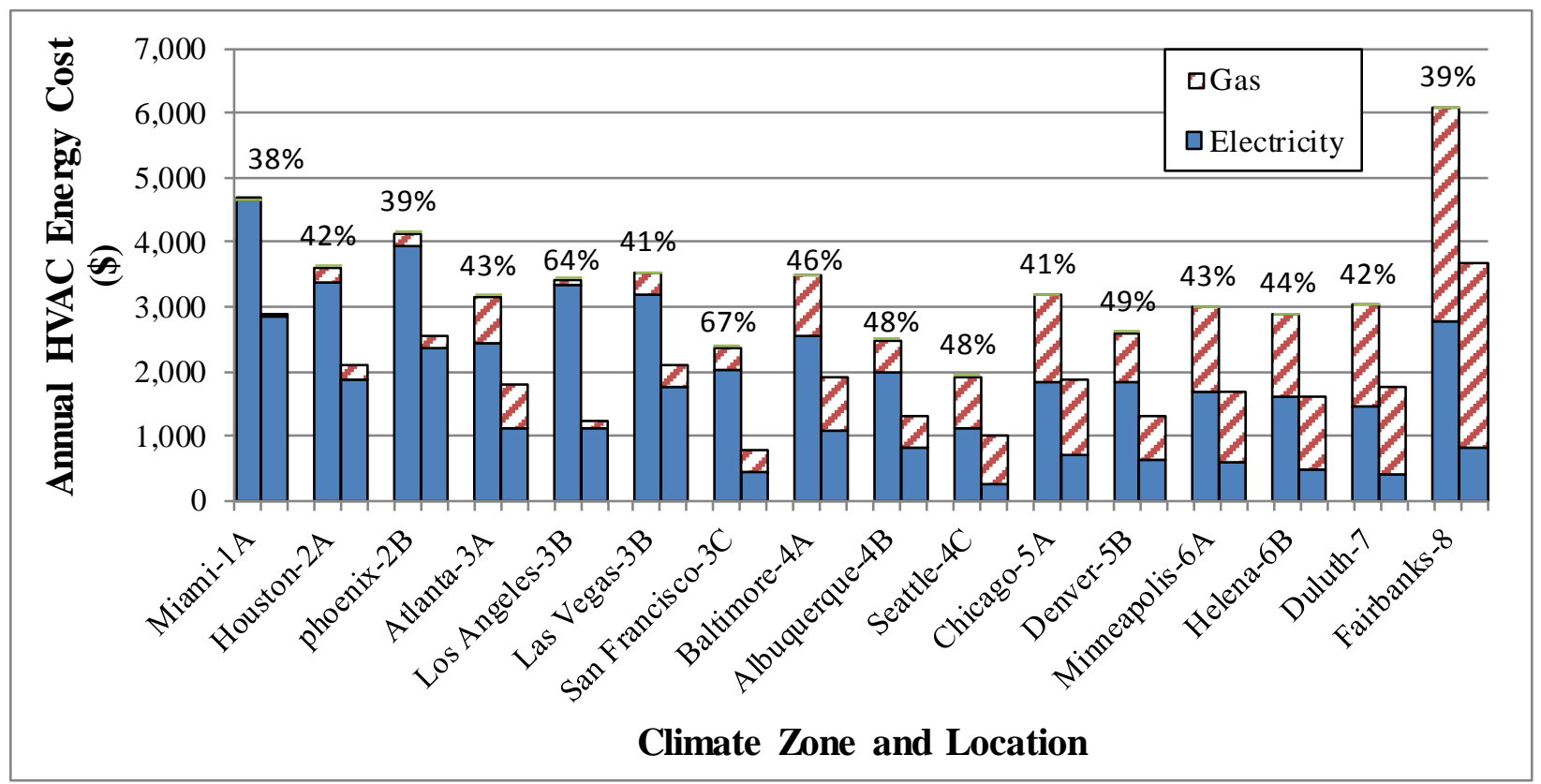

Figure 64: Comparison of HVAC Energy Cost between Case 1(left bar for each location) and Case 22 (right bar for each location) for the Small Office Building. Percent Difference in the Total Energy Cost between Case 1 and Case 22 is also shown for Each Location. 


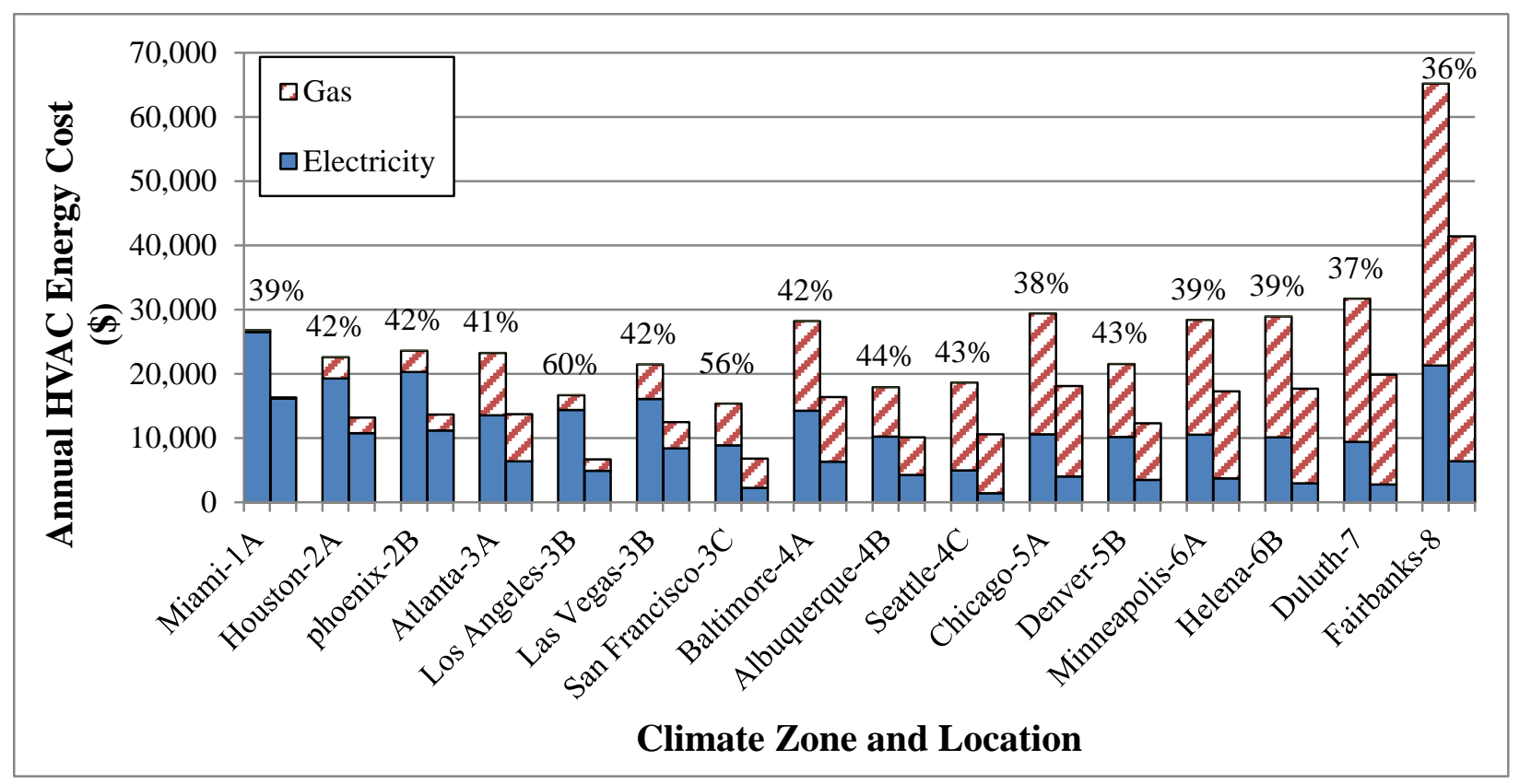

Figure 65: Comparison of HVAC Energy Cost between Case 1(left bar for each location) and Case 22 (right bar for each location) for the Stand-alone Retail Building. Percent Difference in the Total Energy Cost between Case 1 and Case 22 is also shown for Each Location.

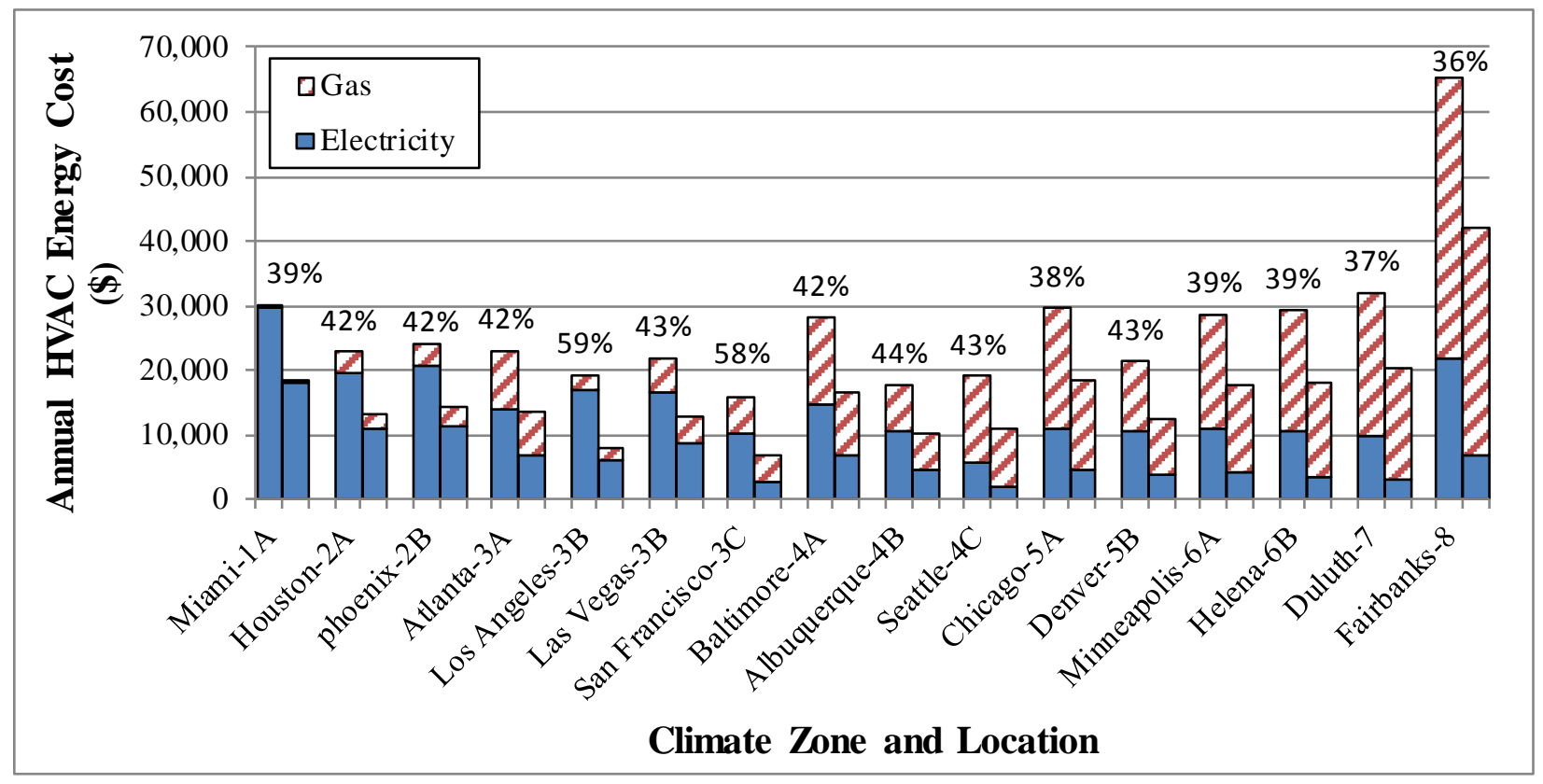

Figure 66: Comparison of HVAC Energy Cost between Case 1 (left bar for each location) and Case 22 (right bar for each location) for the Strip Mall Building. Percent Difference in the Total Energy Cost between Case 1 and Case 22 is also shown for Each Location. 


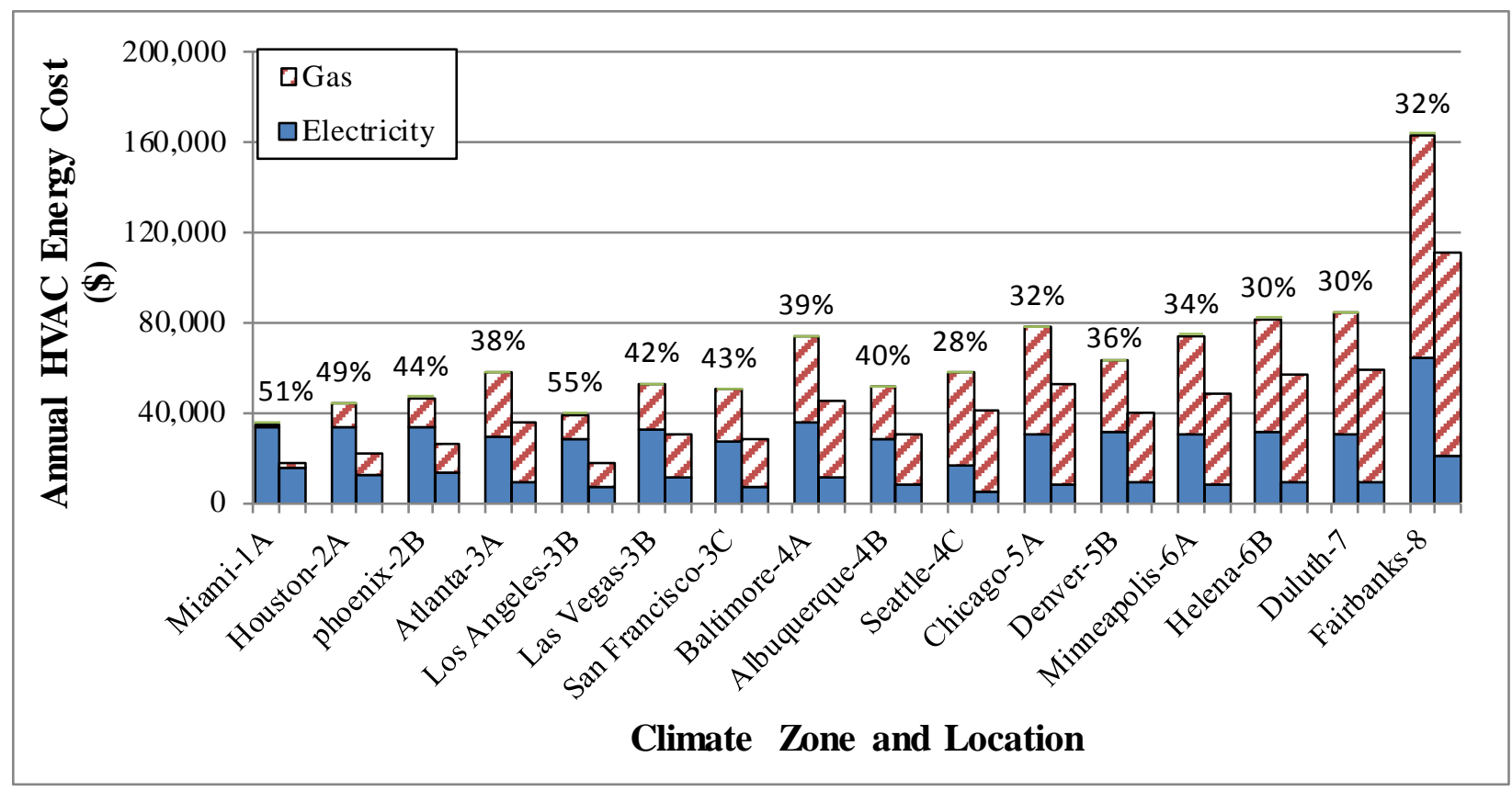

Figure 67: Comparison of HVAC Energy Cost between Case 1(left bar for each location) and Case 22 (right bar for each location) for the Supermarket Building. Percent Difference in the Total Energy Cost between Case 1 and Case 22 is also shown for Each Location. 
Table 11: Summary of Energy Cost Savings for Case 22 Relative to the Base Case (Case 1)

\begin{tabular}{|c|c|c|c|c|}
\hline \multirow{2}{*}{ 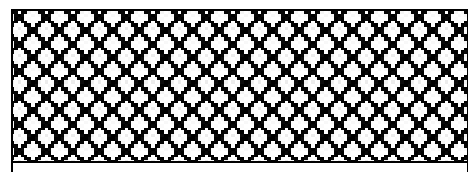 } & \multicolumn{4}{|c|}{ Building Type } \\
\hline & Small Office & $\begin{array}{l}\text { Stand-alone } \\
\text { Retail }\end{array}$ & Strip Mall & Supermarket \\
\hline Maximum savings & $67 \%$ & $60 \%$ & $59 \%$ & $55 \%$ \\
\hline $\begin{array}{l}\text { Location for maximum } \\
\text { savings }\end{array}$ & San Francisco & Los Angeles & Los Angeles & Los Angeles \\
\hline Minimum savings & $38 \%$ & $36 \%$ & $36 \%$ & $28 \%$ \\
\hline $\begin{array}{l}\text { Location for minimum } \\
\text { savings }\end{array}$ & Miami & Fairbanks & Fairbanks & Seattle \\
\hline Average savings & $46 \%$ & $43 \%$ & $43 \%$ & $39 \%$ \\
\hline $\begin{array}{l}\text { Maximum absolute } \\
\text { savings }(\$ / y r)\end{array}$ & 2393 & 23779 & 23414 & 52217 \\
\hline $\begin{array}{l}\text { Location for maximum } \\
\text { absolute savings }\end{array}$ & Fairbanks & Fairbanks & Fairbanks & Fairbanks \\
\hline $\begin{array}{l}\text { Minimum absolute } \\
\text { savings ( } \$ / \mathbf{y r})\end{array}$ & 923 & 7,864 & 7,633 & 16,087 \\
\hline $\begin{array}{l}\text { Location for minimum } \\
\text { absolute savings }\end{array}$ & Seattle & Albuquerque & Albuquerque & Seattle \\
\hline $\begin{array}{l}\text { Average absolute } \\
\text { savings (\$/yr) }\end{array}$ & 1,496 & 10,820 & 11,000 & 24,200 \\
\hline
\end{tabular}

\subsection{Controller Cost}

One major objective of this study is to support the development of cost-effective controller that saves significant energy for packaged units on existing buildings. The maximum installed cost of advanced controllers that will yield a specific simple payback period is important for potential users to evaluate the financial merits of installing advanced controllers but also for vendors and developers in pricing their advanced control products. Because an add-on controller is usually associated with each rooftop unit, the total energy cost savings for a whole building needs to be normalized before calculating the maximum acceptable controller installed cost. Based on the cost savings per unit and the assumed simple payback period, the maximum total installed cost per controller can be calculated according to Equation 3. Table D49 through Table D52 in Appendix D lists the results that achieve a 3-year simple payback period for different cases covering all 21 advanced control combinations, 16 locations, and 4 building types. The results are based on the numbers of packaged units specified for the prototype buildings in Table 2 (five for the small office building, 4 for the stand-alone retail building, 10 for the strip mall, and 6 for the supermarket). In addition, all packaged units on the building are assumed to be retrofitted with the advanced controller so that the total savings possible for the building are achieved.

Controllers with different combinations of advanced control capabilities are likely to have different manufacturing and installation costs. Controllers with greater functionality will likely cost more. On the other hand, the examined control strategies have different degrees of impact 
on energy cost savings, as discussed in Section 6.1. Controllers with greater functionality (actually, the best combination of functionality) provide greater energy and cost savings. Therefore, analysis of the savings provided by a controller relative to its cost is important. We examine this by determining the maximum total installed cost per controller that yields specific simple payback periods for controllers with different combinations of control functionality. A total of four scenarios are considered:

- Scenario 1: the advanced controller with only multi-speed supply-fan control (Case 6) is retrofit to an existing packaged unit having a base case controller with no advanced control capabilities (including no economizer).

- Scenario 2: the advanced controller with only DCV is retrofit to an existing packaged unit (Case 14) having a base case (Case 1) controller with no advanced control capabilities (including no economizer)

- Scenario 3: the advanced controller with both multi-speed fan control and DCV (Case 18 ) is retrofit to an existing packaged unit with a controller having an integrated differential dry-bulb economizer, single-speed fan control, one-stage cooling, and no DCV (Case 4).

- Scenario 4: the advanced controller with an integrated differential dry-blub differential economizer control, multi-speed supply fan control, two-stage compressor control and DCV (Case 22) is retrofit to existing packaged units having a base case (Case 1) controller with no advanced control capabilities (including no economizer).

The maximum total installed costs per advanced controller for the above four scenarios are compared in Figure 68 through Figure 71for the four building types (The results are also provided in Table D49 through Table D60 in Appendix D). These figures show that the maximum total installed controller cost per packaged unit providing a 3-year payback period varies with the four scenarios. For all four building types, Scenarios 3 and 4 sequentially have the first two largest maximum cost per controller for all 16 locations. Because these two scenarios differ only in air-side economizer control, the magnitude of their maximum controller cost differences largely depends on the impact of air-side economizer control and the electricity prices. The maximum acceptable controller cost is larger in those locations, where the air-side economizer control contributes to significant cooling energy savings and the electricity price is high (such as Los Angeles, San Francisco, and Fairbanks). The order of Scenarios 1 and 2 in terms of the maximum controller cost depends on both locations and building types. For the small office building, Scenario 1 with multi-speed fan control achieves a higher maximum controller cost than Scenario 2 with DCV for all 16 locations. For the two retail buildings, Scenario 1 usually has a higher maximum controller cost than Scenario 2 in hot (e.g., Miami, Houston, Phoenix) or warm climates (e.g., Los Angeles, Las Vegas, and San Francisco), while the reverse is true in cold climates (e.g., Chicago, Helena, and Duluth). For the supermarket building, Scenario 2 has a higher maximum controller cost than Scenario 1 only in four locations including Seattle, Chicago, Helena, and Duluth.

As indicated in Figure 68 through Figure 71, the maximum total installed controller cost per packaged unit that provides a 3-year payback period varies significantly with the building type. For a given scenario and location, the maximum acceptable installed cost decreases in the order supermarket, stand-alone retail building, strip mall, and small office building. For example, for Scenario 4, the calculated maximum controller cost lies in the range between \$8,040 and \$26,110 
for the supermarket building, $\$ 5,900$ and $\$ 17,830$ for the stand-alone retail building, $\$ 2,290$ and $\$ 7,020$ for the strip mall building, and $\$ 550$ and $\$ 1,435$ for the small office building. Two causes drive these differences. First, the maximum controller installed cost per packaged unit providing the designated payback period is proportional to the energy cost saving of each specific building. Figure 64 through Figure 67 show that for a specific location, the supermarket has the largest energy cost savings, the small office building has the smallest cost savings, and the two retail buildings have comparable cost savings that in magnitude are between the values for the supermarket and the small office building. Second, the maximum controller installed cost per packaged unit providing the designated payback period is inversely proportional to the number of the packaged units on that building. Because each unit requires a controller, the number of controllers required is identical to the number of packaged units. As the number of units (and, therefore, advanced controllers required) increases, the cost savings for the building are distributed among more controllers and the savings per controller decreases. In the four building models, the small office building has 5 packaged units and the stand-alone retail building, the strip mall and the supermarket, respectively, have 4, 10, and 6 packaged units. The fraction of building savings per unit decreases as the number of units increases but not sufficiently, for example, to make the maximum controller installed cost per unit providing the designated payback period for the strip mall (with 10 units) to be less than that for the office building (with 6 units).

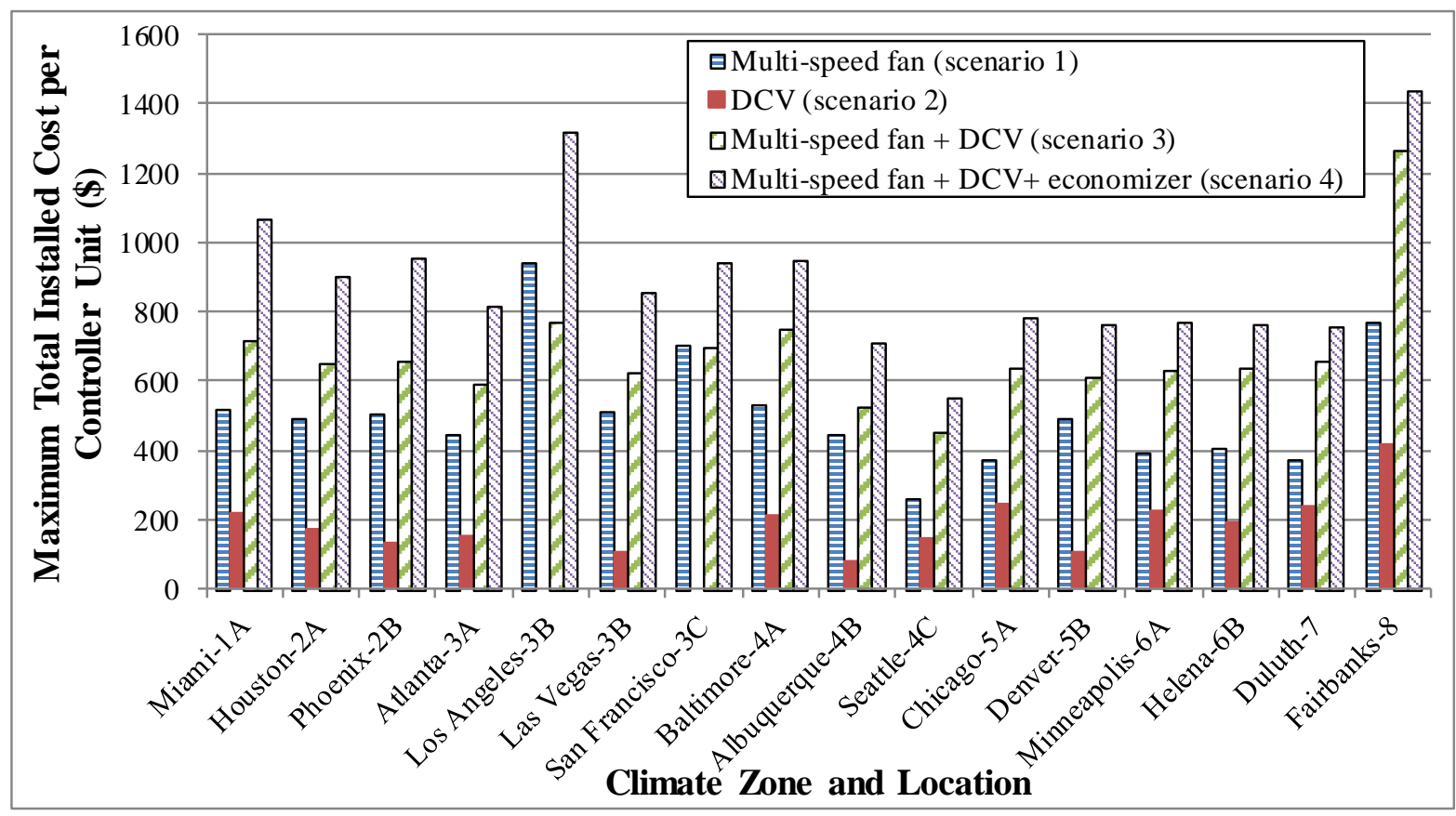

Figure 68: Maximum Total Installed Cost per Controller Unit to Achieve a Payback Period of 3 Years for the Small Office Building with Different Control Capabilities Added to an Existing Packaged Unit That Has Integrated Dry-Bulb Economizer for Scenario 3 but No Advanced Control in the Other Three Scenarios 


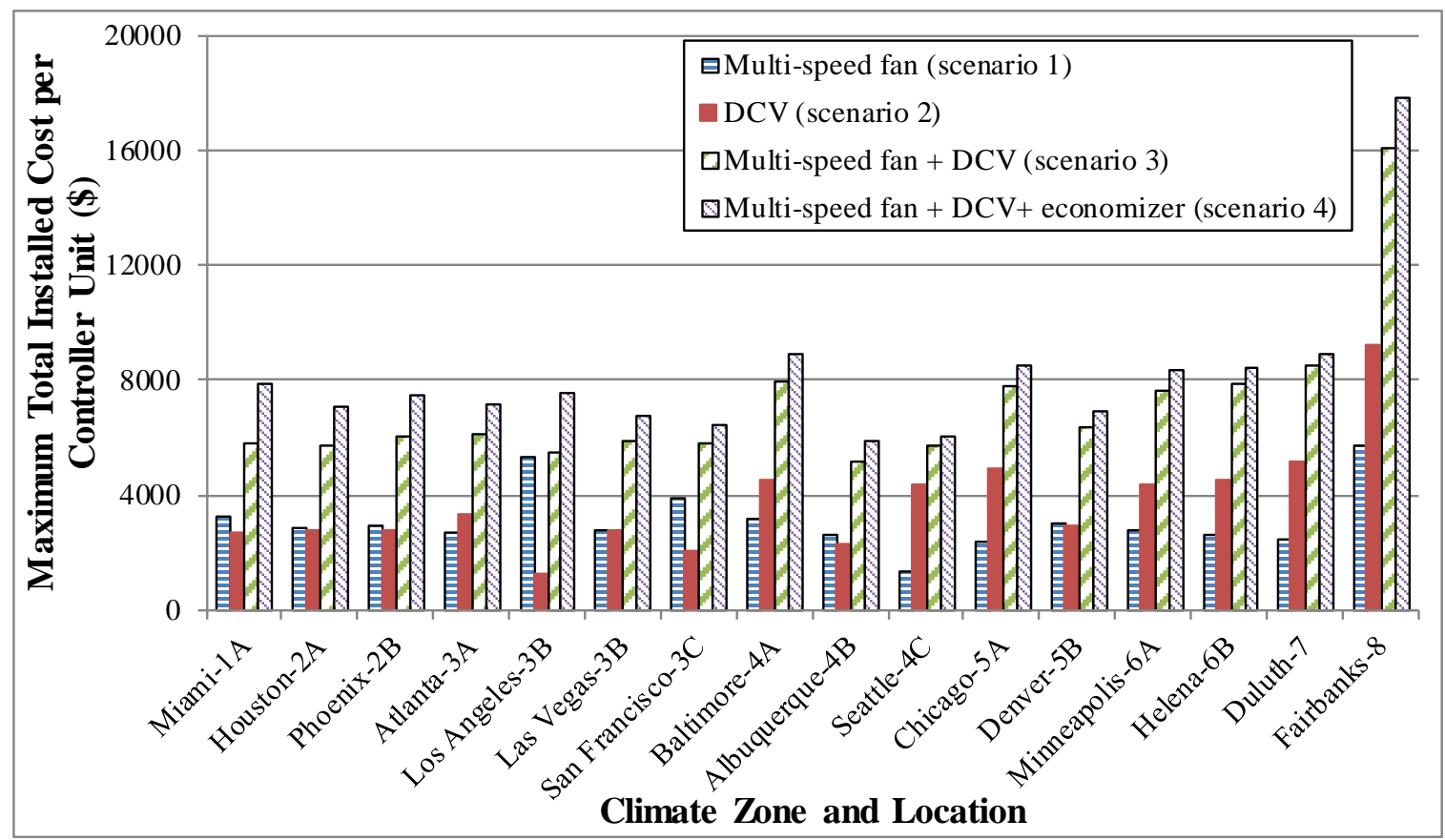

Figure 69: Maximum Total Installed Cost per Controller Unit to Achieve a Payback Period of 3 Years for the Stand-alone Retail Building with Different Control Capabilities Added to an Existing Packaged Unit That Has Integrated Dry-Bulb Economizer for Scenario 3 but No Advanced Control in the Other Three Scenarios

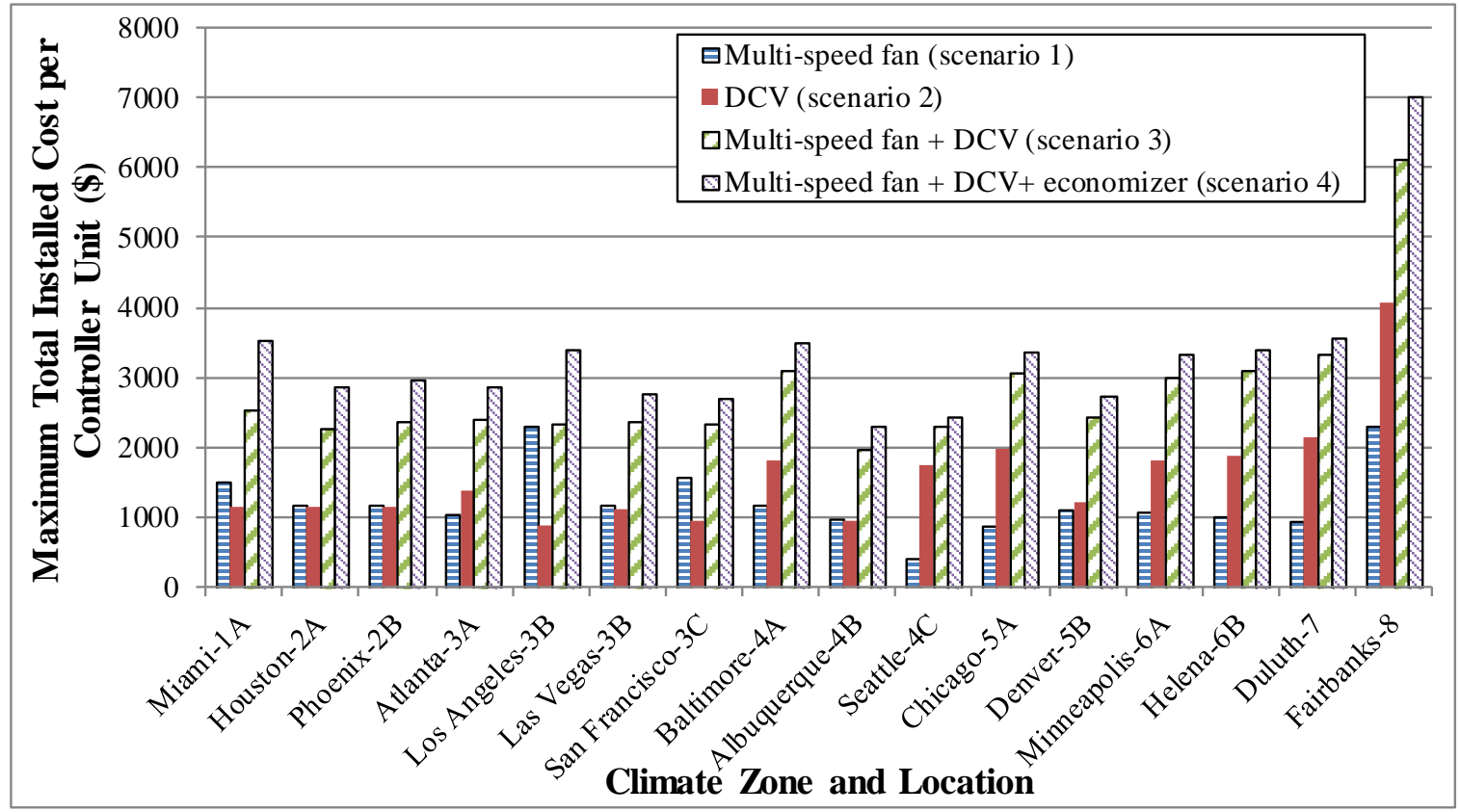

Figure 70: Maximum Total Installed Cost per Controller Unit to Achieve a Payback Period of 3 Years for the Strip Mall Building with Different Control Capabilities Added to an Existing Packaged Unit That Has Integrated Dry-Bulb Economizer for Scenario 3 but No Advanced Control in the Other Three Scenarios 


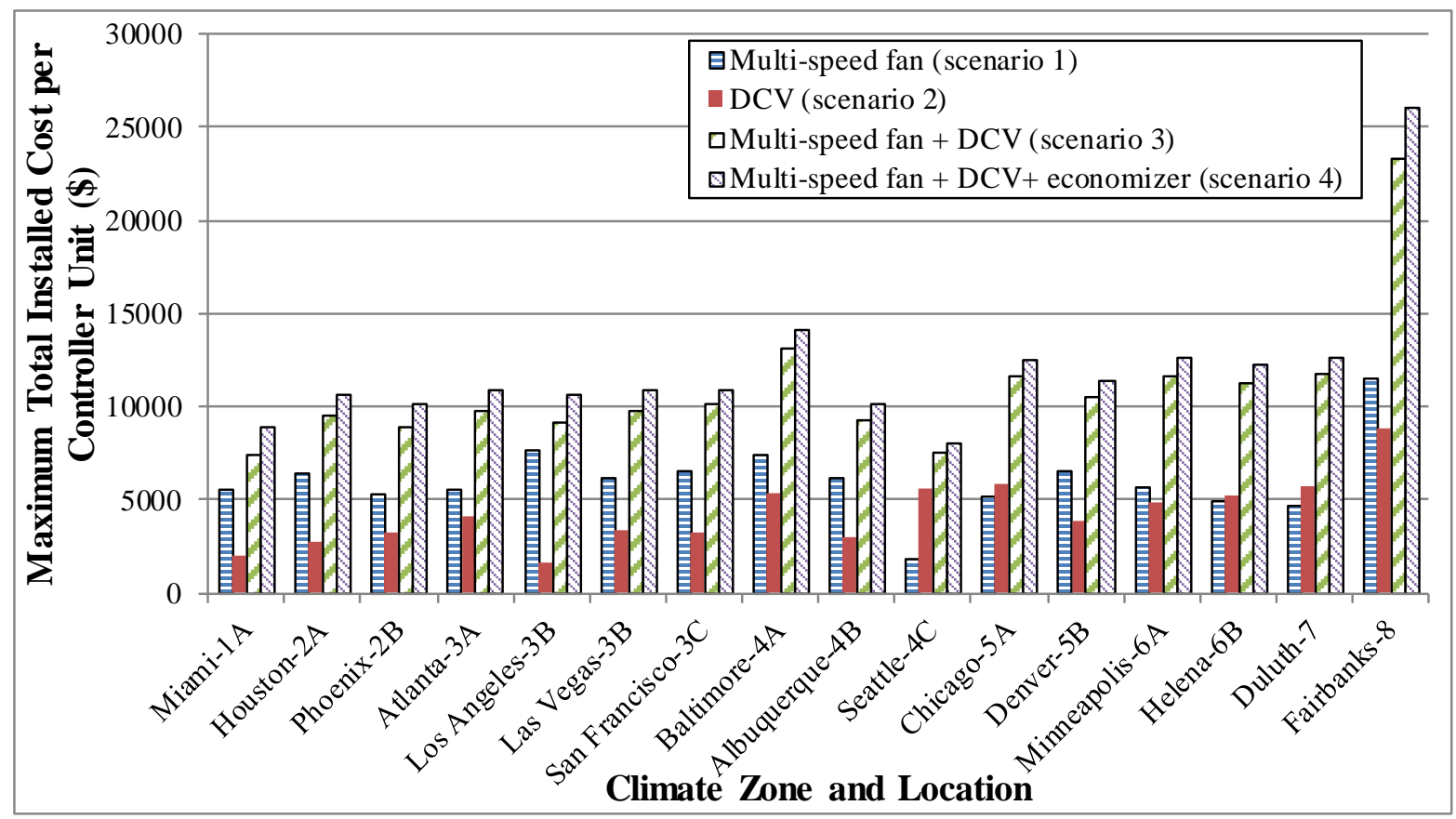

Figure 71: Maximum Total Installed Cost per Controller Unit to Achieve a Payback Period of 3 Years for the Supermarket Building with Different Control Capabilities Added to an Existing Packaged Unit That Has Integrated Dry-Bulb Economizer for Scenario 3 but No Advanced Control in the Other Three Scenarios

Based on the results in Table D49 through D52 that are calculated from the simple payback period of 3 years and the blended utility rates in the year of 2010 (Table 7), the maximum installed cost per controller can be easily calculated for other payback periods and utility rates. For example, for the small office building in Miami, if the maximum total installed controller cost assuming a 3-year simple payback period at the original utility rate is known to be \$1,065 (Table D49) for Scenario 4 retrofit, the controller cost for 1-year simple payback at the original utility rate is equal to $1065 / 3=\$ 355$; the cost for 3-year simple payback at $5 \%$ increased rate equals $\$ 1065$ x $(1+0.05)=\$ 1,118$. As an illustration, Figure 72 through Figure 75 shows the maximum total installed controller cost per packaged unit that provides a 5-year payback period for the same four scenarios covered by Figure 68 through Figure 71.

In addition, for the convenience, the maximum installed controller cost per rooftop unit providing designated payback periods of 1,3 and 5 years with different utility rates are provided in Appendix D for all 16 locations and four building types. The utility rates include the rates for both electricity and gas at $\pm 5 \%$ and $\pm 10 \%$ from the original rates (see Table 7 ). Table D53 through D56 lists the maximum installed cost per controller for Scenario 3 retrofit, which has multi-speed fan control and DCV added to an existing packaged unit with a controller having an integrated dry-bulb economizer, single-speed fan control, single-stage cooling and no DCV. Table D57 through D60 lists the maximum installed cost per controller for Scenario 4 retrofit, which has integrated dry-bulb economizer control, multi-speed fan control, and DCV added to an existing packaged unit with no advanced control capabilities. 


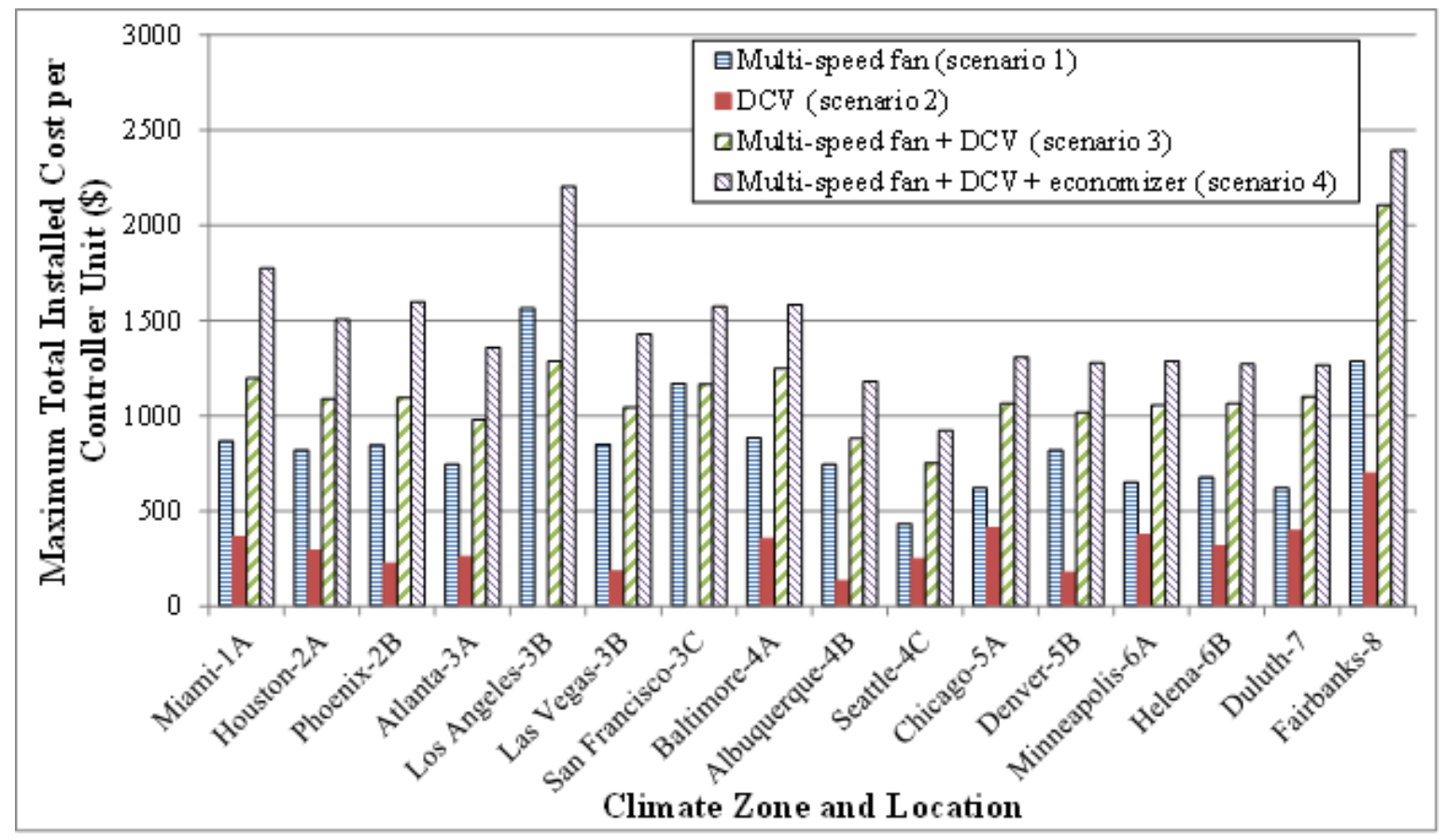

Figure 72: Maximum Total Installed Cost per Controller that Provides a Payback of 5 Years for the Small Office Building with Different Control Capabilities Added to an Existing Packaged Unit that has Integrated Differential Dry-Bulb Economizer for Scenario 3 but no Advanced Control in the Other 3 Scenarios

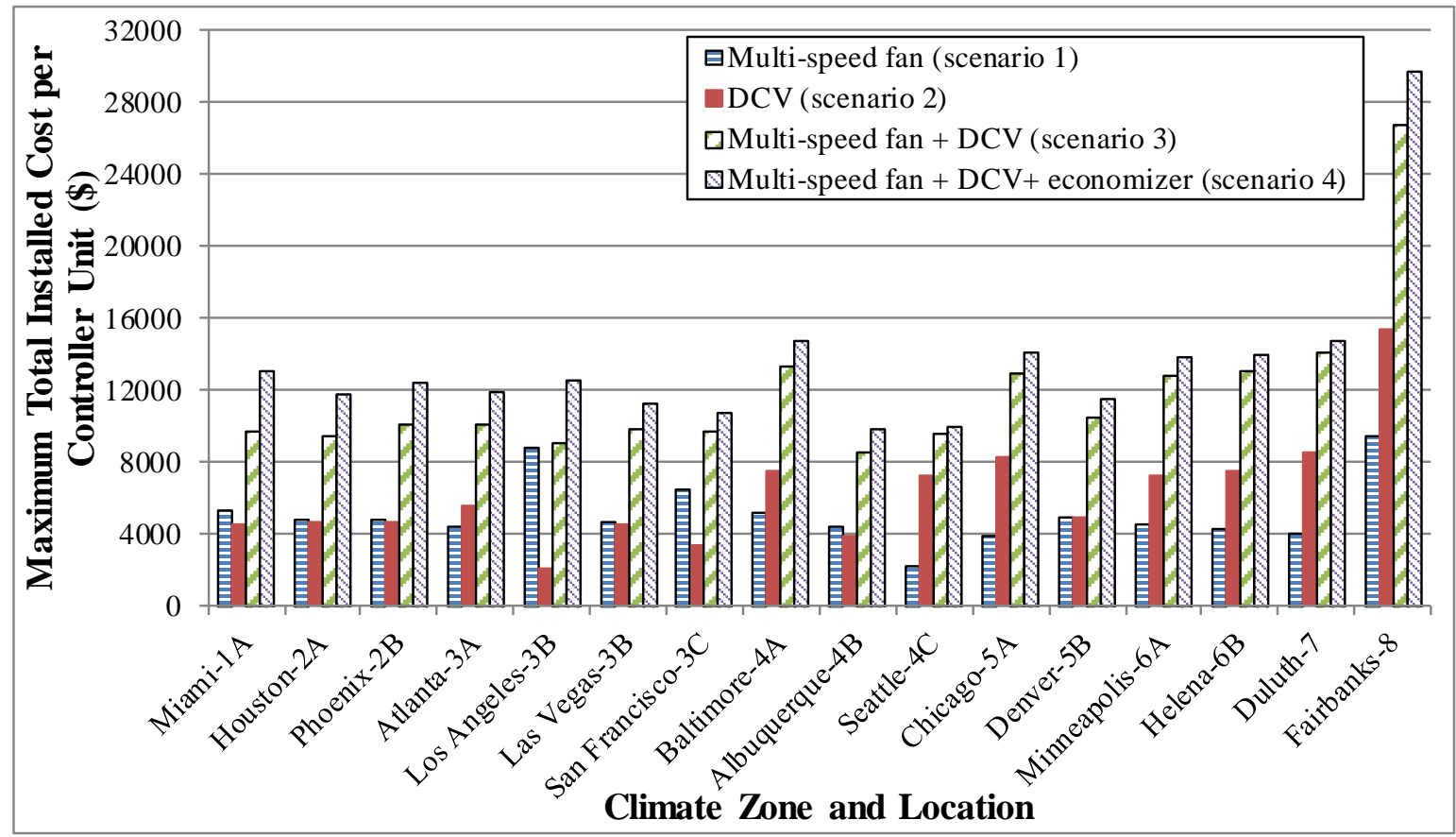

Figure 73: Maximum Total Installed Cost per Controller that Provides a Payback of 5 Years for the Stand-alone Retail Building with Different Control Capabilities Added to an Existing Packaged Unit that has Integrated Differential Dry-Bulb Economizer for Scenario 3 but no Advanced Control in the Other 3 Scenarios 


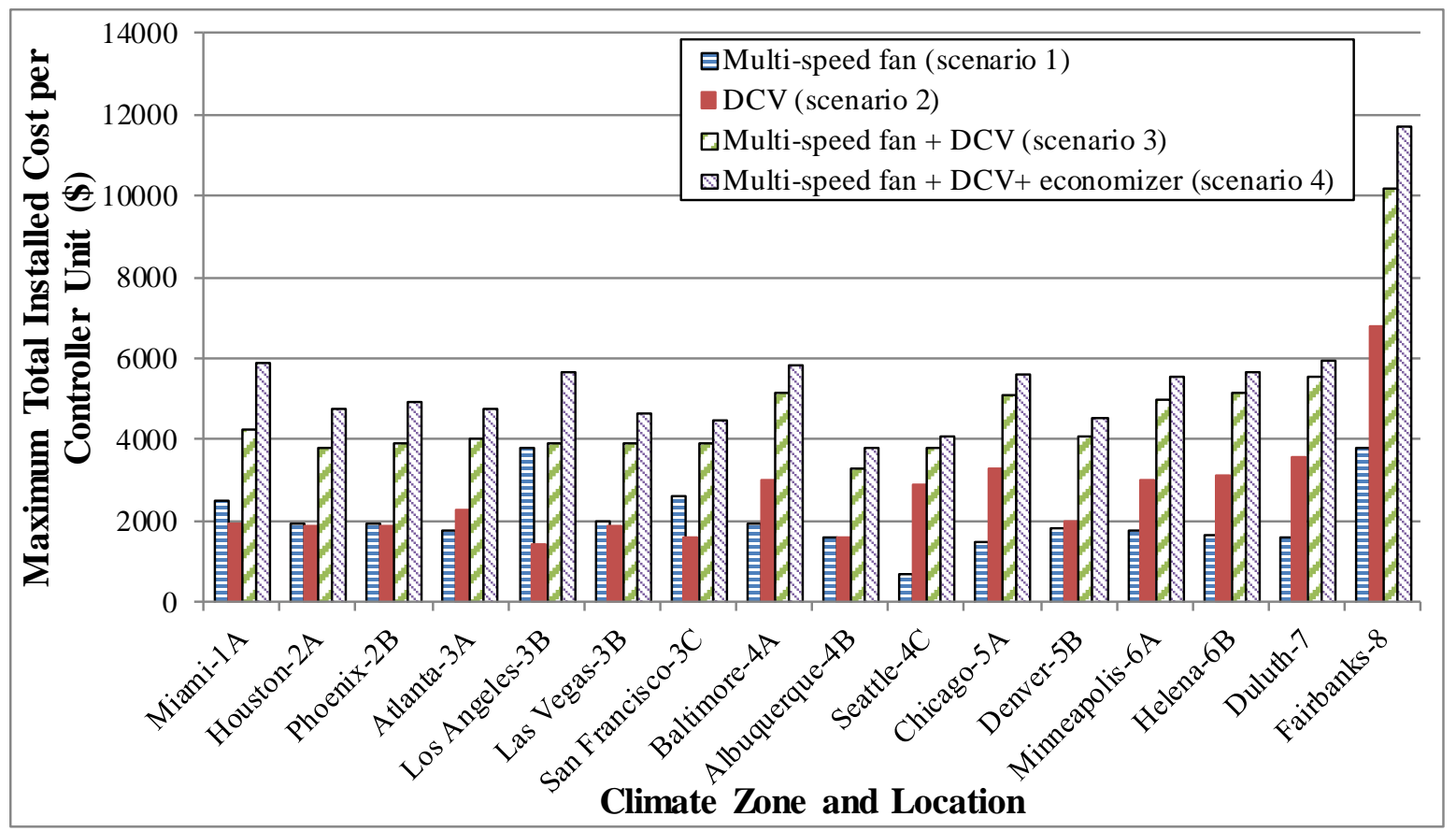

Figure 74: Maximum Total Installed Cost per Controller Unit that Provides a Payback of 5 Years for the Strip Mall Building with Different Control Capabilities Added to an Existing Packaged Unit that has Integrated Differential Dry-Bulb Economizer for Scenario 3 but no Advanced Control in the Other 3 Scenarios

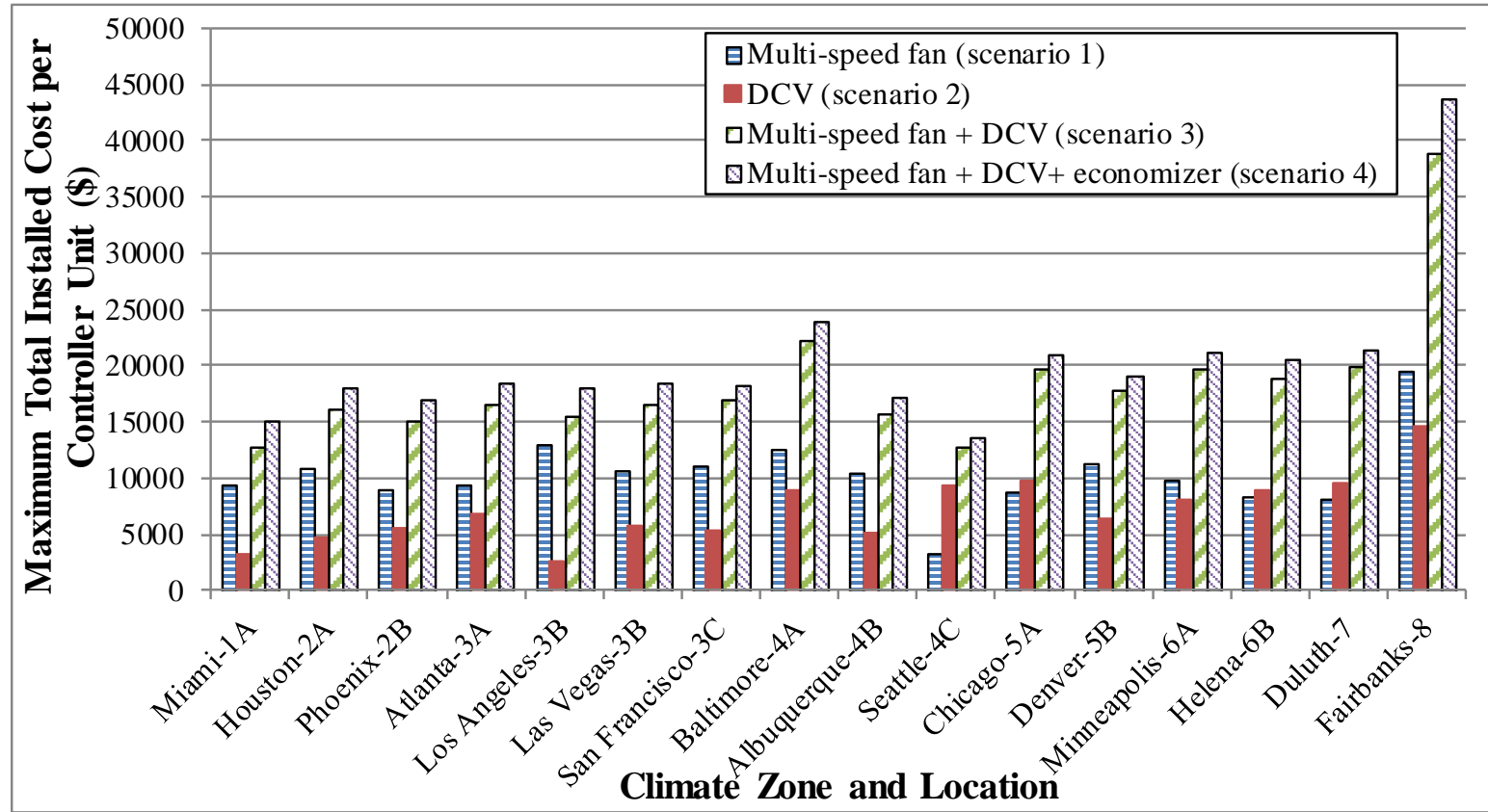

Figure 75: Maximum Total Installed Cost per Controller Unit that Provides a Payback of 5 Years for the Supermarket Building with Different Control Capabilities Added to an Existing Packaged Unit That has Integrated Differential Dry-Bulb Economizer for Scenario 3 but no Advanced Control in the Other 3 Scenarios 
Table 12 shows the smallest values of the maximum installed cost for advanced controllers across all locations and climate zones that provide simple payback periods of 3 and 5 years and the corresponding specific locations and climate zones where they occur. Results are shown for two retrofit scenarios that the authors consider common opportunities: 1) retrofit of a unit having differential dry-bulb temperature-based integrated economizer, single-speed fan, and single-stage compressor control (and no DCV) with an advanced controller that adds multi-speed fan and DCV control (Scenario 3) and 2) retrofit of a unit having no advanced controls with an advanced controller having differential enthalpy-based integrated economizer, multi-speed fan, two-stage compressor control, and DCV (Scenario 4). These results are particularly important because they establish the maximum total installed cost that makes advanced controllers for packaged air conditioners with gas heating economic to building owners for all four building types that predominately use packaged units in all climate zones across the U.S. Vendors of advanced controllers can use this information to determine the maximum price that can be charged for these controllers to compete in the marketplace.

On a national basis, the maximum total installed cost for stand-alone retail, strip mall and supermarket buildings is $\$ 1,967$ per controller, which is found for Scenario 3 for the strip mall in Albuquerque to achieve a 3-year payback period. For a 5-yar payback period, the maximum installed cost is \$3,278 per controller, which also is found for Scenario 3 in Albuquerque. For the small office building the maximum total installed costs are $\$ 451$ and $\$ 752$ per controller for 3-year and 5-year paybacks, respectively, which are found for Scenario 3 in Seattle.

The results for Seattle are very low because the small office building model used for analysis has a floor area of only $5500 \mathrm{ft}^{2}$ but uses 5 packaged units to provide space conditioning. The results can be approximately scaled by multiplying the cost results by the ratio (5 packaged units)/(number of packaged unit on average found on a $5500 \mathrm{ft}^{2}$ building). For two units per $5500 \mathrm{ft}^{2}$ this ratio is 2.5 , yielding maximum costs per control of $\$ 1,128$ and $\$ 1,880$ per controller for 3-year and 5-year payback periods, respectively.

Vendors could choose to target specific building types rather than all building types on which packaged units are commonly installed. For example, the most favorable market for use of the advanced controllers is supermarkets for which the maximum total cost per advanced controller is $\$ 7,523$ for a 3-year payback period and $\$ 12,539$ for a 5-year payback period. Likewise, vendors could decide to target only specific geographic regions, choosing those with the largest savings. These decisions would likely consider many additional factors such as the cost of manufacturing the advanced controllers, the cost of controller installation, and the size of the market in various geographic regions (and climate zones). The information provided here can be used as input for vendors to use in making these decisions. 
Table 12: Maximum Values of the Installed Cost for Advanced Controllers that Provide Simple Payback Periods of 3 and 5 Years across the U.S. and the Specific Locations and Climate Zones to which these Values Correspond

\begin{tabular}{|c|c|c|c|c|c|}
\hline & Scenario* & Small Office & Standalone Retail & Strip mall & Supermarket \\
\hline \multirow{2}{*}{$\begin{array}{l}\text { 3-year } \\
\text { payback }\end{array}$} & $\begin{array}{c}\text { Scenario } \\
3\end{array}$ & $\begin{array}{c}451 \\
\text { [Seattle-4C] }\end{array}$ & $\begin{array}{c}5,151 \\
\text { [Albuquerque-4B] }\end{array}$ & $\begin{array}{c}2,967 \\
\text { [Albuquerque-4B] }\end{array}$ & $\begin{array}{c}\text { 7,523 } \\
{[\text { Miami-1A] }}\end{array}$ \\
\hline & $\begin{array}{c}\text { Scenario } \\
4\end{array}$ & $\begin{array}{c}554 \\
\text { [Seattle-4C] }\end{array}$ & $\begin{array}{c}5,898 \\
\text { [Albuquerque-4B] }\end{array}$ & $\begin{array}{c}2,290 \\
\text { [Albuquerque-4B] }\end{array}$ & $\begin{array}{c}8,044 \\
\text { [Seattle-4C] }\end{array}$ \\
\hline \multirow{2}{*}{$\begin{array}{c}\text { 5-year } \\
\text { payback }\end{array}$} & $\begin{array}{c}\text { Scenario } \\
3\end{array}$ & $\begin{array}{c}752 \\
\text { [Seattle-4C] }\end{array}$ & $\begin{array}{c}8,585 \\
\text { [Albuquerque-4B] }\end{array}$ & $\begin{array}{c}3,278 \\
\text { [Albuquerque-4B] }\end{array}$ & $\begin{array}{c}12,539 \\
{[\text { Miami-1A] }}\end{array}$ \\
\hline & $\begin{array}{c}\text { Scenario } \\
4\end{array}$ & $\begin{array}{c}923 \\
\text { [Seattle-4C] }\end{array}$ & $\begin{array}{c}9,830 \\
\text { [Albuquerque-4B] }\end{array}$ & $\begin{array}{c}3,817 \\
\text { [Albuquerque-4B] }\end{array}$ & $\begin{array}{c}13,406 \\
\text { [Seattle-4C] }\end{array}$ \\
\hline
\end{tabular}

* Scenario 3: retrofit of a unit having dry-bulb temperature-based integrated economizer, singlespeed fan, and single-stage compressor control (and no DCV) with an advanced controller that adds multi-speed fan and DCV control (Case 4 to Case 18); Scenario 4: retrofit of a unit having no advanced controls with an advanced controller having integrated enthalpy-based economizer, multi-speed fan, two-stage (speed) compressor control, and DCV (Case 1 to Case 22)

As noted above, the maximum controller cost per unit for each building type is based on the number of packaged units used in the simulation model, which may not reflect the actual numbers of units in a building with similar size, use pattern and climate condition. For example, the simulation model used for small office buildings use 5 packaged units and all controller costs for small office building are calculated based five packaged units. If the number of packaged units where to be reduced from 5 to 2, the maximum installed cost per controller units (Figure 76) are increased by a factor of 2.5 in comparison with the results shown in Figure 68. 


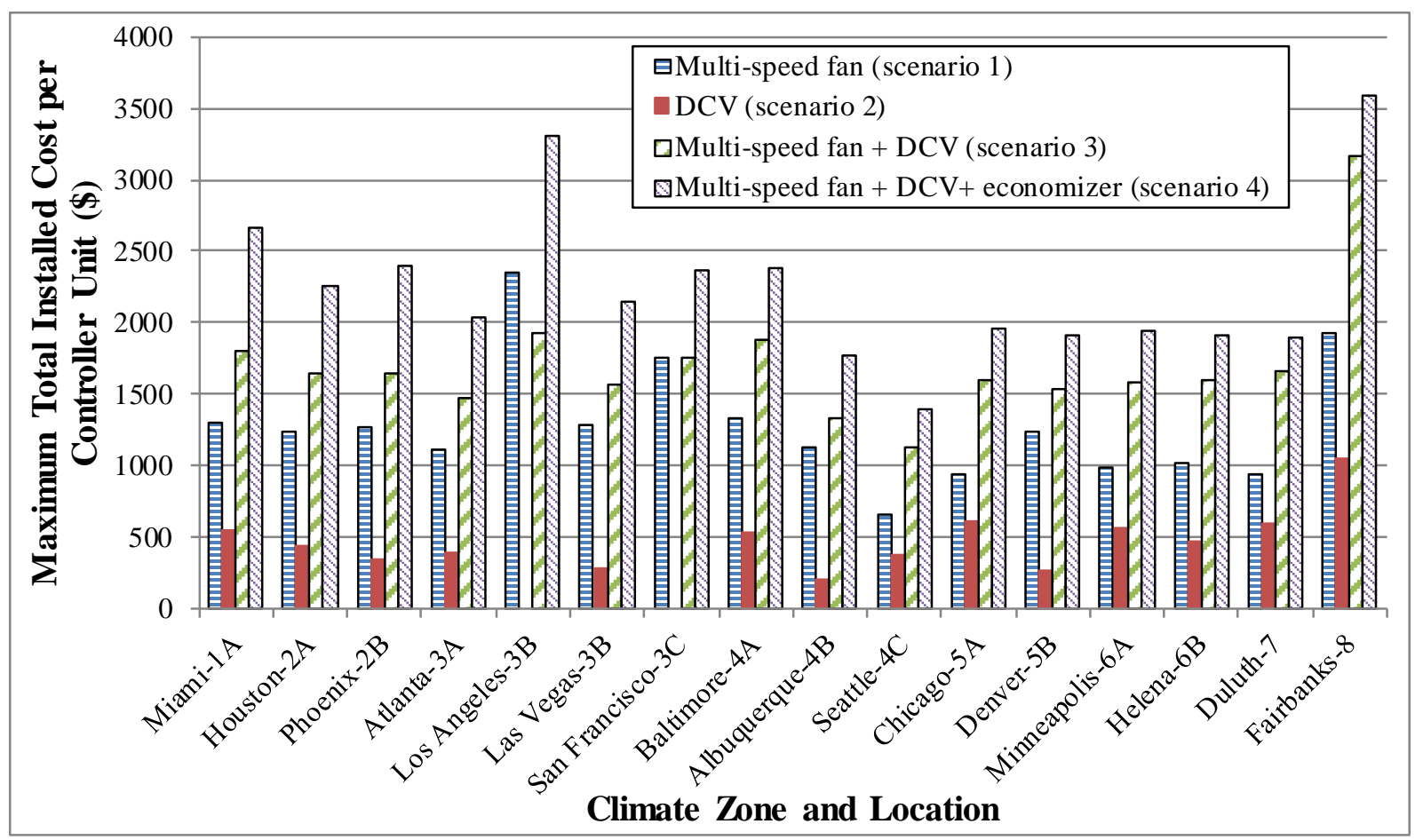

Figure 76: Maximum Total Installed Cost per Controller Unit that Provide Simple Payback of 3 Years for the Small Office Building with Different Control Capabilities and the Number of Packaged Units is reduced from 5 to 2 


\section{Conclusions and Future Planned Work}

The conclusion from the energy savings and economics of advanced control strategies for packaged air-conditioning units with gas heat and the recommend future work is presented in this section.

\subsection{Conclusions}

The results based on simulations presented in Sections 5 and 6 show that advanced control combining an air-side economizer, DCV, multi-speed supply fan, and staged cooling achieves significant energy and cost savings across all locations and building types. The maximum percentage of HVAC energy savings relative to the base case is more than $45 \%$ for all four building types. This maximum occurs in Los Angeles for small office, stand-alone retail and strip mall buildings; the maximum occurs in Miami for the supermarket. The smallest percentage savings is about 16\%, estimated for the supermarket in Fairbanks. For Case 22 with the fullest set of advanced control strategies (integrated differential enthalpy economizer, multi-speed fan, 2-stage cooling capacity and DCV) the average percentage HVAC energy savings across the 16 locations representing all US climate zones is around 24\% for the supermarket and around 35\% for the other three building types.

The annual absolute HVAC energy savings relative to the base case lies in the ranges between 40 and 100 MMBtu for the small office building, 300 and 1,390 MMBtu for the stand-alone retail building, 320 and 1,320 MMbtu for the strip mall, and 580 and 2,030 MMBtu for the supermarket. The maximum absolute energy savings relative to the base case all occur for Fairbanks. The average absolute savings across the 16 locations is about $60 \mathrm{MMBtu}$ for the small office building, $610 \mathrm{MMBtu}$ for the two retail buildings, and 1,010 MMBtu for the supermarket building.

For Case 22, the most energy efficiency package considered, the HVAC energy cost savings as a percentage of the base case energy cost lies in the range between $38 \%$ and $67 \%$ for the small office building, 36\% and 60\% for the stand-alone retail building, 36\% and 59\% for the strip mall, and $28 \%$ and $55 \%$ for the supermarket. The maximum percentage of HVAC energy cost saving relative to the base case occurs either in San Francisco or Los Angeles, where the electricity prices are high and the baseline building energy consumption is low. The smallest percentage energy cost savings is about $28 \%$ for the supermarket in Seattle, where the electricity price is low. The average percentage cost savings across the 16 locations is about $46 \%$ for the small office building, 43\% for the two retail buildings, and 39\% for the supermarket building.

With the fullest set of advanced control options, the annual absolute energy cost savings relative to the base case lies in the ranges between $\$ 920$ and $\$ 2,390$ for the small office building, $\$ 7,860$ and $\$ 23,780$ for the stand-alone retail building, $\$ 7,600$ and $\$ 23,410$ for the strip mall, and $\$ 16,090$ and $\$ 52,220$ for the supermarket. The maximum absolute cost savings relative to the base case all occur for Fairbanks. The average percentage cost savings across the 16 locations is about \$1,500 for the small office building, \$11,000 for the two retail buildings, and \$24,200 for the supermarket building.

A more realistic comparison is with a unit with integrated dry-bulb differential economizer, single-stage compressor and constant speed fan (Case 4) to a unit that has integrated dry-bulb differential economizer, single-state compressor, multi-speed fan and DCV (Case 18), which 
achieves more than 40\% HVAC energy savings for all four building types. This maximum occurs in Los Angeles for the small office and stand-alone retail buildings, in San Francisco for the strip mall building, in Miami for the supermarket building. The smallest percentage savings is about $14 \%$, estimated for the supermarket in Fairbanks. Relative to Case 4, the average percentage HVAC energy savings across the 16 locations for Case 18 is around $28 \%$ for the small office building, 32\% for the two retail buildings, and $22 \%$ for the supermarket building.

For Case 18, the annual absolute HVAC energy savings relative to Case 4 lies in the range between 30 and 90 MMBtu for the small office building, 230 and 1,270 MMBtu for the standalone retail building, 240 and 1,170 MMbtu for the strip mall, and 500 and 1,770 MMBtu for the supermarket. The maximum absolute energy savings relative to Case 4 all occur in Fairbanks. The average absolute savings across the 16 locations is about $46 \mathrm{MMBtu}$ for the small office building, 550 MMBtu for the two retail buildings, and 910 MMBtu for the supermarket building.

With multi-speed fan and DCV added to Case 4 that already has the air-side economizer, the HVAC energy cost savings as a percentage of Case 4 energy cost lies in the range between $27 \%$ and 59\% for the small office building, 30\% and 53\% for the stand-alone retail building, 29\% and $54 \%$ for the strip mall, and $27 \%$ and $50 \%$ for the supermarket. The maximum percentage of HVAC energy cost saving relative to Case 4 occurs either in San Francisco or Los Angeles, where the electricity prices are high and the building energy consumption is low. The smallest percentage energy cost savings occurs in either Miami or Seattle. The average percentage cost savings across the 16 locations is about 36\% for the supermarket building and 38\% for the other three building types.

The annual absolute energy cost savings of Case 18 relative to Case 4 lies in the ranges between $\$ 750$ and $\$ 2,110$ for the small office building, $\$ 6,870$ and $\$ 21,380$ for the stand-alone retail building, \$6,556 and \$20,370 for the strip mall, and \$15,050 and \$46,600 for the supermarket. The maximum absolute cost savings relative to Case 4 all occur in Fairbanks. The average percentage cost savings across the 16 locations is about \$1,130 for the small office building, $\$ 9,400$ for the two retail buildings, and $\$ 22,000$ for the supermarket building.

Individual control strategies have different degrees of impact on energy and cost savings. The simulation results indicate that multi-speed fan control and DCV are the two control strategies contributing the most to savings. In many cases, multi-speed fan control dominates the impact in hot and mild climates, such as Miami and Los Angeles, while DCV dominates the impact in mixed and cold climates, such as Seattle, Chicago, and Duluth. Applying multi-speed fan control alone may lead to an increase in overall HVAC energy consumption in cold climates, but that is not the case for energy cost. Following the sequence of operation as specified in this study, whether an air-side economizer is integrated with mechanical cooling or not has little if any noticeable impact on energy or cost savings.

The maximum installed cost per controller that can achieve a 3-year simple payback varies significantly with the building type. If the controller incorporates all considered control strategies (Case 22), the maximum total installed cost varies in the range $\$ 8,040$ and $\$ 26,110$ for the supermarket building to achieve a payback period of 3 years, between $\$ 5,900$ and $\$ 17,830$ for the stand-alone retail building, between $\$ 2,290$ and \$7,020 for the strip mall building, and between $\$ 550$ and \$1,435 for the small office building. Advanced controllers with the complete set of control features corresponding to Cases 22 will need to have a total cost less than these 
values to provide savings that justify the investment by building owners in the absence of an incentive that decreases the cost to the owner with a subsidy.

\subsection{Future Work}

Bringing retrofitable advanced control packages rapidly to the mass market to realize the large energy and cost savings potential found in this study will likely require additional information and further development of the technology. Some key needs identified by the project team include the following.

- The energy savings estimated with simulations in this study should be validated with field tests of retrofitable controllers for packaged units that are beginning to enter the marketplace. Testing can be used to validate overall energy savings as well as savings from individual control strategies and specific combinations of control strategies.

- As this study considered packaged rooftop air conditioners with direct expansion cooling and gas furnace heating, similar analyses of packaged air source heat pumps and air conditioners with electric resistive heating would prove valuable.

- The small office building model is a single-story building with just less than $5000 \mathrm{ft}^{2}$ floor area. The small size, together with its somewhat atypical attic roof construction, makes it not representative of most office buildings served by packaged rooftop units. Therefore, results may be improved by using an office building model that corresponds closer to the size and construction of the median office building that uses packaged rooftop units, such as the DOE reference building model for a medium office building, which has a conditioned floor area of about 50,000 $\mathrm{ft}^{2}$.

- If the cost of advanced controllers on the market exceeds the maximum cost for a payback period commonly found acceptable by building owners, additional technological innovation may be required to lower the cost of advanced controllers to acceptable levels. This technology development may be best performed in government-industry collaborations (e.g., national laboratories with building controller manufacturers).

- Development of a guide or software tool for building owners and managers to assist them in making decisions to install advanced controllers may be important to accelerate the market penetration of advanced controllers, which based on this study can save considerable energy (approximately 25\% to 60\% of the energy consumption of rooftop units over a broad range of U.S. climates).

- In addition to the measures considered (air-side economizer, multiple supply-fan speed control, DCV and staged direct expansion cooling using multi-speed control of compressor motors), other advanced control technologies applicable to packaged rooftop units should be evaluated. Such technologies include optimal start times, closing outdoorair dampers during morning warm up or cool down periods, and fully variable-speed control of the supply fan, condenser fan and compressor.

- The analysis in this report assumes that all sensors are accurate. However, sensors are rarely perfectly accurate and control precise in practice. For this reason, it is important to consider the uncertainty of sensor measurements. The impacts of uncertainty on energy savings, cost savings, and the maximum economical total cost of the control retrofits should be investigated. 
- The impact assessment was made for a single set of predefined values for the key control parameters (Table 6). Because these values are likely to vary in field applications, it is worthwhile to investigate the impact on energy and cost savings of using different parameter values. The control parameters could even be optimized.

- The EnergyPlus program and DOE reference building models were used in the current work to evaluate the energy saving potential of advanced rooftop unit control strategies. The impact of compressor cycling on cooling efficiency was not considered in this analysis. Because ignoring cycling losses underestimates the savings potential from staged cooling, the simulation of control needs to be improved to incorporate compressor cycling.

- Based on the DOE reference models, EnergyPlus was used in the current work to evaluate the energy saving potential with advanced rooftop unit control strategies. The impact of compressor cycling on cooling efficiency was not considered in the current simulation. Because ignoring cycling losses underestimates the saving potential from staged cooling, the simulation control needs to be improved to incorporate compressor cycling. 


\section{References}

ASHRAE. 1999. ASHRAE Standard 62.1-1999: Ventilation for Acceptable Indoor Air Quality. American Society of Heating, Refrigerating and Air-Conditioning Engineers Inc., Atlanta, GA.

ASHRAE. 2008. Handbook of HVAC Systems and Equipment. American Society of Heating, Refrigerating and Air-Conditioning Engineers, Atlanta, GA.

ASHRAE. 2009. Handbook of Fundamentals. American Society of Heating, Refrigerating and Air-Conditioning Engineers, Atlanta, GA.

ASHRAE. 2010a. ASHRAE Standard 62.1-2010: Ventilation for Acceptable Indoor Air Quality. American Society of Heating, Refrigerating and Air-Conditioning Engineers Inc., Atlanta, GA.

ASHRAE. 2010b. ASHRAE Standard 90.1-2010: Energy Standard for Buildings Except LowRise Residential Buildings. American Society of Heating, Refrigerating and Air-Conditioning Engineers Inc. Atlanta, GA.

Brandemuel M.J. and J.E. Braun. 1999. The impact of demand-controlled and economizer ventilation strategies on energy use in buildings. ASHRAE Transactions 105(2): 39-50.

Chan T. 2004. Beyond the affinity laws. Engineered Systems, August, 2004.

Criscione P. 2011. A dramatic boost for existing RTUs. E Source Research Brief, TAS-RB-47.

Deru, M., K. Field, D. Studer, K. Benne, B. Griffith, P. Torcellini, B. Liu, M. Halverson, D. Winiarski, M. Yazdazian, J. Huang, and D. Crawley. 2011. U.S. Department of Energy Commercial Reference Building Models of the National Building Stock. NREL/TP-550046861, National Renewable Energy Laboratory, Golden, CO.

DOE. Department of Energy. 2010. EnergyPlus Energy Simulation Software, (version 6.0), US Department of Energy, Washington, DC.

EIA. Energy Information Administration. 2003. Commercial Buildings Energy Consumption Survey 2003. U.S. Department of Energy, Washington, D.C. Last accessed in July 2011 at http://www.eia.doe.gov/emeu/cbecs/contents.html.

EIA. Energy Information Administration. 2011. Electricity and Natural Gas Prices. Last accessed in July 2011 at http://www.eia.gov/electricity/data.cfm\#sales and http://www.eia.gov/dnav/ng/ng_pri_sum_dcu_nus_m.htm.

Field, K., M. Deru, and D. Studer. 2010. Using DOE commercial reference buildings for simulation studies. Proceedings of the 4th National Conference of IBPSA-USA, pp. 85-93.

Ford R.W. 2011. Affinity laws: why they work and when they don't. ASHRAE Journal 53(3): 42-43.

Fumo, N., P. Mago, and R. Luck. 2010. Methodology to estimate building energy consumption using EnergyPlus benchmark models. Energy and Buildings 42 (12): 2331-2337.

Roth, K.W., J. Dieckmann, and J. Brodrick. 2003. Demand control ventilation. ASHRAE Journal 45(7): 91-92.

Stanke, D. 2006. System operation: dynamic reset operations. ASHRAE Journal 48(12): 18-32.

Taylor, S.T. and C.H. Cheng. 2010. Economizer high limit controls and why enthalpy economizers don’t work. ASHRAE Journal 52(11): 12-28. 


\section{A. APPENDIX A Prototype Building Characteristics}


Table A-1: Key Geometric, Envelope, HVAC, Water Heating and Internal Load Characteristics for the Small Office Building Prototype

\begin{tabular}{|c|c|}
\hline \multicolumn{2}{|l|}{ Geometry } \\
\hline Floor area & $5,500 \mathrm{ft}^{2}$ \\
\hline Aspect ratio & 1.5 \\
\hline Number of floor & 1 \\
\hline Window-to-wall ratio & $21.2 \%$ \\
\hline Floor-to-ceiling height & $10.2 \mathrm{ft}$ \\
\hline \multicolumn{2}{|l|}{ Envelope } \\
\hline Exterior Wall & Steel-frame wall (R-value: 4.35 to 8) \\
\hline Roof & Insulation entirely above deck (IEAD) (R-value: 10 to 17 ) \\
\hline Window & $\begin{array}{l}\text { U-value } 0.62 \text { to } 1.03 \\
\text { Solar heat gain coefficient (SHGC) } 0.41 \text { to } 0.54 \\
\text { Visible transmittance (VT) } 0.32 \text { to } 0.38\end{array}$ \\
\hline Foundation & Mass floor 4-in. slab with carpet \\
\hline \multicolumn{2}{|l|}{ HVAC } \\
\hline Type & Packaged single zone, constant air volume system \\
\hline Heating & Gas furnace (80\% efficiency) \\
\hline Cooling & Unitary DX (3.07 COP) \\
\hline Ventilation & $20 \mathrm{cfm} /$ person \\
\hline System schedule & 7am-11pm (weekdays) 7am-7pm (Saturday) \\
\hline Cooling set point and setback & $75^{\circ} \mathrm{F} / 80^{\circ} \mathrm{F}$ \\
\hline Heating set point and setback & $70{ }^{\circ} \mathrm{F} / 60^{\circ} \mathrm{F}$ \\
\hline \multicolumn{2}{|l|}{ Service Water Heating } \\
\hline Tуре & Gas (80\% efficiency) \\
\hline Temperature set point & $140^{\circ} \mathrm{F}$ \\
\hline Water usage & $11.4 \mathrm{~L} / \mathrm{h}$ \\
\hline \multicolumn{2}{|l|}{ Internal Load } \\
\hline Occupancy density & $200 \mathrm{ft}^{2} /$ per person (total 28 persons in the building) \\
\hline Lighting & $1.8 \mathrm{~W} / \mathrm{ft}^{2}$ \\
\hline Plug equipment & $1.0 \mathrm{~W} / \mathrm{ft}^{2}$ \\
\hline
\end{tabular}


Table A-2: Key Geometric, Envelope, HVAC, Water Heating and Internal Load Characteristics for the Stand-alone Retail Building Prototype

\begin{tabular}{|c|c|}
\hline \multicolumn{2}{|l|}{ Geometry } \\
\hline Floor area & $25,000 \mathrm{ft}^{2}$ \\
\hline Aspect ratio & 1.3 \\
\hline Number of floor & 1 \\
\hline Window-to-wall ratio & $7.1 \%$ \\
\hline Floor-to-ceiling height & $20 \mathrm{ft}$ \\
\hline \multicolumn{2}{|l|}{ Envelope } \\
\hline Exterior wall & Steel-frame wall (R-value: 2.4 to 22 ) \\
\hline Roof & IEAD (R-value: 10 to 33) \\
\hline Window & $\begin{array}{l}\text { U-value } 0.52 \text { to } 1.03 \text {; } \\
\text { SHGC } 0.04 \text { to } 0.11 ; \\
\text { VT } 0.02 \text { to } 0.1\end{array}$ \\
\hline Foundation & Mass floor 4-in. slab \\
\hline \multicolumn{2}{|l|}{ HVAC } \\
\hline Type & Packaged single zone, constant air volume system \\
\hline Heating & Gas furnace (78\% to 80\% efficiency) \\
\hline Cooling & Unitary DX (3.23 to 3.7 COP) \\
\hline Ventilation & $\begin{array}{l}0.3 \mathrm{cfm} / \mathrm{ft}^{2} \text { in cashier and two sales zones; } \\
0.15 \mathrm{cfm} / \mathrm{ft}^{2} \text { in storage zone. }\end{array}$ \\
\hline System schedule & $\begin{array}{l}7 \text { am-10 pm (weekdays) } \\
7 \text { am-11 pm (Sat.) } 9 \text { am-10 pm (Sun.) }\end{array}$ \\
\hline Cooling set point and setback & $75^{\circ} \mathrm{F} / 86^{\circ} \mathrm{F}$ \\
\hline Heating set point and setback & $70{ }^{\circ} \mathrm{F} / 60^{\circ} \mathrm{F}$ \\
\hline \multicolumn{2}{|l|}{ Internal Load } \\
\hline Occupancy density & $\begin{array}{l}300 \mathrm{ft}^{2} / \text { per person in storage zone } \\
\text { (total } 323 \text { persons in the building) } \\
67 \mathrm{ft}^{2} / \text { per person in four other zones }\end{array}$ \\
\hline Lighting & $\begin{array}{l}1.2 \mathrm{~W} / \mathrm{ft}^{2} \text { in storage zone } \\
3.4 \mathrm{~W} / \mathrm{ft}^{2} \text { in four other zones }\end{array}$ \\
\hline Plug equipment & $\begin{array}{l}0.3 \mathrm{~W} / \mathrm{ft}^{2} \text { in two Sales zones; } \\
0.7 \mathrm{~W} / \mathrm{ft}^{2} \text { in storage zone; } \\
2.0 \mathrm{~W} / \mathrm{ft}^{2} \text { in cashier zone. }\end{array}$ \\
\hline
\end{tabular}


Table A-3: Key Geometric, Envelope, HVAC, Water Heating, and Internal Load Characteristics for the Strip Mall Building Prototype

\begin{tabular}{|c|c|}
\hline \multicolumn{2}{|l|}{ Geometry } \\
\hline Floor area & $22,500 \mathrm{ft}^{2}$ \\
\hline Aspect ratio & 4 \\
\hline Number of floor & 1 \\
\hline Window-to-wall ratio & $10.5 \%$ \\
\hline Floor-to-ceiling height & $17 \mathrm{ft}$ \\
\hline \multicolumn{2}{|l|}{ Envelope } \\
\hline Exterior wall & Steel-frame wall (R-value: 1.8 to 22) \\
\hline Roof & IEAD (R-value: 10 to 33) \\
\hline Window & $\begin{array}{l}\text { U-value } 0.52 \text { to } 1.03 \\
\text { SHGC } 0.04 \text { to } 0.11 \\
\text { VT } 0.02 \text { to } 0.1\end{array}$ \\
\hline Foundation & Mass Floor 4-in slab (R-value: 1.8 ) \\
\hline \multicolumn{2}{|l|}{ HVAC } \\
\hline Type & Packaged single zone, constant air volume system \\
\hline Heating & Gas furnace ( $78 \%$ to $80 \%$ efficiency) \\
\hline Cooling & Unitary DX (3.2 to 3.7 COP) \\
\hline Ventilation & $0.3 \mathrm{cfm} / \mathrm{ft}^{2}$ in all zones \\
\hline System schedule & $\begin{array}{l}7 \text { am-10 pm (weekdays) } \\
7 \text { am-11 pm (Sat.) } 9 \text { am-8 pm (Sun.) }\end{array}$ \\
\hline Cooling set point and setback & $75^{\circ} \mathrm{F} / 86^{\circ} \mathrm{F}$ \\
\hline Heating set point and setback & $70^{\circ} \mathrm{F} / 60^{\circ} \mathrm{F}$ \\
\hline \multicolumn{2}{|l|}{ Internal Load } \\
\hline Occupancy density & $67 \mathrm{ft}^{2} /$ per person \\
\hline Lighting & $\begin{array}{l}\text { 5.6 W/ft }{ }^{2} \text { in one large-store zone, and one small-store zone; } \\
3.3 \mathrm{~W} / \mathrm{ft}^{2} \text { in three small-store zones; } \\
2.7 \mathrm{~W} / \mathrm{ft} 2 \text { in one large-store zone, and four small-store } \\
\text { zones. }\end{array}$ \\
\hline Plug equipment & $0.4 \mathrm{~W} / \mathrm{ft}^{2}$ in all the zones \\
\hline
\end{tabular}


Table A-4: Key Geometric, Envelope, HVAC, Water Heating, and Internal Load Characteristics for the Supermarket Building Prototype

\begin{tabular}{|c|c|}
\hline \multicolumn{2}{|l|}{ Geometry } \\
\hline Floor area & $45,000 \mathrm{ft}^{2}$ \\
\hline Aspect ratio & 1.5 \\
\hline Number of floor & 1 \\
\hline Window-to-wall ratio & $11 \%$ \\
\hline Floor-to-ceiling height & $20 \mathrm{ft}$ \\
\hline \multicolumn{2}{|l|}{ Envelope } \\
\hline Exterior wall & Steel-frame wall (R-value: 2.4 to 21.3 ) \\
\hline Roof & IEAD (R-value: 10 to 33) \\
\hline Window & $\begin{array}{l}\text { U-value } 0.52 \text { to } 1.03 \text {; } \\
\text { SHGC } 0.04 \text { to } 0.11 \text {; } \\
\text { VT } 0.02 \text { to } 0.1\end{array}$ \\
\hline Foundation & Mass floor 4-in slab (R-value: 1.8 ) \\
\hline \multicolumn{2}{|l|}{ HVAC } \\
\hline Type & Packaged single zone, constant air volume system \\
\hline Heating & Gas furnace (78\% - 80\% efficiency) \\
\hline Cooling & Unitary DX (3.1 - 3.7 COP) \\
\hline Ventilation & $\begin{array}{l}20 \mathrm{cfm} / \mathrm{person} \text { in office } \\
0.3 \mathrm{cfm} / \mathrm{ft}^{2} \text { in sales, deli, produce and bakery zones } \\
0.15 \mathrm{cfm} / \mathrm{ft}^{2} \text { in dry storage zones }\end{array}$ \\
\hline System schedule & 7 am-11 pm \\
\hline Cooling set point and setback & $75^{\circ} \mathrm{F} / 86^{\circ} \mathrm{F}$ \\
\hline Heating set point and setback & $70{ }^{\circ} \mathrm{F} / 60^{\circ} \mathrm{F}$ \\
\hline \multicolumn{2}{|l|}{ Internal Load } \\
\hline Occupancy density & $\begin{array}{l}125 \mathrm{ft}^{2} / \text { per person in sales, deli, produce and bakery zones } \\
200 \mathrm{ft}^{2} / \text { per person in office } \\
300 \mathrm{ft}^{2} / \text { per person in dry storage zone }\end{array}$ \\
\hline Lighting & $\begin{array}{l}2.8 \mathrm{~W} / \mathrm{ft}^{2} \text { in sales, deli, produce and bakery zones } \\
2.0 \mathrm{~W} / \mathrm{ft}^{2} \text { in office } \\
1.1 \mathrm{~W} / \mathrm{ft}^{2} \text { in dry storage zone }\end{array}$ \\
\hline Plug equipment & $0.4 \mathrm{~W} / \mathrm{ft}^{2}$ in all the zones \\
\hline
\end{tabular}




\section{B. APPENDIX B Tables of HVAC Energy Uses}


Table B-1: HVAC Energy Uses for the Small Office Building in Climate Zones 1A and 2A

Units: [10 $10^{6}$ Btus]

\begin{tabular}{|c|c|c|c|c|c|c|c|c|c|}
\hline \multirow[b]{2}{*}{$\begin{array}{c}\text { Case } \\
\text { No }\end{array}$} & \multirow[b]{2}{*}{ Case Name } & \multicolumn{4}{|c|}{ Miami-1A } & \multicolumn{4}{|c|}{ Houston-2A } \\
\hline & & $\begin{array}{c}\text { Fan } \\
\text { Energy }\end{array}$ & $\begin{array}{l}\text { Cooling } \\
\text { Energy }\end{array}$ & $\begin{array}{c}\text { Heating } \\
\text { Energy }\end{array}$ & $\begin{array}{c}\text { Total } \\
\text { HVAC } \\
\text { Energy }\end{array}$ & $\begin{array}{c}\text { Fan } \\
\text { Energy }\end{array}$ & $\begin{array}{l}\text { Cooling } \\
\text { Energy }\end{array}$ & $\begin{array}{c}\text { Heating } \\
\text { Energy }\end{array}$ & $\begin{array}{c}\text { Total } \\
\text { HVAC } \\
\text { Energy }\end{array}$ \\
\hline 1 & NoEcon.SSFan.CS1.DCV0 (Baseline) & 49 & 113 & 1 & 162 & 47 & 78 & 30 & 155 \\
\hline 2 & NIEcon.DB.SSFan.CS1.DCV0 & 52 & 105 & 1 & 157 & 48 & 71 & 30 & 149 \\
\hline 3 & NIEcon.EH.SSFan.CS1.DCV0 & 49 & 108 & 1 & 158 & 47 & 73 & 30 & 150 \\
\hline 4 & IEcon.DB.SSFan.CS1.DCV0 & 52 & 105 & 1 & 158 & 48 & 71 & 30 & 149 \\
\hline 5 & IEcon.EH.SSFan.CS1.DCV0 & 49 & 108 & 1 & 158 & 47 & 73 & 30 & 150 \\
\hline 6 & NoEcon.MSFan.CS1.DCV0 & 21 & 110 & 1 & 132 & 17 & 75 & 39 & 131 \\
\hline 7 & NIEcon.DB.MSFan.CS1.DCV0 & 25 & 103 & 1 & 130 & 19 & 69 & 39 & 128 \\
\hline 8 & NIEcon.EH.MSFan.CS1.DCV0 & 22 & 107 & 1 & 130 & 18 & 72 & 39 & 128 \\
\hline 9 & IEcon.DB.MSFan.CS1.DCV0 & 25 & 104 & 1 & 130 & 19 & 70 & 39 & 128 \\
\hline 10 & IEcon.EH.MSFan.CS1.DCV0 & 22 & 107 & 1 & 130 & 18 & 71 & 39 & 128 \\
\hline 11 & NoEcon.MSFan.CS2.DCV0 & 18 & 96 & 1 & 115 & 14 & 66 & 39 & 119 \\
\hline 12 & IEcon.DB.MSFan.CS2.DCV0 & 22 & 92 & 1 & 115 & 17 & 62 & 39 & 119 \\
\hline 13 & IEcon.EH.MSFan.CS2.DCV0 & 19 & 93 & 1 & 113 & 16 & 63 & 39 & 117 \\
\hline 14 & NoEcon.SSFan.CS1.DCV1 & 49 & 100 & 1 & 149 & 47 & 70 & 22 & 138 \\
\hline 15 & IEcon.DB.SSFan.CS1.DCV1 & 51 & 93 & 1 & 146 & 48 & 62 & 22 & 132 \\
\hline 16 & IEcon.EH.SSFan.CS1.DCV1 & 49 & 95 & 1 & 145 & 47 & 64 & 22 & 133 \\
\hline 17 & NoEcon.MSFan.CS1.DCV1 & 20 & 97 & 1 & 117 & 15 & 66 & 29 & 110 \\
\hline 18 & IEcon.DB.MSFan.CS1.DCV1 & 23 & 92 & 1 & 116 & 18 & 61 & 29 & 108 \\
\hline 19 & IEcon.EH.MSFan.CS1.DCV1 & 20 & 93 & 1 & 115 & 16 & 62 & 29 & 107 \\
\hline 20 & NoEcon.MSFan.CS2.DCV1 & 16 & 85 & 1 & 102 & 13 & 58 & 29 & 100 \\
\hline 21 & IEcon.DB.MSFan.CS2.DCV1 & 20 & 82 & 1 & 103 & 16 & 55 & 29 & 100 \\
\hline 22 & IEcon.EH.MSFan.CS2.DCV1 & 18 & 82 & 1 & 100 & 14 & 55 & 29 & 98 \\
\hline
\end{tabular}


Table B-2: HVAC Energy Uses for the Small Office Building in Climate Zones 2B and 3A

Units: [10 $10^{6}$ Btus]

\begin{tabular}{|c|c|c|c|c|c|c|c|c|c|}
\hline \multirow[b]{2}{*}{$\begin{array}{c}\text { Case } \\
\text { No }\end{array}$} & \multirow[b]{2}{*}{ Case Name } & \multicolumn{4}{|c|}{ Phoenix-2B } & \multicolumn{4}{|c|}{ Atlanta-3A } \\
\hline & & $\begin{array}{c}\text { Fan } \\
\text { Energy }\end{array}$ & $\begin{array}{l}\text { Cooling } \\
\text { Energy }\end{array}$ & $\begin{array}{c}\text { Heating } \\
\text { Energy }\end{array}$ & $\begin{array}{c}\text { Total } \\
\text { HVAC } \\
\text { Energy }\end{array}$ & $\begin{array}{c}\text { Fan } \\
\text { Energy }\end{array}$ & $\begin{array}{l}\text { Cooling } \\
\text { Energy }\end{array}$ & $\begin{array}{c}\text { Heating } \\
\text { Energy }\end{array}$ & $\begin{array}{c}\text { Total } \\
\text { HVAC } \\
\text { Energy }\end{array}$ \\
\hline 1 & NoEcon.SSFan.CS1.DCV0 (Baseline) & 49 & 95 & 17 & 161 & 46 & 46 & 63 & 155 \\
\hline 2 & NIEcon.DB.SSFan.CS1.DCV0 & 50 & 89 & 17 & 156 & 47 & 37 & 63 & 146 \\
\hline 3 & NIEcon.EH.SSFan.CS1.DCV0 & 49 & 89 & 17 & 155 & 46 & 39 & 63 & 148 \\
\hline 4 & IEcon.DB.SSFan.CS1.DCV0 & 50 & 89 & 17 & 156 & 47 & 37 & 63 & 146 \\
\hline 5 & IEcon.EH.SSFan.CS1.DCV0 & 49 & 89 & 17 & 155 & 46 & 39 & 63 & 148 \\
\hline 6 & NoEcon.MSFan.CS1.DCV0 & 18 & 92 & 25 & 135 & 14 & 42 & 81 & 137 \\
\hline 7 & NIEcon.DB.MSFan.CS1.DCV0 & 19 & 88 & 25 & 133 & 16 & 36 & 81 & 133 \\
\hline 8 & NIEcon.EH.MSFan.CS1.DCV0 & 19 & 88 & 25 & 132 & 15 & 38 & 81 & 133 \\
\hline 9 & IEcon.DB.MSFan.CS1.DCV0 & 19 & 88 & 25 & 132 & 16 & 36 & 81 & 133 \\
\hline 10 & IEcon.EH.MSFan.CS1.DCV0 & 19 & 88 & 25 & 132 & 15 & 38 & 81 & 133 \\
\hline 11 & NoEcon.MSFan.CS2.DCV0 & 15 & 80 & 25 & 120 & 12 & 36 & 81 & 129 \\
\hline 12 & IEcon.DB.MSFan.CS2.DCV0 & 17 & 76 & 25 & 118 & 14 & 32 & 81 & 127 \\
\hline 13 & IEcon.EH.MSFan.CS2.DCV0 & 17 & 76 & 25 & 118 & 14 & 32 & 81 & 127 \\
\hline 14 & NoEcon.SSFan.CS1.DCV1 & 49 & 89 & 12 & 150 & 46 & 43 & 46 & 135 \\
\hline 15 & IEcon.DB.SSFan.CS1.DCV1 & 50 & 82 & 12 & 143 & 47 & 33 & 46 & 126 \\
\hline 16 & IEcon.EH.SSFan.CS1.DCV1 & 49 & 82 & 12 & 143 & 46 & 35 & 47 & 127 \\
\hline 17 & NoEcon.MSFan.CS1.DCV1 & 17 & 86 & 18 & 120 & 13 & 39 & 60 & 112 \\
\hline 18 & IEcon.DB.MSFan.CS1.DCV1 & 18 & 80 & 18 & 116 & 15 & 33 & 60 & 107 \\
\hline 19 & IEcon.EH.MSFan.CS1.DCV1 & 18 & 80 & 18 & 116 & 14 & 34 & 60 & 107 \\
\hline 20 & NoEcon.MSFan.CS2.DCV1 & 14 & 74 & 18 & 106 & 11 & 34 & 60 & 105 \\
\hline 21 & IEcon.DB.MSFan.CS2.DCV1 & 16 & 70 & 18 & 103 & 14 & 29 & 60 & 103 \\
\hline 22 & IEcon.EH.MSFan.CS2.DCV1 & 16 & 70 & 18 & 103 & 13 & 29 & 60 & 102 \\
\hline
\end{tabular}


Table B-3: HVAC Energy Uses for the Small Office Building in Climate Zone 3B

Units: [10 $10^{6}$ Btus]

\begin{tabular}{|c|c|c|c|c|c|c|c|c|c|}
\hline \multirow[b]{2}{*}{$\begin{array}{l}\text { Case } \\
\text { No }\end{array}$} & \multirow[b]{2}{*}{ Case Name } & \multicolumn{4}{|c|}{ Los Angeles-3B } & \multicolumn{4}{|c|}{ Las Vegas-3B } \\
\hline & & $\begin{array}{c}\text { Fan } \\
\text { Energy }\end{array}$ & $\begin{array}{l}\text { Cooling } \\
\text { Energy }\end{array}$ & $\begin{array}{c}\text { Heating } \\
\text { Energy }\end{array}$ & $\begin{array}{c}\text { Total } \\
\text { HVAC } \\
\text { Energy }\end{array}$ & $\begin{array}{c}\text { Fan } \\
\text { Energy }\end{array}$ & $\begin{array}{l}\text { Cooling } \\
\text { Energy }\end{array}$ & $\begin{array}{c}\text { Heating } \\
\text { Energy }\end{array}$ & $\begin{array}{c}\text { Total } \\
\text { HVAC } \\
\text { Energy }\end{array}$ \\
\hline 1 & NoEcon.SSFan.CS1.DCV0 (Baseline) & 46 & 36 & 12 & 94 & 45 & 65 & 33 & 143 \\
\hline 2 & NIEcon.DB.SSFan.CS1.DCV0 & 47 & 15 & 12 & 74 & 45 & 59 & 33 & 137 \\
\hline 3 & NIEcon.EH.SSFan.CS1.DCV0 & 47 & 19 & 12 & 78 & 45 & 59 & 33 & 137 \\
\hline 4 & IEcon.DB.SSFan.CS1.DCV0 & 47 & 15 & 12 & 74 & 45 & 59 & 33 & 137 \\
\hline 5 & IEcon.EH.SSFan.CS1.DCV0 & 47 & 19 & 12 & 78 & 45 & 59 & 33 & 137 \\
\hline 6 & NoEcon.MSFan.CS1.DCV0 & 11 & 31 & 20 & 62 & 14 & 62 & 46 & 122 \\
\hline 7 & NIEcon.DB.MSFan.CS1.DCV0 & 14 & 16 & 20 & 49 & 15 & 59 & 46 & 120 \\
\hline 8 & NIEcon.EH.MSFan.CS1.DCV0 & 13 & 20 & 20 & 52 & 15 & 59 & 46 & 120 \\
\hline 9 & IEcon.DB.MSFan.CS1.DCV0 & 14 & 16 & 20 & 49 & 15 & 59 & 46 & 119 \\
\hline 10 & IEcon.EH.MSFan.CS1.DCV0 & 13 & 19 & 20 & 52 & 15 & 59 & 46 & 119 \\
\hline 11 & NoEcon.MSFan.CS2.DCV0 & 9 & 25 & 20 & 54 & 12 & 55 & 46 & 113 \\
\hline 12 & IEcon.DB.MSFan.CS2.DCV0 & 13 & 14 & 20 & 47 & 14 & 52 & 46 & 111 \\
\hline 13 & IEcon.EH.MSFan.CS2.DCV0 & 12 & 15 & 20 & 47 & 14 & 52 & 46 & 111 \\
\hline 14 & NoEcon.SSFan.CS1.DCV1 & 46 & 38 & 9 & 93 & 45 & 62 & 24 & 130 \\
\hline 15 & IEcon.DB.SSFan.CS1.DCV1 & 47 & 15 & 10 & 71 & 45 & 55 & 24 & 123 \\
\hline 16 & IEcon.EH.SSFan.CS1.DCV1 & 47 & 19 & 10 & 75 & 45 & 55 & 24 & 123 \\
\hline 17 & NoEcon.MSFan.CS1.DCV1 & 11 & 32 & 14 & 58 & 13 & 58 & 33 & 105 \\
\hline 18 & IEcon.DB.MSFan.CS1.DCV1 & 14 & 15 & 14 & 43 & 14 & 54 & 33 & 101 \\
\hline 19 & IEcon.EH.MSFan.CS1.DCV1 & 13 & 19 & 14 & 46 & 15 & 54 & 33 & 101 \\
\hline 20 & NoEcon.MSFan.CS2.DCV1 & 10 & 27 & 14 & 50 & 11 & 51 & 33 & 96 \\
\hline 21 & IEcon.DB.MSFan.CS2.DCV1 & 13 & 14 & 14 & 41 & 13 & 47 & 33 & 93 \\
\hline 22 & IEcon.EH.MSFan.CS2.DCV1 & 12 & 15 & 14 & 41 & 13 & 47 & 33 & 94 \\
\hline
\end{tabular}


Table B-4: HVAC Energy Uses for the Small Office Building in Climate Zones 3C and 4A

Units: [10 $10^{6}$ Btus]

\begin{tabular}{|c|c|c|c|c|c|c|c|c|c|}
\hline \multirow[b]{2}{*}{$\begin{array}{c}\text { Case } \\
\text { No }\end{array}$} & \multirow[b]{2}{*}{ Case Name } & \multicolumn{4}{|c|}{ San Francisco-3C } & \multicolumn{4}{|c|}{ Baltimore-4A } \\
\hline & & $\begin{array}{c}\text { Fan } \\
\text { Energy }\end{array}$ & $\begin{array}{l}\text { Cooling } \\
\text { Energy }\end{array}$ & $\begin{array}{c}\text { Heating } \\
\text { Energy }\end{array}$ & $\begin{array}{c}\text { Total } \\
\text { HVAC } \\
\text { Energy }\end{array}$ & $\begin{array}{c}\text { Fan } \\
\text { Energy }\end{array}$ & $\begin{array}{l}\text { Cooling } \\
\text { Energy }\end{array}$ & $\begin{array}{c}\text { Heating } \\
\text { Energy }\end{array}$ & $\begin{array}{c}\text { Total } \\
\text { HVAC } \\
\text { Energy }\end{array}$ \\
\hline 1 & NoEcon.SSFan.CS1.DCV0 (Baseline) & 37 & 13 & 42 & 91 & 42 & 33 & 93 & 167 \\
\hline 2 & NIEcon.DB.SSFan.CS1.DCV0 & 37 & 4 & 41 & 82 & 42 & 27 & 93 & 161 \\
\hline 3 & NIEcon.EH.SSFan.CS1.DCV0 & 37 & 4 & 41 & 82 & 42 & 28 & 93 & 162 \\
\hline 4 & IEcon.DB.SSFan.CS1.DCV0 & 37 & 3 & 41 & 82 & 42 & 27 & 93 & 161 \\
\hline 5 & IEcon.EH.SSFan.CS1.DCV0 & 37 & 4 & 41 & 82 & 42 & 28 & 93 & 162 \\
\hline 6 & NoEcon.MSFan.CS1.DCV0 & 8 & 10 & 60 & 77 & 12 & 30 & 115 & 157 \\
\hline 7 & NIEcon.DB.MSFan.CS1.DCV0 & 8 & 4 & 59 & 72 & 14 & 26 & 115 & 154 \\
\hline 8 & NIEcon.EH.MSFan.CS1.DCV0 & 8 & 4 & 59 & 72 & 13 & 27 & 115 & 154 \\
\hline 9 & IEcon.DB.MSFan.CS1.DCV0 & 8 & 4 & 59 & 71 & 14 & 26 & 115 & 154 \\
\hline 10 & IEcon.EH.MSFan.CS1.DCV0 & 8 & 4 & 59 & 72 & 13 & 27 & 115 & 154 \\
\hline 11 & NoEcon.MSFan.CS2.DCV0 & 7 & 8 & 59 & 74 & 11 & 26 & 115 & 152 \\
\hline 12 & IEcon.DB.MSFan.CS2.DCV0 & 8 & 3 & 59 & 70 & 13 & 23 & 115 & 151 \\
\hline 13 & IEcon.EH.MSFan.CS2.DCV0 & 8 & 3 & 59 & 70 & 12 & 23 & 115 & 150 \\
\hline 14 & NoEcon.SSFan.CS1.DCV1 & 37 & 15 & 28 & 81 & 42 & 31 & 64 & 137 \\
\hline 15 & IEcon.DB.SSFan.CS1.DCV1 & 37 & 3 & 28 & 69 & 42 & 24 & 64 & 129 \\
\hline 16 & IEcon.EH.SSFan.CS1.DCV1 & 37 & 4 & 28 & 69 & 42 & 24 & 64 & 130 \\
\hline 17 & NoEcon.MSFan.CS1.DCV1 & 8 & 12 & 41 & 61 & 11 & 27 & 81 & 119 \\
\hline 18 & IEcon.DB.MSFan.CS1.DCV1 & 8 & 4 & 41 & 53 & 12 & 23 & 80 & 116 \\
\hline 19 & IEcon.EH.MSFan.CS1.DCV1 & 8 & 4 & 41 & 53 & 12 & 23 & 80 & 116 \\
\hline 20 & NoEcon.MSFan.CS2.DCV1 & 7 & 10 & 41 & 57 & 10 & 24 & 80 & 115 \\
\hline 21 & IEcon.DB.MSFan.CS2.DCV1 & 8 & 3 & 41 & 52 & 12 & 21 & 80 & 113 \\
\hline 22 & IEcon.EH.MSFan.CS2.DCV1 & 8 & 3 & 41 & 52 & 11 & 21 & 80 & 112 \\
\hline
\end{tabular}


Table B-5: HVAC Energy Uses for the Small Office Building in Climate Zones 4B and 4C

Units: [10 ${ }^{6}$ Btus]

\begin{tabular}{|c|c|c|c|c|c|c|c|c|c|}
\hline \multirow[b]{2}{*}{$\begin{array}{l}\text { Case } \\
\text { No }\end{array}$} & \multirow[b]{2}{*}{ Case Name } & \multicolumn{4}{|c|}{ Albuquerque-4B } & \multicolumn{4}{|c|}{ Seattle-4C } \\
\hline & & $\begin{array}{c}\text { Fan } \\
\text { Energy }\end{array}$ & $\begin{array}{l}\text { Cooling } \\
\text { Energy }\end{array}$ & $\begin{array}{c}\text { Heating } \\
\text { Energy }\end{array}$ & $\begin{array}{c}\text { Total } \\
\text { HVAC } \\
\text { Energy }\end{array}$ & $\begin{array}{c}\text { Fan } \\
\text { Energy }\end{array}$ & $\begin{array}{l}\text { Cooling } \\
\text { Energy }\end{array}$ & $\begin{array}{c}\text { Heating } \\
\text { Energy }\end{array}$ & $\begin{array}{c}\text { Total } \\
\text { HVAC } \\
\text { Energy }\end{array}$ \\
\hline 1 & NoEcon.SSFan.CS1.DCV0 (Baseline) & 44 & 34 & 67 & 145 & 40 & 11 & 77 & 128 \\
\hline 2 & NIEcon.DB.SSFan.CS1.DCV0 & 44 & 27 & 67 & 138 & 40 & 5 & 77 & 121 \\
\hline 3 & NIEcon.EH.SSFan.CS1.DCV0 & 44 & 28 & 67 & 139 & 40 & 5 & 77 & 121 \\
\hline 4 & IEcon.DB.SSFan.CS1.DCV0 & 44 & 27 & 67 & 138 & 40 & 4 & 77 & 121 \\
\hline 5 & IEcon.EH.SSFan.CS1.DCV0 & 44 & 27 & 67 & 139 & 40 & 5 & 77 & 121 \\
\hline 6 & NoEcon.MSFan.CS1.DCV0 & 12 & 31 & 86 & 129 & 9 & 9 & 103 & 121 \\
\hline 7 & NIEcon.DB.MSFan.CS1.DCV0 & 14 & 26 & 85 & 125 & 10 & 5 & 103 & 117 \\
\hline 8 & NIEcon.EH.MSFan.CS1.DCV0 & 13 & 27 & 85 & 125 & 10 & 5 & 103 & 118 \\
\hline 9 & IEcon.DB.MSFan.CS1.DCV0 & 14 & 26 & 85 & 125 & 10 & 4 & 103 & 117 \\
\hline 10 & IEcon.EH.MSFan.CS1.DCV0 & 13 & 27 & 85 & 125 & 10 & 5 & 103 & 117 \\
\hline 11 & NoEcon.MSFan.CS2.DCV0 & 11 & 25 & 85 & 121 & 8 & 7 & 103 & 118 \\
\hline 12 & IEcon.DB.MSFan.CS2.DCV0 & 13 & 22 & 85 & 119 & 9 & 4 & 103 & 116 \\
\hline 13 & IEcon.EH.MSFan.CS2.DCV0 & 13 & 22 & 85 & 119 & 9 & 4 & 103 & 116 \\
\hline 14 & NoEcon.SSFan.CS1.DCV1 & 44 & 33 & 50 & 128 & 40 & 13 & 50 & 103 \\
\hline 15 & IEcon.DB.SSFan.CS1.DCV1 & 44 & 25 & 50 & 120 & 40 & 4 & 49 & 93 \\
\hline 16 & IEcon.EH.SSFan.CS1.DCV1 & 44 & 26 & 50 & 120 & 40 & 5 & 49 & 94 \\
\hline 17 & NoEcon.MSFan.CS1.DCV1 & 12 & 30 & 64 & 105 & 8 & 10 & 69 & 87 \\
\hline 18 & IEcon.DB.MSFan.CS1.DCV1 & 13 & 24 & 63 & 100 & 9 & 4 & 68 & 82 \\
\hline 19 & IEcon.EH.MSFan.CS1.DCV1 & 13 & 25 & 63 & 101 & 9 & 5 & 68 & 82 \\
\hline 20 & NoEcon.MSFan.CS2.DCV1 & 10 & 25 & 63 & 98 & 8 & 8 & 68 & 84 \\
\hline 21 & IEcon.DB.MSFan.CS2.DCV1 & 12 & 20 & 63 & 95 & 9 & 3 & 68 & 81 \\
\hline 22 & IEcon.EH.MSFan.CS2.DCV1 & 12 & 20 & 63 & 95 & 9 & 3 & 68 & 81 \\
\hline
\end{tabular}


Table B-6: HVAC Energy Uses for the Small Office Building in Climate Zones 5A and 5B

\begin{tabular}{|c|c|c|c|c|c|c|c|c|c|}
\hline \multirow[b]{2}{*}{$\begin{array}{l}\text { Case } \\
\text { No }\end{array}$} & \multirow[b]{2}{*}{ Case Name } & \multicolumn{4}{|c|}{ Chicago-5A } & \multicolumn{4}{|c|}{ Denver-5B } \\
\hline & & $\begin{array}{c}\text { Fan } \\
\text { Energy }\end{array}$ & $\begin{array}{l}\text { Cooling } \\
\text { Energy }\end{array}$ & $\begin{array}{l}\text { Heating } \\
\text { Energy }\end{array}$ & $\begin{array}{c}\text { Total } \\
\text { HVAC } \\
\text { Energy }\end{array}$ & $\begin{array}{c}\text { Fan } \\
\text { Energy }\end{array}$ & $\begin{array}{l}\text { Cooling } \\
\text { Energy }\end{array}$ & $\begin{array}{l}\text { Heating } \\
\text { Energy }\end{array}$ & $\begin{array}{c}\text { Total } \\
\text { HVAC } \\
\text { Energy }\end{array}$ \\
\hline 1 & NoEcon.SSFan.CS1.DCV0 (Baseline) & 45 & 26 & 137 & 208 & 47 & 22 & 99 & 168 \\
\hline 2 & NIEcon.DB.SSFan.CS1.DCV0 & 46 & 20 & 136 & 202 & 47 & 16 & 98 & 161 \\
\hline 3 & NIEcon.EH.SSFan.CS1.DCV0 & 45 & 21 & 136 & 203 & 47 & 17 & 98 & 162 \\
\hline 4 & IEcon.DB.SSFan.CS1.DCV0 & 46 & 20 & 136 & 201 & 47 & 16 & 98 & 161 \\
\hline 5 & IEcon.EH.SSFan.CS1.DCV0 & 45 & 21 & 136 & 203 & 47 & 17 & 98 & 162 \\
\hline 6 & NoEcon.MSFan.CS1.DCV0 & 13 & 23 & 166 & 201 & 12 & 18 & 124 & 155 \\
\hline 7 & NIEcon.DB.MSFan.CS1.DCV0 & 14 & 19 & 165 & 199 & 13 & 15 & 124 & 152 \\
\hline 8 & NIEcon.EH.MSFan.CS1.DCV0 & 14 & 20 & 165 & 199 & 13 & 15 & 124 & 152 \\
\hline 9 & IEcon.DB.MSFan.CS1.DCV0 & 14 & 19 & 165 & 199 & 13 & 15 & 124 & 152 \\
\hline 10 & IEcon.EH.MSFan.CS1.DCV0 & 14 & 20 & 165 & 199 & 13 & 15 & 124 & 152 \\
\hline 11 & NoEcon.MSFan.CS2.DCV0 & 12 & 19 & 165 & 197 & 11 & 14 & 124 & 150 \\
\hline 12 & IEcon.DB.MSFan.CS2.DCV0 & 14 & 16 & 165 & 195 & 13 & 12 & 124 & 148 \\
\hline 13 & IEcon.EH.MSFan.CS2.DCV0 & 13 & 17 & 165 & 195 & 13 & 12 & 124 & 148 \\
\hline 14 & NoEcon.SSFan.CS1.DCV1 & 46 & 25 & 97 & 167 & 47 & 23 & 73 & 143 \\
\hline 15 & IEcon.DB.SSFan.CS1.DCV1 & 46 & 18 & 96 & 160 & 47 & 15 & 72 & 134 \\
\hline 16 & IEcon.EH.SSFan.CS1.DCV1 & 46 & 19 & 96 & 161 & 47 & 16 & 72 & 135 \\
\hline 17 & NoEcon.MSFan.CS1.DCV1 & 12 & 22 & 119 & 153 & 11 & 19 & 92 & 122 \\
\hline 18 & IEcon.DB.MSFan.CS1.DCV1 & 13 & 17 & 119 & 149 & 12 & 14 & 91 & 118 \\
\hline 19 & IEcon.EH.MSFan.CS1.DCV1 & 12 & 18 & 119 & 150 & 12 & 15 & 91 & 118 \\
\hline 20 & NoEcon.MSFan.CS2.DCV1 & 11 & 18 & 119 & 148 & 10 & 15 & 92 & 117 \\
\hline 21 & IEcon.DB.MSFan.CS2.DCV1 & 12 & 15 & 119 & 146 & 12 & 11 & 91 & 114 \\
\hline 22 & IEcon.EH.MSFan.CS2.DCV1 & 12 & 15 & 119 & 146 & 12 & 11 & 91 & 114 \\
\hline
\end{tabular}


Table B-7: HVAC Energy Uses for the Small Office Building in Climate Zones 6A and 6B

Units: [10 $10^{6}$ Btus]

\begin{tabular}{|c|c|c|c|c|c|c|c|c|c|}
\hline \multirow[b]{2}{*}{$\begin{array}{l}\text { Case } \\
\text { No }\end{array}$} & \multirow[b]{2}{*}{ Case Name } & \multicolumn{4}{|c|}{ Minneapolis-6A } & \multicolumn{4}{|c|}{ Helena-6B } \\
\hline & & $\begin{array}{c}\text { Fan } \\
\text { Energy }\end{array}$ & $\begin{array}{l}\text { Cooling } \\
\text { Energy }\end{array}$ & $\begin{array}{c}\text { Heating } \\
\text { Energy }\end{array}$ & $\begin{array}{c}\text { Total } \\
\text { HVAC } \\
\text { Energy }\end{array}$ & $\begin{array}{c}\text { Fan } \\
\text { Energy }\end{array}$ & $\begin{array}{l}\text { Cooling } \\
\text { Energy }\end{array}$ & $\begin{array}{c}\text { Heating } \\
\text { Energy }\end{array}$ & $\begin{array}{c}\text { Total } \\
\text { HVAC } \\
\text { Energy }\end{array}$ \\
\hline 1 & NoEcon.SSFan.CS1.DCV0 (Baseline) & 47 & 22 & 175 & 245 & 49 & 15 & 142 & 206 \\
\hline 2 & NIEcon.DB.SSFan.CS1.DCV0 & 47 & 16 & 175 & 238 & 49 & 9 & 142 & 200 \\
\hline 3 & NIEcon.EH.SSFan.CS1.DCV0 & 47 & 17 & 175 & 239 & 49 & 10 & 142 & 201 \\
\hline 4 & IEcon.DB.SSFan.CS1.DCV0 & 47 & 16 & 175 & 238 & 49 & 9 & 142 & 200 \\
\hline 5 & IEcon.EH.SSFan.CS1.DCV0 & 47 & 17 & 175 & 239 & 49 & 10 & 142 & 201 \\
\hline 6 & NoEcon.MSFan.CS1.DCV0 & 14 & 19 & 206 & 240 & 13 & 12 & 176 & 201 \\
\hline 7 & NIEcon.DB.MSFan.CS1.DCV0 & 15 & 15 & 206 & 236 & 14 & 9 & 175 & 198 \\
\hline 8 & NIEcon.EH.MSFan.CS1.DCV0 & 15 & 16 & 206 & 237 & 14 & 9 & 175 & 198 \\
\hline 9 & IEcon.DB.MSFan.CS1.DCV0 & 15 & 15 & 206 & 236 & 14 & 9 & 176 & 198 \\
\hline 10 & IEcon.EH.MSFan.CS1.DCV0 & 15 & 16 & 206 & 237 & 14 & 9 & 176 & 198 \\
\hline 11 & NoEcon.MSFan.CS2.DCV0 & 13 & 16 & 206 & 235 & 12 & 9 & 176 & 197 \\
\hline 12 & IEcon.DB.MSFan.CS2.DCV0 & 15 & 13 & 206 & 234 & 13 & 7 & 175 & 195 \\
\hline 13 & IEcon.EH.MSFan.CS2.DCV0 & 14 & 13 & 206 & 233 & 13 & 7 & 175 & 195 \\
\hline 14 & NoEcon.SSFan.CS1.DCV1 & 47 & 22 & 124 & 193 & 49 & 17 & 103 & 169 \\
\hline 15 & IEcon.DB.SSFan.CS1.DCV1 & 47 & 14 & 124 & 185 & 49 & 9 & 102 & 160 \\
\hline 16 & IEcon.EH.SSFan.CS1.DCV1 & 47 & 15 & 124 & 186 & 49 & 9 & 102 & 161 \\
\hline 17 & NoEcon.MSFan.CS1.DCV1 & 12 & 19 & 149 & 180 & 12 & 13 & 128 & 153 \\
\hline 18 & IEcon.DB.MSFan.CS1.DCV1 & 14 & 14 & 149 & 176 & 12 & 8 & 128 & 148 \\
\hline 19 & IEcon.EH.MSFan.CS1.DCV1 & 13 & 15 & 149 & 176 & 12 & 9 & 128 & 149 \\
\hline 20 & NoEcon.MSFan.CS2.DCV1 & 11 & 16 & 149 & 176 & 11 & 10 & 128 & 149 \\
\hline 21 & IEcon.DB.MSFan.CS2.DCV1 & 13 & 12 & 149 & 174 & 12 & 6 & 128 & 146 \\
\hline 22 & IEcon.EH.MSFan.CS2.DCV1 & 13 & 12 & 149 & 173 & 12 & 6 & 128 & 146 \\
\hline
\end{tabular}


Table B-8: HVAC Energy Uses for the Small Office Building in Climate Zones 7 and 8

Units: [10 $10^{6}$ Btus]

\begin{tabular}{|c|c|c|c|c|c|c|c|c|c|}
\hline \multirow[b]{2}{*}{$\begin{array}{l}\text { Case } \\
\text { No }\end{array}$} & \multirow[b]{2}{*}{ Case Name } & \multicolumn{4}{|c|}{ Duluth-7 } & \multicolumn{4}{|c|}{ Fairbanks-8 } \\
\hline & & $\begin{array}{c}\text { Fan } \\
\text { Energy }\end{array}$ & $\begin{array}{l}\text { Cooling } \\
\text { Energy }\end{array}$ & $\begin{array}{c}\text { Heating } \\
\text { Energy }\end{array}$ & $\begin{array}{c}\text { Total } \\
\text { HVAC } \\
\text { Energy }\end{array}$ & $\begin{array}{c}\text { Fan } \\
\text { Energy }\end{array}$ & $\begin{array}{l}\text { Cooling } \\
\text { Energy }\end{array}$ & $\begin{array}{c}\text { Heating } \\
\text { Energy }\end{array}$ & $\begin{array}{c}\text { Total } \\
\text { HVAC } \\
\text { Energy }\end{array}$ \\
\hline 1 & NoEcon.SSFan.CS1.DCV0 (Baseline) & 48 & 11 & 213 & 272 & 58 & 9 & 383 & 450 \\
\hline 2 & NIEcon.DB.SSFan.CS1.DCV0 & 48 & 5 & 212 & 266 & 58 & 3 & 384 & 444 \\
\hline 3 & NIEcon.EH.SSFan.CS1.DCV0 & 48 & 6 & 212 & 267 & 58 & 3 & 384 & 444 \\
\hline 4 & IEcon.DB.SSFan.CS1.DCV0 & 48 & 5 & 212 & 266 & 58 & 2 & 384 & 444 \\
\hline 5 & IEcon.EH.SSFan.CS1.DCV0 & 48 & 6 & 212 & 267 & 58 & 3 & 384 & 444 \\
\hline 6 & NoEcon.MSFan.CS1.DCV0 & 14 & 9 & 251 & 273 & 19 & 6 & 432 & 458 \\
\hline 7 & NIEcon.DB.MSFan.CS1.DCV0 & 15 & 5 & 250 & 270 & 20 & 3 & 431 & 453 \\
\hline 8 & NIEcon.EH.MSFan.CS1.DCV0 & 14 & 6 & 250 & 271 & 20 & 3 & 431 & 453 \\
\hline 9 & IEcon.DB.MSFan.CS1.DCV0 & 15 & 5 & 250 & 270 & 20 & 2 & 431 & 453 \\
\hline 10 & IEcon.EH.MSFan.CS1.DCV0 & 14 & 6 & 250 & 271 & 20 & 3 & 431 & 453 \\
\hline 11 & NoEcon.MSFan.CS2.DCV0 & 13 & 7 & 250 & 271 & 19 & 5 & 431 & 455 \\
\hline 12 & IEcon.DB.MSFan.CS2.DCV0 & 14 & 4 & 250 & 269 & 20 & 2 & 431 & 452 \\
\hline 13 & IEcon.EH.MSFan.CS2.DCV0 & 14 & 4 & 250 & 269 & 20 & 2 & 431 & 452 \\
\hline 14 & NoEcon.SSFan.CS1.DCV1 & 48 & 13 & 154 & 215 & 58 & 10 & 294 & 362 \\
\hline 15 & IEcon.DB.SSFan.CS1.DCV1 & 48 & 5 & 153 & 207 & 58 & 2 & 297 & 357 \\
\hline 16 & IEcon.EH.SSFan.CS1.DCV1 & 48 & 6 & 153 & 208 & 58 & 3 & 297 & 358 \\
\hline 17 & NoEcon.MSFan.CS1.DCV1 & 12 & 10 & 183 & 205 & 17 & 8 & 335 & 360 \\
\hline 18 & IEcon.DB.MSFan.CS1.DCV1 & 13 & 5 & 182 & 200 & 18 & 2 & 334 & 354 \\
\hline 19 & IEcon.EH.MSFan.CS1.DCV1 & 13 & 6 & 182 & 201 & 17 & 3 & 334 & 354 \\
\hline 20 & NoEcon.MSFan.CS2.DCV1 & 12 & 8 & 183 & 202 & 16 & 6 & 334 & 356 \\
\hline 21 & IEcon.DB.MSFan.CS2.DCV1 & 13 & 4 & 182 & 199 & 17 & 2 & 334 & 353 \\
\hline 22 & IEcon.EH.MSFan.CS2.DCV1 & 13 & 4 & 182 & 199 & 17 & 2 & 334 & 353 \\
\hline
\end{tabular}


Table B-9: HVAC Energy Uses for the Stand-alone Retail Building in Climate Zones 1A and 2A

Units: [10 $10^{6}$ Btus]

\begin{tabular}{|c|c|c|c|c|c|c|c|c|c|}
\hline \multirow[b]{2}{*}{$\begin{array}{c}\text { Case } \\
\text { No }\end{array}$} & \multirow[b]{2}{*}{ Case Name } & \multicolumn{4}{|c|}{ Miami-1A } & \multicolumn{4}{|c|}{ Houston-2A } \\
\hline & & $\begin{array}{c}\text { Fan } \\
\text { Energy }\end{array}$ & $\begin{array}{l}\text { Cooling } \\
\text { Energy }\end{array}$ & $\begin{array}{c}\text { Heating } \\
\text { Energy }\end{array}$ & $\begin{array}{c}\text { Total } \\
\text { HVAC } \\
\text { Energy }\end{array}$ & $\begin{array}{c}\text { Fan } \\
\text { Energy }\end{array}$ & $\begin{array}{l}\text { Cooling } \\
\text { Energy }\end{array}$ & $\begin{array}{c}\text { Heating } \\
\text { Energy }\end{array}$ & $\begin{array}{c}\text { Total } \\
\text { HVAC } \\
\text { Energy }\end{array}$ \\
\hline 1 & NoEcon.SSFan.CS1.DCV0 (Baseline) & 247 & 678 & 24 & 948 & 240 & 478 & 409 & 1127 \\
\hline 2 & NIEcon.DB.SSFan.CS1.DCV0 & 247 & 651 & 23 & 921 & 240 & 456 & 408 & 1105 \\
\hline 3 & NIEcon.EH.SSFan.CS1.DCV0 & 247 & 662 & 23 & 932 & 240 & 464 & 408 & 1112 \\
\hline 4 & IEcon.DB.SSFan.CS1.DCV0 & 247 & 651 & 23 & 921 & 240 & 456 & 408 & 1105 \\
\hline 5 & IEcon.EH.SSFan.CS1.DCV0 & 247 & 661 & 23 & 931 & 240 & 463 & 408 & 1112 \\
\hline 6 & NoEcon.MSFan.CS1.DCV0 & 121 & 650 & 34 & 804 & 101 & 455 & 476 & 1032 \\
\hline 7 & NIEcon.DB.MSFan.CS1.DCV0 & 128 & 633 & 34 & 794 & 106 & 444 & 475 & 1025 \\
\hline 8 & NIEcon.EH.MSFan.CS1.DCV0 & 125 & 641 & 34 & 799 & 104 & 448 & 476 & 1028 \\
\hline 9 & IEcon.DB.MSFan.CS1.DCV0 & 128 & 633 & 34 & 794 & 106 & 444 & 475 & 1025 \\
\hline 10 & IEcon.EH.MSFan.CS1.DCV0 & 125 & 640 & 34 & 798 & 104 & 448 & 476 & 1027 \\
\hline 11 & NoEcon.MSFan.CS2.DCV0 & 104 & 585 & 34 & 722 & 90 & 413 & 476 & 979 \\
\hline 12 & IEcon.DB.MSFan.CS2.DCV0 & 110 & 571 & 34 & 714 & 95 & 404 & 475 & 974 \\
\hline 13 & IEcon.EH.MSFan.CS2.DCV0 & 108 & 575 & 34 & 716 & 94 & 406 & 475 & 975 \\
\hline 14 & NoEcon.SSFan.CS1.DCV1 & 247 & 558 & 10 & 815 & 240 & 386 & 256 & 882 \\
\hline 15 & IEcon.DB.SSFan.CS1.DCV1 & 247 & 539 & 10 & 796 & 240 & 370 & 255 & 866 \\
\hline 16 & IEcon.EH.SSFan.CS1.DCV1 & 247 & 547 & 10 & 804 & 240 & 375 & 255 & 871 \\
\hline 17 & NoEcon.MSFan.CS1.DCV1 & 105 & 536 & 16 & 656 & 85 & 370 & 300 & 755 \\
\hline 18 & IEcon.DB.MSFan.CS1.DCV1 & 111 & 519 & 15 & 646 & 90 & 357 & 300 & 746 \\
\hline 19 & IEcon.EH.MSFan.CS1.DCV1 & 108 & 526 & 15 & 649 & 88 & 361 & 300 & 748 \\
\hline 20 & NoEcon.MSFan.CS2.DCV1 & 87 & 481 & 15 & 584 & 74 & 332 & 300 & 706 \\
\hline 21 & IEcon.DB.MSFan.CS2.DCV1 & 94 & 469 & 15 & 578 & 79 & 322 & 300 & 701 \\
\hline 22 & IEcon.EH.MSFan.CS2.DCV1 & 92 & 471 & 15 & 579 & 78 & 324 & 300 & 701 \\
\hline
\end{tabular}


Table B-10: HVAC Energy Uses for the Stand-alone Retail Building in Climate Zones 2B and 3A

\begin{tabular}{|c|c|c|c|c|c|c|c|c|c|}
\hline \multirow[b]{2}{*}{$\begin{array}{c}\text { Case } \\
\text { No }\end{array}$} & \multirow[b]{2}{*}{ Case Name } & \multicolumn{4}{|c|}{ Phoenix-2B } & \multicolumn{4}{|c|}{ Atlanta-3A } \\
\hline & & $\begin{array}{c}\text { Fan } \\
\text { Energy }\end{array}$ & $\begin{array}{l}\text { Cooling } \\
\text { Energy }\end{array}$ & $\begin{array}{l}\text { Heating } \\
\text { Energy }\end{array}$ & $\begin{array}{c}\text { Total } \\
\text { HVAC } \\
\text { Energy }\end{array}$ & $\begin{array}{c}\text { Fan } \\
\text { Energy }\end{array}$ & $\begin{array}{l}\text { Cooling } \\
\text { Energy }\end{array}$ & $\begin{array}{l}\text { Heating } \\
\text { Energy }\end{array}$ & $\begin{array}{c}\text { Total } \\
\text { HVAC } \\
\text { Energy }\end{array}$ \\
\hline 1 & NoEcon.SSFan.CS1.DCV0 (Baseline) & 244 & 497 & 311 & 1053 & 252 & 259 & 854 & 1365 \\
\hline 2 & NIEcon.DB.SSFan.CS1.DCV0 & 244 & 484 & 311 & 1039 & 252 & 236 & 854 & 1342 \\
\hline 3 & NIEcon.EH.SSFan.CS1.DCV0 & 244 & 482 & 311 & 1037 & 252 & 241 & 854 & 1347 \\
\hline 4 & IEcon.DB.SSFan.CS1.DCV0 & 244 & 483 & 311 & 1038 & 252 & 236 & 854 & 1341 \\
\hline 5 & IEcon.EH.SSFan.CS1.DCV0 & 244 & 482 & 311 & 1037 & 252 & 241 & 854 & 1346 \\
\hline 6 & NoEcon.MSFan.CS1.DCV0 & 93 & 480 & 380 & 953 & 86 & 239 & 977 & 1302 \\
\hline 7 & NIEcon.DB.MSFan.CS1.DCV0 & 96 & 472 & 380 & 948 & 91 & 228 & 977 & 1295 \\
\hline 8 & NIEcon.EH.MSFan.CS1.DCV0 & 97 & 471 & 380 & 947 & 90 & 231 & 977 & 1298 \\
\hline 9 & IEcon.DB.MSFan.CS1.DCV0 & 96 & 472 & 380 & 948 & 91 & 227 & 977 & 1295 \\
\hline 10 & IEcon.EH.MSFan.CS1.DCV0 & 97 & 471 & 380 & 947 & 89 & 230 & 977 & 1297 \\
\hline 11 & NoEcon.MSFan.CS2.DCV0 & 81 & 430 & 380 & 891 & 78 & 208 & 977 & 1263 \\
\hline 12 & IEcon.DB.MSFan.CS2.DCV0 & 85 & 424 & 380 & 889 & 83 & 199 & 977 & 1259 \\
\hline 13 & IEcon.EH.MSFan.CS2.DCV0 & 86 & 423 & 379 & 888 & 82 & 200 & 977 & 1259 \\
\hline 14 & NoEcon.SSFan.CS1.DCV1 & 244 & 408 & 192 & 844 & 252 & 217 & 559 & 1028 \\
\hline 15 & IEcon.DB.SSFan.CS1.DCV1 & 244 & 396 & 191 & 832 & 252 & 201 & 559 & 1012 \\
\hline 16 & IEcon.EH.SSFan.CS1.DCV1 & 244 & 395 & 191 & 830 & 252 & 205 & 559 & 1016 \\
\hline 17 & NoEcon.MSFan.CS1.DCV1 & 79 & 391 & 236 & 705 & 73 & 206 & 644 & 923 \\
\hline 18 & IEcon.DB.MSFan.CS1.DCV1 & 82 & 382 & 235 & 699 & 78 & 193 & 644 & 915 \\
\hline 19 & IEcon.EH.MSFan.CS1.DCV1 & 83 & 380 & 235 & 698 & 77 & 196 & 644 & 916 \\
\hline 20 & NoEcon.MSFan.CS2.DCV1 & 67 & 343 & 235 & 645 & 66 & 181 & 644 & 890 \\
\hline 21 & IEcon.DB.MSFan.CS2.DCV1 & 71 & 337 & 235 & 642 & 71 & 171 & 644 & 885 \\
\hline 22 & IEcon.EH.MSFan.CS2.DCV1 & 72 & 335 & 235 & 642 & 70 & 172 & 644 & 886 \\
\hline
\end{tabular}


Table B-11: HVAC Energy Uses for the Stand-alone Retail Building in Climate Zone 3B

Units: [10 $10^{6}$ Btus]

\begin{tabular}{|c|c|c|c|c|c|c|c|c|c|}
\hline \multirow[b]{2}{*}{$\begin{array}{l}\text { Case } \\
\text { No }\end{array}$} & \multirow[b]{2}{*}{ Case Name } & \multicolumn{4}{|c|}{ Los Angeles-3B } & \multicolumn{4}{|c|}{ Las Vegas-3B } \\
\hline & & $\begin{array}{c}\text { Fan } \\
\text { Energy }\end{array}$ & $\begin{array}{l}\text { Cooling } \\
\text { Energy }\end{array}$ & $\begin{array}{c}\text { Heating } \\
\text { Energy }\end{array}$ & $\begin{array}{c}\text { Total } \\
\text { HVAC } \\
\text { Energy }\end{array}$ & $\begin{array}{c}\text { Fan } \\
\text { Energy }\end{array}$ & $\begin{array}{l}\text { Cooling } \\
\text { Energy }\end{array}$ & $\begin{array}{c}\text { Heating } \\
\text { Energy }\end{array}$ & $\begin{array}{c}\text { Total } \\
\text { HVAC } \\
\text { Energy }\end{array}$ \\
\hline 1 & NoEcon.SSFan.CS1.DCV0 (Baseline) & 224 & 131 & 281 & 637 & 223 & 332 & 551 & 1106 \\
\hline 2 & NIEcon.DB.SSFan.CS1.DCV0 & 224 & 77 & 281 & 581 & 223 & 322 & 550 & 1095 \\
\hline 3 & NIEcon.EH.SSFan.CS1.DCV0 & 224 & 85 & 281 & 590 & 223 & 321 & 550 & 1094 \\
\hline 4 & IEcon.DB.SSFan.CS1.DCV0 & 224 & 74 & 281 & 579 & 223 & 322 & 550 & 1095 \\
\hline 5 & IEcon.EH.SSFan.CS1.DCV0 & 224 & 83 & 281 & 588 & 223 & 321 & 550 & 1094 \\
\hline 6 & NoEcon.MSFan.CS1.DCV0 & 53 & 112 & 365 & 530 & 79 & 318 & 642 & 1039 \\
\hline 7 & NIEcon.DB.MSFan.CS1.DCV0 & 62 & 77 & 365 & 504 & 81 & 313 & 641 & 1035 \\
\hline 8 & NIEcon.EH.MSFan.CS1.DCV0 & 61 & 84 & 365 & 510 & 81 & 312 & 641 & 1035 \\
\hline 9 & IEcon.DB.MSFan.CS1.DCV0 & 61 & 75 & 365 & 501 & 81 & 313 & 642 & 1035 \\
\hline 10 & IEcon.EH.MSFan.CS1.DCV0 & 61 & 82 & 365 & 507 & 81 & 312 & 641 & 1035 \\
\hline 11 & NoEcon.MSFan.CS2.DCV0 & 47 & 95 & 365 & 507 & 71 & 291 & 642 & 1004 \\
\hline 12 & IEcon.DB.MSFan.CS2.DCV0 & 57 & 67 & 364 & 488 & 74 & 287 & 641 & 1002 \\
\hline 13 & IEcon.EH.MSFan.CS2.DCV0 & 57 & 69 & 364 & 490 & 75 & 286 & 641 & 1002 \\
\hline 14 & NoEcon.SSFan.CS1.DCV1 & 224 & 113 & 165 & 503 & 223 & 272 & 356 & 851 \\
\hline 15 & IEcon.DB.SSFan.CS1.DCV1 & 224 & 71 & 165 & 460 & 223 & 262 & 356 & 840 \\
\hline 16 & IEcon.EH.SSFan.CS1.DCV1 & 224 & 79 & 165 & 467 & 223 & 261 & 356 & 840 \\
\hline 17 & NoEcon.MSFan.CS1.DCV1 & 50 & 117 & 216 & 382 & 66 & 258 & 418 & 742 \\
\hline 18 & IEcon.DB.MSFan.CS1.DCV1 & 58 & 74 & 215 & 347 & 68 & 250 & 417 & 736 \\
\hline 19 & IEcon.EH.MSFan.CS1.DCV1 & 57 & 81 & 215 & 353 & 69 & 250 & 417 & 736 \\
\hline 20 & NoEcon.MSFan.CS2.DCV1 & 44 & 98 & 215 & 357 & 59 & 233 & 417 & 709 \\
\hline 21 & IEcon.DB.MSFan.CS2.DCV1 & 54 & 65 & 215 & 334 & 62 & 227 & 417 & 706 \\
\hline 22 & IEcon.EH.MSFan.CS2.DCV1 & 53 & 68 & 215 & 336 & 63 & 226 & 417 & 706 \\
\hline
\end{tabular}


Table B-12: HVAC Energy Uses for the Stand-alone Retail Building in Climate Zones 3C and 4A

Units: [10 $10^{6}$ Btus]

\begin{tabular}{|c|c|c|c|c|c|c|c|c|c|}
\hline \multirow[b]{2}{*}{$\begin{array}{c}\text { Case } \\
\text { No }\end{array}$} & \multirow[b]{2}{*}{ Case Name } & \multicolumn{4}{|c|}{ San Francisco-3C } & \multicolumn{4}{|c|}{ Baltimore-4A } \\
\hline & & $\begin{array}{c}\text { Fan } \\
\text { Energy }\end{array}$ & $\begin{array}{l}\text { Cooling } \\
\text { Energy }\end{array}$ & $\begin{array}{l}\text { Heating } \\
\text { Energy }\end{array}$ & $\begin{array}{c}\text { Total } \\
\text { HVAC } \\
\text { Energy }\end{array}$ & $\begin{array}{c}\text { Fan } \\
\text { Energy }\end{array}$ & $\begin{array}{l}\text { Cooling } \\
\text { Energy }\end{array}$ & $\begin{array}{l}\text { Heating } \\
\text { Energy }\end{array}$ & $\begin{array}{c}\text { Total } \\
\text { HVAC } \\
\text { Energy }\end{array}$ \\
\hline 1 & NoEcon.SSFan.CS1.DCV0 (Baseline) & 187 & 33 & 781 & 1002 & 236 & 184 & 1385 & 1804 \\
\hline 2 & NIEcon.DB.SSFan.CS1.DCV0 & 187 & 18 & 781 & 985 & 236 & 169 & 1384 & 1789 \\
\hline 3 & NIEcon.EH.SSFan.CS1.DCV0 & 187 & 18 & 781 & 985 & 236 & 172 & 1384 & 1792 \\
\hline 4 & IEcon.DB.SSFan.CS1.DCV0 & 187 & 17 & 781 & 985 & 236 & 169 & 1384 & 1789 \\
\hline 5 & IEcon.EH.SSFan.CS1.DCV0 & 187 & 17 & 781 & 985 & 236 & 172 & 1384 & 1792 \\
\hline 6 & NoEcon.MSFan.CS1.DCV0 & 46 & 27 & 874 & 947 & 84 & 169 & 1532 & 1785 \\
\hline 7 & NIEcon.DB.MSFan.CS1.DCV0 & 49 & 18 & 873 & 941 & 87 & 161 & 1532 & 1781 \\
\hline 8 & NIEcon.EH.MSFan.CS1.DCV0 & 49 & 18 & 873 & 941 & 87 & 163 & 1532 & 1782 \\
\hline 9 & IEcon.DB.MSFan.CS1.DCV0 & 49 & 17 & 873 & 940 & 87 & 161 & 1532 & 1781 \\
\hline 10 & IEcon.EH.MSFan.CS1.DCV0 & 49 & 17 & 873 & 940 & 86 & 163 & 1532 & 1782 \\
\hline 11 & NoEcon.MSFan.CS2.DCV0 & 45 & 22 & 874 & 940 & 79 & 149 & 1532 & 1760 \\
\hline 12 & IEcon.DB.MSFan.CS2.DCV0 & 48 & 14 & 873 & 936 & 82 & 143 & 1532 & 1757 \\
\hline 13 & IEcon.EH.MSFan.CS2.DCV0 & 48 & 14 & 873 & 936 & 82 & 143 & 1532 & 1757 \\
\hline 14 & NoEcon.SSFan.CS1.DCV1 & 187 & 31 & 466 & 684 & 235 & 152 & 896 & 1284 \\
\hline 15 & IEcon.DB.SSFan.CS1.DCV1 & 187 & 16 & 465 & 668 & 235 & 141 & 896 & 1273 \\
\hline 16 & IEcon.EH.SSFan.CS1.DCV1 & 187 & 16 & 465 & 668 & 235 & 143 & 896 & 1275 \\
\hline 17 & NoEcon.MSFan.CS1.DCV1 & 39 & 31 & 553 & 624 & 69 & 142 & 1000 & 1211 \\
\hline 18 & IEcon.DB.MSFan.CS1.DCV1 & 42 & 17 & 553 & 612 & 72 & 134 & 1000 & 1206 \\
\hline 19 & IEcon.EH.MSFan.CS1.DCV1 & 42 & 17 & 553 & 612 & 71 & 135 & 1000 & 1207 \\
\hline 20 & NoEcon.MSFan.CS2.DCV1 & 37 & 26 & 553 & 616 & 64 & 125 & 1000 & 1189 \\
\hline 21 & IEcon.DB.MSFan.CS2.DCV1 & 41 & 14 & 553 & 608 & 67 & 119 & 1000 & 1186 \\
\hline 22 & IEcon.EH.MSFan.CS2.DCV1 & 42 & 14 & 553 & 608 & 67 & 119 & 1000 & 1186 \\
\hline
\end{tabular}


Table B-13: HVAC Energy Uses for the Stand-alone Retail Building in Climate Zones 4B and 4C

Units: [10 $10^{6}$ Btus]

\begin{tabular}{|c|c|c|c|c|c|c|c|c|c|}
\hline \multirow[b]{2}{*}{$\begin{array}{l}\text { Case } \\
\text { No }\end{array}$} & \multirow[b]{2}{*}{ Case Name } & \multicolumn{4}{|c|}{ Albuquerque-4B } & \multicolumn{4}{|c|}{ Seattle-4C } \\
\hline & & $\begin{array}{c}\text { Fan } \\
\text { Energy }\end{array}$ & $\begin{array}{l}\text { Cooling } \\
\text { Energy }\end{array}$ & $\begin{array}{l}\text { Heating } \\
\text { Energy }\end{array}$ & $\begin{array}{c}\text { Total } \\
\text { HVAC } \\
\text { Energy }\end{array}$ & $\begin{array}{c}\text { Fan } \\
\text { Energy }\end{array}$ & $\begin{array}{l}\text { Cooling } \\
\text { Energy }\end{array}$ & $\begin{array}{l}\text { Heating } \\
\text { Energy }\end{array}$ & $\begin{array}{c}\text { Total } \\
\text { HVAC } \\
\text { Energy }\end{array}$ \\
\hline 1 & NoEcon.SSFan.CS1.DCV0 (Baseline) & 242 & 165 & 1020 & 1426 & 196 & 36 & 1274 & 1506 \\
\hline 2 & NIEcon.DB.SSFan.CS1.DCV0 & 242 & 151 & 1019 & 1412 & 196 & 25 & 1274 & 1495 \\
\hline 3 & NIEcon.EH.SSFan.CS1.DCV0 & 242 & 152 & 1019 & 1412 & 196 & 25 & 1274 & 1495 \\
\hline 4 & IEcon.DB.SSFan.CS1.DCV0 & 242 & 151 & 1019 & 1411 & 196 & 25 & 1274 & 1495 \\
\hline 5 & IEcon.EH.SSFan.CS1.DCV0 & 242 & 151 & 1019 & 1412 & 196 & 25 & 1274 & 1495 \\
\hline 6 & NoEcon.MSFan.CS1.DCV0 & 79 & 149 & 1153 & 1382 & 58 & 30 & 1393 & 1481 \\
\hline 7 & NIEcon.DB.MSFan.CS1.DCV0 & 82 & 142 & 1152 & 1377 & 60 & 24 & 1393 & 1477 \\
\hline 8 & NIEcon.EH.MSFan.CS1.DCV0 & 82 & 143 & 1152 & 1377 & 60 & 24 & 1393 & 1477 \\
\hline 9 & IEcon.DB.MSFan.CS1.DCV0 & 82 & 142 & 1152 & 1376 & 60 & 23 & 1393 & 1477 \\
\hline 10 & IEcon.EH.MSFan.CS1.DCV0 & 82 & 142 & 1152 & 1377 & 60 & 24 & 1393 & 1477 \\
\hline 11 & NoEcon.MSFan.CS2.DCV0 & 73 & 125 & 1152 & 1350 & 56 & 24 & 1393 & 1473 \\
\hline 12 & IEcon.DB.MSFan.CS2.DCV0 & 77 & 119 & 1152 & 1348 & 59 & 19 & 1393 & 1471 \\
\hline 13 & IEcon.EH.MSFan.CS2.DCV0 & 77 & 118 & 1152 & 1347 & 59 & 19 & 1393 & 1471 \\
\hline 14 & NoEcon.SSFan.CS1.DCV1 & 241 & 146 & 677 & 1064 & 196 & 33 & 739 & 968 \\
\hline 15 & IEcon.DB.SSFan.CS1.DCV1 & 241 & 134 & 676 & 1051 & 196 & 23 & 739 & 958 \\
\hline 16 & IEcon.EH.SSFan.CS1.DCV1 & 241 & 135 & 676 & 1052 & 196 & 23 & 739 & 958 \\
\hline 17 & NoEcon.MSFan.CS1.DCV1 & 67 & 134 & 771 & 972 & 46 & 31 & 859 & 936 \\
\hline 18 & IEcon.DB.MSFan.CS1.DCV1 & 70 & 125 & 770 & 965 & 49 & 22 & 858 & 929 \\
\hline 19 & IEcon.EH.MSFan.CS1.DCV1 & 70 & 125 & 770 & 965 & 49 & 23 & 858 & 930 \\
\hline 20 & NoEcon.MSFan.CS2.DCV1 & 61 & 112 & 770 & 943 & 45 & 26 & 858 & 929 \\
\hline 21 & IEcon.DB.MSFan.CS2.DCV1 & 65 & 105 & 770 & 940 & 48 & 18 & 858 & 924 \\
\hline 22 & IEcon.EH.MSFan.CS2.DCV1 & 66 & 104 & 769 & 939 & 48 & 18 & 858 & 924 \\
\hline
\end{tabular}


Table B-14: HVAC Energy Uses for the Stand-alone Retail Building in Climate Zones 5A and 5B

\begin{tabular}{|c|c|c|c|c|c|c|c|c|c|}
\hline \multirow[b]{2}{*}{$\begin{array}{c}\text { Case } \\
\text { No }\end{array}$} & \multirow[b]{2}{*}{ Case Name } & \multicolumn{4}{|c|}{ Chicago-5A } & \multicolumn{4}{|c|}{ Denver-5B } \\
\hline & & $\begin{array}{c}\text { Fan } \\
\text { Energy }\end{array}$ & $\begin{array}{l}\text { Cooling } \\
\text { Energy }\end{array}$ & $\begin{array}{l}\text { Heating } \\
\text { Energy }\end{array}$ & $\begin{array}{l}\text { Total } \\
\text { HVAC } \\
\text { Energy }\end{array}$ & $\begin{array}{c}\text { Fan } \\
\text { Energy }\end{array}$ & $\begin{array}{l}\text { Cooling } \\
\text { Energy }\end{array}$ & $\begin{array}{l}\text { Heating } \\
\text { Energy }\end{array}$ & $\begin{array}{c}\text { Total } \\
\text { HVAC } \\
\text { Energy }\end{array}$ \\
\hline 1 & NoEcon.SSFan.CS1.DCV0 (Baseline) & 278 & 136 & 1913 & 2327 & 279 & 106 & 1466 & 1851 \\
\hline 2 & NIEcon.DB.SSFan.CS1.DCV0 & 278 & 118 & 1911 & 2308 & 279 & 92 & 1464 & 1836 \\
\hline 3 & NIEcon.EH.SSFan.CS1.DCV0 & 278 & 122 & 1911 & 2312 & 279 & 93 & 1464 & 1836 \\
\hline 4 & IEcon.DB.SSFan.CS1.DCV0 & 278 & 118 & 1911 & 2308 & 279 & 92 & 1464 & 1835 \\
\hline 5 & IEcon.EH.SSFan.CS1.DCV0 & 278 & 122 & 1911 & 2312 & 279 & 93 & 1464 & 1836 \\
\hline 6 & NoEcon.MSFan.CS1.DCV0 & 94 & 119 & 2118 & 2331 & 87 & 90 & 1663 & 1839 \\
\hline 7 & NIEcon.DB.MSFan.CS1.DCV0 & 98 & 111 & 2117 & 2326 & 90 & 84 & 1662 & 1836 \\
\hline 8 & NIEcon.EH.MSFan.CS1.DCV0 & 97 & 113 & 2117 & 2327 & 90 & 84 & 1662 & 1836 \\
\hline 9 & IEcon.DB.MSFan.CS1.DCV0 & 98 & 110 & 2117 & 2325 & 90 & 83 & 1662 & 1835 \\
\hline 10 & IEcon.EH.MSFan.CS1.DCV0 & 97 & 113 & 2117 & 2326 & 90 & 83 & 1662 & 1836 \\
\hline 11 & NoEcon.MSFan.CS2.DCV0 & 89 & 99 & 2117 & 2305 & 83 & 73 & 1662 & 1818 \\
\hline 12 & IEcon.DB.MSFan.CS2.DCV0 & 93 & 93 & 2117 & 2303 & 87 & 68 & 1661 & 1816 \\
\hline 13 & IEcon.EH.MSFan.CS2.DCV0 & 93 & 93 & 2117 & 2303 & 87 & 67 & 1661 & 1816 \\
\hline 14 & NoEcon.SSFan.CS1.DCV1 & 278 & 115 & 1297 & 1690 & 279 & 94 & 998 & 1371 \\
\hline 15 & IEcon.DB.SSFan.CS1.DCV1 & 278 & 102 & 1299 & 1679 & 279 & 82 & 996 & 1357 \\
\hline 16 & IEcon.EH.SSFan.CS1.DCV1 & 278 & 105 & 1299 & 1682 & 279 & 83 & 996 & 1358 \\
\hline 17 & NoEcon.MSFan.CS1.DCV1 & 78 & 104 & 1439 & 1621 & 73 & 81 & 1140 & 1294 \\
\hline 18 & IEcon.DB.MSFan.CS1.DCV1 & 81 & 94 & 1434 & 1610 & 76 & 73 & 1138 & 1287 \\
\hline 19 & IEcon.EH.MSFan.CS1.DCV1 & 80 & 96 & 1434 & 1611 & 76 & 73 & 1138 & 1288 \\
\hline 20 & NoEcon.MSFan.CS2.DCV1 & 73 & 87 & 1436 & 1597 & 69 & 65 & 1138 & 1272 \\
\hline 21 & IEcon.DB.MSFan.CS2.DCV1 & 77 & 80 & 1434 & 1591 & 73 & 59 & 1138 & 1269 \\
\hline 22 & IEcon.EH.MSFan.CS2.DCV1 & 77 & 80 & 1434 & 1591 & 74 & 58 & 1138 & 1270 \\
\hline
\end{tabular}


Table B-15: HVAC Energy Uses for the Stand-alone Retail Building in Climate Zones 6A and 6B

\begin{tabular}{|c|c|c|c|c|c|c|c|c|c|}
\hline \multirow[b]{2}{*}{$\begin{array}{l}\text { Case } \\
\text { No }\end{array}$} & \multirow[b]{2}{*}{ Case Name } & \multicolumn{4}{|c|}{ Minneapolis-6A } & \multicolumn{4}{|c|}{ Helena-6B } \\
\hline & & $\begin{array}{c}\text { Fan } \\
\text { Energy }\end{array}$ & $\begin{array}{l}\text { Cooling } \\
\text { Energy }\end{array}$ & $\begin{array}{l}\text { Heating } \\
\text { Energy }\end{array}$ & $\begin{array}{l}\text { Total } \\
\text { HVAC } \\
\text { Energy }\end{array}$ & $\begin{array}{c}\text { Fan } \\
\text { Energy }\end{array}$ & $\begin{array}{l}\text { Cooling } \\
\text { Energy }\end{array}$ & $\begin{array}{l}\text { Heating } \\
\text { Energy }\end{array}$ & $\begin{array}{c}\text { Total } \\
\text { HVAC } \\
\text { Energy }\end{array}$ \\
\hline 1 & NoEcon.SSFan.CS1.DCV0 (Baseline) & 316 & 117 & 2424 & 2857 & 336 & 71 & 2099 & 2506 \\
\hline 2 & NIEcon.DB.SSFan.CS1.DCV0 & 316 & 98 & 2421 & 2834 & 336 & 56 & 2096 & 2488 \\
\hline 3 & NIEcon.EH.SSFan.CS1.DCV0 & 316 & 101 & 2421 & 2837 & 336 & 56 & 2096 & 2488 \\
\hline 4 & IEcon.DB.SSFan.CS1.DCV0 & 316 & 97 & 2421 & 2834 & 336 & 55 & 2096 & 2487 \\
\hline 5 & IEcon.EH.SSFan.CS1.DCV0 & 316 & 100 & 2421 & 2837 & 336 & 56 & 2096 & 2487 \\
\hline 6 & NoEcon.MSFan.CS1.DCV0 & 108 & 99 & 2672 & 2879 & 105 & 57 & 2395 & 2556 \\
\hline 7 & NIEcon.DB.MSFan.CS1.DCV0 & 111 & 89 & 2664 & 2865 & 107 & 50 & 2387 & 2543 \\
\hline 8 & NIEcon.EH.MSFan.CS1.DCV0 & 111 & 91 & 2664 & 2866 & 107 & 49 & 2387 & 2543 \\
\hline 9 & IEcon.DB.MSFan.CS1.DCV0 & 111 & 89 & 2664 & 2864 & 107 & 49 & 2387 & 2543 \\
\hline 10 & IEcon.EH.MSFan.CS1.DCV0 & 111 & 91 & 2664 & 2866 & 107 & 49 & 2387 & 2543 \\
\hline 11 & NoEcon.MSFan.CS2.DCV0 & 103 & 81 & 2667 & 2851 & 101 & 43 & 2392 & 2537 \\
\hline 12 & IEcon.DB.MSFan.CS2.DCV0 & 107 & 74 & 2664 & 2845 & 105 & 39 & 2386 & 2529 \\
\hline 13 & IEcon.EH.MSFan.CS2.DCV0 & 107 & 74 & 2664 & 2845 & 105 & 38 & 2386 & 2529 \\
\hline 14 & NoEcon.SSFan.CS1.DCV1 & 316 & 98 & 1697 & 2111 & 336 & 62 & 1448 & 1845 \\
\hline 15 & IEcon.DB.SSFan.CS1.DCV1 & 316 & 84 & 1697 & 2096 & 336 & 50 & 1452 & 1837 \\
\hline 16 & IEcon.EH.SSFan.CS1.DCV1 & 316 & 86 & 1697 & 2099 & 336 & 50 & 1452 & 1838 \\
\hline 17 & NoEcon.MSFan.CS1.DCV1 & 89 & 87 & 1857 & 2033 & 87 & 52 & 1661 & 1800 \\
\hline 18 & IEcon.DB.MSFan.CS1.DCV1 & 92 & 76 & 1846 & 2014 & 88 & 43 & 1647 & 1778 \\
\hline 19 & IEcon.EH.MSFan.CS1.DCV1 & 92 & 77 & 1846 & 2015 & 88 & 43 & 1647 & 1778 \\
\hline 20 & NoEcon.MSFan.CS2.DCV1 & 85 & 71 & 1848 & 2004 & 83 & 39 & 1652 & 1775 \\
\hline 21 & IEcon.DB.MSFan.CS2.DCV1 & 89 & 63 & 1846 & 1998 & 86 & 33 & 1646 & 1766 \\
\hline 22 & IEcon.EH.MSFan.CS2.DCV1 & 89 & 63 & 1846 & 1998 & 87 & 33 & 1646 & 1766 \\
\hline
\end{tabular}


Table B-16: HVAC Energy Uses for the Stand-alone Retail Building in Climate Zones 7 and 8

\begin{tabular}{|c|c|c|c|c|c|c|c|c|c|}
\hline \multirow[b]{2}{*}{$\begin{array}{l}\text { Case } \\
\text { No }\end{array}$} & \multirow[b]{2}{*}{ Case Name } & \multicolumn{4}{|c|}{ Duluth-7 } & \multicolumn{4}{|c|}{ Fairbanks-8 } \\
\hline & & $\begin{array}{c}\text { Fan } \\
\text { Energy }\end{array}$ & $\begin{array}{l}\text { Cooling } \\
\text { Energy }\end{array}$ & $\begin{array}{l}\text { Heating } \\
\text { Energy }\end{array}$ & $\begin{array}{c}\text { Total } \\
\text { HVAC } \\
\text { Energy }\end{array}$ & $\begin{array}{c}\text { Fan } \\
\text { Energy }\end{array}$ & $\begin{array}{l}\text { Cooling } \\
\text { Energy }\end{array}$ & $\begin{array}{l}\text { Heating } \\
\text { Energy }\end{array}$ & $\begin{array}{c}\text { Total } \\
\text { HVAC } \\
\text { Energy }\end{array}$ \\
\hline 1 & NoEcon.SSFan.CS1.DCV0 (Baseline) & 341 & 44 & 3033 & 3418 & 465 & 49 & 5095 & 5609 \\
\hline 2 & NIEcon.DB.SSFan.CS1.DCV0 & 341 & 29 & 3031 & 3401 & 465 & 10 & 5017 & 5492 \\
\hline 3 & NIEcon.EH.SSFan.CS1.DCV0 & 341 & 30 & 3031 & 3402 & 465 & 11 & 5017 & 5492 \\
\hline 4 & IEcon.DB.SSFan.CS1.DCV0 & 341 & 28 & 3031 & 3401 & 465 & 10 & 5017 & 5492 \\
\hline 5 & IEcon.EH.SSFan.CS1.DCV0 & 341 & 30 & 3031 & 3402 & 465 & 11 & 5017 & 5492 \\
\hline 6 & NoEcon.MSFan.CS1.DCV0 & 118 & 33 & 3368 & 3519 & 184 & 40 & 5606 & 5830 \\
\hline 7 & NIEcon.DB.MSFan.CS1.DCV0 & 120 & 25 & 3353 & 3498 & 179 & 8 & 5485 & 5672 \\
\hline 8 & NIEcon.EH.MSFan.CS1.DCV0 & 120 & 25 & 3353 & 3498 & 179 & 8 & 5485 & 5672 \\
\hline 9 & IEcon.DB.MSFan.CS1.DCV0 & 120 & 25 & 3353 & 3498 & 179 & 8 & 5485 & 5672 \\
\hline 10 & IEcon.EH.MSFan.CS1.DCV0 & 120 & 25 & 3353 & 3498 & 179 & 8 & 5485 & 5672 \\
\hline 11 & NoEcon.MSFan.CS2.DCV0 & 116 & 25 & 3360 & 3501 & 176 & 20 & 5500 & 5696 \\
\hline 12 & IEcon.DB.MSFan.CS2.DCV0 & 119 & 20 & 3353 & 3491 & 179 & 5 & 5484 & 5668 \\
\hline 13 & IEcon.EH.MSFan.CS2.DCV0 & 119 & 19 & 3353 & 3491 & 179 & 5 & 5484 & 5668 \\
\hline 14 & NoEcon.SSFan.CS1.DCV1 & 341 & 38 & 2124 & 2502 & 465 & 30 & 3756 & 4251 \\
\hline 15 & IEcon.DB.SSFan.CS1.DCV1 & 341 & 25 & 2121 & 2487 & 465 & 10 & 3754 & 4228 \\
\hline 16 & IEcon.EH.SSFan.CS1.DCV1 & 341 & 26 & 2121 & 2488 & 465 & 10 & 3754 & 4228 \\
\hline 17 & NoEcon.MSFan.CS1.DCV1 & 96 & 31 & 2345 & 2473 & 156 & 39 & 4228 & 4422 \\
\hline 18 & IEcon.DB.MSFan.CS1.DCV1 & 97 & 21 & 2326 & 2445 & 149 & 7 & 4068 & 4224 \\
\hline 19 & IEcon.EH.MSFan.CS1.DCV1 & 97 & 22 & 2326 & 2446 & 149 & 7 & 4068 & 4224 \\
\hline 20 & NoEcon.MSFan.CS2.DCV1 & 94 & 24 & 2329 & 2447 & 146 & 19 & 4074 & 4240 \\
\hline 21 & IEcon.DB.MSFan.CS2.DCV1 & 97 & 17 & 2326 & 2440 & 149 & 5 & 4066 & 4220 \\
\hline 22 & IEcon.EH.MSFan.CS2.DCV1 & 97 & 17 & 2326 & 2440 & 149 & 5 & 4066 & 4220 \\
\hline
\end{tabular}


Table B-17: HVAC Energy Uses for the Strip Mall Building in Climate Zones 1A and 2A

Units: [10 $10^{6}$ Btus]

\begin{tabular}{|c|c|c|c|c|c|c|c|c|c|}
\hline \multirow[b]{2}{*}{$\begin{array}{c}\text { Case } \\
\text { No }\end{array}$} & \multirow[b]{2}{*}{ Case Name } & \multicolumn{4}{|c|}{ Miami-1A } & \multicolumn{4}{|c|}{ Houston-2A } \\
\hline & & $\begin{array}{c}\text { Fan } \\
\text { Energy }\end{array}$ & $\begin{array}{l}\text { Cooling } \\
\text { Energy }\end{array}$ & $\begin{array}{l}\text { Heating } \\
\text { Energy }\end{array}$ & $\begin{array}{c}\text { Total } \\
\text { HVAC } \\
\text { Energy }\end{array}$ & $\begin{array}{c}\text { Fan } \\
\text { Energy }\end{array}$ & $\begin{array}{l}\text { Cooling } \\
\text { Energy }\end{array}$ & $\begin{array}{c}\text { Heating } \\
\text { Energy }\end{array}$ & $\begin{array}{c}\text { Total } \\
\text { HVAC } \\
\text { Energy }\end{array}$ \\
\hline 1 & NoEcon.SSFan.CS1.DCV0 (Baseline) & 297 & 730 & 40 & 1068 & 251 & 468 & 399 & 1118 \\
\hline 2 & NIEcon.DB.SSFan.CS1.DCV0 & 297 & 693 & 38 & 1029 & 251 & 442 & 398 & 1091 \\
\hline 3 & NIEcon.EH.SSFan.CS1.DCV0 & 297 & 709 & 38 & 1045 & 251 & 450 & 398 & 1099 \\
\hline 4 & IEcon.DB.SSFan.CS1.DCV0 & 297 & 692 & 38 & 1027 & 251 & 441 & 398 & 1091 \\
\hline 5 & IEcon.EH.SSFan.CS1.DCV0 & 297 & 709 & 38 & 1044 & 251 & 449 & 398 & 1099 \\
\hline 6 & NoEcon.MSFan.CS1.DCV0 & 143 & 706 & 55 & 904 & 105 & 447 & 469 & 1022 \\
\hline 7 & NIEcon.DB.MSFan.CS1.DCV0 & 151 & 681 & 53 & 885 & 111 & 432 & 469 & 1012 \\
\hline 8 & NIEcon.EH.MSFan.CS1.DCV0 & 147 & 693 & 54 & 894 & 109 & 438 & 469 & 1015 \\
\hline 9 & IEcon.DB.MSFan.CS1.DCV0 & 150 & 680 & 53 & 884 & 111 & 432 & 469 & 1011 \\
\hline 10 & IEcon.EH.MSFan.CS1.DCV0 & 146 & 693 & 54 & 893 & 109 & 437 & 469 & 1015 \\
\hline 11 & NoEcon.MSFan.CS2.DCV0 & 121 & 629 & 54 & 804 & 93 & 403 & 469 & 965 \\
\hline 12 & IEcon.DB.MSFan.CS2.DCV0 & 129 & 611 & 53 & 794 & 99 & 391 & 468 & 959 \\
\hline 13 & IEcon.EH.MSFan.CS2.DCV0 & 127 & 616 & 53 & 796 & 98 & 393 & 469 & 960 \\
\hline 14 & NoEcon.SSFan.CS1.DCV1 & 297 & 603 & 24 & 924 & 251 & 371 & 253 & 875 \\
\hline 15 & IEcon.DB.SSFan.CS1.DCV1 & 297 & 577 & 24 & 898 & 251 & 358 & 252 & 861 \\
\hline 16 & IEcon.EH.SSFan.CS1.DCV1 & 297 & 593 & 24 & 914 & 251 & 364 & 252 & 867 \\
\hline 17 & NoEcon.MSFan.CS1.DCV1 & 124 & 589 & 33 & 746 & 88 & 362 & 294 & 744 \\
\hline 18 & IEcon.DB.MSFan.CS1.DCV1 & 132 & 564 & 32 & 728 & 94 & 347 & 293 & 734 \\
\hline 19 & IEcon.EH.MSFan.CS1.DCV1 & 128 & 578 & 32 & 738 & 92 & 353 & 293 & 738 \\
\hline 20 & NoEcon.MSFan.CS2.DCV1 & 103 & 521 & 32 & 656 & 76 & 323 & 294 & 693 \\
\hline 21 & IEcon.DB.MSFan.CS2.DCV1 & 111 & 506 & 32 & 649 & 82 & 313 & 293 & 688 \\
\hline 22 & IEcon.EH.MSFan.CS2.DCV1 & 109 & 511 & 32 & 652 & 81 & 316 & 293 & 689 \\
\hline
\end{tabular}


Table B-18: HVAC Energy Uses for the Strip Mall Building in Climate Zones 2B and 3A

\begin{tabular}{|c|c|c|c|c|c|c|c|c|c|}
\hline \multirow[b]{2}{*}{$\begin{array}{l}\text { Case } \\
\text { No }\end{array}$} & \multirow[b]{2}{*}{ Case Name } & \multicolumn{4}{|c|}{ Phoenix-2B } & \multicolumn{4}{|c|}{ Atlanta-3A } \\
\hline & & $\begin{array}{c}\text { Fan } \\
\text { Energy }\end{array}$ & $\begin{array}{l}\text { Cooling } \\
\text { Energy }\end{array}$ & $\begin{array}{l}\text { Heating } \\
\text { Energy }\end{array}$ & $\begin{array}{c}\text { Total } \\
\text { HVAC } \\
\text { Energy }\end{array}$ & $\begin{array}{c}\text { Fan } \\
\text { Energy }\end{array}$ & $\begin{array}{l}\text { Cooling } \\
\text { Energy }\end{array}$ & $\begin{array}{l}\text { Heating } \\
\text { Energy }\end{array}$ & $\begin{array}{c}\text { Total } \\
\text { HVAC } \\
\text { Energy }\end{array}$ \\
\hline 1 & NoEcon.SSFan.CS1.DCV0 (Baseline) & 254 & 485 & 333 & 1073 & 254 & 259 & 810 & 1322 \\
\hline 2 & NIEcon.DB.SSFan.CS1.DCV0 & 254 & 469 & 332 & 1055 & 254 & 231 & 808 & 1293 \\
\hline 3 & NIEcon.EH.SSFan.CS1.DCV0 & 254 & 466 & 332 & 1052 & 254 & 236 & 808 & 1299 \\
\hline 4 & IEcon.DB.SSFan.CS1.DCV0 & 254 & 468 & 332 & 1054 & 254 & 230 & 808 & 1292 \\
\hline 5 & IEcon.EH.SSFan.CS1.DCV0 & 254 & 466 & 332 & 1052 & 254 & 236 & 808 & 1298 \\
\hline 6 & NoEcon.MSFan.CS1.DCV0 & 98 & 471 & 404 & 972 & 88 & 242 & 929 & 1259 \\
\hline 7 & NIEcon.DB.MSFan.CS1.DCV0 & 102 & 461 & 403 & 966 & 94 & 225 & 928 & 1248 \\
\hline 8 & NIEcon.EH.MSFan.CS1.DCV0 & 103 & 459 & 402 & 964 & 93 & 229 & 929 & 1251 \\
\hline 9 & IEcon.DB.MSFan.CS1.DCV0 & 102 & 461 & 403 & 965 & 94 & 225 & 928 & 1247 \\
\hline 10 & IEcon.EH.MSFan.CS1.DCV0 & 103 & 458 & 402 & 963 & 93 & 229 & 929 & 1250 \\
\hline 11 & NoEcon.MSFan.CS2.DCV0 & 85 & 420 & 402 & 908 & 79 & 208 & 929 & 1216 \\
\hline 12 & IEcon.DB.MSFan.CS2.DCV0 & 90 & 413 & 402 & 905 & 85 & 197 & 928 & 1210 \\
\hline 13 & IEcon.EH.MSFan.CS2.DCV0 & 91 & 411 & 402 & 904 & 85 & 197 & 928 & 1210 \\
\hline 14 & NoEcon.SSFan.CS1.DCV1 & 254 & 391 & 220 & 866 & 254 & 207 & 528 & 989 \\
\hline 15 & IEcon.DB.SSFan.CS1.DCV1 & 254 & 386 & 220 & 860 & 254 & 196 & 528 & 978 \\
\hline 16 & IEcon.EH.SSFan.CS1.DCV1 & 254 & 383 & 220 & 857 & 254 & 200 & 528 & 982 \\
\hline 17 & NoEcon.MSFan.CS1.DCV1 & 83 & 382 & 264 & 729 & 74 & 205 & 601 & 880 \\
\hline 18 & IEcon.DB.MSFan.CS1.DCV1 & 86 & 375 & 263 & 725 & 79 & 190 & 601 & 870 \\
\hline 19 & IEcon.EH.MSFan.CS1.DCV1 & 88 & 373 & 263 & 723 & 78 & 194 & 601 & 873 \\
\hline 20 & NoEcon.MSFan.CS2.DCV1 & 71 & 336 & 263 & 669 & 66 & 179 & 601 & 845 \\
\hline 21 & IEcon.DB.MSFan.CS2.DCV1 & 75 & 331 & 262 & 669 & 72 & 169 & 601 & 842 \\
\hline 22 & IEcon.EH.MSFan.CS2.DCV1 & 77 & 329 & 262 & 668 & 71 & 170 & 601 & 842 \\
\hline
\end{tabular}


Table B-19: HVAC Energy Uses for the Strip Mall Building in Climate Zone 3B

Units: [10 $10^{6}$ Btus]

\begin{tabular}{|c|c|c|c|c|c|c|c|c|c|}
\hline \multirow[b]{2}{*}{$\begin{array}{l}\text { Case } \\
\text { No }\end{array}$} & \multirow[b]{2}{*}{ Case Name } & \multicolumn{4}{|c|}{ Los Angeles-3B } & \multicolumn{4}{|c|}{ Las Vegas-3B } \\
\hline & & $\begin{array}{c}\text { Fan } \\
\text { Energy }\end{array}$ & $\begin{array}{l}\text { Cooling } \\
\text { Energy }\end{array}$ & $\begin{array}{l}\text { Heating } \\
\text { Energy }\end{array}$ & $\begin{array}{c}\text { Total } \\
\text { HVAC } \\
\text { Energy }\end{array}$ & $\begin{array}{c}\text { Fan } \\
\text { Energy }\end{array}$ & $\begin{array}{l}\text { Cooling } \\
\text { Energy }\end{array}$ & $\begin{array}{c}\text { Heating } \\
\text { Energy }\end{array}$ & $\begin{array}{c}\text { Total } \\
\text { HVAC } \\
\text { Energy }\end{array}$ \\
\hline 1 & NoEcon.SSFan.CS1.DCV0 (Baseline) & 250 & 159 & 297 & 706 & 236 & 328 & 546 & 1110 \\
\hline 2 & NIEcon.DB.SSFan.CS1.DCV0 & 250 & 87 & 296 & 632 & 236 & 313 & 545 & 1093 \\
\hline 3 & NIEcon.EH.SSFan.CS1.DCV0 & 250 & 96 & 296 & 642 & 236 & 312 & 545 & 1092 \\
\hline 4 & IEcon.DB.SSFan.CS1.DCV0 & 250 & 83 & 296 & 629 & 236 & 313 & 545 & 1093 \\
\hline 5 & IEcon.EH.SSFan.CS1.DCV0 & 250 & 93 & 296 & 639 & 236 & 311 & 545 & 1092 \\
\hline 6 & NoEcon.MSFan.CS1.DCV0 & 63 & 138 & 392 & 593 & 83 & 315 & 636 & 1033 \\
\hline 7 & NIEcon.DB.MSFan.CS1.DCV0 & 75 & 89 & 390 & 554 & 86 & 307 & 635 & 1028 \\
\hline 8 & NIEcon.EH.MSFan.CS1.DCV0 & 74 & 97 & 390 & 561 & 87 & 305 & 635 & 1026 \\
\hline 9 & IEcon.DB.MSFan.CS1.DCV0 & 74 & 86 & 390 & 550 & 86 & 306 & 635 & 1027 \\
\hline 10 & IEcon.EH.MSFan.CS1.DCV0 & 73 & 94 & 390 & 558 & 87 & 305 & 635 & 1026 \\
\hline 11 & NoEcon.MSFan.CS2.DCV0 & 56 & 116 & 391 & 562 & 74 & 285 & 635 & 994 \\
\hline 12 & IEcon.DB.MSFan.CS2.DCV0 & 69 & 79 & 390 & 538 & 79 & 278 & 635 & 992 \\
\hline 13 & IEcon.EH.MSFan.CS2.DCV0 & 68 & 81 & 390 & 539 & 79 & 277 & 634 & 991 \\
\hline 14 & NoEcon.SSFan.CS1.DCV1 & 250 & 109 & 188 & 548 & 236 & 260 & 366 & 862 \\
\hline 15 & IEcon.DB.SSFan.CS1.DCV1 & 250 & 79 & 188 & 517 & 236 & 256 & 366 & 857 \\
\hline 16 & IEcon.EH.SSFan.CS1.DCV1 & 250 & 86 & 188 & 524 & 236 & 254 & 365 & 855 \\
\hline 17 & NoEcon.MSFan.CS1.DCV1 & 57 & 131 & 242 & 431 & 69 & 253 & 421 & 743 \\
\hline 18 & IEcon.DB.MSFan.CS1.DCV1 & 68 & 84 & 241 & 392 & 72 & 247 & 420 & 739 \\
\hline 19 & IEcon.EH.MSFan.CS1.DCV1 & 67 & 92 & 241 & 400 & 73 & 245 & 420 & 738 \\
\hline 20 & NoEcon.MSFan.CS2.DCV1 & 50 & 106 & 241 & 397 & 61 & 227 & 420 & 708 \\
\hline 21 & IEcon.DB.MSFan.CS2.DCV1 & 62 & 77 & 241 & 380 & 65 & 222 & 420 & 707 \\
\hline 22 & IEcon.EH.MSFan.CS2.DCV1 & 62 & 79 & 241 & 382 & 66 & 221 & 420 & 706 \\
\hline
\end{tabular}


Table B-20: HVAC Energy Uses for the Strip Mall Building in Climate Zones 3C and 4A

Units: [10 $10^{6}$ Btus]

\begin{tabular}{|c|c|c|c|c|c|c|c|c|c|}
\hline \multirow[b]{2}{*}{$\begin{array}{c}\text { Case } \\
\text { No }\end{array}$} & \multirow[b]{2}{*}{ Case Name } & \multicolumn{4}{|c|}{ San Francisco-3C } & \multicolumn{4}{|c|}{ Baltimore-4A } \\
\hline & & $\begin{array}{c}\text { Fan } \\
\text { Energy }\end{array}$ & $\begin{array}{l}\text { Cooling } \\
\text { Energy }\end{array}$ & $\begin{array}{l}\text { Heating } \\
\text { Energy }\end{array}$ & $\begin{array}{c}\text { Total } \\
\text { HVAC } \\
\text { Energy }\end{array}$ & $\begin{array}{c}\text { Fan } \\
\text { Energy }\end{array}$ & $\begin{array}{l}\text { Cooling } \\
\text { Energy }\end{array}$ & $\begin{array}{c}\text { Heating } \\
\text { Energy }\end{array}$ & $\begin{array}{c}\text { Total } \\
\text { HVAC } \\
\text { Energy }\end{array}$ \\
\hline 1 & NoEcon.SSFan.CS1.DCV0 (Baseline) & 194 & 45 & 700 & 939 & 232 & 187 & 1356 & 1776 \\
\hline 2 & NIEcon.DB.SSFan.CS1.DCV0 & 194 & 21 & 699 & 914 & 232 & 169 & 1356 & 1757 \\
\hline 3 & NIEcon.EH.SSFan.CS1.DCV0 & 194 & 21 & 699 & 914 & 232 & 172 & 1356 & 1761 \\
\hline 4 & IEcon.DB.SSFan.CS1.DCV0 & 194 & 20 & 699 & 913 & 232 & 168 & 1356 & 1756 \\
\hline 5 & IEcon.EH.SSFan.CS1.DCV0 & 194 & 20 & 699 & 913 & 232 & 172 & 1356 & 1760 \\
\hline 6 & NoEcon.MSFan.CS1.DCV0 & 48 & 37 & 822 & 907 & 86 & 175 & 1504 & 1765 \\
\hline 7 & NIEcon.DB.MSFan.CS1.DCV0 & 53 & 22 & 822 & 897 & 90 & 164 & 1504 & 1757 \\
\hline 8 & NIEcon.EH.MSFan.CS1.DCV0 & 53 & 22 & 822 & 897 & 89 & 166 & 1504 & 1759 \\
\hline 9 & IEcon.DB.MSFan.CS1.DCV0 & 53 & 21 & 822 & 896 & 90 & 164 & 1504 & 1757 \\
\hline 10 & IEcon.EH.MSFan.CS1.DCV0 & 53 & 21 & 822 & 896 & 89 & 166 & 1504 & 1759 \\
\hline 11 & NoEcon.MSFan.CS2.DCV0 & 46 & 30 & 822 & 898 & 80 & 153 & 1504 & 1737 \\
\hline 12 & IEcon.DB.MSFan.CS2.DCV0 & 51 & 18 & 822 & 891 & 84 & 145 & 1504 & 1733 \\
\hline 13 & IEcon.EH.MSFan.CS2.DCV0 & 51 & 18 & 822 & 891 & 84 & 145 & 1504 & 1733 \\
\hline 14 & NoEcon.SSFan.CS1.DCV1 & 193 & 25 & 419 & 637 & 232 & 149 & 883 & 1265 \\
\hline 15 & IEcon.DB.SSFan.CS1.DCV1 & 193 & 19 & 419 & 631 & 232 & 141 & 883 & 1256 \\
\hline 16 & IEcon.EH.SSFan.CS1.DCV1 & 193 & 19 & 419 & 631 & 232 & 143 & 883 & 1259 \\
\hline 17 & NoEcon.MSFan.CS1.DCV1 & 39 & 35 & 488 & 562 & 69 & 146 & 974 & 1189 \\
\hline 18 & IEcon.DB.MSFan.CS1.DCV1 & 44 & 21 & 487 & 552 & 73 & 136 & 974 & 1183 \\
\hline 19 & IEcon.EH.MSFan.CS1.DCV1 & 44 & 21 & 487 & 552 & 72 & 138 & 974 & 1185 \\
\hline 20 & NoEcon.MSFan.CS2.DCV1 & 37 & 27 & 487 & 552 & 64 & 128 & 974 & 1166 \\
\hline 21 & IEcon.DB.MSFan.CS2.DCV1 & 42 & 18 & 487 & 547 & 68 & 121 & 974 & 1163 \\
\hline 22 & IEcon.EH.MSFan.CS2.DCV1 & 42 & 17 & 487 & 547 & 68 & 122 & 974 & 1163 \\
\hline
\end{tabular}


Table B-21: HVAC Energy Uses for the Strip Mall Building in Climate Zones 4B and 4C

Units: [10 $10^{6}$ Btus]

\begin{tabular}{|c|c|c|c|c|c|c|c|c|c|}
\hline \multirow[b]{2}{*}{$\begin{array}{c}\text { Case } \\
\text { No }\end{array}$} & \multirow[b]{2}{*}{ Case Name } & \multicolumn{4}{|c|}{ Albuquerque-4B } & \multicolumn{4}{|c|}{ Seattle-4C } \\
\hline & & $\begin{array}{c}\text { Fan } \\
\text { Energy }\end{array}$ & $\begin{array}{l}\text { Cooling } \\
\text { Energy }\end{array}$ & $\begin{array}{l}\text { Heating } \\
\text { Energy }\end{array}$ & $\begin{array}{c}\text { Total } \\
\text { HVAC } \\
\text { Energy }\end{array}$ & $\begin{array}{c}\text { Fan } \\
\text { Energy }\end{array}$ & $\begin{array}{l}\text { Cooling } \\
\text { Energy }\end{array}$ & $\begin{array}{l}\text { Heating } \\
\text { Energy }\end{array}$ & $\begin{array}{c}\text { Total } \\
\text { HVAC } \\
\text { Energy }\end{array}$ \\
\hline 1 & NoEcon.SSFan.CS1.DCV0 (Baseline) & 233 & 166 & 982 & 1381 & 203 & 43 & 1252 & 1499 \\
\hline 2 & NIEcon.DB.SSFan.CS1.DCV0 & 233 & 150 & 981 & 1363 & 203 & 28 & 1252 & 1483 \\
\hline 3 & NIEcon.EH.SSFan.CS1.DCV0 & 233 & 150 & 981 & 1364 & 203 & 28 & 1252 & 1483 \\
\hline 4 & IEcon.DB.SSFan.CS1.DCV0 & 233 & 149 & 981 & 1362 & 203 & 27 & 1252 & 1482 \\
\hline 5 & IEcon.EH.SSFan.CS1.DCV0 & 233 & 150 & 981 & 1363 & 203 & 28 & 1252 & 1483 \\
\hline 6 & NoEcon.MSFan.CS1.DCV0 & 79 & 154 & 1106 & 1339 & 62 & 37 & 1416 & 1514 \\
\hline 7 & NIEcon.DB.MSFan.CS1.DCV0 & 83 & 144 & 1105 & 1332 & 65 & 28 & 1416 & 1508 \\
\hline 8 & NIEcon.EH.MSFan.CS1.DCV0 & 83 & 144 & 1105 & 1332 & 65 & 28 & 1416 & 1509 \\
\hline 9 & IEcon.DB.MSFan.CS1.DCV0 & 83 & 144 & 1105 & 1332 & 65 & 27 & 1416 & 1508 \\
\hline 10 & IEcon.EH.MSFan.CS1.DCV0 & 83 & 144 & 1105 & 1332 & 65 & 27 & 1416 & 1508 \\
\hline 11 & NoEcon.MSFan.CS2.DCV0 & 73 & 129 & 1105 & 1306 & 60 & 30 & 1416 & 1505 \\
\hline 12 & IEcon.DB.MSFan.CS2.DCV0 & 77 & 122 & 1104 & 1303 & 64 & 22 & 1416 & 1501 \\
\hline 13 & IEcon.EH.MSFan.CS2.DCV0 & 78 & 120 & 1104 & 1302 & 64 & 22 & 1416 & 1501 \\
\hline 14 & NoEcon.SSFan.CS1.DCV1 & 233 & 140 & 654 & 1026 & 203 & 31 & 740 & 974 \\
\hline 15 & IEcon.DB.SSFan.CS1.DCV1 & 233 & 133 & 653 & 1019 & 203 & 25 & 740 & 968 \\
\hline 16 & IEcon.EH.SSFan.CS1.DCV1 & 233 & 133 & 653 & 1019 & 203 & 26 & 740 & 969 \\
\hline 17 & NoEcon.MSFan.CS1.DCV1 & 66 & 136 & 733 & 935 & 47 & 35 & 847 & 929 \\
\hline 18 & IEcon.DB.MSFan.CS1.DCV1 & 69 & 127 & 733 & 929 & 51 & 25 & 846 & 922 \\
\hline 19 & IEcon.EH.MSFan.CS1.DCV1 & 70 & 127 & 733 & 929 & 51 & 26 & 846 & 923 \\
\hline 20 & NoEcon.MSFan.CS2.DCV1 & 60 & 114 & 733 & 906 & 45 & 28 & 846 & 919 \\
\hline 21 & IEcon.DB.MSFan.CS2.DCV1 & 64 & 108 & 732 & 905 & 49 & 21 & 846 & 917 \\
\hline 22 & IEcon.EH.MSFan.CS2.DCV1 & 66 & 106 & 732 & 904 & 50 & 21 & 846 & 917 \\
\hline
\end{tabular}


Table B-22: HVAC Energy Uses for the Strip Mall Building in Climate Zones 5A and 5B

\begin{tabular}{|c|c|c|c|c|c|c|c|c|c|}
\hline \multirow[b]{2}{*}{$\begin{array}{l}\text { Case } \\
\text { No }\end{array}$} & \multirow[b]{2}{*}{ Case Name } & \multicolumn{4}{|c|}{ Chicago-5A } & \multicolumn{4}{|c|}{ Denver-5B } \\
\hline & & $\begin{array}{c}\text { Fan } \\
\text { Energy }\end{array}$ & $\begin{array}{l}\text { Cooling } \\
\text { Energy }\end{array}$ & $\begin{array}{l}\text { Heating } \\
\text { Energy }\end{array}$ & $\begin{array}{c}\text { Total } \\
\text { HVAC } \\
\text { Energy }\end{array}$ & $\begin{array}{c}\text { Fan } \\
\text { Energy }\end{array}$ & $\begin{array}{l}\text { Cooling } \\
\text { Energy }\end{array}$ & $\begin{array}{l}\text { Heating } \\
\text { Energy }\end{array}$ & $\begin{array}{c}\text { Total } \\
\text { HVAC } \\
\text { Energy }\end{array}$ \\
\hline 1 & NoEcon.SSFan.CS1.DCV0 (Baseline) & 279 & 140 & 1887 & 2306 & 270 & 111 & 1416 & 1797 \\
\hline 2 & NIEcon.DB.SSFan.CS1.DCV0 & 279 & 119 & 1885 & 2283 & 270 & 94 & 1413 & 1778 \\
\hline 3 & NIEcon.EH.SSFan.CS1.DCV0 & 279 & 123 & 1885 & 2287 & 270 & 95 & 1413 & 1778 \\
\hline 4 & IEcon.DB.SSFan.CS1.DCV0 & 279 & 118 & 1885 & 2282 & 270 & 94 & 1413 & 1777 \\
\hline 5 & IEcon.EH.SSFan.CS1.DCV0 & 279 & 123 & 1885 & 2287 & 270 & 94 & 1413 & 1778 \\
\hline 6 & NoEcon.MSFan.CS1.DCV0 & 97 & 126 & 2099 & 2322 & 88 & 98 & 1606 & 1791 \\
\hline 7 & NIEcon.DB.MSFan.CS1.DCV0 & 102 & 114 & 2098 & 2314 & 91 & 89 & 1605 & 1785 \\
\hline 8 & NIEcon.EH.MSFan.CS1.DCV0 & 101 & 117 & 2098 & 2316 & 92 & 89 & 1605 & 1785 \\
\hline 9 & IEcon.DB.MSFan.CS1.DCV0 & 102 & 113 & 2098 & 2313 & 91 & 89 & 1605 & 1785 \\
\hline 10 & IEcon.EH.MSFan.CS1.DCV0 & 101 & 116 & 2098 & 2315 & 92 & 88 & 1605 & 1785 \\
\hline 11 & NoEcon.MSFan.CS2.DCV0 & 92 & 105 & 2098 & 2294 & 83 & 79 & 1604 & 1766 \\
\hline 12 & IEcon.DB.MSFan.CS2.DCV0 & 97 & 96 & 2098 & 2291 & 87 & 72 & 1604 & 1764 \\
\hline 13 & IEcon.EH.MSFan.CS2.DCV0 & 97 & 96 & 2098 & 2291 & 88 & 71 & 1604 & 1763 \\
\hline 14 & NoEcon.SSFan.CS1.DCV1 & 279 & 111 & 1289 & 1679 & 270 & 91 & 966 & 1326 \\
\hline 15 & IEcon.DB.SSFan.CS1.DCV1 & 279 & 102 & 1289 & 1670 & 270 & 84 & 965 & 1319 \\
\hline 16 & IEcon.EH.SSFan.CS1.DCV1 & 279 & 105 & 1289 & 1673 & 270 & 84 & 965 & 1319 \\
\hline 17 & NoEcon.MSFan.CS1.DCV1 & 79 & 107 & 1415 & 1601 & 71 & 86 & 1085 & 1242 \\
\hline 18 & IEcon.DB.MSFan.CS1.DCV1 & 83 & 97 & 1414 & 1594 & 75 & 78 & 1085 & 1238 \\
\hline 19 & IEcon.EH.MSFan.CS1.DCV1 & 82 & 99 & 1415 & 1596 & 75 & 78 & 1084 & 1238 \\
\hline 20 & NoEcon.MSFan.CS2.DCV1 & 74 & 90 & 1414 & 1578 & 67 & 68 & 1084 & 1219 \\
\hline 21 & IEcon.DB.MSFan.CS2.DCV1 & 79 & 83 & 1414 & 1576 & 71 & 63 & 1084 & 1218 \\
\hline 22 & IEcon.EH.MSFan.CS2.DCV1 & 79 & 83 & 1414 & 1576 & 73 & 62 & 1083 & 1218 \\
\hline
\end{tabular}


Table B-23: HVAC Energy Uses for the Strip Mall Building in Climate Zones 6A and 6B

\begin{tabular}{|c|c|c|c|c|c|c|c|c|c|}
\hline \multirow[b]{2}{*}{$\begin{array}{l}\text { Case } \\
\text { No }\end{array}$} & \multirow[b]{2}{*}{ Case Name } & \multicolumn{4}{|c|}{ Minneapolis-6A } & \multicolumn{4}{|c|}{ Helena-6B } \\
\hline & & $\begin{array}{c}\text { Fan } \\
\text { Energy }\end{array}$ & $\begin{array}{l}\text { Cooling } \\
\text { Energy }\end{array}$ & $\begin{array}{l}\text { Heating } \\
\text { Energy }\end{array}$ & $\begin{array}{c}\text { Total } \\
\text { HVAC } \\
\text { Energy }\end{array}$ & $\begin{array}{c}\text { Fan } \\
\text { Energy }\end{array}$ & $\begin{array}{l}\text { Cooling } \\
\text { Energy }\end{array}$ & $\begin{array}{l}\text { Heating } \\
\text { Energy }\end{array}$ & $\begin{array}{c}\text { Total } \\
\text { HVAC } \\
\text { Energy }\end{array}$ \\
\hline 1 & NoEcon.SSFan.CS1.DCV0 (Baseline) & 316 & 122 & 2409 & 2848 & 335 & 78 & 2091 & 2504 \\
\hline 2 & NIEcon.DB.SSFan.CS1.DCV0 & 316 & 98 & 2398 & 2812 & 334 & 58 & 2082 & 2475 \\
\hline 3 & NIEcon.EH.SSFan.CS1.DCV0 & 316 & 101 & 2398 & 2816 & 334 & 58 & 2082 & 2475 \\
\hline 4 & IEcon.DB.SSFan.CS1.DCV0 & 316 & 97 & 2398 & 2812 & 334 & 58 & 2082 & 2474 \\
\hline 5 & IEcon.EH.SSFan.CS1.DCV0 & 316 & 101 & 2398 & 2816 & 334 & 58 & 2082 & 2475 \\
\hline 6 & NoEcon.MSFan.CS1.DCV0 & 112 & 106 & 2659 & 2877 & 108 & 65 & 2387 & 2559 \\
\hline 7 & NIEcon.DB.MSFan.CS1.DCV0 & 116 & 93 & 2649 & 2858 & 111 & 55 & 2376 & 2542 \\
\hline 8 & NIEcon.EH.MSFan.CS1.DCV0 & 115 & 95 & 2649 & 2859 & 111 & 54 & 2376 & 2542 \\
\hline 9 & IEcon.DB.MSFan.CS1.DCV0 & 116 & 92 & 2649 & 2857 & 111 & 55 & 2376 & 2542 \\
\hline 10 & IEcon.EH.MSFan.CS1.DCV0 & 115 & 95 & 2649 & 2859 & 111 & 54 & 2376 & 2541 \\
\hline 11 & NoEcon.MSFan.CS2.DCV0 & 106 & 86 & 2652 & 2844 & 104 & 48 & 2382 & 2534 \\
\hline 12 & IEcon.DB.MSFan.CS2.DCV0 & 112 & 77 & 2649 & 2837 & 108 & 41 & 2375 & 2524 \\
\hline 13 & IEcon.EH.MSFan.CS2.DCV0 & 112 & 77 & 2648 & 2837 & 109 & 40 & 2375 & 2524 \\
\hline 14 & NoEcon.SSFan.CS1.DCV1 & 316 & 91 & 1698 & 2106 & 334 & 57 & 1448 & 1839 \\
\hline 15 & IEcon.DB.SSFan.CS1.DCV1 & 316 & 84 & 1698 & 2098 & 334 & 52 & 1447 & 1834 \\
\hline 16 & IEcon.EH.SSFan.CS1.DCV1 & 316 & 87 & 1698 & 2101 & 334 & 52 & 1447 & 1834 \\
\hline 17 & NoEcon.MSFan.CS1.DCV1 & 90 & 89 & 1848 & 2027 & 86 & 55 & 1645 & 1786 \\
\hline 18 & IEcon.DB.MSFan.CS1.DCV1 & 94 & 78 & 1840 & 2012 & 89 & 48 & 1637 & 1774 \\
\hline 19 & IEcon.EH.MSFan.CS1.DCV1 & 93 & 81 & 1840 & 2014 & 89 & 48 & 1637 & 1774 \\
\hline 20 & NoEcon.MSFan.CS2.DCV1 & 86 & 72 & 1844 & 2001 & 83 & 40 & 1642 & 1765 \\
\hline 21 & IEcon.DB.MSFan.CS2.DCV1 & 90 & 66 & 1840 & 1996 & 87 & 36 & 1636 & 1758 \\
\hline 22 & IEcon.EH.MSFan.CS2.DCV1 & 90 & 66 & 1840 & 1996 & 88 & 35 & 1636 & 1758 \\
\hline
\end{tabular}


Table B-24: HVAC Energy Uses for the Strip Mall Building in Climate Zones 7 and 8

Units: [10 $10^{6}$ Btus]

\begin{tabular}{|c|c|c|c|c|c|c|c|c|c|}
\hline \multirow[b]{2}{*}{$\begin{array}{c}\text { Case } \\
\text { No }\end{array}$} & \multirow[b]{2}{*}{ Case Name } & \multicolumn{4}{|c|}{ Duluth-7 } & \multicolumn{4}{|c|}{ Fairbanks-8 } \\
\hline & & $\begin{array}{c}\text { Fan } \\
\text { Energy }\end{array}$ & $\begin{array}{l}\text { Cooling } \\
\text { Energy }\end{array}$ & $\begin{array}{l}\text { Heating } \\
\text { Energy }\end{array}$ & $\begin{array}{c}\text { Total } \\
\text { HVAC } \\
\text { Energy }\end{array}$ & $\begin{array}{c}\text { Fan } \\
\text { Energy }\end{array}$ & $\begin{array}{l}\text { Cooling } \\
\text { Energy }\end{array}$ & $\begin{array}{l}\text { Heating } \\
\text { Energy }\end{array}$ & $\begin{array}{c}\text { Total } \\
\text { HVAC } \\
\text { Energy }\end{array}$ \\
\hline 1 & NoEcon.SSFan.CS1.DCV0 (Baseline) & 341 & 51 & 3015 & 3407 & 464 & 57 & 5070 & 5591 \\
\hline 2 & NIEcon.DB.SSFan.CS1.DCV0 & 341 & 30 & 2994 & 3365 & 463 & 12 & 4951 & 5426 \\
\hline 3 & NIEcon.EH.SSFan.CS1.DCV0 & 341 & 32 & 2994 & 3367 & 463 & 12 & 4951 & 5426 \\
\hline 4 & IEcon.DB.SSFan.CS1.DCV0 & 341 & 30 & 2994 & 3365 & 463 & 12 & 4951 & 5426 \\
\hline 5 & IEcon.EH.SSFan.CS1.DCV0 & 341 & 32 & 2994 & 3367 & 463 & 12 & 4951 & 5427 \\
\hline 6 & NoEcon.MSFan.CS1.DCV0 & 122 & 39 & 3349 & 3510 & 188 & 43 & 5571 & 5802 \\
\hline 7 & NIEcon.DB.MSFan.CS1.DCV0 & 124 & 28 & 3327 & 3479 & 183 & 10 & 5425 & 5618 \\
\hline 8 & NIEcon.EH.MSFan.CS1.DCV0 & 124 & 28 & 3327 & 3479 & 183 & 10 & 5425 & 5618 \\
\hline 9 & IEcon.DB.MSFan.CS1.DCV0 & 124 & 27 & 3327 & 3478 & 183 & 10 & 5425 & 5618 \\
\hline 10 & IEcon.EH.MSFan.CS1.DCV0 & 123 & 28 & 3327 & 3479 & 183 & 10 & 5425 & 5618 \\
\hline 11 & NoEcon.MSFan.CS2.DCV0 & 119 & 28 & 3334 & 3481 & 179 & 21 & 5448 & 5648 \\
\hline 12 & IEcon.DB.MSFan.CS2.DCV0 & 122 & 21 & 3327 & 3471 & 182 & 7 & 5425 & 5614 \\
\hline 13 & IEcon.EH.MSFan.CS2.DCV0 & 123 & 21 & 3327 & 3471 & 183 & 6 & 5425 & 5614 \\
\hline 14 & NoEcon.SSFan.CS1.DCV1 & 341 & 30 & 2113 & 2485 & 463 & 14 & 3707 & 4185 \\
\hline 15 & IEcon.DB.SSFan.CS1.DCV1 & 341 & 26 & 2113 & 2480 & 463 & 11 & 3717 & 4191 \\
\hline 16 & IEcon.EH.SSFan.CS1.DCV1 & 341 & 28 & 2113 & 2482 & 463 & 11 & 3717 & 4191 \\
\hline 17 & NoEcon.MSFan.CS1.DCV1 & 96 & 32 & 2331 & 2460 & 161 & 46 & 4330 & 4537 \\
\hline 18 & IEcon.DB.MSFan.CS1.DCV1 & 98 & 24 & 2315 & 2437 & 151 & 9 & 4101 & 4261 \\
\hline 19 & IEcon.EH.MSFan.CS1.DCV1 & 98 & 25 & 2315 & 2438 & 151 & 9 & 4101 & 4261 \\
\hline 20 & NoEcon.MSFan.CS2.DCV1 & 94 & 24 & 2323 & 2440 & 147 & 18 & 4093 & 4258 \\
\hline 21 & IEcon.DB.MSFan.CS2.DCV1 & 97 & 19 & 2315 & 2431 & 150 & 6 & 4101 & 4257 \\
\hline 22 & IEcon.EH.MSFan.CS2.DCV1 & 97 & 19 & 2315 & 2431 & 151 & 6 & 4101 & 4257 \\
\hline
\end{tabular}


Table B-25: HVAC Energy Uses for the Supermarket Building in Climate Zones 1A and 2A

\begin{tabular}{|c|c|c|c|c|c|c|c|c|c|}
\hline \multirow[b]{2}{*}{$\begin{array}{l}\text { Case } \\
\text { No }\end{array}$} & \multirow[b]{2}{*}{ Case Name } & \multicolumn{4}{|c|}{ Miami-1A } & \multicolumn{4}{|c|}{ Houston-2A } \\
\hline & & $\begin{array}{c}\text { Fan } \\
\text { Energy }\end{array}$ & $\begin{array}{l}\text { Cooling } \\
\text { Energy }\end{array}$ & $\begin{array}{l}\text { Heating } \\
\text { Energy }\end{array}$ & $\begin{array}{l}\text { Total } \\
\text { HVAC } \\
\text { Energy }\end{array}$ & $\begin{array}{c}\text { Fan } \\
\text { Energy }\end{array}$ & $\begin{array}{l}\text { Cooling } \\
\text { Energy }\end{array}$ & $\begin{array}{l}\text { Heating } \\
\text { Energy }\end{array}$ & $\begin{array}{c}\text { Total } \\
\text { HVAC } \\
\text { Energy }\end{array}$ \\
\hline 1 & NoEcon.SSFan.CS1.DCV0 (Baseline) & 498 & 674 & 143 & 1315 & 710 & 529 & 1290 & 2529 \\
\hline 2 & NIEcon.DB.SSFan.CS1.DCV0 & 498 & 647 & 141 & 1286 & 710 & 498 & 1281 & 2489 \\
\hline 3 & NIEcon.EH.SSFan.CS1.DCV0 & 498 & 661 & 141 & 1299 & 710 & 509 & 1281 & 2500 \\
\hline 4 & IEcon.DB.SSFan.CS1.DCV0 & 498 & 648 & 141 & 1286 & 710 & 498 & 1281 & 2488 \\
\hline 5 & IEcon.EH.SSFan.CS1.DCV0 & 498 & 660 & 141 & 1299 & 710 & 509 & 1281 & 2500 \\
\hline 6 & NoEcon.MSFan.CS1.DCV0 & 171 & 598 & 185 & 955 & 214 & 458 & 1570 & 2242 \\
\hline 7 & NIEcon.DB.MSFan.CS1.DCV0 & 177 & 579 & 183 & 938 & 218 & 437 & 1556 & 2211 \\
\hline 8 & NIEcon.EH.MSFan.CS1.DCV0 & 173 & 589 & 183 & 945 & 215 & 444 & 1557 & 2217 \\
\hline 9 & IEcon.DB.MSFan.CS1.DCV0 & 177 & 579 & 183 & 938 & 218 & 437 & 1556 & 2211 \\
\hline 10 & IEcon.EH.MSFan.CS1.DCV0 & 173 & 589 & 183 & 945 & 215 & 444 & 1557 & 2217 \\
\hline 11 & NoEcon.MSFan.CS2.DCV0 & 146 & 527 & 183 & 856 & 191 & 391 & 1560 & 2141 \\
\hline 12 & IEcon.DB.MSFan.CS2.DCV0 & 152 & 512 & 183 & 846 & 197 & 376 & 1556 & 2128 \\
\hline 13 & IEcon.EH.MSFan.CS2.DCV0 & 149 & 519 & 183 & 851 & 194 & 380 & 1557 & 2131 \\
\hline 14 & NoEcon.SSFan.CS1.DCV1 & 498 & 554 & 96 & 1147 & 709 & 428 & 941 & 2078 \\
\hline 15 & IEcon.DB.SSFan.CS1.DCV1 & 498 & 527 & 93 & 1118 & 709 & 396 & 931 & 2037 \\
\hline 16 & IEcon.EH.SSFan.CS1.DCV1 & 498 & 540 & 93 & 1131 & 709 & 408 & 931 & 2049 \\
\hline 17 & NoEcon.MSFan.CS1.DCV1 & 145 & 488 & 145 & 779 & 179 & 354 & 1229 & 1762 \\
\hline 18 & IEcon.DB.MSFan.CS1.DCV1 & 151 & 469 & 143 & 764 & 184 & 333 & 1216 & 1733 \\
\hline 19 & IEcon.EH.MSFan.CS1.DCV1 & 147 & 479 & 143 & 770 & 180 & 341 & 1216 & 1738 \\
\hline 20 & NoEcon.MSFan.CS2.DCV1 & 125 & 429 & 144 & 697 & 162 & 306 & 1219 & 1687 \\
\hline 21 & IEcon.DB.MSFan.CS2.DCV1 & 131 & 414 & 143 & 688 & 169 & 291 & 1215 & 1675 \\
\hline 22 & IEcon.EH.MSFan.CS2.DCV1 & 128 & 421 & 143 & 692 & 166 & 295 & 1216 & 1677 \\
\hline
\end{tabular}


Table B-26: HVAC Energy Uses for the Supermarket Building in Climate Zones 2B and 3A

\begin{tabular}{|c|c|c|c|c|c|c|c|c|c|}
\hline \multirow[b]{2}{*}{$\begin{array}{c}\text { Case } \\
\text { No }\end{array}$} & \multirow[b]{2}{*}{ Case Name } & \multicolumn{4}{|c|}{ Phoenix-2B } & \multicolumn{4}{|c|}{ Atlanta-3A } \\
\hline & & $\begin{array}{c}\text { Fan } \\
\text { Energy }\end{array}$ & $\begin{array}{l}\text { Cooling } \\
\text { Energy }\end{array}$ & $\begin{array}{l}\text { Heating } \\
\text { Energy }\end{array}$ & $\begin{array}{l}\text { Total } \\
\text { HVAC } \\
\text { Energy }\end{array}$ & $\begin{array}{c}\text { Fan } \\
\text { Energy }\end{array}$ & $\begin{array}{l}\text { Cooling } \\
\text { Energy }\end{array}$ & $\begin{array}{l}\text { Heating } \\
\text { Energy }\end{array}$ & $\begin{array}{c}\text { Total } \\
\text { HVAC } \\
\text { Energy }\end{array}$ \\
\hline 1 & NoEcon.SSFan.CS1.DCV0 (Baseline) & 644 & 570 & 1217 & 2431 & 821 & 296 & 2475 & 3592 \\
\hline 2 & NIEcon.DB.SSFan.CS1.DCV0 & 644 & 548 & 1203 & 2396 & 821 & 256 & 2455 & 3532 \\
\hline 3 & NIEcon.EH.SSFan.CS1.DCV0 & 644 & 548 & 1203 & 2396 & 821 & 266 & 2456 & 3543 \\
\hline 4 & IEcon.DB.SSFan.CS1.DCV0 & 644 & 547 & 1204 & 2395 & 821 & 256 & 2455 & 3532 \\
\hline 5 & IEcon.EH.SSFan.CS1.DCV0 & 644 & 548 & 1203 & 2395 & 821 & 266 & 2456 & 3543 \\
\hline 6 & NoEcon.MSFan.CS1.DCV0 & 205 & 521 & 1471 & 2197 & 237 & 237 & 2990 & 3465 \\
\hline 7 & NIEcon.DB.MSFan.CS1.DCV0 & 207 & 506 & 1453 & 2166 & 242 & 211 & 2964 & 3416 \\
\hline 8 & NIEcon.EH.MSFan.CS1.DCV0 & 207 & 506 & 1453 & 2166 & 239 & 218 & 2964 & 3421 \\
\hline 9 & IEcon.DB.MSFan.CS1.DCV0 & 207 & 505 & 1453 & 2166 & 242 & 210 & 2964 & 3416 \\
\hline 10 & IEcon.EH.MSFan.CS1.DCV0 & 207 & 505 & 1453 & 2165 & 239 & 217 & 2964 & 3421 \\
\hline 11 & NoEcon.MSFan.CS2.DCV0 & 184 & 455 & 1455 & 2094 & 223 & 194 & 2970 & 3387 \\
\hline 12 & IEcon.DB.MSFan.CS2.DCV0 & 188 & 444 & 1451 & 2084 & 230 & 176 & 2963 & 3369 \\
\hline 13 & IEcon.EH.MSFan.CS2.DCV0 & 188 & 444 & 1451 & 2084 & 228 & 180 & 2963 & 3371 \\
\hline 14 & NoEcon.SSFan.CS1.DCV1 & 644 & 442 & 932 & 2018 & 821 & 257 & 1839 & 2917 \\
\hline 15 & IEcon.DB.SSFan.CS1.DCV1 & 644 & 419 & 918 & 1982 & 821 & 216 & 1820 & 2856 \\
\hline 16 & IEcon.EH.SSFan.CS1.DCV1 & 644 & 420 & 918 & 1982 & 821 & 227 & 1820 & 2868 \\
\hline 17 & NoEcon.MSFan.CS1.DCV1 & 170 & 389 & 1209 & 1768 & 205 & 197 & 2367 & 2769 \\
\hline 18 & IEcon.DB.MSFan.CS1.DCV1 & 173 & 373 & 1193 & 1738 & 210 & 170 & 2342 & 2723 \\
\hline 19 & IEcon.EH.MSFan.CS1.DCV1 & 173 & 373 & 1193 & 1738 & 207 & 178 & 2343 & 2728 \\
\hline 20 & NoEcon.MSFan.CS2.DCV1 & 155 & 336 & 1195 & 1686 & 194 & 161 & 2348 & 2703 \\
\hline 21 & IEcon.DB.MSFan.CS2.DCV1 & 159 & 325 & 1191 & 1676 & 201 & 144 & 2341 & 2687 \\
\hline 22 & IEcon.EH.MSFan.CS2.DCV1 & 159 & 325 & 1191 & 1675 & 199 & 147 & 2342 & 2688 \\
\hline
\end{tabular}


Table B-27: HVAC Energy Uses for the Supermarket Building in Climate Zone 3B

Units: [10 $10^{6}$ Btus]

\begin{tabular}{|c|c|c|c|c|c|c|c|c|c|}
\hline \multirow[b]{2}{*}{$\begin{array}{c}\text { Case } \\
\text { No }\end{array}$} & \multirow[b]{2}{*}{ Case Name } & \multicolumn{4}{|c|}{ Los Angeles-3B } & \multicolumn{4}{|c|}{ Las Vegas-3B } \\
\hline & & $\begin{array}{c}\text { Fan } \\
\text { Energy }\end{array}$ & $\begin{array}{l}\text { Cooling } \\
\text { Energy }\end{array}$ & $\begin{array}{l}\text { Heating } \\
\text { Energy }\end{array}$ & $\begin{array}{c}\text { Total } \\
\text { HVAC } \\
\text { Energy }\end{array}$ & $\begin{array}{c}\text { Fan } \\
\text { Energy }\end{array}$ & $\begin{array}{l}\text { Cooling } \\
\text { Energy }\end{array}$ & $\begin{array}{l}\text { Heating } \\
\text { Energy }\end{array}$ & $\begin{array}{c}\text { Total } \\
\text { HVAC } \\
\text { Energy }\end{array}$ \\
\hline 1 & NoEcon.SSFan.CS1.DCV0 (Baseline) & 575 & 120 & 1335 & 2031 & 740 & 392 & 1994 & 3126 \\
\hline 2 & NIEcon.DB.SSFan.CS1.DCV0 & 575 & 57 & 1327 & 1960 & 740 & 369 & 1975 & 3083 \\
\hline 3 & NIEcon.EH.SSFan.CS1.DCV0 & 575 & 68 & 1327 & 1971 & 740 & 369 & 1975 & 3083 \\
\hline 4 & IEcon.DB.SSFan.CS1.DCV0 & 575 & 56 & 1327 & 1958 & 740 & 369 & 1975 & 3083 \\
\hline 5 & IEcon.EH.SSFan.CS1.DCV0 & 575 & 67 & 1327 & 1970 & 740 & 369 & 1975 & 3083 \\
\hline 6 & NoEcon.MSFan.CS1.DCV0 & 145 & 97 & 1684 & 1926 & 224 & 344 & 2393 & 2961 \\
\hline 7 & NIEcon.DB.MSFan.CS1.DCV0 & 152 & 53 & 1676 & 1881 & 226 & 327 & 2373 & 2927 \\
\hline 8 & NIEcon.EH.MSFan.CS1.DCV0 & 150 & 60 & 1676 & 1886 & 226 & 327 & 2373 & 2927 \\
\hline 9 & IEcon.DB.MSFan.CS1.DCV0 & 152 & 51 & 1676 & 1879 & 226 & 327 & 2373 & 2926 \\
\hline 10 & IEcon.EH.MSFan.CS1.DCV0 & 149 & 59 & 1676 & 1885 & 226 & 327 & 2373 & 2926 \\
\hline 11 & NoEcon.MSFan.CS2.DCV0 & 137 & 77 & 1678 & 1892 & 210 & 299 & 2377 & 2885 \\
\hline 12 & IEcon.DB.MSFan.CS2.DCV0 & 148 & 45 & 1676 & 1869 & 214 & 287 & 2372 & 2873 \\
\hline 13 & IEcon.EH.MSFan.CS2.DCV0 & 147 & 47 & 1676 & 1870 & 214 & 287 & 2372 & 2873 \\
\hline 14 & NoEcon.SSFan.CS1.DCV1 & 575 & 121 & 947 & 1643 & 740 & 306 & 1548 & 2593 \\
\hline 15 & IEcon.DB.SSFan.CS1.DCV1 & 575 & 53 & 937 & 1566 & 740 & 282 & 1529 & 2551 \\
\hline 16 & IEcon.EH.SSFan.CS1.DCV1 & 575 & 69 & 937 & 1582 & 740 & 282 & 1529 & 2551 \\
\hline 17 & NoEcon.MSFan.CS1.DCV1 & 129 & 97 & 1280 & 1506 & 192 & 255 & 1984 & 2431 \\
\hline 18 & IEcon.DB.MSFan.CS1.DCV1 & 138 & 49 & 1272 & 1459 & 194 & 239 & 1965 & 2397 \\
\hline 19 & IEcon.EH.MSFan.CS1.DCV1 & 134 & 59 & 1272 & 1465 & 194 & 239 & 1965 & 2397 \\
\hline 20 & NoEcon.MSFan.CS2.DCV1 & 122 & 76 & 1273 & 1471 & 181 & 216 & 1968 & 2365 \\
\hline 21 & IEcon.DB.MSFan.CS2.DCV1 & 134 & 43 & 1271 & 1449 & 185 & 205 & 1963 & 2352 \\
\hline 22 & IEcon.EH.MSFan.CS2.DCV1 & 131 & 47 & 1271 & 1449 & 185 & 205 & 1963 & 2352 \\
\hline
\end{tabular}


Table B-28: HVAC Energy Uses for the Supermarket Building in Climate Zones 3C and 4A

\begin{tabular}{|c|c|c|c|c|c|c|c|c|c|}
\hline \multirow[b]{2}{*}{$\begin{array}{l}\text { Case } \\
\text { No }\end{array}$} & \multirow[b]{2}{*}{ Case Name } & \multicolumn{4}{|c|}{ San Francisco-3C } & \multicolumn{4}{|c|}{ Baltimore-4A } \\
\hline & & $\begin{array}{c}\text { Fan } \\
\text { Energy }\end{array}$ & $\begin{array}{l}\text { Cooling } \\
\text { Energy }\end{array}$ & $\begin{array}{l}\text { Heating } \\
\text { Energy }\end{array}$ & $\begin{array}{c}\text { Total } \\
\text { HVAC } \\
\text { Energy }\end{array}$ & $\begin{array}{c}\text { Fan } \\
\text { Energy }\end{array}$ & $\begin{array}{l}\text { Cooling } \\
\text { Energy }\end{array}$ & $\begin{array}{l}\text { Heating } \\
\text { Energy }\end{array}$ & $\begin{array}{c}\text { Total } \\
\text { HVAC } \\
\text { Energy }\end{array}$ \\
\hline 1 & NoEcon.SSFan.CS1.DCV0 (Baseline) & 622 & 47 & 2778 & 3447 & 844 & 211 & 3749 & 4804 \\
\hline 2 & NIEcon.DB.SSFan.CS1.DCV0 & 622 & 15 & 2772 & 3410 & 844 & 181 & 3727 & 4751 \\
\hline 3 & NIEcon.EH.SSFan.CS1.DCV0 & 622 & 16 & 2772 & 3410 & 844 & 188 & 3727 & 4758 \\
\hline 4 & IEcon.DB.SSFan.CS1.DCV0 & 622 & 15 & 2772 & 3409 & 844 & 181 & 3727 & 4751 \\
\hline 5 & IEcon.EH.SSFan.CS1.DCV0 & 622 & 15 & 2773 & 3410 & 844 & 187 & 3727 & 4758 \\
\hline 6 & NoEcon.MSFan.CS1.DCV0 & 194 & 37 & 3314 & 3546 & 266 & 167 & 4369 & 4802 \\
\hline 7 & NIEcon.DB.MSFan.CS1.DCV0 & 197 & 15 & 3309 & 3521 & 269 & 147 & 4332 & 4747 \\
\hline 8 & NIEcon.EH.MSFan.CS1.DCV0 & 197 & 15 & 3309 & 3521 & 267 & 151 & 4332 & 4750 \\
\hline 9 & IEcon.DB.MSFan.CS1.DCV0 & 196 & 15 & 3309 & 3520 & 268 & 146 & 4332 & 4747 \\
\hline 10 & IEcon.EH.MSFan.CS1.DCV0 & 196 & 15 & 3309 & 3520 & 267 & 151 & 4333 & 4750 \\
\hline 11 & NoEcon.MSFan.CS2.DCV0 & 191 & 28 & 3310 & 3529 & 256 & 136 & 4339 & 4731 \\
\hline 12 & IEcon.DB.MSFan.CS2.DCV0 & 195 & 12 & 3309 & 3516 & 261 & 122 & 4332 & 4715 \\
\hline 13 & IEcon.EH.MSFan.CS2.DCV0 & 195 & 12 & 3309 & 3516 & 259 & 124 & 4332 & 4715 \\
\hline 14 & NoEcon.SSFan.CS1.DCV1 & 622 & 45 & 2001 & 2668 & 843 & 178 & 2804 & 3825 \\
\hline 15 & IEcon.DB.SSFan.CS1.DCV1 & 622 & 13 & 1995 & 2630 & 843 & 147 & 2782 & 3773 \\
\hline 16 & IEcon.EH.SSFan.CS1.DCV1 & 622 & 14 & 1995 & 2631 & 843 & 155 & 2782 & 3781 \\
\hline 17 & NoEcon.MSFan.CS1.DCV1 & 166 & 36 & 2553 & 2754 & 227 & 134 & 3446 & 3807 \\
\hline 18 & IEcon.DB.MSFan.CS1.DCV1 & 168 & 13 & 2549 & 2730 & 230 & 113 & 3411 & 3754 \\
\hline 19 & IEcon.EH.MSFan.CS1.DCV1 & 168 & 14 & 2549 & 2730 & 228 & 118 & 3411 & 3757 \\
\hline 20 & NoEcon.MSFan.CS2.DCV1 & 163 & 27 & 2550 & 2739 & 219 & 109 & 3419 & 3747 \\
\hline 21 & IEcon.DB.MSFan.CS2.DCV1 & 167 & 10 & 2548 & 2726 & 224 & 96 & 3410 & 3730 \\
\hline 22 & IEcon.EH.MSFan.CS2.DCV1 & 167 & 11 & 2548 & 2726 & 222 & 98 & 3411 & 3731 \\
\hline
\end{tabular}


Table B-29: HVAC Energy Uses for the Supermarket Building in Climate Zones 4B and 4C

\begin{tabular}{|c|c|c|c|c|c|c|c|c|c|}
\hline \multirow[b]{2}{*}{$\begin{array}{l}\text { Case } \\
\text { No }\end{array}$} & \multirow[b]{2}{*}{ Case Name } & \multicolumn{4}{|c|}{ Albuquerque-4B } & \multicolumn{4}{|c|}{ Seattle-4C } \\
\hline & & $\begin{array}{c}\text { Fan } \\
\text { Energy }\end{array}$ & $\begin{array}{l}\text { Cooling } \\
\text { Energy }\end{array}$ & $\begin{array}{l}\text { Heating } \\
\text { Energy }\end{array}$ & $\begin{array}{c}\text { Total } \\
\text { HVAC } \\
\text { Energy }\end{array}$ & $\begin{array}{c}\text { Fan } \\
\text { Energy }\end{array}$ & $\begin{array}{l}\text { Cooling } \\
\text { Energy }\end{array}$ & $\begin{array}{l}\text { Heating } \\
\text { Energy }\end{array}$ & $\begin{array}{c}\text { Total } \\
\text { HVAC } \\
\text { Energy }\end{array}$ \\
\hline 1 & NoEcon.SSFan.CS1.DCV0 (Baseline) & 907 & 196 & 3078 & 4180 & 721 & 48 & 3822 & 4591 \\
\hline 2 & NIEcon.DB.SSFan.CS1.DCV0 & 907 & 166 & 3050 & 4123 & 721 & 21 & 3802 & 4545 \\
\hline 3 & NIEcon.EH.SSFan.CS1.DCV0 & 907 & 169 & 3050 & 4126 & 721 & 23 & 3803 & 4546 \\
\hline 4 & IEcon.DB.SSFan.CS1.DCV0 & 907 & 165 & 3050 & 4122 & 721 & 21 & 3802 & 4545 \\
\hline 5 & IEcon.EH.SSFan.CS1.DCV0 & 907 & 169 & 3050 & 4126 & 721 & 22 & 3802 & 4546 \\
\hline 6 & NoEcon.MSFan.CS1.DCV0 & 279 & 148 & 3704 & 4130 & 240 & 37 & 4460 & 4737 \\
\hline 7 & NIEcon.DB.MSFan.CS1.DCV0 & 281 & 128 & 3675 & 4084 & 241 & 18 & 4435 & 4694 \\
\hline 8 & NIEcon.EH.MSFan.CS1.DCV0 & 281 & 130 & 3676 & 4086 & 241 & 19 & 4435 & 4695 \\
\hline 9 & IEcon.DB.MSFan.CS1.DCV0 & 281 & 127 & 3675 & 4084 & 241 & 18 & 4435 & 4694 \\
\hline 10 & IEcon.EH.MSFan.CS1.DCV0 & 280 & 130 & 3676 & 4086 & 241 & 19 & 4435 & 4695 \\
\hline 11 & NoEcon.MSFan.CS2.DCV0 & 268 & 111 & 3681 & 4060 & 237 & 27 & 4441 & 4704 \\
\hline 12 & IEcon.DB.MSFan.CS2.DCV0 & 273 & 97 & 3673 & 4043 & 240 & 14 & 4434 & 4688 \\
\hline 13 & IEcon.EH.MSFan.CS2.DCV0 & 273 & 97 & 3674 & 4044 & 240 & 14 & 4434 & 4689 \\
\hline 14 & NoEcon.SSFan.CS1.DCV1 & 907 & 168 & 2359 & 3434 & 721 & 45 & 2787 & 3552 \\
\hline 15 & IEcon.DB.SSFan.CS1.DCV1 & 907 & 137 & 2333 & 3377 & 721 & 18 & 2767 & 3506 \\
\hline 16 & IEcon.EH.SSFan.CS1.DCV1 & 907 & 142 & 2333 & 3382 & 721 & 20 & 2767 & 3508 \\
\hline 17 & NoEcon.MSFan.CS1.DCV1 & 244 & 123 & 3025 & 3392 & 203 & 35 & 3451 & 3689 \\
\hline 18 & IEcon.DB.MSFan.CS1.DCV1 & 247 & 102 & 3000 & 3349 & 205 & 16 & 3428 & 3649 \\
\hline 19 & IEcon.EH.MSFan.CS1.DCV1 & 246 & 106 & 3000 & 3352 & 205 & 17 & 3428 & 3650 \\
\hline 20 & NoEcon.MSFan.CS2.DCV1 & 236 & 93 & 3006 & 3334 & 200 & 25 & 3434 & 3659 \\
\hline 21 & IEcon.DB.MSFan.CS2.DCV1 & 241 & 79 & 2999 & 3318 & 204 & 12 & 3427 & 3644 \\
\hline 22 & IEcon.EH.MSFan.CS2.DCV1 & 241 & 79 & 2999 & 3319 & 204 & 13 & 3427 & 3644 \\
\hline
\end{tabular}


Table B-30: HVAC Energy Uses for the Supermarket Building in Climate Zones 5A and 5B

\begin{tabular}{|c|c|c|c|c|c|c|c|c|c|}
\hline \multirow[b]{2}{*}{$\begin{array}{c}\text { Case } \\
\text { No }\end{array}$} & \multirow[b]{2}{*}{ Case Name } & \multicolumn{4}{|c|}{ Chicago-5A } & \multicolumn{4}{|c|}{ Denver-5B } \\
\hline & & $\begin{array}{c}\text { Fan } \\
\text { Energy }\end{array}$ & $\begin{array}{l}\text { Cooling } \\
\text { Energy }\end{array}$ & $\begin{array}{l}\text { Heating } \\
\text { Energy }\end{array}$ & $\begin{array}{l}\text { Total } \\
\text { HVAC } \\
\text { Energy }\end{array}$ & $\begin{array}{c}\text { Fan } \\
\text { Energy }\end{array}$ & $\begin{array}{l}\text { Cooling } \\
\text { Energy }\end{array}$ & $\begin{array}{l}\text { Heating } \\
\text { Energy }\end{array}$ & $\begin{array}{c}\text { Total } \\
\text { HVAC } \\
\text { Energy }\end{array}$ \\
\hline 1 & NoEcon.SSFan.CS1.DCV0 (Baseline) & 1014 & 162 & 4857 & 6033 & 1059 & 128 & 4087 & 5275 \\
\hline 2 & NIEcon.DB.SSFan.CS1.DCV0 & 1014 & 129 & 4823 & 5966 & 1059 & 99 & 4050 & 5208 \\
\hline 3 & NIEcon.EH.SSFan.CS1.DCV0 & 1014 & 137 & 4823 & 5974 & 1059 & 101 & 4049 & 5210 \\
\hline 4 & IEcon.DB.SSFan.CS1.DCV0 & 1014 & 129 & 4823 & 5965 & 1059 & 98 & 4050 & 5207 \\
\hline 5 & IEcon.EH.SSFan.CS1.DCV0 & 1014 & 137 & 4823 & 5974 & 1059 & 101 & 4050 & 5210 \\
\hline 6 & NoEcon.MSFan.CS1.DCV0 & 318 & 117 & 5726 & 6162 & 332 & 89 & 4987 & 5408 \\
\hline 7 & NIEcon.DB.MSFan.CS1.DCV0 & 320 & 94 & 5672 & 6086 & 333 & 70 & 4950 & 5353 \\
\hline 8 & NIEcon.EH.MSFan.CS1.DCV0 & 318 & 99 & 5672 & 6090 & 333 & 71 & 4950 & 5354 \\
\hline 9 & IEcon.DB.MSFan.CS1.DCV0 & 319 & 94 & 5672 & 6085 & 333 & 69 & 4950 & 5352 \\
\hline 10 & IEcon.EH.MSFan.CS1.DCV0 & 318 & 99 & 5672 & 6089 & 333 & 71 & 4950 & 5354 \\
\hline 11 & NoEcon.MSFan.CS2.DCV0 & 309 & 89 & 5678 & 6076 & 325 & 66 & 4960 & 5351 \\
\hline 12 & IEcon.DB.MSFan.CS2.DCV0 & 314 & 75 & 5671 & 6059 & 329 & 53 & 4948 & 5329 \\
\hline 13 & IEcon.EH.MSFan.CS2.DCV0 & 313 & 77 & 5671 & 6061 & 329 & 53 & 4947 & 5329 \\
\hline 14 & NoEcon.SSFan.CS1.DCV1 & 1014 & 147 & 3692 & 4853 & 1059 & 114 & 3144 & 4316 \\
\hline 15 & IEcon.DB.SSFan.CS1.DCV1 & 1014 & 107 & 3635 & 4756 & 1059 & 81 & 3099 & 4239 \\
\hline 16 & IEcon.EH.SSFan.CS1.DCV1 & 1014 & 118 & 3639 & 4770 & 1059 & 85 & 3100 & 4244 \\
\hline 17 & NoEcon.MSFan.CS1.DCV1 & 277 & 105 & 4589 & 4971 & 293 & 80 & 4100 & 4474 \\
\hline 18 & IEcon.DB.MSFan.CS1.DCV1 & 276 & 75 & 4503 & 4854 & 294 & 59 & 4054 & 4407 \\
\hline 19 & IEcon.EH.MSFan.CS1.DCV1 & 275 & 83 & 4512 & 4869 & 293 & 61 & 4056 & 4410 \\
\hline 20 & NoEcon.MSFan.CS2.DCV1 & 267 & 77 & 4521 & 4865 & 286 & 59 & 4067 & 4411 \\
\hline 21 & IEcon.DB.MSFan.CS2.DCV1 & 272 & 60 & 4499 & 4830 & 290 & 45 & 4048 & 4383 \\
\hline 22 & IEcon.EH.MSFan.CS2.DCV1 & 270 & 63 & 4501 & 4834 & 290 & 45 & 4048 & 4383 \\
\hline
\end{tabular}


Table B-31: HVAC Energy Uses for the Supermarket Building in Climate Zones 6A and 6B

\begin{tabular}{|c|c|c|c|c|c|c|c|c|c|}
\hline \multirow[b]{2}{*}{$\begin{array}{l}\text { Case } \\
\text { No }\end{array}$} & \multirow[b]{2}{*}{ Case Name } & \multicolumn{4}{|c|}{ Minneapolis-6A } & \multicolumn{4}{|c|}{ Helena-6B } \\
\hline & & $\begin{array}{c}\text { Fan } \\
\text { Energy }\end{array}$ & $\begin{array}{l}\text { Cooling } \\
\text { Energy }\end{array}$ & $\begin{array}{l}\text { Heating } \\
\text { Energy }\end{array}$ & $\begin{array}{c}\text { Total } \\
\text { HVAC } \\
\text { Energy }\end{array}$ & $\begin{array}{c}\text { Fan } \\
\text { Energy }\end{array}$ & $\begin{array}{l}\text { Cooling } \\
\text { Energy }\end{array}$ & $\begin{array}{l}\text { Heating } \\
\text { Energy }\end{array}$ & $\begin{array}{c}\text { Total } \\
\text { HVAC } \\
\text { Energy }\end{array}$ \\
\hline 1 & NoEcon.SSFan.CS1.DCV0 (Baseline) & 1104 & 152 & 5889 & 7144 & 1184 & 101 & 5513 & 6798 \\
\hline 2 & NIEcon.DB.SSFan.CS1.DCV0 & 1103 & 109 & 5817 & 7030 & 1183 & 62 & 5439 & 6684 \\
\hline 3 & NIEcon.EH.SSFan.CS1.DCV0 & 1103 & 115 & 5818 & 7036 & 1183 & 63 & 5439 & 6685 \\
\hline 4 & IEcon.DB.SSFan.CS1.DCV0 & 1103 & 109 & 5817 & 7029 & 1183 & 61 & 5439 & 6684 \\
\hline 5 & IEcon.EH.SSFan.CS1.DCV0 & 1103 & 115 & 5818 & 7036 & 1183 & 63 & 5439 & 6686 \\
\hline 6 & NoEcon.MSFan.CS1.DCV0 & 365 & 110 & 6912 & 7387 & 392 & 73 & 6685 & 7150 \\
\hline 7 & NIEcon.DB.MSFan.CS1.DCV0 & 362 & 75 & 6794 & 7231 & 388 & 41 & 6572 & 7001 \\
\hline 8 & NIEcon.EH.MSFan.CS1.DCV0 & 361 & 79 & 6798 & 7238 & 388 & 43 & 6577 & 7008 \\
\hline 9 & IEcon.DB.MSFan.CS1.DCV0 & 362 & 74 & 6794 & 7231 & 388 & 41 & 6573 & 7001 \\
\hline 10 & IEcon.EH.MSFan.CS1.DCV0 & 361 & 79 & 6798 & 7238 & 388 & 43 & 6578 & 7008 \\
\hline 11 & NoEcon.MSFan.CS2.DCV0 & 353 & 79 & 6820 & 7251 & 383 & 50 & 6619 & 7051 \\
\hline 12 & IEcon.DB.MSFan.CS2.DCV0 & 357 & 59 & 6792 & 7209 & 385 & 30 & 6570 & 6985 \\
\hline 13 & IEcon.EH.MSFan.CS2.DCV0 & 356 & 61 & 6793 & 7210 & 385 & 31 & 6571 & 6986 \\
\hline 14 & NoEcon.SSFan.CS1.DCV1 & 1104 & 147 & 4572 & 5823 & 1184 & 106 & 4315 & 5605 \\
\hline 15 & IEcon.DB.SSFan.CS1.DCV1 & 1103 & 91 & 4451 & 5645 & 1183 & 50 & 4242 & 5475 \\
\hline 16 & IEcon.EH.SSFan.CS1.DCV1 & 1103 & 98 & 4455 & 5657 & 1183 & 52 & 4242 & 5477 \\
\hline 17 & NoEcon.MSFan.CS1.DCV1 & 322 & 111 & 5604 & 6037 & 352 & 88 & 5530 & 5969 \\
\hline 18 & IEcon.DB.MSFan.CS1.DCV1 & 314 & 60 & 5416 & 5789 & 341 & 36 & 5331 & 5708 \\
\hline 19 & IEcon.EH.MSFan.CS1.DCV1 & 314 & 69 & 5436 & 5819 & 342 & 40 & 5349 & 5731 \\
\hline 20 & NoEcon.MSFan.CS2.DCV1 & 306 & 74 & 5469 & 5849 & 338 & 55 & 5413 & 5806 \\
\hline 21 & IEcon.DB.MSFan.CS2.DCV1 & 310 & 48 & 5411 & 5769 & 338 & 26 & 5319 & 5683 \\
\hline 22 & IEcon.EH.MSFan.CS2.DCV1 & 309 & 51 & 5418 & 5778 & 338 & 27 & 5322 & 5687 \\
\hline
\end{tabular}


Table B-32: HVAC Energy Uses for the Supermarket Building in Climate Zones 7 and 8

\begin{tabular}{|c|c|c|c|c|c|c|c|c|c|}
\hline \multirow[b]{2}{*}{$\begin{array}{l}\text { Case } \\
\text { No }\end{array}$} & \multirow[b]{2}{*}{ Case Name } & \multicolumn{4}{|c|}{ Duluth-7 } & \multicolumn{4}{|c|}{ Fairbanks-8 } \\
\hline & & $\begin{array}{c}\text { Fan } \\
\text { Energy }\end{array}$ & $\begin{array}{l}\text { Cooling } \\
\text { Energy }\end{array}$ & $\begin{array}{l}\text { Heating } \\
\text { Energy }\end{array}$ & $\begin{array}{l}\text { Total } \\
\text { HVAC } \\
\text { Energy }\end{array}$ & $\begin{array}{c}\text { Fan } \\
\text { Energy }\end{array}$ & $\begin{array}{l}\text { Cooling } \\
\text { Energy }\end{array}$ & $\begin{array}{l}\text { Heating } \\
\text { Energy }\end{array}$ & $\begin{array}{c}\text { Total } \\
\text { HVAC } \\
\text { Energy }\end{array}$ \\
\hline 1 & NoEcon.SSFan.CS1.DCV0 (Baseline) & 1162 & 74 & 7343 & 8579 & 1453 & 110 & 11369 & 12933 \\
\hline 2 & NIEcon.DB.SSFan.CS1.DCV0 & 1162 & 30 & 7250 & 8442 & 1452 & 11 & 11217 & 12681 \\
\hline 3 & NIEcon.EH.SSFan.CS1.DCV0 & 1162 & 33 & 7251 & 8446 & 1452 & 12 & 11218 & 12682 \\
\hline 4 & IEcon.DB.SSFan.CS1.DCV0 & 1162 & 30 & 7249 & 8441 & 1452 & 11 & 11218 & 12681 \\
\hline 5 & IEcon.EH.SSFan.CS1.DCV0 & 1162 & 33 & 7251 & 8446 & 1452 & 12 & 11219 & 12683 \\
\hline 6 & NoEcon.MSFan.CS1.DCV0 & 422 & 56 & 8564 & 9042 & 587 & 92 & 12930 & 13609 \\
\hline 7 & NIEcon.DB.MSFan.CS1.DCV0 & 416 & 20 & 8430 & 8866 & 566 & 7 & 12646 & 13220 \\
\hline 8 & NIEcon.EH.MSFan.CS1.DCV0 & 416 & 23 & 8436 & 8875 & 567 & 8 & 12651 & 13226 \\
\hline 9 & IEcon.DB.MSFan.CS1.DCV0 & 416 & 20 & 8430 & 8865 & 566 & 7 & 12647 & 13220 \\
\hline 10 & IEcon.EH.MSFan.CS1.DCV0 & 416 & 23 & 8436 & 8875 & 566 & 8 & 12651 & 13226 \\
\hline 11 & NoEcon.MSFan.CS2.DCV0 & 413 & 36 & 8478 & 8927 & 563 & 46 & 12689 & 13298 \\
\hline 12 & IEcon.DB.MSFan.CS2.DCV0 & 414 & 15 & 8430 & 8860 & 566 & 4 & 12643 & 13213 \\
\hline 13 & IEcon.EH.MSFan.CS2.DCV0 & 414 & 16 & 8431 & 8862 & 566 & 5 & 12645 & 13215 \\
\hline 14 & NoEcon.SSFan.CS1.DCV1 & 1162 & 88 & 5737 & 6987 & 1454 & 133 & 9214 & 10802 \\
\hline 15 & IEcon.DB.SSFan.CS1.DCV1 & 1162 & 25 & 5612 & 6800 & 1453 & 10 & 9033 & 10496 \\
\hline 16 & IEcon.EH.SSFan.CS1.DCV1 & 1162 & 29 & 5616 & 6807 & 1453 & 11 & 9035 & 10499 \\
\hline 17 & NoEcon.MSFan.CS1.DCV1 & 372 & 74 & 6949 & 7395 & 529 & 127 & 10760 & 11417 \\
\hline 18 & IEcon.DB.MSFan.CS1.DCV1 & 359 & 17 & 6736 & 7113 & 501 & 7 & 10402 & 10910 \\
\hline 19 & IEcon.EH.MSFan.CS1.DCV1 & 360 & 25 & 6761 & 7146 & 502 & 11 & 10420 & 10933 \\
\hline 20 & NoEcon.MSFan.CS2.DCV1 & 357 & 44 & 6816 & 7217 & 491 & 61 & 10367 & 10919 \\
\hline 21 & IEcon.DB.MSFan.CS2.DCV1 & 358 & 14 & 6734 & 7106 & 500 & 4 & 10396 & 10900 \\
\hline 22 & IEcon.EH.MSFan.CS2.DCV1 & 357 & 16 & 6741 & 7114 & 500 & 5 & 10399 & 10904 \\
\hline
\end{tabular}




\section{APPENDIX C Tables of Energy Savings}


Table C-1: HVAC Energy Savings Compared to Case 1 for the Small Office Building in Climate Zones 1, 2 and 3A

\begin{tabular}{|c|c|c|c|c|c|c|c|c|c|}
\hline \multirow{2}{*}{$\begin{array}{c}\text { Case } \\
\text { No }\end{array}$} & \multirow[b]{2}{*}{ Case Name } & \multicolumn{2}{|c|}{ Miami-1A } & \multicolumn{2}{|c|}{ Houston-2A } & \multicolumn{2}{|c|}{ Phoenix-2B } & \multicolumn{2}{|c|}{ Atlanta-3A } \\
\hline & & $\begin{array}{c}\text { Abs. } \\
\left(10^{6}\right. \\
\text { Btus })\end{array}$ & $\begin{array}{l}\text { Rel. } \\
\text { (\%) }\end{array}$ & $\begin{array}{c}\text { Abs. } \\
\left(10^{6}\right. \\
\text { Btus })\end{array}$ & $\begin{array}{l}\text { Rel. } \\
(\%)\end{array}$ & $\begin{array}{c}\text { Abs. } \\
\left(10^{6}\right. \\
\text { Btus })\end{array}$ & $\begin{array}{l}\text { Rel. } \\
\text { (\%) }\end{array}$ & $\begin{array}{c}\text { Abs. } \\
\left(10^{6}\right. \\
\text { Btus })\end{array}$ & $\begin{array}{l}\text { Rel. } \\
(\%)\end{array}$ \\
\hline 2 & NIEcon.DB.SSFan.CS1.DCV0 & 5 & 2.8 & 6 & 3.8 & 5 & 3.4 & 8 & 5.5 \\
\hline 3 & NIEcon.EH.SSFan.CS1.DCV0 & 4 & 2.5 & 5 & 3.2 & 6 & 3.6 & 7 & 4.5 \\
\hline 4 & IEcon.DB.SSFan.CS1.DCV0 & 5 & 2.8 & 6 & 3.8 & 6 & 3.5 & 8 & 5.5 \\
\hline 5 & IEcon.EH.SSFan.CS1.DCV0 & 4 & 2.5 & 5 & 3.3 & 6 & 3.7 & 7 & 4.6 \\
\hline 6 & NoEcon.MSFan.CS1.DCV0 & 30 & 18.5 & 24 & 15.4 & 26 & 16.0 & 18 & 11.5 \\
\hline 7 & NIEcon.DB.MSFan.CS1.DCV0 & 32 & 20.0 & 27 & 17.3 & 29 & 17.8 & 22 & 14.1 \\
\hline 8 & NIEcon.EH.MSFan.CS1.DCV0 & 32 & 19.8 & 26 & 17.1 & 29 & 17.9 & 21 & 13.8 \\
\hline 9 & IEcon.DB.MSFan.CS1.DCV0 & 32 & 19.9 & 26 & 17.1 & 29 & 18.0 & 22 & 14.2 \\
\hline 10 & IEcon.EH.MSFan.CS1.DCV0 & 32 & 19.9 & 26 & 17.1 & 29 & 18.0 & 21 & 13.8 \\
\hline 11 & NoEcon.MSFan.CS2.DCV0 & 47 & 29.0 & 35 & 22.9 & 41 & 25.7 & 26 & 16.6 \\
\hline 12 & IEcon.DB.MSFan.CS2.DCV0 & 47 & 29.0 & 36 & 23.3 & 43 & 26.7 & 27 & 17.7 \\
\hline 13 & IEcon.EH.MSFan.CS2.DCV0 & 49 & 30.0 & 37 & 24.0 & 43 & 26.8 & 28 & 18.1 \\
\hline 14 & NoEcon.SSFan.CS1.DCV1 & 13 & 7.9 & 16 & 10.7 & 11 & 7.0 & 19 & 12.5 \\
\hline 15 & IEcon.DB.SSFan.CS1.DCV1 & 16 & 10.2 & 22 & 14.4 & 18 & 11.2 & 28 & 18.3 \\
\hline 16 & IEcon.EH.SSFan.CS1.DCV1 & 17 & 10.5 & 22 & 14.1 & 18 & 11.4 & 27 & 17.7 \\
\hline 17 & NoEcon.MSFan.CS1.DCV1 & 45 & 27.7 & 44 & 28.6 & 41 & 25.4 & 43 & 27.5 \\
\hline 18 & IEcon.DB.MSFan.CS1.DCV1 & 46 & 28.6 & 47 & 30.4 & 45 & 27.9 & 47 & 30.6 \\
\hline 19 & IEcon.EH.MSFan.CS1.DCV1 & 48 & 29.3 & 48 & 30.7 & 45 & 28.0 & 47 & 30.6 \\
\hline 20 & NoEcon.MSFan.CS2.DCV1 & 60 & 36.9 & 54 & 35.2 & 55 & 34.3 & 50 & 32.3 \\
\hline 21 & IEcon.DB.MSFan.CS2.DCV1 & 59 & 36.6 & 55 & 35.6 & 58 & 35.9 & 52 & 33.6 \\
\hline 22 & IEcon.EH.MSFan.CS2.DCV1 & 62 & 38.1 & 57 & 36.7 & 58 & 35.9 & 53 & 34.3 \\
\hline
\end{tabular}


Table C-2: HVAC Energy Savings Compared to Case 1 for the Small Office Building in Climate Zones 3B, 3C and 4A

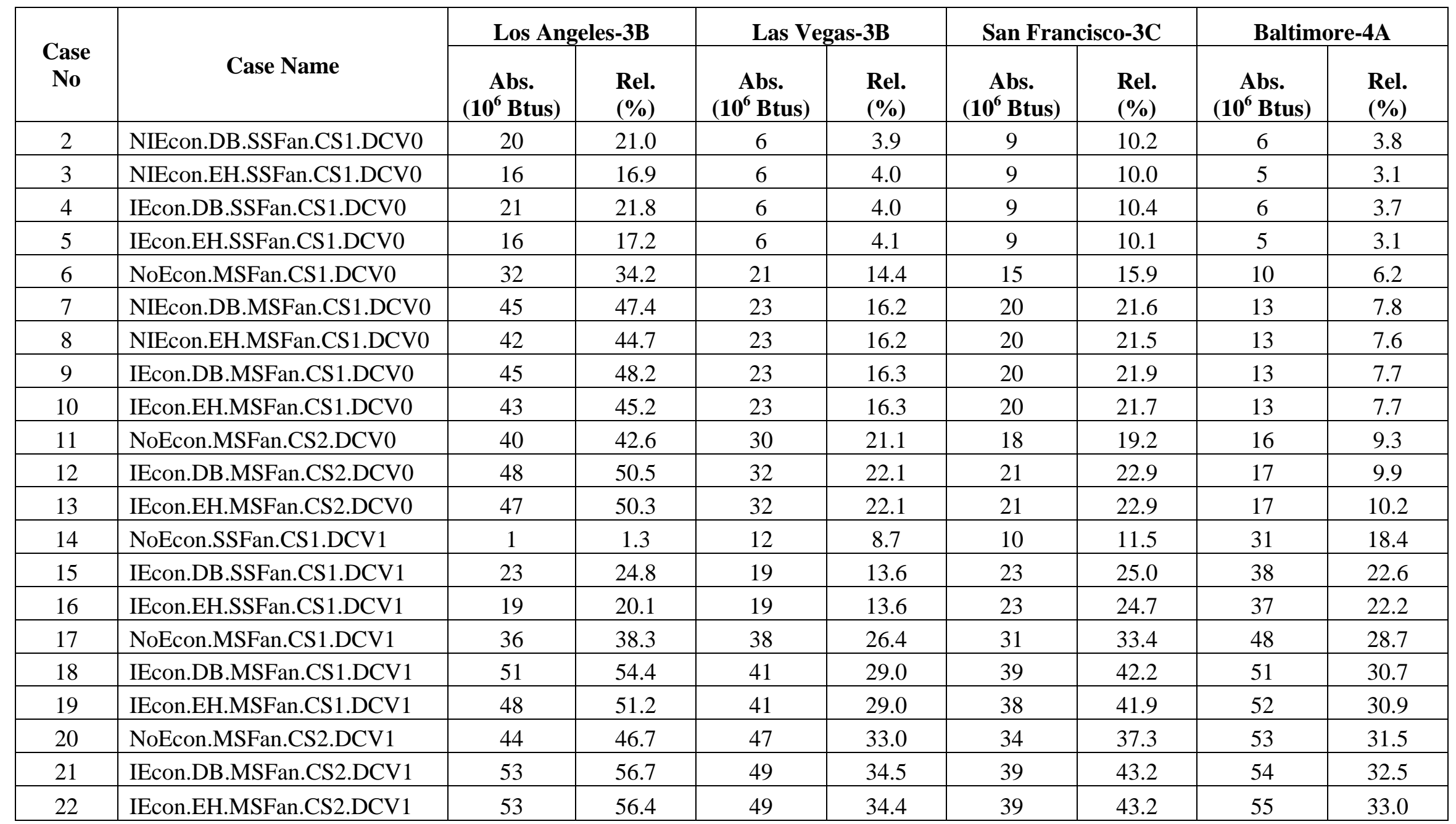


Table C-3: HVAC Energy Savings Compared to Case 1 for the Small Office Building in Climate Zones 4B, 4C, 5A and 5B

\begin{tabular}{|c|c|c|c|c|c|c|c|c|c|}
\hline $\begin{array}{c}\text { Case } \\
\text { No }\end{array}$ & Case Name & \multicolumn{2}{|c|}{ Albuquerque-4B } & \multicolumn{2}{|c|}{ Seattle-4C } & \multicolumn{2}{|c|}{ Chicago-5A } & \multicolumn{2}{|c|}{ Denver-5B } \\
\hline 3 & NIEcon.EH.SSFan.CS1.DCV0 & 6 & 4.4 & 7 & 5.1 & 5 & 2.2 & 6 & 3.6 \\
\hline 4 & IEcon.DB.SSFan.CS1.DCV0 & 7 & 5.0 & 7 & 5.5 & 6 & 3.1 & 7 & 4.1 \\
\hline 5 & IEcon.EH.SSFan.CS1.DCV0 & 6 & 4.4 & 7 & 5.2 & 5 & 2.3 & 6 & 3.6 \\
\hline 7 & NIEcon.DB.MSFan.CS1.DCV0 & 20 & 13.8 & 10 & 8.1 & 9 & 4.4 & 16 & 9.3 \\
\hline 8 & NIEcon.EH.MSFan.CS1.DCV0 & 20 & 13.6 & 10 & 8.0 & 8 & 4.1 & 15 & 9.2 \\
\hline 9 & IEcon.DB.MSFan.CS1.DCV0 & 20 & 14.0 & 11 & 8.3 & 9 & 4.4 & 16 & 9.4 \\
\hline 10 & IEcon.EH.MSFan.CS1.DCV0 & 20 & 13.7 & 10 & 8.1 & 9 & 4.1 & 15 & 9.2 \\
\hline 11 & NoEcon.MSFan.CS2.DCV0 & 24 & 16.4 & 10 & 7.4 & 11 & 5.4 & 18 & 10.8 \\
\hline 12 & IEcon.DB.MSFan.CS2.DCV0 & 26 & 17.8 & 12 & 9.2 & 13 & 6.0 & 20 & 11.7 \\
\hline 16 & IEcon.EH.SSFan.CS1.DCV1 & 25 & 17.0 & 34 & 26.6 & 46 & 22.3 & 32 & 19.2 \\
\hline 17 & NoEcon.MSFan.CS1.DCV1 & 40 & 27.5 & 41 & 31.8 & 55 & 26.6 & 46 & 27.2 \\
\hline 18 & IEcon.DB.MSFan.CS1.DCV1 & 45 & 30.9 & 46 & 36.2 & 59 & 28.3 & 50 & 29.8 \\
\hline 19 & IEcon.EH.MSFan.CS1.DCV1 & 44 & 30.6 & 46 & 36.0 & 58 & 28.0 & 50 & 29.6 \\
\hline 20 & NoEcon.MSFan.CS2.DCV1 & 47 & 32.2 & 44 & 34.1 & 60 & 28.7 & 51 & 30.5 \\
\hline 21 & IEcon.DB.MSFan.CS2.DCV1 & 50 & 34.2 & 47 & 37.0 & 62 & 29.7 & 54 & 31.9 \\
\hline 22 & IEcon.EH.MSFan.CS2.DCV1 & 50 & 34.2 & 47 & 37.0 & 62 & 29.8 & 53 & 31.9 \\
\hline
\end{tabular}


Table C-4: HVAC Energy Savings Compared to Case 1 for the Small Office Building in Climate Zones 6, 7 and 8

\begin{tabular}{|c|c|c|c|c|c|c|c|c|c|}
\hline \multirow{2}{*}{$\begin{array}{l}\text { Case } \\
\text { No }\end{array}$} & \multirow{2}{*}{ Case Name } & \multicolumn{2}{|c|}{ Minneapolis-6A } & \multicolumn{2}{|c|}{ Helena-6B } & \multicolumn{2}{|c|}{ Duluth-7 } & \multicolumn{2}{|c|}{ Fairbanks-8 } \\
\hline & & $\begin{array}{c}\text { Abs. } \\
\left(10^{6} \text { Btus }\right)\end{array}$ & $\begin{array}{l}\text { Rel. } \\
\text { (\%) }\end{array}$ & $\begin{array}{c}\text { Abs. } \\
\left(10^{6} \text { Btus }\right)\end{array}$ & $\begin{array}{l}\text { Rel. } \\
\text { (\%) }\end{array}$ & $\begin{array}{c}\text { Abs. } \\
\left(10^{6} \text { Btus }\right)\end{array}$ & $\begin{array}{l}\text { Rel. } \\
\text { (\%) }\end{array}$ & $\begin{array}{c}\text { Abs. } \\
\left(10^{6} \text { Btus }\right)\end{array}$ & $\begin{array}{l}\text { Rel. } \\
\text { (\%) }\end{array}$ \\
\hline 3 & NIEcon.EH.SSFan.CS1.DCV0 & 6 & 2.4 & 6 & 2.8 & 5 & 1.9 & 6 & 1.3 \\
\hline 4 & IEcon.DB.SSFan.CS1.DCV0 & 7 & 2.9 & 6 & 3.1 & 6 & 2.2 & 6 & 1.3 \\
\hline 5 & IEcon.EH.SSFan.CS1.DCV0 & 6 & 2.4 & 6 & 2.8 & 5 & 1.9 & 6 & 1.3 \\
\hline 7 & NIEcon.DB.MSFan.CS1.DCV0 & 8 & 3.3 & 8 & 4.0 & 2 & 0.7 & -3 & -0.8 \\
\hline 8 & NIEcon.EH.MSFan.CS1.DCV0 & 8 & 3.1 & 8 & 3.9 & 2 & 0.6 & -4 & -0.8 \\
\hline 9 & IEcon.DB.MSFan.CS1.DCV0 & 8 & 3.4 & 8 & 4.0 & 2 & 0.7 & -3 & -0.7 \\
\hline 10 & IEcon.EH.MSFan.CS1.DCV0 & 8 & 3.2 & 8 & 4.0 & 2 & 0.6 & -3 & -0.8 \\
\hline 11 & NoEcon.MSFan.CS2.DCV0 & 9 & 3.8 & 9 & 4.5 & 1 & 0.5 & -5 & -1.0 \\
\hline 12 & IEcon.DB.MSFan.CS2.DCV0 & 11 & 4.4 & 11 & 5.3 & 3 & 1.1 & -3 & -0.6 \\
\hline 16 & IEcon.EH.SSFan.CS1.DCV1 & 58 & 23.8 & 45 & 22.0 & 64 & 23.6 & 92 & 20.5 \\
\hline 17 & NoEcon.MSFan.CS1.DCV1 & 64 & 26.2 & 54 & 26.0 & 67 & 24.8 & 90 & 20.0 \\
\hline 18 & IEcon.DB.MSFan.CS1.DCV1 & 69 & 28.0 & 58 & 28.1 & 72 & 26.5 & 96 & 21.4 \\
\hline 19 & IEcon.EH.MSFan.CS1.DCV1 & 68 & 27.9 & 58 & 28.0 & 72 & 26.3 & 96 & 21.4 \\
\hline 20 & NoEcon.MSFan.CS2.DCV1 & 69 & 28.0 & 58 & 27.9 & 70 & 25.8 & 94 & 20.8 \\
\hline 21 & IEcon.DB.MSFan.CS2.DCV1 & 71 & 29.0 & 60 & 29.2 & 73 & 26.8 & 97 & 21.6 \\
\hline 22 & IEcon.EH.MSFan.CS2.DCV1 & 71 & 29.2 & 60 & 29.2 & 73 & 26.9 & 97 & 21.6 \\
\hline
\end{tabular}


Table C-5: HVAC Energy Savings Compared to Case 1 for the Stand-alone Retail Building in Climate Zones 1, 2 and 3A

\begin{tabular}{|c|c|c|c|c|c|c|c|c|c|}
\hline \multirow{2}{*}{$\begin{array}{c}\text { Case } \\
\text { No }\end{array}$} & \multirow[b]{2}{*}{ Case Name } & \multicolumn{2}{|c|}{ Miami-1A } & \multicolumn{2}{|c|}{ Houston-2A } & \multicolumn{2}{|c|}{ Phoenix-2B } & \multicolumn{2}{|c|}{ Atlanta-3A } \\
\hline & & $\begin{array}{c}\text { Abs. } \\
\left(10^{6}\right. \\
\text { Btus }) \\
\end{array}$ & $\begin{array}{l}\text { Rel. } \\
\text { (\%) }\end{array}$ & $\begin{array}{c}\text { Abs. } \\
\left(10^{6}\right. \\
\text { Btus })\end{array}$ & $\begin{array}{l}\text { Rel. } \\
\text { (\%) }\end{array}$ & $\begin{array}{c}\text { Abs. } \\
\left(10^{6}\right. \\
\text { Btus }) \\
\end{array}$ & $\begin{array}{l}\text { Rel. } \\
\text { (\%) }\end{array}$ & $\begin{array}{c}\text { Abs. } \\
\left(10^{6}\right. \\
\text { Btus })\end{array}$ & $\begin{array}{l}\text { Rel. } \\
(\%)\end{array}$ \\
\hline 2 & NIEcon.DB.SSFan.CS1.DCV0 & 27 & 2.9 & 22 & 2.0 & 14 & 1.3 & 24 & 1.7 \\
\hline 3 & NIEcon.EH.SSFan.CS1.DCV0 & 16 & 1.7 & 15 & 1.3 & 16 & 1.5 & 18 & 1.3 \\
\hline 4 & IEcon.DB.SSFan.CS1.DCV0 & 27 & 2.8 & 22 & 2.0 & 14 & 1.4 & 24 & 1.7 \\
\hline 5 & IEcon.EH.SSFan.CS1.DCV0 & 17 & 1.8 & 15 & 1.4 & 16 & 1.5 & 19 & 1.4 \\
\hline 6 & NoEcon.MSFan.CS1.DCV0 & 143 & 15.1 & 95 & 8.4 & 100 & 9.5 & 63 & 4.6 \\
\hline 7 & NIEcon.DB.MSFan.CS1.DCV0 & 154 & 16.2 & 102 & 9.1 & 104 & 9.9 & 70 & 5.1 \\
\hline 8 & NIEcon.EH.MSFan.CS1.DCV0 & 149 & 15.7 & 99 & 8.8 & 106 & 10.0 & 68 & 4.9 \\
\hline 9 & IEcon.DB.MSFan.CS1.DCV0 & 154 & 16.2 & 102 & 9.1 & 105 & 10.0 & 70 & 5.1 \\
\hline 10 & IEcon.EH.MSFan.CS1.DCV0 & 150 & 15.8 & 100 & 8.8 & 106 & 10.1 & 68 & 5.0 \\
\hline 11 & NoEcon.MSFan.CS2.DCV0 & 226 & 23.9 & 148 & 13.1 & 162 & 15.4 & 102 & 7.5 \\
\hline 12 & IEcon.DB.MSFan.CS2.DCV0 & 234 & 24.7 & 153 & 13.5 & 164 & 15.6 & 106 & 7.8 \\
\hline 13 & IEcon.EH.MSFan.CS2.DCV0 & 232 & 24.4 & 152 & 13.5 & 164 & 15.6 & 106 & 7.8 \\
\hline 14 & NoEcon.SSFan.CS1.DCV1 & 133 & 14.1 & 245 & 21.7 & 209 & 19.8 & 337 & 24.7 \\
\hline 15 & IEcon.DB.SSFan.CS1.DCV1 & 152 & 16.0 & 261 & 23.2 & 221 & 21.0 & 353 & 25.9 \\
\hline 16 & IEcon.EH.SSFan.CS1.DCV1 & 144 & 15.2 & 256 & 22.7 & 223 & 21.1 & 349 & 25.6 \\
\hline 17 & NoEcon.MSFan.CS1.DCV1 & 292 & 30.8 & 372 & 33.0 & 348 & 33.0 & 442 & 32.4 \\
\hline 18 & IEcon.DB.MSFan.CS1.DCV1 & 302 & 31.8 & 381 & 33.8 & 354 & 33.6 & 450 & 33.0 \\
\hline 19 & IEcon.EH.MSFan.CS1.DCV1 & 298 & 31.5 & 378 & 33.6 & 354 & 33.7 & 449 & 32.9 \\
\hline 20 & NoEcon.MSFan.CS2.DCV1 & 364 & 38.4 & 421 & 37.4 & 407 & 38.7 & 475 & 34.8 \\
\hline 21 & IEcon.DB.MSFan.CS2.DCV1 & 370 & 39.0 & 426 & 37.8 & 410 & 39.0 & 480 & 35.1 \\
\hline 22 & IEcon.EH.MSFan.CS2.DCV1 & 369 & 39.0 & 426 & 37.8 & 410 & 39.0 & 480 & 35.1 \\
\hline
\end{tabular}


Table C-6: HVAC Energy Savings Compared to Case 1 for the Stand-alone Retail Building in Climate Zones 3B, 3C and 4A

\begin{tabular}{|c|c|c|c|c|c|c|c|c|c|}
\hline \multirow[b]{2}{*}{$\begin{array}{c}\text { Case } \\
\text { No }\end{array}$} & \multirow[b]{2}{*}{ Case Name } & \multicolumn{2}{|c|}{ Los Angeles-3B } & \multicolumn{2}{|c|}{ Las Vegas-3B } & \multicolumn{2}{|c|}{ San Francisco-3C } & \multicolumn{2}{|c|}{ Baltimore-4A } \\
\hline & & $\begin{array}{c}\text { Abs. } \\
\left(10^{6}\right. \\
\text { Btus) }\end{array}$ & $\begin{array}{l}\text { Rel. } \\
\text { (\%) }\end{array}$ & $\begin{array}{c}\text { Abs. } \\
\left(10^{6}\right. \\
\text { Btus) }\end{array}$ & $\begin{array}{l}\text { Rel. } \\
\text { (\%) }\end{array}$ & $\begin{array}{c}\text { Abs. } \\
\left(10^{6}\right. \\
\text { Btus) }\end{array}$ & $\begin{array}{l}\text { Rel. } \\
\text { (\%) }\end{array}$ & $\begin{array}{c}\text { Abs. } \\
\left(10^{6}\right. \\
\text { Btus) }\end{array}$ & $\begin{array}{l}\text { Rel. } \\
(\%)\end{array}$ \\
\hline 2 & NIEcon.DB.SSFan.CS1.DCV0 & 55 & 8.7 & 11 & 1.0 & 16 & 1.6 & 15 & 0.9 \\
\hline 3 & NIEcon.EH.SSFan.CS1.DCV0 & 47 & 7.4 & 12 & 1.1 & 16 & 1.6 & 12 & 0.7 \\
\hline 4 & IEcon.DB.SSFan.CS1.DCV0 & 58 & 9.0 & 11 & 1.0 & 17 & 1.7 & 16 & 0.9 \\
\hline 5 & IEcon.EH.SSFan.CS1.DCV0 & 49 & 7.7 & 12 & 1.1 & 17 & 1.7 & 12 & 0.7 \\
\hline 6 & NoEcon.MSFan.CS1.DCV0 & 107 & 16.8 & 67 & 6.0 & 55 & 5.5 & 19 & 1.0 \\
\hline 7 & NIEcon.DB.MSFan.CS1.DCV0 & 133 & 20.9 & 71 & 6.4 & 61 & 6.1 & 23 & 1.3 \\
\hline 8 & NIEcon.EH.MSFan.CS1.DCV0 & 127 & 20.0 & 71 & 6.4 & 61 & 6.1 & 22 & 1.2 \\
\hline 9 & IEcon.DB.MSFan.CS1.DCV0 & 136 & 21.3 & 71 & 6.4 & 62 & 6.2 & 24 & 1.3 \\
\hline 10 & IEcon.EH.MSFan.CS1.DCV0 & 130 & 20.4 & 71 & 6.4 & 62 & 6.2 & 23 & 1.2 \\
\hline 11 & NoEcon.MSFan.CS2.DCV0 & 130 & 20.3 & 102 & 9.2 & 62 & 6.2 & 44 & 2.5 \\
\hline 12 & IEcon.DB.MSFan.CS2.DCV0 & 148 & 23.3 & 103 & 9.4 & 66 & 6.5 & 47 & 2.6 \\
\hline 13 & IEcon.EH.MSFan.CS2.DCV0 & 147 & 23.0 & 104 & 9.4 & 66 & 6.6 & 47 & 2.6 \\
\hline 14 & NoEcon.SSFan.CS1.DCV1 & 134 & 21.1 & 255 & 23.0 & 318 & 31.7 & 520 & 28.8 \\
\hline 15 & IEcon.DB.SSFan.CS1.DCV1 & 177 & 27.7 & 265 & 24.0 & 333 & 33.3 & 532 & 29.5 \\
\hline 16 & IEcon.EH.SSFan.CS1.DCV1 & 169 & 26.6 & 266 & 24.1 & 333 & 33.3 & 529 & 29.3 \\
\hline 17 & NoEcon.MSFan.CS1.DCV1 & 254 & 40.0 & 364 & 32.9 & 378 & 37.7 & 593 & 32.9 \\
\hline 18 & IEcon.DB.MSFan.CS1.DCV1 & 290 & 45.5 & 370 & 33.4 & 389 & 38.9 & 598 & 33.2 \\
\hline 19 & IEcon.EH.MSFan.CS1.DCV1 & 283 & 44.5 & 370 & 33.5 & 389 & 38.9 & 598 & 33.1 \\
\hline 20 & NoEcon.MSFan.CS2.DCV1 & 279 & 43.8 & 397 & 35.9 & 385 & 38.5 & 615 & 34.1 \\
\hline 21 & IEcon.DB.MSFan.CS2.DCV1 & 302 & 47.5 & 400 & 36.2 & 393 & 39.3 & 618 & 34.3 \\
\hline 22 & IEcon.EH.MSFan.CS2.DCV1 & 300 & 47.2 & 400 & 36.2 & 394 & 39.3 & 619 & 34.3 \\
\hline
\end{tabular}


Table C-7: HVAC Energy Savings Compared to Case 1 for the Stand-alone Retail Building in Climate Zones 4B, 4C, 5A and 5B

\begin{tabular}{|c|c|c|c|c|c|c|c|c|c|}
\hline \multirow[b]{2}{*}{$\begin{array}{c}\text { Case } \\
\text { No }\end{array}$} & \multirow[b]{2}{*}{ Case Name } & \multicolumn{2}{|c|}{ Albuquerque-4B } & \multicolumn{2}{|c|}{ Seattle-4C } & \multicolumn{2}{|c|}{ Chicago-5A } & \multicolumn{2}{|c|}{ Denver-5B } \\
\hline & & $\begin{array}{c}\text { Abs. } \\
\left(10^{6}\right. \\
\text { Btus }) \\
\end{array}$ & $\begin{array}{l}\text { Rel. } \\
\text { (\%) }\end{array}$ & $\begin{array}{c}\text { Abs. } \\
\left(10^{6}\right. \\
\text { Btus }) \\
\end{array}$ & $\begin{array}{l}\text { Rel. } \\
\text { (\%) }\end{array}$ & $\begin{array}{c}\text { Abs. } \\
\left(10^{6}\right. \\
\text { Btus }) \\
\end{array}$ & $\begin{array}{l}\text { Rel. } \\
\text { (\%) }\end{array}$ & $\begin{array}{c}\text { Abs. } \\
\left(10^{6}\right. \\
\text { Btus }) \\
\end{array}$ & $\begin{array}{l}\text { Rel. } \\
(\%)\end{array}$ \\
\hline 2 & NIEcon.DB.SSFan.CS1.DCV0 & 15 & 1.0 & 11 & 0.7 & 19 & 0.8 & 16 & 0.8 \\
\hline 3 & NIEcon.EH.SSFan.CS1.DCV0 & 14 & 1.0 & 11 & 0.7 & 15 & 0.6 & 15 & 0.8 \\
\hline 4 & IEcon.DB.SSFan.CS1.DCV0 & 15 & 1.1 & 11 & 0.8 & 19 & 0.8 & 16 & 0.9 \\
\hline 5 & IEcon.EH.SSFan.CS1.DCV0 & 14 & 1.0 & 11 & 0.7 & 15 & 0.7 & 15 & 0.8 \\
\hline 6 & NoEcon.MSFan.CS1.DCV0 & 45 & 3.1 & 25 & 1.7 & -4 & -0.2 & 12 & 0.6 \\
\hline 7 & NIEcon.DB.MSFan.CS1.DCV0 & 49 & 3.5 & 29 & 1.9 & 1 & 0.0 & 15 & 0.8 \\
\hline 8 & NIEcon.EH.MSFan.CS1.DCV0 & 49 & 3.4 & 29 & 1.9 & 0 & 0.0 & 15 & 0.8 \\
\hline 9 & IEcon.DB.MSFan.CS1.DCV0 & 50 & 3.5 & 29 & 1.9 & 2 & 0.1 & 16 & 0.9 \\
\hline 10 & IEcon.EH.MSFan.CS1.DCV0 & 50 & 3.5 & 29 & 1.9 & 0 & 0.0 & 16 & 0.8 \\
\hline 11 & NoEcon.MSFan.CS2.DCV0 & 76 & 5.3 & 33 & 2.2 & 22 & 0.9 & 33 & 1.8 \\
\hline 12 & IEcon.DB.MSFan.CS2.DCV0 & 79 & 5.5 & 35 & 2.3 & 24 & 1.0 & 35 & 1.9 \\
\hline 13 & IEcon.EH.MSFan.CS2.DCV0 & 79 & 5.6 & 35 & 2.3 & 24 & 1.0 & 35 & 1.9 \\
\hline 14 & NoEcon.SSFan.CS1.DCV1 & 362 & 25.4 & 538 & 35.7 & 637 & 27.4 & 480 & 26.0 \\
\hline 15 & IEcon.DB.SSFan.CS1.DCV1 & 375 & 26.3 & 548 & 36.4 & 648 & 27.8 & 494 & 26.7 \\
\hline 16 & IEcon.EH.SSFan.CS1.DCV1 & 375 & 26.3 & 548 & 36.4 & 645 & 27.7 & 493 & 26.7 \\
\hline 17 & NoEcon.MSFan.CS1.DCV1 & 454 & 31.9 & 570 & 37.8 & 706 & 30.3 & 557 & 30.1 \\
\hline 18 & IEcon.DB.MSFan.CS1.DCV1 & 462 & 32.4 & 576 & 38.3 & 717 & 30.8 & 564 & 30.5 \\
\hline 19 & IEcon.EH.MSFan.CS1.DCV1 & 461 & 32.3 & 576 & 38.3 & 716 & 30.8 & 564 & 30.4 \\
\hline 20 & NoEcon.MSFan.CS2.DCV1 & 483 & 33.9 & 577 & 38.3 & 730 & 31.4 & 579 & 31.3 \\
\hline 21 & IEcon.DB.MSFan.CS2.DCV1 & 486 & 34.1 & 581 & 38.6 & 735 & 31.6 & 582 & 31.4 \\
\hline 22 & IEcon.EH.MSFan.CS2.DCV1 & 487 & 34.1 & 582 & 38.6 & 736 & 31.6 & 581 & 31.4 \\
\hline
\end{tabular}


Table C-8: HVAC Energy Savings Compared to Case 1 for the Stand-alone Retail Building in Climate Zones 6, 7 and 8

\begin{tabular}{|c|c|c|c|c|c|c|c|c|c|}
\hline \multirow[b]{2}{*}{$\begin{array}{c}\text { Case } \\
\text { No }\end{array}$} & \multirow[b]{2}{*}{ Case Name } & \multicolumn{2}{|c|}{ Minneapolis-6A } & \multicolumn{2}{|c|}{ Helena-6B } & \multicolumn{2}{|c|}{ Duluth-7 } & \multicolumn{2}{|c|}{ Fairbanks-8 } \\
\hline & & $\begin{array}{c}\text { Abs. } \\
\left(10^{6}\right. \\
\text { Btus }) \\
\end{array}$ & $\begin{array}{l}\text { Rel. } \\
\text { (\%) }\end{array}$ & $\begin{array}{c}\text { Abs. } \\
\left(10^{6}\right. \\
\text { Btus }) \\
\end{array}$ & $\begin{array}{l}\text { Rel. } \\
\text { (\%) }\end{array}$ & $\begin{array}{c}\text { Abs. } \\
\left(10^{6}\right. \\
\text { Btus }) \\
\end{array}$ & $\begin{array}{l}\text { Rel. } \\
\text { (\%) }\end{array}$ & $\begin{array}{c}\text { Abs. } \\
\left(10^{6}\right. \\
\text { Btus }) \\
\end{array}$ & $\begin{array}{l}\text { Rel. } \\
\text { (\%) }\end{array}$ \\
\hline 2 & NIEcon.DB.SSFan.CS1.DCV0 & 23 & 0.8 & 18 & 0.7 & 17 & 0.5 & 117 & 2.1 \\
\hline 3 & NIEcon.EH.SSFan.CS1.DCV0 & 20 & 0.7 & 18 & 0.7 & 16 & 0.5 & 116 & 2.1 \\
\hline 4 & IEcon.DB.SSFan.CS1.DCV0 & 24 & 0.8 & 19 & 0.7 & 17 & 0.5 & 117 & 2.1 \\
\hline 5 & IEcon.EH.SSFan.CS1.DCV0 & 20 & 0.7 & 19 & 0.7 & 16 & 0.5 & 116 & 2.1 \\
\hline 6 & NoEcon.MSFan.CS1.DCV0 & -22 & -0.8 & -50 & -2.0 & -101 & -3.0 & -222 & -4.0 \\
\hline 7 & NIEcon.DB.MSFan.CS1.DCV0 & -7 & -0.3 & -37 & -1.5 & -80 & -2.3 & -64 & -1.1 \\
\hline 8 & NIEcon.EH.MSFan.CS1.DCV0 & -9 & -0.3 & -37 & -1.5 & -80 & -2.3 & -63 & -1.1 \\
\hline 9 & IEcon.DB.MSFan.CS1.DCV0 & -7 & -0.2 & -37 & -1.5 & -80 & -2.3 & -64 & -1.1 \\
\hline 10 & IEcon.EH.MSFan.CS1.DCV0 & -8 & -0.3 & -37 & -1.5 & -80 & -2.3 & -64 & -1.1 \\
\hline 11 & NoEcon.MSFan.CS2.DCV0 & 7 & 0.2 & -31 & -1.2 & -82 & -2.4 & -88 & -1.6 \\
\hline 12 & IEcon.DB.MSFan.CS2.DCV0 & 12 & 0.4 & -23 & -0.9 & -73 & -2.1 & -59 & -1.1 \\
\hline 13 & IEcon.EH.MSFan.CS2.DCV0 & 12 & 0.4 & -23 & -0.9 & -73 & -2.1 & -59 & -1.1 \\
\hline 14 & NoEcon.SSFan.CS1.DCV1 & 747 & 26.1 & 661 & 26.4 & 916 & 26.8 & 1358 & 24.2 \\
\hline 15 & IEcon.DB.SSFan.CS1.DCV1 & 761 & 26.6 & 669 & 26.7 & 932 & 27.3 & 1380 & 24.6 \\
\hline 16 & IEcon.EH.SSFan.CS1.DCV1 & 759 & 26.6 & 668 & 26.7 & 930 & 27.2 & 1380 & 24.6 \\
\hline 17 & NoEcon.MSFan.CS1.DCV1 & 824 & 28.8 & 706 & 28.2 & 945 & 27.7 & 1186 & 21.2 \\
\hline 18 & IEcon.DB.MSFan.CS1.DCV1 & 844 & 29.5 & 728 & 29.1 & 973 & 28.5 & 1384 & 24.7 \\
\hline 19 & IEcon.EH.MSFan.CS1.DCV1 & 842 & 29.5 & 728 & 29.1 & 972 & 28.4 & 1384 & 24.7 \\
\hline 20 & NoEcon.MSFan.CS2.DCV1 & 853 & 29.9 & 731 & 29.2 & 971 & 28.4 & 1369 & 24.4 \\
\hline 21 & IEcon.DB.MSFan.CS2.DCV1 & 859 & 30.1 & 741 & 29.6 & 978 & 28.6 & 1389 & 24.8 \\
\hline 22 & IEcon.EH.MSFan.CS2.DCV1 & 859 & 30.1 & 740 & 29.5 & 978 & 28.6 & 1388 & 24.8 \\
\hline
\end{tabular}


Table C-9: HVAC Energy Savings Compared to Case 1 for the Strip Mall Retail Building in Climate Zones 1, 2 and 3A

\begin{tabular}{|c|c|c|c|c|c|c|c|c|c|}
\hline \multirow{2}{*}{$\begin{array}{c}\text { Case } \\
\text { No }\end{array}$} & \multirow[b]{2}{*}{ Case Name } & \multicolumn{2}{|c|}{ Miami-1A } & \multicolumn{2}{|c|}{ Houston-2A } & \multicolumn{2}{|c|}{ Phoenix-2B } & \multicolumn{2}{|c|}{ Atlanta-3A } \\
\hline & & $\begin{array}{c}\text { Abs. } \\
\left(10^{6}\right. \\
\text { Btus }) \\
\end{array}$ & $\begin{array}{l}\text { Rel. } \\
\text { (\%) }\end{array}$ & $\begin{array}{c}\text { Abs. } \\
\left(10^{6}\right. \\
\text { Btus }) \\
\end{array}$ & $\begin{array}{l}\text { Rel. } \\
\text { (\%) }\end{array}$ & $\begin{array}{c}\text { Abs. } \\
\left(10^{6}\right. \\
\text { Btus }) \\
\end{array}$ & $\begin{array}{l}\text { Rel. } \\
(\%)\end{array}$ & $\begin{array}{c}\text { Abs. } \\
\left(10^{6}\right. \\
\text { Btus }) \\
\end{array}$ & $\begin{array}{l}\text { Rel. } \\
\text { (\%) }\end{array}$ \\
\hline 2 & NIEcon.DB.SSFan.CS1.DCV0 & 39 & 3.7 & 27 & 2.4 & 18 & 1.7 & 29 & 2.2 \\
\hline 3 & NIEcon.EH.SSFan.CS1.DCV0 & 23 & 2.1 & 19 & 1.7 & 21 & 1.9 & 23 & 1.8 \\
\hline 4 & IEcon.DB.SSFan.CS1.DCV0 & 41 & 3.8 & 27 & 2.4 & 18 & 1.7 & 30 & 2.3 \\
\hline 5 & IEcon.EH.SSFan.CS1.DCV0 & 23 & 2.2 & 19 & 1.7 & 21 & 2.0 & 24 & 1.8 \\
\hline 6 & NoEcon.MSFan.CS1.DCV0 & 164 & 15.3 & 96 & 8.6 & 101 & 9.4 & 63 & 4.8 \\
\hline 7 & NIEcon.DB.MSFan.CS1.DCV0 & 182 & 17.1 & 106 & 9.5 & 107 & 10.0 & 74 & 5.6 \\
\hline 8 & NIEcon.EH.MSFan.CS1.DCV0 & 174 & 16.3 & 103 & 9.2 & 109 & 10.2 & 72 & 5.4 \\
\hline 9 & IEcon.DB.MSFan.CS1.DCV0 & 184 & 17.2 & 107 & 9.5 & 107 & 10.0 & 75 & 5.7 \\
\hline 10 & IEcon.EH.MSFan.CS1.DCV0 & 175 & 16.4 & 103 & 9.2 & 110 & 10.2 & 72 & 5.5 \\
\hline 11 & NoEcon.MSFan.CS2.DCV0 & 264 & 24.7 & 153 & 13.7 & 165 & 15.4 & 106 & 8.0 \\
\hline 12 & IEcon.DB.MSFan.CS2.DCV0 & 274 & 25.7 & 159 & 14.2 & 168 & 15.6 & 112 & 8.5 \\
\hline 13 & IEcon.EH.MSFan.CS2.DCV0 & 272 & 25.4 & 158 & 14.1 & 169 & 15.7 & 112 & 8.5 \\
\hline 14 & NoEcon.SSFan.CS1.DCV1 & 144 & 13.5 & 243 & 21.7 & 207 & 19.3 & 333 & 25.2 \\
\hline 15 & IEcon.DB.SSFan.CS1.DCV1 & 169 & 15.9 & 257 & 23.0 & 213 & 19.8 & 345 & 26.1 \\
\hline 16 & IEcon.EH.SSFan.CS1.DCV1 & 154 & 14.4 & 251 & 22.4 & 216 & 20.1 & 340 & 25.7 \\
\hline 17 & NoEcon.MSFan.CS1.DCV1 & 322 & 30.1 & 374 & 33.4 & 344 & 32.0 & 442 & 33.5 \\
\hline 18 & IEcon.DB.MSFan.CS1.DCV1 & 340 & 31.8 & 384 & 34.3 & 348 & 32.4 & 452 & 34.2 \\
\hline 19 & IEcon.EH.MSFan.CS1.DCV1 & 330 & 30.9 & 380 & 34.0 & 349 & 32.6 & 449 & 34.0 \\
\hline 20 & NoEcon.MSFan.CS2.DCV1 & 412 & 38.6 & 425 & 38.0 & 403 & 37.6 & 477 & 36.1 \\
\hline 21 & IEcon.DB.MSFan.CS2.DCV1 & 418 & 39.2 & 429 & 38.4 & 404 & 37.7 & 481 & 36.4 \\
\hline 22 & IEcon.EH.MSFan.CS2.DCV1 & 416 & 39.0 & 428 & 38.3 & 405 & 37.7 & 480 & 36.3 \\
\hline
\end{tabular}


Table C-10: HVAC Energy Savings Compared to Case 1 for the Strip Mall Retail Building in Climate Zones 3B, 3C and 4A

\begin{tabular}{|c|c|c|c|c|c|c|c|c|c|}
\hline \multirow[b]{2}{*}{$\begin{array}{c}\text { Case } \\
\text { No }\end{array}$} & \multirow[b]{2}{*}{ Case Name } & \multicolumn{2}{|c|}{ Los Angeles-3B } & \multicolumn{2}{|c|}{ Las Vegas-3B } & \multicolumn{2}{|c|}{ San Francisco-3C } & \multicolumn{2}{|c|}{ Baltimore-4A } \\
\hline & & $\begin{array}{c}\text { Abs. } \\
\left(\mathbf{1 0}^{6}\right. \\
\text { Btus })\end{array}$ & $\begin{array}{l}\text { Rel. } \\
\text { (\%) }\end{array}$ & $\begin{array}{c}\text { Abs. } \\
\left(10^{6}\right. \\
\text { Btus })\end{array}$ & $\begin{array}{l}\text { Rel. } \\
\text { (\%) }\end{array}$ & $\begin{array}{c}\text { Abs. } \\
\left(10^{6}\right. \\
\text { Btus })\end{array}$ & $\begin{array}{l}\text { Rel. } \\
\text { (\%) }\end{array}$ & $\begin{array}{c}\text { Abs. } \\
\left(\mathbf{1 0}^{6}\right. \\
\text { Btus })\end{array}$ & $\begin{array}{l}\text { Rel. } \\
\text { (\%) }\end{array}$ \\
\hline 2 & NIEcon.DB.SSFan.CS1.DCV0 & 74 & 10.5 & 16 & 1.5 & 25 & 2.6 & 19 & 1.1 \\
\hline 3 & NIEcon.EH.SSFan.CS1.DCV0 & 64 & 9.1 & 18 & 1.6 & 25 & 2.6 & 15 & 0.8 \\
\hline 4 & IEcon.DB.SSFan.CS1.DCV0 & 77 & 10.9 & 17 & 1.5 & 26 & 2.7 & 19 & 1.1 \\
\hline 5 & IEcon.EH.SSFan.CS1.DCV0 & 67 & 9.4 & 18 & 1.6 & 26 & 2.7 & 15 & 0.9 \\
\hline 6 & NoEcon.MSFan.CS1.DCV0 & 113 & 16.1 & 77 & 6.9 & 31 & 3.3 & 11 & 0.6 \\
\hline 7 & NIEcon.DB.MSFan.CS1.DCV0 & 152 & 21.5 & 82 & 7.4 & 42 & 4.4 & 18 & 1.0 \\
\hline 8 & NIEcon.EH.MSFan.CS1.DCV0 & 145 & 20.5 & 83 & 7.5 & 42 & 4.4 & 16 & 0.9 \\
\hline 9 & IEcon.DB.MSFan.CS1.DCV0 & 156 & 22.1 & 83 & 7.4 & 43 & 4.6 & 19 & 1.0 \\
\hline 10 & IEcon.EH.MSFan.CS1.DCV0 & 148 & 21.0 & 84 & 7.5 & 43 & 4.6 & 17 & 1.0 \\
\hline 11 & NoEcon.MSFan.CS2.DCV0 & 144 & 20.4 & 116 & 10.4 & 41 & 4.3 & 39 & 2.2 \\
\hline 12 & IEcon.DB.MSFan.CS2.DCV0 & 168 & 23.8 & 118 & 10.6 & 47 & 5.0 & 43 & 2.4 \\
\hline 13 & IEcon.EH.MSFan.CS2.DCV0 & 167 & 23.7 & 119 & 10.7 & 47 & 5.1 & 43 & 2.4 \\
\hline 14 & NoEcon.SSFan.CS1.DCV1 & 158 & 22.4 & 248 & 22.4 & 301 & 32.1 & 511 & 28.8 \\
\hline 15 & IEcon.DB.SSFan.CS1.DCV1 & 189 & 26.8 & 253 & 22.8 & 307 & 32.8 & 520 & 29.3 \\
\hline 16 & IEcon.EH.SSFan.CS1.DCV1 & 182 & 25.8 & 254 & 22.9 & 307 & 32.7 & 517 & 29.1 \\
\hline 17 & NoEcon.MSFan.CS1.DCV1 & 275 & 39.0 & 367 & 33.1 & 377 & 40.1 & 586 & 33.0 \\
\hline 18 & IEcon.DB.MSFan.CS1.DCV1 & 314 & 44.4 & 371 & 33.4 & 387 & 41.2 & 593 & 33.4 \\
\hline 19 & IEcon.EH.MSFan.CS1.DCV1 & 306 & 43.3 & 372 & 33.5 & 387 & 41.2 & 591 & 33.3 \\
\hline 20 & NoEcon.MSFan.CS2.DCV1 & 309 & 43.8 & 402 & 36.2 & 387 & 41.2 & 610 & 34.4 \\
\hline 21 & IEcon.DB.MSFan.CS2.DCV1 & 326 & 46.1 & 403 & 36.3 & 392 & 41.7 & 612 & 34.5 \\
\hline 22 & IEcon.EH.MSFan.CS2.DCV1 & 324 & 45.9 & 403 & 36.3 & 392 & 41.7 & 612 & 34.5 \\
\hline
\end{tabular}


Table C-11: HVAC Energy Savings Compared to Case 1 for the Strip Mall Retail Building in Climate Zones 4B, 4C, 5A and 5B

\begin{tabular}{|c|c|c|c|c|c|c|c|c|c|}
\hline \multirow[b]{2}{*}{$\begin{array}{c}\text { Case } \\
\text { No }\end{array}$} & \multirow[b]{2}{*}{ Case Name } & \multicolumn{2}{|c|}{ Albuquerque-4B } & \multicolumn{2}{|c|}{ Seattle-4C } & \multicolumn{2}{|c|}{ Chicago-5A } & \multicolumn{2}{|c|}{ Denver-5B } \\
\hline & & $\begin{array}{c}\text { Abs. } \\
\left(10^{6}\right. \\
\text { Btus) } \\
\end{array}$ & $\begin{array}{l}\text { Rel. } \\
\text { (\%) }\end{array}$ & $\begin{array}{c}\text { Abs. } \\
\left(10^{6}\right. \\
\text { Btus) } \\
\end{array}$ & $\begin{array}{l}\text { Rel. } \\
\text { (\%) }\end{array}$ & $\begin{array}{c}\text { Abs. } \\
\left(10^{6}\right. \\
\text { Btus) } \\
\end{array}$ & $\begin{array}{l}\text { Rel. } \\
\text { (\%) }\end{array}$ & $\begin{array}{c}\text { Abs. } \\
\left(10^{6}\right. \\
\text { Btus) } \\
\end{array}$ & $\begin{array}{l}\text { Rel. } \\
\text { (\%) }\end{array}$ \\
\hline 2 & NIEcon.DB.SSFan.CS1.DCV0 & 19 & 1.3 & 16 & 1.1 & 23 & 1.0 & 19 & 1.1 \\
\hline 3 & NIEcon.EH.SSFan.CS1.DCV0 & 18 & 1.3 & 16 & 1.0 & 19 & 0.8 & 19 & 1.0 \\
\hline 4 & IEcon.DB.SSFan.CS1.DCV0 & 19 & 1.4 & 17 & 1.1 & 24 & 1.0 & 19 & 1.1 \\
\hline 5 & IEcon.EH.SSFan.CS1.DCV0 & 18 & 1.3 & 16 & 1.1 & 19 & 0.8 & 19 & 1.1 \\
\hline 6 & NoEcon.MSFan.CS1.DCV0 & 42 & 3.1 & -16 & -1.0 & -16 & -0.7 & 6 & 0.3 \\
\hline 7 & NIEcon.DB.MSFan.CS1.DCV0 & 49 & 3.6 & -9 & -0.6 & -8 & -0.4 & 11 & 0.6 \\
\hline 8 & NIEcon.EH.MSFan.CS1.DCV0 & 49 & 3.6 & -10 & -0.6 & -10 & -0.4 & 12 & 0.6 \\
\hline 9 & IEcon.DB.MSFan.CS1.DCV0 & 50 & 3.6 & -9 & -0.6 & -7 & -0.3 & 12 & 0.7 \\
\hline 10 & IEcon.EH.MSFan.CS1.DCV0 & 50 & 3.6 & -9 & -0.6 & -9 & -0.4 & 12 & 0.7 \\
\hline 11 & NoEcon.MSFan.CS2.DCV0 & 75 & 5.5 & -6 & -0.4 & 11 & 0.5 & 31 & 1.7 \\
\hline 12 & IEcon.DB.MSFan.CS2.DCV0 & 78 & 5.7 & -2 & -0.2 & 15 & 0.7 & 33 & 1.9 \\
\hline 13 & IEcon.EH.MSFan.CS2.DCV0 & 79 & 5.7 & -2 & -0.1 & 15 & 0.7 & 34 & 1.9 \\
\hline 14 & NoEcon.SSFan.CS1.DCV1 & 355 & 25.7 & 525 & 35.0 & 627 & 27.2 & 471 & 26.2 \\
\hline 15 & IEcon.DB.SSFan.CS1.DCV1 & 363 & 26.3 & 531 & 35.4 & 636 & 27.6 & 477 & 26.6 \\
\hline 16 & IEcon.EH.SSFan.CS1.DCV1 & 363 & 26.3 & 530 & 35.4 & 633 & 27.4 & 478 & 26.6 \\
\hline 17 & NoEcon.MSFan.CS1.DCV1 & 447 & 32.3 & 570 & 38.1 & 705 & 30.6 & 555 & 30.9 \\
\hline 18 & IEcon.DB.MSFan.CS1.DCV1 & 452 & 32.7 & 577 & 38.5 & 712 & 30.9 & 559 & 31.1 \\
\hline 19 & IEcon.EH.MSFan.CS1.DCV1 & 452 & 32.7 & 576 & 38.4 & 710 & 30.8 & 559 & 31.1 \\
\hline 20 & NoEcon.MSFan.CS2.DCV1 & 475 & 34.4 & 580 & 38.7 & 728 & 31.6 & 578 & 32.2 \\
\hline 21 & IEcon.DB.MSFan.CS2.DCV1 & 477 & 34.5 & 582 & 38.8 & 730 & 31.7 & 579 & 32.2 \\
\hline 22 & IEcon.EH.MSFan.CS2.DCV1 & 478 & 34.6 & 582 & 38.8 & 730 & 31.6 & 579 & 32.2 \\
\hline
\end{tabular}


Table C-12: HVAC Energy Savings Compared to Case 1 for the Strip Mall Retail Building in Climate Zones 6, 7 and 8

\begin{tabular}{|c|c|c|c|c|c|c|c|c|c|}
\hline \multirow[b]{2}{*}{$\begin{array}{c}\text { Case } \\
\text { No }\end{array}$} & \multirow[b]{2}{*}{ Case Name } & \multicolumn{2}{|c|}{ Minneapolis-6A } & \multicolumn{2}{|c|}{ Helena-6B } & \multicolumn{2}{|c|}{ Duluth-7 } & \multicolumn{2}{|c|}{ Fairbanks-8 } \\
\hline & & $\begin{array}{c}\text { Abs. } \\
\left(10^{6}\right. \\
\text { Btus) } \\
\end{array}$ & $\begin{array}{l}\text { Rel. } \\
\text { (\%) }\end{array}$ & $\begin{array}{c}\text { Abs. } \\
\left(10^{6}\right. \\
\text { Btus) }\end{array}$ & $\begin{array}{l}\text { Rel. } \\
\text { (\%) }\end{array}$ & $\begin{array}{c}\text { Abs. } \\
\left(10^{6}\right. \\
\text { Btus) }\end{array}$ & $\begin{array}{l}\text { Rel. } \\
(\%)\end{array}$ & $\begin{array}{c}\text { Abs. } \\
\left(10^{6}\right. \\
\text { Btus) } \\
\end{array}$ & $\begin{array}{l}\text { Rel. } \\
\text { (\%) }\end{array}$ \\
\hline 2 & NIEcon.DB.SSFan.CS1.DCV0 & 36 & 1.3 & 29 & 1.2 & 41 & 1.2 & 164 & 2.9 \\
\hline 3 & NIEcon.EH.SSFan.CS1.DCV0 & 32 & 1.1 & 29 & 1.2 & 40 & 1.2 & 164 & 2.9 \\
\hline 4 & IEcon.DB.SSFan.CS1.DCV0 & 36 & 1.3 & 30 & 1.2 & 42 & 1.2 & 164 & 2.9 \\
\hline 5 & IEcon.EH.SSFan.CS1.DCV0 & 32 & 1.1 & 29 & 1.2 & 40 & 1.2 & 164 & 2.9 \\
\hline 6 & NoEcon.MSFan.CS1.DCV0 & -29 & -1.0 & -55 & -2.2 & -103 & -3.0 & -212 & -3.8 \\
\hline 7 & NIEcon.DB.MSFan.CS1.DCV0 & -10 & -0.3 & -38 & -1.5 & -72 & -2.1 & -28 & -0.5 \\
\hline 8 & NIEcon.EH.MSFan.CS1.DCV0 & -11 & -0.4 & -38 & -1.5 & -73 & -2.1 & -27 & -0.5 \\
\hline 9 & IEcon.DB.MSFan.CS1.DCV0 & -9 & -0.3 & -38 & -1.5 & -72 & -2.1 & -27 & -0.5 \\
\hline 10 & IEcon.EH.MSFan.CS1.DCV0 & -11 & -0.4 & -38 & -1.5 & -72 & -2.1 & -27 & -0.5 \\
\hline 11 & NoEcon.MSFan.CS2.DCV0 & 4 & 0.1 & -30 & -1.2 & -74 & -2.2 & -58 & -1.0 \\
\hline 12 & IEcon.DB.MSFan.CS2.DCV0 & 11 & 0.4 & -20 & -0.8 & -64 & -1.9 & -23 & -0.4 \\
\hline 13 & IEcon.EH.MSFan.CS2.DCV0 & 11 & 0.4 & -20 & -0.8 & -64 & -1.9 & -23 & -0.4 \\
\hline 14 & NoEcon.SSFan.CS1.DCV1 & 742 & 26.1 & 665 & 26.6 & 922 & 27.1 & 1406 & 25.2 \\
\hline 15 & IEcon.DB.SSFan.CS1.DCV1 & 750 & 26.3 & 670 & 26.8 & 926 & 27.2 & 1399 & 25.0 \\
\hline 16 & IEcon.EH.SSFan.CS1.DCV1 & 747 & 26.2 & 670 & 26.8 & 925 & 27.2 & 1400 & 25.0 \\
\hline 17 & NoEcon.MSFan.CS1.DCV1 & 821 & 28.8 & 718 & 28.7 & 947 & 27.8 & 1054 & 18.8 \\
\hline 18 & IEcon.DB.MSFan.CS1.DCV1 & 836 & 29.3 & 730 & 29.1 & 969 & 28.5 & 1329 & 23.8 \\
\hline 19 & IEcon.EH.MSFan.CS1.DCV1 & 834 & 29.3 & 730 & 29.2 & 969 & 28.4 & 1329 & 23.8 \\
\hline 20 & NoEcon.MSFan.CS2.DCV1 & 847 & 29.7 & 739 & 29.5 & 967 & 28.4 & 1333 & 23.8 \\
\hline 21 & IEcon.DB.MSFan.CS2.DCV1 & 852 & 29.9 & 746 & 29.8 & 976 & 28.7 & 1333 & 23.8 \\
\hline 22 & IEcon.EH.MSFan.CS2.DCV1 & 851 & 29.9 & 746 & 29.8 & 976 & 28.6 & 1333 & 23.8 \\
\hline
\end{tabular}


Table C-13: HVAC Energy Savings Compared to Case 1 for the Supermarket Building in Climate Zones 1, 2 and 3A

\begin{tabular}{|c|c|c|c|c|c|c|c|c|c|}
\hline \multirow{2}{*}{$\begin{array}{c}\text { Case } \\
\text { No }\end{array}$} & \multirow[b]{2}{*}{ Case Name } & \multicolumn{2}{|c|}{ Miami-1A } & \multicolumn{2}{|c|}{ Houston-2A } & \multicolumn{2}{|c|}{ Phoenix-2B } & \multicolumn{2}{|c|}{ Atlanta-3A } \\
\hline & & $\begin{array}{c}\text { Abs. } \\
\left(10^{6}\right. \\
\text { Btus }) \\
\end{array}$ & $\begin{array}{l}\text { Rel. } \\
\text { (\%) }\end{array}$ & $\begin{array}{c}\text { Abs. } \\
\left(10^{6}\right. \\
\text { Btus }) \\
\end{array}$ & $\begin{array}{l}\text { Rel. } \\
\text { (\%) }\end{array}$ & $\begin{array}{c}\text { Abs. } \\
\left(10^{6}\right. \\
\text { Btus }) \\
\end{array}$ & $\begin{array}{l}\text { Rel. } \\
(\%)\end{array}$ & $\begin{array}{c}\text { Abs. } \\
\left(10^{6}\right. \\
\text { Btus }) \\
\end{array}$ & $\begin{array}{l}\text { Rel. } \\
\text { (\%) }\end{array}$ \\
\hline 2 & NIEcon.DB.SSFan.CS1.DCV0 & 29 & 2.2 & 40 & 1.6 & 36 & 1.5 & 59 & 1.7 \\
\hline 3 & NIEcon.EH.SSFan.CS1.DCV0 & 16 & 1.2 & 29 & 1.2 & 36 & 1.5 & 49 & 1.4 \\
\hline 4 & IEcon.DB.SSFan.CS1.DCV0 & 29 & 2.2 & 40 & 1.6 & 36 & 1.5 & 60 & 1.7 \\
\hline 5 & IEcon.EH.SSFan.CS1.DCV0 & 16 & 1.2 & 29 & 1.2 & 36 & 1.5 & 49 & 1.4 \\
\hline 6 & NoEcon.MSFan.CS1.DCV0 & 360 & 27.4 & 287 & 11.3 & 235 & 9.7 & 127 & 3.5 \\
\hline 7 & NIEcon.DB.MSFan.CS1.DCV0 & 377 & 28.7 & 317 & 12.5 & 266 & 10.9 & 176 & 4.9 \\
\hline 8 & NIEcon.EH.MSFan.CS1.DCV0 & 369 & 28.1 & 312 & 12.3 & 266 & 10.9 & 171 & 4.7 \\
\hline 9 & IEcon.DB.MSFan.CS1.DCV0 & 376 & 28.6 & 317 & 12.5 & 266 & 10.9 & 176 & 4.9 \\
\hline 10 & IEcon.EH.MSFan.CS1.DCV0 & 370 & 28.1 & 312 & 12.3 & 266 & 11.0 & 171 & 4.8 \\
\hline 11 & NoEcon.MSFan.CS2.DCV0 & 459 & 34.9 & 388 & 15.3 & 337 & 13.9 & 205 & 5.7 \\
\hline 12 & IEcon.DB.MSFan.CS2.DCV0 & 469 & 35.6 & 400 & 15.8 & 348 & 14.3 & 222 & 6.2 \\
\hline 13 & IEcon.EH.MSFan.CS2.DCV0 & 464 & 35.3 & 398 & 15.7 & 348 & 14.3 & 221 & 6.1 \\
\hline 14 & NoEcon.SSFan.CS1.DCV1 & 168 & 12.8 & 451 & 17.8 & 413 & 17.0 & 675 & 18.8 \\
\hline 15 & IEcon.DB.SSFan.CS1.DCV1 & 197 & 15.0 & 492 & 19.5 & 450 & 18.5 & 735 & 20.5 \\
\hline 16 & IEcon.EH.SSFan.CS1.DCV1 & 184 & 14.0 & 480 & 19.0 & 449 & 18.5 & 724 & 20.1 \\
\hline 17 & NoEcon.MSFan.CS1.DCV1 & 536 & 40.8 & 766 & 30.3 & 663 & 27.3 & 822 & 22.9 \\
\hline 18 & IEcon.DB.MSFan.CS1.DCV1 & 551 & 41.9 & 796 & 31.5 & 693 & 28.5 & 869 & 24.2 \\
\hline 19 & IEcon.EH.MSFan.CS1.DCV1 & 545 & 41.5 & 791 & 31.3 & 693 & 28.5 & 864 & 24.0 \\
\hline 20 & NoEcon.MSFan.CS2.DCV1 & 618 & 47.0 & 842 & 33.3 & 746 & 30.7 & 889 & 24.7 \\
\hline 21 & IEcon.DB.MSFan.CS2.DCV1 & 627 & 47.7 & 854 & 33.8 & 756 & 31.1 & 905 & 25.2 \\
\hline 22 & IEcon.EH.MSFan.CS2.DCV1 & 623 & 47.4 & 852 & 33.7 & 756 & 31.1 & 903 & 25.2 \\
\hline
\end{tabular}


Table C-14: HVAC Energy Savings Compared to Case 1 for the Supermarket Building in Climate Zones 3B, 3C and 4A

\begin{tabular}{|c|c|c|c|c|c|c|c|c|c|}
\hline \multirow[b]{2}{*}{$\begin{array}{c}\text { Case } \\
\text { No }\end{array}$} & \multirow[b]{2}{*}{ Case Name } & \multicolumn{2}{|c|}{ Los Angeles-3B } & \multicolumn{2}{|c|}{ Las Vegas-3B } & \multicolumn{2}{|c|}{ San Francisco-3C } & \multicolumn{2}{|c|}{ Baltimore-4A } \\
\hline & & $\begin{array}{c}\text { Abs. } \\
\left(10^{6}\right. \\
\text { Btus }) \\
\end{array}$ & $\begin{array}{l}\text { Rel. } \\
\text { (\%) }\end{array}$ & $\begin{array}{c}\text { Abs. } \\
\left(10^{6}\right. \\
\text { Btus) } \\
\end{array}$ & $\begin{array}{l}\text { Rel. } \\
\text { (\%) }\end{array}$ & $\begin{array}{c}\text { Abs. } \\
\left(10^{6}\right. \\
\text { Btus }) \\
\end{array}$ & $\begin{array}{l}\text { Rel. } \\
\text { (\%) }\end{array}$ & $\begin{array}{c}\text { Abs. } \\
\left(10^{6}\right. \\
\text { Btus }) \\
\end{array}$ & $\begin{array}{l}\text { Rel. } \\
\text { (\%) }\end{array}$ \\
\hline 2 & NIEcon.DB.SSFan.CS1.DCV0 & 71 & 3.5 & 42 & 1.4 & 37 & 1.1 & 53 & 1.1 \\
\hline 3 & NIEcon.EH.SSFan.CS1.DCV0 & 60 & 3.0 & 42 & 1.4 & 36 & 1.1 & 46 & 1.0 \\
\hline 4 & IEcon.DB.SSFan.CS1.DCV0 & 73 & 3.6 & 43 & 1.4 & 37 & 1.1 & 53 & 1.1 \\
\hline 5 & IEcon.EH.SSFan.CS1.DCV0 & 61 & 3.0 & 43 & 1.4 & 37 & 1.1 & 46 & 1.0 \\
\hline 6 & NoEcon.MSFan.CS1.DCV0 & 105 & 5.2 & 165 & 5.3 & -99 & -2.9 & 1 & 0.0 \\
\hline 7 & NIEcon.DB.MSFan.CS1.DCV0 & 150 & 7.4 & 199 & 6.4 & -74 & -2.1 & 57 & 1.2 \\
\hline 8 & NIEcon.EH.MSFan.CS1.DCV0 & 144 & 7.1 & 199 & 6.4 & -74 & -2.2 & 53 & 1.1 \\
\hline 9 & IEcon.DB.MSFan.CS1.DCV0 & 152 & 7.5 & 199 & 6.4 & -73 & -2.1 & 57 & 1.2 \\
\hline 10 & IEcon.EH.MSFan.CS1.DCV0 & 146 & 7.2 & 199 & 6.4 & -74 & -2.1 & 54 & 1.1 \\
\hline 11 & NoEcon.MSFan.CS2.DCV0 & 139 & 6.8 & 240 & 7.7 & -82 & -2.4 & 73 & 1.5 \\
\hline 12 & IEcon.DB.MSFan.CS2.DCV0 & 162 & 8.0 & 253 & 8.1 & -69 & -2.0 & 89 & 1.9 \\
\hline 13 & IEcon.EH.MSFan.CS2.DCV0 & 161 & 7.9 & 253 & 8.1 & -69 & -2.0 & 88 & 1.8 \\
\hline 14 & NoEcon.SSFan.CS1.DCV1 & 388 & 19.1 & 532 & 17.0 & 778 & 22.6 & 979 & 20.4 \\
\hline 15 & IEcon.DB.SSFan.CS1.DCV1 & 465 & 22.9 & 575 & 18.4 & 816 & 23.7 & 1031 & 21.5 \\
\hline 16 & IEcon.EH.SSFan.CS1.DCV1 & 449 & 22.1 & 575 & 18.4 & 816 & 23.7 & 1023 & 21.3 \\
\hline 17 & NoEcon.MSFan.CS1.DCV1 & 525 & 25.9 & 695 & 22.2 & 692 & 20.1 & 997 & 20.8 \\
\hline 18 & IEcon.DB.MSFan.CS1.DCV1 & 572 & 28.2 & 729 & 23.3 & 717 & 20.8 & 1050 & 21.9 \\
\hline 19 & IEcon.EH.MSFan.CS1.DCV1 & 566 & 27.9 & 729 & 23.3 & 716 & 20.8 & 1047 & 21.8 \\
\hline 20 & NoEcon.MSFan.CS2.DCV1 & 560 & 27.6 & 761 & 24.3 & 708 & 20.5 & 1057 & 22.0 \\
\hline 21 & IEcon.DB.MSFan.CS2.DCV1 & 582 & 28.7 & 773 & 24.7 & 721 & 20.9 & 1074 & 22.4 \\
\hline 22 & IEcon.EH.MSFan.CS2.DCV1 & 582 & 28.6 & 774 & 24.7 & 721 & 20.9 & 1073 & 22.3 \\
\hline
\end{tabular}


Table C-15: HVAC Energy Savings Compared to Case 1 for the Supermarket Building in Climate Zones 4B, 4C, 5A and 5B

\begin{tabular}{|c|c|c|c|c|c|c|c|c|c|}
\hline \multirow[b]{2}{*}{$\begin{array}{c}\text { Case } \\
\text { No }\end{array}$} & \multirow[b]{2}{*}{ Case Name } & \multicolumn{2}{|c|}{ Albuquerque-4B } & \multicolumn{2}{|c|}{ Seattle-4C } & \multicolumn{2}{|c|}{ Chicago-5A } & \multicolumn{2}{|c|}{ Denver-5B } \\
\hline & & $\begin{array}{c}\text { Abs. } \\
\left(10^{6}\right. \\
\text { Btus })\end{array}$ & $\begin{array}{l}\text { Rel. } \\
\text { (\%) }\end{array}$ & $\begin{array}{c}\text { Abs. } \\
\left(10^{6}\right. \\
\text { Btus })\end{array}$ & $\begin{array}{l}\text { Rel. } \\
\text { (\%) }\end{array}$ & $\begin{array}{c}\text { Abs. } \\
\left(10^{6}\right. \\
\text { Btus) }\end{array}$ & $\begin{array}{l}\text { Rel. } \\
\text { (\%) }\end{array}$ & $\begin{array}{c}\text { Abs. } \\
\left(10^{6}\right. \\
\text { Btus) }\end{array}$ & $\begin{array}{l}\text { Rel. } \\
(\%)\end{array}$ \\
\hline 2 & NIEcon.DB.SSFan.CS1.DCV0 & 58 & 1.4 & 46 & 1.0 & 68 & 1.1 & 67 & 1.3 \\
\hline 3 & NIEcon.EH.SSFan.CS1.DCV0 & 54 & 1.3 & 45 & 1.0 & 59 & 1.0 & 65 & 1.2 \\
\hline 4 & IEcon.DB.SSFan.CS1.DCV0 & 58 & 1.4 & 47 & 1.0 & 68 & 1.1 & 67 & 1.3 \\
\hline 5 & IEcon.EH.SSFan.CS1.DCV0 & 55 & 1.3 & 45 & 1.0 & 59 & 1.0 & 65 & 1.2 \\
\hline 6 & NoEcon.MSFan.CS1.DCV0 & 50 & 1.2 & -146 & -3.2 & -129 & -2.1 & -133 & -2.5 \\
\hline 7 & NIEcon.DB.MSFan.CS1.DCV0 & 96 & 2.3 & -103 & -2.2 & -52 & -0.9 & -78 & -1.5 \\
\hline 8 & NIEcon.EH.MSFan.CS1.DCV0 & 94 & 2.2 & -104 & -2.3 & -56 & -0.9 & -80 & -1.5 \\
\hline 9 & IEcon.DB.MSFan.CS1.DCV0 & 97 & 2.3 & -103 & -2.2 & -52 & -0.9 & -78 & -1.5 \\
\hline 10 & IEcon.EH.MSFan.CS1.DCV0 & 94 & 2.3 & -103 & -2.3 & -56 & -0.9 & -80 & -1.5 \\
\hline 11 & NoEcon.MSFan.CS2.DCV0 & 120 & 2.9 & -113 & -2.5 & -42 & -0.7 & -77 & -1.5 \\
\hline 12 & IEcon.DB.MSFan.CS2.DCV0 & 137 & 3.3 & -97 & -2.1 & -26 & -0.4 & -55 & -1.0 \\
\hline 13 & IEcon.EH.MSFan.CS2.DCV0 & 136 & 3.3 & -97 & -2.1 & -27 & -0.4 & -55 & -1.0 \\
\hline 14 & NoEcon.SSFan.CS1.DCV1 & 746 & 17.9 & 1039 & 22.6 & 1181 & 19.6 & 958 & 18.2 \\
\hline 15 & IEcon.DB.SSFan.CS1.DCV1 & 803 & 19.2 & 1085 & 23.6 & 1278 & 21.2 & 1036 & 19.6 \\
\hline 16 & IEcon.EH.SSFan.CS1.DCV1 & 799 & 19.1 & 1083 & 23.6 & 1263 & 20.9 & 1031 & 19.5 \\
\hline 17 & NoEcon.MSFan.CS1.DCV1 & 789 & 18.9 & 902 & 19.6 & 1062 & 17.6 & 801 & 15.2 \\
\hline 18 & IEcon.DB.MSFan.CS1.DCV1 & 831 & 19.9 & 943 & 20.5 & 1179 & 19.5 & 868 & 16.5 \\
\hline 19 & IEcon.EH.MSFan.CS1.DCV1 & 829 & 19.8 & 941 & 20.5 & 1164 & 19.3 & 865 & 16.4 \\
\hline 20 & NoEcon.MSFan.CS2.DCV1 & 846 & 20.2 & 932 & 20.3 & 1168 & 19.4 & 863 & 16.4 \\
\hline 21 & IEcon.DB.MSFan.CS2.DCV1 & 862 & 20.6 & 947 & 20.6 & 1203 & 19.9 & 891 & 16.9 \\
\hline 22 & IEcon.EH.MSFan.CS2.DCV1 & 862 & 20.6 & 947 & 20.6 & 1199 & 19.9 & 891 & 16.9 \\
\hline
\end{tabular}


Table C-16: HVAC Energy Savings Compared to Case 1 for the Supermarket Building in Climate Zones 6, 7 and 8

\begin{tabular}{|c|c|c|c|c|c|c|c|c|c|}
\hline \multirow[b]{2}{*}{$\begin{array}{c}\text { Case } \\
\text { No }\end{array}$} & \multirow[b]{2}{*}{ Case Name } & \multicolumn{2}{|c|}{ Minneapolis-6A } & \multicolumn{2}{|c|}{ Helena-6B } & \multicolumn{2}{|c|}{ Duluth-7 } & \multicolumn{2}{|c|}{ Fairbanks-8 } \\
\hline & & $\begin{array}{c}\text { Abs. } \\
\left(10^{6}\right. \\
\text { Btus) }\end{array}$ & $\begin{array}{l}\text { Rel. } \\
(\%)\end{array}$ & $\begin{array}{c}\text { Abs. } \\
\left(10^{6}\right. \\
\text { Btus })\end{array}$ & $\begin{array}{l}\text { Rel. } \\
(\%)\end{array}$ & $\begin{array}{c}\text { Abs. } \\
\left(10^{6}\right. \\
\text { Btus })\end{array}$ & $\begin{array}{l}\text { Rel. } \\
\text { (\%) }\end{array}$ & $\begin{array}{c}\text { Abs. } \\
\left(10^{6}\right. \\
\text { Btus })\end{array}$ & $\begin{array}{l}\text { Rel. } \\
\text { (\%) }\end{array}$ \\
\hline 2 & NIEcon.DB.SSFan.CS1.DCV0 & 114 & 1.6 & 115 & 1.7 & 137 & 1.6 & 252 & 1.9 \\
\hline 3 & NIEcon.EH.SSFan.CS1.DCV0 & 108 & 1.5 & 113 & 1.7 & 133 & 1.6 & 251 & 1.9 \\
\hline 4 & IEcon.DB.SSFan.CS1.DCV0 & 115 & 1.6 & 114 & 1.7 & 138 & 1.6 & 252 & 1.9 \\
\hline 5 & IEcon.EH.SSFan.CS1.DCV0 & 108 & 1.5 & 113 & 1.7 & 133 & 1.6 & 250 & 1.9 \\
\hline 6 & NoEcon.MSFan.CS1.DCV0 & -244 & -3.4 & -351 & -5.2 & -463 & -5.4 & -677 & -5.2 \\
\hline 7 & NIEcon.DB.MSFan.CS1.DCV0 & -87 & -1.2 & -203 & -3.0 & -287 & -3.3 & -287 & -2.2 \\
\hline 8 & NIEcon.EH.MSFan.CS1.DCV0 & -94 & -1.3 & -209 & -3.1 & -296 & -3.5 & -293 & -2.3 \\
\hline 9 & IEcon.DB.MSFan.CS1.DCV0 & -87 & -1.2 & -203 & -3.0 & -286 & -3.3 & -287 & -2.2 \\
\hline 10 & IEcon.EH.MSFan.CS1.DCV0 & -94 & -1.3 & -210 & -3.1 & -296 & -3.5 & -293 & -2.3 \\
\hline 11 & NoEcon.MSFan.CS2.DCV0 & -107 & -1.5 & -253 & -3.7 & -348 & -4.1 & -365 & -2.8 \\
\hline 12 & IEcon.DB.MSFan.CS2.DCV0 & -65 & -0.9 & -187 & -2.8 & -281 & -3.3 & -280 & -2.2 \\
\hline 13 & IEcon.EH.MSFan.CS2.DCV0 & -66 & -0.9 & -188 & -2.8 & -283 & -3.3 & -282 & -2.2 \\
\hline 14 & NoEcon.SSFan.CS1.DCV1 & 1321 & 18.5 & 1193 & 17.6 & 1592 & 18.6 & 2131 & 16.5 \\
\hline 15 & IEcon.DB.SSFan.CS1.DCV1 & 1499 & 21.0 & 1324 & 19.5 & 1779 & 20.7 & 2436 & 18.8 \\
\hline 16 & IEcon.EH.SSFan.CS1.DCV1 & 1487 & 20.8 & 1321 & 19.4 & 1772 & 20.7 & 2434 & 18.8 \\
\hline 17 & NoEcon.MSFan.CS1.DCV1 & 1106 & 15.5 & 829 & 12.2 & 1184 & 13.8 & 1516 & 11.7 \\
\hline 18 & IEcon.DB.MSFan.CS1.DCV1 & 1355 & 19.0 & 1091 & 16.0 & 1466 & 17.1 & 2023 & 15.6 \\
\hline 19 & IEcon.EH.MSFan.CS1.DCV1 & 1325 & 18.5 & 1067 & 15.7 & 1433 & 16.7 & 2000 & 15.5 \\
\hline 20 & NoEcon.MSFan.CS2.DCV1 & 1295 & 18.1 & 992 & 14.6 & 1362 & 15.9 & 2014 & 15.6 \\
\hline 21 & IEcon.DB.MSFan.CS2.DCV1 & 1375 & 19.3 & 1115 & 16.4 & 1473 & 17.2 & 2033 & 15.7 \\
\hline 22 & IEcon.EH.MSFan.CS2.DCV1 & 1366 & 19.1 & 1111 & 16.3 & 1465 & 17.1 & 2029 & 15.7 \\
\hline
\end{tabular}


Table C-17: Electricity Savings Compared to Case 1 for the Small Office Building in Climate Zones 1, 2 and 3A

\begin{tabular}{|c|c|c|c|c|c|c|c|c|c|}
\hline \multirow{2}{*}{$\begin{array}{c}\text { Case } \\
\text { No }\end{array}$} & \multirow[b]{2}{*}{ Case Name } & \multicolumn{2}{|c|}{ Miami-1A } & \multicolumn{2}{|c|}{ Houston-2A } & \multicolumn{2}{|c|}{ Phoenix-2B } & \multicolumn{2}{|c|}{ Atlanta-3A } \\
\hline & & $\begin{array}{c}\text { Abs. } \\
\left(10^{6}\right. \\
\text { Btus }) \\
\end{array}$ & $\begin{array}{l}\text { Rel. } \\
\text { (\%) }\end{array}$ & $\begin{array}{c}\text { Abs. } \\
\left(10^{6}\right. \\
\text { Btus) } \\
\end{array}$ & $\begin{array}{l}\text { Rel. } \\
\text { (\%) }\end{array}$ & $\begin{array}{c}\text { Abs. } \\
\left(10^{6}\right. \\
\text { Btus }) \\
\end{array}$ & $\begin{array}{l}\text { Rel. } \\
(\%)\end{array}$ & $\begin{array}{c}\text { Abs. } \\
\left(10^{6}\right. \\
\text { Btus }) \\
\end{array}$ & $\begin{array}{l}\text { Rel. } \\
(\%)\end{array}$ \\
\hline 2 & NIEcon.DB.SSFan.CS1.DCV0 & 5 & 3.0 & 6 & 4.7 & 5 & 3.7 & 8 & 9.0 \\
\hline 3 & NIEcon.EH.SSFan.CS1.DCV0 & 4 & 2.6 & 5 & 4.0 & 6 & 3.9 & 7 & 7.5 \\
\hline 4 & IEcon.DB.SSFan.CS1.DCV0 & 5 & 3.0 & 6 & 4.6 & 6 & 3.8 & 8 & 9.0 \\
\hline 5 & IEcon.EH.SSFan.CS1.DCV0 & 4 & 2.7 & 5 & 4.0 & 6 & 4.0 & 7 & 7.5 \\
\hline 6 & NoEcon.MSFan.CS1.DCV0 & 30 & 18.8 & 33 & 26.7 & 34 & 23.7 & 36 & 39.0 \\
\hline 7 & NIEcon.DB.MSFan.CS1.DCV0 & 33 & 20.3 & 36 & 28.8 & 37 & 25.6 & 39 & 43.1 \\
\hline 8 & NIEcon.EH.MSFan.CS1.DCV0 & 32 & 20.1 & 36 & 28.5 & 37 & 25.6 & 39 & 42.5 \\
\hline 9 & IEcon.DB.MSFan.CS1.DCV0 & 33 & 20.2 & 36 & 28.6 & 37 & 25.7 & 39 & 43.1 \\
\hline 10 & IEcon.EH.MSFan.CS1.DCV0 & 33 & 20.2 & 36 & 28.6 & 37 & 25.8 & 39 & 42.6 \\
\hline 11 & NoEcon.MSFan.CS2.DCV0 & 47 & 29.3 & 45 & 35.8 & 49 & 34.3 & 43 & 47.4 \\
\hline 12 & IEcon.DB.MSFan.CS2.DCV0 & 47 & 29.4 & 45 & 36.2 & 51 & 35.5 & 45 & 49.0 \\
\hline 13 & IEcon.EH.MSFan.CS2.DCV0 & 49 & 30.3 & 46 & 37.1 & 51 & 35.5 & 46 & 49.8 \\
\hline 14 & NoEcon.SSFan.CS1.DCV1 & 13 & 7.8 & 9 & 6.8 & 6 & 4.3 & 3 & 2.9 \\
\hline 15 & IEcon.DB.SSFan.CS1.DCV1 & 17 & 10.3 & 15 & 11.7 & 13 & 8.9 & 12 & 12.8 \\
\hline 16 & IEcon.EH.SSFan.CS1.DCV1 & 17 & 10.7 & 14 & 11.4 & 13 & 9.2 & 11 & 11.7 \\
\hline 17 & NoEcon.MSFan.CS1.DCV1 & 45 & 27.8 & 43 & 34.8 & 42 & 29.1 & 40 & 43.1 \\
\hline 18 & IEcon.DB.MSFan.CS1.DCV1 & 46 & 28.7 & 46 & 36.9 & 46 & 31.7 & 44 & 47.9 \\
\hline 19 & IEcon.EH.MSFan.CS1.DCV1 & 47 & 29.4 & 47 & 37.3 & 46 & 31.8 & 44 & 48.0 \\
\hline 20 & NoEcon.MSFan.CS2.DCV1 & 60 & 37.0 & 53 & 42.8 & 56 & 38.9 & 47 & 50.9 \\
\hline 21 & IEcon.DB.MSFan.CS2.DCV1 & 59 & 36.8 & 54 & 43.2 & 59 & 40.6 & 49 & 53.0 \\
\hline 22 & IEcon.EH.MSFan.CS2.DCV1 & 62 & 38.3 & 56 & 44.6 & 59 & 40.6 & 50 & 54.3 \\
\hline
\end{tabular}


Table C-18: Electricity Savings Compared to Case 1 for the Small Office Building in Climate Zones 3B, 3C and 4A

\begin{tabular}{|c|c|c|c|c|c|c|c|c|c|}
\hline \multirow[b]{2}{*}{$\begin{array}{c}\text { Case } \\
\text { No }\end{array}$} & \multirow[b]{2}{*}{ Case Name } & \multicolumn{2}{|c|}{ Los Angeles-3B } & \multicolumn{2}{|c|}{ Las Vegas-3B } & \multicolumn{2}{|c|}{ San Francisco-3C } & \multicolumn{2}{|c|}{ Baltimore-4A } \\
\hline & & $\begin{array}{c}\text { Abs. } \\
\left(10^{6}\right. \\
\text { Btus }) \\
\end{array}$ & $\begin{array}{l}\text { Rel. } \\
\text { (\%) }\end{array}$ & $\begin{array}{c}\text { Abs. } \\
\left(10^{6}\right. \\
\text { Btus }) \\
\end{array}$ & $\begin{array}{l}\text { Rel. } \\
\text { (\%) }\end{array}$ & $\begin{array}{c}\text { Abs. } \\
\left(10^{6}\right. \\
\text { Btus }) \\
\end{array}$ & $\begin{array}{l}\text { Rel. } \\
\text { (\%) }\end{array}$ & $\begin{array}{c}\text { Abs. } \\
\left(10^{6}\right. \\
\text { Btus }) \\
\end{array}$ & $\begin{array}{l}\text { Rel. } \\
\text { (\%) }\end{array}$ \\
\hline 2 & NIEcon.DB.SSFan.CS1.DCV0 & 20 & 24.4 & 5 & 4.7 & 9 & 17.9 & 6 & 8.1 \\
\hline 3 & NIEcon.EH.SSFan.CS1.DCV0 & 16 & 19.7 & 5 & 4.8 & 9 & 17.5 & 5 & 6.5 \\
\hline 4 & IEcon.DB.SSFan.CS1.DCV0 & 21 & 25.3 & 5 & 4.9 & 9 & 18.2 & 6 & 8.0 \\
\hline 5 & IEcon.EH.SSFan.CS1.DCV0 & 16 & 20.0 & 5 & 5.0 & 9 & 17.8 & 5 & 6.7 \\
\hline 6 & NoEcon.MSFan.CS1.DCV0 & 40 & 49.1 & 34 & 30.6 & 33 & 65.4 & 32 & 43.6 \\
\hline 7 & NIEcon.DB.MSFan.CS1.DCV0 & 52 & 63.6 & 36 & 32.6 & 37 & 75.2 & 35 & 46.9 \\
\hline 8 & NIEcon.EH.MSFan.CS1.DCV0 & 50 & 60.4 & 36 & 32.6 & 37 & 74.9 & 35 & 46.6 \\
\hline 9 & IEcon.DB.MSFan.CS1.DCV0 & 53 & 64.5 & 36 & 32.7 & 38 & 75.7 & 35 & 46.7 \\
\hline 10 & IEcon.EH.MSFan.CS1.DCV0 & 50 & 61.0 & 36 & 32.7 & 38 & 75.4 & 35 & 46.8 \\
\hline 11 & NoEcon.MSFan.CS2.DCV0 & 48 & 58.1 & 43 & 39.0 & 35 & 71.0 & 37 & 50.3 \\
\hline 12 & IEcon.DB.MSFan.CS2.DCV0 & 55 & 67.1 & 44 & 40.2 & 39 & 77.5 & 39 & 51.7 \\
\hline 13 & IEcon.EH.MSFan.CS2.DCV0 & 55 & 66.8 & 44 & 40.2 & 39 & 77.5 & 39 & 52.3 \\
\hline 14 & NoEcon.SSFan.CS1.DCV1 & -2 & -2.2 & 3 & 3.0 & -3 & -5.8 & 2 & 2.6 \\
\hline 15 & IEcon.DB.SSFan.CS1.DCV1 & 21 & 25.5 & 10 & 9.1 & 9 & 18.3 & 9 & 11.9 \\
\hline 16 & IEcon.EH.SSFan.CS1.DCV1 & 17 & 20.2 & 10 & 9.1 & 9 & 17.7 & 8 & 11.0 \\
\hline 17 & NoEcon.MSFan.CS1.DCV1 & 38 & 46.6 & 38 & 34.7 & 30 & 60.6 & 36 & 48.2 \\
\hline 18 & IEcon.DB.MSFan.CS1.DCV1 & 53 & 64.3 & 41 & 37.8 & 38 & 75.9 & 39 & 52.4 \\
\hline 19 & IEcon.EH.MSFan.CS1.DCV1 & 50 & 60.6 & 41 & 37.8 & 38 & 75.5 & 39 & 52.7 \\
\hline 20 & NoEcon.MSFan.CS2.DCV1 & 46 & 55.5 & 47 & 43.0 & 33 & 67.0 & 40 & 54.3 \\
\hline 21 & IEcon.DB.MSFan.CS2.DCV1 & 55 & 66.9 & 49 & 44.9 & 39 & 77.6 & 42 & 56.4 \\
\hline 22 & IEcon.EH.MSFan.CS2.DCV1 & 55 & 66.7 & 49 & 44.8 & 39 & 77.7 & 43 & 57.5 \\
\hline
\end{tabular}


Table C-19: Electricity Savings Compared to Case 1 for the Small Office Building in Climate Zones 4B, 4C, 5A and 5B

\begin{tabular}{|c|c|c|c|c|c|c|c|c|c|}
\hline \multirow[b]{2}{*}{$\begin{array}{c}\text { Case } \\
\text { No }\end{array}$} & \multirow[b]{2}{*}{ Case Name } & \multicolumn{2}{|c|}{ Albuquerque-4B } & \multicolumn{2}{|c|}{ Seattle-4C } & \multicolumn{2}{|c|}{ Chicago-5A } & \multicolumn{2}{|c|}{ Denver-5B } \\
\hline & & $\begin{array}{c}\text { Abs. } \\
\left(10^{6}\right. \\
\text { Btus }) \\
\end{array}$ & $\begin{array}{l}\text { Rel. } \\
\text { (\%) }\end{array}$ & $\begin{array}{c}\text { Abs. } \\
\left(10^{6}\right. \\
\text { Btus }) \\
\end{array}$ & $\begin{array}{l}\text { Rel. } \\
\text { (\%) }\end{array}$ & $\begin{array}{c}\text { Abs. } \\
\left(10^{6}\right. \\
\text { Btus }) \\
\end{array}$ & $\begin{array}{l}\text { Rel. } \\
(\%)\end{array}$ & $\begin{array}{c}\text { Abs. } \\
\left(10^{6}\right. \\
\text { Btus }) \\
\end{array}$ & $\begin{array}{l}\text { Rel. } \\
\text { (\%) }\end{array}$ \\
\hline 2 & NIEcon.DB.SSFan.CS1.DCV0 & 7 & 8.7 & 7 & 13.1 & 6 & 8.6 & 6 & 8.9 \\
\hline 3 & NIEcon.EH.SSFan.CS1.DCV0 & 6 & 7.7 & 6 & 12.4 & 4 & 6.3 & 5 & 7.8 \\
\hline 4 & IEcon.DB.SSFan.CS1.DCV0 & 7 & 9.0 & 7 & 13.4 & 6 & 8.7 & 6 & 9.1 \\
\hline 5 & IEcon.EH.SSFan.CS1.DCV0 & 6 & 7.9 & 6 & 12.5 & 4 & 6.3 & 5 & 7.8 \\
\hline 6 & NoEcon.MSFan.CS1.DCV0 & 35 & 44.9 & 33 & 65.5 & 35 & 49.5 & 38 & 55.7 \\
\hline 7 & NIEcon.DB.MSFan.CS1.DCV0 & 38 & 48.8 & 37 & 71.9 & 38 & 53.0 & 41 & 59.1 \\
\hline 8 & NIEcon.EH.MSFan.CS1.DCV0 & 38 & 48.4 & 36 & 71.5 & 37 & 52.1 & 41 & 58.7 \\
\hline 9 & IEcon.DB.MSFan.CS1.DCV0 & 38 & 49.2 & 37 & 72.2 & 38 & 53.2 & 41 & 59.3 \\
\hline 10 & IEcon.EH.MSFan.CS1.DCV0 & 38 & 48.6 & 37 & 71.8 & 37 & 52.2 & 41 & 58.9 \\
\hline 11 & NoEcon.MSFan.CS2.DCV0 & 42 & 53.7 & 36 & 70.2 & 40 & 56.0 & 43 & 62.8 \\
\hline 12 & IEcon.DB.MSFan.CS2.DCV0 & 44 & 56.1 & 38 & 74.4 & 41 & 57.8 & 45 & 64.8 \\
\hline 13 & IEcon.EH.MSFan.CS2.DCV0 & 44 & 56.1 & 38 & 74.4 & 41 & 58.0 & 45 & 64.7 \\
\hline 14 & NoEcon.SSFan.CS1.DCV1 & 0 & 0.3 & -2 & -4.2 & 1 & 1.0 & -1 & -1.1 \\
\hline 15 & IEcon.DB.SSFan.CS1.DCV1 & 9 & 11.0 & 7 & 13.6 & 8 & 11.2 & 7 & 10.3 \\
\hline 16 & IEcon.EH.SSFan.CS1.DCV1 & 8 & 9.9 & 6 & 12.5 & 6 & 8.8 & 6 & 8.7 \\
\hline 17 & NoEcon.MSFan.CS1.DCV1 & 36 & 46.7 & 32 & 63.5 & 38 & 52.9 & 39 & 56.7 \\
\hline 18 & IEcon.DB.MSFan.CS1.DCV1 & 41 & 52.3 & 38 & 73.8 & 41 & 57.6 & 43 & 62.1 \\
\hline 19 & IEcon.EH.MSFan.CS1.DCV1 & 40 & 51.7 & 37 & 73.3 & 40 & 56.8 & 42 & 61.4 \\
\hline 20 & NoEcon.MSFan.CS2.DCV1 & 43 & 54.9 & 35 & 68.7 & 42 & 59.0 & 44 & 63.7 \\
\hline 21 & IEcon.DB.MSFan.CS2.DCV1 & 46 & 58.4 & 39 & 75.9 & 44 & 61.6 & 46 & 67.0 \\
\hline 22 & IEcon.EH.MSFan.CS2.DCV1 & 46 & 58.4 & 39 & 75.9 & 44 & 62.0 & 46 & 66.8 \\
\hline
\end{tabular}


Table C-20: Electricity Savings Compared to Case 1 for the Small Office Building in Climate Zones 6, 7 and 8

\begin{tabular}{|c|c|c|c|c|c|c|c|c|c|}
\hline \multirow[b]{2}{*}{$\begin{array}{c}\text { Case } \\
\text { No }\end{array}$} & \multirow[b]{2}{*}{ Case Name } & \multicolumn{2}{|c|}{ Minneapolis-6A } & \multicolumn{2}{|c|}{ Helena-6B } & \multicolumn{2}{|c|}{ Duluth-7 } & \multicolumn{2}{|c|}{ Fairbanks-8 } \\
\hline & & $\begin{array}{c}\text { Abs. } \\
\left(10^{6}\right. \\
\text { Btus }) \\
\end{array}$ & $\begin{array}{l}\text { Rel. } \\
\text { (\%) }\end{array}$ & $\begin{array}{c}\text { Abs. } \\
\left(10^{6}\right. \\
\text { Btus }) \\
\end{array}$ & $\begin{array}{l}\text { Rel. } \\
\text { (\%) }\end{array}$ & $\begin{array}{c}\text { Abs. } \\
\left(10^{6}\right. \\
\text { Btus }) \\
\end{array}$ & $\begin{array}{l}\text { Rel. } \\
(\%)\end{array}$ & $\begin{array}{c}\text { Abs. } \\
\left(10^{6}\right. \\
\text { Btus }) \\
\end{array}$ & $\begin{array}{l}\text { Rel. } \\
\text { (\%) }\end{array}$ \\
\hline 2 & NIEcon.DB.SSFan.CS1.DCV0 & 7 & 9.6 & 6 & 9.1 & 6 & 9.3 & 6 & 9.2 \\
\hline 3 & NIEcon.EH.SSFan.CS1.DCV0 & 6 & 8.0 & 5 & 8.5 & 5 & 8.1 & 6 & 8.9 \\
\hline 4 & IEcon.DB.SSFan.CS1.DCV0 & 7 & 9.7 & 6 & 9.2 & 6 & 9.4 & 6 & 9.3 \\
\hline 5 & IEcon.EH.SSFan.CS1.DCV0 & 6 & 8.0 & 5 & 8.5 & 5 & 8.1 & 6 & 9.0 \\
\hline 6 & NoEcon.MSFan.CS1.DCV0 & 36 & 51.9 & 39 & 61.1 & 37 & 61.9 & 41 & 61.9 \\
\hline 7 & NIEcon.DB.MSFan.CS1.DCV0 & 39 & 56.2 & 42 & 64.8 & 40 & 66.4 & 44 & 66.4 \\
\hline 8 & NIEcon.EH.MSFan.CS1.DCV0 & 39 & 55.6 & 42 & 64.6 & 39 & 65.9 & 44 & 66.3 \\
\hline 9 & IEcon.DB.MSFan.CS1.DCV0 & 39 & 56.4 & 42 & 65.0 & 40 & 66.6 & 44 & 66.5 \\
\hline 10 & IEcon.EH.MSFan.CS1.DCV0 & 39 & 55.8 & 42 & 64.7 & 39 & 66.0 & 44 & 66.4 \\
\hline 11 & NoEcon.MSFan.CS2.DCV0 & 40 & 58.0 & 43 & 66.7 & 39 & 65.8 & 43 & 64.8 \\
\hline 12 & IEcon.DB.MSFan.CS2.DCV0 & 42 & 60.1 & 44 & 68.9 & 41 & 68.5 & 45 & 67.7 \\
\hline 13 & IEcon.EH.MSFan.CS2.DCV0 & 42 & 60.5 & 44 & 68.8 & 41 & 68.5 & 45 & 67.7 \\
\hline 14 & NoEcon.SSFan.CS1.DCV1 & 0 & 0.2 & -1 & -2.0 & -2 & -2.6 & -2 & -2.6 \\
\hline 15 & IEcon.DB.SSFan.CS1.DCV1 & 8 & 11.7 & 6 & 10.0 & 6 & 10.0 & 6 & 9.4 \\
\hline 16 & IEcon.EH.SSFan.CS1.DCV1 & 7 & 10.2 & 6 & 9.1 & 5 & 8.6 & 6 & 9.0 \\
\hline 17 & NoEcon.MSFan.CS1.DCV1 & 38 & 54.8 & 40 & 62.0 & 38 & 63.2 & 42 & 63.0 \\
\hline 18 & IEcon.DB.MSFan.CS1.DCV1 & 42 & 60.7 & 44 & 67.9 & 42 & 70.1 & 47 & 70.1 \\
\hline 19 & IEcon.EH.MSFan.CS1.DCV1 & 42 & 60.2 & 43 & 67.6 & 41 & 69.5 & 47 & 69.9 \\
\hline 20 & NoEcon.MSFan.CS2.DCV1 & 42 & 60.7 & 43 & 67.6 & 40 & 67.4 & 44 & 66.3 \\
\hline 21 & IEcon.DB.MSFan.CS2.DCV1 & 45 & 64.1 & 46 & 71.4 & 43 & 71.8 & 47 & 71.2 \\
\hline 22 & IEcon.EH.MSFan.CS2.DCV1 & 45 & 64.6 & 46 & 71.3 & 43 & 71.8 & 47 & 71.2 \\
\hline
\end{tabular}


Table C-21: Electricity Savings Compared to Case 1 for the Stand-alone Retail Building in Climate Zones 1, 2 and 3A

\begin{tabular}{|c|c|c|c|c|c|c|c|c|c|}
\hline \multirow{2}{*}{$\begin{array}{c}\text { Case } \\
\text { No }\end{array}$} & \multirow[b]{2}{*}{ Case Name } & \multicolumn{2}{|c|}{ Miami-1A } & \multicolumn{2}{|c|}{ Houston-2A } & \multicolumn{2}{|c|}{ Phoenix-2B } & \multicolumn{2}{|c|}{ Atlanta-3A } \\
\hline & & $\begin{array}{c}\text { Abs. } \\
\left(10^{6}\right. \\
\text { Btus }) \\
\end{array}$ & $\begin{array}{l}\text { Rel. } \\
\text { (\%) }\end{array}$ & $\begin{array}{c}\text { Abs. } \\
\left(10^{6}\right. \\
\text { Btus }) \\
\end{array}$ & $\begin{array}{l}\text { Rel. } \\
\text { (\%) }\end{array}$ & $\begin{array}{c}\text { Abs. } \\
\left(10^{6}\right. \\
\text { Btus }) \\
\end{array}$ & $\begin{array}{l}\text { Rel. } \\
(\%)\end{array}$ & $\begin{array}{c}\text { Abs. } \\
\left(10^{6}\right. \\
\text { Btus }) \\
\end{array}$ & $\begin{array}{l}\text { Rel. } \\
\text { (\%) }\end{array}$ \\
\hline 2 & NIEcon.DB.SSFan.CS1.DCV0 & 27 & 2.9 & 22 & 3.0 & 13 & 1.8 & 23 & 4.5 \\
\hline 3 & NIEcon.EH.SSFan.CS1.DCV0 & 16 & 1.7 & 15 & 2.0 & 15 & 2.0 & 18 & 3.5 \\
\hline 4 & IEcon.DB.SSFan.CS1.DCV0 & 27 & 2.9 & 22 & 3.1 & 14 & 1.9 & 23 & 4.6 \\
\hline 5 & IEcon.EH.SSFan.CS1.DCV0 & 17 & 1.8 & 15 & 2.1 & 15 & 2.1 & 18 & 3.6 \\
\hline 6 & NoEcon.MSFan.CS1.DCV0 & 154 & 16.6 & 162 & 22.6 & 169 & 22.8 & 186 & 36.4 \\
\hline 7 & NIEcon.DB.MSFan.CS1.DCV0 & 164 & 17.7 & 169 & 23.5 & 173 & 23.3 & 193 & 37.7 \\
\hline 8 & NIEcon.EH.MSFan.CS1.DCV0 & 159 & 17.2 & 166 & 23.1 & 174 & 23.4 & 190 & 37.3 \\
\hline 9 & IEcon.DB.MSFan.CS1.DCV0 & 164 & 17.7 & 169 & 23.5 & 173 & 23.4 & 193 & 37.8 \\
\hline 10 & IEcon.EH.MSFan.CS1.DCV0 & 160 & 17.3 & 167 & 23.2 & 174 & 23.5 & 191 & 37.4 \\
\hline 11 & NoEcon.MSFan.CS2.DCV0 & 236 & 25.6 & 215 & 29.9 & 230 & 31.1 & 225 & 44.1 \\
\hline 12 & IEcon.DB.MSFan.CS2.DCV0 & 244 & 26.4 & 219 & 30.6 & 232 & 31.3 & 229 & 44.9 \\
\hline 13 & IEcon.EH.MSFan.CS2.DCV0 & 242 & 26.1 & 219 & 30.4 & 232 & 31.3 & 229 & 44.8 \\
\hline 14 & NoEcon.SSFan.CS1.DCV1 & 120 & 13.0 & 92 & 12.8 & 89 & 12.0 & 42 & 8.2 \\
\hline 15 & IEcon.DB.SSFan.CS1.DCV1 & 139 & 15.0 & 108 & 15.0 & 101 & 13.6 & 58 & 11.3 \\
\hline 16 & IEcon.EH.SSFan.CS1.DCV1 & 130 & 14.1 & 103 & 14.3 & 102 & 13.8 & 54 & 10.6 \\
\hline 17 & NoEcon.MSFan.CS1.DCV1 & 284 & 30.7 & 263 & 36.7 & 272 & 36.7 & 232 & 45.3 \\
\hline 18 & IEcon.DB.MSFan.CS1.DCV1 & 294 & 31.8 & 272 & 37.8 & 278 & 37.5 & 240 & 47.0 \\
\hline 19 & IEcon.EH.MSFan.CS1.DCV1 & 290 & 31.4 & 270 & 37.5 & 278 & 37.5 & 238 & 46.7 \\
\hline 20 & NoEcon.MSFan.CS2.DCV1 & 356 & 38.5 & 312 & 43.5 & 331 & 44.7 & 265 & 51.8 \\
\hline 21 & IEcon.DB.MSFan.CS2.DCV1 & 362 & 39.1 & 317 & 44.1 & 334 & 45.0 & 269 & 52.7 \\
\hline 22 & IEcon.EH.MSFan.CS2.DCV1 & 361 & 39.1 & 317 & 44.1 & 334 & 45.0 & 269 & 52.7 \\
\hline
\end{tabular}


Table C-22: Electricity Savings Compared to Case 1 for the Stand-alone Retail Building in Climate Zones 3B, 3C and 4A

\begin{tabular}{|c|c|c|c|c|c|c|c|c|c|}
\hline \multirow[b]{2}{*}{$\begin{array}{c}\text { Case } \\
\text { No }\end{array}$} & \multirow[b]{2}{*}{ Case Name } & \multicolumn{2}{|c|}{ Los Angeles-3B } & \multicolumn{2}{|c|}{ Las Vegas-3B } & \multicolumn{2}{|c|}{ San Francisco-3C } & \multicolumn{2}{|c|}{ Baltimore-4A } \\
\hline & & $\begin{array}{c}\text { Abs. } \\
\left(10^{6}\right. \\
\text { Btus }) \\
\end{array}$ & $\begin{array}{l}\text { Rel. } \\
\text { (\%) }\end{array}$ & $\begin{array}{c}\text { Abs. } \\
\left(10^{6}\right. \\
\text { Btus }) \\
\end{array}$ & $\begin{array}{l}\text { Rel. } \\
\text { (\%) }\end{array}$ & $\begin{array}{c}\text { Abs. } \\
\left(10^{6}\right. \\
\text { Btus }) \\
\end{array}$ & $\begin{array}{l}\text { Rel. } \\
\text { (\%) }\end{array}$ & $\begin{array}{c}\text { Abs. } \\
\left(10^{6}\right. \\
\text { Btus }) \\
\end{array}$ & $\begin{array}{l}\text { Rel. } \\
\text { (\%) }\end{array}$ \\
\hline 2 & NIEcon.DB.SSFan.CS1.DCV0 & 55 & 15.3 & 10 & 1.8 & 16 & 7.1 & 15 & 3.6 \\
\hline 3 & NIEcon.EH.SSFan.CS1.DCV0 & 47 & 13.1 & 11 & 2.0 & 16 & 7.1 & 12 & 2.8 \\
\hline 4 & IEcon.DB.SSFan.CS1.DCV0 & 57 & 16.0 & 11 & 1.9 & 16 & 7.4 & 15 & 3.7 \\
\hline 5 & IEcon.EH.SSFan.CS1.DCV0 & 49 & 13.7 & 11 & 2.0 & 16 & 7.4 & 12 & 2.9 \\
\hline 6 & NoEcon.MSFan.CS1.DCV0 & 191 & 53.7 & 158 & 28.5 & 147 & 66.8 & 167 & 39.7 \\
\hline 7 & NIEcon.DB.MSFan.CS1.DCV0 & 216 & 60.8 & 161 & 29.1 & 153 & 69.5 & 171 & 40.7 \\
\hline 8 & NIEcon.EH.MSFan.CS1.DCV0 & 210 & 59.2 & 162 & 29.1 & 153 & 69.5 & 170 & 40.4 \\
\hline 9 & IEcon.DB.MSFan.CS1.DCV0 & 219 & 61.6 & 162 & 29.1 & 154 & 69.9 & 171 & 40.8 \\
\hline 10 & IEcon.EH.MSFan.CS1.DCV0 & 213 & 60.0 & 162 & 29.2 & 154 & 69.9 & 170 & 40.5 \\
\hline 11 & NoEcon.MSFan.CS2.DCV0 & 213 & 60.0 & 193 & 34.7 & 154 & 69.9 & 192 & 45.8 \\
\hline 12 & IEcon.DB.MSFan.CS2.DCV0 & 231 & 65.1 & 194 & 35.0 & 158 & 71.6 & 195 & 46.4 \\
\hline 13 & IEcon.EH.MSFan.CS2.DCV0 & 230 & 64.6 & 194 & 35.0 & 158 & 71.6 & 195 & 46.4 \\
\hline 14 & NoEcon.SSFan.CS1.DCV1 & 18 & 5.0 & 60 & 10.9 & 2 & 1.0 & 32 & 7.6 \\
\hline 15 & IEcon.DB.SSFan.CS1.DCV1 & 60 & 16.9 & 70 & 12.7 & 17 & 7.8 & 43 & 10.2 \\
\hline 16 & IEcon.EH.SSFan.CS1.DCV1 & 53 & 14.8 & 71 & 12.8 & 17 & 7.8 & 41 & 9.7 \\
\hline 17 & NoEcon.MSFan.CS1.DCV1 & 189 & 53.2 & 231 & 41.6 & 150 & 67.9 & 208 & 49.7 \\
\hline 18 & IEcon.DB.MSFan.CS1.DCV1 & 224 & 62.9 & 236 & 42.6 & 161 & 73.0 & 214 & 50.9 \\
\hline 19 & IEcon.EH.MSFan.CS1.DCV1 & 217 & 61.1 & 236 & 42.6 & 161 & 73.0 & 213 & 50.7 \\
\hline 20 & NoEcon.MSFan.CS2.DCV1 & 213 & 60.0 & 263 & 47.5 & 157 & 71.2 & 231 & 55.0 \\
\hline 21 & IEcon.DB.MSFan.CS2.DCV1 & 236 & 66.5 & 266 & 48.0 & 165 & 74.8 & 234 & 55.7 \\
\hline 22 & IEcon.EH.MSFan.CS2.DCV1 & 234 & 65.9 & 266 & 47.9 & 165 & 74.8 & 234 & 55.7 \\
\hline
\end{tabular}


Table C-23: Electricity Savings Compared to Case 1 for the Stand-alone Retail Building in Climate Zones 4B, 4C, 5A and 5B

\begin{tabular}{|c|c|c|c|c|c|c|c|c|c|}
\hline \multirow[b]{2}{*}{$\begin{array}{c}\text { Case } \\
\text { No }\end{array}$} & \multirow[b]{2}{*}{ Case Name } & \multicolumn{2}{|c|}{ Albuquerque-4B } & \multicolumn{2}{|c|}{ Seattle-4C } & \multicolumn{2}{|c|}{ Chicago-5A } & \multicolumn{2}{|c|}{ Denver-5B } \\
\hline & & $\begin{array}{c}\text { Abs. } \\
\left(10^{6}\right. \\
\text { Btus }) \\
\end{array}$ & $\begin{array}{l}\text { Rel. } \\
\text { (\%) }\end{array}$ & $\begin{array}{c}\text { Abs. } \\
\left(10^{6}\right. \\
\text { Btus }) \\
\end{array}$ & $\begin{array}{l}\text { Rel. } \\
\text { (\%) }\end{array}$ & $\begin{array}{c}\text { Abs. } \\
\left(10^{6}\right. \\
\text { Btus }) \\
\end{array}$ & $\begin{array}{l}\text { Rel. } \\
\text { (\%) }\end{array}$ & $\begin{array}{c}\text { Abs. } \\
\left(10^{6}\right. \\
\text { Btus }) \\
\end{array}$ & $\begin{array}{l}\text { Rel. } \\
(\%)\end{array}$ \\
\hline 2 & NIEcon.DB.SSFan.CS1.DCV0 & 14 & 3.4 & 11 & 4.6 & 17 & 4.1 & 13 & 3.5 \\
\hline 3 & NIEcon.EH.SSFan.CS1.DCV0 & 13 & 3.2 & 10 & 4.5 & 13 & 3.2 & 13 & 3.4 \\
\hline 4 & IEcon.DB.SSFan.CS1.DCV0 & 14 & 3.5 & 11 & 4.8 & 17 & 4.2 & 14 & 3.6 \\
\hline 5 & IEcon.EH.SSFan.CS1.DCV0 & 13 & 3.3 & 11 & 4.6 & 13 & 3.3 & 13 & 3.4 \\
\hline 6 & NoEcon.MSFan.CS1.DCV0 & 178 & 43.7 & 144 & 62.2 & 201 & 48.5 & 208 & 54.1 \\
\hline 7 & NIEcon.DB.MSFan.CS1.DCV0 & 182 & 44.7 & 147 & 63.6 & 205 & 49.6 & 211 & 54.9 \\
\hline 8 & NIEcon.EH.MSFan.CS1.DCV0 & 181 & 44.6 & 147 & 63.6 & 204 & 49.3 & 211 & 54.9 \\
\hline 9 & IEcon.DB.MSFan.CS1.DCV0 & 182 & 44.8 & 148 & 63.8 & 206 & 49.7 & 212 & 55.0 \\
\hline 10 & IEcon.EH.MSFan.CS1.DCV0 & 182 & 44.8 & 148 & 63.8 & 204 & 49.4 & 212 & 54.9 \\
\hline 11 & NoEcon.MSFan.CS2.DCV0 & 208 & 51.3 & 151 & 65.3 & 226 & 54.5 & 229 & 59.5 \\
\hline 12 & IEcon.DB.MSFan.CS2.DCV0 & 211 & 51.8 & 153 & 66.2 & 228 & 55.1 & 230 & 59.8 \\
\hline 13 & IEcon.EH.MSFan.CS2.DCV0 & 211 & 52.0 & 154 & 66.3 & 228 & 55.1 & 230 & 59.8 \\
\hline 14 & NoEcon.SSFan.CS1.DCV1 & 19 & 4.6 & 3 & 1.2 & 21 & 5.1 & 12 & 3.2 \\
\hline 15 & IEcon.DB.SSFan.CS1.DCV1 & 31 & 7.6 & 13 & 5.5 & 34 & 8.2 & 24 & 6.2 \\
\hline 16 & IEcon.EH.SSFan.CS1.DCV1 & 30 & 7.5 & 12 & 5.3 & 30 & 7.4 & 23 & 6.0 \\
\hline 17 & NoEcon.MSFan.CS1.DCV1 & 205 & 50.5 & 154 & 66.6 & 232 & 56.1 & 231 & 60.0 \\
\hline 18 & IEcon.DB.MSFan.CS1.DCV1 & 212 & 52.1 & 161 & 69.3 & 239 & 57.7 & 236 & 61.4 \\
\hline 19 & IEcon.EH.MSFan.CS1.DCV1 & 211 & 51.9 & 160 & 69.2 & 237 & 57.3 & 236 & 61.2 \\
\hline 20 & NoEcon.MSFan.CS2.DCV1 & 233 & 57.3 & 161 & 69.7 & 253 & 61.2 & 251 & 65.3 \\
\hline 21 & IEcon.DB.MSFan.CS2.DCV1 & 236 & 58.1 & 166 & 71.5 & 257 & 62.1 & 253 & 65.8 \\
\hline 22 & IEcon.EH.MSFan.CS2.DCV1 & 236 & 58.2 & 166 & 71.5 & 257 & 62.1 & 253 & 65.7 \\
\hline
\end{tabular}


Table C-24: Electricity Savings Compared to Case 1 for the Stand-alone Retail Building in Climate Zones 6, 7 and 8

\begin{tabular}{|c|c|c|c|c|c|c|c|c|c|}
\hline \multirow[b]{2}{*}{$\begin{array}{c}\text { Case } \\
\text { No }\end{array}$} & \multirow[b]{2}{*}{ Case Name } & \multicolumn{2}{|c|}{ Minneapolis-6A } & \multicolumn{2}{|c|}{ Helena-6B } & \multicolumn{2}{|c|}{ Duluth-7 } & \multicolumn{2}{|c|}{ Fairbanks-8 } \\
\hline & & $\begin{array}{c}\text { Abs. } \\
\left(10^{6}\right. \\
\text { Btus }) \\
\end{array}$ & $\begin{array}{l}\text { Rel. } \\
\text { (\%) }\end{array}$ & $\begin{array}{c}\text { Abs. } \\
\left(10^{6}\right. \\
\text { Btus }) \\
\end{array}$ & $\begin{array}{l}\text { Rel. } \\
\text { (\%) }\end{array}$ & $\begin{array}{c}\text { Abs. } \\
\left(10^{6}\right. \\
\text { Btus }) \\
\end{array}$ & $\begin{array}{l}\text { Rel. } \\
(\%)\end{array}$ & $\begin{array}{c}\text { Abs. } \\
\left(10^{6}\right. \\
\text { Btus }) \\
\end{array}$ & $\begin{array}{l}\text { Rel. } \\
\text { (\%) }\end{array}$ \\
\hline 2 & NIEcon.DB.SSFan.CS1.DCV0 & 19 & 4.5 & 16 & 3.8 & 16 & 4.1 & 39 & 7.5 \\
\hline 3 & NIEcon.EH.SSFan.CS1.DCV0 & 16 & 3.8 & 16 & 3.8 & 15 & 3.8 & 38 & 7.5 \\
\hline 4 & IEcon.DB.SSFan.CS1.DCV0 & 20 & 4.6 & 16 & 3.9 & 16 & 4.1 & 39 & 7.5 \\
\hline 5 & IEcon.EH.SSFan.CS1.DCV0 & 17 & 3.9 & 16 & 3.8 & 15 & 3.8 & 38 & 7.5 \\
\hline 6 & NoEcon.MSFan.CS1.DCV0 & 226 & 52.2 & 246 & 60.4 & 234 & 60.7 & 290 & 56.4 \\
\hline 7 & NIEcon.DB.MSFan.CS1.DCV0 & 232 & 53.6 & 251 & 61.6 & 241 & 62.5 & 327 & 63.5 \\
\hline 8 & NIEcon.EH.MSFan.CS1.DCV0 & 231 & 53.4 & 251 & 61.6 & 240 & 62.4 & 327 & 63.6 \\
\hline 9 & IEcon.DB.MSFan.CS1.DCV0 & 232 & 53.7 & 251 & 61.6 & 241 & 62.5 & 327 & 63.6 \\
\hline 10 & IEcon.EH.MSFan.CS1.DCV0 & 231 & 53.4 & 251 & 61.7 & 241 & 62.4 & 327 & 63.6 \\
\hline 11 & NoEcon.MSFan.CS2.DCV0 & 249 & 57.5 & 262 & 64.5 & 244 & 63.4 & 318 & 61.9 \\
\hline 12 & IEcon.DB.MSFan.CS2.DCV0 & 251 & 58.1 & 264 & 64.8 & 247 & 64.2 & 330 & 64.2 \\
\hline 13 & IEcon.EH.MSFan.CS2.DCV0 & 251 & 58.1 & 264 & 64.8 & 247 & 64.2 & 330 & 64.1 \\
\hline 14 & NoEcon.SSFan.CS1.DCV1 & 19 & 4.4 & 9 & 2.2 & 7 & 1.7 & 19 & 3.8 \\
\hline 15 & IEcon.DB.SSFan.CS1.DCV1 & 33 & 7.7 & 21 & 5.3 & 19 & 5.0 & 39 & 7.7 \\
\hline 16 & IEcon.EH.SSFan.CS1.DCV1 & 31 & 7.1 & 21 & 5.2 & 18 & 4.7 & 39 & 7.6 \\
\hline 17 & NoEcon.MSFan.CS1.DCV1 & 256 & 59.2 & 268 & 65.8 & 258 & 66.8 & 319 & 62.1 \\
\hline 18 & IEcon.DB.MSFan.CS1.DCV1 & 265 & 61.2 & 276 & 67.7 & 267 & 69.2 & 357 & 69.5 \\
\hline 19 & IEcon.EH.MSFan.CS1.DCV1 & 264 & 61.0 & 276 & 67.7 & 266 & 69.1 & 357 & 69.5 \\
\hline 20 & NoEcon.MSFan.CS2.DCV1 & 277 & 64.0 & 285 & 69.9 & 268 & 69.5 & 348 & 67.8 \\
\hline 21 & IEcon.DB.MSFan.CS2.DCV1 & 280 & 64.8 & 287 & 70.6 & 272 & 70.5 & 360 & 70.1 \\
\hline 22 & IEcon.EH.MSFan.CS2.DCV1 & 280 & 64.8 & 287 & 70.6 & 272 & 70.5 & 360 & 70.1 \\
\hline
\end{tabular}


Table C-25: Electricity Savings Compared to Case 1 for the Strip Mall Building in Climate Zones 1, 2 and 3A

\begin{tabular}{|c|c|c|c|c|c|c|c|c|c|}
\hline \multirow{2}{*}{$\begin{array}{c}\text { Case } \\
\text { No }\end{array}$} & \multirow[b]{2}{*}{ Case Name } & \multicolumn{2}{|c|}{ Miami-1A } & \multicolumn{2}{|c|}{ Houston-2A } & \multicolumn{2}{|c|}{ Phoenix-2B } & \multicolumn{2}{|c|}{ Atlanta-3A } \\
\hline & & $\begin{array}{c}\text { Abs. } \\
\left(10^{6}\right. \\
\text { Btus) } \\
\end{array}$ & $\begin{array}{l}\text { Rel. } \\
(\%)\end{array}$ & $\begin{array}{c}\text { Abs. } \\
\left(10^{6}\right. \\
\text { Btus) } \\
\end{array}$ & $\begin{array}{l}\text { Rel. } \\
(\%)\end{array}$ & $\begin{array}{c}\text { Abs. } \\
\left(10^{6}\right. \\
\text { Btus }) \\
\end{array}$ & $\begin{array}{l}\text { Rel. } \\
(\%)\end{array}$ & $\begin{array}{c}\text { Abs. } \\
\left(10^{6}\right. \\
\text { Btus }) \\
\end{array}$ & $\begin{array}{l}\text { Rel. } \\
(\%)\end{array}$ \\
\hline 2 & NIEcon.DB.SSFan.CS1.DCV0 & 37 & 10.6 & 26 & 54.3 & 16 & 48.6 & 28 & 77.3 \\
\hline 3 & NIEcon.EH.SSFan.CS1.DCV0 & 21 & 9.1 & 18 & 53.8 & 19 & 48.8 & 22 & 77.0 \\
\hline 4 & IEcon.DB.SSFan.CS1.DCV0 & 39 & 10.7 & 26 & 54.3 & 17 & 48.6 & 29 & 77.3 \\
\hline 5 & IEcon.EH.SSFan.CS1.DCV0 & 22 & 9.2 & 18 & 53.8 & 19 & 48.8 & 23 & 77.0 \\
\hline 6 & NoEcon.MSFan.CS1.DCV0 & 179 & 23.4 & 166 & 63.5 & 171 & 59.6 & 183 & 84.5 \\
\hline 7 & NIEcon.DB.MSFan.CS1.DCV0 & 196 & 24.9 & 176 & 64.2 & 176 & 59.9 & 193 & 85.0 \\
\hline 8 & NIEcon.EH.MSFan.CS1.DCV0 & 188 & 24.2 & 172 & 64.0 & 178 & 60.1 & 191 & 84.9 \\
\hline 9 & IEcon.DB.MSFan.CS1.DCV0 & 197 & 25.0 & 176 & 64.2 & 177 & 60.0 & 194 & 85.1 \\
\hline 10 & IEcon.EH.MSFan.CS1.DCV0 & 189 & 24.3 & 173 & 64.0 & 178 & 60.1 & 192 & 84.9 \\
\hline 11 & NoEcon.MSFan.CS2.DCV0 & 278 & 32.3 & 223 & 67.3 & 234 & 64.1 & 225 & 86.5 \\
\hline 12 & IEcon.DB.MSFan.CS2.DCV0 & 287 & 33.2 & 229 & 67.7 & 236 & 64.2 & 231 & 86.8 \\
\hline 13 & IEcon.EH.MSFan.CS2.DCV0 & 285 & 33.0 & 228 & 67.6 & 237 & 64.3 & 231 & 86.8 \\
\hline 14 & NoEcon.SSFan.CS1.DCV1 & 128 & 18.7 & 96 & 58.9 & 94 & 54.1 & 52 & 78.4 \\
\hline 15 & IEcon.DB.SSFan.CS1.DCV1 & 153 & 21.0 & 110 & 59.9 & 99 & 54.5 & 63 & 78.9 \\
\hline 16 & IEcon.EH.SSFan.CS1.DCV1 & 138 & 19.6 & 104 & 59.5 & 102 & 54.7 & 59 & 78.7 \\
\hline 17 & NoEcon.MSFan.CS1.DCV1 & 315 & 35.6 & 269 & 70.3 & 274 & 66.9 & 234 & 86.9 \\
\hline 18 & IEcon.DB.MSFan.CS1.DCV1 & 332 & 37.2 & 278 & 70.9 & 277 & 67.1 & 243 & 87.4 \\
\hline 19 & IEcon.EH.MSFan.CS1.DCV1 & 322 & 36.3 & 275 & 70.7 & 279 & 67.3 & 241 & 87.2 \\
\hline 20 & NoEcon.MSFan.CS2.DCV1 & 404 & 43.7 & 320 & 73.7 & 332 & 71.1 & 268 & 88.5 \\
\hline 21 & IEcon.DB.MSFan.CS2.DCV1 & 411 & 44.3 & 324 & 73.9 & 333 & 71.1 & 272 & 88.7 \\
\hline 22 & IEcon.EH.MSFan.CS2.DCV1 & 408 & 44.1 & 323 & 73.9 & 333 & 71.1 & 271 & 88.7 \\
\hline
\end{tabular}


Table C-26: Electricity Savings Compared to Case 1 for the Strip Mall Building in Climate Zones 3B, 3C and 4A

\begin{tabular}{|c|c|c|c|c|c|c|c|c|c|}
\hline \multirow[b]{2}{*}{$\begin{array}{c}\text { Case } \\
\text { No }\end{array}$} & \multirow[b]{2}{*}{ Case Name } & \multicolumn{2}{|c|}{ Los Angeles-3B } & \multicolumn{2}{|c|}{ Las Vegas-3B } & \multicolumn{2}{|c|}{ San Francisco-3C } & \multicolumn{2}{|c|}{ Baltimore-4A } \\
\hline & & $\begin{array}{c}\text { Abs. } \\
\left(10^{6}\right. \\
\text { Btus }) \\
\end{array}$ & $\begin{array}{l}\text { Rel. } \\
\text { (\%) }\end{array}$ & $\begin{array}{c}\text { Abs. } \\
\left(10^{6}\right. \\
\text { Btus }) \\
\end{array}$ & $\begin{array}{l}\text { Rel. } \\
(\%)\end{array}$ & $\begin{array}{c}\text { Abs. } \\
\left(10^{6}\right. \\
\text { Btus }) \\
\end{array}$ & $\begin{array}{l}\text { Rel. } \\
\text { (\%) }\end{array}$ & $\begin{array}{c}\text { Abs. } \\
\left(10^{6}\right. \\
\text { Btus }) \\
\end{array}$ & $\begin{array}{l}\text { Rel. } \\
\text { (\%) }\end{array}$ \\
\hline 2 & NIEcon.DB.SSFan.CS1.DCV0 & 72 & 66.5 & 15 & 66.9 & 24 & 86.9 & 18 & 87.2 \\
\hline 3 & NIEcon.EH.SSFan.CS1.DCV0 & 63 & 65.5 & 16 & 66.9 & 24 & 86.9 & 14 & 87.1 \\
\hline 4 & IEcon.DB.SSFan.CS1.DCV0 & 75 & 66.8 & 15 & 66.9 & 25 & 86.9 & 19 & 87.2 \\
\hline 5 & IEcon.EH.SSFan.CS1.DCV0 & 65 & 65.8 & 16 & 67.0 & 25 & 86.9 & 15 & 87.1 \\
\hline 6 & NoEcon.MSFan.CS1.DCV0 & 208 & 80.0 & 166 & 76.0 & 154 & 94.8 & 159 & 91.7 \\
\hline 7 & NIEcon.DB.MSFan.CS1.DCV0 & 244 & 83.6 & 171 & 76.3 & 164 & 95.4 & 165 & 91.9 \\
\hline 8 & NIEcon.EH.MSFan.CS1.DCV0 & 238 & 83.0 & 172 & 76.3 & 164 & 95.4 & 164 & 91.8 \\
\hline 9 & IEcon.DB.MSFan.CS1.DCV0 & 248 & 84.0 & 171 & 76.3 & 165 & 95.5 & 166 & 91.9 \\
\hline 10 & IEcon.EH.MSFan.CS1.DCV0 & 241 & 83.3 & 172 & 76.4 & 165 & 95.5 & 164 & 91.9 \\
\hline 11 & NoEcon.MSFan.CS2.DCV0 & 237 & 82.9 & 204 & 78.3 & 163 & 95.4 & 186 & 92.6 \\
\hline 12 & IEcon.DB.MSFan.CS2.DCV0 & 261 & 85.3 & 206 & 78.4 & 169 & 95.8 & 190 & 92.7 \\
\hline 13 & IEcon.EH.MSFan.CS2.DCV0 & 260 & 85.2 & 207 & 78.5 & 170 & 95.8 & 190 & 92.7 \\
\hline 14 & NoEcon.SSFan.CS1.DCV1 & 49 & 64.2 & 68 & 70.1 & 21 & 86.7 & 38 & 87.8 \\
\hline 15 & IEcon.DB.SSFan.CS1.DCV1 & 80 & 67.2 & 72 & 70.3 & 26 & 87.0 & 46 & 88.1 \\
\hline 16 & IEcon.EH.SSFan.CS1.DCV1 & 73 & 66.5 & 74 & 70.4 & 26 & 87.0 & 44 & 88.0 \\
\hline 17 & NoEcon.MSFan.CS1.DCV1 & 220 & 81.2 & 242 & 80.6 & 165 & 95.5 & 204 & 93.1 \\
\hline 18 & IEcon.DB.MSFan.CS1.DCV1 & 257 & 84.9 & 245 & 80.7 & 174 & 96.1 & 210 & 93.3 \\
\hline 19 & IEcon.EH.MSFan.CS1.DCV1 & 249 & 84.1 & 245 & 80.8 & 174 & 96.1 & 209 & 93.3 \\
\hline 20 & NoEcon.MSFan.CS2.DCV1 & 253 & 84.5 & 276 & 82.6 & 174 & 96.1 & 227 & 93.9 \\
\hline 21 & IEcon.DB.MSFan.CS2.DCV1 & 269 & 86.1 & 276 & 82.7 & 179 & 96.3 & 230 & 93.9 \\
\hline 22 & IEcon.EH.MSFan.CS2.DCV1 & 267 & 85.9 & 277 & 82.7 & 179 & 96.4 & 230 & 94.0 \\
\hline
\end{tabular}


Table C-27: Electricity Savings Compared to Case 1 for the Strip Mall Building in Climate Zones 4B, 4C, 5A and 5B

\begin{tabular}{|c|c|c|c|c|c|c|c|c|c|}
\hline \multirow[b]{2}{*}{$\begin{array}{c}\text { Case } \\
\text { No }\end{array}$} & \multirow[b]{2}{*}{ Case Name } & \multicolumn{2}{|c|}{ Albuquerque-4B } & \multicolumn{2}{|c|}{ Seattle-4C } & \multicolumn{2}{|c|}{ Chicago-5A } & \multicolumn{2}{|c|}{ Denver-5B } \\
\hline & & $\begin{array}{c}\text { Abs. } \\
\left(10^{6}\right. \\
\text { Btus) } \\
\end{array}$ & $\begin{array}{l}\text { Rel. } \\
\text { (\%) }\end{array}$ & $\begin{array}{c}\text { Abs. } \\
\left(10^{6}\right. \\
\text { Btus) }\end{array}$ & $\begin{array}{l}\text { Rel. } \\
\text { (\%) }\end{array}$ & $\begin{array}{c}\text { Abs. } \\
\left(10^{6}\right. \\
\text { Btus) } \\
\end{array}$ & $\begin{array}{l}\text { Rel. } \\
(\%)\end{array}$ & $\begin{array}{c}\text { Abs. } \\
\left(10^{6}\right. \\
\text { Btus) } \\
\end{array}$ & $\begin{array}{l}\text { Rel. } \\
\text { (\%) }\end{array}$ \\
\hline 2 & NIEcon.DB.SSFan.CS1.DCV0 & 17 & 83.8 & 16 & 91.6 & 21 & 90.5 & 17 & 88.7 \\
\hline 3 & NIEcon.EH.SSFan.CS1.DCV0 & 16 & 83.8 & 15 & 91.6 & 16 & 90.4 & 16 & 88.6 \\
\hline 4 & IEcon.DB.SSFan.CS1.DCV0 & 17 & 83.8 & 16 & 91.6 & 21 & 90.5 & 17 & 88.7 \\
\hline 5 & IEcon.EH.SSFan.CS1.DCV0 & 17 & 83.8 & 16 & 91.6 & 17 & 90.4 & 17 & 88.7 \\
\hline 6 & NoEcon.MSFan.CS1.DCV0 & 166 & 90.1 & 148 & 96.4 & 195 & 94.7 & 196 & 94.2 \\
\hline 7 & NIEcon.DB.MSFan.CS1.DCV0 & 172 & 90.4 & 154 & 96.6 & 202 & 94.8 & 201 & 94.4 \\
\hline 8 & NIEcon.EH.MSFan.CS1.DCV0 & 172 & 90.4 & 153 & 96.6 & 201 & 94.8 & 201 & 94.4 \\
\hline 9 & IEcon.DB.MSFan.CS1.DCV0 & 172 & 90.4 & 155 & 96.7 & 203 & 94.9 & 201 & 94.4 \\
\hline 10 & IEcon.EH.MSFan.CS1.DCV0 & 172 & 90.4 & 154 & 96.7 & 201 & 94.8 & 201 & 94.4 \\
\hline 11 & NoEcon.MSFan.CS2.DCV0 & 198 & 91.5 & 157 & 96.8 & 222 & 95.3 & 220 & 95.0 \\
\hline 12 & IEcon.DB.MSFan.CS2.DCV0 & 201 & 91.6 & 161 & 96.9 & 225 & 95.4 & 222 & 95.0 \\
\hline 13 & IEcon.EH.MSFan.CS2.DCV0 & 201 & 91.6 & 161 & 96.9 & 225 & 95.4 & 222 & 95.0 \\
\hline 14 & NoEcon.SSFan.CS1.DCV1 & 27 & 84.2 & 13 & 91.5 & 29 & 90.7 & 20 & 88.8 \\
\hline 15 & IEcon.DB.SSFan.CS1.DCV1 & 34 & 84.5 & 18 & 91.7 & 38 & 90.9 & 27 & 89.0 \\
\hline 16 & IEcon.EH.SSFan.CS1.DCV1 & 34 & 84.5 & 18 & 91.7 & 35 & 90.9 & 27 & 89.0 \\
\hline 17 & NoEcon.MSFan.CS1.DCV1 & 198 & 91.5 & 164 & 97.0 & 233 & 95.6 & 224 & 95.1 \\
\hline 18 & IEcon.DB.MSFan.CS1.DCV1 & 203 & 91.7 & 170 & 97.2 & 239 & 95.7 & 228 & 95.2 \\
\hline 19 & IEcon.EH.MSFan.CS1.DCV1 & 203 & 91.7 & 170 & 97.2 & 237 & 95.7 & 228 & 95.2 \\
\hline 20 & NoEcon.MSFan.CS2.DCV1 & 225 & 92.6 & 173 & 97.3 & 255 & 96.1 & 246 & 95.8 \\
\hline 21 & IEcon.DB.MSFan.CS2.DCV1 & 227 & 92.7 & 176 & 97.4 & 257 & 96.1 & 247 & 95.8 \\
\hline 22 & IEcon.EH.MSFan.CS2.DCV1 & 227 & 92.7 & 176 & 97.4 & 257 & 96.1 & 247 & 95.8 \\
\hline
\end{tabular}


Table C-28: Electricity Savings Compared to Case 1 for the Strip Mall Building in Climate Zones 6, 7 and 8

\begin{tabular}{|c|c|c|c|c|c|c|c|c|c|}
\hline \multirow[b]{2}{*}{$\begin{array}{c}\text { Case } \\
\text { No }\end{array}$} & \multirow[b]{2}{*}{ Case Name } & \multicolumn{2}{|c|}{ Minneapolis-6A } & \multicolumn{2}{|c|}{ Helena-6B } & \multicolumn{2}{|c|}{ Duluth-7 } & \multicolumn{2}{|c|}{ Fairbanks-8 } \\
\hline & & $\begin{array}{c}\text { Abs. } \\
\left(10^{6}\right. \\
\text { Btus }) \\
\end{array}$ & $\begin{array}{l}\text { Rel. } \\
(\%)\end{array}$ & $\begin{array}{c}\text { Abs. } \\
\left(10^{6}\right. \\
\text { Btus }) \\
\end{array}$ & $\begin{array}{l}\text { Rel. } \\
(\%)\end{array}$ & $\begin{array}{c}\text { Abs. } \\
\left(10^{6}\right. \\
\text { Btus }) \\
\end{array}$ & $\begin{array}{l}\text { Rel. } \\
(\%)\end{array}$ & $\begin{array}{c}\text { Abs. } \\
\left(10^{6}\right. \\
\text { Btus }) \\
\end{array}$ & $\begin{array}{l}\text { Rel. } \\
(\%)\end{array}$ \\
\hline 2 & NIEcon.DB.SSFan.CS1.DCV0 & 25 & 92.1 & 20 & 91.5 & 21 & 94.2 & 45 & 95.5 \\
\hline 3 & NIEcon.EH.SSFan.CS1.DCV0 & 21 & 92.1 & 20 & 91.4 & 19 & 94.2 & 45 & 95.5 \\
\hline 4 & IEcon.DB.SSFan.CS1.DCV0 & 25 & 92.1 & 20 & 91.5 & 21 & 94.2 & 45 & 95.5 \\
\hline 5 & IEcon.EH.SSFan.CS1.DCV0 & 21 & 92.1 & 20 & 91.5 & 19 & 94.2 & 45 & 95.5 \\
\hline 6 & NoEcon.MSFan.CS1.DCV0 & 221 & 95.9 & 240 & 96.2 & 231 & 97.5 & 289 & 97.8 \\
\hline 7 & NIEcon.DB.MSFan.CS1.DCV0 & 230 & 96.0 & 247 & 96.4 & 241 & 97.6 & 327 & 98.2 \\
\hline 8 & NIEcon.EH.MSFan.CS1.DCV0 & 229 & 96.0 & 247 & 96.4 & 240 & 97.6 & 327 & 98.2 \\
\hline 9 & IEcon.DB.MSFan.CS1.DCV0 & 230 & 96.0 & 247 & 96.4 & 241 & 97.6 & 327 & 98.2 \\
\hline 10 & IEcon.EH.MSFan.CS1.DCV0 & 229 & 96.0 & 247 & 96.4 & 240 & 97.6 & 327 & 98.2 \\
\hline 11 & NoEcon.MSFan.CS2.DCV0 & 247 & 96.4 & 261 & 96.7 & 245 & 97.7 & 320 & 98.1 \\
\hline 12 & IEcon.DB.MSFan.CS2.DCV0 & 250 & 96.4 & 264 & 96.8 & 248 & 97.8 & 331 & 98.2 \\
\hline 13 & IEcon.EH.MSFan.CS2.DCV0 & 250 & 96.4 & 263 & 96.8 & 248 & 97.8 & 331 & 98.2 \\
\hline 14 & NoEcon.SSFan.CS1.DCV1 & 31 & 92.3 & 22 & 91.5 & 21 & 94.2 & 43 & 95.5 \\
\hline 15 & IEcon.DB.SSFan.CS1.DCV1 & 39 & 92.4 & 26 & 91.6 & 25 & 94.3 & 46 & 95.6 \\
\hline 16 & IEcon.EH.SSFan.CS1.DCV1 & 36 & 92.3 & 26 & 91.6 & 23 & 94.3 & 46 & 95.6 \\
\hline 17 & NoEcon.MSFan.CS1.DCV1 & 260 & 96.6 & 272 & 96.9 & 264 & 98.0 & 313 & 98.1 \\
\hline 18 & IEcon.DB.MSFan.CS1.DCV1 & 267 & 96.7 & 276 & 97.0 & 270 & 98.1 & 360 & 98.5 \\
\hline 19 & IEcon.EH.MSFan.CS1.DCV1 & 265 & 96.7 & 276 & 97.0 & 269 & 98.1 & 360 & 98.5 \\
\hline 20 & NoEcon.MSFan.CS2.DCV1 & 281 & 97.0 & 290 & 97.3 & 275 & 98.2 & 355 & 98.5 \\
\hline 21 & IEcon.DB.MSFan.CS2.DCV1 & 283 & 97.0 & 291 & 97.3 & 276 & 98.2 & 364 & 98.5 \\
\hline 22 & IEcon.EH.MSFan.CS2.DCV1 & 282 & 97.0 & 290 & 97.3 & 276 & 98.2 & 363 & 98.5 \\
\hline
\end{tabular}


Table C-29: Electricity Savings Compared to Case 1 for the Supermarket Building in Climate Zones 1, 2 and 3A

\begin{tabular}{|c|c|c|c|c|c|c|c|c|c|}
\hline \multirow[b]{2}{*}{$\begin{array}{c}\text { Case } \\
\text { No }\end{array}$} & \multirow[b]{2}{*}{ Case Name } & \multicolumn{2}{|c|}{ Miami-1A } & \multicolumn{2}{|c|}{ Houston-2A } & \multicolumn{2}{|c|}{ Phoenix-2B } & \multicolumn{2}{|c|}{ Atlanta-3A } \\
\hline & & $\begin{array}{c}\text { Abs. } \\
\left(10^{6}\right. \\
\text { Btus }) \\
\end{array}$ & $\begin{array}{l}\text { Rel. } \\
\text { (\%) }\end{array}$ & $\begin{array}{c}\text { Abs. } \\
\left(10^{6}\right. \\
\text { Btus }) \\
\end{array}$ & $\begin{array}{l}\text { Rel. } \\
(\%)\end{array}$ & $\begin{array}{c}\text { Abs. } \\
\left(10^{6}\right. \\
\text { Btus }) \\
\end{array}$ & $\begin{array}{l}\text { Rel. } \\
\text { (\%) }\end{array}$ & $\begin{array}{c}\text { Abs. } \\
\left(10^{6}\right. \\
\text { Btus }) \\
\end{array}$ & $\begin{array}{l}\text { Rel. } \\
\text { (\%) }\end{array}$ \\
\hline 2 & NIEcon.DB.SSFan.CS1.DCV0 & 27 & 21.4 & 31 & 68.4 & 22 & 67.3 & 40 & 82.2 \\
\hline 3 & NIEcon.EH.SSFan.CS1.DCV0 & 14 & 20.5 & 20 & 68.1 & 22 & 67.3 & 30 & 82.1 \\
\hline 4 & IEcon.DB.SSFan.CS1.DCV0 & 27 & 21.4 & 31 & 68.4 & 22 & 67.3 & 40 & 82.3 \\
\hline 5 & IEcon.EH.SSFan.CS1.DCV0 & 14 & 20.5 & 20 & 68.1 & 22 & 67.3 & 30 & 82.1 \\
\hline 6 & NoEcon.MSFan.CS1.DCV0 & 403 & 47.2 & 567 & 82.4 & 488 & 80.1 & 642 & 92.2 \\
\hline 7 & NIEcon.DB.MSFan.CS1.DCV0 & 417 & 48.2 & 583 & 82.8 & 501 & 80.5 & 664 & 92.5 \\
\hline 8 & NIEcon.EH.MSFan.CS1.DCV0 & 410 & 47.7 & 579 & 82.7 & 502 & 80.5 & 660 & 92.5 \\
\hline 9 & IEcon.DB.MSFan.CS1.DCV0 & 417 & 48.2 & 583 & 82.8 & 502 & 80.5 & 665 & 92.5 \\
\hline 10 & IEcon.EH.MSFan.CS1.DCV0 & 410 & 47.7 & 579 & 82.7 & 502 & 80.5 & 660 & 92.5 \\
\hline 11 & NoEcon.MSFan.CS2.DCV0 & 499 & 53.8 & 657 & 84.8 & 575 & 82.5 & 700 & 93.1 \\
\hline 12 & IEcon.DB.MSFan.CS2.DCV0 & 509 & 54.5 & 666 & 85.0 & 582 & 82.7 & 710 & 93.3 \\
\hline 13 & IEcon.EH.MSFan.CS2.DCV0 & 504 & 54.2 & 664 & 85.0 & 582 & 82.7 & 709 & 93.3 \\
\hline 14 & NoEcon.SSFan.CS1.DCV1 & 121 & 27.8 & 101 & 70.2 & 128 & 70.2 & 39 & 82.2 \\
\hline 15 & IEcon.DB.SSFan.CS1.DCV1 & 148 & 29.7 & 133 & 71.1 & 150 & 70.8 & 80 & 82.9 \\
\hline 16 & IEcon.EH.SSFan.CS1.DCV1 & 134 & 28.8 & 121 & 70.7 & 150 & 70.8 & 69 & 82.7 \\
\hline 17 & NoEcon.MSFan.CS1.DCV1 & 538 & 56.5 & 705 & 86.0 & 655 & 84.7 & 714 & 93.4 \\
\hline 18 & IEcon.DB.MSFan.CS1.DCV1 & 552 & 57.4 & 722 & 86.5 & 669 & 85.1 & 736 & 93.7 \\
\hline 19 & IEcon.EH.MSFan.CS1.DCV1 & 546 & 57.0 & 717 & 86.3 & 669 & 85.1 & 732 & 93.6 \\
\hline 20 & NoEcon.MSFan.CS2.DCV1 & 618 & 62.0 & 770 & 87.7 & 723 & 86.5 & 762 & 94.1 \\
\hline 21 & IEcon.DB.MSFan.CS2.DCV1 & 627 & 62.6 & 779 & 88.0 & 730 & 86.7 & 772 & 94.3 \\
\hline 22 & IEcon.EH.MSFan.CS2.DCV1 & 624 & 62.4 & 777 & 87.9 & 730 & 86.7 & 771 & 94.3 \\
\hline
\end{tabular}


Table C-30: Electricity Savings Compared to Case 1 for the Supermarket Building in Climate Zones 3B, 3C and 4A

\begin{tabular}{|c|c|c|c|c|c|c|c|c|c|}
\hline \multirow[b]{2}{*}{$\begin{array}{c}\text { Case } \\
\text { No }\end{array}$} & \multirow[b]{2}{*}{ Case Name } & \multicolumn{2}{|c|}{ Los Angeles-3B } & \multicolumn{2}{|c|}{ Las Vegas-3B } & \multicolumn{2}{|c|}{ San Francisco-3C } & \multicolumn{2}{|c|}{ Baltimore-4A } \\
\hline & & $\begin{array}{c}\text { Abs. } \\
\left(10^{6}\right. \\
\text { Btus })\end{array}$ & $\begin{array}{l}\text { Rel. } \\
\text { (\%) }\end{array}$ & $\begin{array}{c}\text { Abs. } \\
\left(10^{6}\right. \\
\text { Btus }) \\
\end{array}$ & $\begin{array}{l}\text { Rel. } \\
\text { (\%) }\end{array}$ & $\begin{array}{c}\text { Abs. } \\
\left(10^{6}\right. \\
\text { Btus }) \\
\end{array}$ & $\begin{array}{l}\text { Rel. } \\
\text { (\%) }\end{array}$ & $\begin{array}{c}\text { Abs. } \\
\left(10^{6}\right. \\
\text { Btus }) \\
\end{array}$ & $\begin{array}{l}\text { Rel. } \\
\text { (\%) }\end{array}$ \\
\hline 2 & NIEcon.DB.SSFan.CS1.DCV0 & 63 & 81.2 & 23 & 78.3 & 31 & 89.8 & 30 & 88.0 \\
\hline 3 & NIEcon.EH.SSFan.CS1.DCV0 & 52 & 80.9 & 23 & 78.3 & 31 & 89.8 & 23 & 87.9 \\
\hline 4 & IEcon.DB.SSFan.CS1.DCV0 & 65 & 81.3 & 24 & 78.3 & 32 & 89.8 & 30 & 88.0 \\
\hline 5 & IEcon.EH.SSFan.CS1.DCV0 & 53 & 80.9 & 24 & 78.3 & 31 & 89.8 & 24 & 87.9 \\
\hline 6 & NoEcon.MSFan.CS1.DCV0 & 454 & 92.8 & 564 & 88.9 & 437 & 96.3 & 621 & 94.9 \\
\hline 7 & NIEcon.DB.MSFan.CS1.DCV0 & 491 & 93.9 & 578 & 89.2 & 457 & 96.6 & 640 & 95.1 \\
\hline 8 & NIEcon.EH.MSFan.CS1.DCV0 & 485 & 93.8 & 578 & 89.2 & 457 & 96.6 & 637 & 95.1 \\
\hline 9 & IEcon.DB.MSFan.CS1.DCV0 & 493 & 94.0 & 579 & 89.2 & 458 & 96.6 & 640 & 95.2 \\
\hline 10 & IEcon.EH.MSFan.CS1.DCV0 & 487 & 93.8 & 579 & 89.2 & 457 & 96.6 & 637 & 95.1 \\
\hline 11 & NoEcon.MSFan.CS2.DCV0 & 481 & 93.6 & 623 & 90.1 & 449 & 96.5 & 663 & 95.4 \\
\hline 12 & IEcon.DB.MSFan.CS2.DCV0 & 503 & 94.3 & 631 & 90.2 & 461 & 96.7 & 672 & 95.5 \\
\hline 13 & IEcon.EH.MSFan.CS2.DCV0 & 502 & 94.2 & 631 & 90.2 & 461 & 96.7 & 671 & 95.5 \\
\hline 14 & NoEcon.SSFan.CS1.DCV1 & -1 & 79.3 & 86 & 79.6 & 2 & 89.3 & 33 & 88.1 \\
\hline 15 & IEcon.DB.SSFan.CS1.DCV1 & 67 & 81.3 & 110 & 80.0 & 33 & 89.8 & 64 & 88.4 \\
\hline 16 & IEcon.EH.SSFan.CS1.DCV1 & 51 & 80.8 & 110 & 80.0 & 33 & 89.8 & 56 & 88.3 \\
\hline 17 & NoEcon.MSFan.CS1.DCV1 & 470 & 93.3 & 685 & 91.3 & 467 & 96.8 & 694 & 95.8 \\
\hline 18 & IEcon.DB.MSFan.CS1.DCV1 & 508 & 94.4 & 700 & 91.6 & 487 & 97.1 & 712 & 96.0 \\
\hline 19 & IEcon.EH.MSFan.CS1.DCV1 & 503 & 94.3 & 700 & 91.6 & 487 & 97.1 & 709 & 96.0 \\
\hline 20 & NoEcon.MSFan.CS2.DCV1 & 498 & 94.1 & 735 & 92.2 & 479 & 97.0 & 727 & 96.2 \\
\hline 21 & IEcon.DB.MSFan.CS2.DCV1 & 518 & 94.7 & 743 & 92.4 & 491 & 97.1 & 735 & 96.3 \\
\hline 22 & IEcon.EH.MSFan.CS2.DCV1 & 518 & 94.7 & 743 & 92.4 & 491 & 97.1 & 735 & 96.3 \\
\hline
\end{tabular}


Table C-31: Electricity Savings Compared to Case 1 for the Supermarket Building in Climate Zones 4B, 4C, 5A and 5B

\begin{tabular}{|c|c|c|c|c|c|c|c|c|c|}
\hline \multirow[b]{2}{*}{$\begin{array}{c}\text { Case } \\
\text { No }\end{array}$} & \multirow[b]{2}{*}{ Case Name } & \multicolumn{2}{|c|}{ Albuquerque-4B } & \multicolumn{2}{|c|}{ Seattle-4C } & \multicolumn{2}{|c|}{ Chicago-5A } & \multicolumn{2}{|c|}{ Denver-5B } \\
\hline & & $\begin{array}{c}\text { Abs. } \\
\left(10^{6}\right. \\
\text { Btus }) \\
\end{array}$ & $\begin{array}{l}\text { Rel. } \\
\text { (\%) }\end{array}$ & $\begin{array}{c}\text { Abs. } \\
\left(10^{6}\right. \\
\text { Btus }) \\
\end{array}$ & $\begin{array}{l}\text { Rel. } \\
\text { (\%) }\end{array}$ & $\begin{array}{c}\text { Abs. } \\
\left(10^{6}\right. \\
\text { Btus }) \\
\end{array}$ & $\begin{array}{l}\text { Rel. } \\
(\%)\end{array}$ & $\begin{array}{c}\text { Abs. } \\
\left(10^{6}\right. \\
\text { Btus }) \\
\end{array}$ & $\begin{array}{l}\text { Rel. } \\
\text { (\%) }\end{array}$ \\
\hline 2 & NIEcon.DB.SSFan.CS1.DCV0 & 30 & 85.2 & 26 & 91.2 & 33 & 89.5 & 30 & 87.6 \\
\hline 3 & NIEcon.EH.SSFan.CS1.DCV0 & 26 & 85.2 & 25 & 91.2 & 25 & 89.4 & 27 & 87.6 \\
\hline 4 & IEcon.DB.SSFan.CS1.DCV0 & 31 & 85.2 & 27 & 91.2 & 34 & 89.5 & 30 & 87.6 \\
\hline 5 & IEcon.EH.SSFan.CS1.DCV0 & 27 & 85.2 & 25 & 91.2 & 25 & 89.4 & 27 & 87.6 \\
\hline 6 & NoEcon.MSFan.CS1.DCV0 & 676 & 94.1 & 492 & 96.7 & 740 & 96.0 & 767 & 95.5 \\
\hline 7 & NIEcon.DB.MSFan.CS1.DCV0 & 693 & 94.4 & 509 & 96.9 & 762 & 96.2 & 785 & 95.7 \\
\hline 8 & NIEcon.EH.MSFan.CS1.DCV0 & 692 & 94.3 & 508 & 96.9 & 759 & 96.2 & 784 & 95.7 \\
\hline 9 & IEcon.DB.MSFan.CS1.DCV0 & 694 & 94.4 & 510 & 96.9 & 763 & 96.2 & 785 & 95.7 \\
\hline 10 & IEcon.EH.MSFan.CS1.DCV0 & 692 & 94.3 & 509 & 96.9 & 759 & 96.2 & 784 & 95.7 \\
\hline 11 & NoEcon.MSFan.CS2.DCV0 & 724 & 94.8 & 505 & 96.9 & 778 & 96.3 & 797 & 95.8 \\
\hline 12 & IEcon.DB.MSFan.CS2.DCV0 & 732 & 94.9 & 515 & 97.0 & 788 & 96.4 & 806 & 95.9 \\
\hline 13 & IEcon.EH.MSFan.CS2.DCV0 & 732 & 94.9 & 515 & 97.0 & 787 & 96.4 & 806 & 95.9 \\
\hline 14 & NoEcon.SSFan.CS1.DCV1 & 27 & 85.2 & 3 & 90.9 & 15 & 89.3 & 15 & 87.5 \\
\hline 15 & IEcon.DB.SSFan.CS1.DCV1 & 58 & 85.6 & 30 & 91.2 & 56 & 89.7 & 48 & 87.8 \\
\hline 16 & IEcon.EH.SSFan.CS1.DCV1 & 54 & 85.6 & 28 & 91.2 & 45 & 89.6 & 44 & 87.8 \\
\hline 17 & NoEcon.MSFan.CS1.DCV1 & 735 & 94.9 & 530 & 97.2 & 794 & 96.5 & 814 & 96.0 \\
\hline 18 & IEcon.DB.MSFan.CS1.DCV1 & 753 & 95.2 & 548 & 97.4 & 825 & 96.8 & 835 & 96.2 \\
\hline 19 & IEcon.EH.MSFan.CS1.DCV1 & 751 & 95.2 & 547 & 97.4 & 818 & 96.7 & 834 & 96.2 \\
\hline 20 & NoEcon.MSFan.CS2.DCV1 & 774 & 95.5 & 544 & 97.3 & 832 & 96.8 & 843 & 96.3 \\
\hline 21 & IEcon.DB.MSFan.CS2.DCV1 & 783 & 95.6 & 552 & 97.4 & 844 & 97.0 & 853 & 96.4 \\
\hline 22 & IEcon.EH.MSFan.CS2.DCV1 & 782 & 95.6 & 552 & 97.4 & 843 & 96.9 & 853 & 96.4 \\
\hline
\end{tabular}


Table C-32: Electricity Savings Compared to Case 1 for the Supermarket Building in Climate Zones 6, 7 and 8

\begin{tabular}{|c|c|c|c|c|c|c|c|c|c|}
\hline \multirow[b]{2}{*}{$\begin{array}{c}\text { Case } \\
\text { No }\end{array}$} & \multirow[b]{2}{*}{ Case Name } & \multicolumn{2}{|c|}{ Minneapolis-6A } & \multicolumn{2}{|c|}{ Helena-6B } & \multicolumn{2}{|c|}{ Duluth-7 } & \multicolumn{2}{|c|}{ Fairbanks-8 } \\
\hline & & $\begin{array}{c}\text { Abs. } \\
\left(10^{6}\right. \\
\text { Btus) }\end{array}$ & $\begin{array}{l}\text { Rel. } \\
(\%)\end{array}$ & $\begin{array}{c}\text { Abs. } \\
\left(10^{6}\right. \\
\text { Btus) }\end{array}$ & $\begin{array}{l}\text { Rel. } \\
(\%)\end{array}$ & $\begin{array}{c}\text { Abs. } \\
\left(10^{6}\right. \\
\text { Btus }) \\
\end{array}$ & $\begin{array}{l}\text { Rel. } \\
(\%) \\
\end{array}$ & $\begin{array}{c}\text { Abs. } \\
\left(10^{6}\right. \\
\text { Btus }) \\
\end{array}$ & $\begin{array}{l}\text { Rel. } \\
(\%)\end{array}$ \\
\hline 2 & NIEcon.DB.SSFan.CS1.DCV0 & 43 & 90.7 & 40 & 89.9 & 44 & 92.5 & 100 & 94.0 \\
\hline 3 & NIEcon.EH.SSFan.CS1.DCV0 & 37 & 90.7 & 39 & 89.9 & 41 & 92.5 & 100 & 94.0 \\
\hline 4 & IEcon.DB.SSFan.CS1.DCV0 & 43 & 90.7 & 40 & 89.9 & 44 & 92.5 & 100 & 94.0 \\
\hline 5 & IEcon.EH.SSFan.CS1.DCV0 & 37 & 90.7 & 39 & 89.9 & 41 & 92.5 & 100 & 94.0 \\
\hline 6 & NoEcon.MSFan.CS1.DCV0 & 780 & 96.4 & 820 & 96.2 & 758 & 97.0 & 885 & 97.2 \\
\hline 7 & NIEcon.DB.MSFan.CS1.DCV0 & 818 & 96.6 & 856 & 96.5 & 800 & 97.3 & 990 & 97.6 \\
\hline 8 & NIEcon.EH.MSFan.CS1.DCV0 & 815 & 96.6 & 854 & 96.5 & 797 & 97.2 & 989 & 97.6 \\
\hline 9 & IEcon.DB.MSFan.CS1.DCV0 & 819 & 96.7 & 857 & 96.5 & 801 & 97.3 & 990 & 97.6 \\
\hline 10 & IEcon.EH.MSFan.CS1.DCV0 & 815 & 96.6 & 855 & 96.5 & 797 & 97.2 & 989 & 97.6 \\
\hline 11 & NoEcon.MSFan.CS2.DCV0 & 824 & 96.7 & 852 & 96.5 & 787 & 97.2 & 955 & 97.5 \\
\hline 12 & IEcon.DB.MSFan.CS2.DCV0 & 839 & 96.8 & 870 & 96.6 & 806 & 97.3 & 994 & 97.7 \\
\hline 13 & IEcon.EH.MSFan.CS2.DCV0 & 838 & 96.8 & 869 & 96.6 & 806 & 97.3 & 993 & 97.7 \\
\hline 14 & NoEcon.SSFan.CS1.DCV1 & 5 & 90.4 & -5 & 89.5 & -14 & 92.1 & -24 & 93.5 \\
\hline 15 & IEcon.DB.SSFan.CS1.DCV1 & 61 & 90.8 & 52 & 90.0 & 49 & 92.5 & 100 & 94.0 \\
\hline 16 & IEcon.EH.SSFan.CS1.DCV1 & 53 & 90.8 & 50 & 90.0 & 45 & 92.5 & 99 & 94.0 \\
\hline 17 & NoEcon.MSFan.CS1.DCV1 & 822 & 96.7 & 845 & 96.4 & 790 & 97.2 & 907 & 97.3 \\
\hline 18 & IEcon.DB.MSFan.CS1.DCV1 & 882 & 97.1 & 908 & 96.9 & 860 & 97.6 & 1056 & 97.9 \\
\hline 19 & IEcon.EH.MSFan.CS1.DCV1 & 873 & 97.1 & 902 & 96.9 & 851 & 97.6 & 1051 & 97.9 \\
\hline 20 & NoEcon.MSFan.CS2.DCV1 & 875 & 97.1 & 892 & 96.8 & 835 & 97.5 & 1011 & 97.7 \\
\hline 21 & IEcon.DB.MSFan.CS2.DCV1 & 898 & 97.3 & 921 & 97.0 & 865 & 97.7 & 1059 & 97.9 \\
\hline 22 & IEcon.EH.MSFan.CS2.DCV1 & 896 & 97.2 & 920 & 97.0 & 863 & 97.7 & 1059 & 97.9 \\
\hline
\end{tabular}


Table C-33: Gas Savings Compared to Case 1 for the Small Office Building in Climate Zones 1, 2 and 3A

\begin{tabular}{|c|c|c|c|c|c|c|c|c|c|}
\hline \multirow[b]{2}{*}{$\begin{array}{c}\text { Case } \\
\text { No }\end{array}$} & \multirow[b]{2}{*}{ Case Name } & \multicolumn{2}{|c|}{ Miami-1A } & \multicolumn{2}{|c|}{ Houston-2A } & \multicolumn{2}{|c|}{ Phoenix-2B } & \multicolumn{2}{|c|}{ Atlanta-3A } \\
\hline & & $\begin{array}{c}\text { Abs. } \\
\left(10^{6}\right. \\
\text { Btus) }\end{array}$ & $\begin{array}{l}\text { Rel. } \\
(\%)\end{array}$ & $\begin{array}{c}\text { Abs. } \\
\left(10^{6}\right. \\
\text { Btus })\end{array}$ & $\begin{array}{l}\text { Rel. } \\
(\%)\end{array}$ & $\begin{array}{c}\text { Abs. } \\
\left(10^{6}\right. \\
\text { Btus })\end{array}$ & $\begin{array}{l}\text { Rel. } \\
(\%)\end{array}$ & $\begin{array}{c}\text { Abs. } \\
\left(10^{6}\right. \\
\text { Btus })\end{array}$ & $\begin{array}{l}\text { Rel. } \\
\text { (\%) }\end{array}$ \\
\hline 2 & NIEcon.DB.SSFan.CS1.DCV0 & 0 & -35.7 & 0 & 0.1 & 0 & 0.5 & 0 & 0.3 \\
\hline 3 & NIEcon.EH.SSFan.CS1.DCV0 & 0 & -35.4 & 0 & 0.0 & 0 & 0.6 & 0 & 0.3 \\
\hline 4 & IEcon.DB.SSFan.CS1.DCV0 & 0 & -35.3 & 0 & 0.1 & 0 & 0.6 & 0 & 0.3 \\
\hline 5 & IEcon.EH.SSFan.CS1.DCV0 & 0 & -35.4 & 0 & 0.0 & 0 & 0.8 & 0 & 0.3 \\
\hline 6 & NoEcon.MSFan.CS1.DCV0 & 0 & -60.5 & -9 & -31.8 & -8 & -49.4 & -18 & -28.3 \\
\hline 7 & NIEcon.DB.MSFan.CS1.DCV0 & 0 & -52.6 & -9 & -31.0 & -8 & -47.9 & -18 & -27.9 \\
\hline 8 & NIEcon.EH.MSFan.CS1.DCV0 & 0 & -54.0 & -9 & -31.2 & -8 & -47.8 & -18 & -27.9 \\
\hline 9 & IEcon.DB.MSFan.CS1.DCV0 & 0 & -53.4 & -9 & -31.0 & -8 & -47.9 & -18 & -27.9 \\
\hline 10 & IEcon.EH.MSFan.CS1.DCV0 & 0 & -54.5 & -9 & -31.2 & -8 & -47.8 & -18 & -27.9 \\
\hline 11 & NoEcon.MSFan.CS2.DCV0 & 0 & -54.5 & -9 & -31.1 & -8 & -47.6 & -18 & -28.0 \\
\hline 12 & IEcon.DB.MSFan.CS2.DCV0 & 0 & -53.0 & -9 & -31.0 & -8 & -47.5 & -18 & -27.9 \\
\hline 13 & IEcon.EH.MSFan.CS2.DCV0 & 0 & -53.3 & -9 & -31.0 & -8 & -47.4 & -18 & -27.9 \\
\hline 14 & NoEcon.SSFan.CS1.DCV1 & 0 & 23.2 & 8 & 26.8 & 5 & 29.9 & 17 & 26.5 \\
\hline 15 & IEcon.DB.SSFan.CS1.DCV1 & 0 & -21.7 & 8 & 25.7 & 5 & 30.0 & 17 & 26.3 \\
\hline 16 & IEcon.EH.SSFan.CS1.DCV1 & 0 & -21.4 & 8 & 25.6 & 5 & 30.0 & 17 & 26.3 \\
\hline 17 & NoEcon.MSFan.CS1.DCV1 & 0 & -0.7 & 1 & 2.6 & -1 & -6.3 & 3 & 4.9 \\
\hline 18 & IEcon.DB.MSFan.CS1.DCV1 & 0 & 7.7 & 1 & 3.4 & -1 & -4.6 & 3 & 5.3 \\
\hline 19 & IEcon.EH.MSFan.CS1.DCV1 & 0 & 6.3 & 1 & 3.3 & -1 & -4.6 & 3 & 5.3 \\
\hline 20 & NoEcon.MSFan.CS2.DCV1 & 0 & 6.5 & 1 & 3.3 & -1 & -4.8 & 3 & 5.3 \\
\hline 21 & IEcon.DB.MSFan.CS2.DCV1 & 0 & 8.1 & 1 & 3.5 & -1 & -4.3 & 3 & 5.4 \\
\hline 22 & IEcon.EH.MSFan.CS2.DCV1 & 0 & 7.7 & 1 & 3.5 & -1 & -4.3 & 3 & 5.4 \\
\hline
\end{tabular}


Table C-34: Gas Savings Compared to Case 1 for the Small Office Building in Climate Zones 3B, 3C and 4A

\begin{tabular}{|c|c|c|c|c|c|c|c|c|c|}
\hline \multirow[b]{2}{*}{$\begin{array}{c}\text { Case } \\
\text { No }\end{array}$} & \multirow[b]{2}{*}{ Case Name } & \multicolumn{2}{|c|}{ Los Angeles-3B } & \multicolumn{2}{|c|}{ Las Vegas-3B } & \multicolumn{2}{|c|}{ San Francisco-3C } & \multicolumn{2}{|c|}{ Baltimore-4A } \\
\hline & & $\begin{array}{c}\text { Abs. } \\
\left(10^{6}\right. \\
\text { Btus })\end{array}$ & $\begin{array}{l}\text { Rel. } \\
(\%)\end{array}$ & $\begin{array}{c}\text { Abs. } \\
\left(10^{6}\right. \\
\text { Btus }) \\
\end{array}$ & $\begin{array}{c}\text { Rel. } \\
(\%)\end{array}$ & $\begin{array}{c}\text { Abs. } \\
\left(10^{6}\right. \\
\text { Btus) }\end{array}$ & $\begin{array}{l}\text { Rel. } \\
(\%)\end{array}$ & $\begin{array}{c}\text { Abs. } \\
\left(10^{6}\right. \\
\text { Btus }) \\
\end{array}$ & $\begin{array}{l}\text { Rel. } \\
\text { (\%) }\end{array}$ \\
\hline 2 & NIEcon.DB.SSFan.CS1.DCV0 & 0 & -2.1 & 0 & 1.1 & 0 & 1.0 & 0 & 0.3 \\
\hline 3 & NIEcon.EH.SSFan.CS1.DCV0 & 0 & -2.1 & 0 & 1.1 & 0 & 1.0 & 0 & 0.3 \\
\hline 4 & IEcon.DB.SSFan.CS1.DCV0 & 0 & -2.1 & 0 & 1.2 & 0 & 1.0 & 0 & 0.3 \\
\hline 5 & IEcon.EH.SSFan.CS1.DCV0 & 0 & -2.1 & 0 & 1.1 & 0 & 0.9 & 0 & 0.3 \\
\hline 6 & NoEcon.MSFan.CS1.DCV0 & -8 & -67.3 & -13 & -39.3 & -18 & -43.5 & -22 & -23.9 \\
\hline 7 & NIEcon.DB.MSFan.CS1.DCV0 & -8 & -62.6 & -13 & -38.1 & -18 & -42.5 & -22 & -23.6 \\
\hline 8 & NIEcon.EH.MSFan.CS1.DCV0 & -8 & -62.5 & -13 & -38.1 & -18 & -42.5 & -22 & -23.6 \\
\hline 9 & IEcon.DB.MSFan.CS1.DCV0 & -8 & -62.6 & -13 & -38.2 & -18 & -42.5 & -22 & -23.6 \\
\hline 10 & IEcon.EH.MSFan.CS1.DCV0 & -8 & -62.6 & -13 & -38.1 & -18 & -42.5 & -22 & -23.6 \\
\hline 11 & NoEcon.MSFan.CS2.DCV0 & -8 & -63.0 & -13 & -38.3 & -18 & -42.8 & -22 & -23.6 \\
\hline 12 & IEcon.DB.MSFan.CS2.DCV0 & -8 & -62.4 & -13 & -37.9 & -18 & -42.5 & -22 & -23.6 \\
\hline 13 & IEcon.EH.MSFan.CS2.DCV0 & -8 & -62.4 & -13 & -37.9 & -18 & -42.5 & -22 & -23.6 \\
\hline 14 & NoEcon.SSFan.CS1.DCV1 & 3 & 24.8 & 9 & 27.6 & 13 & 32.2 & 29 & 31.0 \\
\hline 15 & IEcon.DB.SSFan.CS1.DCV1 & 2 & 19.7 & 9 & 28.6 & 14 & 33.0 & 29 & 31.2 \\
\hline 16 & IEcon.EH.SSFan.CS1.DCV1 & 2 & 19.7 & 9 & 28.6 & 14 & 33.0 & 29 & 31.2 \\
\hline 17 & NoEcon.MSFan.CS1.DCV1 & -2 & -18.4 & 0 & -1.3 & 0 & 0.8 & 12 & 13.0 \\
\hline 18 & IEcon.DB.MSFan.CS1.DCV1 & -2 & -13.2 & 0 & -0.1 & 1 & 1.8 & 12 & 13.3 \\
\hline 19 & IEcon.EH.MSFan.CS1.DCV1 & -2 & -13.3 & 0 & -0.1 & 1 & 1.8 & 12 & 13.3 \\
\hline 20 & NoEcon.MSFan.CS2.DCV1 & -2 & -13.3 & 0 & -0.3 & 1 & 1.6 & 12 & 13.3 \\
\hline 21 & IEcon.DB.MSFan.CS2.DCV1 & -2 & -13.0 & 0 & 0.0 & 1 & 1.9 & 12 & 13.3 \\
\hline 22 & IEcon.EH.MSFan.CS2.DCV1 & -2 & -13.0 & 0 & 0.0 & 1 & 1.9 & 12 & 13.3 \\
\hline
\end{tabular}


Table C-35: Gas Savings Compared to Case 1 for the Small Office Building in Climate Zones 4B, 4C, 5A and 5B

\begin{tabular}{|c|c|c|c|c|c|c|c|c|c|}
\hline \multirow[b]{2}{*}{$\begin{array}{c}\text { Case } \\
\text { No }\end{array}$} & \multirow[b]{2}{*}{ Case Name } & \multicolumn{2}{|c|}{ Albuquerque-4B } & \multicolumn{2}{|c|}{ Seattle-4C } & \multicolumn{2}{|c|}{ Chicago-5A } & \multicolumn{2}{|c|}{ Denver-5B } \\
\hline & & $\begin{array}{c}\text { Abs. } \\
\left(10^{6}\right. \\
\text { Btus })\end{array}$ & $\begin{array}{l}\text { Rel. } \\
\text { (\%) }\end{array}$ & $\begin{array}{c}\text { Abs. } \\
\left(10^{6}\right. \\
\text { Btus })\end{array}$ & $\begin{array}{l}\text { Rel. } \\
\text { (\%) }\end{array}$ & $\begin{array}{c}\text { Abs. } \\
\left(10^{6}\right. \\
\text { Btus })\end{array}$ & $\begin{array}{l}\text { Rel. } \\
\text { (\%) }\end{array}$ & $\begin{array}{c}\text { Abs. } \\
\left(10^{6}\right. \\
\text { Btus })\end{array}$ & $\begin{array}{l}\text { Rel. } \\
\text { (\%) }\end{array}$ \\
\hline 2 & NIEcon.DB.SSFan.CS1.DCV0 & 0 & 0.4 & 0 & 0.3 & 0 & 0.2 & 1 & 0.7 \\
\hline 3 & NIEcon.EH.SSFan.CS1.DCV0 & 0 & 0.4 & 0 & 0.3 & 0 & 0.1 & 1 & 0.7 \\
\hline 4 & IEcon.DB.SSFan.CS1.DCV0 & 0 & 0.4 & 0 & 0.3 & 0 & 0.2 & 1 & 0.6 \\
\hline 5 & IEcon.EH.SSFan.CS1.DCV0 & 0 & 0.4 & 0 & 0.3 & 0 & 0.1 & 1 & 0.6 \\
\hline 6 & NoEcon.MSFan.CS1.DCV0 & -19 & -27.8 & -26 & -34.4 & -29 & -21.1 & -26 & -26.0 \\
\hline 7 & NIEcon.DB.MSFan.CS1.DCV0 & -18 & -27.0 & -26 & -34.1 & -29 & -21.0 & -25 & -25.5 \\
\hline 8 & NIEcon.EH.MSFan.CS1.DCV0 & -18 & -27.0 & -26 & -34.1 & -29 & -21.0 & -25 & -25.5 \\
\hline 9 & IEcon.DB.MSFan.CS1.DCV0 & -18 & -27.0 & -26 & -34.1 & -29 & -21.0 & -25 & -25.5 \\
\hline 10 & IEcon.EH.MSFan.CS1.DCV0 & -18 & -27.0 & -26 & -34.1 & -29 & -21.0 & -25 & -25.5 \\
\hline 11 & NoEcon.MSFan.CS2.DCV0 & -18 & -27.1 & -26 & -34.1 & -29 & -21.0 & -25 & -25.6 \\
\hline 12 & IEcon.DB.MSFan.CS2.DCV0 & -18 & -26.9 & -26 & -34.0 & -29 & -20.9 & -25 & -25.4 \\
\hline 13 & IEcon.EH.MSFan.CS2.DCV0 & -18 & -26.9 & -26 & -34.0 & -29 & -20.9 & -25 & -25.3 \\
\hline 14 & NoEcon.SSFan.CS1.DCV1 & 17 & 25.3 & 27 & 35.6 & 40 & 29.3 & 26 & 26.0 \\
\hline 15 & IEcon.DB.SSFan.CS1.DCV1 & 17 & 25.2 & 28 & 35.9 & 40 & 29.4 & 26 & 26.6 \\
\hline 16 & IEcon.EH.SSFan.CS1.DCV1 & 17 & 25.2 & 28 & 35.9 & 40 & 29.4 & 26 & 26.6 \\
\hline 17 & NoEcon.MSFan.CS1.DCV1 & 3 & 5.1 & 8 & 10.8 & 18 & 12.8 & 7 & 6.6 \\
\hline 18 & IEcon.DB.MSFan.CS1.DCV1 & 4 & 6.0 & 9 & 11.3 & 18 & 13.0 & 7 & 7.3 \\
\hline 19 & IEcon.EH.MSFan.CS1.DCV1 & 4 & 6.0 & 9 & 11.3 & 18 & 13.0 & 7 & 7.3 \\
\hline 20 & NoEcon.MSFan.CS2.DCV1 & 4 & 5.8 & 9 & 11.2 & 18 & 13.0 & 7 & 7.2 \\
\hline 21 & IEcon.DB.MSFan.CS2.DCV1 & 4 & 6.0 & 9 & 11.3 & 18 & 13.0 & 7 & 7.4 \\
\hline 22 & IEcon.EH.MSFan.CS2.DCV1 & 4 & 6.1 & 9 & 11.3 & 18 & 13.0 & 7 & 7.4 \\
\hline
\end{tabular}


Table C-36: Gas Savings Compared to Case 1 for the Small Office Building in Climate Zones 6, 7 and 8

\begin{tabular}{|c|c|c|c|c|c|c|c|c|c|}
\hline \multirow[b]{2}{*}{$\begin{array}{c}\text { Case } \\
\text { No }\end{array}$} & \multirow[b]{2}{*}{ Case Name } & \multicolumn{2}{|c|}{ Minneapolis-6A } & \multicolumn{2}{|c|}{ Helena-6B } & \multicolumn{2}{|c|}{ Duluth-7A } & \multicolumn{2}{|c|}{ Fairbanks-8A } \\
\hline & & $\begin{array}{c}\text { Abs. } \\
\left(10^{6}\right. \\
\text { Btus })\end{array}$ & $\begin{array}{l}\text { Rel. } \\
\text { (\%) }\end{array}$ & $\begin{array}{c}\text { Abs. } \\
\left(10^{6}\right. \\
\text { Btus })\end{array}$ & $\begin{array}{l}\text { Rel. } \\
\text { (\%) }\end{array}$ & $\begin{array}{c}\text { Abs. } \\
\left(10^{6}\right. \\
\text { Btus })\end{array}$ & $\begin{array}{l}\text { Rel. } \\
\text { (\%) }\end{array}$ & $\begin{array}{c}\text { Abs. } \\
\left(10^{6}\right. \\
\text { Btus })\end{array}$ & $\begin{array}{l}\text { Rel. } \\
\text { (\%) }\end{array}$ \\
\hline 2 & NIEcon.DB.SSFan.CS1.DCV0 & 0 & 0.2 & 0 & 0.3 & 0 & 0.2 & 0 & -0.1 \\
\hline 3 & NIEcon.EH.SSFan.CS1.DCV0 & 0 & 0.2 & 0 & 0.3 & 0 & 0.1 & 0 & -0.1 \\
\hline 4 & IEcon.DB.SSFan.CS1.DCV0 & 0 & 0.2 & 0 & 0.3 & 0 & 0.2 & 0 & -0.1 \\
\hline 5 & IEcon.EH.SSFan.CS1.DCV0 & 0 & 0.2 & 0 & 0.3 & 0 & 0.1 & 0 & -0.1 \\
\hline 6 & NoEcon.MSFan.CS1.DCV0 & -31 & -17.8 & -34 & -23.9 & -38 & -17.8 & -49 & -12.7 \\
\hline 7 & NIEcon.DB.MSFan.CS1.DCV0 & -31 & -17.7 & -33 & -23.6 & -38 & -17.7 & -48 & -12.4 \\
\hline 8 & NIEcon.EH.MSFan.CS1.DCV0 & -31 & -17.7 & -33 & -23.6 & -38 & -17.7 & -48 & -12.4 \\
\hline 9 & IEcon.DB.MSFan.CS1.DCV0 & -31 & -17.7 & -34 & -23.6 & -38 & -17.7 & -48 & -12.4 \\
\hline 10 & IEcon.EH.MSFan.CS1.DCV0 & -31 & -17.7 & -34 & -23.6 & -38 & -17.7 & -48 & -12.4 \\
\hline 11 & NoEcon.MSFan.CS2.DCV0 & -31 & -17.7 & -34 & -23.6 & -38 & -17.7 & -48 & -12.4 \\
\hline 12 & IEcon.DB.MSFan.CS2.DCV0 & -31 & -17.7 & -33 & -23.5 & -38 & -17.7 & -48 & -12.4 \\
\hline 13 & IEcon.EH.MSFan.CS2.DCV0 & -31 & -17.7 & -33 & -23.5 & -38 & -17.7 & -48 & -12.4 \\
\hline 14 & NoEcon.SSFan.CS1.DCV1 & 51 & 29.1 & 39 & 27.5 & 59 & 27.7 & 90 & 23.4 \\
\hline 15 & IEcon.DB.SSFan.CS1.DCV1 & 51 & 29.3 & 40 & 27.9 & 59 & 27.9 & 86 & 22.5 \\
\hline 16 & IEcon.EH.SSFan.CS1.DCV1 & 51 & 29.3 & 40 & 27.8 & 59 & 27.9 & 86 & 22.5 \\
\hline 17 & NoEcon.MSFan.CS1.DCV1 & 26 & 14.9 & 14 & 9.7 & 30 & 14.0 & 48 & 12.6 \\
\hline 18 & IEcon.DB.MSFan.CS1.DCV1 & 26 & 15.1 & 14 & 10.0 & 30 & 14.3 & 50 & 13.0 \\
\hline 19 & IEcon.EH.MSFan.CS1.DCV1 & 26 & 15.1 & 14 & 10.0 & 30 & 14.3 & 50 & 13.0 \\
\hline 20 & NoEcon.MSFan.CS2.DCV1 & 26 & 15.0 & 14 & 9.9 & 30 & 14.1 & 49 & 12.9 \\
\hline 21 & IEcon.DB.MSFan.CS2.DCV1 & 26 & 15.1 & 14 & 10.1 & 30 & 14.3 & 50 & 13.0 \\
\hline 22 & IEcon.EH.MSFan.CS2.DCV1 & 26 & 15.1 & 14 & 10.1 & 30 & 14.3 & 50 & 13.0 \\
\hline
\end{tabular}


Table C-37: Gas Savings Compared to Case 1 for the Stand-alone Retail Building in Climate Zones 1, 2 and 3A

\begin{tabular}{|c|c|c|c|c|c|c|c|c|c|}
\hline \multirow{2}{*}{$\begin{array}{c}\text { Case } \\
\text { No }\end{array}$} & \multirow[b]{2}{*}{ Case Name } & \multicolumn{2}{|c|}{ Miami-1A } & \multicolumn{2}{|c|}{ Houston-2A } & \multicolumn{2}{|c|}{ Phoenix-2B } & \multicolumn{2}{|c|}{ Atlanta-3A } \\
\hline & & $\begin{array}{c}\text { Abs. } \\
\left(10^{6}\right. \\
\text { Btus })\end{array}$ & $\begin{array}{l}\text { Rel. } \\
\text { (\%) }\end{array}$ & $\begin{array}{c}\text { Abs. } \\
\left(10^{6}\right. \\
\text { Btus }) \\
\end{array}$ & $\begin{array}{l}\text { Rel. } \\
\text { (\%) }\end{array}$ & $\begin{array}{c}\text { Abs. } \\
\left(10^{6}\right. \\
\text { Btus })\end{array}$ & $\begin{array}{l}\text { Rel. } \\
\text { (\%) }\end{array}$ & $\begin{array}{c}\text { Abs. } \\
\left(10^{6}\right. \\
\text { Btus }) \\
\end{array}$ & $\begin{array}{l}\text { Rel. } \\
\text { (\%) }\end{array}$ \\
\hline 2 & NIEcon.DB.SSFan.CS1.DCV0 & 0 & 0.7 & 0 & 0.1 & 0 & 0.1 & 0 & 0.1 \\
\hline 3 & NIEcon.EH.SSFan.CS1.DCV0 & 0 & 0.4 & 0 & 0.1 & 1 & 0.2 & 0 & 0.0 \\
\hline 4 & IEcon.DB.SSFan.CS1.DCV0 & 0 & 0.7 & 0 & 0.1 & 0 & 0.1 & 0 & 0.1 \\
\hline 5 & IEcon.EH.SSFan.CS1.DCV0 & 0 & 0.4 & 0 & 0.0 & 1 & 0.2 & 0 & 0.1 \\
\hline 6 & NoEcon.MSFan.CS1.DCV0 & -10 & -43.0 & -67 & -16.4 & -69 & -22.2 & -123 & -14.4 \\
\hline 7 & NIEcon.DB.MSFan.CS1.DCV0 & -10 & -42.3 & -67 & -16.3 & -68 & -22.0 & -123 & -14.4 \\
\hline 8 & NIEcon.EH.MSFan.CS1.DCV0 & -10 & -42.4 & -67 & -16.4 & -68 & -21.9 & -123 & -14.4 \\
\hline 9 & IEcon.DB.MSFan.CS1.DCV0 & -10 & -42.3 & -67 & -16.3 & -68 & -22.0 & -123 & -14.4 \\
\hline 10 & IEcon.EH.MSFan.CS1.DCV0 & -10 & -42.4 & -67 & -16.4 & -68 & -21.9 & -123 & -14.4 \\
\hline 11 & NoEcon.MSFan.CS2.DCV0 & -10 & -42.5 & -67 & -16.4 & -68 & -21.9 & -123 & -14.4 \\
\hline 12 & IEcon.DB.MSFan.CS2.DCV0 & -10 & -42.4 & -67 & -16.3 & -68 & -21.9 & -123 & -14.4 \\
\hline 13 & IEcon.EH.MSFan.CS2.DCV0 & -10 & -42.4 & -67 & -16.3 & -68 & -21.8 & -123 & -14.4 \\
\hline 14 & NoEcon.SSFan.CS1.DCV1 & 13 & 55.9 & 153 & 37.4 & 120 & 38.4 & 295 & 34.5 \\
\hline 15 & IEcon.DB.SSFan.CS1.DCV1 & 13 & 56.5 & 153 & 37.5 & 120 & 38.7 & 295 & 34.6 \\
\hline 16 & IEcon.EH.SSFan.CS1.DCV1 & 13 & 56.4 & 153 & 37.5 & 120 & 38.7 & 295 & 34.6 \\
\hline 17 & NoEcon.MSFan.CS1.DCV1 & 8 & 34.0 & 109 & 26.6 & 76 & 24.4 & 210 & 24.6 \\
\hline 18 & IEcon.DB.MSFan.CS1.DCV1 & 8 & 34.6 & 109 & 26.7 & 76 & 24.5 & 210 & 24.6 \\
\hline 19 & IEcon.EH.MSFan.CS1.DCV1 & 8 & 34.5 & 109 & 26.7 & 76 & 24.5 & 210 & 24.6 \\
\hline 20 & NoEcon.MSFan.CS2.DCV1 & 8 & 34.4 & 109 & 26.6 & 76 & 24.5 & 210 & 24.6 \\
\hline 21 & IEcon.DB.MSFan.CS2.DCV1 & 8 & 34.7 & 109 & 26.7 & 77 & 24.6 & 210 & 24.6 \\
\hline 22 & IEcon.EH.MSFan.CS2.DCV1 & 8 & 34.6 & 109 & 26.7 & 77 & 24.6 & 210 & 24.6 \\
\hline
\end{tabular}


Table C-38: Gas Savings Compared to Case 1 for the Stand-alone Retail Building in Climate Zones 3B, 3C and 4A

\begin{tabular}{|c|c|c|c|c|c|c|c|c|c|}
\hline \multirow[b]{2}{*}{$\begin{array}{c}\text { Case } \\
\text { No }\end{array}$} & \multirow[b]{2}{*}{ Case Name } & \multicolumn{2}{|c|}{ Los Angeles-3B } & \multicolumn{2}{|c|}{ Las Vegas-3B } & \multicolumn{2}{|c|}{ San Francisco-3C } & \multicolumn{2}{|c|}{ Baltimore-4A } \\
\hline & & $\begin{array}{c}\text { Abs. } \\
\left(10^{6}\right. \\
\text { Btus }) \\
\end{array}$ & $\begin{array}{l}\text { Rel. } \\
\text { (\%) }\end{array}$ & $\begin{array}{c}\text { Abs. } \\
\left(10^{6}\right. \\
\text { Btus }) \\
\end{array}$ & $\begin{array}{l}\text { Rel. } \\
\text { (\%) }\end{array}$ & $\begin{array}{c}\text { Abs. } \\
\left(10^{6}\right. \\
\text { Btus }) \\
\end{array}$ & $\begin{array}{l}\text { Rel. } \\
\text { (\%) }\end{array}$ & $\begin{array}{c}\text { Abs. } \\
\left(10^{6}\right. \\
\text { Btus }) \\
\end{array}$ & $\begin{array}{l}\text { Rel. } \\
\text { (\%) }\end{array}$ \\
\hline 2 & NIEcon.DB.SSFan.CS1.DCV0 & 1 & 0.2 & 1 & 0.1 & 1 & 0.1 & 0 & 0.0 \\
\hline 3 & NIEcon.EH.SSFan.CS1.DCV0 & 1 & 0.2 & 1 & 0.1 & 1 & 0.1 & 0 & 0.0 \\
\hline 4 & IEcon.DB.SSFan.CS1.DCV0 & 1 & 0.2 & 1 & 0.1 & 1 & 0.1 & 0 & 0.0 \\
\hline 5 & IEcon.EH.SSFan.CS1.DCV0 & 0 & 0.2 & 1 & 0.1 & 1 & 0.1 & 0 & 0.0 \\
\hline 6 & NoEcon.MSFan.CS1.DCV0 & -84 & -29.9 & -91 & -16.6 & -92 & -11.8 & -148 & -10.7 \\
\hline 7 & NIEcon.DB.MSFan.CS1.DCV0 & -83 & -29.6 & -91 & -16.5 & -92 & -11.8 & -147 & -10.7 \\
\hline 8 & NIEcon.EH.MSFan.CS1.DCV0 & -83 & -29.6 & -91 & -16.5 & -92 & -11.8 & -148 & -10.7 \\
\hline 9 & IEcon.DB.MSFan.CS1.DCV0 & -83 & -29.6 & -91 & -16.5 & -92 & -11.8 & -147 & -10.7 \\
\hline 10 & IEcon.EH.MSFan.CS1.DCV0 & -83 & -29.6 & -91 & -16.5 & -92 & -11.8 & -148 & -10.7 \\
\hline 11 & NoEcon.MSFan.CS2.DCV0 & -84 & -29.7 & -91 & -16.5 & -92 & -11.8 & -148 & -10.7 \\
\hline 12 & IEcon.DB.MSFan.CS2.DCV0 & -83 & -29.5 & -91 & -16.5 & -92 & -11.8 & -147 & -10.6 \\
\hline 13 & IEcon.EH.MSFan.CS2.DCV0 & -83 & -29.5 & -91 & -16.5 & -92 & -11.8 & -147 & -10.6 \\
\hline 14 & NoEcon.SSFan.CS1.DCV1 & 116 & 41.3 & 194 & 35.3 & 316 & 40.4 & 488 & 35.3 \\
\hline 15 & IEcon.DB.SSFan.CS1.DCV1 & 117 & 41.4 & 195 & 35.4 & 316 & 40.5 & 489 & 35.3 \\
\hline 16 & IEcon.EH.SSFan.CS1.DCV1 & 117 & 41.4 & 195 & 35.4 & 316 & 40.5 & 489 & 35.3 \\
\hline 17 & NoEcon.MSFan.CS1.DCV1 & 66 & 23.3 & 133 & 24.1 & 228 & 29.2 & 385 & 27.8 \\
\hline 18 & IEcon.DB.MSFan.CS1.DCV1 & 66 & 23.5 & 134 & 24.2 & 229 & 29.3 & 385 & 27.8 \\
\hline 19 & IEcon.EH.MSFan.CS1.DCV1 & 66 & 23.5 & 134 & 24.2 & 229 & 29.3 & 385 & 27.8 \\
\hline 20 & NoEcon.MSFan.CS2.DCV1 & 66 & 23.5 & 133 & 24.2 & 229 & 29.3 & 385 & 27.8 \\
\hline 21 & IEcon.DB.MSFan.CS2.DCV1 & 66 & 23.5 & 134 & 24.3 & 229 & 29.3 & 385 & 27.8 \\
\hline 22 & IEcon.EH.MSFan.CS2.DCV1 & 66 & 23.5 & 134 & 24.3 & 229 & 29.3 & 385 & 27.8 \\
\hline
\end{tabular}


Table C-39: Gas Savings Compared to Case 1 for the Stand-alone Retail Building in Climate Zones 4B, 4C, 5A and 5B

\begin{tabular}{|c|c|c|c|c|c|c|c|c|c|}
\hline \multirow[b]{2}{*}{$\begin{array}{c}\text { Case } \\
\text { No }\end{array}$} & \multirow[b]{2}{*}{ Case Name } & \multicolumn{2}{|c|}{ Albuquerque-4B } & \multicolumn{2}{|c|}{ Seattle-4C } & \multicolumn{2}{|c|}{ Chicago-5A } & \multicolumn{2}{|c|}{ Denver-5B } \\
\hline & & $\begin{array}{c}\text { Abs. } \\
\left(10^{6}\right. \\
\text { Btus) }\end{array}$ & $\begin{array}{l}\text { Rel. } \\
(\%)\end{array}$ & $\begin{array}{c}\text { Abs. } \\
\left(10^{6}\right. \\
\text { Btus })\end{array}$ & $\begin{array}{l}\text { Rel. } \\
\text { (\%) }\end{array}$ & $\begin{array}{c}\text { Abs. } \\
\left(10^{6}\right. \\
\text { Btus }) \\
\end{array}$ & $\begin{array}{l}\text { Rel. } \\
\text { (\%) }\end{array}$ & $\begin{array}{c}\text { Abs. } \\
\left(10^{6}\right. \\
\text { Btus })\end{array}$ & $\begin{array}{l}\text { Rel. } \\
\text { (\%) }\end{array}$ \\
\hline 2 & NIEcon.DB.SSFan.CS1.DCV0 & 1 & 0.1 & 0 & 0.0 & 2 & 0.1 & 2 & 0.1 \\
\hline 3 & NIEcon.EH.SSFan.CS1.DCV0 & 1 & 0.1 & 0 & 0.0 & 2 & 0.1 & 2 & 0.1 \\
\hline 4 & IEcon.DB.SSFan.CS1.DCV0 & 1 & 0.1 & 0 & 0.0 & 2 & 0.1 & 2 & 0.1 \\
\hline 5 & IEcon.EH.SSFan.CS1.DCV0 & 1 & 0.1 & 0 & 0.0 & 2 & 0.1 & 2 & 0.1 \\
\hline 6 & NoEcon.MSFan.CS1.DCV0 & -133 & -13.0 & -119 & -9.3 & -205 & -10.7 & -197 & -13.4 \\
\hline 7 & NIEcon.DB.MSFan.CS1.DCV0 & -132 & -13.0 & -119 & -9.3 & -204 & -10.7 & -196 & -13.4 \\
\hline 8 & NIEcon.EH.MSFan.CS1.DCV0 & -132 & -13.0 & -119 & -9.3 & -204 & -10.7 & -196 & -13.4 \\
\hline 9 & IEcon.DB.MSFan.CS1.DCV0 & -132 & -13.0 & -119 & -9.3 & -204 & -10.7 & -196 & -13.4 \\
\hline 10 & IEcon.EH.MSFan.CS1.DCV0 & -132 & -13.0 & -119 & -9.3 & -204 & -10.7 & -196 & -13.4 \\
\hline 11 & NoEcon.MSFan.CS2.DCV0 & -132 & -13.0 & -119 & -9.3 & -204 & -10.7 & -196 & -13.3 \\
\hline 12 & IEcon.DB.MSFan.CS2.DCV0 & -132 & -12.9 & -119 & -9.3 & -204 & -10.7 & -195 & -13.3 \\
\hline 13 & IEcon.EH.MSFan.CS2.DCV0 & -132 & -12.9 & -118 & -9.3 & -204 & -10.7 & -195 & -13.3 \\
\hline 14 & NoEcon.SSFan.CS1.DCV1 & 343 & 33.6 & 535 & 42.0 & 616 & 32.2 & 468 & 31.9 \\
\hline 15 & IEcon.DB.SSFan.CS1.DCV1 & 344 & 33.7 & 536 & 42.0 & 614 & 32.1 & 470 & 32.1 \\
\hline 16 & IEcon.EH.SSFan.CS1.DCV1 & 344 & 33.7 & 535 & 42.0 & 614 & 32.1 & 470 & 32.1 \\
\hline 17 & NoEcon.MSFan.CS1.DCV1 & 249 & 24.4 & 416 & 32.6 & 474 & 24.8 & 326 & 22.2 \\
\hline 18 & IEcon.DB.MSFan.CS1.DCV1 & 250 & 24.5 & 416 & 32.6 & 478 & 25.0 & 328 & 22.4 \\
\hline 19 & IEcon.EH.MSFan.CS1.DCV1 & 250 & 24.5 & 416 & 32.6 & 478 & 25.0 & 328 & 22.4 \\
\hline 20 & NoEcon.MSFan.CS2.DCV1 & 250 & 24.5 & 416 & 32.6 & 477 & 24.9 & 328 & 22.4 \\
\hline 21 & IEcon.DB.MSFan.CS2.DCV1 & 250 & 24.5 & 416 & 32.6 & 479 & 25.0 & 328 & 22.4 \\
\hline 22 & IEcon.EH.MSFan.CS2.DCV1 & 251 & 24.6 & 416 & 32.6 & 479 & 25.0 & 328 & 22.4 \\
\hline
\end{tabular}


Table C-40: Gas Savings Compared to Case 1 for the Stand-alone Retail Building in Climate Zones 6, 7 and 8

\begin{tabular}{|c|c|c|c|c|c|c|c|c|c|}
\hline \multirow[b]{2}{*}{$\begin{array}{c}\text { Case } \\
\text { No }\end{array}$} & \multirow[b]{2}{*}{ Case Name } & \multicolumn{2}{|c|}{ Minneapolis-6A } & \multicolumn{2}{|c|}{ Helena-6B } & \multicolumn{2}{|c|}{ Duluth-7A } & \multicolumn{2}{|c|}{ Fairbanks-8A } \\
\hline & & $\begin{array}{c}\text { Abs. } \\
\left(10^{6}\right. \\
\text { Btus }) \\
\end{array}$ & $\begin{array}{l}\text { Rel. } \\
(\%)\end{array}$ & $\begin{array}{c}\text { Abs. } \\
\left(10^{6}\right. \\
\text { Btus }) \\
\end{array}$ & $\begin{array}{l}\text { Rel. } \\
(\%)\end{array}$ & $\begin{array}{c}\text { Abs. } \\
\left(10^{6}\right. \\
\text { Btus }) \\
\end{array}$ & $\begin{array}{l}\text { Rel. } \\
(\%)\end{array}$ & $\begin{array}{c}\text { Abs. } \\
\left(10^{6}\right. \\
\text { Btus }) \\
\end{array}$ & $\begin{array}{l}\text { Rel. } \\
(\%)\end{array}$ \\
\hline 2 & NIEcon.DB.SSFan.CS1.DCV0 & 4 & 0.2 & 3 & 0.1 & 1 & 0.0 & 78 & 1.5 \\
\hline 3 & NIEcon.EH.SSFan.CS1.DCV0 & 4 & 0.1 & 3 & 0.1 & 1 & 0.0 & 78 & 1.5 \\
\hline 4 & IEcon.DB.SSFan.CS1.DCV0 & 4 & 0.2 & 3 & 0.1 & 1 & 0.0 & 78 & 1.5 \\
\hline 5 & IEcon.EH.SSFan.CS1.DCV0 & 4 & 0.1 & 3 & 0.1 & 1 & 0.0 & 78 & 1.5 \\
\hline 6 & NoEcon.MSFan.CS1.DCV0 & -248 & -10.2 & -296 & -14.1 & -335 & -11.0 & -511 & -10.0 \\
\hline 7 & NIEcon.DB.MSFan.CS1.DCV0 & -240 & -9.9 & -288 & -13.7 & -321 & -10.6 & -390 & -7.7 \\
\hline 8 & NIEcon.EH.MSFan.CS1.DCV0 & -240 & -9.9 & -288 & -13.7 & -321 & -10.6 & -390 & -7.7 \\
\hline 9 & IEcon.DB.MSFan.CS1.DCV0 & -240 & -9.9 & -288 & -13.7 & -321 & -10.6 & -390 & -7.7 \\
\hline 10 & IEcon.EH.MSFan.CS1.DCV0 & -240 & -9.9 & -288 & -13.7 & -321 & -10.6 & -390 & -7.7 \\
\hline 11 & NoEcon.MSFan.CS2.DCV0 & -242 & -10.0 & -293 & -14.0 & -327 & -10.8 & -406 & -8.0 \\
\hline 12 & IEcon.DB.MSFan.CS2.DCV0 & -239 & -9.9 & -287 & -13.7 & -320 & -10.6 & -389 & -7.6 \\
\hline 13 & IEcon.EH.MSFan.CS2.DCV0 & -239 & -9.9 & -287 & -13.7 & -320 & -10.6 & -389 & -7.6 \\
\hline 14 & NoEcon.SSFan.CS1.DCV1 & 728 & 30.0 & 652 & 31.0 & 909 & 30.0 & 1338 & 26.3 \\
\hline 15 & IEcon.DB.SSFan.CS1.DCV1 & 728 & 30.0 & 647 & 30.8 & 912 & 30.1 & 1341 & 26.3 \\
\hline 16 & IEcon.EH.SSFan.CS1.DCV1 & 728 & 30.0 & 647 & 30.8 & 912 & 30.1 & 1341 & 26.3 \\
\hline 17 & NoEcon.MSFan.CS1.DCV1 & 568 & 23.4 & 439 & 20.9 & 688 & 22.7 & 867 & 17.0 \\
\hline 18 & IEcon.DB.MSFan.CS1.DCV1 & 579 & 23.9 & 453 & 21.6 & 706 & 23.3 & 1027 & 20.2 \\
\hline 19 & IEcon.EH.MSFan.CS1.DCV1 & 579 & 23.9 & 452 & 21.6 & 706 & 23.3 & 1027 & 20.2 \\
\hline 20 & NoEcon.MSFan.CS2.DCV1 & 576 & 23.8 & 447 & 21.3 & 703 & 23.2 & 1021 & 20.0 \\
\hline 21 & IEcon.DB.MSFan.CS2.DCV1 & 579 & 23.9 & 453 & 21.6 & 706 & 23.3 & 1028 & 20.2 \\
\hline 22 & IEcon.EH.MSFan.CS2.DCV1 & 579 & 23.9 & 453 & 21.6 & 707 & 23.3 & 1028 & 20.2 \\
\hline
\end{tabular}


Table C-41: Gas Savings Compared to Case 1 for the Strip Mall Building in Climate Zones 1, 2 and 3A

\begin{tabular}{|c|c|c|c|c|c|c|c|c|c|}
\hline \multirow{2}{*}{$\begin{array}{c}\text { Case } \\
\text { No }\end{array}$} & \multirow[b]{2}{*}{ Case Name } & \multicolumn{2}{|c|}{ Miami-1A } & \multicolumn{2}{|c|}{ Houston-2A } & \multicolumn{2}{|c|}{ Phoenix-2B } & \multicolumn{2}{|c|}{ Atlanta-3A } \\
\hline & & $\begin{array}{c}\text { Abs. } \\
\left(10^{6}\right. \\
\text { Btus })\end{array}$ & $\begin{array}{l}\text { Rel. } \\
\text { (\%) }\end{array}$ & $\begin{array}{c}\text { Abs. } \\
\left(10^{6}\right. \\
\text { Btus }) \\
\end{array}$ & $\begin{array}{l}\text { Rel. } \\
\text { (\%) }\end{array}$ & $\begin{array}{c}\text { Abs. } \\
\left(10^{6}\right. \\
\text { Btus })\end{array}$ & $\begin{array}{l}\text { Rel. } \\
\text { (\%) }\end{array}$ & $\begin{array}{c}\text { Abs. } \\
\left(10^{6}\right. \\
\text { Btus }) \\
\end{array}$ & $\begin{array}{l}\text { Rel. } \\
\text { (\%) }\end{array}$ \\
\hline 2 & NIEcon.DB.SSFan.CS1.DCV0 & 2 & 5.0 & 1 & 0.3 & 2 & 0.5 & 1 & 0.2 \\
\hline 3 & NIEcon.EH.SSFan.CS1.DCV0 & 2 & 4.6 & 1 & 0.2 & 2 & 0.5 & 1 & 0.1 \\
\hline 4 & IEcon.DB.SSFan.CS1.DCV0 & 2 & 5.0 & 1 & 0.2 & 2 & 0.5 & 1 & 0.2 \\
\hline 5 & IEcon.EH.SSFan.CS1.DCV0 & 2 & 4.5 & 1 & 0.2 & 2 & 0.5 & 1 & 0.2 \\
\hline 6 & NoEcon.MSFan.CS1.DCV0 & -15 & -37.9 & -70 & -17.6 & -70 & -21.0 & -120 & -14.8 \\
\hline 7 & NIEcon.DB.MSFan.CS1.DCV0 & -14 & -33.9 & -70 & -17.5 & -69 & -20.7 & -119 & -14.7 \\
\hline 8 & NIEcon.EH.MSFan.CS1.DCV0 & -14 & -34.4 & -70 & -17.5 & -69 & -20.6 & -119 & -14.7 \\
\hline 9 & IEcon.DB.MSFan.CS1.DCV0 & -14 & -33.9 & -70 & -17.5 & -69 & -20.7 & -119 & -14.7 \\
\hline 10 & IEcon.EH.MSFan.CS1.DCV0 & -14 & -34.4 & -70 & -17.5 & -69 & -20.7 & -119 & -14.7 \\
\hline 11 & NoEcon.MSFan.CS2.DCV0 & -14 & -35.1 & -70 & -17.5 & -69 & -20.7 & -119 & -14.7 \\
\hline 12 & IEcon.DB.MSFan.CS2.DCV0 & -13 & -33.8 & -70 & -17.5 & -68 & -20.5 & -119 & -14.7 \\
\hline 13 & IEcon.EH.MSFan.CS2.DCV0 & -14 & -33.9 & -70 & -17.5 & -68 & -20.4 & -119 & -14.7 \\
\hline 14 & NoEcon.SSFan.CS1.DCV1 & 16 & 40.5 & 146 & 36.7 & 113 & 33.9 & 281 & 34.7 \\
\hline 15 & IEcon.DB.SSFan.CS1.DCV1 & 16 & 41.0 & 147 & 36.8 & 114 & 34.1 & 282 & 34.8 \\
\hline 16 & IEcon.EH.SSFan.CS1.DCV1 & 16 & 40.9 & 146 & 36.7 & 114 & 34.2 & 281 & 34.8 \\
\hline 17 & NoEcon.MSFan.CS1.DCV1 & 7 & 17.9 & 105 & 26.3 & 70 & 20.9 & 208 & 25.7 \\
\hline 18 & IEcon.DB.MSFan.CS1.DCV1 & 8 & 19.1 & 106 & 26.5 & 70 & 21.1 & 209 & 25.8 \\
\hline 19 & IEcon.EH.MSFan.CS1.DCV1 & 7 & 18.8 & 105 & 26.4 & 71 & 21.2 & 209 & 25.8 \\
\hline 20 & NoEcon.MSFan.CS2.DCV1 & 7 & 18.6 & 105 & 26.4 & 71 & 21.3 & 209 & 25.8 \\
\hline 21 & IEcon.DB.MSFan.CS2.DCV1 & 8 & 19.2 & 106 & 26.5 & 71 & 21.3 & 209 & 25.8 \\
\hline 22 & IEcon.EH.MSFan.CS2.DCV1 & 8 & 19.0 & 106 & 26.5 & 71 & 21.4 & 209 & 25.8 \\
\hline
\end{tabular}


Table C-42: Gas Savings Compared to Case 1 for the Strip Mall Building in Climate Zones 3B, 3C and 4A

\begin{tabular}{|c|c|c|c|c|c|c|c|c|c|}
\hline \multirow[b]{2}{*}{$\begin{array}{c}\text { Case } \\
\text { No }\end{array}$} & \multirow[b]{2}{*}{ Case Name } & \multicolumn{2}{|c|}{ Los Angeles-3B } & \multicolumn{2}{|c|}{ Las Vegas-3B } & \multicolumn{2}{|c|}{ San Francisco-3C } & \multicolumn{2}{|c|}{ Baltimore-4A } \\
\hline & & $\begin{array}{c}\text { Abs. } \\
\left(10^{6}\right. \\
\text { Btus }) \\
\end{array}$ & $\begin{array}{l}\text { Rel. } \\
\text { (\%) }\end{array}$ & $\begin{array}{c}\text { Abs. } \\
\left(10^{6}\right. \\
\text { Btus }) \\
\end{array}$ & $\begin{array}{l}\text { Rel. } \\
\text { (\%) }\end{array}$ & $\begin{array}{c}\text { Abs. } \\
\left(10^{6}\right. \\
\text { Btus }) \\
\end{array}$ & $\begin{array}{l}\text { Rel. } \\
\text { (\%) }\end{array}$ & $\begin{array}{c}\text { Abs. } \\
\left(10^{6}\right. \\
\text { Btus }) \\
\end{array}$ & $\begin{array}{l}\text { Rel. } \\
\text { (\%) }\end{array}$ \\
\hline 2 & NIEcon.DB.SSFan.CS1.DCV0 & 2 & 0.6 & 2 & 0.3 & 1 & 0.1 & 1 & 0.0 \\
\hline 3 & NIEcon.EH.SSFan.CS1.DCV0 & 2 & 0.5 & 2 & 0.3 & 1 & 0.1 & 0 & 0.0 \\
\hline 4 & IEcon.DB.SSFan.CS1.DCV0 & 2 & 0.6 & 1 & 0.3 & 1 & 0.1 & 1 & 0.0 \\
\hline 5 & IEcon.EH.SSFan.CS1.DCV0 & 2 & 0.5 & 2 & 0.3 & 1 & 0.1 & 1 & 0.0 \\
\hline 6 & NoEcon.MSFan.CS1.DCV0 & -94 & -31.7 & -90 & -16.4 & -123 & -17.5 & -148 & -10.9 \\
\hline 7 & NIEcon.DB.MSFan.CS1.DCV0 & -93 & -31.1 & -89 & -16.2 & -122 & -17.5 & -147 & -10.9 \\
\hline 8 & NIEcon.EH.MSFan.CS1.DCV0 & -93 & -31.2 & -88 & -16.2 & -122 & -17.5 & -147 & -10.9 \\
\hline 9 & IEcon.DB.MSFan.CS1.DCV0 & -93 & -31.1 & -89 & -16.2 & -122 & -17.5 & -147 & -10.9 \\
\hline 10 & IEcon.EH.MSFan.CS1.DCV0 & -93 & -31.2 & -88 & -16.2 & -122 & -17.5 & -147 & -10.9 \\
\hline 11 & NoEcon.MSFan.CS2.DCV0 & -93 & -31.4 & -89 & -16.2 & -122 & -17.5 & -147 & -10.9 \\
\hline 12 & IEcon.DB.MSFan.CS2.DCV0 & -93 & -31.2 & -88 & -16.1 & -122 & -17.5 & -147 & -10.9 \\
\hline 13 & IEcon.EH.MSFan.CS2.DCV0 & -93 & -31.2 & -88 & -16.1 & -122 & -17.5 & -147 & -10.9 \\
\hline 14 & NoEcon.SSFan.CS1.DCV1 & 109 & 36.7 & 180 & 33.0 & 281 & 40.1 & 473 & 34.9 \\
\hline 15 & IEcon.DB.SSFan.CS1.DCV1 & 110 & 36.8 & 181 & 33.1 & 281 & 40.2 & 473 & 34.9 \\
\hline 16 & IEcon.EH.SSFan.CS1.DCV1 & 110 & 36.8 & 181 & 33.1 & 281 & 40.2 & 473 & 34.9 \\
\hline 17 & NoEcon.MSFan.CS1.DCV1 & 55 & 18.6 & 126 & 23.0 & 212 & 30.3 & 382 & 28.2 \\
\hline 18 & IEcon.DB.MSFan.CS1.DCV1 & 56 & 19.0 & 126 & 23.1 & 213 & 30.4 & 383 & 28.2 \\
\hline 19 & IEcon.EH.MSFan.CS1.DCV1 & 56 & 18.9 & 126 & 23.1 & 213 & 30.4 & 383 & 28.2 \\
\hline 20 & NoEcon.MSFan.CS2.DCV1 & 56 & 18.9 & 126 & 23.1 & 212 & 30.4 & 383 & 28.2 \\
\hline 21 & IEcon.DB.MSFan.CS2.DCV1 & 56 & 19.0 & 126 & 23.1 & 213 & 30.4 & 383 & 28.2 \\
\hline 22 & IEcon.EH.MSFan.CS2.DCV1 & 56 & 19.0 & 127 & 23.2 & 213 & 30.4 & 383 & 28.2 \\
\hline
\end{tabular}


Table C-43: Gas Savings Compared to Case 1 for the Strip Mall Building in Climate Zones 4B, 4C, 5A and 5B

\begin{tabular}{|c|c|c|c|c|c|c|c|c|c|}
\hline \multirow[b]{2}{*}{$\begin{array}{c}\text { Case } \\
\text { No }\end{array}$} & \multirow[b]{2}{*}{ Case Name } & \multicolumn{2}{|c|}{ Albuquerque-4B } & \multicolumn{2}{|c|}{ Seattle-4C } & \multicolumn{2}{|c|}{ Chicago-5A } & \multicolumn{2}{|c|}{ Denver-5B } \\
\hline & & $\begin{array}{c}\text { Abs. } \\
\left(10^{6}\right. \\
\text { Btus }) \\
\end{array}$ & $\begin{array}{l}\text { Rel. } \\
\text { (\%) }\end{array}$ & $\begin{array}{c}\text { Abs. } \\
\left(10^{6}\right. \\
\text { Btus }) \\
\end{array}$ & $\begin{array}{l}\text { Rel. } \\
(\%)\end{array}$ & $\begin{array}{c}\text { Abs. } \\
\left(10^{6}\right. \\
\text { Btus }) \\
\end{array}$ & $\begin{array}{l}\text { Rel. } \\
\text { (\%) }\end{array}$ & $\begin{array}{c}\text { Abs. } \\
\left(10^{6}\right. \\
\text { Btus }) \\
\end{array}$ & $\begin{array}{l}\text { Rel. } \\
\text { (\%) }\end{array}$ \\
\hline 2 & NIEcon.DB.SSFan.CS1.DCV0 & 2 & 0.2 & 1 & 0.0 & 2 & 0.1 & 2 & 0.2 \\
\hline 3 & NIEcon.EH.SSFan.CS1.DCV0 & 2 & 0.2 & 1 & 0.0 & 2 & 0.1 & 2 & 0.2 \\
\hline 4 & IEcon.DB.SSFan.CS1.DCV0 & 2 & 0.2 & 1 & 0.0 & 2 & 0.1 & 2 & 0.2 \\
\hline 5 & IEcon.EH.SSFan.CS1.DCV0 & 2 & 0.2 & 0 & 0.0 & 2 & 0.1 & 2 & 0.2 \\
\hline 6 & NoEcon.MSFan.CS1.DCV0 & -124 & -12.6 & -164 & -13.1 & -212 & -11.2 & -190 & -13.4 \\
\hline 7 & NIEcon.DB.MSFan.CS1.DCV0 & -122 & -12.5 & -163 & -13.0 & -211 & -11.2 & -189 & -13.4 \\
\hline 8 & NIEcon.EH.MSFan.CS1.DCV0 & -122 & -12.5 & -163 & -13.0 & -211 & -11.2 & -189 & -13.4 \\
\hline 9 & IEcon.DB.MSFan.CS1.DCV0 & -123 & -12.5 & -163 & -13.0 & -211 & -11.2 & -189 & -13.4 \\
\hline 10 & IEcon.EH.MSFan.CS1.DCV0 & -123 & -12.5 & -163 & -13.0 & -211 & -11.2 & -189 & -13.4 \\
\hline 11 & NoEcon.MSFan.CS2.DCV0 & -122 & -12.5 & -163 & -13.0 & -211 & -11.2 & -189 & -13.3 \\
\hline 12 & IEcon.DB.MSFan.CS2.DCV0 & -122 & -12.4 & -163 & -13.0 & -210 & -11.1 & -188 & -13.3 \\
\hline 13 & IEcon.EH.MSFan.CS2.DCV0 & -122 & -12.4 & -163 & -13.0 & -210 & -11.1 & -188 & -13.3 \\
\hline 14 & NoEcon.SSFan.CS1.DCV1 & 328 & 33.4 & 512 & 40.9 & 598 & 31.7 & 450 & 31.8 \\
\hline 15 & IEcon.DB.SSFan.CS1.DCV1 & 329 & 33.5 & 512 & 40.9 & 598 & 31.7 & 451 & 31.8 \\
\hline 16 & IEcon.EH.SSFan.CS1.DCV1 & 329 & 33.5 & 512 & 40.9 & 598 & 31.7 & 451 & 31.8 \\
\hline 17 & NoEcon.MSFan.CS1.DCV1 & 249 & 25.3 & 406 & 32.4 & 472 & 25.0 & 331 & 23.4 \\
\hline 18 & IEcon.DB.MSFan.CS1.DCV1 & 249 & 25.4 & 406 & 32.4 & 473 & 25.1 & 331 & 23.4 \\
\hline 19 & IEcon.EH.MSFan.CS1.DCV1 & 249 & 25.4 & 406 & 32.4 & 473 & 25.1 & 331 & 23.4 \\
\hline 20 & NoEcon.MSFan.CS2.DCV1 & 250 & 25.4 & 406 & 32.4 & 473 & 25.1 & 332 & 23.4 \\
\hline 21 & IEcon.DB.MSFan.CS2.DCV1 & 250 & 25.4 & 406 & 32.4 & 473 & 25.1 & 332 & 23.5 \\
\hline 22 & IEcon.EH.MSFan.CS2.DCV1 & 250 & 25.5 & 406 & 32.4 & 473 & 25.1 & 332 & 23.5 \\
\hline
\end{tabular}


Table C-44: Gas Savings Compared to Case 1 for the Strip Mall Building in Climate Zones 6, 7 and 8

\begin{tabular}{|c|c|c|c|c|c|c|c|c|c|}
\hline \multirow[b]{2}{*}{$\begin{array}{c}\text { Case } \\
\text { No }\end{array}$} & \multirow[b]{2}{*}{ Case Name } & \multicolumn{2}{|c|}{ Minneapolis-6A } & \multicolumn{2}{|c|}{ Helena-6B } & \multicolumn{2}{|c|}{ Duluth-7A } & \multicolumn{2}{|c|}{ Fairbanks-8A } \\
\hline & & $\begin{array}{c}\text { Abs. } \\
\left(10^{6}\right. \\
\text { Btus }) \\
\end{array}$ & $\begin{array}{l}\text { Rel. } \\
\text { (\%) }\end{array}$ & $\begin{array}{c}\text { Abs. } \\
\left(10^{6}\right. \\
\text { Btus }) \\
\end{array}$ & $\begin{array}{l}\text { Rel. } \\
(\%)\end{array}$ & $\begin{array}{c}\text { Abs. } \\
\left(10^{6}\right. \\
\text { Btus }) \\
\end{array}$ & $\begin{array}{l}\text { Rel. } \\
\text { (\%) }\end{array}$ & $\begin{array}{c}\text { Abs. } \\
\left(10^{6}\right. \\
\text { Btus }) \\
\end{array}$ & $\begin{array}{l}\text { Rel. } \\
\text { (\%) }\end{array}$ \\
\hline 2 & NIEcon.DB.SSFan.CS1.DCV0 & 11 & 0.5 & 9 & 0.4 & 20 & 0.7 & 119 & 2.3 \\
\hline 3 & NIEcon.EH.SSFan.CS1.DCV0 & 11 & 0.5 & 9 & 0.5 & 20 & 0.7 & 119 & 2.4 \\
\hline 4 & IEcon.DB.SSFan.CS1.DCV0 & 11 & 0.5 & 9 & 0.4 & 20 & 0.7 & 119 & 2.3 \\
\hline 5 & IEcon.EH.SSFan.CS1.DCV0 & 11 & 0.5 & 9 & 0.4 & 20 & 0.7 & 119 & 2.3 \\
\hline 6 & NoEcon.MSFan.CS1.DCV0 & -250 & -10.4 & -296 & -14.1 & -334 & -11.1 & -501 & -9.9 \\
\hline 7 & NIEcon.DB.MSFan.CS1.DCV0 & -240 & -9.9 & -285 & -13.6 & -313 & -10.4 & -355 & -7.0 \\
\hline 8 & NIEcon.EH.MSFan.CS1.DCV0 & -240 & -10.0 & -285 & -13.6 & -313 & -10.4 & -355 & -7.0 \\
\hline 9 & IEcon.DB.MSFan.CS1.DCV0 & -240 & -9.9 & -285 & -13.6 & -313 & -10.4 & -355 & -7.0 \\
\hline 10 & IEcon.EH.MSFan.CS1.DCV0 & -240 & -10.0 & -285 & -13.6 & -313 & -10.4 & -355 & -7.0 \\
\hline 11 & NoEcon.MSFan.CS2.DCV0 & -243 & -10.1 & -291 & -13.9 & -319 & -10.6 & -378 & -7.4 \\
\hline 12 & IEcon.DB.MSFan.CS2.DCV0 & -239 & -9.9 & -284 & -13.6 & -313 & -10.4 & -354 & -7.0 \\
\hline 13 & IEcon.EH.MSFan.CS2.DCV0 & -239 & -9.9 & -284 & -13.6 & -313 & -10.4 & -354 & -7.0 \\
\hline 14 & NoEcon.SSFan.CS1.DCV1 & 711 & 29.5 & 643 & 30.8 & 901 & 29.9 & 1363 & 26.9 \\
\hline 15 & IEcon.DB.SSFan.CS1.DCV1 & 711 & 29.5 & 644 & 30.8 & 902 & 29.9 & 1353 & 26.7 \\
\hline 16 & IEcon.EH.SSFan.CS1.DCV1 & 711 & 29.5 & 644 & 30.8 & 902 & 29.9 & 1354 & 26.7 \\
\hline 17 & NoEcon.MSFan.CS1.DCV1 & 561 & 23.3 & 446 & 21.3 & 683 & 22.7 & 740 & 14.6 \\
\hline 18 & IEcon.DB.MSFan.CS1.DCV1 & 569 & 23.6 & 454 & 21.7 & 699 & 23.2 & 969 & 19.1 \\
\hline 19 & IEcon.EH.MSFan.CS1.DCV1 & 569 & 23.6 & 454 & 21.7 & 699 & 23.2 & 969 & 19.1 \\
\hline 20 & NoEcon.MSFan.CS2.DCV1 & 566 & 23.5 & 449 & 21.5 & 692 & 23.0 & 978 & 19.3 \\
\hline 21 & IEcon.DB.MSFan.CS2.DCV1 & 569 & 23.6 & 455 & 21.8 & 700 & 23.2 & 970 & 19.1 \\
\hline 22 & IEcon.EH.MSFan.CS2.DCV1 & 569 & 23.6 & 455 & 21.8 & 700 & 23.2 & 970 & 19.1 \\
\hline
\end{tabular}


Table C-45: Gas Savings Compared to Case 1 for the Supermarket Building in Climate Zones 1, 2 and 3A

\begin{tabular}{|c|c|c|c|c|c|c|c|c|c|}
\hline \multirow{2}{*}{$\begin{array}{c}\text { Case } \\
\text { No }\end{array}$} & \multirow[b]{2}{*}{ Case Name } & \multicolumn{2}{|c|}{ Miami-1A } & \multicolumn{2}{|c|}{ Houston-2A } & \multicolumn{2}{|c|}{ Phoenix-2B } & \multicolumn{2}{|c|}{ Atlanta-3A } \\
\hline & & $\begin{array}{c}\text { Abs. } \\
\left(10^{6}\right. \\
\text { Btus })\end{array}$ & $\begin{array}{l}\text { Rel. } \\
\text { (\%) }\end{array}$ & $\begin{array}{c}\text { Abs. } \\
\left(10^{6}\right. \\
\text { Btus }) \\
\end{array}$ & $\begin{array}{l}\text { Rel. } \\
\text { (\%) }\end{array}$ & $\begin{array}{c}\text { Abs. } \\
\left(10^{6}\right. \\
\text { Btus })\end{array}$ & $\begin{array}{l}\text { Rel. } \\
\text { (\%) }\end{array}$ & $\begin{array}{c}\text { Abs. } \\
\left(10^{6}\right. \\
\text { Btus }) \\
\end{array}$ & $\begin{array}{l}\text { Rel. } \\
\text { (\%) }\end{array}$ \\
\hline 2 & NIEcon.DB.SSFan.CS1.DCV0 & 2 & 1.2 & 9 & 0.7 & 14 & 1.1 & 20 & 0.8 \\
\hline 3 & NIEcon.EH.SSFan.CS1.DCV0 & 2 & 1.2 & 9 & 0.7 & 14 & 1.1 & 19 & 0.8 \\
\hline 4 & IEcon.DB.SSFan.CS1.DCV0 & 2 & 1.2 & 9 & 0.7 & 14 & 1.1 & 20 & 0.8 \\
\hline 5 & IEcon.EH.SSFan.CS1.DCV0 & 2 & 1.2 & 9 & 0.7 & 14 & 1.1 & 19 & 0.8 \\
\hline 6 & NoEcon.MSFan.CS1.DCV0 & -43 & -29.8 & -280 & -21.7 & -253 & -20.8 & -516 & -20.8 \\
\hline 7 & NIEcon.DB.MSFan.CS1.DCV0 & -40 & -28.1 & -266 & -20.6 & -236 & -19.4 & -489 & -19.8 \\
\hline 8 & NIEcon.EH.MSFan.CS1.DCV0 & -40 & -28.3 & -266 & -20.7 & -236 & -19.4 & -489 & -19.8 \\
\hline 9 & IEcon.DB.MSFan.CS1.DCV0 & -40 & -28.2 & -266 & -20.6 & -236 & -19.4 & -489 & -19.8 \\
\hline 10 & IEcon.EH.MSFan.CS1.DCV0 & -40 & -28.4 & -266 & -20.7 & -236 & -19.4 & -489 & -19.8 \\
\hline 11 & NoEcon.MSFan.CS2.DCV0 & -41 & -28.5 & -269 & -20.9 & -238 & -19.5 & -495 & -20.0 \\
\hline 12 & IEcon.DB.MSFan.CS2.DCV0 & -40 & -28.1 & -266 & -20.6 & -234 & -19.2 & -488 & -19.7 \\
\hline 13 & IEcon.EH.MSFan.CS2.DCV0 & -40 & -28.2 & -266 & -20.6 & -234 & -19.2 & -488 & -19.7 \\
\hline 14 & NoEcon.SSFan.CS1.DCV1 & 47 & 33.0 & 350 & 27.1 & 285 & 23.4 & 636 & 25.7 \\
\hline 15 & IEcon.DB.SSFan.CS1.DCV1 & 49 & 34.5 & 359 & 27.8 & 299 & 24.6 & 655 & 26.5 \\
\hline 16 & IEcon.EH.SSFan.CS1.DCV1 & 49 & 34.5 & 359 & 27.8 & 299 & 24.6 & 655 & 26.5 \\
\hline 17 & NoEcon.MSFan.CS1.DCV1 & -3 & -1.8 & 61 & 4.7 & 8 & 0.7 & 108 & 4.4 \\
\hline 18 & IEcon.DB.MSFan.CS1.DCV1 & -1 & -0.4 & 75 & 5.8 & 24 & 2.0 & 133 & 5.4 \\
\hline 19 & IEcon.EH.MSFan.CS1.DCV1 & -1 & -0.5 & 74 & 5.7 & 25 & 2.0 & 132 & 5.3 \\
\hline 20 & NoEcon.MSFan.CS2.DCV1 & -1 & -0.7 & 71 & 5.5 & 22 & 1.8 & 127 & 5.1 \\
\hline 21 & IEcon.DB.MSFan.CS2.DCV1 & 0 & -0.3 & 75 & 5.8 & 26 & 2.1 & 133 & 5.4 \\
\hline 22 & IEcon.EH.MSFan.CS2.DCV1 & -1 & -0.4 & 75 & 5.8 & 26 & 2.2 & 133 & 5.4 \\
\hline
\end{tabular}


Table C-46: Gas Savings Compared to Case 1 for the Supermarket Building in Climate Zones 3B, 3C and 4A

\begin{tabular}{|c|c|c|c|c|c|c|c|c|c|}
\hline \multirow[b]{2}{*}{$\begin{array}{c}\text { Case } \\
\text { No }\end{array}$} & \multirow[b]{2}{*}{ Case Name } & \multicolumn{2}{|c|}{ Los Angeles-3B } & \multicolumn{2}{|c|}{ Las Vegas-3B } & \multicolumn{2}{|c|}{ San Francisco-3C } & \multicolumn{2}{|c|}{ Baltimore-4A } \\
\hline & & $\begin{array}{c}\text { Abs. } \\
\left(10^{6}\right. \\
\text { Btus) } \\
\end{array}$ & $\begin{array}{l}\text { Rel. } \\
\text { (\%) }\end{array}$ & $\begin{array}{c}\text { Abs. } \\
\left(10^{6}\right. \\
\text { Btus) }\end{array}$ & $\begin{array}{l}\text { Rel. } \\
\text { (\%) }\end{array}$ & $\begin{array}{c}\text { Abs. } \\
\left(10^{6}\right. \\
\text { Btus }) \\
\end{array}$ & $\begin{array}{l}\text { Rel. } \\
\text { (\%) }\end{array}$ & $\begin{array}{c}\text { Abs. } \\
\left(10^{6}\right. \\
\text { Btus) } \\
\end{array}$ & $\begin{array}{l}\text { Rel. } \\
\text { (\%) }\end{array}$ \\
\hline 2 & NIEcon.DB.SSFan.CS1.DCV0 & 9 & 0.6 & 19 & 1.0 & 6 & 0.2 & 23 & 0.6 \\
\hline 3 & NIEcon.EH.SSFan.CS1.DCV0 & 9 & 0.6 & 19 & 1.0 & 6 & 0.2 & 22 & 0.6 \\
\hline 4 & IEcon.DB.SSFan.CS1.DCV0 & 8 & 0.6 & 19 & 1.0 & 6 & 0.2 & 22 & 0.6 \\
\hline 5 & IEcon.EH.SSFan.CS1.DCV0 & 8 & 0.6 & 19 & 1.0 & 6 & 0.2 & 22 & 0.6 \\
\hline 6 & NoEcon.MSFan.CS1.DCV0 & -349 & -26.1 & -399 & -20.0 & -536 & -19.3 & -620 & -16.5 \\
\hline 7 & NIEcon.DB.MSFan.CS1.DCV0 & -341 & -25.5 & -380 & -19.0 & -531 & -19.1 & -583 & -15.6 \\
\hline 8 & NIEcon.EH.MSFan.CS1.DCV0 & -341 & -25.5 & -380 & -19.0 & -531 & -19.1 & -583 & -15.6 \\
\hline 9 & IEcon.DB.MSFan.CS1.DCV0 & -341 & -25.5 & -380 & -19.0 & -531 & -19.1 & -583 & -15.6 \\
\hline 10 & IEcon.EH.MSFan.CS1.DCV0 & -341 & -25.5 & -380 & -19.0 & -531 & -19.1 & -583 & -15.6 \\
\hline 11 & NoEcon.MSFan.CS2.DCV0 & -343 & -25.7 & -383 & -19.2 & -532 & -19.1 & -590 & -15.7 \\
\hline 12 & IEcon.DB.MSFan.CS2.DCV0 & -341 & -25.5 & -378 & -19.0 & -530 & -19.1 & -583 & -15.5 \\
\hline 13 & IEcon.EH.MSFan.CS2.DCV0 & -341 & -25.5 & -378 & -19.0 & -530 & -19.1 & -583 & -15.5 \\
\hline 14 & NoEcon.SSFan.CS1.DCV1 & 389 & 29.1 & 446 & 22.4 & 777 & 28.0 & 945 & 25.2 \\
\hline 15 & IEcon.DB.SSFan.CS1.DCV1 & 398 & 29.8 & 465 & 23.3 & 783 & 28.2 & 967 & 25.8 \\
\hline 16 & IEcon.EH.SSFan.CS1.DCV1 & 398 & 29.8 & 465 & 23.3 & 783 & 28.2 & 967 & 25.8 \\
\hline 17 & NoEcon.MSFan.CS1.DCV1 & 55 & 4.1 & 9 & 0.5 & 225 & 8.1 & 303 & 8.1 \\
\hline 18 & IEcon.DB.MSFan.CS1.DCV1 & 64 & 4.8 & 29 & 1.5 & 229 & 8.2 & 338 & 9.0 \\
\hline 19 & IEcon.EH.MSFan.CS1.DCV1 & 63 & 4.7 & 29 & 1.4 & 229 & 8.2 & 338 & 9.0 \\
\hline 20 & NoEcon.MSFan.CS2.DCV1 & 62 & 4.6 & 26 & 1.3 & 228 & 8.2 & 330 & 8.8 \\
\hline 21 & IEcon.DB.MSFan.CS2.DCV1 & 64 & 4.8 & 31 & 1.5 & 230 & 8.3 & 339 & 9.0 \\
\hline 22 & IEcon.EH.MSFan.CS2.DCV1 & 64 & 4.8 & 31 & 1.5 & 230 & 8.3 & 338 & 9.0 \\
\hline
\end{tabular}


Table C-47: Gas Savings Compared to Case 1 for the Supermarket Building in Climate Zones 4B, 4C, 5A and 5B

\begin{tabular}{|c|c|c|c|c|c|c|c|c|c|}
\hline \multirow[b]{2}{*}{$\begin{array}{c}\text { Case } \\
\text { No }\end{array}$} & \multirow[b]{2}{*}{ Case Name } & \multicolumn{2}{|c|}{ Albuquerque-4B } & \multicolumn{2}{|c|}{ Seattle-4C } & \multicolumn{2}{|c|}{ Chicago-5A } & \multicolumn{2}{|c|}{ Denver-5B } \\
\hline & & $\begin{array}{c}\text { Abs. } \\
\left(10^{6}\right. \\
\text { Btus }) \\
\end{array}$ & $\begin{array}{l}\text { Rel. } \\
\text { (\%) }\end{array}$ & $\begin{array}{c}\text { Abs. } \\
\left(10^{6}\right. \\
\text { Btus }) \\
\end{array}$ & $\begin{array}{l}\text { Rel. } \\
(\%)\end{array}$ & $\begin{array}{c}\text { Abs. } \\
\left(10^{6}\right. \\
\text { Btus }) \\
\end{array}$ & $\begin{array}{l}\text { Rel. } \\
\text { (\%) }\end{array}$ & $\begin{array}{c}\text { Abs. } \\
\left(10^{6}\right. \\
\text { Btus }) \\
\end{array}$ & $\begin{array}{l}\text { Rel. } \\
\text { (\%) }\end{array}$ \\
\hline 2 & NIEcon.DB.SSFan.CS1.DCV0 & 28 & 0.9 & 20 & 0.5 & 34 & 0.7 & 37 & 0.9 \\
\hline 3 & NIEcon.EH.SSFan.CS1.DCV0 & 28 & 0.9 & 20 & 0.5 & 34 & 0.7 & 38 & 0.9 \\
\hline 4 & IEcon.DB.SSFan.CS1.DCV0 & 28 & 0.9 & 20 & 0.5 & 34 & 0.7 & 37 & 0.9 \\
\hline 5 & IEcon.EH.SSFan.CS1.DCV0 & 28 & 0.9 & 20 & 0.5 & 34 & 0.7 & 37 & 0.9 \\
\hline 6 & NoEcon.MSFan.CS1.DCV0 & -626 & -20.3 & -637 & -16.7 & -869 & -17.9 & -900 & -22.0 \\
\hline 7 & NIEcon.DB.MSFan.CS1.DCV0 & -597 & -19.4 & -612 & -16.0 & -814 & -16.8 & -863 & -21.1 \\
\hline 8 & NIEcon.EH.MSFan.CS1.DCV0 & -598 & -19.4 & -612 & -16.0 & -815 & -16.8 & -863 & -21.1 \\
\hline 9 & IEcon.DB.MSFan.CS1.DCV0 & -598 & -19.4 & -612 & -16.0 & -815 & -16.8 & -863 & -21.1 \\
\hline 10 & IEcon.EH.MSFan.CS1.DCV0 & -598 & -19.4 & -612 & -16.0 & -815 & -16.8 & -864 & -21.1 \\
\hline 11 & NoEcon.MSFan.CS2.DCV0 & -603 & -19.6 & -618 & -16.2 & -820 & -16.9 & -874 & -21.4 \\
\hline 12 & IEcon.DB.MSFan.CS2.DCV0 & -596 & -19.3 & -612 & -16.0 & -814 & -16.8 & -861 & -21.1 \\
\hline 13 & IEcon.EH.MSFan.CS2.DCV0 & -596 & -19.4 & -612 & -16.0 & -814 & -16.8 & -861 & -21.1 \\
\hline 14 & NoEcon.SSFan.CS1.DCV1 & 719 & 23.4 & 1036 & 27.1 & 1165 & 24.0 & 943 & 23.1 \\
\hline 15 & IEcon.DB.SSFan.CS1.DCV1 & 745 & 24.2 & 1055 & 27.6 & 1222 & 25.2 & 988 & 24.2 \\
\hline 16 & IEcon.EH.SSFan.CS1.DCV1 & 745 & 24.2 & 1055 & 27.6 & 1218 & 25.1 & 987 & 24.1 \\
\hline 17 & NoEcon.MSFan.CS1.DCV1 & 53 & 1.7 & 372 & 9.7 & 269 & 5.5 & -14 & -0.3 \\
\hline 18 & IEcon.DB.MSFan.CS1.DCV1 & 78 & 2.5 & 395 & 10.3 & 355 & 7.3 & 32 & 0.8 \\
\hline 19 & IEcon.EH.MSFan.CS1.DCV1 & 78 & 2.5 & 394 & 10.3 & 346 & 7.1 & 31 & 0.8 \\
\hline 20 & NoEcon.MSFan.CS2.DCV1 & 72 & 2.4 & 389 & 10.2 & 336 & 6.9 & 20 & 0.5 \\
\hline 21 & IEcon.DB.MSFan.CS2.DCV1 & 79 & 2.6 & 395 & 10.3 & 359 & 7.4 & 38 & 0.9 \\
\hline 22 & IEcon.EH.MSFan.CS2.DCV1 & 79 & 2.6 & 395 & 10.3 & 357 & 7.3 & 38 & 0.9 \\
\hline
\end{tabular}


Table C-48: Gas Savings Compared to Case 1 for the Supermarket Building in Climate Zones 6, 7 and 8

\begin{tabular}{|c|c|c|c|c|c|c|c|c|c|}
\hline \multirow[b]{2}{*}{$\begin{array}{c}\text { Case } \\
\text { No }\end{array}$} & \multirow[b]{2}{*}{ Case Name } & \multicolumn{2}{|c|}{ Minneapolis-6A } & \multicolumn{2}{|c|}{ Helena-6B } & \multicolumn{2}{|c|}{ Duluth-7A } & \multicolumn{2}{|c|}{ Fairbanks-8A } \\
\hline & & $\begin{array}{c}\text { Abs. } \\
\left(10^{6}\right. \\
\text { Btus }) \\
\end{array}$ & $\begin{array}{l}\text { Rel. } \\
\text { (\%) }\end{array}$ & $\begin{array}{c}\text { Abs. } \\
\left(10^{6}\right. \\
\text { Btus }) \\
\end{array}$ & $\begin{array}{l}\text { Rel. } \\
\text { (\%) }\end{array}$ & $\begin{array}{c}\text { Abs. } \\
\left(10^{6}\right. \\
\text { Btus }) \\
\end{array}$ & $\begin{array}{l}\text { Rel. } \\
\text { (\%) }\end{array}$ & $\begin{array}{c}\text { Abs. } \\
\left(10^{6}\right. \\
\text { Btus }) \\
\end{array}$ & $\begin{array}{l}\text { Rel. } \\
\text { (\%) }\end{array}$ \\
\hline 2 & NIEcon.DB.SSFan.CS1.DCV0 & 72 & 1.2 & 74 & 1.4 & 93 & 1.3 & 152 & 1.3 \\
\hline 3 & NIEcon.EH.SSFan.CS1.DCV0 & 71 & 1.2 & 74 & 1.3 & 92 & 1.3 & 151 & 1.3 \\
\hline 4 & IEcon.DB.SSFan.CS1.DCV0 & 72 & 1.2 & 74 & 1.3 & 93 & 1.3 & 151 & 1.3 \\
\hline 5 & IEcon.EH.SSFan.CS1.DCV0 & 71 & 1.2 & 74 & 1.3 & 92 & 1.2 & 150 & 1.3 \\
\hline 6 & NoEcon.MSFan.CS1.DCV0 & -1023 & -17.4 & -1171 & -21.2 & -1221 & -16.6 & -1561 & -13.7 \\
\hline 7 & NIEcon.DB.MSFan.CS1.DCV0 & -906 & -15.4 & -1059 & -19.2 & -1087 & -14.8 & -1277 & -11.2 \\
\hline 8 & NIEcon.EH.MSFan.CS1.DCV0 & -909 & -15.4 & -1064 & -19.3 & -1094 & -14.9 & -1282 & -11.3 \\
\hline 9 & IEcon.DB.MSFan.CS1.DCV0 & -906 & -15.4 & -1060 & -19.2 & -1087 & -14.8 & -1277 & -11.2 \\
\hline 10 & IEcon.EH.MSFan.CS1.DCV0 & -909 & -15.4 & -1064 & -19.3 & -1093 & -14.9 & -1282 & -11.3 \\
\hline 11 & NoEcon.MSFan.CS2.DCV0 & -931 & -15.8 & -1106 & -20.1 & -1135 & -15.5 & -1320 & -11.6 \\
\hline 12 & IEcon.DB.MSFan.CS2.DCV0 & -904 & -15.3 & -1057 & -19.2 & -1087 & -14.8 & -1274 & -11.2 \\
\hline 13 & IEcon.EH.MSFan.CS2.DCV0 & -904 & -15.4 & -1057 & -19.2 & -1088 & -14.8 & -1276 & -11.2 \\
\hline 14 & NoEcon.SSFan.CS1.DCV1 & 1316 & 22.4 & 1198 & 21.7 & 1606 & 21.9 & 2155 & 19.0 \\
\hline 15 & IEcon.DB.SSFan.CS1.DCV1 & 1438 & 24.4 & 1272 & 23.1 & 1731 & 23.6 & 2336 & 20.5 \\
\hline 16 & IEcon.EH.SSFan.CS1.DCV1 & 1434 & 24.4 & 1271 & 23.1 & 1726 & 23.5 & 2335 & 20.5 \\
\hline 17 & NoEcon.MSFan.CS1.DCV1 & 284 & 4.8 & -16 & -0.3 & 394 & 5.4 & 609 & 5.4 \\
\hline 18 & IEcon.DB.MSFan.CS1.DCV1 & 473 & 8.0 & 182 & 3.3 & 607 & 8.3 & 967 & 8.5 \\
\hline 19 & IEcon.EH.MSFan.CS1.DCV1 & 452 & 7.7 & 165 & 3.0 & 582 & 7.9 & 949 & 8.3 \\
\hline 20 & NoEcon.MSFan.CS2.DCV1 & 420 & 7.1 & 100 & 1.8 & 527 & 7.2 & 1002 & 8.8 \\
\hline 21 & IEcon.DB.MSFan.CS2.DCV1 & 478 & 8.1 & 194 & 3.5 & 609 & 8.3 & 973 & 8.6 \\
\hline 22 & IEcon.EH.MSFan.CS2.DCV1 & 471 & 8.0 & 191 & 3.5 & 602 & 8.2 & 970 & 8.5 \\
\hline
\end{tabular}




\section{APPENDIX D Tables of Energy Cost Savings and Maximum Acceptable Controller Costs}


Table D-1: HVAC Energy Cost Savings Compared to Case 1 for the Small Office Building in Climate Zones 1, 2 and 3A

\begin{tabular}{|c|c|c|c|c|c|c|c|c|c|}
\hline \multirow{2}{*}{$\begin{array}{c}\text { Case } \\
\text { No }\end{array}$} & \multirow[b]{2}{*}{ Case Name } & \multicolumn{2}{|c|}{ Miami-1A } & \multicolumn{2}{|c|}{ Houston-2A } & \multicolumn{2}{|c|}{ Phoenix-2B } & \multicolumn{2}{|c|}{ Atlanta-3A } \\
\hline & & $\begin{array}{c}\text { Abs. } \\
\text { (\$) }\end{array}$ & $\begin{array}{l}\text { Rel. } \\
\text { (\%) }\end{array}$ & $\begin{array}{c}\text { Abs. } \\
\text { (\$) }\end{array}$ & $\begin{array}{l}\text { Rel. } \\
\text { (\%) }\end{array}$ & $\begin{array}{c}\text { Abs. } \\
\text { (\$) }\end{array}$ & $\begin{array}{l}\text { Rel. } \\
\text { (\%) }\end{array}$ & $\begin{array}{l}\text { Abs. } \\
\text { (\$) }\end{array}$ & $\begin{array}{l}\text { Rel. } \\
\text { (\%) }\end{array}$ \\
\hline 2 & NIEcon.DB.SSFan.CS1.DCV0 & 136 & 2.9 & 158 & 4.4 & 148 & 3.6 & 221 & 7.0 \\
\hline 3 & NIEcon.EH.SSFan.CS1.DCV0 & 119 & 2.6 & 133 & 3.7 & 156 & 3.8 & 183 & 5.8 \\
\hline 4 & IEcon.DB.SSFan.CS1.DCV0 & 135 & 2.9 & 156 & 4.3 & 152 & 3.7 & 222 & 7.1 \\
\hline 5 & IEcon.EH.SSFan.CS1.DCV0 & 121 & 2.6 & 136 & 3.8 & 160 & 3.9 & 184 & 5.9 \\
\hline 6 & NoEcon.MSFan.CS1.DCV0 & 866 & 18.7 & 820 & 22.8 & 847 & 20.5 & 744 & 23.6 \\
\hline 7 & NIEcon.DB.MSFan.CS1.DCV0 & 939 & 20.2 & 891 & 24.8 & 924 & 22.3 & 847 & 26.9 \\
\hline 8 & NIEcon.EH.MSFan.CS1.DCV0 & 927 & 20.0 & 883 & 24.6 & 925 & 22.4 & 832 & 26.4 \\
\hline 9 & IEcon.DB.MSFan.CS1.DCV0 & 930 & 20.0 & 886 & 24.6 & 930 & 22.5 & 847 & 26.9 \\
\hline 10 & IEcon.EH.MSFan.CS1.DCV0 & 932 & 20.1 & 887 & 24.7 & 930 & 22.5 & 835 & 26.5 \\
\hline 11 & NoEcon.MSFan.CS2.DCV0 & 1355 & 29.2 & 1126 & 31.3 & 1269 & 30.7 & 950 & 30.2 \\
\hline 12 & IEcon.DB.MSFan.CS2.DCV0 & 1358 & 29.3 & 1140 & 31.7 & 1315 & 31.8 & 990 & 31.5 \\
\hline 13 & IEcon.EH.MSFan.CS2.DCV0 & 1402 & 30.2 & 1171 & 32.6 & 1317 & 31.9 & 1010 & 32.1 \\
\hline 14 & NoEcon.SSFan.CS1.DCV1 & 365 & 7.9 & 293 & 8.1 & 225 & 5.4 & 259 & 8.2 \\
\hline 15 & IEcon.DB.SSFan.CS1.DCV1 & 475 & 10.2 & 453 & 12.6 & 408 & 9.9 & 499 & 15.9 \\
\hline 16 & IEcon.EH.SSFan.CS1.DCV1 & 493 & 10.6 & 443 & 12.3 & 418 & 10.1 & 473 & 15.0 \\
\hline 17 & NoEcon.MSFan.CS1.DCV1 & 1289 & 27.8 & 1175 & 32.7 & 1138 & 27.5 & 1083 & 34.4 \\
\hline 18 & IEcon.DB.MSFan.CS1.DCV1 & 1332 & 28.7 & 1245 & 34.6 & 1245 & 30.1 & 1203 & 38.2 \\
\hline 19 & IEcon.EH.MSFan.CS1.DCV1 & 1364 & 29.4 & 1259 & 35.0 & 1248 & 30.2 & 1203 & 38.2 \\
\hline 20 & NoEcon.MSFan.CS2.DCV1 & 1717 & 37.0 & 1444 & 40.1 & 1529 & 37.0 & 1274 & 40.5 \\
\hline 21 & IEcon.DB.MSFan.CS2.DCV1 & 1705 & 36.7 & 1459 & 40.6 & 1597 & 38.6 & 1327 & 42.2 \\
\hline 22 & IEcon.EH.MSFan.CS2.DCV1 & 1774 & 38.2 & 1506 & 41.9 & 1597 & 38.6 & 1357 & 43.1 \\
\hline
\end{tabular}


Table D-2: HVAC Energy Cost Savings Compared to Case 1 for the Small Office Building in Climate Zone 3B, 3C and 4A

\begin{tabular}{|c|c|c|c|c|c|c|c|c|c|}
\hline \multirow{2}{*}{$\begin{array}{c}\text { Case } \\
\text { No }\end{array}$} & \multirow[b]{2}{*}{ Case Name } & \multicolumn{2}{|c|}{ Los Angeles-3B } & \multicolumn{2}{|c|}{ Las Vegas-3B } & \multicolumn{2}{|c|}{ San Francisco-3C } & \multicolumn{2}{|c|}{ Baltimore-4A } \\
\hline & & $\begin{array}{c}\text { Abs. } \\
(\$)\end{array}$ & $\begin{array}{l}\text { Rel. } \\
\text { (\%) }\end{array}$ & $\begin{array}{c}\text { Abs. } \\
\text { (\$) }\end{array}$ & $\begin{array}{l}\text { Rel. } \\
\text { (\%) }\end{array}$ & $\begin{array}{c}\text { Abs. } \\
\text { (\$) }\end{array}$ & $\begin{array}{l}\text { Rel. } \\
\text { (\%) }\end{array}$ & $\begin{array}{c}\text { Abs. } \\
\text { (\$) }\end{array}$ & $\begin{array}{l}\text { Rel. } \\
(\%)\end{array}$ \\
\hline 2 & NIEcon.DB.SSFan.CS1.DCV0 & 811 & 23.7 & 154 & 4.4 & 363 & 15.4 & 208 & 6.0 \\
\hline 3 & NIEcon.EH.SSFan.CS1.DCV0 & 652 & 19.0 & 157 & 4.5 & 356 & 15.1 & 169 & 4.9 \\
\hline 4 & IEcon.DB.SSFan.CS1.DCV0 & 838 & 24.5 & 159 & 4.5 & 371 & 15.7 & 205 & 5.9 \\
\hline 5 & IEcon.EH.SSFan.CS1.DCV0 & 663 & 19.4 & 162 & 4.6 & 362 & 15.3 & 173 & 5.0 \\
\hline 6 & NoEcon.MSFan.CS1.DCV0 & 1566 & 45.7 & 849 & 24.2 & 1170 & 49.5 & 884 & 25.5 \\
\hline 7 & NIEcon.DB.MSFan.CS1.DCV0 & 2051 & 59.9 & 915 & 26.1 & 1370 & 58.0 & 971 & 28.0 \\
\hline 8 & NIEcon.EH.MSFan.CS1.DCV0 & 1946 & 56.8 & 915 & 26.1 & 1365 & 57.8 & 962 & 27.7 \\
\hline 9 & IEcon.DB.MSFan.CS1.DCV0 & 2083 & 60.8 & 920 & 26.2 & 1380 & 58.4 & 966 & 27.8 \\
\hline 10 & IEcon.EH.MSFan.CS1.DCV0 & 1965 & 57.4 & 921 & 26.2 & 1374 & 58.2 & 966 & 27.8 \\
\hline 11 & NoEcon.MSFan.CS2.DCV0 & 1867 & 54.5 & 1120 & 31.9 & 1285 & 54.4 & 1056 & 30.4 \\
\hline 12 & IEcon.DB.MSFan.CS2.DCV0 & 2168 & 63.3 & 1159 & 33.0 & 1417 & 60.0 & 1092 & 31.5 \\
\hline 13 & IEcon.EH.MSFan.CS2.DCV0 & 2159 & 63.0 & 1158 & 33.0 & 1417 & 60.0 & 1108 & 31.9 \\
\hline 14 & NoEcon.SSFan.CS1.DCV1 & -48 & -1.4 & 183 & 5.2 & -7 & -0.3 & 355 & 10.2 \\
\hline 15 & IEcon.DB.SSFan.CS1.DCV1 & 867 & 25.3 & 381 & 10.8 & 483 & 20.5 & 594 & 17.1 \\
\hline 16 & IEcon.EH.SSFan.CS1.DCV1 & 691 & 20.2 & 383 & 10.9 & 471 & 20.0 & 570 & 16.4 \\
\hline 17 & NoEcon.MSFan.CS1.DCV1 & 1531 & 44.7 & 1102 & 31.4 & 1226 & 51.9 & 1346 & 38.8 \\
\hline 18 & IEcon.DB.MSFan.CS1.DCV1 & 2125 & 62.0 & 1204 & 34.3 & 1537 & 65.0 & 1453 & 41.9 \\
\hline 19 & IEcon.EH.MSFan.CS1.DCV1 & 2003 & 58.5 & 1204 & 34.3 & 1529 & 64.7 & 1462 & 42.1 \\
\hline 20 & NoEcon.MSFan.CS2.DCV1 & 1831 & 53.5 & 1369 & 39.0 & 1357 & 57.5 & 1501 & 43.3 \\
\hline 21 & IEcon.DB.MSFan.CS2.DCV1 & 2211 & 64.6 & 1431 & 40.8 & 1573 & 66.6 & 1557 & 44.9 \\
\hline 22 & IEcon.EH.MSFan.CS2.DCV1 & 2203 & 64.3 & 1428 & 40.7 & 1573 & 66.6 & 1583 & 45.6 \\
\hline
\end{tabular}


Table D-3: HVAC Energy Cost Savings Compared to Case 1 for the Small Office Building in Climate Zones 4B, 4C and 5

\begin{tabular}{|c|c|c|c|c|c|c|c|c|c|}
\hline \multirow[b]{2}{*}{$\begin{array}{c}\text { Case } \\
\text { No }\end{array}$} & \multirow[b]{2}{*}{ Case Name } & \multicolumn{2}{|c|}{ Albuquerque-4B } & \multicolumn{2}{|c|}{ Seattle-4C } & \multicolumn{2}{|c|}{ Chicago-5A } & \multicolumn{2}{|c|}{ Denver-5B } \\
\hline & & $\begin{array}{c}\text { Abs. } \\
\text { (\$) }\end{array}$ & $\begin{array}{l}\text { Rel. } \\
\text { (\%) }\end{array}$ & $\begin{array}{c}\text { Abs. } \\
\text { (\$) }\end{array}$ & $\begin{array}{l}\text { Rel. } \\
\text { (\%) }\end{array}$ & $\begin{array}{c}\text { Abs. } \\
\text { (\$) }\end{array}$ & $\begin{array}{l}\text { Rel. } \\
\text { (\%) }\end{array}$ & $\begin{array}{c}\text { Abs. } \\
\text { (\$) }\end{array}$ & $\begin{array}{l}\text { Rel. } \\
(\%)\end{array}$ \\
\hline 2 & NIEcon.DB.SSFan.CS1.DCV0 & 174 & 7.0 & 145 & 7.6 & 159 & 5.0 & 167 & 6.5 \\
\hline 3 & NIEcon.EH.SSFan.CS1.DCV0 & 155 & 6.2 & 137 & 7.2 & 117 & 3.7 & 147 & 5.7 \\
\hline 4 & IEcon.DB.SSFan.CS1.DCV0 & 179 & 7.2 & 148 & 7.7 & 162 & 5.1 & 171 & 6.6 \\
\hline 5 & IEcon.EH.SSFan.CS1.DCV0 & 157 & 6.4 & 139 & 7.3 & 117 & 3.7 & 147 & 5.7 \\
\hline 6 & NoEcon.MSFan.CS1.DCV0 & 744 & 30.1 & 433 & 22.6 & 621 & 19.6 & 818 & 31.6 \\
\hline 7 & NIEcon.DB.MSFan.CS1.DCV0 & 827 & 33.4 & 505 & 26.4 & 687 & 21.7 & 884 & 34.2 \\
\hline 8 & NIEcon.EH.MSFan.CS1.DCV0 & 818 & 33.0 & 501 & 26.1 & 671 & 21.2 & 877 & 33.9 \\
\hline 9 & IEcon.DB.MSFan.CS1.DCV0 & 833 & 33.6 & 509 & 26.6 & 690 & 21.8 & 888 & 34.3 \\
\hline 10 & IEcon.EH.MSFan.CS1.DCV0 & 822 & 33.2 & 504 & 26.3 & 673 & 21.2 & 879 & 34.0 \\
\hline 11 & NoEcon.MSFan.CS2.DCV0 & 921 & 37.2 & 487 & 25.4 & 742 & 23.4 & 951 & 36.7 \\
\hline 12 & IEcon.DB.MSFan.CS2.DCV0 & 970 & 39.2 & 533 & 27.8 & 775 & 24.4 & 988 & 38.2 \\
\hline 13 & IEcon.EH.MSFan.CS2.DCV0 & 969 & 39.1 & 533 & 27.8 & 778 & 24.5 & 986 & 38.1 \\
\hline 14 & NoEcon.SSFan.CS1.DCV1 & 133 & 5.4 & 247 & 12.9 & 412 & 13.0 & 178 & 6.9 \\
\hline 15 & IEcon.DB.SSFan.CS1.DCV1 & 344 & 13.9 & 444 & 23.2 & 599 & 18.9 & 391 & 15.1 \\
\hline 16 & IEcon.EH.SSFan.CS1.DCV1 & 322 & 13.0 & 433 & 22.6 & 556 & 17.5 & 362 & 14.0 \\
\hline 17 & NoEcon.MSFan.CS1.DCV1 & 946 & 38.2 & 783 & 40.9 & 1139 & 35.9 & 1085 & 41.9 \\
\hline 18 & IEcon.DB.MSFan.CS1.DCV1 & 1061 & 42.8 & 900 & 46.9 & 1227 & 38.7 & 1188 & 45.9 \\
\hline 19 & IEcon.EH.MSFan.CS1.DCV1 & 1049 & 42.4 & 894 & 46.6 & 1213 & 38.3 & 1177 & 45.4 \\
\hline 20 & NoEcon.MSFan.CS2.DCV1 & 1111 & 44.9 & 843 & 44.0 & 1252 & 39.5 & 1218 & 47.1 \\
\hline 21 & IEcon.DB.MSFan.CS2.DCV1 & 1182 & 47.7 & 923 & 48.1 & 1301 & 41.0 & 1279 & 49.4 \\
\hline 22 & IEcon.EH.MSFan.CS2.DCV1 & 1181 & 47.7 & 923 & 48.1 & 1307 & 41.2 & 1276 & 49.3 \\
\hline
\end{tabular}


Table D-4: HVAC Energy Cost Savings Compared to Case 1 for the Small Office Building in Climate Zones 6, 7 and 8

\begin{tabular}{|c|c|c|c|c|c|c|c|c|c|}
\hline \multirow[b]{2}{*}{$\begin{array}{c}\text { Case } \\
\text { No }\end{array}$} & \multirow[b]{2}{*}{ Case Name } & \multicolumn{2}{|c|}{ Minneapolis-6A } & \multicolumn{2}{|c|}{ Helena-6B } & \multicolumn{2}{|c|}{ Duluth-7 } & \multicolumn{2}{|c|}{ Fairbanks-8 } \\
\hline & & $\begin{array}{c}\text { Abs. } \\
\text { (\$) }\end{array}$ & $\begin{array}{l}\text { Rel. } \\
\text { (\%) }\end{array}$ & $\begin{array}{c}\text { Abs. } \\
\text { (\$) }\end{array}$ & $\begin{array}{l}\text { Rel. } \\
\text { (\%) }\end{array}$ & $\begin{array}{c}\text { Abs. } \\
\text { (\$) }\end{array}$ & $\begin{array}{l}\text { Rel. } \\
\text { (\%) }\end{array}$ & $\begin{array}{c}\text { Abs. } \\
\text { (\$) }\end{array}$ & $\begin{array}{l}\text { Rel. } \\
\text { (\%) }\end{array}$ \\
\hline 2 & NIEcon.DB.SSFan.CS1.DCV0 & 164 & 5.5 & 149 & 5.2 & 138 & 4.6 & 252 & 4.2 \\
\hline 3 & NIEcon.EH.SSFan.CS1.DCV0 & 138 & 4.6 & 139 & 4.8 & 119 & 4.0 & 245 & 4.0 \\
\hline 4 & IEcon.DB.SSFan.CS1.DCV0 & 167 & 5.6 & 151 & 5.3 & 139 & 4.6 & 255 & 4.2 \\
\hline 5 & IEcon.EH.SSFan.CS1.DCV0 & 138 & 4.6 & 139 & 4.8 & 120 & 4.0 & 245 & 4.0 \\
\hline 6 & NoEcon.MSFan.CS1.DCV0 & 651 & 21.8 & 677 & 23.5 & 619 & 20.5 & 1286 & 21.2 \\
\hline 7 & NIEcon.DB.MSFan.CS1.DCV0 & 724 & 24.3 & 739 & 25.7 & 687 & 22.8 & 1421 & 23.4 \\
\hline 8 & NIEcon.EH.MSFan.CS1.DCV0 & 715 & 24.0 & 736 & 25.6 & 679 & 22.5 & 1417 & 23.4 \\
\hline 9 & IEcon.DB.MSFan.CS1.DCV0 & 728 & 24.4 & 742 & 25.8 & 689 & 22.9 & 1425 & 23.5 \\
\hline 10 & IEcon.EH.MSFan.CS1.DCV0 & 717 & 24.1 & 738 & 25.7 & 680 & 22.6 & 1421 & 23.4 \\
\hline 11 & NoEcon.MSFan.CS2.DCV0 & 755 & 25.3 & 768 & 26.7 & 678 & 22.5 & 1376 & 22.7 \\
\hline 12 & IEcon.DB.MSFan.CS2.DCV0 & 791 & 26.5 & 804 & 28.0 & 716 & 23.8 & 1457 & 24.0 \\
\hline 13 & IEcon.EH.MSFan.CS2.DCV0 & 797 & 26.7 & 804 & 28.0 & 716 & 23.8 & 1457 & 24.0 \\
\hline 14 & NoEcon.SSFan.CS1.DCV1 & 377 & 12.7 & 317 & 11.0 & 395 & 13.1 & 699 & 11.5 \\
\hline 15 & IEcon.DB.SSFan.CS1.DCV1 & 574 & 19.3 & 514 & 17.9 & 581 & 19.3 & 1003 & 16.5 \\
\hline 16 & IEcon.EH.SSFan.CS1.DCV1 & 549 & 18.4 & 500 & 17.4 & 560 & 18.6 & 992 & 16.4 \\
\hline 17 & NoEcon.MSFan.CS1.DCV1 & 1120 & 37.6 & 1117 & 38.9 & 1136 & 37.7 & 2153 & 35.5 \\
\hline 18 & IEcon.DB.MSFan.CS1.DCV1 & 1222 & 41.0 & 1215 & 42.3 & 1240 & 41.1 & 2362 & 39.0 \\
\hline 19 & IEcon.EH.MSFan.CS1.DCV1 & 1214 & 40.7 & 1210 & 42.1 & 1231 & 40.8 & 2357 & 38.9 \\
\hline 20 & NoEcon.MSFan.CS2.DCV1 & 1222 & 41.0 & 1209 & 42.1 & 1199 & 39.8 & 2256 & 37.2 \\
\hline 21 & IEcon.DB.MSFan.CS2.DCV1 & 1280 & 42.9 & 1272 & 44.3 & 1264 & 41.9 & 2393 & 39.5 \\
\hline 22 & IEcon.EH.MSFan.CS2.DCV1 & 1289 & 43.2 & 1271 & 44.2 & 1266 & 42.0 & 2393 & 39.5 \\
\hline
\end{tabular}


Table D-5: HVAC Energy Cost Savings Compared to Case 1 for the Stand-alone Retail Building in Climate Zones 1, 2 and 3A

\begin{tabular}{|c|c|c|c|c|c|c|c|c|c|}
\hline \multirow{2}{*}{$\begin{array}{c}\text { Case } \\
\text { No }\end{array}$} & \multirow{2}{*}{ Case Name } & \multicolumn{2}{|c|}{ Miami-1A } & \multicolumn{2}{|c|}{ Houston-2A } & \multicolumn{2}{|c|}{ Phoenix-2B } & \multicolumn{2}{|c|}{ Atlanta-3A } \\
\hline & & $\begin{array}{c}\text { Abs. } \\
\text { (\$) }\end{array}$ & $\begin{array}{l}\text { Rel. } \\
\text { (\%) }\end{array}$ & $\begin{array}{c}\text { Abs. } \\
\text { (\$) }\end{array}$ & $\begin{array}{l}\text { Rel. } \\
\text { (\%) }\end{array}$ & $\begin{array}{l}\text { Abs. } \\
\text { (\$) }\end{array}$ & $\begin{array}{l}\text { Rel. } \\
\text { (\%) }\end{array}$ & $\begin{array}{c}\text { Abs. } \\
\text { (\$) }\end{array}$ & $\begin{array}{l}\text { Rel. } \\
\text { (\%) }\end{array}$ \\
\hline 2 & NIEcon.DB.SSFan.CS1.DCV0 & 779 & 2.9 & 591 & 2.6 & 374 & 1.6 & 617 & 2.7 \\
\hline 3 & NIEcon.EH.SSFan.CS1.DCV0 & 461 & 1.7 & 392 & 1.7 & 415 & 1.8 & 477 & 2.1 \\
\hline 4 & IEcon.DB.SSFan.CS1.DCV0 & 772 & 2.9 & 592 & 2.6 & 383 & 1.6 & 625 & 2.7 \\
\hline 5 & IEcon.EH.SSFan.CS1.DCV0 & 481 & 1.8 & 406 & 1.8 & 424 & 1.8 & 490 & 2.1 \\
\hline 6 & NoEcon.MSFan.CS1.DCV0 & 4302 & 16.1 & 3816 & 16.9 & 3888 & 16.4 & 3528 & 15.2 \\
\hline 7 & NIEcon.DB.MSFan.CS1.DCV0 & 4603 & 17.2 & 4009 & 17.7 & 4001 & 16.9 & 3711 & 16.0 \\
\hline 8 & NIEcon.EH.MSFan.CS1.DCV0 & 4451 & 16.6 & 3924 & 17.4 & 4028 & 17.0 & 3655 & 15.7 \\
\hline 9 & IEcon.DB.MSFan.CS1.DCV0 & 4598 & 17.2 & 4009 & 17.7 & 4015 & 17.0 & 3722 & 16.0 \\
\hline 10 & IEcon.EH.MSFan.CS1.DCV0 & 4480 & 16.7 & 3940 & 17.4 & 4039 & 17.1 & 3676 & 15.8 \\
\hline 11 & NoEcon.MSFan.CS2.DCV0 & 6679 & 24.9 & 5244 & 23.2 & 5575 & 23.6 & 4574 & 19.7 \\
\hline 12 & IEcon.DB.MSFan.CS2.DCV0 & 6899 & 25.8 & 5362 & 23.7 & 5622 & 23.8 & 4685 & 20.1 \\
\hline 13 & IEcon.EH.MSFan.CS2.DCV0 & 6833 & 25.5 & 5341 & 23.6 & 5636 & 23.8 & 4673 & 20.1 \\
\hline 14 & NoEcon.SSFan.CS1.DCV1 & 3586 & 13.4 & 3699 & 16.4 & 3729 & 15.8 & 4459 & 19.2 \\
\hline 15 & IEcon.DB.SSFan.CS1.DCV1 & 4122 & 15.4 & 4139 & 18.3 & 4045 & 17.1 & 4887 & 21.0 \\
\hline 16 & IEcon.EH.SSFan.CS1.DCV1 & 3887 & 14.5 & 3999 & 17.7 & 4089 & 17.3 & 4790 & 20.6 \\
\hline 17 & NoEcon.MSFan.CS1.DCV1 & 8241 & 30.8 & 7958 & 35.2 & 8263 & 34.9 & 8531 & 36.7 \\
\hline 18 & IEcon.DB.MSFan.CS1.DCV1 & 8516 & 31.8 & 8179 & 36.2 & 8424 & 35.6 & 8757 & 37.7 \\
\hline 19 & IEcon.EH.MSFan.CS1.DCV1 & 8420 & 31.4 & 8125 & 35.9 & 8436 & 35.7 & 8712 & 37.5 \\
\hline 20 & NoEcon.MSFan.CS2.DCV1 & 10310 & 38.5 & 9276 & 41.0 & 9888 & 41.8 & 9406 & 40.4 \\
\hline 21 & IEcon.DB.MSFan.CS2.DCV1 & 10476 & 39.1 & 9403 & 41.6 & 9964 & 42.1 & 9530 & 41.0 \\
\hline 22 & IEcon.EH.MSFan.CS2.DCV1 & 10453 & 39.0 & 9395 & 41.6 & 9960 & 42.1 & 9529 & 41.0 \\
\hline
\end{tabular}


Table D-6: HVAC Energy Cost Savings Compared to Case 1 for the Stand-alone Retail Building in Climate Zone 3B, 3C and 4A

\begin{tabular}{|c|c|c|c|c|c|c|c|c|c|}
\hline \multirow{2}{*}{$\begin{array}{c}\text { Case } \\
\text { No }\end{array}$} & \multirow[b]{2}{*}{ Case Name } & \multicolumn{2}{|c|}{ Los Angeles-3B } & \multicolumn{2}{|c|}{ Las Vegas-3B } & \multicolumn{2}{|c|}{ San Francisco-3C } & \multicolumn{2}{|c|}{ Baltimore-4A } \\
\hline & & $\begin{array}{c}\text { Abs. } \\
\text { (\$) }\end{array}$ & $\begin{array}{l}\text { Rel. } \\
(\%)\end{array}$ & $\begin{array}{l}\text { Abs. } \\
(\$)\end{array}$ & $\begin{array}{l}\text { Rel. } \\
(\%)\end{array}$ & $\begin{array}{c}\text { Abs. } \\
\text { (\$) }\end{array}$ & $\begin{array}{l}\text { Rel. } \\
(\%)\end{array}$ & $\begin{array}{c}\text { Abs. } \\
\text { (\$) }\end{array}$ & $\begin{array}{l}\text { Rel. } \\
(\%)\end{array}$ \\
\hline 2 & NIEcon.DB.SSFan.CS1.DCV0 & 2213 & 13.2 & 305 & 1.4 & 636 & 4.1 & 516 & 1.8 \\
\hline 3 & NIEcon.EH.SSFan.CS1.DCV0 & 1891 & 11.3 & 326 & 1.5 & 637 & 4.1 & 401 & 1.4 \\
\hline 4 & IEcon.DB.SSFan.CS1.DCV0 & 2311 & 13.8 & 314 & 1.5 & 662 & 4.3 & 525 & 1.9 \\
\hline 5 & IEcon.EH.SSFan.CS1.DCV0 & 1972 & 11.8 & 333 & 1.5 & 664 & 4.3 & 417 & 1.5 \\
\hline 6 & NoEcon.MSFan.CS1.DCV0 & 7033 & 42.1 & 3707 & 17.2 & 5192 & 33.7 & 4188 & 14.8 \\
\hline 7 & NIEcon.DB.MSFan.CS1.DCV0 & 8060 & 48.2 & 3802 & 17.7 & 5433 & 35.3 & 4337 & 15.4 \\
\hline 8 & NIEcon.EH.MSFan.CS1.DCV0 & 7832 & 46.8 & 3808 & 17.7 & 5433 & 35.3 & 4290 & 15.2 \\
\hline 9 & IEcon.DB.MSFan.CS1.DCV0 & 8177 & 48.9 & 3811 & 17.7 & 5466 & 35.5 & 4344 & 15.4 \\
\hline 10 & IEcon.EH.MSFan.CS1.DCV0 & 7945 & 47.5 & 3819 & 17.8 & 5465 & 35.5 & 4309 & 15.3 \\
\hline 11 & NoEcon.MSFan.CS2.DCV0 & 7937 & 47.5 & 4708 & 21.9 & 5463 & 35.5 & 5058 & 17.9 \\
\hline 12 & IEcon.DB.MSFan.CS2.DCV0 & 8680 & 51.9 & 4756 & 22.1 & 5617 & 36.5 & 5154 & 18.3 \\
\hline 13 & IEcon.EH.MSFan.CS2.DCV0 & 8613 & 51.5 & 4766 & 22.2 & 5625 & 36.5 & 5146 & 18.2 \\
\hline 14 & NoEcon.SSFan.CS1.DCV1 & 1689 & 10.1 & 3649 & 17.0 & 2705 & 17.6 & 5998 & 21.3 \\
\hline 15 & IEcon.DB.SSFan.CS1.DCV1 & 3401 & 20.3 & 3950 & 18.4 & 3318 & 21.5 & 6375 & 22.6 \\
\hline 16 & IEcon.EH.SSFan.CS1.DCV1 & 3098 & 18.5 & 3971 & 18.5 & 3315 & 21.5 & 6303 & 22.3 \\
\hline 17 & NoEcon.MSFan.CS1.DCV1 & 8194 & 49.0 & 8013 & 37.3 & 7950 & 51.6 & 10970 & 38.9 \\
\hline 18 & IEcon.DB.MSFan.CS1.DCV1 & 9608 & 57.4 & 8170 & 38.0 & 8405 & 54.6 & 11149 & 39.5 \\
\hline 19 & IEcon.EH.MSFan.CS1.DCV1 & 9338 & 55.8 & 8173 & 38.0 & 8404 & 54.6 & 11119 & 39.4 \\
\hline 20 & NoEcon.MSFan.CS2.DCV1 & 9179 & 54.9 & 8959 & 41.7 & 8246 & 53.6 & 11723 & 41.5 \\
\hline 21 & IEcon.DB.MSFan.CS2.DCV1 & 10118 & 60.5 & 9042 & 42.0 & 8566 & 55.6 & 11827 & 41.9 \\
\hline 22 & IEcon.EH.MSFan.CS2.DCV1 & 10031 & 60.0 & 9042 & 42.0 & 8571 & 55.7 & 11834 & 41.9 \\
\hline
\end{tabular}


Table D-7: HVAC Energy Cost Savings Compared to Case 1 for the Stand-alone Retail Building in Climate Zones 4B, 4C and 5

\begin{tabular}{|c|c|c|c|c|c|c|c|c|c|}
\hline \multirow{2}{*}{$\begin{array}{c}\text { Case } \\
\text { No }\end{array}$} & \multirow{2}{*}{ Case Name } & \multicolumn{2}{|c|}{ Albuquerque-4B } & \multicolumn{2}{|c|}{ Seattle-4C } & \multicolumn{2}{|c|}{ Chicago-5A } & \multicolumn{2}{|c|}{ Denver-5B } \\
\hline & & $\begin{array}{l}\text { Abs. } \\
\text { (\$) }\end{array}$ & $\begin{array}{l}\text { Rel. } \\
\text { (\%) }\end{array}$ & $\begin{array}{c}\text { Abs. } \\
\text { (\$) }\end{array}$ & $\begin{array}{l}\text { Rel. } \\
\text { (\%) }\end{array}$ & $\begin{array}{c}\text { Abs. } \\
(\$)\end{array}$ & $\begin{array}{l}\text { Rel. } \\
\text { (\%) }\end{array}$ & $\begin{array}{c}\text { Abs. } \\
\text { (\$) }\end{array}$ & $\begin{array}{l}\text { Rel. } \\
\text { (\%) }\end{array}$ \\
\hline 2 & NIEcon.DB.SSFan.CS1.DCV0 & 352 & 2.0 & 232 & 1.2 & 456 & 1.5 & 372 & 1.7 \\
\hline 3 & NIEcon.EH.SSFan.CS1.DCV0 & 335 & 1.9 & 225 & 1.2 & 355 & 1.2 & 357 & 1.7 \\
\hline 4 & IEcon.DB.SSFan.CS1.DCV0 & 364 & 2.0 & 243 & 1.3 & 465 & 1.6 & 380 & 1.8 \\
\hline 5 & IEcon.EH.SSFan.CS1.DCV0 & 344 & 1.9 & 234 & 1.3 & 362 & 1.2 & 362 & 1.7 \\
\hline 6 & NoEcon.MSFan.CS1.DCV0 & 3487 & 19.4 & 1819 & 9.8 & 3134 & 10.7 & 3985 & 18.5 \\
\hline 7 & NIEcon.DB.MSFan.CS1.DCV0 & 3590 & 20.0 & 1894 & 10.2 & 3260 & 11.1 & 4070 & 18.9 \\
\hline 8 & NIEcon.EH.MSFan.CS1.DCV0 & 3584 & 19.9 & 1893 & 10.2 & 3226 & 11.0 & 4069 & 18.9 \\
\hline 9 & IEcon.DB.MSFan.CS1.DCV0 & 3606 & 20.1 & 1906 & 10.2 & 3274 & 11.1 & 4078 & 18.9 \\
\hline 10 & IEcon.EH.MSFan.CS1.DCV0 & 3599 & 20.0 & 1902 & 10.2 & 3238 & 11.0 & 4075 & 18.9 \\
\hline 11 & NoEcon.MSFan.CS2.DCV0 & 4270 & 23.8 & 1977 & 10.6 & 3785 & 12.9 & 4540 & 21.1 \\
\hline 12 & IEcon.DB.MSFan.CS2.DCV0 & 4325 & 24.1 & 2025 & 10.9 & 3846 & 13.1 & 4577 & 21.2 \\
\hline 13 & IEcon.EH.MSFan.CS2.DCV0 & 4344 & 24.2 & 2028 & 10.9 & 3848 & 13.1 & 4580 & 21.3 \\
\hline 14 & NoEcon.SSFan.CS1.DCV1 & 3066 & 17.1 & 5791 & 31.1 & 6588 & 22.4 & 3952 & 18.4 \\
\hline 15 & IEcon.DB.SSFan.CS1.DCV1 & 3378 & 18.8 & 6012 & 32.3 & 6902 & 23.5 & 4272 & 19.8 \\
\hline 16 & IEcon.EH.SSFan.CS1.DCV1 & 3365 & 18.7 & 6002 & 32.2 & 6815 & 23.2 & 4257 & 19.8 \\
\hline 17 & NoEcon.MSFan.CS1.DCV1 & 7068 & 39.3 & 7764 & 41.7 & 10610 & 36.1 & 8635 & 40.1 \\
\hline 18 & IEcon.DB.MSFan.CS1.DCV1 & 7232 & 40.3 & 7903 & 42.4 & 10825 & 36.8 & 8790 & 40.8 \\
\hline 19 & IEcon.EH.MSFan.CS1.DCV1 & 7219 & 40.2 & 7899 & 42.4 & 10786 & 36.7 & 8774 & 40.7 \\
\hline 20 & NoEcon.MSFan.CS2.DCV1 & 7772 & 43.3 & 7920 & 42.5 & 11186 & 38.0 & 9185 & 42.6 \\
\hline 21 & IEcon.DB.MSFan.CS2.DCV1 & 7856 & 43.7 & 8011 & 43.0 & 11289 & 38.4 & 9245 & 42.9 \\
\hline 22 & IEcon.EH.MSFan.CS2.DCV1 & 7864 & 43.8 & 8015 & 43.0 & 11292 & 38.4 & 9233 & 42.9 \\
\hline
\end{tabular}


Table D-8: HVAC Energy Cost Savings Compared to Case 1 for the Stand-alone Retail Building in Climate Zones 6,7 and 8

\begin{tabular}{|c|c|c|c|c|c|c|c|c|c|}
\hline \multirow{2}{*}{$\begin{array}{c}\text { Case } \\
\text { No }\end{array}$} & \multirow{2}{*}{ Case Name } & \multicolumn{2}{|c|}{ Minneapolis-6A } & \multicolumn{2}{|c|}{ Helena-6B } & \multicolumn{2}{|c|}{ Duluth-7 } & \multicolumn{2}{|c|}{ Fairbanks-8 } \\
\hline & & $\begin{array}{c}\text { Abs. } \\
\text { (\$) }\end{array}$ & $\begin{array}{l}\text { Rel. } \\
\text { (\%) }\end{array}$ & $\begin{array}{l}\text { Abs. } \\
\text { (\$) }\end{array}$ & $\begin{array}{l}\text { Rel. } \\
\text { (\%) }\end{array}$ & $\begin{array}{l}\text { Abs. } \\
\text { (\$) }\end{array}$ & $\begin{array}{l}\text { Rel. } \\
\text { (\%) }\end{array}$ & $\begin{array}{l}\text { Abs. } \\
(\$)\end{array}$ & $\begin{array}{l}\text { Rel. } \\
(\%)\end{array}$ \\
\hline 2 & NIEcon.DB.SSFan.CS1.DCV0 & 501 & 1.8 & 414 & 1.4 & 395 & 1.2 & 2273 & 3.5 \\
\hline 3 & NIEcon.EH.SSFan.CS1.DCV0 & 428 & 1.5 & 413 & 1.4 & 364 & 1.1 & 2264 & 3.5 \\
\hline 4 & IEcon.DB.SSFan.CS1.DCV0 & 512 & 1.8 & 417 & 1.4 & 399 & 1.3 & 2274 & 3.5 \\
\hline 5 & IEcon.EH.SSFan.CS1.DCV0 & 434 & 1.5 & 416 & 1.4 & 366 & 1.2 & 2262 & 3.5 \\
\hline 6 & NoEcon.MSFan.CS1.DCV0 & 3685 & 13.0 & 3471 & 12.0 & 3244 & 10.2 & 7591 & 11.6 \\
\hline 7 & NIEcon.DB.MSFan.CS1.DCV0 & 3896 & 13.7 & 3663 & 12.7 & 3513 & 11.1 & 10164 & 15.6 \\
\hline 8 & NIEcon.EH.MSFan.CS1.DCV0 & 3871 & 13.6 & 3667 & 12.7 & 3506 & 11.1 & 10167 & 15.6 \\
\hline 9 & IEcon.DB.MSFan.CS1.DCV0 & 3907 & 13.8 & 3669 & 12.7 & 3517 & 11.1 & 10168 & 15.6 \\
\hline 10 & IEcon.EH.MSFan.CS1.DCV0 & 3878 & 13.7 & 3673 & 12.7 & 3509 & 11.1 & 10164 & 15.6 \\
\hline 11 & NoEcon.MSFan.CS2.DCV0 & 4287 & 15.1 & 3907 & 13.5 & 3556 & 11.2 & 9671 & 14.8 \\
\hline 12 & IEcon.DB.MSFan.CS2.DCV0 & 4370 & 15.4 & 4001 & 13.8 & 3674 & 11.6 & 10309 & 15.8 \\
\hline 13 & IEcon.EH.MSFan.CS2.DCV0 & 4369 & 15.4 & 4002 & 13.8 & 3675 & 11.6 & 10300 & 15.8 \\
\hline 14 & NoEcon.SSFan.CS1.DCV1 & 5816 & 20.5 & 6058 & 20.9 & 6848 & 21.6 & 12338 & 18.9 \\
\hline 15 & IEcon.DB.SSFan.CS1.DCV1 & 6164 & 21.7 & 6326 & 21.9 & 7181 & 22.7 & 13192 & 20.2 \\
\hline 16 & IEcon.EH.SSFan.CS1.DCV1 & 6103 & 21.5 & 6323 & 21.9 & 7153 & 22.6 & 13186 & 20.2 \\
\hline 17 & NoEcon.MSFan.CS1.DCV1 & 10425 & 36.7 & 10593 & 36.6 & 11337 & 35.8 & 20702 & 31.7 \\
\hline 18 & IEcon.DB.MSFan.CS1.DCV1 & 10716 & 37.8 & 10913 & 37.7 & 11694 & 36.9 & 23657 & 36.3 \\
\hline 19 & IEcon.EH.MSFan.CS1.DCV1 & 10691 & 37.7 & 10912 & 37.7 & 11682 & 36.9 & 23656 & 36.3 \\
\hline 20 & NoEcon.MSFan.CS2.DCV1 & 10989 & 38.7 & 11082 & 38.3 & 11706 & 36.9 & 23231 & 35.6 \\
\hline 21 & IEcon.DB.MSFan.CS2.DCV1 & 11094 & 39.1 & 11213 & 38.8 & 11820 & 37.3 & 23790 & 36.5 \\
\hline 22 & IEcon.EH.MSFan.CS2.DCV1 & 11093 & 39.1 & 11206 & 38.7 & 11819 & 37.3 & 23779 & 36.5 \\
\hline
\end{tabular}


Table D-9: HVAC Energy Cost Savings Compared to Case 1 for the Strip Mall Building in Climate Zones 1, 2 and 3A

\begin{tabular}{|c|c|c|c|c|c|c|c|c|c|}
\hline \multirow{2}{*}{$\begin{array}{c}\text { Case } \\
\text { No }\end{array}$} & \multirow[b]{2}{*}{ Case Name } & \multicolumn{2}{|c|}{ Miami-1A } & \multicolumn{2}{|c|}{ Houston-2A } & \multicolumn{2}{|c|}{ Phoenix-2B } & \multicolumn{2}{|c|}{ Atlanta-3A } \\
\hline & & $\begin{array}{l}\text { Abs. } \\
\text { (\$) }\end{array}$ & $\begin{array}{l}\text { Rel. } \\
\text { (\%) }\end{array}$ & $\begin{array}{c}\text { Abs. } \\
\text { (\$) }\end{array}$ & $\begin{array}{l}\text { Rel. } \\
\text { (\%) }\end{array}$ & $\begin{array}{l}\text { Abs. } \\
\text { (\$) }\end{array}$ & $\begin{array}{l}\text { Rel. } \\
\text { (\%) }\end{array}$ & $\begin{array}{c}\text { Abs. } \\
\text { (\$) }\end{array}$ & $\begin{array}{l}\text { Rel. } \\
\text { (\%) }\end{array}$ \\
\hline 2 & NIEcon.DB.SSFan.CS1.DCV0 & 1087 & 3.6 & 703 & 3.1 & 466 & 2.0 & 754 & 3.3 \\
\hline 3 & NIEcon.EH.SSFan.CS1.DCV0 & 621 & 2.1 & 487 & 2.2 & 535 & 2.2 & 604 & 2.6 \\
\hline 4 & IEcon.DB.SSFan.CS1.DCV0 & 1129 & 3.8 & 717 & 3.2 & 478 & 2.0 & 772 & 3.4 \\
\hline 5 & IEcon.EH.SSFan.CS1.DCV0 & 641 & 2.1 & 500 & 2.2 & 547 & 2.3 & 620 & 2.7 \\
\hline 6 & NoEcon.MSFan.CS1.DCV0 & 4977 & 16.6 & 3900 & 17.3 & 3923 & 16.5 & 3490 & 15.3 \\
\hline 7 & NIEcon.DB.MSFan.CS1.DCV0 & 5485 & 18.3 & 4160 & 18.5 & 4080 & 17.1 & 3775 & 16.6 \\
\hline 8 & NIEcon.EH.MSFan.CS1.DCV0 & 5248 & 17.5 & 4071 & 18.1 & 4131 & 17.3 & 3705 & 16.3 \\
\hline 9 & IEcon.DB.MSFan.CS1.DCV0 & 5528 & 18.5 & 4177 & 18.5 & 4095 & 17.2 & 3796 & 16.7 \\
\hline 10 & IEcon.EH.MSFan.CS1.DCV0 & 5279 & 17.6 & 4089 & 18.1 & 4148 & 17.4 & 3726 & 16.3 \\
\hline 11 & NoEcon.MSFan.CS2.DCV0 & 7828 & 26.2 & 5436 & 24.1 & 5668 & 23.8 & 4622 & 20.3 \\
\hline 12 & IEcon.DB.MSFan.CS2.DCV0 & 8112 & 27.1 & 5589 & 24.8 & 5734 & 24.1 & 4774 & 20.9 \\
\hline 13 & IEcon.EH.MSFan.CS2.DCV0 & 8046 & 26.9 & 5561 & 24.7 & 5760 & 24.2 & 4767 & 20.9 \\
\hline 14 & NoEcon.SSFan.CS1.DCV1 & 3835 & 12.8 & 3769 & 16.7 & 3778 & 15.9 & 4566 & 20.0 \\
\hline 15 & IEcon.DB.SSFan.CS1.DCV1 & 4564 & 15.2 & 4141 & 18.4 & 3936 & 16.5 & 4873 & 21.4 \\
\hline 16 & IEcon.EH.SSFan.CS1.DCV1 & 4127 & 13.8 & 3982 & 17.7 & 4014 & 16.8 & 4760 & 20.9 \\
\hline 17 & NoEcon.MSFan.CS1.DCV1 & 9111 & 30.4 & 8073 & 35.8 & 8250 & 34.6 & 8574 & 37.6 \\
\hline 18 & IEcon.DB.MSFan.CS1.DCV1 & 9625 & 32.2 & 8328 & 36.9 & 8352 & 35.1 & 8823 & 38.7 \\
\hline 19 & IEcon.EH.MSFan.CS1.DCV1 & 9331 & 31.2 & 8232 & 36.5 & 8397 & 35.2 & 8753 & 38.4 \\
\hline 20 & NoEcon.MSFan.CS2.DCV1 & 11685 & 39.0 & 9446 & 41.9 & 9864 & 41.4 & 9484 & 41.6 \\
\hline 21 & IEcon.DB.MSFan.CS2.DCV1 & 11875 & 39.7 & 9560 & 42.4 & 9878 & 41.5 & 9582 & 42.0 \\
\hline 22 & IEcon.EH.MSFan.CS2.DCV1 & 11807 & 39.4 & 9530 & 42.3 & 9896 & 41.5 & 9570 & 42.0 \\
\hline
\end{tabular}


Table D-10: HVAC Energy Cost Savings Compared to Case 1 for the Strip Mall Building in Climate Zone 3B, 3C and 4A

\begin{tabular}{|c|c|c|c|c|c|c|c|c|c|}
\hline \multirow{2}{*}{$\begin{array}{c}\text { Case } \\
\text { No }\end{array}$} & \multirow[b]{2}{*}{ Case Name } & \multicolumn{2}{|c|}{ Los Angeles-3B } & \multicolumn{2}{|c|}{ Las Vegas-3B } & \multicolumn{2}{|c|}{ San Francisco-3C } & \multicolumn{2}{|c|}{ Baltimore-4A } \\
\hline & & $\begin{array}{c}\text { Abs. } \\
\text { (\$) }\end{array}$ & $\begin{array}{l}\text { Rel. } \\
\text { (\%) }\end{array}$ & $\begin{array}{c}\text { Abs. } \\
\text { (\$) }\end{array}$ & $\begin{array}{l}\text { Rel. } \\
\text { (\%) }\end{array}$ & $\begin{array}{c}\text { Abs. } \\
\text { (\$) }\end{array}$ & $\begin{array}{l}\text { Rel. } \\
\text { (\%) }\end{array}$ & $\begin{array}{c}\text { Abs. } \\
\text { (\$) }\end{array}$ & $\begin{array}{l}\text { Rel. } \\
\text { (\%) }\end{array}$ \\
\hline 2 & NIEcon.DB.SSFan.CS1.DCV0 & 2932 & 15.4 & 443 & 2.0 & 980 & 6.3 & 630 & 2.3 \\
\hline 3 & NIEcon.EH.SSFan.CS1.DCV0 & 2551 & 13.4 & 483 & 2.2 & 979 & 6.3 & 498 & 1.8 \\
\hline 4 & IEcon.DB.SSFan.CS1.DCV0 & 3061 & 16.1 & 453 & 2.1 & 1015 & 6.6 & 642 & 2.3 \\
\hline 5 & IEcon.EH.SSFan.CS1.DCV0 & 2652 & 13.9 & 492 & 2.3 & 1013 & 6.5 & 514 & 1.8 \\
\hline 6 & NoEcon.MSFan.CS1.DCV0 & 7633 & 40.1 & 3951 & 18.2 & 5223 & 33.7 & 3917 & 14.0 \\
\hline 7 & NIEcon.DB.MSFan.CS1.DCV0 & 9129 & 48.0 & 4096 & 18.9 & 5619 & 36.3 & 4151 & 14.9 \\
\hline 8 & NIEcon.EH.MSFan.CS1.DCV0 & 8861 & 46.6 & 4126 & 19.0 & 5619 & 36.3 & 4088 & 14.6 \\
\hline 9 & IEcon.DB.MSFan.CS1.DCV0 & 9296 & 48.9 & 4109 & 18.9 & 5668 & 36.6 & 4165 & 14.9 \\
\hline 10 & IEcon.EH.MSFan.CS1.DCV0 & 9007 & 47.4 & 4138 & 19.1 & 5668 & 36.6 & 4111 & 14.7 \\
\hline 11 & NoEcon.MSFan.CS2.DCV0 & 8845 & 46.5 & 5070 & 23.4 & 5587 & 36.1 & 4858 & 17.4 \\
\hline 12 & IEcon.DB.MSFan.CS2.DCV0 & 9797 & 51.5 & 5134 & 23.7 & 5851 & 37.8 & 4990 & 17.9 \\
\hline 13 & IEcon.EH.MSFan.CS2.DCV0 & 9751 & 51.3 & 5147 & 23.7 & 5858 & 37.8 & 4982 & 17.8 \\
\hline 14 & NoEcon.SSFan.CS1.DCV1 & 2901 & 15.3 & 3730 & 17.2 & 3166 & 20.5 & 6044 & 21.6 \\
\hline 15 & IEcon.DB.SSFan.CS1.DCV1 & 4140 & 21.8 & 3856 & 17.8 & 3398 & 22.0 & 6339 & 22.7 \\
\hline 16 & IEcon.EH.SSFan.CS1.DCV1 & 3848 & 20.2 & 3902 & 18.0 & 3397 & 21.9 & 6254 & 22.4 \\
\hline 17 & NoEcon.MSFan.CS1.DCV1 & 9364 & 49.2 & 8247 & 38.0 & 8425 & 54.4 & 10793 & 38.7 \\
\hline 18 & IEcon.DB.MSFan.CS1.DCV1 & 10888 & 57.2 & 8336 & 38.4 & 8827 & 57.0 & 11006 & 39.4 \\
\hline 19 & IEcon.EH.MSFan.CS1.DCV1 & 10568 & 55.6 & 8360 & 38.5 & 8826 & 57.0 & 10950 & 39.2 \\
\hline 20 & NoEcon.MSFan.CS2.DCV1 & 10705 & 56.3 & 9248 & 42.6 & 8829 & 57.0 & 11595 & 41.5 \\
\hline 21 & IEcon.DB.MSFan.CS2.DCV1 & 11372 & 59.8 & 9264 & 42.7 & 9011 & 58.2 & 11674 & 41.8 \\
\hline 22 & IEcon.EH.MSFan.CS2.DCV1 & 11296 & 59.4 & 9273 & 42.7 & 9018 & 58.3 & 11677 & 41.8 \\
\hline
\end{tabular}


Table D-11: HVAC Energy Cost Savings Compared to Case 1 for the Strip Mall Building in Climate Zones 4 and 4B, 4C and 5

\begin{tabular}{|c|c|c|c|c|c|c|c|c|c|}
\hline \multirow{2}{*}{$\begin{array}{c}\text { Case } \\
\text { No }\end{array}$} & \multirow[b]{2}{*}{ Case Name } & \multicolumn{2}{|c|}{ Albuquerque-4B } & \multicolumn{2}{|c|}{ Seattle-4C } & \multicolumn{2}{|c|}{ Chicago-5A } & \multicolumn{2}{|c|}{ Denver-5B } \\
\hline & & $\begin{array}{l}\text { Abs. } \\
\text { (\$) }\end{array}$ & $\begin{array}{l}\text { Rel. } \\
\text { (\%) }\end{array}$ & $\begin{array}{c}\text { Abs. } \\
\text { (\$) }\end{array}$ & $\begin{array}{l}\text { Rel. } \\
\text { (\%) }\end{array}$ & $\begin{array}{l}\text { Abs. } \\
\text { (\$) }\end{array}$ & $\begin{array}{l}\text { Rel. } \\
\text { (\%) }\end{array}$ & $\begin{array}{l}\text { Abs. } \\
\text { (\$) }\end{array}$ & $\begin{array}{l}\text { Rel. } \\
\text { (\%) }\end{array}$ \\
\hline 2 & NIEcon.DB.SSFan.CS1.DCV0 & 440 & 2.5 & 340 & 1.8 & 553 & 1.9 & 460 & 2.2 \\
\hline 3 & NIEcon.EH.SSFan.CS1.DCV0 & 425 & 2.4 & 327 & 1.7 & 443 & 1.5 & 452 & 2.2 \\
\hline 4 & IEcon.DB.SSFan.CS1.DCV0 & 454 & 2.6 & 355 & 1.9 & 569 & 1.9 & 469 & 2.2 \\
\hline 5 & IEcon.EH.SSFan.CS1.DCV0 & 432 & 2.5 & 340 & 1.8 & 454 & 1.6 & 456 & 2.2 \\
\hline 6 & NoEcon.MSFan.CS1.DCV0 & 3258 & 18.6 & 1426 & 7.6 & 2935 & 10.0 & 3705 & 17.6 \\
\hline 7 & NIEcon.DB.MSFan.CS1.DCV0 & 3416 & 19.5 & 1551 & 8.3 & 3122 & 10.7 & 3842 & 18.3 \\
\hline 8 & NIEcon.EH.MSFan.CS1.DCV0 & 3417 & 19.5 & 1546 & 8.3 & 3076 & 10.5 & 3845 & 18.3 \\
\hline 9 & IEcon.DB.MSFan.CS1.DCV0 & 3433 & 19.6 & 1571 & 8.4 & 3141 & 10.7 & 3854 & 18.3 \\
\hline 10 & IEcon.EH.MSFan.CS1.DCV0 & 3430 & 19.6 & 1564 & 8.4 & 3090 & 10.6 & 3852 & 18.3 \\
\hline 11 & NoEcon.MSFan.CS2.DCV0 & 4077 & 23.3 & 1624 & 8.7 & 3625 & 12.4 & 4349 & 20.7 \\
\hline 12 & IEcon.DB.MSFan.CS2.DCV0 & 4146 & 23.7 & 1702 & 9.1 & 3716 & 12.7 & 4399 & 20.9 \\
\hline 13 & IEcon.EH.MSFan.CS2.DCV0 & 4166 & 23.8 & 1707 & 9.1 & 3714 & 12.7 & 4402 & 20.9 \\
\hline 14 & NoEcon.SSFan.CS1.DCV1 & 3151 & 18.0 & 5761 & 30.8 & 6625 & 22.6 & 4027 & 19.1 \\
\hline 15 & IEcon.DB.SSFan.CS1.DCV1 & 3342 & 19.1 & 5880 & 31.4 & 6855 & 23.4 & 4202 & 20.0 \\
\hline 16 & IEcon.EH.SSFan.CS1.DCV1 & 3336 & 19.1 & 5868 & 31.4 & 6769 & 23.1 & 4203 & 20.0 \\
\hline 17 & NoEcon.MSFan.CS1.DCV1 & 6878 & 39.3 & 7880 & 42.1 & 10612 & 36.2 & 8482 & 40.3 \\
\hline 18 & IEcon.DB.MSFan.CS1.DCV1 & 7010 & 40.1 & 8009 & 42.8 & 10779 & 36.8 & 8594 & 40.8 \\
\hline 19 & IEcon.EH.MSFan.CS1.DCV1 & 7003 & 40.0 & 8000 & 42.8 & 10728 & 36.6 & 8589 & 40.8 \\
\hline 20 & NoEcon.MSFan.CS2.DCV1 & 7580 & 43.3 & 8075 & 43.2 & 11183 & 38.2 & 9087 & 43.2 \\
\hline 21 & IEcon.DB.MSFan.CS2.DCV1 & 7615 & 43.5 & 8125 & 43.4 & 11234 & 38.4 & 9107 & 43.3 \\
\hline 22 & IEcon.EH.MSFan.CS2.DCV1 & 7633 & 43.6 & 8130 & 43.5 & 11229 & 38.4 & 9095 & 43.2 \\
\hline
\end{tabular}


Table D-12: HVAC Energy Cost Savings Compared to Case 1 for the Strip Mall Building in Climate Zones 6, 7 and 8

\begin{tabular}{|c|c|c|c|c|c|c|c|c|c|}
\hline \multirow{2}{*}{$\begin{array}{c}\text { Case } \\
\text { No }\end{array}$} & \multirow[b]{2}{*}{ Case Name } & \multicolumn{2}{|c|}{ Minneapolis-6A } & \multicolumn{2}{|c|}{ Helena-6B } & \multicolumn{2}{|c|}{ Duluth-7 } & \multicolumn{2}{|c|}{ Fairbanks-8 } \\
\hline & & $\begin{array}{l}\text { Abs. } \\
\text { (\$) }\end{array}$ & $\begin{array}{l}\text { Rel. } \\
\text { (\%) }\end{array}$ & $\begin{array}{l}\text { Abs. } \\
\text { (\$) }\end{array}$ & $\begin{array}{l}\text { Rel. } \\
(\%)\end{array}$ & $\begin{array}{l}\text { Abs. } \\
\text { (\$) }\end{array}$ & $\begin{array}{l}\text { Rel. } \\
\text { (\%) }\end{array}$ & $\begin{array}{c}\text { Abs. } \\
\text { (\$) }\end{array}$ & $\begin{array}{l}\text { Rel. } \\
\text { (\%) }\end{array}$ \\
\hline 2 & NIEcon.DB.SSFan.CS1.DCV0 & 680 & 2.4 & 581 & 2.0 & 663 & 2.1 & 2899 & 4.4 \\
\hline 3 & NIEcon.EH.SSFan.CS1.DCV0 & 593 & 2.1 & 578 & 2.0 & 620 & 2.0 & 2895 & 4.4 \\
\hline 4 & IEcon.DB.SSFan.CS1.DCV0 & 692 & 2.4 & 586 & 2.0 & 667 & 2.1 & 2901 & 4.4 \\
\hline 5 & IEcon.EH.SSFan.CS1.DCV0 & 595 & 2.1 & 580 & 2.0 & 620 & 2.0 & 2892 & 4.4 \\
\hline 6 & NoEcon.MSFan.CS1.DCV0 & 3542 & 12.5 & 3337 & 11.5 & 3180 & 10.0 & 7653 & 11.7 \\
\hline 7 & NIEcon.DB.MSFan.CS1.DCV0 & 3843 & 13.5 & 3599 & 12.4 & 3571 & 11.3 & 10492 & 16.1 \\
\hline 8 & NIEcon.EH.MSFan.CS1.DCV0 & 3810 & 13.4 & 3604 & 12.4 & 3556 & 11.2 & 10495 & 16.1 \\
\hline 9 & IEcon.DB.MSFan.CS1.DCV0 & 3856 & 13.6 & 3607 & 12.4 & 3577 & 11.3 & 10497 & 16.1 \\
\hline 10 & IEcon.EH.MSFan.CS1.DCV0 & 3817 & 13.4 & 3608 & 12.4 & 3559 & 11.2 & 10500 & 16.1 \\
\hline 11 & NoEcon.MSFan.CS2.DCV0 & 4235 & 14.9 & 3898 & 13.4 & 3625 & 11.4 & 9991 & 15.3 \\
\hline 12 & IEcon.DB.MSFan.CS2.DCV0 & 4340 & 15.3 & 4020 & 13.9 & 3758 & 11.8 & 10656 & 16.3 \\
\hline 13 & IEcon.EH.MSFan.CS2.DCV0 & 4336 & 15.3 & 4019 & 13.9 & 3755 & 11.8 & 10654 & 16.3 \\
\hline 14 & NoEcon.SSFan.CS1.DCV1 & 5991 & 21.1 & 6296 & 21.7 & 7137 & 22.5 & 13533 & 20.7 \\
\hline 15 & IEcon.DB.SSFan.CS1.DCV1 & 6176 & 21.7 & 6411 & 22.1 & 7232 & 22.8 & 13579 & 20.8 \\
\hline 16 & IEcon.EH.SSFan.CS1.DCV1 & 6100 & 21.5 & 6410 & 22.1 & 7203 & 22.7 & 13583 & 20.8 \\
\hline 17 & NoEcon.MSFan.CS1.DCV1 & 10459 & 36.8 & 10757 & 37.1 & 11457 & 36.1 & 19358 & 29.7 \\
\hline 18 & IEcon.DB.MSFan.CS1.DCV1 & 10686 & 37.6 & 10929 & 37.7 & 11729 & 37.0 & 23271 & 35.7 \\
\hline 19 & IEcon.EH.MSFan.CS1.DCV1 & 10642 & 37.5 & 10931 & 37.7 & 11713 & 36.9 & 23271 & 35.7 \\
\hline 20 & NoEcon.MSFan.CS2.DCV1 & 11011 & 38.8 & 11235 & 38.8 & 11783 & 37.1 & 23142 & 35.5 \\
\hline 21 & IEcon.DB.MSFan.CS2.DCV1 & 11076 & 39.0 & 11311 & 39.0 & 11886 & 37.5 & 23420 & 35.9 \\
\hline 22 & IEcon.EH.MSFan.CS2.DCV1 & 11064 & 38.9 & 11304 & 39.0 & 11881 & 37.4 & 23414 & 35.9 \\
\hline
\end{tabular}


Table D-13: HVAC Energy Cost Savings Compared to Case 1 for the Supermarket Building in Climate Zones 1, 2 and 3A

\begin{tabular}{|c|c|c|c|c|c|c|c|c|c|}
\hline \multirow{2}{*}{$\begin{array}{c}\text { Case } \\
\text { No }\end{array}$} & \multirow[b]{2}{*}{ Case Name } & \multicolumn{2}{|c|}{ Miami-1A } & \multicolumn{2}{|c|}{ Houston-2A } & \multicolumn{2}{|c|}{ Phoenix-2B } & \multicolumn{2}{|c|}{ Atlanta-3A } \\
\hline & & $\begin{array}{l}\text { Abs. } \\
\text { (\$) }\end{array}$ & $\begin{array}{l}\text { Rel. } \\
\text { (\%) }\end{array}$ & $\begin{array}{c}\text { Abs. } \\
\text { (\$) }\end{array}$ & $\begin{array}{l}\text { Rel. } \\
(\%)\end{array}$ & $\begin{array}{l}\text { Abs. } \\
\text { (\$) }\end{array}$ & $\begin{array}{l}\text { Rel. } \\
\text { (\%) }\end{array}$ & $\begin{array}{l}\text { Abs. } \\
\text { (\$) }\end{array}$ & $\begin{array}{l}\text { Rel. } \\
\text { (\%) }\end{array}$ \\
\hline 2 & NIEcon.DB.SSFan.CS1.DCV0 & 797 & 2.3 & 908 & 2.1 & 745 & 1.6 & 1277 & 2.2 \\
\hline 3 & NIEcon.EH.SSFan.CS1.DCV0 & 415 & 1.2 & 613 & 1.4 & 744 & 1.6 & 1009 & 1.7 \\
\hline 4 & IEcon.DB.SSFan.CS1.DCV0 & 790 & 2.2 & 912 & 2.1 & 758 & 1.6 & 1287 & 2.2 \\
\hline 5 & IEcon.EH.SSFan.CS1.DCV0 & 421 & 1.2 & 615 & 1.4 & 754 & 1.6 & 1009 & 1.7 \\
\hline 6 & NoEcon.MSFan.CS1.DCV0 & 11116 & 31.6 & 12980 & 29.7 & 10661 & 23.0 & 11170 & 19.3 \\
\hline 7 & NIEcon.DB.MSFan.CS1.DCV0 & 11553 & 32.9 & 13542 & 31.0 & 11208 & 24.2 & 12066 & 20.9 \\
\hline 8 & NIEcon.EH.MSFan.CS1.DCV0 & 11341 & 32.3 & 13409 & 30.7 & 11213 & 24.2 & 11939 & 20.7 \\
\hline 9 & IEcon.DB.MSFan.CS1.DCV0 & 11539 & 32.8 & 13541 & 31.0 & 11222 & 24.2 & 12077 & 20.9 \\
\hline 10 & IEcon.EH.MSFan.CS1.DCV0 & 11351 & 32.3 & 13416 & 30.7 & 11228 & 24.2 & 11946 & 20.7 \\
\hline 11 & NoEcon.MSFan.CS2.DCV0 & 13909 & 39.6 & 15502 & 35.5 & 13205 & 28.5 & 12934 & 22.4 \\
\hline 12 & IEcon.DB.MSFan.CS2.DCV0 & 14182 & 40.3 & 15769 & 36.1 & 13428 & 29.0 & 13289 & 23.0 \\
\hline 13 & IEcon.EH.MSFan.CS2.DCV0 & 14059 & 40.0 & 15711 & 36.0 & 13433 & 29.0 & 13254 & 23.0 \\
\hline 14 & NoEcon.SSFan.CS1.DCV1 & 3959 & 11.3 & 5541 & 12.7 & 6568 & 14.2 & 8271 & 14.3 \\
\hline 15 & IEcon.DB.SSFan.CS1.DCV1 & 4756 & 13.5 & 6466 & 14.8 & 7328 & 15.8 & 9576 & 16.6 \\
\hline 16 & IEcon.EH.SSFan.CS1.DCV1 & 4379 & 12.5 & 6146 & 14.1 & 7323 & 15.8 & 9267 & 16.0 \\
\hline 17 & NoEcon.MSFan.CS1.DCV1 & 15435 & 43.9 & 19461 & 44.5 & 18043 & 39.0 & 20171 & 34.9 \\
\hline 18 & IEcon.DB.MSFan.CS1.DCV1 & 15837 & 45.0 & 20002 & 45.8 & 18581 & 40.1 & 21038 & 36.4 \\
\hline 19 & IEcon.EH.MSFan.CS1.DCV1 & 15662 & 44.6 & 19876 & 45.5 & 18585 & 40.1 & 20901 & 36.2 \\
\hline 20 & NoEcon.MSFan.CS2.DCV1 & 17748 & 50.5 & 21293 & 48.7 & 20052 & 43.3 & 21643 & 37.5 \\
\hline 21 & IEcon.DB.MSFan.CS2.DCV1 & 18005 & 51.2 & 21544 & 49.3 & 20270 & 43.8 & 21976 & 38.1 \\
\hline 22 & IEcon.EH.MSFan.CS2.DCV1 & 17897 & 50.9 & 21494 & 49.2 & 20275 & 43.8 & 21945 & 38.0 \\
\hline
\end{tabular}


Table D-14: HVAC Energy Cost Savings Compared to Case 1 for the Supermarket Building in Climate Zone 3B, 3C and 4A

\begin{tabular}{|c|c|c|c|c|c|c|c|c|c|}
\hline \multirow{2}{*}{$\begin{array}{c}\text { Case } \\
\text { No }\end{array}$} & \multirow[b]{2}{*}{ Case Name } & \multicolumn{2}{|c|}{ Los Angeles-3B } & \multicolumn{2}{|c|}{ Las Vegas-3B } & \multicolumn{2}{|c|}{ San Francisco-3C } & \multicolumn{2}{|c|}{ Baltimore-4A } \\
\hline & & $\begin{array}{l}\text { Abs. } \\
\text { (\$) }\end{array}$ & $\begin{array}{l}\text { Rel. } \\
\text { (\%) }\end{array}$ & $\begin{array}{l}\text { Abs. } \\
\text { (\$) }\end{array}$ & $\begin{array}{l}\text { Rel. } \\
\text { (\%) }\end{array}$ & $\begin{array}{c}\text { Abs. } \\
\text { (\$) }\end{array}$ & $\begin{array}{l}\text { Rel. } \\
\text { (\%) }\end{array}$ & $\begin{array}{c}\text { Abs. } \\
\text { (\$) }\end{array}$ & $\begin{array}{l}\text { Rel. } \\
\text { (\%) }\end{array}$ \\
\hline 2 & NIEcon.DB.SSFan.CS1.DCV0 & 2616 & 6.7 & 860 & 1.6 & 1312 & 2.6 & 1261 & 1.7 \\
\hline 3 & NIEcon.EH.SSFan.CS1.DCV0 & 2164 & 5.5 & 864 & 1.7 & 1296 & 2.6 & 1023 & 1.4 \\
\hline 4 & IEcon.DB.SSFan.CS1.DCV0 & 2687 & 6.8 & 874 & 1.7 & 1333 & 2.7 & 1263 & 1.7 \\
\hline 5 & IEcon.EH.SSFan.CS1.DCV0 & 2209 & 5.6 & 876 & 1.7 & 1316 & 2.6 & 1027 & 1.4 \\
\hline 6 & NoEcon.MSFan.CS1.DCV0 & 15498 & 39.5 & 12497 & 23.9 & 13240 & 26.4 & 14923 & 20.3 \\
\hline 7 & NIEcon.DB.MSFan.CS1.DCV0 & 17048 & 43.4 & 13101 & 25.0 & 14097 & 28.1 & 15926 & 21.6 \\
\hline 8 & NIEcon.EH.MSFan.CS1.DCV0 & 16835 & 42.9 & 13103 & 25.0 & 14087 & 28.1 & 15822 & 21.5 \\
\hline 9 & IEcon.DB.MSFan.CS1.DCV0 & 17132 & 43.6 & 13118 & 25.1 & 14128 & 28.2 & 15931 & 21.6 \\
\hline 10 & IEcon.EH.MSFan.CS1.DCV0 & 16896 & 43.0 & 13120 & 25.1 & 14114 & 28.2 & 15834 & 21.5 \\
\hline 11 & NoEcon.MSFan.CS2.DCV0 & 16654 & 42.4 & 14377 & 27.5 & 13789 & 27.5 & 16652 & 22.6 \\
\hline 12 & IEcon.DB.MSFan.CS2.DCV0 & 17541 & 44.7 & 14643 & 28.0 & 14287 & 28.5 & 17025 & 23.1 \\
\hline 13 & IEcon.EH.MSFan.CS2.DCV0 & 17494 & 44.6 & 14647 & 28.0 & 14287 & 28.5 & 16999 & 23.1 \\
\hline 14 & NoEcon.SSFan.CS1.DCV1 & 3181 & 8.1 & 6865 & 13.1 & 6505 & 13.0 & 10646 & 14.5 \\
\hline 15 & IEcon.DB.SSFan.CS1.DCV1 & 6017 & 15.3 & 7735 & 14.8 & 7839 & 15.6 & 11915 & 16.2 \\
\hline 16 & IEcon.EH.SSFan.CS1.DCV1 & 5357 & 13.6 & 7738 & 14.8 & 7817 & 15.6 & 11644 & 15.8 \\
\hline 17 & NoEcon.MSFan.CS1.DCV1 & 19502 & 49.7 & 20003 & 38.2 & 20787 & 41.5 & 26687 & 36.2 \\
\hline 18 & IEcon.DB.MSFan.CS1.DCV1 & 21120 & 53.8 & 20614 & 39.4 & 21645 & 43.2 & 27656 & 37.6 \\
\hline 19 & IEcon.EH.MSFan.CS1.DCV1 & 20879 & 53.2 & 20614 & 39.4 & 21629 & 43.2 & 27547 & 37.4 \\
\hline 20 & NoEcon.MSFan.CS2.DCV1 & 20666 & 52.6 & 21611 & 41.3 & 21311 & 42.5 & 28087 & 38.1 \\
\hline 21 & IEcon.DB.MSFan.CS2.DCV1 & 21523 & 54.8 & 21877 & 41.8 & 21791 & 43.5 & 28452 & 38.6 \\
\hline 22 & IEcon.EH.MSFan.CS2.DCV1 & 21498 & 54.8 & 21879 & 41.8 & 21789 & 43.5 & 28426 & 38.6 \\
\hline
\end{tabular}


Table D-15: HVAC Energy Cost Savings Compared to Case 1 for the Supermarket Building in Climate Zones 4B, 4C and 5

\begin{tabular}{|c|c|c|c|c|c|c|c|c|c|}
\hline \multirow{2}{*}{$\begin{array}{c}\text { Case } \\
\text { No }\end{array}$} & \multirow[b]{2}{*}{ Case Name } & \multicolumn{2}{|c|}{ Albuquerque-4B } & \multicolumn{2}{|c|}{ Seattle-4C } & \multicolumn{2}{|c|}{ Chicago-5A } & \multicolumn{2}{|c|}{ Denver-5B } \\
\hline & & $\begin{array}{c}\text { Abs. } \\
\text { (\$) }\end{array}$ & $\begin{array}{l}\text { Rel. } \\
\text { (\%) }\end{array}$ & $\begin{array}{c}\text { Abs. } \\
\text { (\$) }\end{array}$ & $\begin{array}{l}\text { Rel. } \\
\text { (\%) }\end{array}$ & $\begin{array}{l}\text { Abs. } \\
\text { (\$) }\end{array}$ & $\begin{array}{l}\text { Rel. } \\
\text { (\%) }\end{array}$ & $\begin{array}{c}\text { Abs. } \\
\text { (\$) }\end{array}$ & $\begin{array}{l}\text { Rel. } \\
\text { (\%) }\end{array}$ \\
\hline 2 & NIEcon.DB.SSFan.CS1.DCV0 & 966 & 1.9 & 775 & 1.3 & 1187 & 1.5 & 1076 & 1.7 \\
\hline 3 & NIEcon.EH.SSFan.CS1.DCV0 & 876 & 1.7 & 752 & 1.3 & 979 & 1.3 & 1010 & 1.6 \\
\hline 4 & IEcon.DB.SSFan.CS1.DCV0 & 982 & 1.9 & 785 & 1.4 & 1202 & 1.5 & 1087 & 1.7 \\
\hline 5 & IEcon.EH.SSFan.CS1.DCV0 & 884 & 1.7 & 759 & 1.3 & 984 & 1.3 & 1012 & 1.6 \\
\hline 6 & NoEcon.MSFan.CS1.DCV0 & 12357 & 24.2 & 3725 & 6.5 & 10448 & 13.4 & 13301 & 21.1 \\
\hline 7 & NIEcon.DB.MSFan.CS1.DCV0 & 13010 & 25.5 & 4370 & 7.6 & 11545 & 14.8 & 14064 & 22.3 \\
\hline 8 & NIEcon.EH.MSFan.CS1.DCV0 & 12965 & 25.4 & 4355 & 7.6 & 11458 & 14.7 & 14031 & 22.2 \\
\hline 9 & IEcon.DB.MSFan.CS1.DCV0 & 13032 & 25.5 & 4384 & 7.6 & 11562 & 14.8 & 14082 & 22.3 \\
\hline 10 & IEcon.EH.MSFan.CS1.DCV0 & 12977 & 25.4 & 4365 & 7.6 & 11463 & 14.7 & 14041 & 22.3 \\
\hline 11 & NoEcon.MSFan.CS2.DCV0 & 13729 & 26.9 & 4226 & 7.4 & 11898 & 15.3 & 14305 & 22.7 \\
\hline 12 & IEcon.DB.MSFan.CS2.DCV0 & 14013 & 27.4 & 4495 & 7.8 & 12206 & 15.7 & 14645 & 23.2 \\
\hline 13 & IEcon.EH.MSFan.CS2.DCV0 & 14005 & 27.4 & 4491 & 7.8 & 12179 & 15.6 & 14642 & 23.2 \\
\hline 14 & NoEcon.SSFan.CS1.DCV1 & 6116 & 12.0 & 11164 & 19.4 & 11842 & 15.2 & 7702 & 12.2 \\
\hline 15 & IEcon.DB.SSFan.CS1.DCV1 & 7101 & 13.9 & 11942 & 20.8 & 13433 & 17.2 & 8912 & 14.1 \\
\hline 16 & IEcon.EH.SSFan.CS1.DCV1 & 6983 & 13.7 & 11910 & 20.7 & 13126 & 16.9 & 8807 & 14.0 \\
\hline 17 & NoEcon.MSFan.CS1.DCV1 & 18985 & 37.2 & 15371 & 26.8 & 22995 & 29.5 & 21425 & 34.0 \\
\hline 18 & IEcon.DB.MSFan.CS1.DCV1 & 19619 & 38.4 & 15993 & 27.8 & 24635 & 31.6 & 22342 & 35.4 \\
\hline 19 & IEcon.EH.MSFan.CS1.DCV1 & 19560 & 38.3 & 15969 & 27.8 & 24384 & 31.3 & 22282 & 35.3 \\
\hline 20 & NoEcon.MSFan.CS2.DCV1 & 20106 & 39.4 & 15833 & 27.6 & 24638 & 31.6 & 22446 & 35.6 \\
\hline 21 & IEcon.DB.MSFan.CS2.DCV1 & 20374 & 39.9 & 16093 & 28.0 & 25180 & 32.3 & 22853 & 36.2 \\
\hline 22 & IEcon.EH.MSFan.CS2.DCV1 & 20366 & 39.9 & 16087 & 28.0 & 25120 & 32.2 & 22846 & 36.2 \\
\hline
\end{tabular}


Table D-16: HVAC Energy Cost Savings Compared to Case 1 for the Supermarket Building in Climate Zones 6, 7 and 8

\begin{tabular}{|c|c|c|c|c|c|c|c|c|c|}
\hline \multirow{2}{*}{$\begin{array}{c}\text { Case } \\
\text { No }\end{array}$} & \multirow[b]{2}{*}{ Case Name } & \multicolumn{2}{|c|}{ Minneapolis-6A } & \multicolumn{2}{|c|}{ Helena-6B } & \multicolumn{2}{|c|}{ Duluth-7 } & \multicolumn{2}{|c|}{ Fairbanks-8 } \\
\hline & & $\begin{array}{l}\text { Abs. } \\
\text { (\$) }\end{array}$ & $\begin{array}{l}\text { Rel. } \\
\text { (\%) }\end{array}$ & $\begin{array}{l}\text { Abs. } \\
\text { (\$) }\end{array}$ & $\begin{array}{l}\text { Rel. } \\
(\%)\end{array}$ & $\begin{array}{l}\text { Abs. } \\
\text { (\$) }\end{array}$ & $\begin{array}{l}\text { Rel. } \\
\text { (\%) }\end{array}$ & $\begin{array}{c}\text { Abs. } \\
\text { (\$) }\end{array}$ & $\begin{array}{l}\text { Rel. } \\
\text { (\%) }\end{array}$ \\
\hline 2 & NIEcon.DB.SSFan.CS1.DCV0 & 1565 & 2.1 & 1664 & 2.0 & 1758 & 2.1 & 5459 & 3.4 \\
\hline 3 & NIEcon.EH.SSFan.CS1.DCV0 & 1415 & 1.9 & 1626 & 2.0 & 1681 & 2.0 & 5426 & 3.3 \\
\hline 4 & IEcon.DB.SSFan.CS1.DCV0 & 1577 & 2.1 & 1666 & 2.0 & 1766 & 2.1 & 5459 & 3.4 \\
\hline 5 & IEcon.EH.SSFan.CS1.DCV0 & 1416 & 1.9 & 1627 & 2.0 & 1682 & 2.0 & 5417 & 3.3 \\
\hline 6 & NoEcon.MSFan.CS1.DCV0 & 11485 & 15.5 & 9931 & 12.2 & 9495 & 11.3 & 23186 & 14.2 \\
\hline 7 & NIEcon.DB.MSFan.CS1.DCV0 & 13295 & 18.0 & 11840 & 14.6 & 11522 & 13.7 & 30008 & 18.4 \\
\hline 8 & NIEcon.EH.MSFan.CS1.DCV0 & 13186 & 17.8 & 11751 & 14.4 & 11399 & 13.5 & 29915 & 18.4 \\
\hline 9 & IEcon.DB.MSFan.CS1.DCV0 & 13308 & 18.0 & 11846 & 14.6 & 11532 & 13.7 & 30013 & 18.4 \\
\hline 10 & IEcon.EH.MSFan.CS1.DCV0 & 13191 & 17.8 & 11753 & 14.4 & 11403 & 13.6 & 29917 & 18.4 \\
\hline 11 & NoEcon.MSFan.CS2.DCV0 & 13247 & 17.9 & 11330 & 13.9 & 10851 & 12.9 & 28181 & 17.3 \\
\hline 12 & IEcon.DB.MSFan.CS2.DCV0 & 13806 & 18.7 & 12195 & 15.0 & 11664 & 13.9 & 30175 & 18.5 \\
\hline 13 & IEcon.EH.MSFan.CS2.DCV0 & 13789 & 18.7 & 12184 & 15.0 & 11639 & 13.8 & 30147 & 18.5 \\
\hline 14 & NoEcon.SSFan.CS1.DCV1 & 9792 & 13.2 & 10599 & 13.0 & 11470 & 13.6 & 17581 & 10.8 \\
\hline 15 & IEcon.DB.SSFan.CS1.DCV1 & 12064 & 16.3 & 12678 & 15.6 & 13919 & 16.5 & 24297 & 14.9 \\
\hline 16 & IEcon.EH.SSFan.CS1.DCV1 & 11846 & 16.0 & 12622 & 15.5 & 13796 & 16.4 & 24245 & 14.9 \\
\hline 17 & NoEcon.MSFan.CS1.DCV1 & 22137 & 30.0 & 20898 & 25.7 & 22166 & 26.3 & 42812 & 26.3 \\
\hline 18 & IEcon.DB.MSFan.CS1.DCV1 & 24974 & 33.8 & 24244 & 29.8 & 25420 & 30.2 & 52063 & 32.0 \\
\hline 19 & IEcon.EH.MSFan.CS1.DCV1 & 24604 & 33.3 & 23945 & 29.4 & 25034 & 29.8 & 51709 & 31.8 \\
\hline 20 & NoEcon.MSFan.CS2.DCV1 & 24420 & 33.0 & 23111 & 28.4 & 24226 & 28.8 & 50538 & 31.0 \\
\hline 21 & IEcon.DB.MSFan.CS2.DCV1 & 25399 & 34.4 & 24667 & 30.3 & 25560 & 30.4 & 52277 & 32.1 \\
\hline 22 & IEcon.EH.MSFan.CS2.DCV1 & 25299 & 34.2 & 24616 & 30.3 & 25465 & 30.3 & 52217 & 32.1 \\
\hline
\end{tabular}


Table D-17: Electricity Cost Savings Compared to Case 1 for the Small Office Building in Climate Zones 1, 2 and 3A

\begin{tabular}{|c|c|c|c|c|c|c|c|c|c|}
\hline \multirow[b]{2}{*}{$\begin{array}{c}\text { Case } \\
\text { No }\end{array}$} & \multirow[b]{2}{*}{ Case Name } & \multicolumn{2}{|c|}{ Miami-1A } & \multicolumn{2}{|c|}{ Houston-2A } & \multicolumn{2}{|c|}{ Phoenix-2B } & \multicolumn{2}{|c|}{ Atlanta-3A } \\
\hline & & $\begin{array}{c}\text { Abs. } \\
\text { (\$) }\end{array}$ & $\begin{array}{l}\text { Rel. } \\
\text { (\%) }\end{array}$ & $\begin{array}{c}\text { Abs. } \\
\text { (\$) }\end{array}$ & $\begin{array}{l}\text { Rel. } \\
\text { (\%) }\end{array}$ & $\begin{array}{c}\text { Abs. } \\
\text { (\$) }\end{array}$ & $\begin{array}{l}\text { Rel. } \\
\text { (\%) }\end{array}$ & $\begin{array}{c}\text { Abs. } \\
\text { (\$) }\end{array}$ & $\begin{array}{l}\text { Rel. } \\
\text { (\%) }\end{array}$ \\
\hline 2 & NIEcon.DB.SSFan.CS1.DCV0 & 138 & 3.0 & 158 & 4.7 & 147 & 3.7 & 218 & 9.0 \\
\hline 3 & NIEcon.EH.SSFan.CS1.DCV0 & 121 & 2.6 & 133 & 4.0 & 155 & 3.9 & 181 & 7.5 \\
\hline 4 & IEcon.DB.SSFan.CS1.DCV0 & 137 & 3.0 & 156 & 4.6 & 151 & 3.8 & 220 & 9.0 \\
\hline 5 & IEcon.EH.SSFan.CS1.DCV0 & 124 & 2.7 & 136 & 4.0 & 159 & 4.0 & 182 & 7.5 \\
\hline 6 & NoEcon.MSFan.CS1.DCV0 & 871 & 18.8 & 896 & 26.7 & 937 & 23.7 & 946 & 39.0 \\
\hline 7 & NIEcon.DB.MSFan.CS1.DCV0 & 942 & 20.3 & 966 & 28.8 & 1011 & 25.6 & 1047 & 43.1 \\
\hline 8 & NIEcon.EH.MSFan.CS1.DCV0 & 931 & 20.1 & 958 & 28.5 & 1012 & 25.6 & 1032 & 42.5 \\
\hline 9 & IEcon.DB.MSFan.CS1.DCV0 & 934 & 20.2 & 960 & 28.6 & 1017 & 25.7 & 1047 & 43.1 \\
\hline 10 & IEcon.EH.MSFan.CS1.DCV0 & 936 & 20.2 & 961 & 28.6 & 1018 & 25.8 & 1035 & 42.6 \\
\hline 11 & NoEcon.MSFan.CS2.DCV0 & 1359 & 29.3 & 1200 & 35.8 & 1355 & 34.3 & 1151 & 47.4 \\
\hline 12 & IEcon.DB.MSFan.CS2.DCV0 & 1362 & 29.4 & 1214 & 36.2 & 1402 & 35.5 & 1190 & 49.0 \\
\hline 13 & IEcon.EH.MSFan.CS2.DCV0 & 1406 & 30.3 & 1246 & 37.1 & 1403 & 35.5 & 1209 & 49.8 \\
\hline 14 & NoEcon.SSFan.CS1.DCV1 & 364 & 7.8 & 229 & 6.8 & 170 & 4.3 & 70 & 2.9 \\
\hline 15 & IEcon.DB.SSFan.CS1.DCV1 & 477 & 10.3 & 392 & 11.7 & 354 & 8.9 & 311 & 12.8 \\
\hline 16 & IEcon.EH.SSFan.CS1.DCV1 & 495 & 10.7 & 382 & 11.4 & 363 & 9.2 & 285 & 11.7 \\
\hline 17 & NoEcon.MSFan.CS1.DCV1 & 1289 & 27.8 & 1169 & 34.8 & 1150 & 29.1 & 1048 & 43.1 \\
\hline 18 & IEcon.DB.MSFan.CS1.DCV1 & 1331 & 28.7 & 1237 & 36.9 & 1253 & 31.7 & 1164 & 47.9 \\
\hline 19 & IEcon.EH.MSFan.CS1.DCV1 & 1363 & 29.4 & 1251 & 37.3 & 1257 & 31.8 & 1165 & 48.0 \\
\hline 20 & NoEcon.MSFan.CS2.DCV1 & 1717 & 37.0 & 1436 & 42.8 & 1538 & 38.9 & 1236 & 50.9 \\
\hline 21 & IEcon.DB.MSFan.CS2.DCV1 & 1704 & 36.8 & 1451 & 43.2 & 1605 & 40.6 & 1289 & 53.0 \\
\hline 22 & IEcon.EH.MSFan.CS2.DCV1 & 1774 & 38.3 & 1498 & 44.6 & 1605 & 40.6 & 1319 & 54.3 \\
\hline
\end{tabular}


Table D-18: Electricity Cost Savings Compared to Case 1 for the Small Office Building in Climate Zones 3B, 3C and 4A

\begin{tabular}{|c|c|c|c|c|c|c|c|c|c|}
\hline \multirow[b]{2}{*}{$\begin{array}{c}\text { Case } \\
\text { No }\end{array}$} & \multirow[b]{2}{*}{ Case Name } & \multicolumn{2}{|c|}{ Los Angeles-3B } & \multicolumn{2}{|c|}{ Las Vegas-3B } & \multicolumn{2}{|c|}{ San Francisco-3C } & \multicolumn{2}{|c|}{ Baltimore-4A } \\
\hline & & $\begin{array}{c}\text { Abs. } \\
\text { (\$) }\end{array}$ & $\begin{array}{l}\text { Rel. } \\
\text { (\%) }\end{array}$ & $\begin{array}{c}\text { Abs. } \\
\text { (\$) }\end{array}$ & $\begin{array}{l}\text { Rel. } \\
\text { (\%) }\end{array}$ & $\begin{array}{c}\text { Abs. } \\
\text { (\$) }\end{array}$ & $\begin{array}{l}\text { Rel. } \\
\text { (\%) }\end{array}$ & $\begin{array}{c}\text { Abs. } \\
\text { (\$) }\end{array}$ & $\begin{array}{l}\text { Rel. } \\
\text { (\%) }\end{array}$ \\
\hline 2 & NIEcon.DB.SSFan.CS1.DCV0 & 813 & 24.4 & 151 & 4.7 & 360 & 17.9 & 205 & 8.1 \\
\hline 3 & NIEcon.EH.SSFan.CS1.DCV0 & 654 & 19.7 & 154 & 4.8 & 353 & 17.5 & 166 & 6.5 \\
\hline 4 & IEcon.DB.SSFan.CS1.DCV0 & 841 & 25.3 & 156 & 4.9 & 367 & 18.2 & 202 & 8.0 \\
\hline 5 & IEcon.EH.SSFan.CS1.DCV0 & 665 & 20.0 & 159 & 5.0 & 359 & 17.8 & 171 & 6.7 \\
\hline 6 & NoEcon.MSFan.CS1.DCV0 & 1634 & 49.1 & 976 & 30.6 & 1320 & 65.4 & 1106 & 43.6 \\
\hline 7 & NIEcon.DB.MSFan.CS1.DCV0 & 2114 & 63.6 & 1038 & 32.6 & 1516 & 75.2 & 1191 & 46.9 \\
\hline 8 & NIEcon.EH.MSFan.CS1.DCV0 & 2008 & 60.4 & 1038 & 32.6 & 1512 & 74.9 & 1182 & 46.6 \\
\hline 9 & IEcon.DB.MSFan.CS1.DCV0 & 2146 & 64.5 & 1043 & 32.7 & 1526 & 75.7 & 1186 & 46.7 \\
\hline 10 & IEcon.EH.MSFan.CS1.DCV0 & 2028 & 61.0 & 1044 & 32.7 & 1521 & 75.4 & 1187 & 46.8 \\
\hline 11 & NoEcon.MSFan.CS2.DCV0 & 1930 & 58.1 & 1243 & 39.0 & 1432 & 71.0 & 1276 & 50.3 \\
\hline 12 & IEcon.DB.MSFan.CS2.DCV0 & 2230 & 67.1 & 1281 & 40.2 & 1563 & 77.5 & 1312 & 51.7 \\
\hline 13 & IEcon.EH.MSFan.CS2.DCV0 & 2221 & 66.8 & 1280 & 40.2 & 1564 & 77.5 & 1328 & 52.3 \\
\hline 14 & NoEcon.SSFan.CS1.DCV1 & -73 & -2.2 & 94 & 3.0 & -118 & -5.8 & 66 & 2.6 \\
\hline 15 & IEcon.DB.SSFan.CS1.DCV1 & 848 & 25.5 & 289 & 9.1 & 369 & 18.3 & 303 & 11.9 \\
\hline 16 & IEcon.EH.SSFan.CS1.DCV1 & 671 & 20.2 & 291 & 9.1 & 358 & 17.7 & 279 & 11.0 \\
\hline 17 & NoEcon.MSFan.CS1.DCV1 & 1550 & 46.6 & 1106 & 34.7 & 1223 & 60.6 & 1224 & 48.2 \\
\hline 18 & IEcon.DB.MSFan.CS1.DCV1 & 2138 & 64.3 & 1204 & 37.8 & 1530 & 75.9 & 1329 & 52.4 \\
\hline 19 & IEcon.EH.MSFan.CS1.DCV1 & 2017 & 60.6 & 1204 & 37.8 & 1523 & 75.5 & 1338 & 52.7 \\
\hline 20 & NoEcon.MSFan.CS2.DCV1 & 1845 & 55.5 & 1370 & 43.0 & 1352 & 67.0 & 1377 & 54.3 \\
\hline 21 & IEcon.DB.MSFan.CS2.DCV1 & 2224 & 66.9 & 1431 & 44.9 & 1566 & 77.6 & 1432 & 56.4 \\
\hline 22 & IEcon.EH.MSFan.CS2.DCV1 & 2216 & 66.7 & 1429 & 44.8 & 1567 & 77.7 & 1459 & 57.5 \\
\hline
\end{tabular}


Table D-19: Electricity Cost Savings Compared to Case 1 for the Small Office Building in Climate Zones 4B, 4C, and 5

\begin{tabular}{|c|c|c|c|c|c|c|c|c|c|}
\hline \multirow{2}{*}{$\begin{array}{c}\text { Case } \\
\text { No }\end{array}$} & \multirow[b]{2}{*}{ Case Name } & \multicolumn{2}{|c|}{ Albuquerque-4B } & \multicolumn{2}{|c|}{ Seattle-4C } & \multicolumn{2}{|c|}{ Chicago-5A } & \multicolumn{2}{|c|}{ Denver-5B } \\
\hline & & $\begin{array}{c}\text { Abs. } \\
\text { (\$) }\end{array}$ & $\begin{array}{l}\text { Rel. } \\
\text { (\%) }\end{array}$ & $\begin{array}{c}\text { Abs. } \\
\text { (\$) }\end{array}$ & $\begin{array}{l}\text { Rel. } \\
\text { (\%) }\end{array}$ & $\begin{array}{c}\text { Abs. } \\
\text { (\$) }\end{array}$ & $\begin{array}{l}\text { Rel. } \\
\text { (\%) }\end{array}$ & $\begin{array}{c}\text { Abs. } \\
\text { (\$) }\end{array}$ & $\begin{array}{l}\text { Rel. } \\
\text { (\%) }\end{array}$ \\
\hline 2 & NIEcon.DB.SSFan.CS1.DCV0 & 172 & 8.7 & 143 & 13.1 & 156 & 8.6 & 162 & 8.9 \\
\hline 3 & NIEcon.EH.SSFan.CS1.DCV0 & 153 & 7.7 & 135 & 12.4 & 115 & 6.3 & 142 & 7.8 \\
\hline 4 & IEcon.DB.SSFan.CS1.DCV0 & 177 & 9.0 & 146 & 13.4 & 160 & 8.7 & 166 & 9.1 \\
\hline 5 & IEcon.EH.SSFan.CS1.DCV0 & 155 & 7.9 & 137 & 12.5 & 115 & 6.3 & 142 & 7.8 \\
\hline 6 & NoEcon.MSFan.CS1.DCV0 & 885 & 44.9 & 716 & 65.5 & 905 & 49.5 & 1017 & 55.7 \\
\hline 7 & NIEcon.DB.MSFan.CS1.DCV0 & 963 & 48.8 & 786 & 71.9 & 968 & 53.0 & 1079 & 59.1 \\
\hline 8 & NIEcon.EH.MSFan.CS1.DCV0 & 954 & 48.4 & 782 & 71.5 & 953 & 52.1 & 1071 & 58.7 \\
\hline 9 & IEcon.DB.MSFan.CS1.DCV0 & 970 & 49.2 & 790 & 72.2 & 971 & 53.2 & 1082 & 59.3 \\
\hline 10 & IEcon.EH.MSFan.CS1.DCV0 & 958 & 48.6 & 785 & 71.8 & 954 & 52.2 & 1074 & 58.9 \\
\hline 11 & NoEcon.MSFan.CS2.DCV0 & 1059 & 53.7 & 768 & 70.2 & 1024 & 56.0 & 1146 & 62.8 \\
\hline 12 & IEcon.DB.MSFan.CS2.DCV0 & 1106 & 56.1 & 814 & 74.4 & 1056 & 57.8 & 1182 & 64.8 \\
\hline 13 & IEcon.EH.MSFan.CS2.DCV0 & 1105 & 56.1 & 814 & 74.4 & 1059 & 58.0 & 1180 & 64.7 \\
\hline 14 & NoEcon.SSFan.CS1.DCV1 & 5 & 0.3 & -46 & -4.2 & 18 & 1.0 & -20 & -1.1 \\
\hline 15 & IEcon.DB.SSFan.CS1.DCV1 & 217 & 11.0 & 149 & 13.6 & 204 & 11.2 & 188 & 10.3 \\
\hline 16 & IEcon.EH.SSFan.CS1.DCV1 & 195 & 9.9 & 137 & 12.5 & 161 & 8.8 & 159 & 8.7 \\
\hline 17 & NoEcon.MSFan.CS1.DCV1 & 920 & 46.7 & 694 & 63.5 & 966 & 52.9 & 1035 & 56.7 \\
\hline 18 & IEcon.DB.MSFan.CS1.DCV1 & 1030 & 52.3 & 807 & 73.8 & 1052 & 57.6 & 1133 & 62.1 \\
\hline 19 & IEcon.EH.MSFan.CS1.DCV1 & 1019 & 51.7 & 801 & 73.3 & 1038 & 56.8 & 1121 & 61.4 \\
\hline 20 & NoEcon.MSFan.CS2.DCV1 & 1082 & 54.9 & 751 & 68.7 & 1078 & 59.0 & 1163 & 63.7 \\
\hline 21 & IEcon.DB.MSFan.CS2.DCV1 & 1151 & 58.4 & 830 & 75.9 & 1126 & 61.6 & 1222 & 67.0 \\
\hline 22 & IEcon.EH.MSFan.CS2.DCV1 & 1151 & 58.4 & 830 & 75.9 & 1133 & 62.0 & 1219 & 66.8 \\
\hline
\end{tabular}


Table D-20: Electricity Cost Savings Compared to Case 1 for the Small Office Building in Climate Zones 6, 7 and 8

\begin{tabular}{|c|c|c|c|c|c|c|c|c|c|}
\hline \multirow[b]{2}{*}{$\begin{array}{c}\text { Case } \\
\text { No }\end{array}$} & \multirow[b]{2}{*}{ Case Name } & \multicolumn{2}{|c|}{ Minneapolis-6A } & \multicolumn{2}{|c|}{ Helena-6B } & \multicolumn{2}{|c|}{ Duluth-7 } & \multicolumn{2}{|c|}{ Fairbanks-8 } \\
\hline & & $\begin{array}{c}\text { Abs. } \\
\text { (\$) }\end{array}$ & $\begin{array}{l}\text { Rel. } \\
\text { (\%) }\end{array}$ & $\begin{array}{c}\text { Abs. } \\
\text { (\$) }\end{array}$ & $\begin{array}{l}\text { Rel. } \\
\text { (\%) }\end{array}$ & $\begin{array}{c}\text { Abs. } \\
\text { (\$) }\end{array}$ & $\begin{array}{l}\text { Rel. } \\
\text { (\%) }\end{array}$ & $\begin{array}{c}\text { Abs. } \\
\text { (\$) }\end{array}$ & $\begin{array}{l}\text { Rel. } \\
\text { (\%) }\end{array}$ \\
\hline 2 & NIEcon.DB.SSFan.CS1.DCV0 & 162 & 9.6 & 146 & 9.1 & 135 & 9.3 & 254 & 9.2 \\
\hline 3 & NIEcon.EH.SSFan.CS1.DCV0 & 136 & 8.0 & 136 & 8.5 & 117 & 8.1 & 247 & 8.9 \\
\hline 4 & IEcon.DB.SSFan.CS1.DCV0 & 165 & 9.7 & 148 & 9.2 & 137 & 9.4 & 257 & 9.3 \\
\hline 5 & IEcon.EH.SSFan.CS1.DCV0 & 136 & 8.0 & 136 & 8.5 & 118 & 8.1 & 247 & 9.0 \\
\hline 6 & NoEcon.MSFan.CS1.DCV0 & 880 & 51.9 & 980 & 61.1 & 898 & 61.9 & 1707 & 61.9 \\
\hline 7 & NIEcon.DB.MSFan.CS1.DCV0 & 952 & 56.2 & 1038 & 64.8 & 964 & 66.4 & 1832 & 66.4 \\
\hline 8 & NIEcon.EH.MSFan.CS1.DCV0 & 943 & 55.6 & 1035 & 64.6 & 956 & 65.9 & 1828 & 66.3 \\
\hline 9 & IEcon.DB.MSFan.CS1.DCV0 & 955 & 56.4 & 1042 & 65.0 & 966 & 66.6 & 1836 & 66.5 \\
\hline 10 & IEcon.EH.MSFan.CS1.DCV0 & 945 & 55.8 & 1038 & 64.7 & 957 & 66.0 & 1832 & 66.4 \\
\hline 11 & NoEcon.MSFan.CS2.DCV0 & 982 & 58.0 & 1068 & 66.7 & 955 & 65.8 & 1787 & 64.8 \\
\hline 12 & IEcon.DB.MSFan.CS2.DCV0 & 1019 & 60.1 & 1103 & 68.9 & 993 & 68.5 & 1868 & 67.7 \\
\hline 13 & IEcon.EH.MSFan.CS2.DCV0 & 1025 & 60.5 & 1103 & 68.8 & 993 & 68.5 & 1868 & 67.7 \\
\hline 14 & NoEcon.SSFan.CS1.DCV1 & 3 & 0.2 & -33 & -2.0 & -38 & -2.6 & -73 & -2.6 \\
\hline 15 & IEcon.DB.SSFan.CS1.DCV1 & 197 & 11.7 & 160 & 10.0 & 145 & 10.0 & 259 & 9.4 \\
\hline 16 & IEcon.EH.SSFan.CS1.DCV1 & 172 & 10.2 & 146 & 9.1 & 125 & 8.6 & 247 & 9.0 \\
\hline 17 & NoEcon.MSFan.CS1.DCV1 & 928 & 54.8 & 994 & 62.0 & 917 & 63.2 & 1737 & 63.0 \\
\hline 18 & IEcon.DB.MSFan.CS1.DCV1 & 1028 & 60.7 & 1088 & 67.9 & 1016 & 70.1 & 1933 & 70.1 \\
\hline 19 & IEcon.EH.MSFan.CS1.DCV1 & 1020 & 60.2 & 1083 & 67.6 & 1008 & 69.5 & 1928 & 69.9 \\
\hline 20 & NoEcon.MSFan.CS2.DCV1 & 1029 & 60.7 & 1083 & 67.6 & 978 & 67.4 & 1830 & 66.3 \\
\hline 21 & IEcon.DB.MSFan.CS2.DCV1 & 1085 & 64.1 & 1144 & 71.4 & 1041 & 71.8 & 1964 & 71.2 \\
\hline 22 & IEcon.EH.MSFan.CS2.DCV1 & 1095 & 64.6 & 1143 & 71.3 & 1042 & 71.8 & 1964 & 71.2 \\
\hline
\end{tabular}


Table D-21: Electricity Cost Savings Compared to Case 1 for the Stand-alone Retail Building in Climate Zones 1, 2 and 3A

\begin{tabular}{|c|c|c|c|c|c|c|c|c|c|}
\hline \multirow{2}{*}{$\begin{array}{c}\text { Case } \\
\text { No }\end{array}$} & \multirow[b]{2}{*}{ Case Name } & \multicolumn{2}{|c|}{ Miami-1A } & \multicolumn{2}{|c|}{ Houston-2A } & \multicolumn{2}{|c|}{ Phoenix-2B } & \multicolumn{2}{|c|}{ Atlanta-3A } \\
\hline & & $\begin{array}{c}\text { Abs. } \\
(\$)\end{array}$ & $\begin{array}{l}\text { Rel. } \\
\text { (\%) }\end{array}$ & $\begin{array}{c}\text { Abs. } \\
\text { (\$) }\end{array}$ & $\begin{array}{l}\text { Rel. } \\
(\%)\end{array}$ & $\begin{array}{c}\text { Abs. } \\
(\$)\end{array}$ & $\begin{array}{l}\text { Rel. } \\
\text { (\%) }\end{array}$ & $\begin{array}{c}\text { Abs. } \\
\text { (\$) }\end{array}$ & $\begin{array}{l}\text { Rel. } \\
\text { (\%) }\end{array}$ \\
\hline 2 & NIEcon.DB.SSFan.CS1.DCV0 & 777 & 2.9 & 588 & 3.0 & 369 & 1.8 & 611 & 4.5 \\
\hline 3 & NIEcon.EH.SSFan.CS1.DCV0 & 460 & 1.7 & 390 & 2.0 & 409 & 2.0 & 473 & 3.5 \\
\hline 4 & IEcon.DB.SSFan.CS1.DCV0 & 770 & 2.9 & 590 & 3.1 & 378 & 1.9 & 619 & 4.6 \\
\hline 5 & IEcon.EH.SSFan.CS1.DCV0 & 480 & 1.8 & 405 & 2.1 & 417 & 2.1 & 485 & 3.6 \\
\hline 6 & NoEcon.MSFan.CS1.DCV0 & 4408 & 16.6 & 4357 & 22.6 & 4627 & 22.8 & 4928 & 36.4 \\
\hline 7 & NIEcon.DB.MSFan.CS1.DCV0 & 4708 & 17.7 & 4546 & 23.5 & 4734 & 23.3 & 5108 & 37.7 \\
\hline 8 & NIEcon.EH.MSFan.CS1.DCV0 & 4556 & 17.2 & 4463 & 23.1 & 4759 & 23.4 & 5051 & 37.3 \\
\hline 9 & IEcon.DB.MSFan.CS1.DCV0 & 4702 & 17.7 & 4547 & 23.5 & 4749 & 23.4 & 5119 & 37.8 \\
\hline 10 & IEcon.EH.MSFan.CS1.DCV0 & 4585 & 17.3 & 4480 & 23.2 & 4771 & 23.5 & 5072 & 37.4 \\
\hline 11 & NoEcon.MSFan.CS2.DCV0 & 6784 & 25.6 & 5783 & 29.9 & 6307 & 31.1 & 5972 & 44.1 \\
\hline 12 & IEcon.DB.MSFan.CS2.DCV0 & 7004 & 26.4 & 5900 & 30.6 & 6353 & 31.3 & 6081 & 44.9 \\
\hline 13 & IEcon.EH.MSFan.CS2.DCV0 & 6938 & 26.1 & 5878 & 30.4 & 6365 & 31.3 & 6070 & 44.8 \\
\hline 14 & NoEcon.SSFan.CS1.DCV1 & 3448 & 13.0 & 2466 & 12.8 & 2446 & 12.0 & 1108 & 8.2 \\
\hline 15 & IEcon.DB.SSFan.CS1.DCV1 & 3982 & 15.0 & 2902 & 15.0 & 2754 & 13.6 & 1532 & 11.3 \\
\hline 16 & IEcon.EH.SSFan.CS1.DCV1 & 3747 & 14.1 & 2763 & 14.3 & 2797 & 13.8 & 1435 & 10.6 \\
\hline 17 & NoEcon.MSFan.CS1.DCV1 & 8157 & 30.7 & 7082 & 36.7 & 7450 & 36.7 & 6144 & 45.3 \\
\hline 18 & IEcon.DB.MSFan.CS1.DCV1 & 8430 & 31.8 & 7301 & 37.8 & 7607 & 37.5 & 6367 & 47.0 \\
\hline 19 & IEcon.EH.MSFan.CS1.DCV1 & 8334 & 31.4 & 7248 & 37.5 & 7616 & 37.5 & 6322 & 46.7 \\
\hline 20 & NoEcon.MSFan.CS2.DCV1 & 10225 & 38.5 & 8399 & 43.5 & 9069 & 44.7 & 7016 & 51.8 \\
\hline 21 & IEcon.DB.MSFan.CS2.DCV1 & 10390 & 39.1 & 8524 & 44.1 & 9143 & 45.0 & 7139 & 52.7 \\
\hline 22 & IEcon.EH.MSFan.CS2.DCV1 & 10367 & 39.1 & 8517 & 44.1 & 9137 & 45.0 & 7137 & 52.7 \\
\hline
\end{tabular}


Table D-22: Electricity Cost Savings Compared to Case 1 for the Stand-alone Retail Building in Climate Zones 3B, 3C and 4A

\begin{tabular}{|c|c|c|c|c|c|c|c|c|c|}
\hline \multirow{2}{*}{$\begin{array}{c}\text { Case } \\
\text { No }\end{array}$} & \multirow[b]{2}{*}{ Case Name } & \multicolumn{2}{|c|}{ Los Angeles-3B } & \multicolumn{2}{|c|}{ Las Vegas-3B } & \multicolumn{2}{|c|}{ San Francisco-3C } & \multicolumn{2}{|c|}{ Baltimore-4A } \\
\hline & & $\begin{array}{c}\text { Abs. } \\
(\$)\end{array}$ & $\begin{array}{l}\text { Rel. } \\
(\%)\end{array}$ & $\begin{array}{c}\text { Abs. } \\
\text { (\$) }\end{array}$ & $\begin{array}{l}\text { Rel. } \\
\text { (\%) }\end{array}$ & $\begin{array}{c}\text { Abs. } \\
\text { (\$) }\end{array}$ & $\begin{array}{l}\text { Rel. } \\
(\%)\end{array}$ & $\begin{array}{c}\text { Abs. } \\
\text { (\$) }\end{array}$ & $\begin{array}{l}\text { Rel. } \\
(\%)\end{array}$ \\
\hline 2 & NIEcon.DB.SSFan.CS1.DCV0 & 2208 & 15.3 & 298 & 1.8 & 632 & 7.1 & 513 & 3.6 \\
\hline 3 & NIEcon.EH.SSFan.CS1.DCV0 & 1887 & 13.1 & 318 & 2.0 & 632 & 7.1 & 399 & 2.8 \\
\hline 4 & IEcon.DB.SSFan.CS1.DCV0 & 2306 & 16.0 & 306 & 1.9 & 658 & 7.4 & 522 & 3.7 \\
\hline 5 & IEcon.EH.SSFan.CS1.DCV0 & 1968 & 13.7 & 325 & 2.0 & 659 & 7.4 & 414 & 2.9 \\
\hline 6 & NoEcon.MSFan.CS1.DCV0 & 7730 & 53.7 & 4600 & 28.5 & 5958 & 66.8 & 5674 & 39.7 \\
\hline 7 & NIEcon.DB.MSFan.CS1.DCV0 & 8750 & 60.8 & 4688 & 29.1 & 6196 & 69.5 & 5820 & 40.7 \\
\hline 8 & NIEcon.EH.MSFan.CS1.DCV0 & 8523 & 59.2 & 4694 & 29.1 & 6196 & 69.5 & 5774 & 40.4 \\
\hline 9 & IEcon.DB.MSFan.CS1.DCV0 & 8868 & 61.6 & 4699 & 29.1 & 6229 & 69.9 & 5828 & 40.8 \\
\hline 10 & IEcon.EH.MSFan.CS1.DCV0 & 8636 & 60.0 & 4706 & 29.2 & 6228 & 69.9 & 5793 & 40.5 \\
\hline 11 & NoEcon.MSFan.CS2.DCV0 & 8630 & 60.0 & 5595 & 34.7 & 6228 & 69.9 & 6544 & 45.8 \\
\hline 12 & IEcon.DB.MSFan.CS2.DCV0 & 9370 & 65.1 & 5642 & 35.0 & 6379 & 71.6 & 6638 & 46.4 \\
\hline 13 & IEcon.EH.MSFan.CS2.DCV0 & 9302 & 64.6 & 5651 & 35.0 & 6387 & 71.6 & 6629 & 46.4 \\
\hline 14 & NoEcon.SSFan.CS1.DCV1 & 725 & 5.0 & 1752 & 10.9 & 85 & 1.0 & 1085 & 7.6 \\
\hline 15 & IEcon.DB.SSFan.CS1.DCV1 & 2434 & 16.9 & 2046 & 12.7 & 694 & 7.8 & 1459 & 10.2 \\
\hline 16 & IEcon.EH.SSFan.CS1.DCV1 & 2131 & 14.8 & 2067 & 12.8 & 691 & 7.8 & 1388 & 9.7 \\
\hline 17 & NoEcon.MSFan.CS1.DCV1 & 7650 & 53.2 & 6715 & 41.6 & 6057 & 67.9 & 7102 & 49.7 \\
\hline 18 & IEcon.DB.MSFan.CS1.DCV1 & 9059 & 62.9 & 6867 & 42.6 & 6509 & 73.0 & 7279 & 50.9 \\
\hline 19 & IEcon.EH.MSFan.CS1.DCV1 & 8789 & 61.1 & 6870 & 42.6 & 6507 & 73.0 & 7249 & 50.7 \\
\hline 20 & NoEcon.MSFan.CS2.DCV1 & 8631 & 60.0 & 7656 & 47.5 & 6350 & 71.2 & 7854 & 55.0 \\
\hline 21 & IEcon.DB.MSFan.CS2.DCV1 & 9569 & 66.5 & 7737 & 48.0 & 6668 & 74.8 & 7957 & 55.7 \\
\hline 22 & IEcon.EH.MSFan.CS2.DCV1 & 9482 & 65.9 & 7735 & 47.9 & 6673 & 74.8 & 7963 & 55.7 \\
\hline
\end{tabular}


Table D-23: Electricity Cost Savings Compared to Case 1 for the Stand-alone Retail Building in Climate Zones 4B, 4C and 5

\begin{tabular}{|c|c|c|c|c|c|c|c|c|c|}
\hline \multirow{2}{*}{$\begin{array}{c}\text { Case } \\
\text { No }\end{array}$} & \multirow[b]{2}{*}{ Case Name } & \multicolumn{2}{|c|}{ Albuquerque-4B } & \multicolumn{2}{|c|}{ Seattle-4C } & \multicolumn{2}{|c|}{ Chicago-5A } & \multicolumn{2}{|c|}{ Denver-5B } \\
\hline & & $\begin{array}{c}\text { Abs. } \\
\text { (\$) }\end{array}$ & $\begin{array}{l}\text { Rel. } \\
(\%)\end{array}$ & $\begin{array}{c}\text { Abs. } \\
(\$)\end{array}$ & $\begin{array}{l}\text { Rel. } \\
(\%)\end{array}$ & $\begin{array}{c}\text { Abs. } \\
(\$)\end{array}$ & $\begin{array}{l}\text { Rel. } \\
\text { (\%) }\end{array}$ & $\begin{array}{c}\text { Abs. } \\
\text { (\$) }\end{array}$ & $\begin{array}{l}\text { Rel. } \\
\text { (\%) }\end{array}$ \\
\hline 2 & NIEcon.DB.SSFan.CS1.DCV0 & 344 & 3.4 & 229 & 4.6 & 437 & 4.1 & 356 & 3.5 \\
\hline 3 & NIEcon.EH.SSFan.CS1.DCV0 & 327 & 3.2 & 222 & 4.5 & 338 & 3.2 & 341 & 3.4 \\
\hline 4 & IEcon.DB.SSFan.CS1.DCV0 & 357 & 3.5 & 240 & 4.8 & 446 & 4.2 & 365 & 3.6 \\
\hline 5 & IEcon.EH.SSFan.CS1.DCV0 & 337 & 3.3 & 231 & 4.6 & 345 & 3.3 & 347 & 3.4 \\
\hline 8 & NIEcon.EH.MSFan.CS1.DCV0 & 4583 & 44.6 & 3162 & 63.6 & 5231 & 49.3 & 5587 & 54.9 \\
\hline 9 & IEcon.DB.MSFan.CS1.DCV0 & 4605 & 44.8 & 3176 & 63.8 & 5279 & 49.7 & 5596 & 55.0 \\
\hline 10 & IEcon.EH.MSFan.CS1.DCV0 & 4598 & 44.8 & 3172 & 63.8 & 5243 & 49.4 & 5594 & 54.9 \\
\hline 11 & NoEcon.MSFan.CS2.DCV0 & 5268 & 51.3 & 3249 & 65.3 & 5791 & 54.5 & 6055 & 59.5 \\
\hline 12 & IEcon.DB.MSFan.CS2.DCV0 & 5321 & 51.8 & 3294 & 66.2 & 5850 & 55.1 & 6089 & 59.8 \\
\hline 16 & IEcon.EH.SSFan.CS1.DCV1 & 767 & 7.5 & 265 & 5.3 & 782 & 7.4 & 616 & 6.0 \\
\hline 17 & NoEcon.MSFan.CS1.DCV1 & 5188 & 50.5 & 3312 & 66.6 & 5951 & 56.1 & 6111 & 60.0 \\
\hline 18 & IEcon.DB.MSFan.CS1.DCV1 & 5345 & 52.1 & 3447 & 69.3 & 6124 & 57.7 & 6251 & 61.4 \\
\hline 19 & IEcon.EH.MSFan.CS1.DCV1 & 5331 & 51.9 & 3444 & 69.2 & 6085 & 57.3 & 6235 & 61.2 \\
\hline 20 & NoEcon.MSFan.CS2.DCV1 & 5886 & 57.3 & 3465 & 69.7 & 6502 & 61.2 & 6644 & 65.3 \\
\hline 21 & IEcon.DB.MSFan.CS2.DCV1 & 5967 & 58.1 & 3556 & 71.5 & 6587 & 62.1 & 6702 & 65.8 \\
\hline 22 & IEcon.EH.MSFan.CS2.DCV1 & 5973 & 58.2 & 3559 & 71.5 & 6588 & 62.1 & 6689 & 65.7 \\
\hline
\end{tabular}


Table D-24: Electricity Cost Savings Compared to Case 1 for the Stand-alone Retail Building in Climate Zones 6 , 7 and 8

\begin{tabular}{|c|c|c|c|c|c|c|c|c|c|}
\hline \multirow{2}{*}{$\begin{array}{c}\text { Case } \\
\text { No }\end{array}$} & \multirow{2}{*}{ Case Name } & \multicolumn{2}{|c|}{ Minneapolis-6A } & \multicolumn{2}{|c|}{ Helena-6B } & \multicolumn{2}{|c|}{ Duluth-7 } & \multicolumn{2}{|c|}{ Fairbanks-8 } \\
\hline & & $\begin{array}{c}\text { Abs. } \\
\text { (\$) }\end{array}$ & $\begin{array}{l}\text { Rel. } \\
\text { (\%) }\end{array}$ & $\begin{array}{c}\text { Abs. } \\
(\$)\end{array}$ & $\begin{array}{l}\text { Rel. } \\
\text { (\%) }\end{array}$ & $\begin{array}{l}\text { Abs. } \\
\text { (\$) }\end{array}$ & $\begin{array}{l}\text { Rel. } \\
\text { (\%) }\end{array}$ & $\begin{array}{c}\text { Abs. } \\
\text { (\$) }\end{array}$ & $\begin{array}{l}\text { Rel. } \\
\text { (\%) }\end{array}$ \\
\hline 2 & NIEcon.DB.SSFan.CS1.DCV0 & 474 & 4.5 & 388 & 3.8 & 385 & 4.1 & 1599 & 7.5 \\
\hline 3 & NIEcon.EH.SSFan.CS1.DCV0 & 401 & 3.8 & 386 & 3.8 & 355 & 3.8 & 1593 & 7.5 \\
\hline 4 & IEcon.DB.SSFan.CS1.DCV0 & 485 & 4.6 & 391 & 3.9 & 389 & 4.1 & 1602 & 7.5 \\
\hline 5 & IEcon.EH.SSFan.CS1.DCV0 & 408 & 3.9 & 389 & 3.8 & 357 & 3.8 & 1591 & 7.5 \\
\hline 6 & NoEcon.MSFan.CS1.DCV0 & 5506 & 52.2 & 6121 & 60.4 & 5708 & 60.7 & 11999 & 56.4 \\
\hline 7 & NIEcon.DB.MSFan.CS1.DCV0 & 5658 & 53.6 & 6238 & 61.6 & 5870 & 62.5 & 13528 & 63.5 \\
\hline 8 & NIEcon.EH.MSFan.CS1.DCV0 & 5633 & 53.4 & 6241 & 61.6 & 5863 & 62.4 & 13529 & 63.6 \\
\hline 9 & IEcon.DB.MSFan.CS1.DCV0 & 5668 & 53.7 & 6245 & 61.6 & 5875 & 62.5 & 13532 & 63.6 \\
\hline 10 & IEcon.EH.MSFan.CS1.DCV0 & 5640 & 53.4 & 6247 & 61.7 & 5866 & 62.4 & 13529 & 63.6 \\
\hline 11 & NoEcon.MSFan.CS2.DCV0 & 6068 & 57.5 & 6531 & 64.5 & 5959 & 63.4 & 13169 & 61.9 \\
\hline 12 & IEcon.DB.MSFan.CS2.DCV0 & 6130 & 58.1 & 6570 & 64.8 & 6031 & 64.2 & 13662 & 64.2 \\
\hline 13 & IEcon.EH.MSFan.CS2.DCV0 & 6129 & 58.1 & 6570 & 64.8 & 6031 & 64.2 & 13654 & 64.1 \\
\hline 14 & NoEcon.SSFan.CS1.DCV1 & 466 & 4.4 & 226 & 2.2 & 162 & 1.7 & 800 & 3.8 \\
\hline 15 & IEcon.DB.SSFan.CS1.DCV1 & 812 & 7.7 & 534 & 5.3 & 474 & 5.0 & 1630 & 7.7 \\
\hline 16 & IEcon.EH.SSFan.CS1.DCV1 & 751 & 7.1 & 531 & 5.2 & 446 & 4.7 & 1625 & 7.6 \\
\hline 17 & NoEcon.MSFan.CS1.DCV1 & 6250 & 59.2 & 6668 & 65.8 & 6279 & 66.8 & 13227 & 62.1 \\
\hline 18 & IEcon.DB.MSFan.CS1.DCV1 & 6462 & 61.2 & 6863 & 67.7 & 6500 & 69.2 & 14803 & 69.5 \\
\hline 19 & IEcon.EH.MSFan.CS1.DCV1 & 6436 & 61.0 & 6863 & 67.7 & 6489 & 69.1 & 14801 & 69.5 \\
\hline 20 & NoEcon.MSFan.CS2.DCV1 & 6752 & 64.0 & 7084 & 69.9 & 6535 & 69.5 & 14431 & 67.8 \\
\hline 21 & IEcon.DB.MSFan.CS2.DCV1 & 6838 & 64.8 & 7158 & 70.6 & 6625 & 70.5 & 14925 & 70.1 \\
\hline 22 & IEcon.EH.MSFan.CS2.DCV1 & 6836 & 64.8 & 7149 & 70.6 & 6623 & 70.5 & 14914 & 70.1 \\
\hline
\end{tabular}


Table D-25: Electricity Cost Savings Compared to Case 1 for the Strip Mall Building in Climate Zones 1, 2 and 3A

\begin{tabular}{|c|c|c|c|c|c|c|c|c|c|}
\hline \multirow{2}{*}{$\begin{array}{c}\text { Case } \\
\text { No }\end{array}$} & \multirow[b]{2}{*}{ Case Name } & \multicolumn{2}{|c|}{ Miami-1A } & \multicolumn{2}{|c|}{ Houston-2A } & \multicolumn{2}{|c|}{ Phoenix-2B } & \multicolumn{2}{|c|}{ Atlanta-3A } \\
\hline & & $\begin{array}{l}\text { Abs. } \\
\text { (\$) }\end{array}$ & $\begin{array}{l}\text { Rel. } \\
\text { (\%) }\end{array}$ & $\begin{array}{c}\text { Abs. } \\
\text { (\$) }\end{array}$ & $\begin{array}{l}\text { Rel. } \\
\text { (\%) }\end{array}$ & $\begin{array}{l}\text { Abs. } \\
\text { (\$) }\end{array}$ & $\begin{array}{l}\text { Rel. } \\
\text { (\%) }\end{array}$ & $\begin{array}{l}\text { Abs. } \\
\text { (\$) }\end{array}$ & $\begin{array}{l}\text { Rel. } \\
\text { (\%) }\end{array}$ \\
\hline 2 & NIEcon.DB.SSFan.CS1.DCV0 & 1067 & 3.6 & 695 & 3.6 & 449 & 2.2 & 739 & 5.4 \\
\hline 3 & NIEcon.EH.SSFan.CS1.DCV0 & 602 & 2.0 & 481 & 2.5 & 516 & 2.5 & 590 & 4.3 \\
\hline 4 & IEcon.DB.SSFan.CS1.DCV0 & 1108 & 3.8 & 709 & 3.7 & 461 & 2.3 & 757 & 5.6 \\
\hline 5 & IEcon.EH.SSFan.CS1.DCV0 & 622 & 2.1 & 494 & 2.6 & 528 & 2.6 & 607 & 4.5 \\
\hline 6 & NoEcon.MSFan.CS1.DCV0 & 5136 & 17.4 & 4467 & 23.1 & 4674 & 23.1 & 4849 & 35.7 \\
\hline 7 & NIEcon.DB.MSFan.CS1.DCV0 & 5628 & 19.1 & 4721 & 24.4 & 4821 & 23.8 & 5125 & 37.7 \\
\hline 8 & NIEcon.EH.MSFan.CS1.DCV0 & 5392 & 18.3 & 4634 & 24.0 & 4868 & 24.0 & 5057 & 37.2 \\
\hline 9 & IEcon.DB.MSFan.CS1.DCV0 & 5671 & 19.2 & 4738 & 24.5 & 4837 & 23.9 & 5147 & 37.9 \\
\hline 10 & IEcon.EH.MSFan.CS1.DCV0 & 5423 & 18.4 & 4652 & 24.1 & 4887 & 24.1 & 5079 & 37.4 \\
\hline 11 & NoEcon.MSFan.CS2.DCV0 & 7975 & 27.0 & 5999 & 31.0 & 6407 & 31.6 & 5976 & 44.0 \\
\hline 12 & IEcon.DB.MSFan.CS2.DCV0 & 8254 & 28.0 & 6150 & 31.8 & 6467 & 31.9 & 6123 & 45.0 \\
\hline 13 & IEcon.EH.MSFan.CS2.DCV0 & 8189 & 27.7 & 6123 & 31.7 & 6490 & 32.0 & 6116 & 45.0 \\
\hline 14 & NoEcon.SSFan.CS1.DCV1 & 3665 & 12.4 & 2591 & 13.4 & 2565 & 12.7 & 1370 & 10.1 \\
\hline 15 & IEcon.DB.SSFan.CS1.DCV1 & 4392 & 14.9 & 2959 & 15.3 & 2718 & 13.4 & 1674 & 12.3 \\
\hline 16 & IEcon.EH.SSFan.CS1.DCV1 & 3955 & 13.4 & 2802 & 14.5 & 2793 & 13.8 & 1561 & 11.5 \\
\hline 17 & NoEcon.MSFan.CS1.DCV1 & 9036 & 30.6 & 7227 & 37.4 & 7501 & 37.0 & 6207 & 45.7 \\
\hline 18 & IEcon.DB.MSFan.CS1.DCV1 & 9545 & 32.3 & 7478 & 38.7 & 7597 & 37.5 & 6449 & 47.4 \\
\hline 19 & IEcon.EH.MSFan.CS1.DCV1 & 9252 & 31.4 & 7383 & 38.2 & 7639 & 37.7 & 6380 & 46.9 \\
\hline 20 & NoEcon.MSFan.CS2.DCV1 & 11607 & 39.3 & 8597 & 44.5 & 9104 & 45.0 & 7111 & 52.3 \\
\hline 21 & IEcon.DB.MSFan.CS2.DCV1 & 11794 & 40.0 & 8709 & 45.0 & 9116 & 45.0 & 7207 & 53.0 \\
\hline 22 & IEcon.EH.MSFan.CS2.DCV1 & 11727 & 39.7 & 8679 & 44.9 & 9130 & 45.1 & 7195 & 52.9 \\
\hline
\end{tabular}


Table D-26: Electricity Cost Savings Compared to Case 1 for the Strip Mall Building in Climate Zones 3B, 3C and 4A

\begin{tabular}{|c|c|c|c|c|c|c|c|c|c|}
\hline \multirow{2}{*}{$\begin{array}{c}\text { Case } \\
\text { No }\end{array}$} & \multirow[b]{2}{*}{ Case Name } & \multicolumn{2}{|c|}{ Los Angeles-3B } & \multicolumn{2}{|c|}{ Las Vegas-3B } & \multicolumn{2}{|c|}{ San Francisco-3C } & \multicolumn{2}{|c|}{ Baltimore-4A } \\
\hline & & $\begin{array}{l}\text { Abs. } \\
\text { (\$) }\end{array}$ & $\begin{array}{l}\text { Rel. } \\
\text { (\%) }\end{array}$ & $\begin{array}{c}\text { Abs. } \\
\text { (\$) }\end{array}$ & $\begin{array}{l}\text { Rel. } \\
\text { (\%) }\end{array}$ & $\begin{array}{c}\text { Abs. } \\
\text { (\$) }\end{array}$ & $\begin{array}{l}\text { Rel. } \\
\text { (\%) }\end{array}$ & $\begin{array}{c}\text { Abs. } \\
\text { (\$) }\end{array}$ & $\begin{array}{l}\text { Rel. } \\
(\%)\end{array}$ \\
\hline 2 & NIEcon.DB.SSFan.CS1.DCV0 & 2918 & 17.6 & 428 & 2.6 & 974 & 10.1 & 624 & 4.4 \\
\hline 3 & NIEcon.EH.SSFan.CS1.DCV0 & 2538 & 15.3 & 467 & 2.9 & 972 & 10.1 & 493 & 3.5 \\
\hline 4 & IEcon.DB.SSFan.CS1.DCV0 & 3048 & 18.4 & 438 & 2.7 & 1009 & 10.4 & 637 & 4.5 \\
\hline 5 & IEcon.EH.SSFan.CS1.DCV0 & 2639 & 15.9 & 476 & 2.9 & 1007 & 10.4 & 509 & 3.6 \\
\hline 6 & NoEcon.MSFan.CS1.DCV0 & 8416 & 50.8 & 4824 & 29.5 & 6241 & 64.5 & 5402 & 37.8 \\
\hline 7 & NIEcon.DB.MSFan.CS1.DCV0 & 9897 & 59.8 & 4960 & 30.3 & 6633 & 68.6 & 5632 & 39.4 \\
\hline 8 & NIEcon.EH.MSFan.CS1.DCV0 & 9631 & 58.2 & 4988 & 30.5 & 6633 & 68.6 & 5570 & 39.0 \\
\hline 9 & IEcon.DB.MSFan.CS1.DCV0 & 10064 & 60.8 & 4974 & 30.4 & 6682 & 69.1 & 5647 & 39.5 \\
\hline 10 & IEcon.EH.MSFan.CS1.DCV0 & 9778 & 59.1 & 5001 & 30.5 & 6682 & 69.1 & 5593 & 39.2 \\
\hline 11 & NoEcon.MSFan.CS2.DCV0 & 9619 & 58.1 & 5935 & 36.3 & 6602 & 68.2 & 6341 & 44.4 \\
\hline 12 & IEcon.DB.MSFan.CS2.DCV0 & 10566 & 63.8 & 5995 & 36.6 & 6865 & 71.0 & 6471 & 45.3 \\
\hline 13 & IEcon.EH.MSFan.CS2.DCV0 & 10520 & 63.6 & 6007 & 36.7 & 6871 & 71.0 & 6463 & 45.3 \\
\hline 14 & NoEcon.SSFan.CS1.DCV1 & 1995 & 12.1 & 1969 & 12.0 & 837 & 8.6 & 1286 & 9.0 \\
\hline 15 & IEcon.DB.SSFan.CS1.DCV1 & 3232 & 19.5 & 2092 & 12.8 & 1067 & 11.0 & 1579 & 11.1 \\
\hline 16 & IEcon.EH.SSFan.CS1.DCV1 & 2939 & 17.8 & 2136 & 13.0 & 1066 & 11.0 & 1494 & 10.5 \\
\hline 17 & NoEcon.MSFan.CS1.DCV1 & 8905 & 53.8 & 7021 & 42.9 & 6666 & 68.9 & 6947 & 48.6 \\
\hline 18 & IEcon.DB.MSFan.CS1.DCV1 & 10420 & 63.0 & 7106 & 43.4 & 7064 & 73.0 & 7157 & 50.1 \\
\hline 19 & IEcon.EH.MSFan.CS1.DCV1 & 10101 & 61.0 & 7128 & 43.5 & 7063 & 73.0 & 7103 & 49.7 \\
\hline 20 & NoEcon.MSFan.CS2.DCV1 & 10239 & 61.9 & 8015 & 49.0 & 7067 & 73.1 & 7748 & 54.2 \\
\hline 21 & IEcon.DB.MSFan.CS2.DCV1 & 10904 & 65.9 & 8029 & 49.0 & 7248 & 74.9 & 7825 & 54.8 \\
\hline 22 & IEcon.EH.MSFan.CS2.DCV1 & 10828 & 65.4 & 8036 & 49.1 & 7254 & 75.0 & 7827 & 54.8 \\
\hline
\end{tabular}


Table D-27: Electricity Cost Savings Compared to Case 1 for the Strip Mall Building in Climate Zones 4B, 4C, 5A and 5B

\begin{tabular}{|c|c|c|c|c|c|c|c|c|c|}
\hline \multirow{2}{*}{$\begin{array}{c}\text { Case } \\
\text { No }\end{array}$} & \multirow[b]{2}{*}{ Case Name } & \multicolumn{2}{|c|}{ Albuquerque-4B } & \multicolumn{2}{|c|}{ Seattle-4C } & \multicolumn{2}{|c|}{ Chicago-5A } & \multicolumn{2}{|c|}{ Denver-5B } \\
\hline & & $\begin{array}{c}\text { Abs. } \\
\text { (\$) }\end{array}$ & $\begin{array}{l}\text { Rel. } \\
\text { (\%) }\end{array}$ & $\begin{array}{c}\text { Abs. } \\
\text { (\$) }\end{array}$ & $\begin{array}{l}\text { Rel. } \\
\text { (\%) }\end{array}$ & $\begin{array}{c}\text { Abs. } \\
\text { (\$) }\end{array}$ & $\begin{array}{l}\text { Rel. } \\
\text { (\%) }\end{array}$ & $\begin{array}{c}\text { Abs. } \\
\text { (\$) }\end{array}$ & $\begin{array}{l}\text { Rel. } \\
\text { (\%) }\end{array}$ \\
\hline 2 & NIEcon.DB.SSFan.CS1.DCV0 & 427 & 4.2 & 334 & 6.3 & 530 & 4.9 & 442 & 4.4 \\
\hline 3 & NIEcon.EH.SSFan.CS1.DCV0 & 414 & 4.1 & 322 & 6.1 & 422 & 3.9 & 434 & 4.3 \\
\hline 4 & IEcon.DB.SSFan.CS1.DCV0 & 442 & 4.4 & 348 & 6.6 & 546 & 5.1 & 451 & 4.5 \\
\hline 5 & IEcon.EH.SSFan.CS1.DCV0 & 421 & 4.2 & 335 & 6.3 & 433 & 4.0 & 438 & 4.4 \\
\hline 6 & NoEcon.MSFan.CS1.DCV0 & 4191 & 41.5 & 3178 & 60.1 & 5014 & 46.7 & 5180 & 51.4 \\
\hline 7 & NIEcon.DB.MSFan.CS1.DCV0 & 4341 & 43.0 & 3299 & 62.4 & 5191 & 48.4 & 5310 & 52.7 \\
\hline 8 & NIEcon.EH.MSFan.CS1.DCV0 & 4341 & 43.0 & 3294 & 62.3 & 5145 & 47.9 & 5311 & 52.7 \\
\hline 9 & IEcon.DB.MSFan.CS1.DCV0 & 4358 & 43.2 & 3319 & 62.7 & 5210 & 48.5 & 5322 & 52.8 \\
\hline 10 & IEcon.EH.MSFan.CS1.DCV0 & 4355 & 43.2 & 3312 & 62.6 & 5160 & 48.1 & 5319 & 52.8 \\
\hline 11 & NoEcon.MSFan.CS2.DCV0 & 5001 & 49.6 & 3374 & 63.8 & 5694 & 53.1 & 5811 & 57.7 \\
\hline 12 & IEcon.DB.MSFan.CS2.DCV0 & 5068 & 50.2 & 3450 & 65.2 & 5781 & 53.9 & 5857 & 58.1 \\
\hline 13 & IEcon.EH.MSFan.CS2.DCV0 & 5086 & 50.4 & 3454 & 65.3 & 5779 & 53.8 & 5859 & 58.1 \\
\hline 14 & NoEcon.SSFan.CS1.DCV1 & 672 & 6.7 & 275 & 5.2 & 749 & 7.0 & 540 & 5.4 \\
\hline 15 & IEcon.DB.SSFan.CS1.DCV1 & 860 & 8.5 & 392 & 7.4 & 977 & 9.1 & 711 & 7.1 \\
\hline 16 & IEcon.EH.SSFan.CS1.DCV1 & 854 & 8.5 & 380 & 7.2 & 892 & 8.3 & 711 & 7.1 \\
\hline 17 & NoEcon.MSFan.CS1.DCV1 & 5001 & 49.6 & 3531 & 66.7 & 5969 & 55.6 & 5921 & 58.8 \\
\hline 18 & IEcon.DB.MSFan.CS1.DCV1 & 5128 & 50.8 & 3656 & 69.1 & 6131 & 57.1 & 6029 & 59.8 \\
\hline 19 & IEcon.EH.MSFan.CS1.DCV1 & 5120 & 50.7 & 3647 & 68.9 & 6081 & 56.7 & 6022 & 59.8 \\
\hline 20 & NoEcon.MSFan.CS2.DCV1 & 5697 & 56.5 & 3724 & 70.4 & 6536 & 60.9 & 6518 & 64.7 \\
\hline 21 & IEcon.DB.MSFan.CS2.DCV1 & 5729 & 56.8 & 3771 & 71.3 & 6585 & 61.4 & 6534 & 64.8 \\
\hline 22 & IEcon.EH.MSFan.CS2.DCV1 & 5744 & 56.9 & 3776 & 71.4 & 6579 & 61.3 & 6520 & 64.7 \\
\hline
\end{tabular}


Table D-28: Electricity Cost Savings Compared to Case 1 for the Strip Mall Building in Climate Zones 6, 7 and 8

\begin{tabular}{|c|c|c|c|c|c|c|c|c|c|}
\hline \multirow{2}{*}{$\begin{array}{c}\text { Case } \\
\text { No }\end{array}$} & \multirow[b]{2}{*}{ Case Name } & \multicolumn{2}{|c|}{ Minneapolis-6A } & \multicolumn{2}{|c|}{ Helena-6B } & \multicolumn{2}{|c|}{ Duluth-7 } & \multicolumn{2}{|c|}{ Fairbanks-8 } \\
\hline & & $\begin{array}{l}\text { Abs. } \\
\text { (\$) }\end{array}$ & $\begin{array}{l}\text { Rel. } \\
\text { (\%) }\end{array}$ & $\begin{array}{c}\text { Abs. } \\
\text { (\$) }\end{array}$ & $\begin{array}{l}\text { Rel. } \\
\text { (\%) }\end{array}$ & $\begin{array}{l}\text { Abs. } \\
\text { (\$) }\end{array}$ & $\begin{array}{l}\text { Rel. } \\
\text { (\%) }\end{array}$ & $\begin{array}{c}\text { Abs. } \\
\text { (\$) }\end{array}$ & $\begin{array}{l}\text { Rel. } \\
\text { (\%) }\end{array}$ \\
\hline 2 & NIEcon.DB.SSFan.CS1.DCV0 & 598 & 5.6 & 497 & 4.8 & 513 & 5.4 & 1871 & 8.7 \\
\hline 3 & NIEcon.EH.SSFan.CS1.DCV0 & 512 & 4.8 & 493 & 4.8 & 471 & 4.9 & 1867 & 8.7 \\
\hline 4 & IEcon.DB.SSFan.CS1.DCV0 & 610 & 5.7 & 502 & 4.9 & 517 & 5.4 & 1874 & 8.7 \\
\hline 5 & IEcon.EH.SSFan.CS1.DCV0 & 514 & 4.8 & 496 & 4.8 & 471 & 4.9 & 1866 & 8.7 \\
\hline 6 & NoEcon.MSFan.CS1.DCV0 & 5381 & 50.3 & 5985 & 58.2 & 5639 & 59.0 & 11968 & 55.6 \\
\hline 7 & NIEcon.DB.MSFan.CS1.DCV0 & 5606 & 52.4 & 6149 & 59.8 & 5870 & 61.4 & 13549 & 62.9 \\
\hline 8 & NIEcon.EH.MSFan.CS1.DCV0 & 5573 & 52.1 & 6154 & 59.9 & 5856 & 61.3 & 13552 & 62.9 \\
\hline 9 & IEcon.DB.MSFan.CS1.DCV0 & 5618 & 52.5 & 6157 & 59.9 & 5876 & 61.5 & 13555 & 62.9 \\
\hline 10 & IEcon.EH.MSFan.CS1.DCV0 & 5581 & 52.2 & 6159 & 59.9 & 5859 & 61.3 & 13557 & 62.9 \\
\hline 11 & NoEcon.MSFan.CS2.DCV0 & 6020 & 56.3 & 6501 & 63.3 & 5973 & 62.5 & 13247 & 61.5 \\
\hline 12 & IEcon.DB.MSFan.CS2.DCV0 & 6100 & 57.0 & 6561 & 63.8 & 6057 & 63.4 & 13711 & 63.6 \\
\hline 13 & IEcon.EH.MSFan.CS2.DCV0 & 6095 & 57.0 & 6559 & 63.8 & 6053 & 63.3 & 13708 & 63.6 \\
\hline 14 & NoEcon.SSFan.CS1.DCV1 & 764 & 7.1 & 539 & 5.2 & 511 & 5.3 & 1782 & 8.3 \\
\hline 15 & IEcon.DB.SSFan.CS1.DCV1 & 945 & 8.8 & 646 & 6.3 & 600 & 6.3 & 1912 & 8.9 \\
\hline 16 & IEcon.EH.SSFan.CS1.DCV1 & 871 & 8.1 & 646 & 6.3 & 572 & 6.0 & 1913 & 8.9 \\
\hline 17 & NoEcon.MSFan.CS1.DCV1 & 6334 & 59.2 & 6765 & 65.8 & 6431 & 67.3 & 12976 & 60.2 \\
\hline 18 & IEcon.DB.MSFan.CS1.DCV1 & 6501 & 60.8 & 6864 & 66.8 & 6586 & 68.9 & 14916 & 69.2 \\
\hline 19 & IEcon.EH.MSFan.CS1.DCV1 & 6458 & 60.4 & 6866 & 66.8 & 6571 & 68.7 & 14917 & 69.2 \\
\hline 20 & NoEcon.MSFan.CS2.DCV1 & 6852 & 64.1 & 7214 & 70.2 & 6694 & 70.0 & 14711 & 68.3 \\
\hline 21 & IEcon.DB.MSFan.CS2.DCV1 & 6890 & 64.4 & 7237 & 70.4 & 6741 & 70.5 & 15059 & 69.9 \\
\hline 22 & IEcon.EH.MSFan.CS2.DCV1 & 6877 & 64.3 & 7227 & 70.3 & 6736 & 70.5 & 15053 & 69.9 \\
\hline
\end{tabular}


Table D-29: Electricity Cost Savings Compared to Case 1 for the Supermarket Building in Climate Zones 1, 2 and 3A

\begin{tabular}{|c|c|c|c|c|c|c|c|c|c|}
\hline \multirow{2}{*}{$\begin{array}{c}\text { Case } \\
\text { No }\end{array}$} & \multirow[b]{2}{*}{ Case Name } & \multicolumn{2}{|c|}{ Miami-1A } & \multicolumn{2}{|c|}{ Houston-2A } & \multicolumn{2}{|c|}{ Phoenix-2B } & \multicolumn{2}{|c|}{ Atlanta-3A } \\
\hline & & $\begin{array}{l}\text { Abs. } \\
\text { (\$) }\end{array}$ & $\begin{array}{l}\text { Rel. } \\
\text { (\%) }\end{array}$ & $\begin{array}{c}\text { Abs. } \\
\text { (\$) }\end{array}$ & $\begin{array}{l}\text { Rel. } \\
(\%)\end{array}$ & $\begin{array}{l}\text { Abs. } \\
\text { (\$) }\end{array}$ & $\begin{array}{l}\text { Rel. } \\
\text { (\%) }\end{array}$ & $\begin{array}{c}\text { Abs. } \\
\text { (\$) }\end{array}$ & $\begin{array}{l}\text { Rel. } \\
\text { (\%) }\end{array}$ \\
\hline 2 & NIEcon.DB.SSFan.CS1.DCV0 & 778 & 2.3 & 834 & 2.5 & 597 & 1.8 & 1055 & 3.6 \\
\hline 3 & NIEcon.EH.SSFan.CS1.DCV0 & 396 & 1.2 & 539 & 1.6 & 595 & 1.8 & 790 & 2.7 \\
\hline 4 & IEcon.DB.SSFan.CS1.DCV0 & 772 & 2.3 & 838 & 2.5 & 610 & 1.8 & 1065 & 3.6 \\
\hline 5 & IEcon.EH.SSFan.CS1.DCV0 & 403 & 1.2 & 542 & 1.6 & 605 & 1.8 & 790 & 2.7 \\
\hline 6 & NoEcon.MSFan.CS1.DCV0 & 11563 & 34.4 & 15235 & 45.7 & 13379 & 40.2 & 17030 & 57.5 \\
\hline 7 & NIEcon.DB.MSFan.CS1.DCV0 & 11975 & 35.6 & 15685 & 47.1 & 13736 & 41.3 & 17622 & 59.5 \\
\hline 8 & NIEcon.EH.MSFan.CS1.DCV0 & 11765 & 35.0 & 15556 & 46.7 & 13740 & 41.3 & 17501 & 59.1 \\
\hline 9 & IEcon.DB.MSFan.CS1.DCV0 & 11961 & 35.5 & 15684 & 47.1 & 13754 & 41.3 & 17633 & 59.5 \\
\hline 10 & IEcon.EH.MSFan.CS1.DCV0 & 11777 & 35.0 & 15563 & 46.7 & 13757 & 41.4 & 17508 & 59.1 \\
\hline 11 & NoEcon.MSFan.CS2.DCV0 & 14336 & 42.6 & 17672 & 53.1 & 15755 & 47.4 & 18557 & 62.7 \\
\hline 12 & IEcon.DB.MSFan.CS2.DCV0 & 14603 & 43.4 & 17910 & 53.8 & 15938 & 47.9 & 18838 & 63.6 \\
\hline 13 & IEcon.EH.MSFan.CS2.DCV0 & 14481 & 43.0 & 17855 & 53.6 & 15944 & 47.9 & 18805 & 63.5 \\
\hline 14 & NoEcon.SSFan.CS1.DCV1 & 3464 & 10.3 & 2724 & 8.2 & 3507 & 10.5 & 1047 & 3.5 \\
\hline 15 & IEcon.DB.SSFan.CS1.DCV1 & 4239 & 12.6 & 3572 & 10.7 & 4121 & 12.4 & 2131 & 7.2 \\
\hline 16 & IEcon.EH.SSFan.CS1.DCV1 & 3861 & 11.5 & 3253 & 9.8 & 4115 & 12.4 & 1826 & 6.2 \\
\hline 17 & NoEcon.MSFan.CS1.DCV1 & 15462 & 45.9 & 18970 & 57.0 & 17956 & 54.0 & 18944 & 64.0 \\
\hline 18 & IEcon.DB.MSFan.CS1.DCV1 & 15842 & 47.1 & 19402 & 58.3 & 18321 & 55.1 & 19530 & 65.9 \\
\hline 19 & IEcon.EH.MSFan.CS1.DCV1 & 15669 & 46.6 & 19279 & 57.9 & 18322 & 55.1 & 19399 & 65.5 \\
\hline 20 & NoEcon.MSFan.CS2.DCV1 & 17759 & 52.8 & 20718 & 62.2 & 19811 & 59.6 & 20203 & 68.2 \\
\hline 21 & IEcon.DB.MSFan.CS2.DCV1 & 18009 & 53.5 & 20939 & 62.9 & 19990 & 60.1 & 20462 & 69.1 \\
\hline 22 & IEcon.EH.MSFan.CS2.DCV1 & 17903 & 53.2 & 20892 & 62.7 & 19993 & 60.1 & 20434 & 69.0 \\
\hline
\end{tabular}


Table D-30: Electricity Cost Savings Compared to Case 1 for the Supermarket Building in Climate Zones 3B, 3C and 4A

\begin{tabular}{|c|c|c|c|c|c|c|c|c|c|}
\hline \multirow{2}{*}{$\begin{array}{c}\text { Case } \\
\text { No }\end{array}$} & \multirow[b]{2}{*}{ Case Name } & \multicolumn{2}{|c|}{ Los Angeles-3B } & \multicolumn{2}{|c|}{ Las Vegas-3B } & \multicolumn{2}{|c|}{ San Francisco-3C } & \multicolumn{2}{|c|}{ Baltimore-4A } \\
\hline & & $\begin{array}{l}\text { Abs. } \\
\text { (\$) }\end{array}$ & $\begin{array}{l}\text { Rel. } \\
\text { (\%) }\end{array}$ & $\begin{array}{c}\text { Abs. } \\
\text { (\$) }\end{array}$ & $\begin{array}{l}\text { Rel. } \\
\text { (\%) }\end{array}$ & $\begin{array}{c}\text { Abs. } \\
\text { (\$) }\end{array}$ & $\begin{array}{l}\text { Rel. } \\
\text { (\%) }\end{array}$ & $\begin{array}{l}\text { Abs. } \\
\text { (\$) }\end{array}$ & $\begin{array}{l}\text { Rel. } \\
\text { (\%) }\end{array}$ \\
\hline 2 & NIEcon.DB.SSFan.CS1.DCV0 & 2546 & 9.0 & 674 & 2.0 & 1265 & 4.7 & 1034 & 2.9 \\
\hline 3 & NIEcon.EH.SSFan.CS1.DCV0 & 2094 & 7.4 & 679 & 2.1 & 1250 & 4.6 & 799 & 2.2 \\
\hline 4 & IEcon.DB.SSFan.CS1.DCV0 & 2617 & 9.3 & 687 & 2.1 & 1287 & 4.8 & 1038 & 2.9 \\
\hline 5 & IEcon.EH.SSFan.CS1.DCV0 & 2140 & 7.6 & 690 & 2.1 & 1271 & 4.7 & 804 & 2.2 \\
\hline 6 & NoEcon.MSFan.CS1.DCV0 & 18392 & 65.3 & 16395 & 49.8 & 17687 & 65.3 & 21156 & 58.9 \\
\hline 7 & NIEcon.DB.MSFan.CS1.DCV0 & 19876 & 70.5 & 16807 & 51.1 & 18500 & 68.3 & 21790 & 60.7 \\
\hline 8 & NIEcon.EH.MSFan.CS1.DCV0 & 19664 & 69.8 & 16809 & 51.1 & 18491 & 68.3 & 21689 & 60.4 \\
\hline 9 & IEcon.DB.MSFan.CS1.DCV0 & 19960 & 70.8 & 16824 & 51.1 & 18532 & 68.4 & 21798 & 60.7 \\
\hline 10 & IEcon.EH.MSFan.CS1.DCV0 & 19725 & 70.0 & 16826 & 51.2 & 18519 & 68.4 & 21703 & 60.4 \\
\hline 11 & NoEcon.MSFan.CS2.DCV0 & 19496 & 69.2 & 18116 & 55.1 & 18199 & 67.2 & 22588 & 62.9 \\
\hline 12 & IEcon.DB.MSFan.CS2.DCV0 & 20367 & 72.3 & 18338 & 55.7 & 18687 & 69.0 & 22886 & 63.7 \\
\hline 13 & IEcon.EH.MSFan.CS2.DCV0 & 20321 & 72.1 & 18341 & 55.8 & 18687 & 69.0 & 22859 & 63.6 \\
\hline 14 & NoEcon.SSFan.CS1.DCV1 & -42 & -0.1 & 2512 & 7.6 & 63 & 0.2 & 1138 & 3.2 \\
\hline 15 & IEcon.DB.SSFan.CS1.DCV1 & 2714 & 9.6 & 3195 & 9.7 & 1344 & 5.0 & 2191 & 6.1 \\
\hline 16 & IEcon.EH.SSFan.CS1.DCV1 & 2056 & 7.3 & 3199 & 9.7 & 1322 & 4.9 & 1921 & 5.3 \\
\hline 17 & NoEcon.MSFan.CS1.DCV1 & 19046 & 67.6 & 19910 & 60.5 & 18921 & 69.9 & 23636 & 65.8 \\
\hline 18 & IEcon.DB.MSFan.CS1.DCV1 & 20592 & 73.1 & 20332 & 61.8 & 19744 & 72.9 & 24255 & 67.5 \\
\hline 19 & IEcon.EH.MSFan.CS1.DCV1 & 20355 & 72.2 & 20332 & 61.8 & 19728 & 72.9 & 24150 & 67.2 \\
\hline 20 & NoEcon.MSFan.CS2.DCV1 & 20152 & 71.5 & 21361 & 64.9 & 19418 & 71.7 & 24765 & 68.9 \\
\hline 21 & IEcon.DB.MSFan.CS2.DCV1 & 20994 & 74.5 & 21576 & 65.6 & 19887 & 73.4 & 25046 & 69.7 \\
\hline 22 & IEcon.EH.MSFan.CS2.DCV1 & 20969 & 74.4 & 21578 & 65.6 & 19884 & 73.4 & 25021 & 69.6 \\
\hline
\end{tabular}


Table D-31: Electricity Cost Savings Compared to Case 1 for the Supermarket Building in Climate Zones 4B, 4C, 5A and 5B

\begin{tabular}{|c|c|c|c|c|c|c|c|c|c|}
\hline \multirow{2}{*}{$\begin{array}{c}\text { Case } \\
\text { No }\end{array}$} & \multirow[b]{2}{*}{ Case Name } & \multicolumn{2}{|c|}{ Albuquerque-4B } & \multicolumn{2}{|c|}{ Seattle-4C } & \multicolumn{2}{|c|}{ Chicago-5A } & \multicolumn{2}{|c|}{ Denver-5B } \\
\hline & & $\begin{array}{l}\text { Abs. } \\
\text { (\$) }\end{array}$ & $\begin{array}{l}\text { Rel. } \\
\text { (\%) }\end{array}$ & $\begin{array}{l}\text { Abs. } \\
\text { (\$) }\end{array}$ & $\begin{array}{l}\text { Rel. } \\
(\%)\end{array}$ & $\begin{array}{l}\text { Abs. } \\
\text { (\$) }\end{array}$ & $\begin{array}{l}\text { Rel. } \\
\text { (\%) }\end{array}$ & $\begin{array}{l}\text { Abs. } \\
\text { (\$) }\end{array}$ & $\begin{array}{l}\text { Rel. } \\
\text { (\%) }\end{array}$ \\
\hline 2 & NIEcon.DB.SSFan.CS1.DCV0 & 756 & 2.7 & 562 & 3.4 & 848 & 2.8 & 788 & 2.5 \\
\hline 3 & NIEcon.EH.SSFan.CS1.DCV0 & 666 & 2.4 & 539 & 3.3 & 646 & 2.1 & 719 & 2.3 \\
\hline 4 & IEcon.DB.SSFan.CS1.DCV0 & 772 & 2.8 & 571 & 3.5 & 865 & 2.9 & 800 & 2.5 \\
\hline 5 & IEcon.EH.SSFan.CS1.DCV0 & 674 & 2.4 & 546 & 3.3 & 651 & 2.2 & 725 & 2.3 \\
\hline 6 & NoEcon.MSFan.CS1.DCV0 & 17083 & 61.3 & 10554 & 63.9 & 18988 & 62.9 & 20272 & 64.6 \\
\hline 7 & NIEcon.DB.MSFan.CS1.DCV0 & 17520 & 62.9 & 10930 & 66.2 & 19548 & 64.8 & 20748 & 66.1 \\
\hline 8 & NIEcon.EH.MSFan.CS1.DCV0 & 17476 & 62.7 & 10916 & 66.1 & 19467 & 64.5 & 20718 & 66.0 \\
\hline 9 & IEcon.DB.MSFan.CS1.DCV0 & 17542 & 63.0 & 10944 & 66.3 & 19565 & 64.9 & 20767 & 66.1 \\
\hline 10 & IEcon.EH.MSFan.CS1.DCV0 & 17488 & 62.8 & 10927 & 66.2 & 19472 & 64.6 & 20730 & 66.0 \\
\hline 11 & NoEcon.MSFan.CS2.DCV0 & 18284 & 65.6 & 10851 & 65.7 & 19958 & 66.2 & 21073 & 67.1 \\
\hline 12 & IEcon.DB.MSFan.CS2.DCV0 & 18509 & 66.4 & 11052 & 67.0 & 20200 & 67.0 & 21313 & 67.9 \\
\hline 13 & IEcon.EH.MSFan.CS2.DCV0 & 18502 & 66.4 & 11048 & 66.9 & 20175 & 66.9 & 21309 & 67.9 \\
\hline 14 & NoEcon.SSFan.CS1.DCV1 & 688 & 2.5 & 68 & 0.4 & 393 & 1.3 & 396 & 1.3 \\
\hline 15 & IEcon.DB.SSFan.CS1.DCV1 & 1477 & 5.3 & 636 & 3.9 & 1425 & 4.7 & 1259 & 4.0 \\
\hline 16 & IEcon.EH.SSFan.CS1.DCV1 & 1360 & 4.9 & 605 & 3.7 & 1155 & 3.8 & 1163 & 3.7 \\
\hline 17 & NoEcon.MSFan.CS1.DCV1 & 18584 & 66.7 & 11388 & 69.0 & 20355 & 67.5 & 21530 & 68.6 \\
\hline 18 & IEcon.DB.MSFan.CS1.DCV1 & 19032 & 68.3 & 11767 & 71.3 & 21150 & 70.1 & 22090 & 70.3 \\
\hline 19 & IEcon.EH.MSFan.CS1.DCV1 & 18973 & 68.1 & 11744 & 71.2 & 20987 & 69.6 & 22041 & 70.2 \\
\hline 20 & NoEcon.MSFan.CS2.DCV1 & 19559 & 70.2 & 11670 & 70.7 & 21335 & 70.7 & 22289 & 71.0 \\
\hline 21 & IEcon.DB.MSFan.CS2.DCV1 & 19775 & 71.0 & 11862 & 71.9 & 21657 & 71.8 & 22555 & 71.8 \\
\hline 22 & IEcon.EH.MSFan.CS2.DCV1 & 19767 & 71.0 & 11857 & 71.8 & 21616 & 71.7 & 22548 & 71.8 \\
\hline
\end{tabular}


Table D-32: Electricity Cost Savings Compared to Case 1 for the Supermarket Building in Climate Zones 6, 7 and 8

\begin{tabular}{|c|c|c|c|c|c|c|c|c|c|}
\hline \multirow{2}{*}{$\begin{array}{c}\text { Case } \\
\text { No }\end{array}$} & \multirow[b]{2}{*}{ Case Name } & \multicolumn{2}{|c|}{ Minneapolis-6A } & \multicolumn{2}{|c|}{ Helena-6B } & \multicolumn{2}{|c|}{ Duluth-7 } & \multicolumn{2}{|c|}{ Fairbanks-8 } \\
\hline & & $\begin{array}{l}\text { Abs. } \\
\text { (\$) }\end{array}$ & $\begin{array}{l}\text { Rel. } \\
\text { (\%) }\end{array}$ & $\begin{array}{l}\text { Abs. } \\
\text { (\$) }\end{array}$ & $\begin{array}{l}\text { Rel. } \\
(\%)\end{array}$ & $\begin{array}{l}\text { Abs. } \\
\text { (\$) }\end{array}$ & $\begin{array}{l}\text { Rel. } \\
\text { (\%) }\end{array}$ & $\begin{array}{l}\text { Abs. } \\
\text { (\$) }\end{array}$ & $\begin{array}{l}\text { Rel. } \\
\text { (\%) }\end{array}$ \\
\hline 2 & NIEcon.DB.SSFan.CS1.DCV0 & 1039 & 3.4 & 998 & 3.1 & 1072 & 3.6 & 4150 & 6.4 \\
\hline 3 & NIEcon.EH.SSFan.CS1.DCV0 & 893 & 2.9 & 961 & 3.0 & 1006 & 3.3 & 4124 & 6.4 \\
\hline 4 & IEcon.DB.SSFan.CS1.DCV0 & 1051 & 3.4 & 1004 & 3.1 & 1079 & 3.6 & 4154 & 6.4 \\
\hline 5 & IEcon.EH.SSFan.CS1.DCV0 & 896 & 2.9 & 964 & 3.0 & 1007 & 3.3 & 4122 & 6.4 \\
\hline 6 & NoEcon.MSFan.CS1.DCV0 & 19008 & 62.1 & 20415 & 63.8 & 18472 & 61.3 & 36647 & 56.6 \\
\hline 7 & NIEcon.DB.MSFan.CS1.DCV0 & 19955 & 65.2 & 21318 & 66.6 & 19515 & 64.7 & 41020 & 63.3 \\
\hline 8 & NIEcon.EH.MSFan.CS1.DCV0 & 19870 & 64.9 & 21273 & 66.5 & 19440 & 64.5 & 40966 & 63.3 \\
\hline 9 & IEcon.DB.MSFan.CS1.DCV0 & 19967 & 65.2 & 21330 & 66.7 & 19524 & 64.8 & 41027 & 63.3 \\
\hline 10 & IEcon.EH.MSFan.CS1.DCV0 & 19875 & 64.9 & 21280 & 66.5 & 19444 & 64.5 & 40970 & 63.3 \\
\hline 11 & NoEcon.MSFan.CS2.DCV0 & 20092 & 65.6 & 21226 & 66.3 & 19196 & 63.7 & 39564 & 61.1 \\
\hline 12 & IEcon.DB.MSFan.CS2.DCV0 & 20450 & 66.8 & 21653 & 67.7 & 19658 & 65.2 & 41156 & 63.5 \\
\hline 13 & IEcon.EH.MSFan.CS2.DCV0 & 20437 & 66.8 & 21648 & 67.7 & 19642 & 65.2 & 41145 & 63.5 \\
\hline 14 & NoEcon.SSFan.CS1.DCV1 & 112 & 0.4 & -124 & -0.4 & -341 & -1.1 & -996 & -1.5 \\
\hline 15 & IEcon.DB.SSFan.CS1.DCV1 & 1491 & 4.9 & 1297 & 4.1 & 1193 & 4.0 & 4159 & 6.4 \\
\hline 16 & IEcon.EH.SSFan.CS1.DCV1 & 1302 & 4.3 & 1245 & 3.9 & 1100 & 3.7 & 4119 & 6.4 \\
\hline 17 & NoEcon.MSFan.CS1.DCV1 & 20046 & 65.5 & 21044 & 65.8 & 19270 & 63.9 & 37563 & 58.0 \\
\hline 18 & IEcon.DB.MSFan.CS1.DCV1 & 21494 & 70.2 & 22611 & 70.7 & 20960 & 69.5 & 43728 & 67.5 \\
\hline 19 & IEcon.EH.MSFan.CS1.DCV1 & 21276 & 69.5 & 22471 & 70.2 & 20752 & 68.9 & 43528 & 67.2 \\
\hline 20 & NoEcon.MSFan.CS2.DCV1 & 21330 & 69.7 & 22215 & 69.4 & 20350 & 67.5 & 41895 & 64.7 \\
\hline 21 & IEcon.DB.MSFan.CS2.DCV1 & 21885 & 71.5 & 22931 & 71.7 & 21083 & 70.0 & 43885 & 67.8 \\
\hline 22 & IEcon.EH.MSFan.CS2.DCV1 & 21837 & 71.4 & 22905 & 71.6 & 21037 & 69.8 & 43856 & 67.7 \\
\hline
\end{tabular}


Table D-33: Gas Cost Savings Compared to Case 1 for the Small Office Building in Climate Zones 1, 2 and 3A

\begin{tabular}{|c|c|c|c|c|c|c|c|c|c|}
\hline \multirow[b]{2}{*}{$\begin{array}{c}\text { Case } \\
\text { No }\end{array}$} & \multirow[b]{2}{*}{ Case Name } & \multicolumn{2}{|c|}{ Miami-1A } & \multicolumn{2}{|c|}{ Houston-2A } & \multicolumn{2}{|c|}{ Phoenix-2B } & \multicolumn{2}{|c|}{ Atlanta-3A } \\
\hline & & $\begin{array}{c}\text { Abs. } \\
\text { (\$) }\end{array}$ & $\begin{array}{l}\text { Rel. } \\
\text { (\%) }\end{array}$ & $\begin{array}{c}\text { Abs. } \\
\text { (\$) }\end{array}$ & $\begin{array}{l}\text { Rel. } \\
\text { (\%) }\end{array}$ & $\begin{array}{l}\text { Abs. } \\
\text { (\$) }\end{array}$ & $\begin{array}{l}\text { Rel. } \\
\text { (\%) }\end{array}$ & $\begin{array}{l}\text { Abs. } \\
\text { (\$) }\end{array}$ & $\begin{array}{l}\text { Rel. } \\
\text { (\%) }\end{array}$ \\
\hline 2 & NIEcon.DB.SSFan.CS1.DCV0 & -3 & -35.7 & 0 & 0.1 & 1 & 0.5 & 2 & 0.3 \\
\hline 3 & NIEcon.EH.SSFan.CS1.DCV0 & -2 & -35.4 & 0 & 0.0 & 1 & 0.6 & 2 & 0.3 \\
\hline 4 & IEcon.DB.SSFan.CS1.DCV0 & -2 & -35.3 & 0 & 0.1 & 1 & 0.6 & 2 & 0.3 \\
\hline 5 & IEcon.EH.SSFan.CS1.DCV0 & -2 & -35.4 & 0 & 0.0 & 1 & 0.8 & 2 & 0.3 \\
\hline 6 & NoEcon.MSFan.CS1.DCV0 & -4 & -60.5 & -76 & -31.8 & -90 & -49.4 & -203 & -28.3 \\
\hline 7 & NIEcon.DB.MSFan.CS1.DCV0 & -4 & -52.6 & -74 & -31.0 & -87 & -47.9 & -200 & -27.9 \\
\hline 8 & NIEcon.EH.MSFan.CS1.DCV0 & -4 & -54.0 & -75 & -31.2 & -87 & -47.8 & -200 & -27.9 \\
\hline 9 & IEcon.DB.MSFan.CS1.DCV0 & -4 & -53.4 & -74 & -31.0 & -87 & -47.9 & -200 & -27.9 \\
\hline 10 & IEcon.EH.MSFan.CS1.DCV0 & -4 & -54.5 & -75 & -31.2 & -87 & -47.8 & -200 & -27.9 \\
\hline 11 & NoEcon.MSFan.CS2.DCV0 & -4 & -54.5 & -75 & -31.1 & -87 & -47.6 & -200 & -28.0 \\
\hline 12 & IEcon.DB.MSFan.CS2.DCV0 & -4 & -53.0 & -74 & -31.0 & -87 & -47.5 & -200 & -27.9 \\
\hline 13 & IEcon.EH.MSFan.CS2.DCV0 & -4 & -53.3 & -74 & -31.0 & -86 & -47.4 & -200 & -27.9 \\
\hline 14 & NoEcon.SSFan.CS1.DCV1 & 2 & 23.2 & 64 & 26.8 & 55 & 29.9 & 190 & 26.5 \\
\hline 15 & IEcon.DB.SSFan.CS1.DCV1 & -2 & -21.7 & 61 & 25.7 & 55 & 30.0 & 188 & 26.3 \\
\hline 16 & IEcon.EH.SSFan.CS1.DCV1 & -2 & -21.4 & 61 & 25.6 & 55 & 30.0 & 188 & 26.3 \\
\hline 17 & NoEcon.MSFan.CS1.DCV1 & 0 & -0.7 & 6 & 2.6 & -12 & -6.3 & 35 & 4.9 \\
\hline 18 & IEcon.DB.MSFan.CS1.DCV1 & 1 & 7.7 & 8 & 3.4 & -8 & -4.6 & 38 & 5.3 \\
\hline 19 & IEcon.EH.MSFan.CS1.DCV1 & 0 & 6.3 & 8 & 3.3 & -8 & -4.6 & 38 & 5.3 \\
\hline 20 & NoEcon.MSFan.CS2.DCV1 & 0 & 6.5 & 8 & 3.3 & -9 & -4.8 & 38 & 5.3 \\
\hline 21 & IEcon.DB.MSFan.CS2.DCV1 & 1 & 8.1 & 8 & 3.5 & -8 & -4.3 & 39 & 5.4 \\
\hline 22 & IEcon.EH.MSFan.CS2.DCV1 & 1 & 7.7 & 8 & 3.5 & -8 & -4.3 & 38 & 5.4 \\
\hline
\end{tabular}


Table D-34: Gas Cost Savings Compared to Case 1 for the Small Office Building in Climate Zones 3B, 3C and 4A

\begin{tabular}{|c|c|c|c|c|c|c|c|c|c|}
\hline \multirow[b]{2}{*}{$\begin{array}{c}\text { Case } \\
\text { No }\end{array}$} & \multirow[b]{2}{*}{ Case Name } & \multicolumn{2}{|c|}{ Los Angeles-3B } & \multicolumn{2}{|c|}{ Las Vegas-3B } & \multicolumn{2}{|c|}{ San Francisco-3C } & \multicolumn{2}{|c|}{ Baltimore-4A } \\
\hline & & $\begin{array}{l}\text { Abs. } \\
\text { (\$) }\end{array}$ & $\begin{array}{l}\text { Rel. } \\
\text { (\%) }\end{array}$ & $\begin{array}{c}\text { Abs. } \\
\text { (\$) }\end{array}$ & $\begin{array}{l}\text { Rel. } \\
\text { (\%) }\end{array}$ & $\begin{array}{c}\text { Abs. } \\
\text { (\$) }\end{array}$ & $\begin{array}{l}\text { Rel. } \\
\text { (\%) }\end{array}$ & $\begin{array}{c}\text { Abs. } \\
\text { (\$) }\end{array}$ & $\begin{array}{l}\text { Rel. } \\
\text { (\%) }\end{array}$ \\
\hline 2 & NIEcon.DB.SSFan.CS1.DCV0 & -2 & -2.1 & 4 & 1.1 & 3 & 1.0 & 3 & 0.3 \\
\hline 3 & NIEcon.EH.SSFan.CS1.DCV0 & -2 & -2.1 & 4 & 1.1 & 3 & 1.0 & 3 & 0.3 \\
\hline 4 & IEcon.DB.SSFan.CS1.DCV0 & -2 & -2.1 & 4 & 1.2 & 3 & 1.0 & 3 & 0.3 \\
\hline 5 & IEcon.EH.SSFan.CS1.DCV0 & -2 & -2.1 & 4 & 1.1 & 3 & 0.9 & 3 & 0.3 \\
\hline 6 & NoEcon.MSFan.CS1.DCV0 & -67 & -67.3 & -127 & -39.3 & -150 & -43.5 & -223 & -23.9 \\
\hline 7 & NIEcon.DB.MSFan.CS1.DCV0 & -63 & -62.6 & -123 & -38.1 & -146 & -42.5 & -220 & -23.6 \\
\hline 8 & NIEcon.EH.MSFan.CS1.DCV0 & -63 & -62.5 & -123 & -38.1 & -147 & -42.5 & -220 & -23.6 \\
\hline 9 & IEcon.DB.MSFan.CS1.DCV0 & -63 & -62.6 & -123 & -38.2 & -146 & -42.5 & -220 & -23.6 \\
\hline 10 & IEcon.EH.MSFan.CS1.DCV0 & -63 & -62.6 & -123 & -38.1 & -147 & -42.5 & -220 & -23.6 \\
\hline 11 & NoEcon.MSFan.CS2.DCV0 & -63 & -63.0 & -123 & -38.3 & -148 & -42.8 & -221 & -23.6 \\
\hline 12 & IEcon.DB.MSFan.CS2.DCV0 & -62 & -62.4 & -122 & -37.9 & -146 & -42.5 & -220 & -23.6 \\
\hline 13 & IEcon.EH.MSFan.CS2.DCV0 & -62 & -62.4 & -122 & -37.9 & -146 & -42.5 & -220 & -23.6 \\
\hline 14 & NoEcon.SSFan.CS1.DCV1 & 25 & 24.8 & 89 & 27.6 & 111 & 32.2 & 290 & 31.0 \\
\hline 15 & IEcon.DB.SSFan.CS1.DCV1 & 20 & 19.7 & 92 & 28.6 & 114 & 33.0 & 291 & 31.2 \\
\hline 16 & IEcon.EH.SSFan.CS1.DCV1 & 20 & 19.7 & 92 & 28.6 & 114 & 33.0 & 291 & 31.2 \\
\hline 17 & NoEcon.MSFan.CS1.DCV1 & -18 & -18.4 & -4 & -1.3 & 3 & 0.8 & 122 & 13.0 \\
\hline 18 & IEcon.DB.MSFan.CS1.DCV1 & -13 & -13.2 & 0 & -0.1 & 6 & 1.8 & 124 & 13.3 \\
\hline 19 & IEcon.EH.MSFan.CS1.DCV1 & -13 & -13.3 & 0 & -0.1 & 6 & 1.8 & 124 & 13.3 \\
\hline 20 & NoEcon.MSFan.CS2.DCV1 & -13 & -13.3 & -1 & -0.3 & 6 & 1.6 & 124 & 13.3 \\
\hline 21 & IEcon.DB.MSFan.CS2.DCV1 & -13 & -13.0 & 0 & 0.0 & 6 & 1.9 & 124 & 13.3 \\
\hline 22 & IEcon.EH.MSFan.CS2.DCV1 & -13 & -13.0 & 0 & 0.0 & 7 & 1.9 & 124 & 13.3 \\
\hline
\end{tabular}


Table D-35: Gas Cost Savings Compared to Case 1 for the Small Office Building in Climate Zones 4B, 4C, 5A and 5B

\begin{tabular}{|c|c|c|c|c|c|c|c|c|c|}
\hline \multirow[b]{2}{*}{$\begin{array}{c}\text { Case } \\
\text { No }\end{array}$} & \multirow[b]{2}{*}{ Case Name } & \multicolumn{2}{|c|}{ Albuquerque-4B } & \multicolumn{2}{|c|}{ Seattle-4C } & \multicolumn{2}{|c|}{ Chicago-5A } & \multicolumn{2}{|c|}{ Denver-5B } \\
\hline & & $\begin{array}{c}\text { Abs. } \\
\text { (\$) }\end{array}$ & $\begin{array}{l}\text { Rel. } \\
\text { (\%) }\end{array}$ & $\begin{array}{c}\text { Abs. } \\
\text { (\$) }\end{array}$ & $\begin{array}{l}\text { Rel. } \\
\text { (\%) }\end{array}$ & $\begin{array}{c}\text { Abs. } \\
\text { (\$) }\end{array}$ & $\begin{array}{l}\text { Rel. } \\
\text { (\%) }\end{array}$ & $\begin{array}{c}\text { Abs. } \\
\text { (\$) }\end{array}$ & $\begin{array}{l}\text { Rel. } \\
\text { (\%) }\end{array}$ \\
\hline 2 & NIEcon.DB.SSFan.CS1.DCV0 & 2 & 0.4 & 2 & 0.3 & 2 & 0.2 & 5 & 0.7 \\
\hline 3 & NIEcon.EH.SSFan.CS1.DCV0 & 2 & 0.4 & 2 & 0.3 & 2 & 0.1 & 5 & 0.7 \\
\hline 4 & IEcon.DB.SSFan.CS1.DCV0 & 2 & 0.4 & 2 & 0.3 & 2 & 0.2 & 5 & 0.6 \\
\hline 5 & IEcon.EH.SSFan.CS1.DCV0 & 2 & 0.4 & 2 & 0.3 & 2 & 0.1 & 5 & 0.6 \\
\hline 6 & NoEcon.MSFan.CS1.DCV0 & -141 & -27.8 & -283 & -34.4 & -283 & -21.1 & -199 & -26.0 \\
\hline 7 & NIEcon.DB.MSFan.CS1.DCV0 & -136 & -27.0 & -281 & -34.1 & -281 & -21.0 & -195 & -25.5 \\
\hline 8 & NIEcon.EH.MSFan.CS1.DCV0 & -136 & -27.0 & -281 & -34.1 & -282 & -21.0 & -195 & -25.5 \\
\hline 9 & IEcon.DB.MSFan.CS1.DCV0 & -136 & -27.0 & -281 & -34.1 & -281 & -21.0 & -195 & -25.5 \\
\hline 10 & IEcon.EH.MSFan.CS1.DCV0 & -136 & -27.0 & -281 & -34.1 & -282 & -21.0 & -195 & -25.5 \\
\hline 11 & NoEcon.MSFan.CS2.DCV0 & -137 & -27.1 & -281 & -34.1 & -282 & -21.0 & -196 & -25.6 \\
\hline 12 & IEcon.DB.MSFan.CS2.DCV0 & -136 & -26.9 & -280 & -34.0 & -281 & -20.9 & -194 & -25.4 \\
\hline 13 & IEcon.EH.MSFan.CS2.DCV0 & -136 & -26.9 & -280 & -34.0 & -281 & -20.9 & -194 & -25.3 \\
\hline 14 & NoEcon.SSFan.CS1.DCV1 & 128 & 25.3 & 294 & 35.6 & 394 & 29.3 & 199 & 26.0 \\
\hline 15 & IEcon.DB.SSFan.CS1.DCV1 & 127 & 25.2 & 296 & 35.9 & 395 & 29.4 & 203 & 26.6 \\
\hline 16 & IEcon.EH.SSFan.CS1.DCV1 & 127 & 25.2 & 295 & 35.9 & 395 & 29.4 & 203 & 26.6 \\
\hline 17 & NoEcon.MSFan.CS1.DCV1 & 26 & 5.1 & 89 & 10.8 & 172 & 12.8 & 51 & 6.6 \\
\hline 18 & IEcon.DB.MSFan.CS1.DCV1 & 30 & 6.0 & 93 & 11.3 & 175 & 13.0 & 56 & 7.3 \\
\hline 19 & IEcon.EH.MSFan.CS1.DCV1 & 30 & 6.0 & 93 & 11.3 & 174 & 13.0 & 56 & 7.3 \\
\hline 20 & NoEcon.MSFan.CS2.DCV1 & 29 & 5.8 & 92 & 11.2 & 174 & 13.0 & 55 & 7.2 \\
\hline 21 & IEcon.DB.MSFan.CS2.DCV1 & 31 & 6.0 & 93 & 11.3 & 175 & 13.0 & 57 & 7.4 \\
\hline 22 & IEcon.EH.MSFan.CS2.DCV1 & 31 & 6.1 & 93 & 11.3 & 175 & 13.0 & 57 & 7.4 \\
\hline
\end{tabular}


Table D-36: Gas Cost Savings Compared to Case 1 for the Small Office Building in Climate Zones 6, 7 and 8

\begin{tabular}{|c|c|c|c|c|c|c|c|c|c|}
\hline \multirow[b]{2}{*}{$\begin{array}{c}\text { Case } \\
\text { No }\end{array}$} & \multirow[b]{2}{*}{ Case Name } & \multicolumn{2}{|c|}{ Minneapolis-6A } & \multicolumn{2}{|c|}{ Helena-6B } & \multicolumn{2}{|c|}{ Duluth-7 } & \multicolumn{2}{|c|}{ Fairbanks-8 } \\
\hline & & $\begin{array}{c}\text { Abs. } \\
\text { (\$) }\end{array}$ & $\begin{array}{l}\text { Rel. } \\
\text { (\%) }\end{array}$ & $\begin{array}{c}\text { Abs. } \\
\text { (\$) }\end{array}$ & $\begin{array}{l}\text { Rel. } \\
\text { (\%) }\end{array}$ & $\begin{array}{l}\text { Abs. } \\
\text { (\$) }\end{array}$ & $\begin{array}{l}\text { Rel. } \\
\text { (\%) }\end{array}$ & $\begin{array}{c}\text { Abs. } \\
\text { (\$) }\end{array}$ & $\begin{array}{l}\text { Rel. } \\
\text { (\%) }\end{array}$ \\
\hline 2 & NIEcon.DB.SSFan.CS1.DCV0 & 2 & 0.2 & 4 & 0.3 & 2 & 0.2 & -2 & -0.1 \\
\hline 3 & NIEcon.EH.SSFan.CS1.DCV0 & 2 & 0.2 & 3 & 0.3 & 2 & 0.1 & -2 & -0.1 \\
\hline 4 & IEcon.DB.SSFan.CS1.DCV0 & 2 & 0.2 & 4 & 0.3 & 2 & 0.2 & -3 & -0.1 \\
\hline 5 & IEcon.EH.SSFan.CS1.DCV0 & 2 & 0.2 & 3 & 0.3 & 2 & 0.1 & -2 & -0.1 \\
\hline 6 & NoEcon.MSFan.CS1.DCV0 & -229 & -17.8 & -303 & -23.9 & -279 & -17.8 & -421 & -12.7 \\
\hline 7 & NIEcon.DB.MSFan.CS1.DCV0 & -228 & -17.7 & -300 & -23.6 & -277 & -17.7 & -411 & -12.4 \\
\hline 8 & NIEcon.EH.MSFan.CS1.DCV0 & -228 & -17.7 & -300 & -23.6 & -277 & -17.7 & -411 & -12.4 \\
\hline 9 & IEcon.DB.MSFan.CS1.DCV0 & -228 & -17.7 & -300 & -23.6 & -277 & -17.7 & -411 & -12.4 \\
\hline 10 & IEcon.EH.MSFan.CS1.DCV0 & -228 & -17.7 & -300 & -23.6 & -277 & -17.7 & -411 & -12.4 \\
\hline 11 & NoEcon.MSFan.CS2.DCV0 & -228 & -17.7 & -300 & -23.6 & -277 & -17.7 & -411 & -12.4 \\
\hline 12 & IEcon.DB.MSFan.CS2.DCV0 & -227 & -17.7 & -299 & -23.5 & -277 & -17.7 & -411 & -12.4 \\
\hline 13 & IEcon.EH.MSFan.CS2.DCV0 & -227 & -17.7 & -299 & -23.5 & -277 & -17.7 & -411 & -12.4 \\
\hline 14 & NoEcon.SSFan.CS1.DCV1 & 375 & 29.1 & 350 & 27.5 & 433 & 27.7 & 772 & 23.4 \\
\hline 15 & IEcon.DB.SSFan.CS1.DCV1 & 377 & 29.3 & 354 & 27.9 & 436 & 27.9 & 744 & 22.5 \\
\hline 16 & IEcon.EH.SSFan.CS1.DCV1 & 377 & 29.3 & 354 & 27.8 & 436 & 27.9 & 744 & 22.5 \\
\hline 17 & NoEcon.MSFan.CS1.DCV1 & 192 & 14.9 & 123 & 9.7 & 219 & 14.0 & 415 & 12.6 \\
\hline 18 & IEcon.DB.MSFan.CS1.DCV1 & 194 & 15.1 & 127 & 10.0 & 223 & 14.3 & 429 & 13.0 \\
\hline 19 & IEcon.EH.MSFan.CS1.DCV1 & 195 & 15.1 & 127 & 10.0 & 223 & 14.3 & 429 & 13.0 \\
\hline 20 & NoEcon.MSFan.CS2.DCV1 & 194 & 15.0 & 126 & 9.9 & 221 & 14.1 & 426 & 12.9 \\
\hline 21 & IEcon.DB.MSFan.CS2.DCV1 & 194 & 15.1 & 128 & 10.1 & 223 & 14.3 & 429 & 13.0 \\
\hline 22 & IEcon.EH.MSFan.CS2.DCV1 & 194 & 15.1 & 128 & 10.1 & 223 & 14.3 & 429 & 13.0 \\
\hline
\end{tabular}


Table D-37: Gas Cost Savings Compared to Case 1 for the Stand-alone Retail Building in Climate Zones 1, 2 and 3A

\begin{tabular}{|c|c|c|c|c|c|c|c|c|c|}
\hline \multirow{2}{*}{$\begin{array}{c}\text { Case } \\
\text { No }\end{array}$} & \multirow{2}{*}{ Case Name } & \multicolumn{2}{|c|}{ Miami-1A } & \multicolumn{2}{|c|}{ Houston-2A } & \multicolumn{2}{|c|}{ Phoenix-2B } & \multicolumn{2}{|c|}{ Atlanta-3A } \\
\hline & & $\begin{array}{c}\text { Abs. } \\
\text { (\$) }\end{array}$ & $\begin{array}{l}\text { Rel. } \\
\text { (\%) }\end{array}$ & $\begin{array}{c}\text { Abs. } \\
\text { (\$) }\end{array}$ & $\begin{array}{l}\text { Rel. } \\
\text { (\%) }\end{array}$ & $\begin{array}{c}\text { Abs. } \\
\text { (\$) }\end{array}$ & $\begin{array}{l}\text { Rel. } \\
\text { (\%) }\end{array}$ & $\begin{array}{c}\text { Abs. } \\
\text { (\$) }\end{array}$ & $\begin{array}{l}\text { Rel. } \\
\text { (\%) }\end{array}$ \\
\hline 2 & NIEcon.DB.SSFan.CS1.DCV0 & 2 & 0.7 & 3 & 0.1 & 5 & 0.1 & 5 & 0.1 \\
\hline 3 & NIEcon.EH.SSFan.CS1.DCV0 & 1 & 0.4 & 2 & 0.1 & 7 & 0.2 & 4 & 0.0 \\
\hline 4 & IEcon.DB.SSFan.CS1.DCV0 & 2 & 0.7 & 2 & 0.1 & 5 & 0.1 & 5 & 0.1 \\
\hline 5 & IEcon.EH.SSFan.CS1.DCV0 & 1 & 0.4 & 2 & 0.0 & 6 & 0.2 & 5 & 0.1 \\
\hline 6 & NoEcon.MSFan.CS1.DCV0 & -107 & -43.0 & -541 & -16.4 & -740 & -22.2 & -1400 & -14.4 \\
\hline 7 & NIEcon.DB.MSFan.CS1.DCV0 & -105 & -42.3 & -538 & -16.3 & -733 & -22.0 & -1397 & -14.4 \\
\hline 8 & NIEcon.EH.MSFan.CS1.DCV0 & -105 & -42.4 & -539 & -16.4 & -731 & -21.9 & -1397 & -14.4 \\
\hline 9 & IEcon.DB.MSFan.CS1.DCV0 & -105 & -42.3 & -538 & -16.3 & -733 & -22.0 & -1397 & -14.4 \\
\hline 10 & IEcon.EH.MSFan.CS1.DCV0 & -105 & -42.4 & -539 & -16.4 & -731 & -21.9 & -1397 & -14.4 \\
\hline 11 & NoEcon.MSFan.CS2.DCV0 & -105 & -42.5 & -539 & -16.4 & -731 & -21.9 & -1398 & -14.4 \\
\hline 12 & IEcon.DB.MSFan.CS2.DCV0 & -105 & -42.4 & -538 & -16.3 & -731 & -21.9 & -1397 & -14.4 \\
\hline 13 & IEcon.EH.MSFan.CS2.DCV0 & -105 & -42.4 & -538 & -16.3 & -728 & -21.8 & -1396 & -14.4 \\
\hline 14 & NoEcon.SSFan.CS1.DCV1 & 139 & 55.9 & 1233 & 37.4 & 1283 & 38.4 & 3351 & 34.5 \\
\hline 15 & IEcon.DB.SSFan.CS1.DCV1 & 140 & 56.5 & 1236 & 37.5 & 1291 & 38.7 & 3355 & 34.6 \\
\hline 16 & IEcon.EH.SSFan.CS1.DCV1 & 140 & 56.4 & 1235 & 37.5 & 1292 & 38.7 & 3355 & 34.6 \\
\hline 17 & NoEcon.MSFan.CS1.DCV1 & 84 & 34.0 & 875 & 26.6 & 813 & 24.4 & 2387 & 24.6 \\
\hline 18 & IEcon.DB.MSFan.CS1.DCV1 & 86 & 34.6 & 878 & 26.7 & 817 & 24.5 & 2390 & 24.6 \\
\hline 19 & IEcon.EH.MSFan.CS1.DCV1 & 86 & 34.5 & 878 & 26.7 & 819 & 24.5 & 2390 & 24.6 \\
\hline 20 & NoEcon.MSFan.CS2.DCV1 & 85 & 34.4 & 877 & 26.6 & 819 & 24.5 & 2390 & 24.6 \\
\hline 21 & IEcon.DB.MSFan.CS2.DCV1 & 86 & 34.7 & 879 & 26.7 & 821 & 24.6 & 2391 & 24.6 \\
\hline 22 & IEcon.EH.MSFan.CS2.DCV1 & 86 & 34.6 & 879 & 26.7 & 823 & 24.6 & 2391 & 24.6 \\
\hline
\end{tabular}


Table D-38: Gas Cost Savings Compared to Case 1 for the Stand-alone Retail Building in Climate Zones 3B, 3C and 4A

\begin{tabular}{|c|c|c|c|c|c|c|c|c|c|}
\hline \multirow{2}{*}{$\begin{array}{c}\text { Case } \\
\text { No }\end{array}$} & \multirow{2}{*}{ Case Name } & \multicolumn{2}{|c|}{ Los Angeles-3B } & \multicolumn{2}{|c|}{ Las Vegas-3B } & \multicolumn{2}{|c|}{ San Francisco-3C } & \multicolumn{2}{|c|}{ Baltimore-4A } \\
\hline & & $\begin{array}{c}\text { Abs. } \\
\text { (\$) }\end{array}$ & $\begin{array}{l}\text { Rel. } \\
\text { (\%) }\end{array}$ & $\begin{array}{c}\text { Abs. } \\
\text { (\$) }\end{array}$ & $\begin{array}{l}\text { Rel. } \\
\text { (\%) }\end{array}$ & $\begin{array}{c}\text { Abs. } \\
\text { (\$) }\end{array}$ & $\begin{array}{l}\text { Rel. } \\
\text { (\%) }\end{array}$ & $\begin{array}{c}\text { Abs. } \\
\text { (\$) }\end{array}$ & $\begin{array}{l}\text { Rel. } \\
\text { (\%) }\end{array}$ \\
\hline 2 & NIEcon.DB.SSFan.CS1.DCV0 & 5 & 0.2 & 7 & 0.1 & 4 & 0.1 & 3 & 0.0 \\
\hline 3 & NIEcon.EH.SSFan.CS1.DCV0 & 5 & 0.2 & 8 & 0.1 & 4 & 0.1 & 2 & 0.0 \\
\hline 4 & IEcon.DB.SSFan.CS1.DCV0 & 5 & 0.2 & 8 & 0.1 & 4 & 0.1 & 3 & 0.0 \\
\hline 5 & IEcon.EH.SSFan.CS1.DCV0 & 4 & 0.2 & 8 & 0.1 & 4 & 0.1 & 3 & 0.0 \\
\hline 6 & NoEcon.MSFan.CS1.DCV0 & -697 & -29.9 & -893 & -16.6 & -766 & -11.8 & -1486 & -10.7 \\
\hline 7 & NIEcon.DB.MSFan.CS1.DCV0 & -690 & -29.6 & -887 & -16.5 & -763 & -11.8 & -1483 & -10.7 \\
\hline 8 & NIEcon.EH.MSFan.CS1.DCV0 & -691 & -29.6 & -887 & -16.5 & -763 & -11.8 & -1484 & -10.7 \\
\hline 9 & IEcon.DB.MSFan.CS1.DCV0 & -690 & -29.6 & -888 & -16.5 & -763 & -11.8 & -1483 & -10.7 \\
\hline 10 & IEcon.EH.MSFan.CS1.DCV0 & -691 & -29.6 & -887 & -16.5 & -763 & -11.8 & -1484 & -10.7 \\
\hline 11 & NoEcon.MSFan.CS2.DCV0 & -693 & -29.7 & -888 & -16.5 & -764 & -11.8 & -1485 & -10.7 \\
\hline 12 & IEcon.DB.MSFan.CS2.DCV0 & -689 & -29.5 & -885 & -16.5 & -763 & -11.8 & -1483 & -10.6 \\
\hline 13 & IEcon.EH.MSFan.CS2.DCV0 & -689 & -29.5 & -885 & -16.5 & -762 & -11.8 & -1483 & -10.6 \\
\hline 14 & NoEcon.SSFan.CS1.DCV1 & 963 & 41.3 & 1897 & 35.3 & 2620 & 40.4 & 4913 & 35.3 \\
\hline 15 & IEcon.DB.SSFan.CS1.DCV1 & 967 & 41.4 & 1904 & 35.4 & 2624 & 40.5 & 4916 & 35.3 \\
\hline 16 & IEcon.EH.SSFan.CS1.DCV1 & 967 & 41.4 & 1905 & 35.4 & 2624 & 40.5 & 4915 & 35.3 \\
\hline 17 & NoEcon.MSFan.CS1.DCV1 & 544 & 23.3 & 1298 & 24.1 & 1893 & 29.2 & 3868 & 27.8 \\
\hline 18 & IEcon.DB.MSFan.CS1.DCV1 & 549 & 23.5 & 1303 & 24.2 & 1897 & 29.3 & 3870 & 27.8 \\
\hline 19 & IEcon.EH.MSFan.CS1.DCV1 & 549 & 23.5 & 1303 & 24.2 & 1897 & 29.3 & 3870 & 27.8 \\
\hline 20 & NoEcon.MSFan.CS2.DCV1 & 548 & 23.5 & 1303 & 24.2 & 1896 & 29.3 & 3869 & 27.8 \\
\hline 21 & IEcon.DB.MSFan.CS2.DCV1 & 549 & 23.5 & 1305 & 24.3 & 1898 & 29.3 & 3870 & 27.8 \\
\hline 22 & IEcon.EH.MSFan.CS2.DCV1 & 549 & 23.5 & 1307 & 24.3 & 1898 & 29.3 & 3871 & 27.8 \\
\hline
\end{tabular}


Table D-39: Gas Cost Savings Compared to Case 1 for the Stand-alone Retail Building in Climate Zones 4B, 4C, 5A and 5B

\begin{tabular}{|c|c|c|c|c|c|c|c|c|c|}
\hline \multirow{2}{*}{$\begin{array}{l}\text { Case } \\
\text { No }\end{array}$} & \multirow[b]{2}{*}{ Case Name } & \multicolumn{2}{|c|}{ Albuquerque-4B } & \multicolumn{2}{|c|}{ Seattle-4C } & \multicolumn{2}{|c|}{ Chicago-5A } & \multicolumn{2}{|c|}{ Denver-5B } \\
\hline & & $\begin{array}{c}\text { Abs. } \\
\text { (\$) }\end{array}$ & $\begin{array}{l}\text { Rel. } \\
\text { (\%) }\end{array}$ & $\begin{array}{c}\text { Abs. } \\
\text { (\$) }\end{array}$ & $\begin{array}{l}\text { Rel. } \\
\text { (\%) }\end{array}$ & $\begin{array}{c}\text { Abs. } \\
(\$)\end{array}$ & $\begin{array}{l}\text { Rel. } \\
(\%)\end{array}$ & $\begin{array}{c}\text { Abs. } \\
\text { (\$) }\end{array}$ & $\begin{array}{l}\text { Rel. } \\
(\%)\end{array}$ \\
\hline 2 & NIEcon.DB.SSFan.CS1.DCV0 & 8 & 0.1 & 3 & 0.0 & 19 & 0.1 & 16 & 0.1 \\
\hline 3 & NIEcon.EH.SSFan.CS1.DCV0 & 8 & 0.1 & 3 & 0.0 & 17 & 0.1 & 16 & 0.1 \\
\hline 4 & IEcon.DB.SSFan.CS1.DCV0 & 8 & 0.1 & 3 & 0.0 & 19 & 0.1 & 16 & 0.1 \\
\hline 5 & IEcon.EH.SSFan.CS1.DCV0 & 8 & 0.1 & 3 & 0.0 & 17 & 0.1 & 16 & 0.1 \\
\hline 6 & NoEcon.MSFan.CS1.DCV0 & -1004 & -13.0 & -1274 & -9.3 & -2017 & -10.7 & -1523 & -13.4 \\
\hline 7 & NIEcon.DB.MSFan.CS1.DCV0 & -999 & -13.0 & -1270 & -9.3 & -2006 & -10.7 & -1517 & -13.4 \\
\hline 8 & NIEcon.EH.MSFan.CS1.DCV0 & -999 & -13.0 & -1270 & -9.3 & -2005 & -10.7 & -1518 & -13.4 \\
\hline 9 & IEcon.DB.MSFan.CS1.DCV0 & -999 & -13.0 & -1270 & -9.3 & -2005 & -10.7 & -1517 & -13.4 \\
\hline 10 & IEcon.EH.MSFan.CS1.DCV0 & -999 & -13.0 & -1271 & -9.3 & -2005 & -10.7 & -1518 & -13.4 \\
\hline 11 & NoEcon.MSFan.CS2.DCV0 & -998 & -13.0 & -1271 & -9.3 & -2006 & -10.7 & -1515 & -13.3 \\
\hline 12 & IEcon.DB.MSFan.CS2.DCV0 & -996 & -12.9 & -1270 & -9.3 & -2003 & -10.7 & -1512 & -13.3 \\
\hline 13 & IEcon.EH.MSFan.CS2.DCV0 & -995 & -12.9 & -1269 & -9.3 & -2003 & -10.7 & -1511 & -13.3 \\
\hline 14 & NoEcon.SSFan.CS1.DCV1 & 2590 & 33.6 & 5732 & 42.0 & 6050 & 32.2 & 3626 & 31.9 \\
\hline 15 & IEcon.DB.SSFan.CS1.DCV1 & 2597 & 33.7 & 5737 & 42.0 & 6034 & 32.1 & 3641 & 32.1 \\
\hline 16 & IEcon.EH.SSFan.CS1.DCV1 & 2598 & 33.7 & 5737 & 42.0 & 6033 & 32.1 & 3642 & 32.1 \\
\hline 17 & NoEcon.MSFan.CS1.DCV1 & 1881 & 24.4 & 4452 & 32.6 & 4659 & 24.8 & 2524 & 22.2 \\
\hline 18 & IEcon.DB.MSFan.CS1.DCV1 & 1887 & 24.5 & 4456 & 32.6 & 4701 & 25.0 & 2539 & 22.4 \\
\hline 19 & IEcon.EH.MSFan.CS1.DCV1 & 1887 & 24.5 & 4455 & 32.6 & 4701 & 25.0 & 2539 & 22.4 \\
\hline 20 & NoEcon.MSFan.CS2.DCV1 & 1887 & 24.5 & 4455 & 32.6 & 4684 & 24.9 & 2540 & 22.4 \\
\hline 21 & IEcon.DB.MSFan.CS2.DCV1 & 1889 & 24.5 & 4455 & 32.6 & 4702 & 25.0 & 2543 & 22.4 \\
\hline 22 & IEcon.EH.MSFan.CS2.DCV1 & 1891 & 24.6 & 4456 & 32.6 & 4703 & 25.0 & 2544 & 22.4 \\
\hline
\end{tabular}


Table D-40: Gas Cost Savings Compared to Case 1 for the Stand-alone Retail Building in Climate Zones 6, 7 and 8

\begin{tabular}{|c|c|c|c|c|c|c|c|c|c|}
\hline \multirow{2}{*}{$\begin{array}{c}\text { Case } \\
\text { No }\end{array}$} & \multirow[b]{2}{*}{ Case Name } & \multicolumn{2}{|c|}{ Minneapolis-6A } & \multicolumn{2}{|c|}{ Helena-6B } & \multicolumn{2}{|c|}{ Duluth-7 } & \multicolumn{2}{|c|}{ Fairbanks-8 } \\
\hline & & $\begin{array}{c}\text { Abs. } \\
(\$)\end{array}$ & $\begin{array}{l}\text { Rel. } \\
(\%)\end{array}$ & $\begin{array}{c}\text { Abs. } \\
(\$)\end{array}$ & $\begin{array}{l}\text { Rel. } \\
(\%)\end{array}$ & $\begin{array}{c}\text { Abs. } \\
\text { (\$) }\end{array}$ & $\begin{array}{l}\text { Rel. } \\
(\%)\end{array}$ & $\begin{array}{c}\text { Abs. } \\
(\$)\end{array}$ & $\begin{array}{l}\text { Rel. } \\
(\%)\end{array}$ \\
\hline 2 & NIEcon.DB.SSFan.CS1.DCV0 & 27 & 0.2 & 26 & 0.1 & 10 & 0.0 & 674 & 1.5 \\
\hline 3 & NIEcon.EH.SSFan.CS1.DCV0 & 26 & 0.1 & 27 & 0.1 & 9 & 0.0 & 670 & 1.5 \\
\hline 4 & IEcon.DB.SSFan.CS1.DCV0 & 27 & 0.2 & 26 & 0.1 & 10 & 0.0 & 672 & 1.5 \\
\hline 5 & IEcon.EH.SSFan.CS1.DCV0 & 27 & 0.1 & 26 & 0.1 & 9 & 0.0 & 670 & 1.5 \\
\hline 8 & NIEcon.EH.MSFan.CS1.DCV0 & -1762 & -9.9 & -2573 & -13.7 & -2357 & -10.6 & -3362 & -7.7 \\
\hline 9 & IEcon.DB.MSFan.CS1.DCV0 & -1761 & -9.9 & -2575 & -13.7 & -2357 & -10.6 & -3364 & -7.7 \\
\hline 10 & IEcon.EH.MSFan.CS1.DCV0 & -1762 & -9.9 & -2573 & -13.7 & -2357 & -10.6 & -3365 & -7.7 \\
\hline 11 & NoEcon.MSFan.CS2.DCV0 & -1782 & -10.0 & -2624 & -14.0 & -2403 & -10.8 & -3497 & -8.0 \\
\hline 12 & IEcon.DB.MSFan.CS2.DCV0 & -1760 & -9.9 & -2569 & -13.7 & -2356 & -10.6 & -3353 & -7.6 \\
\hline 16 & IEcon.EH.SSFan.CS1.DCV1 & 5353 & 30.0 & 5792 & 30.8 & 6707 & 30.1 & 11561 & 26.3 \\
\hline 17 & NoEcon.MSFan.CS1.DCV1 & 4174 & 23.4 & 3925 & 20.9 & 5058 & 22.7 & 7475 & 17.0 \\
\hline 18 & IEcon.DB.MSFan.CS1.DCV1 & 4254 & 23.9 & 4050 & 21.6 & 5194 & 23.3 & 8855 & 20.2 \\
\hline 19 & IEcon.EH.MSFan.CS1.DCV1 & 4254 & 23.9 & 4049 & 21.6 & 5194 & 23.3 & 8855 & 20.2 \\
\hline 20 & NoEcon.MSFan.CS2.DCV1 & 4237 & 23.8 & 3998 & 21.3 & 5172 & 23.2 & 8800 & 20.0 \\
\hline 21 & IEcon.DB.MSFan.CS2.DCV1 & 4256 & 23.9 & 4055 & 21.6 & 5195 & 23.3 & 8865 & 20.2 \\
\hline 22 & IEcon.EH.MSFan.CS2.DCV1 & 4257 & 23.9 & 4056 & 21.6 & 5196 & 23.3 & 8865 & 20.2 \\
\hline
\end{tabular}


Table D-41: Gas Cost Savings Compared to Case 1 for the Strip Mall Building in Climate Zones 1, 2 and 3A

\begin{tabular}{|c|c|c|c|c|c|c|c|c|c|}
\hline \multirow{2}{*}{$\begin{array}{c}\text { Case } \\
\text { No }\end{array}$} & \multirow[b]{2}{*}{ Case Name } & \multicolumn{2}{|c|}{ Miami-1A } & \multicolumn{2}{|c|}{ Houston-2A } & \multicolumn{2}{|c|}{ Phoenix-2B } & \multicolumn{2}{|c|}{ Atlanta-3A } \\
\hline & & $\begin{array}{c}\text { Abs. } \\
\text { (\$) }\end{array}$ & $\begin{array}{l}\text { Rel. } \\
\text { (\%) }\end{array}$ & $\begin{array}{c}\text { Abs. } \\
\text { (\$) }\end{array}$ & $\begin{array}{l}\text { Rel. } \\
(\%)\end{array}$ & $\begin{array}{c}\text { Abs. } \\
\text { (\$) }\end{array}$ & $\begin{array}{l}\text { Rel. } \\
\text { (\%) }\end{array}$ & $\begin{array}{c}\text { Abs. } \\
\text { (\$) }\end{array}$ & $\begin{array}{l}\text { Rel. } \\
\text { (\%) }\end{array}$ \\
\hline 2 & NIEcon.DB.SSFan.CS1.DCV0 & 21 & 5.0 & 8 & 0.3 & 17 & 0.5 & 15 & 0.2 \\
\hline 3 & NIEcon.EH.SSFan.CS1.DCV0 & 19 & 4.6 & 6 & 0.2 & 19 & 0.5 & 14 & 0.1 \\
\hline 4 & IEcon.DB.SSFan.CS1.DCV0 & 21 & 5.0 & 8 & 0.2 & 16 & 0.5 & 15 & 0.2 \\
\hline 5 & IEcon.EH.SSFan.CS1.DCV0 & 19 & 4.5 & 6 & 0.2 & 19 & 0.5 & 14 & 0.2 \\
\hline 6 & NoEcon.MSFan.CS1.DCV0 & -159 & -37.9 & -567 & -17.6 & -752 & -21.0 & -1359 & -14.8 \\
\hline 7 & NIEcon.DB.MSFan.CS1.DCV0 & -142 & -33.9 & -561 & -17.5 & -741 & -20.7 & -1351 & -14.7 \\
\hline 8 & NIEcon.EH.MSFan.CS1.DCV0 & -144 & -34.4 & -563 & -17.5 & -737 & -20.6 & -1352 & -14.7 \\
\hline 9 & IEcon.DB.MSFan.CS1.DCV0 & -142 & -33.9 & -562 & -17.5 & -742 & -20.7 & -1351 & -14.7 \\
\hline 10 & IEcon.EH.MSFan.CS1.DCV0 & -144 & -34.4 & -563 & -17.5 & -738 & -20.7 & -1353 & -14.7 \\
\hline 11 & NoEcon.MSFan.CS2.DCV0 & -147 & -35.1 & -563 & -17.5 & -738 & -20.7 & -1354 & -14.7 \\
\hline 12 & IEcon.DB.MSFan.CS2.DCV0 & -142 & -33.8 & -561 & -17.5 & -733 & -20.5 & -1349 & -14.7 \\
\hline 13 & IEcon.EH.MSFan.CS2.DCV0 & -142 & -33.9 & -562 & -17.5 & -730 & -20.4 & -1349 & -14.7 \\
\hline 14 & NoEcon.SSFan.CS1.DCV1 & 170 & 40.5 & 1178 & 36.7 & 1213 & 33.9 & 3196 & 34.7 \\
\hline 15 & IEcon.DB.SSFan.CS1.DCV1 & 172 & 41.0 & 1181 & 36.8 & 1218 & 34.1 & 3199 & 34.8 \\
\hline 16 & IEcon.EH.SSFan.CS1.DCV1 & 172 & 40.9 & 1180 & 36.7 & 1221 & 34.2 & 3198 & 34.8 \\
\hline 17 & NoEcon.MSFan.CS1.DCV1 & 75 & 17.9 & 846 & 26.3 & 749 & 20.9 & 2367 & 25.7 \\
\hline 18 & IEcon.DB.MSFan.CS1.DCV1 & 80 & 19.1 & 850 & 26.5 & 755 & 21.1 & 2374 & 25.8 \\
\hline 19 & IEcon.EH.MSFan.CS1.DCV1 & 79 & 18.8 & 849 & 26.4 & 758 & 21.2 & 2373 & 25.8 \\
\hline 20 & NoEcon.MSFan.CS2.DCV1 & 78 & 18.6 & 849 & 26.4 & 760 & 21.3 & 2372 & 25.8 \\
\hline 21 & IEcon.DB.MSFan.CS2.DCV1 & 81 & 19.2 & 851 & 26.5 & 762 & 21.3 & 2375 & 25.8 \\
\hline 22 & IEcon.EH.MSFan.CS2.DCV1 & 80 & 19.0 & 851 & 26.5 & 765 & 21.4 & 2375 & 25.8 \\
\hline
\end{tabular}


Table D-42: Gas Cost Savings Compared to Case 1 for the Strip Mall Building in Climate Zones 3B, 3C and 4A

\begin{tabular}{|c|c|c|c|c|c|c|c|c|c|}
\hline \multirow{2}{*}{$\begin{array}{c}\text { Case } \\
\text { No }\end{array}$} & \multirow[b]{2}{*}{ Case Name } & \multicolumn{2}{|c|}{ Los Angeles-3B } & \multicolumn{2}{|c|}{ Las Vegas-3B } & \multicolumn{2}{|c|}{ San Francisco-3C } & \multicolumn{2}{|c|}{ Baltimore-4A } \\
\hline & & $\begin{array}{l}\text { Abs. } \\
\text { (\$) }\end{array}$ & $\begin{array}{l}\text { Rel. } \\
\text { (\%) }\end{array}$ & $\begin{array}{c}\text { Abs. } \\
\text { (\$) }\end{array}$ & $\begin{array}{l}\text { Rel. } \\
\text { (\%) }\end{array}$ & $\begin{array}{c}\text { Abs. } \\
\text { (\$) }\end{array}$ & $\begin{array}{l}\text { Rel. } \\
(\%)\end{array}$ & $\begin{array}{c}\text { Abs. } \\
\text { (\$) }\end{array}$ & $\begin{array}{l}\text { Rel. } \\
\text { (\%) }\end{array}$ \\
\hline 2 & NIEcon.DB.SSFan.CS1.DCV0 & 15 & 0.6 & 15 & 0.3 & 7 & 0.1 & 6 & 0.0 \\
\hline 3 & NIEcon.EH.SSFan.CS1.DCV0 & 13 & 0.5 & 17 & 0.3 & 7 & 0.1 & 5 & 0.0 \\
\hline 4 & IEcon.DB.SSFan.CS1.DCV0 & 14 & 0.6 & 14 & 0.3 & 7 & 0.1 & 5 & 0.0 \\
\hline 5 & IEcon.EH.SSFan.CS1.DCV0 & 13 & 0.5 & 16 & 0.3 & 7 & 0.1 & 5 & 0.0 \\
\hline 6 & NoEcon.MSFan.CS1.DCV0 & -783 & -31.7 & -874 & -16.4 & -1018 & -17.5 & -1485 & -10.9 \\
\hline 7 & NIEcon.DB.MSFan.CS1.DCV0 & -768 & -31.1 & -864 & -16.2 & -1013 & -17.5 & -1481 & -10.9 \\
\hline 8 & NIEcon.EH.MSFan.CS1.DCV0 & -770 & -31.2 & -862 & -16.2 & -1013 & -17.5 & -1482 & -10.9 \\
\hline 9 & IEcon.DB.MSFan.CS1.DCV0 & -768 & -31.1 & -865 & -16.2 & -1014 & -17.5 & -1481 & -10.9 \\
\hline 10 & IEcon.EH.MSFan.CS1.DCV0 & -771 & -31.2 & -863 & -16.2 & -1014 & -17.5 & -1482 & -10.9 \\
\hline 11 & NoEcon.MSFan.CS2.DCV0 & -774 & -31.4 & -864 & -16.2 & -1015 & -17.5 & -1483 & -10.9 \\
\hline 12 & IEcon.DB.MSFan.CS2.DCV0 & -769 & -31.2 & -861 & -16.1 & -1013 & -17.5 & -1481 & -10.9 \\
\hline 13 & IEcon.EH.MSFan.CS2.DCV0 & -769 & -31.2 & -860 & -16.1 & -1013 & -17.5 & -1481 & -10.9 \\
\hline 14 & NoEcon.SSFan.CS1.DCV1 & 906 & 36.7 & 1762 & 33.0 & 2329 & 40.1 & 4758 & 34.9 \\
\hline 15 & IEcon.DB.SSFan.CS1.DCV1 & 909 & 36.8 & 1764 & 33.1 & 2331 & 40.2 & 4760 & 34.9 \\
\hline 16 & IEcon.EH.SSFan.CS1.DCV1 & 909 & 36.8 & 1766 & 33.1 & 2331 & 40.2 & 4760 & 34.9 \\
\hline 17 & NoEcon.MSFan.CS1.DCV1 & 459 & 18.6 & 1226 & 23.0 & 1760 & 30.3 & 3846 & 28.2 \\
\hline 18 & IEcon.DB.MSFan.CS1.DCV1 & 468 & 19.0 & 1230 & 23.1 & 1763 & 30.4 & 3849 & 28.2 \\
\hline 19 & IEcon.EH.MSFan.CS1.DCV1 & 467 & 18.9 & 1232 & 23.1 & 1763 & 30.4 & 3847 & 28.2 \\
\hline 20 & NoEcon.MSFan.CS2.DCV1 & 466 & 18.9 & 1233 & 23.1 & 1763 & 30.4 & 3847 & 28.2 \\
\hline 21 & IEcon.DB.MSFan.CS2.DCV1 & 468 & 19.0 & 1234 & 23.1 & 1763 & 30.4 & 3849 & 28.2 \\
\hline 22 & IEcon.EH.MSFan.CS2.DCV1 & 468 & 19.0 & 1237 & 23.2 & 1763 & 30.4 & 3849 & 28.2 \\
\hline
\end{tabular}


Table D-43: Gas Cost Savings Compared to Case 1 for the Strip Mall Building in Climate Zones 4B, 4C, 5A and 5B

\begin{tabular}{|c|c|c|c|c|c|c|c|c|c|}
\hline \multirow{2}{*}{$\begin{array}{c}\text { Case } \\
\text { No }\end{array}$} & \multirow[b]{2}{*}{ Case Name } & \multicolumn{2}{|c|}{ Albuquerque-4B } & \multicolumn{2}{|c|}{ Seattle-4C } & \multicolumn{2}{|c|}{ Chicago-5A } & \multicolumn{2}{|c|}{ Denver-5B } \\
\hline & & $\begin{array}{c}\text { Abs. } \\
\text { (\$) }\end{array}$ & $\begin{array}{l}\text { Rel. } \\
\text { (\%) }\end{array}$ & $\begin{array}{c}\text { Abs. } \\
\text { (\$) }\end{array}$ & $\begin{array}{l}\text { Rel. } \\
\text { (\%) }\end{array}$ & $\begin{array}{c}\text { Abs. } \\
\text { (\$) }\end{array}$ & $\begin{array}{l}\text { Rel. } \\
\text { (\%) }\end{array}$ & $\begin{array}{c}\text { Abs. } \\
\text { (\$) }\end{array}$ & $\begin{array}{l}\text { Rel. } \\
\text { (\%) }\end{array}$ \\
\hline 2 & NIEcon.DB.SSFan.CS1.DCV0 & 12 & 0.2 & 6 & 0.0 & 23 & 0.1 & 18 & 0.2 \\
\hline 3 & NIEcon.EH.SSFan.CS1.DCV0 & 12 & 0.2 & 6 & 0.0 & 21 & 0.1 & 18 & 0.2 \\
\hline 4 & IEcon.DB.SSFan.CS1.DCV0 & 12 & 0.2 & 6 & 0.0 & 23 & 0.1 & 18 & 0.2 \\
\hline 5 & IEcon.EH.SSFan.CS1.DCV0 & 11 & 0.2 & 5 & 0.0 & 21 & 0.1 & 18 & 0.2 \\
\hline 6 & NoEcon.MSFan.CS1.DCV0 & -933 & -12.6 & -1752 & -13.1 & -2079 & -11.2 & -1475 & -13.4 \\
\hline 7 & NIEcon.DB.MSFan.CS1.DCV0 & -924 & -12.5 & -1748 & -13.0 & -2068 & -11.2 & -1467 & -13.4 \\
\hline 8 & NIEcon.EH.MSFan.CS1.DCV0 & -925 & -12.5 & -1748 & -13.0 & -2069 & -11.2 & -1466 & -13.4 \\
\hline 9 & IEcon.DB.MSFan.CS1.DCV0 & -925 & -12.5 & -1748 & -13.0 & -2069 & -11.2 & -1467 & -13.4 \\
\hline 10 & IEcon.EH.MSFan.CS1.DCV0 & -925 & -12.5 & -1748 & -13.0 & -2070 & -11.2 & -1466 & -13.4 \\
\hline 11 & NoEcon.MSFan.CS2.DCV0 & -924 & -12.5 & -1750 & -13.0 & -2069 & -11.2 & -1462 & -13.3 \\
\hline 12 & IEcon.DB.MSFan.CS2.DCV0 & -922 & -12.4 & -1747 & -13.0 & -2066 & -11.1 & -1458 & -13.3 \\
\hline 13 & IEcon.EH.MSFan.CS2.DCV0 & -920 & -12.4 & -1747 & -13.0 & -2065 & -11.1 & -1457 & -13.3 \\
\hline 14 & NoEcon.SSFan.CS1.DCV1 & 2478 & 33.4 & 5486 & 40.9 & 5876 & 31.7 & 3487 & 31.8 \\
\hline 15 & IEcon.DB.SSFan.CS1.DCV1 & 2482 & 33.5 & 5489 & 40.9 & 5878 & 31.7 & 3491 & 31.8 \\
\hline 16 & IEcon.EH.SSFan.CS1.DCV1 & 2483 & 33.5 & 5488 & 40.9 & 5877 & 31.7 & 3492 & 31.8 \\
\hline 17 & NoEcon.MSFan.CS1.DCV1 & 1878 & 25.3 & 4349 & 32.4 & 4643 & 25.0 & 2561 & 23.4 \\
\hline 18 & IEcon.DB.MSFan.CS1.DCV1 & 1882 & 25.4 & 4353 & 32.4 & 4648 & 25.1 & 2566 & 23.4 \\
\hline 19 & IEcon.EH.MSFan.CS1.DCV1 & 1883 & 25.4 & 4353 & 32.4 & 4647 & 25.1 & 2566 & 23.4 \\
\hline 20 & NoEcon.MSFan.CS2.DCV1 & 1884 & 25.4 & 4351 & 32.4 & 4648 & 25.1 & 2569 & 23.4 \\
\hline 21 & IEcon.DB.MSFan.CS2.DCV1 & 1886 & 25.4 & 4354 & 32.4 & 4650 & 25.1 & 2573 & 23.5 \\
\hline 22 & IEcon.EH.MSFan.CS2.DCV1 & 1889 & 25.5 & 4354 & 32.4 & 4650 & 25.1 & 2575 & 23.5 \\
\hline
\end{tabular}


Table D-44: Gas Cost Savings Compared to Case 1 for the Strip Mall Building in Climate Zones 6, 7 and 8

\begin{tabular}{|c|c|c|c|c|c|c|c|c|c|}
\hline \multirow{2}{*}{$\begin{array}{c}\text { Case } \\
\text { No }\end{array}$} & \multirow[b]{2}{*}{ Case Name } & \multicolumn{2}{|c|}{ Minneapolis-6A } & \multicolumn{2}{|c|}{ Helena-6B } & \multicolumn{2}{|c|}{ Duluth-7 } & \multicolumn{2}{|c|}{ Fairbanks-8 } \\
\hline & & $\begin{array}{c}\text { Abs. } \\
\text { (\$) }\end{array}$ & $\begin{array}{l}\text { Rel. } \\
\text { (\%) }\end{array}$ & $\begin{array}{c}\text { Abs. } \\
\text { (\$) }\end{array}$ & $\begin{array}{l}\text { Rel. } \\
\text { (\%) }\end{array}$ & $\begin{array}{c}\text { Abs. } \\
\text { (\$) }\end{array}$ & $\begin{array}{l}\text { Rel. } \\
\text { (\%) }\end{array}$ & $\begin{array}{c}\text { Abs. } \\
\text { (\$) }\end{array}$ & $\begin{array}{l}\text { Rel. } \\
\text { (\%) }\end{array}$ \\
\hline 2 & NIEcon.DB.SSFan.CS1.DCV0 & 82 & 0.5 & 84 & 0.4 & 150 & 0.7 & 1027 & 2.3 \\
\hline 3 & NIEcon.EH.SSFan.CS1.DCV0 & 81 & 0.5 & 85 & 0.5 & 149 & 0.7 & 1027 & 2.4 \\
\hline 4 & IEcon.DB.SSFan.CS1.DCV0 & 82 & 0.5 & 84 & 0.4 & 150 & 0.7 & 1026 & 2.3 \\
\hline 5 & IEcon.EH.SSFan.CS1.DCV0 & 81 & 0.5 & 84 & 0.4 & 149 & 0.7 & 1026 & 2.3 \\
\hline 6 & NoEcon.MSFan.CS1.DCV0 & -1840 & -10.4 & -2648 & -14.1 & -2459 & -11.1 & -4315 & -9.9 \\
\hline 7 & NIEcon.DB.MSFan.CS1.DCV0 & -1763 & -9.9 & -2550 & -13.6 & -2299 & -10.4 & -3057 & -7.0 \\
\hline 8 & NIEcon.EH.MSFan.CS1.DCV0 & -1763 & -10.0 & -2550 & -13.6 & -2300 & -10.4 & -3057 & -7.0 \\
\hline 9 & IEcon.DB.MSFan.CS1.DCV0 & -1762 & -9.9 & -2551 & -13.6 & -2299 & -10.4 & -3058 & -7.0 \\
\hline 10 & IEcon.EH.MSFan.CS1.DCV0 & -1764 & -10.0 & -2550 & -13.6 & -2300 & -10.4 & -3058 & -7.0 \\
\hline 11 & NoEcon.MSFan.CS2.DCV0 & -1785 & -10.1 & -2603 & -13.9 & -2349 & -10.6 & -3256 & -7.4 \\
\hline 12 & IEcon.DB.MSFan.CS2.DCV0 & -1760 & -9.9 & -2541 & -13.6 & -2298 & -10.4 & -3055 & -7.0 \\
\hline 13 & IEcon.EH.MSFan.CS2.DCV0 & -1759 & -9.9 & -2540 & -13.6 & -2298 & -10.4 & -3054 & -7.0 \\
\hline 14 & NoEcon.SSFan.CS1.DCV1 & 5227 & 29.5 & 5757 & 30.8 & 6627 & 29.9 & 11751 & 26.9 \\
\hline 15 & IEcon.DB.SSFan.CS1.DCV1 & 5230 & 29.5 & 5764 & 30.8 & 6632 & 29.9 & 11666 & 26.7 \\
\hline 16 & IEcon.EH.SSFan.CS1.DCV1 & 5230 & 29.5 & 5764 & 30.8 & 6631 & 29.9 & 11671 & 26.7 \\
\hline 17 & NoEcon.MSFan.CS1.DCV1 & 4125 & 23.3 & 3992 & 21.3 & 5026 & 22.7 & 6382 & 14.6 \\
\hline 18 & IEcon.DB.MSFan.CS1.DCV1 & 4184 & 23.6 & 4064 & 21.7 & 5142 & 23.2 & 8355 & 19.1 \\
\hline 19 & IEcon.EH.MSFan.CS1.DCV1 & 4184 & 23.6 & 4065 & 21.7 & 5142 & 23.2 & 8354 & 19.1 \\
\hline 20 & NoEcon.MSFan.CS2.DCV1 & 4160 & 23.5 & 4021 & 21.5 & 5089 & 23.0 & 8431 & 19.3 \\
\hline 21 & IEcon.DB.MSFan.CS2.DCV1 & 4186 & 23.6 & 4075 & 21.8 & 5144 & 23.2 & 8360 & 19.1 \\
\hline 22 & IEcon.EH.MSFan.CS2.DCV1 & 4187 & 23.6 & 4077 & 21.8 & 5145 & 23.2 & 8361 & 19.1 \\
\hline
\end{tabular}


Table D-45: Gas Cost Savings Compared to Case 1 for the Supermarket Building in Climate Zones 1, 2 and 3A

\begin{tabular}{|c|c|c|c|c|c|c|c|c|c|}
\hline \multirow{2}{*}{$\begin{array}{c}\text { Case } \\
\text { No }\end{array}$} & \multirow[b]{2}{*}{ Case Name } & \multicolumn{2}{|c|}{ Miami-1A } & \multicolumn{2}{|c|}{ Houston-2A } & \multicolumn{2}{|c|}{ Phoenix-2B } & \multicolumn{2}{|c|}{ Atlanta-3A } \\
\hline & & $\begin{array}{c}\text { Abs. } \\
\text { (\$) }\end{array}$ & $\begin{array}{l}\text { Rel. } \\
\text { (\%) }\end{array}$ & $\begin{array}{c}\text { Abs. } \\
\text { (\$) }\end{array}$ & $\begin{array}{l}\text { Rel. } \\
\text { (\%) }\end{array}$ & $\begin{array}{c}\text { Abs. } \\
\text { (\$) }\end{array}$ & $\begin{array}{l}\text { Rel. } \\
\text { (\%) }\end{array}$ & $\begin{array}{c}\text { Abs. } \\
\text { (\$) }\end{array}$ & $\begin{array}{l}\text { Rel. } \\
\text { (\%) }\end{array}$ \\
\hline 2 & NIEcon.DB.SSFan.CS1.DCV0 & 19 & 1.2 & 74 & 0.7 & 148 & 1.1 & 222 & 0.8 \\
\hline 3 & NIEcon.EH.SSFan.CS1.DCV0 & 18 & 1.2 & 74 & 0.7 & 149 & 1.1 & 218 & 0.8 \\
\hline 4 & IEcon.DB.SSFan.CS1.DCV0 & 19 & 1.2 & 74 & 0.7 & 148 & 1.1 & 222 & 0.8 \\
\hline 5 & IEcon.EH.SSFan.CS1.DCV0 & 18 & 1.2 & 72 & 0.7 & 149 & 1.1 & 218 & 0.8 \\
\hline 6 & NoEcon.MSFan.CS1.DCV0 & -447 & -29.8 & -2255 & -21.7 & -2718 & -20.8 & -5860 & -20.8 \\
\hline 7 & NIEcon.DB.MSFan.CS1.DCV0 & -422 & -28.1 & -2143 & -20.6 & -2528 & -19.4 & -5555 & -19.8 \\
\hline 8 & NIEcon.EH.MSFan.CS1.DCV0 & -424 & -28.3 & -2147 & -20.7 & -2527 & -19.4 & -5561 & -19.8 \\
\hline 9 & IEcon.DB.MSFan.CS1.DCV0 & -423 & -28.2 & -2143 & -20.6 & -2532 & -19.4 & -5556 & -19.8 \\
\hline 10 & IEcon.EH.MSFan.CS1.DCV0 & -425 & -28.4 & -2147 & -20.7 & -2529 & -19.4 & -5562 & -19.8 \\
\hline 11 & NoEcon.MSFan.CS2.DCV0 & -427 & -28.5 & -2170 & -20.9 & -2551 & -19.5 & -5623 & -20.0 \\
\hline 12 & IEcon.DB.MSFan.CS2.DCV0 & -421 & -28.1 & -2141 & -20.6 & -2511 & -19.2 & -5549 & -19.7 \\
\hline 13 & IEcon.EH.MSFan.CS2.DCV0 & -422 & -28.2 & -2145 & -20.6 & -2511 & -19.2 & -5552 & -19.7 \\
\hline 14 & NoEcon.SSFan.CS1.DCV1 & 495 & 33.0 & 2817 & 27.1 & 3060 & 23.4 & 7224 & 25.7 \\
\hline 15 & IEcon.DB.SSFan.CS1.DCV1 & 517 & 34.5 & 2894 & 27.8 & 3207 & 24.6 & 7445 & 26.5 \\
\hline 16 & IEcon.EH.SSFan.CS1.DCV1 & 518 & 34.5 & 2893 & 27.8 & 3208 & 24.6 & 7441 & 26.5 \\
\hline 17 & NoEcon.MSFan.CS1.DCV1 & -26 & -1.8 & 491 & 4.7 & 87 & 0.7 & 1227 & 4.4 \\
\hline 18 & IEcon.DB.MSFan.CS1.DCV1 & -6 & -0.4 & 601 & 5.8 & 260 & 2.0 & 1508 & 5.4 \\
\hline 19 & IEcon.EH.MSFan.CS1.DCV1 & -7 & -0.5 & 597 & 5.7 & 263 & 2.0 & 1502 & 5.3 \\
\hline 20 & NoEcon.MSFan.CS2.DCV1 & -10 & -0.7 & 576 & 5.5 & 241 & 1.8 & 1440 & 5.1 \\
\hline 21 & IEcon.DB.MSFan.CS2.DCV1 & -5 & -0.3 & 605 & 5.8 & 280 & 2.1 & 1515 & 5.4 \\
\hline 22 & IEcon.EH.MSFan.CS2.DCV1 & -5 & -0.4 & 602 & 5.8 & 281 & 2.2 & 1511 & 5.4 \\
\hline
\end{tabular}


Table D-46: Gas Cost Savings Compared to Case 1 for the Supermarket Building in Climate Zones 3B, 3C and 4A

\begin{tabular}{|c|c|c|c|c|c|c|c|c|c|}
\hline \multirow{2}{*}{$\begin{array}{c}\text { Case } \\
\text { No }\end{array}$} & \multirow[b]{2}{*}{ Case Name } & \multicolumn{2}{|c|}{ Los Angeles-3B } & \multicolumn{2}{|c|}{ Las Vegas-3B } & \multicolumn{2}{|c|}{ San Francisco-3C } & \multicolumn{2}{|c|}{ Baltimore-4A } \\
\hline & & $\begin{array}{c}\text { Abs. } \\
(\$)\end{array}$ & $\begin{array}{l}\text { Rel. } \\
(\%)\end{array}$ & $\begin{array}{c}\text { Abs. } \\
(\$)\end{array}$ & $\begin{array}{l}\text { Rel. } \\
\text { (\%) }\end{array}$ & $\begin{array}{c}\text { Abs. } \\
(\$)\end{array}$ & $\begin{array}{l}\text { Rel. } \\
(\%)\end{array}$ & $\begin{array}{c}\text { Abs. } \\
\text { (\$) }\end{array}$ & $\begin{array}{l}\text { Rel. } \\
(\%)\end{array}$ \\
\hline 2 & NIEcon.DB.SSFan.CS1.DCV0 & 71 & 0.6 & 186 & 1.0 & 47 & 0.2 & 227 & 0.6 \\
\hline 3 & NIEcon.EH.SSFan.CS1.DCV0 & 71 & 0.6 & 185 & 1.0 & 46 & 0.2 & 224 & 0.6 \\
\hline 4 & IEcon.DB.SSFan.CS1.DCV0 & 70 & 0.6 & 186 & 1.0 & 46 & 0.2 & 225 & 0.6 \\
\hline 5 & IEcon.EH.SSFan.CS1.DCV0 & 70 & 0.6 & 186 & 1.0 & 46 & 0.2 & 223 & 0.6 \\
\hline 6 & NoEcon.MSFan.CS1.DCV0 & -2894 & -26.1 & -3899 & -20.0 & -4446 & -19.3 & -6233 & -16.5 \\
\hline 7 & NIEcon.DB.MSFan.CS1.DCV0 & -2828 & -25.5 & -3706 & -19.0 & -4403 & -19.1 & -5865 & -15.6 \\
\hline 8 & NIEcon.EH.MSFan.CS1.DCV0 & -2829 & -25.5 & -3706 & -19.0 & -4403 & -19.1 & -5867 & -15.6 \\
\hline 9 & IEcon.DB.MSFan.CS1.DCV0 & -2828 & -25.5 & -3706 & -19.0 & -4404 & -19.1 & -5867 & -15.6 \\
\hline 10 & IEcon.EH.MSFan.CS1.DCV0 & -2829 & -25.5 & -3706 & -19.0 & -4405 & -19.1 & -5868 & -15.6 \\
\hline 11 & NoEcon.MSFan.CS2.DCV0 & -2842 & -25.7 & -3739 & -19.2 & -4410 & -19.1 & -5936 & -15.7 \\
\hline 12 & IEcon.DB.MSFan.CS2.DCV0 & -2826 & -25.5 & -3694 & -19.0 & -4400 & -19.1 & -5860 & -15.5 \\
\hline 13 & IEcon.EH.MSFan.CS2.DCV0 & -2826 & -25.5 & -3693 & -19.0 & -4400 & -19.1 & -5860 & -15.5 \\
\hline 14 & NoEcon.SSFan.CS1.DCV1 & 3223 & 29.1 & 4353 & 22.4 & 6441 & 28.0 & 9508 & 25.2 \\
\hline 15 & IEcon.DB.SSFan.CS1.DCV1 & 3303 & 29.8 & 4540 & 23.3 & 6495 & 28.2 & 9724 & 25.8 \\
\hline 16 & IEcon.EH.SSFan.CS1.DCV1 & 3301 & 29.8 & 4539 & 23.3 & 6495 & 28.2 & 9723 & 25.8 \\
\hline 17 & NoEcon.MSFan.CS1.DCV1 & 455 & 4.1 & 92 & 0.5 & 1867 & 8.1 & 3052 & 8.1 \\
\hline 18 & IEcon.DB.MSFan.CS1.DCV1 & 527 & 4.8 & 282 & 1.5 & 1901 & 8.2 & 3401 & 9.0 \\
\hline 19 & IEcon.EH.MSFan.CS1.DCV1 & 525 & 4.7 & 282 & 1.4 & 1901 & 8.2 & 3397 & 9.0 \\
\hline 20 & NoEcon.MSFan.CS2.DCV1 & 514 & 4.6 & 250 & 1.3 & 1894 & 8.2 & 3321 & 8.8 \\
\hline 21 & IEcon.DB.MSFan.CS2.DCV1 & 529 & 4.8 & 301 & 1.5 & 1905 & 8.3 & 3406 & 9.0 \\
\hline 22 & IEcon.EH.MSFan.CS2.DCV1 & 529 & 4.8 & 301 & 1.5 & 1905 & 8.3 & 3405 & 9.0 \\
\hline
\end{tabular}


Table D-47: Gas Cost Savings Compared to Case 1 for the Supermarket Building in Climate Zones 4B, 4C, 5A and 5B

\begin{tabular}{|c|c|c|c|c|c|c|c|c|c|}
\hline \multirow{2}{*}{$\begin{array}{c}\text { Case } \\
\text { No }\end{array}$} & \multirow[b]{2}{*}{ Case Name } & \multicolumn{2}{|c|}{ Albuquerque-4B } & \multicolumn{2}{|c|}{ Seattle-4C } & \multicolumn{2}{|c|}{ Chicago-5A } & \multicolumn{2}{|c|}{ Denver-5B } \\
\hline & & $\begin{array}{c}\text { Abs. } \\
\text { (\$) }\end{array}$ & $\begin{array}{l}\text { Rel. } \\
\text { (\%) }\end{array}$ & $\begin{array}{c}\text { Abs. } \\
\text { (\$) }\end{array}$ & $\begin{array}{l}\text { Rel. } \\
\text { (\%) }\end{array}$ & $\begin{array}{c}\text { Abs. } \\
\text { (\$) }\end{array}$ & $\begin{array}{l}\text { Rel. } \\
\text { (\%) }\end{array}$ & $\begin{array}{c}\text { Abs. } \\
\text { (\$) }\end{array}$ & $\begin{array}{l}\text { Rel. } \\
(\%)\end{array}$ \\
\hline 2 & NIEcon.DB.SSFan.CS1.DCV0 & 210 & 0.9 & 213 & 0.5 & 338 & 0.7 & 288 & 0.9 \\
\hline 3 & NIEcon.EH.SSFan.CS1.DCV0 & 210 & 0.9 & 212 & 0.5 & 333 & 0.7 & 291 & 0.9 \\
\hline 4 & IEcon.DB.SSFan.CS1.DCV0 & 209 & 0.9 & 214 & 0.5 & 337 & 0.7 & 286 & 0.9 \\
\hline 5 & IEcon.EH.SSFan.CS1.DCV0 & 210 & 0.9 & 213 & 0.5 & 333 & 0.7 & 287 & 0.9 \\
\hline 6 & NoEcon.MSFan.CS1.DCV0 & -4726 & -20.3 & -6829 & -16.7 & -8540 & -17.9 & -6972 & -22.0 \\
\hline 7 & NIEcon.DB.MSFan.CS1.DCV0 & -4510 & -19.4 & -6561 & -16.0 & -8003 & -16.8 & -6684 & -21.1 \\
\hline 8 & NIEcon.EH.MSFan.CS1.DCV0 & -4511 & -19.4 & -6561 & -16.0 & -8009 & -16.8 & -6686 & -21.1 \\
\hline 9 & IEcon.DB.MSFan.CS1.DCV0 & -4510 & -19.4 & -6561 & -16.0 & -8003 & -16.8 & -6685 & -21.1 \\
\hline 10 & IEcon.EH.MSFan.CS1.DCV0 & -4511 & -19.4 & -6561 & -16.0 & -8009 & -16.8 & -6690 & -21.1 \\
\hline 11 & NoEcon.MSFan.CS2.DCV0 & -4555 & -19.6 & -6625 & -16.2 & -8060 & -16.9 & -6768 & -21.4 \\
\hline 12 & IEcon.DB.MSFan.CS2.DCV0 & -4496 & -19.3 & -6557 & -16.0 & -7995 & -16.8 & -6669 & -21.1 \\
\hline 13 & IEcon.EH.MSFan.CS2.DCV0 & -4497 & -19.4 & -6557 & -16.0 & -7996 & -16.8 & -6667 & -21.1 \\
\hline 14 & NoEcon.SSFan.CS1.DCV1 & 5428 & 23.4 & 11096 & 27.1 & 11449 & 24.0 & 7306 & 23.1 \\
\hline 15 & IEcon.DB.SSFan.CS1.DCV1 & 5624 & 24.2 & 11306 & 27.6 & 12009 & 25.2 & 7653 & 24.2 \\
\hline 16 & IEcon.EH.SSFan.CS1.DCV1 & 5624 & 24.2 & 11305 & 27.6 & 11971 & 25.1 & 7644 & 24.1 \\
\hline 17 & NoEcon.MSFan.CS1.DCV1 & 401 & 1.7 & 3983 & 9.7 & 2640 & 5.5 & -105 & -0.3 \\
\hline 18 & IEcon.DB.MSFan.CS1.DCV1 & 586 & 2.5 & 4227 & 10.3 & 3485 & 7.3 & 252 & 0.8 \\
\hline 19 & IEcon.EH.MSFan.CS1.DCV1 & 587 & 2.5 & 4224 & 10.3 & 3397 & 7.1 & 241 & 0.8 \\
\hline 20 & NoEcon.MSFan.CS2.DCV1 & 546 & 2.4 & 4163 & 10.2 & 3304 & 6.9 & 156 & 0.5 \\
\hline 21 & IEcon.DB.MSFan.CS2.DCV1 & 599 & 2.6 & 4231 & 10.3 & 3524 & 7.4 & 298 & 0.9 \\
\hline 22 & IEcon.EH.MSFan.CS2.DCV1 & 599 & 2.6 & 4231 & 10.3 & 3504 & 7.3 & 298 & 0.9 \\
\hline
\end{tabular}


Table D-48: Gas Cost Savings Compared to Case 1 for the Supermarket Building in Climate Zones 6, 7 and 8

\begin{tabular}{|c|c|c|c|c|c|c|c|c|c|}
\hline \multirow{2}{*}{$\begin{array}{c}\text { Case } \\
\text { No }\end{array}$} & \multirow[b]{2}{*}{ Case Name } & \multicolumn{2}{|c|}{ Minneapolis-6A } & \multicolumn{2}{|c|}{ Helena-6B } & \multicolumn{2}{|c|}{ Duluth-7 } & \multicolumn{2}{|c|}{ Fairbanks-8 } \\
\hline & & $\begin{array}{c}\text { Abs. } \\
(\$)\end{array}$ & $\begin{array}{l}\text { Rel. } \\
\text { (\%) }\end{array}$ & $\begin{array}{l}\text { Abs. } \\
(\$)\end{array}$ & $\begin{array}{l}\text { Rel. } \\
(\%)\end{array}$ & $\begin{array}{c}\text { Abs. } \\
\text { (\$) }\end{array}$ & $\begin{array}{l}\text { Rel. } \\
(\%)\end{array}$ & $\begin{array}{c}\text { Abs. } \\
\text { (\$) }\end{array}$ & $\begin{array}{l}\text { Rel. } \\
(\%)\end{array}$ \\
\hline 2 & NIEcon.DB.SSFan.CS1.DCV0 & 526 & 1.2 & 667 & 1.4 & 687 & 1.3 & 1310 & 1.3 \\
\hline 3 & NIEcon.EH.SSFan.CS1.DCV0 & 521 & 1.2 & 665 & 1.3 & 675 & 1.3 & 1302 & 1.3 \\
\hline 4 & IEcon.DB.SSFan.CS1.DCV0 & 526 & 1.2 & 662 & 1.3 & 687 & 1.3 & 1305 & 1.3 \\
\hline 5 & IEcon.EH.SSFan.CS1.DCV0 & 521 & 1.2 & 662 & 1.3 & 675 & 1.2 & 1295 & 1.3 \\
\hline 6 & NoEcon.MSFan.CS1.DCV0 & -7523 & -17.4 & -10484 & -21.2 & -8977 & -16.6 & -13462 & -13.7 \\
\hline 7 & NIEcon.DB.MSFan.CS1.DCV0 & -6660 & -15.4 & -9478 & -19.2 & -7993 & -14.8 & -11013 & -11.2 \\
\hline 8 & NIEcon.EH.MSFan.CS1.DCV0 & -6684 & -15.4 & -9521 & -19.3 & -8041 & -14.9 & -11052 & -11.3 \\
\hline 9 & IEcon.DB.MSFan.CS1.DCV0 & -6660 & -15.4 & -9484 & -19.2 & -7993 & -14.8 & -11014 & -11.2 \\
\hline 10 & IEcon.EH.MSFan.CS1.DCV0 & -6684 & -15.4 & -9527 & -19.3 & -8041 & -14.9 & -11053 & -11.3 \\
\hline 11 & NoEcon.MSFan.CS2.DCV0 & -6845 & -15.8 & -9896 & -20.1 & -8345 & -15.5 & -11383 & -11.6 \\
\hline 12 & IEcon.DB.MSFan.CS2.DCV0 & -6644 & -15.3 & -9458 & -19.2 & -7994 & -14.8 & -10981 & -11.2 \\
\hline 13 & IEcon.EH.MSFan.CS2.DCV0 & -6648 & -15.4 & -9463 & -19.2 & -8003 & -14.8 & -10998 & -11.2 \\
\hline 14 & NoEcon.SSFan.CS1.DCV1 & 9681 & 22.4 & 10723 & 21.7 & 11811 & 21.9 & 18577 & 19.0 \\
\hline 15 & IEcon.DB.SSFan.CS1.DCV1 & 10573 & 24.4 & 11381 & 23.1 & 12725 & 23.6 & 20137 & 20.5 \\
\hline 16 & IEcon.EH.SSFan.CS1.DCV1 & 10544 & 24.4 & 11377 & 23.1 & 12696 & 23.5 & 20127 & 20.5 \\
\hline 17 & NoEcon.MSFan.CS1.DCV1 & 2091 & 4.8 & -146 & -0.3 & 2896 & 5.4 & 5249 & 5.4 \\
\hline 18 & IEcon.DB.MSFan.CS1.DCV1 & 3480 & 8.0 & 1633 & 3.3 & 4461 & 8.3 & 8336 & 8.5 \\
\hline 19 & IEcon.EH.MSFan.CS1.DCV1 & 3327 & 7.7 & 1475 & 3.0 & 4282 & 7.9 & 8181 & 8.3 \\
\hline 20 & NoEcon.MSFan.CS2.DCV1 & 3090 & 7.1 & 896 & 1.8 & 3876 & 7.2 & 8643 & 8.8 \\
\hline 21 & IEcon.DB.MSFan.CS2.DCV1 & 3514 & 8.1 & 1735 & 3.5 & 4477 & 8.3 & 8392 & 8.6 \\
\hline 22 & IEcon.EH.MSFan.CS2.DCV1 & 3462 & 8.0 & 1711 & 3.5 & 4427 & 8.2 & 8361 & 8.5 \\
\hline
\end{tabular}


Table D-49: Maximum Controller Installed Cost per Unit Supporting Different Retrofits for the Small Office Building Based on the Payback Period of 3 Years and the Original Utility Rates

\begin{tabular}{|l|c|c|c|c|}
\hline $\begin{array}{l}\text { Climate zone and } \\
\text { Location }\end{array}$ & $\begin{array}{c}\text { Multi-speed fan } \\
\text { (Case 6 vs. Case 1) }\end{array}$ & $\begin{array}{c}\text { DCV } \\
\text { (Case 14 vs. Case 1) }\end{array}$ & $\begin{array}{c}\text { Multi-speed fan + DCV } \\
\text { (Case 18 vs. Case 4) }\end{array}$ & $\begin{array}{c}\text { Multi-speed fan + DCV+ economizer } \\
\text { (Case 22 vs. Case 1) }\end{array}$ \\
\hline Miami-1A & 520 & 219 & 718 & 1065 \\
\hline Houston-2A & 492 & 176 & 654 & 904 \\
\hline Phoenix-2B & 508 & 135 & 656 & 958 \\
\hline Atlanta-3A & 446 & 156 & 588 & 814 \\
\hline Los Angeles-3B & 940 & 0 & 772 & 1322 \\
\hline Las Vegas-3B & 510 & 110 & 627 & 857 \\
\hline San Francisco-3C & 702 & 0 & 700 & 944 \\
\hline Baltimore-4A & 530 & 213 & 749 & 950 \\
\hline Albuquerque-4B & 447 & 80 & 529 & 709 \\
\hline Seattle-4C & 260 & 148 & 451 & 554 \\
\hline Chicago-5A & 373 & 247 & 639 & 784 \\
\hline Denver-5B & 491 & 107 & 611 & 766 \\
\hline Minneapolis-6A & 391 & 226 & 634 & 773 \\
\hline Helena-6B & 406 & 190 & 638 & 763 \\
\hline Duluth-7 & 372 & 237 & 660 & 759 \\
\hline Fairbanks-8 & 772 & 419 & 1265 & 1436 \\
\hline
\end{tabular}


Table D-50: Maximum Controller Installed Cost per Unit Supporting Different Retrofits for the Stand-alone Retail Building Based on the Payback Period of 3 Years and the Original Utility Rates

\begin{tabular}{|l|c|c|c|c|}
\hline $\begin{array}{l}\text { Climate zone and } \\
\text { Location }\end{array}$ & $\begin{array}{c}\text { Multi-speed fan } \\
\text { (Case 6 vs. Case 1) }\end{array}$ & $\begin{array}{c}\text { DCV } \\
\text { (Case 14 vs. Case 1) }\end{array}$ & $\begin{array}{c}\text { Multi-speed fan + DCV } \\
\text { (Case 18 vs. Case 4) }\end{array}$ & $\begin{array}{c}\text { Multi-speed fan + DCV+ economizer } \\
\text { (Case 22 vs. Case 1) }\end{array}$ \\
\hline Miami-1A & 3226 & 2690 & 5808 & 7840 \\
\hline Houston-2A & 2862 & 2774 & 5690 & 7046 \\
\hline Phoenix-2B & 2916 & 2797 & 6031 & 7470 \\
\hline Atlanta-3A & 2646 & 3345 & 6099 & 7523 \\
\hline Los Angeles-3B & 5275 & 1267 & 5473 & 6781 \\
\hline Las Vegas-3B & 2780 & 2737 & 5892 & 6428 \\
\hline San Francisco-3C & 3894 & 2029 & 5807 & 8876 \\
\hline Baltimore-4A & 3141 & 4499 & 7968 & 5898 \\
\hline Albuquerque-4B & 2615 & 2299 & 5151 & 6011 \\
\hline Seattle-4C & 1365 & 4343 & 5745 & 8469 \\
\hline Chicago-5A & 2350 & 4941 & 7771 & 6925 \\
\hline Denver-5B & 2989 & 2964 & 6307 & 8320 \\
\hline Minneapolis-6A & 2764 & 4362 & 7653 & 8404 \\
\hline Helena-6B & 2604 & 4543 & 7872 & 8864 \\
\hline Duluth-7 & 2433 & 5136 & 8471 & 17834 \\
\hline Fairbanks-8 & 5693 & 9254 & 16037 & \\
\hline
\end{tabular}


Table D-51: Maximum Controller Installed Cost per Unit Supporting Different Retrofits for the Strip Mall Building Based on the Payback Period of 3 Years and the Original Utility Rates

\begin{tabular}{|l|c|c|c|c|}
\hline $\begin{array}{l}\text { Climate zone and } \\
\text { Location }\end{array}$ & $\begin{array}{c}\text { Multi-speed fan } \\
\text { (Case 6 vs. Case 1) }\end{array}$ & $\begin{array}{c}\text { DCV } \\
\text { (Case 14 vs. Case 1) }\end{array}$ & $\begin{array}{c}\text { Multi-speed fan + DCV } \\
\text { (Case 18 vs. Case 4) }\end{array}$ & $\begin{array}{c}\text { Multi-speed fan + DCV+ economizer } \\
\text { (Case 22 vs. Case 1) }\end{array}$ \\
\hline Miami-1A & 1493 & 1150 & 2549 & 3542 \\
\hline Houston-2A & 1170 & 1131 & 2284 & 2859 \\
\hline Phoenix-2B & 1177 & 1133 & 2362 & 2969 \\
\hline Atlanta-3A & 1047 & 1370 & 2415 & 3389 \\
\hline Los Angeles-3B & 2290 & 870 & 2348 & 2782 \\
\hline Las Vegas-3B & 1185 & 1119 & 2365 & 2705 \\
\hline San Francisco-3C & 1567 & 950 & 2344 & 3503 \\
\hline Baltimore-4A & 1175 & 1813 & 3109 & 2290 \\
\hline Albuquerque-4B & 977 & 945 & 1967 & 2439 \\
\hline Seattle-4C & 428 & 1728 & 2296 & 3369 \\
\hline Chicago-5A & 881 & 1988 & 3063 & 2728 \\
\hline Denver-5B & 1112 & 1208 & 2438 & 3319 \\
\hline Minneapolis-6A & 1062 & 1797 & 2998 & 3391 \\
\hline Helena-6B & 1001 & 1889 & 3103 & 3564 \\
\hline Duluth-7 & 954 & 2141 & 3318 & \\
\hline Fairbanks-8 & 2296 & 4060 & 6111 & \\
\hline
\end{tabular}


Table D-52: Maximum Controller Installed Cost per Unit Supporting Different Retrofits for the Supermarket Building Based on the Payback Period of 3 Years and the Original Utility Rates

\begin{tabular}{|l|c|c|c|c|}
\hline $\begin{array}{l}\text { Climate zone and } \\
\text { Location }\end{array}$ & $\begin{array}{c}\text { Multi-speed fan } \\
\text { (Case 6 vs. Case 1) }\end{array}$ & $\begin{array}{c}\text { DCV } \\
\text { (Case 14 vs. Case 1) }\end{array}$ & $\begin{array}{c}\text { Multi-speed fan + DCV } \\
\text { (Case 18 vs. Case 4) }\end{array}$ & $\begin{array}{c}\text { Multi-speed fan + DCV+ economizer } \\
\text { (Case 22 vs. Case 1) }\end{array}$ \\
\hline Miami-1A & 5558 & 1980 & 7523 & 8949 \\
\hline Houston-2A & 6490 & 2770 & 9545 & 10747 \\
\hline Phoenix-2B & 5330 & 3284 & 8912 & 10137 \\
\hline Atlanta-3A & 5585 & 4135 & 9875 & 10972 \\
\hline Los Angeles-3B & 7749 & 1591 & 9216 & 10749 \\
\hline Las Vegas-3B & 6248 & 3433 & 9870 & 10940 \\
\hline San Francisco-3C & 6620 & 3252 & 10156 & 10894 \\
\hline Baltimore-4A & 7461 & 5323 & 13196 & 10183 \\
\hline Albuquerque-4B & 6179 & 3058 & 9318 & 8044 \\
\hline Seattle-4C & 1862 & 5582 & 7604 & 12560 \\
\hline Chicago-5A & 5224 & 5921 & 11716 & 11423 \\
\hline Denver-5B & 6650 & 3851 & 10627 & 12650 \\
\hline Minneapolis-6A & 5742 & 4896 & 11699 & 12308 \\
\hline Helena-6B & 4966 & 5300 & 11289 & 12732 \\
\hline Duluth-7 & 4748 & 5735 & 11827 & 26109 \\
\hline Fairbanks-8 & 11593 & 8790 & 23302 & \\
\hline
\end{tabular}


Table D-53: Maximum Installed Cost per Controller Unit Supporting the Retrofit from Case 4 to Case 18 to Achieve Payback Periods of 1, 3 and 5 Years as Functions of Different Utility Rates in Climate Zones 1A, 2A, 2B, and 3A

\begin{tabular}{|c|c|c|c|c|c|c|c|c|c|c|c|c|c|}
\hline \multirow{2}{*}{ Building Type } & \multirow{2}{*}{$\begin{array}{c}\text { Utility } \\
\text { Rate } \\
\text { Change } \\
\end{array}$} & \multicolumn{3}{|c|}{ 1A_Miami } & \multicolumn{3}{|c|}{ 2A_Houston } & \multicolumn{3}{|c|}{ 2B_Phoenix } & \multicolumn{3}{|c|}{ 3A_Atlanta } \\
\hline & & 1 year & 3 years & 5 years & 1 year & 3 years & 5 years & 1 year & 3 years & 5 years & 1 year & 3 years & 5 years \\
\hline \multirow{5}{*}{ Small Office } & 0 & 239 & 718 & 1197 & 218 & 654 & 1089 & 219 & 656 & 1093 & 196 & 588 & 981 \\
\hline & $5 \%$ & 251 & 754 & 1257 & 229 & 686 & 1144 & 229 & 688 & 1147 & 206 & 618 & 1030 \\
\hline & $10 \%$ & 263 & 790 & 1316 & 240 & 719 & 1198 & 240 & 721 & 1202 & 216 & 647 & 1079 \\
\hline & $-5 \%$ & 227 & 682 & 1137 & 207 & 621 & 1035 & 208 & 623 & 1038 & 186 & 559 & 932 \\
\hline & $-10 \%$ & 215 & 646 & 1077 & 196 & 588 & 980 & 197 & 590 & 983 & 177 & 530 & 883 \\
\hline \multirow{5}{*}{$\begin{array}{l}\text { Standalone } \\
\text { Retail }\end{array}$} & 0 & 1936 & 5808 & 9680 & 1897 & 5690 & 9484 & 2010 & 6031 & 10051 & 2033 & 6099 & 10166 \\
\hline & $5 \%$ & 2033 & 6099 & 10164 & 1992 & 5975 & 9958 & 2111 & 6332 & 10554 & 2135 & 6404 & 10674 \\
\hline & $10 \%$ & 2130 & 6389 & 10648 & 2086 & 6259 & 10432 & 2211 & 6634 & 11056 & 2236 & 6709 & 11182 \\
\hline & $-5 \%$ & 1839 & 5518 & 9196 & 1802 & 5406 & 9010 & 1910 & 5729 & 9549 & 1931 & 5794 & 9657 \\
\hline & $-10 \%$ & 1742 & 5227 & 8712 & 1707 & 5121 & 8535 & 1809 & 5428 & 9046 & 1830 & 5490 & 9149 \\
\hline \multirow{5}{*}{ Strip Mall } & 0 & 850 & 2549 & 4248 & 761 & 2284 & 3806 & 787 & 2362 & 3937 & 805 & 2415 & 4025 \\
\hline & $5 \%$ & 892 & 2676 & 4460 & 799 & 2398 & 3996 & 827 & 2480 & 4134 & 845 & 2536 & 4227 \\
\hline & $10 \%$ & 935 & 2804 & 4673 & 837 & 2512 & 4186 & 866 & 2598 & 4330 & 886 & 2657 & 4428 \\
\hline & $-5 \%$ & 807 & 2421 & 4036 & 723 & 2169 & 3616 & 748 & 2244 & 3740 & 765 & 2294 & 3824 \\
\hline & $-10 \%$ & 765 & 2294 & 3823 & 685 & 2055 & 3425 & 709 & 2126 & 3543 & 725 & 2174 & 3623 \\
\hline \multirow{5}{*}{ Supermarket } & 0 & 2508 & 7523 & 12539 & 3182 & 9545 & 15909 & 2971 & 8912 & 14853 & 3292 & 9875 & 16459 \\
\hline & $5 \%$ & 2633 & 7899 & 13166 & 3341 & 10023 & 16705 & 3119 & 9357 & 15596 & 3456 & 10369 & 17282 \\
\hline & $10 \%$ & 2758 & 8275 & 13792 & 3500 & 10500 & 17500 & 3268 & 9803 & 16338 & 3621 & 10863 & 18105 \\
\hline & $-5 \%$ & 2382 & 7147 & 11912 & 3023 & 9068 & 15114 & 2822 & 8466 & 14110 & 3127 & 9382 & 15636 \\
\hline & $-10 \%$ & 2257 & 6771 & 11285 & 2864 & 8591 & 14318 & 2674 & 8021 & 13368 & 2963 & 8888 & 14813 \\
\hline
\end{tabular}


Table D-54: Maximum Installed Cost per Controller Unit Supporting the Retrofit from Case 4 to Case 18 to Achieve Payback Periods of 1, 3 and 5 Years as Functions of Different Utility Rates in Climate Zones 3B, 3C, and 4A

\begin{tabular}{|c|c|c|c|c|c|c|c|c|c|c|c|c|c|}
\hline \multirow{2}{*}{ Building Type } & \multirow{2}{*}{$\begin{array}{c}\text { Utility } \\
\text { Rate } \\
\text { Change } \\
\end{array}$} & \multicolumn{3}{|c|}{ 3B_Los_Angeles } & \multicolumn{3}{|c|}{ 3B_Las_Vegas } & \multicolumn{3}{|c|}{ 3C_San_Francisco } & \multicolumn{3}{|c|}{ 4A_Baltimore } \\
\hline & & 1 year & 3 years & 5 years & 1 year & 3 years & 5 years & 1 year & 3 years & 5 years & 1 year & 3 years & 5 years \\
\hline \multirow{5}{*}{ Small Office } & 0 & 257 & 772 & 1287 & 209 & 627 & 1044 & 233 & 700 & 1166 & 250 & 749 & 1248 \\
\hline & $5 \%$ & 270 & 811 & 1351 & 219 & 658 & 1097 & 245 & 735 & 1224 & 262 & 786 & 1311 \\
\hline & $10 \%$ & 283 & 849 & 1415 & 230 & 689 & 1149 & 257 & 770 & 1283 & 275 & 824 & 1373 \\
\hline & $-5 \%$ & 244 & 733 & 1222 & 198 & 595 & 992 & 222 & 665 & 1108 & 237 & 711 & 1186 \\
\hline & $-10 \%$ & 232 & 695 & 1158 & 188 & 564 & 940 & 210 & 630 & 1049 & 225 & 674 & 1123 \\
\hline \multirow{5}{*}{$\begin{array}{l}\text { Standalone } \\
\text { Retail }\end{array}$} & 0 & 1824 & 5473 & 9121 & 1964 & 5892 & 9820 & 1936 & 5807 & 9679 & 2656 & 7968 & 13280 \\
\hline & $5 \%$ & 1915 & 5746 & 9577 & 2062 & 6187 & 10311 & 2033 & 6098 & 10163 & 2789 & 8366 & 13944 \\
\hline & $10 \%$ & 2007 & 6020 & 10033 & 2161 & 6482 & 10803 & 2129 & 6388 & 10646 & 2922 & 8765 & 14608 \\
\hline & $-5 \%$ & 1733 & 5199 & 8665 & 1866 & 5598 & 9329 & 1839 & 5517 & 9195 & 2523 & 7570 & 12616 \\
\hline & $-10 \%$ & 1642 & 4926 & 8209 & 1768 & 5303 & 8838 & 1742 & 5226 & 8711 & 2390 & 7171 & 11952 \\
\hline \multirow{5}{*}{ Strip Mall } & 0 & 783 & 2348 & 3913 & 788 & 2365 & 3942 & 781 & 2344 & 3906 & 1036 & 3109 & 5182 \\
\hline & $5 \%$ & 822 & 2465 & 4109 & 828 & 2483 & 4139 & 820 & 2461 & 4101 & 1088 & 3265 & 5441 \\
\hline & $10 \%$ & 861 & 2583 & 4305 & 867 & 2602 & 4336 & 859 & 2578 & 4297 & 1140 & 3420 & 5700 \\
\hline & $-5 \%$ & 744 & 2231 & 3718 & 749 & 2247 & 3745 & 742 & 2226 & 3711 & 985 & 2954 & 4923 \\
\hline & $-10 \%$ & 704 & 2113 & 3522 & 710 & 2129 & 3548 & 703 & 2109 & 3515 & 933 & 2798 & 4664 \\
\hline \multirow{5}{*}{ Supermarket } & 0 & 3072 & 9216 & 15360 & 3290 & 9870 & 16450 & 3385 & 10156 & 16927 & 4399 & 13196 & 21994 \\
\hline & $5 \%$ & 3226 & 9677 & 16128 & 3455 & 10364 & 17273 & 3555 & 10664 & 17773 & 4619 & 13856 & 23094 \\
\hline & $10 \%$ & 3379 & 10138 & 16896 & 3619 & 10857 & 18095 & 3724 & 11172 & 18619 & 4839 & 14516 & 24193 \\
\hline & $-5 \%$ & 2918 & 8755 & 14592 & 3126 & 9377 & 15628 & 3216 & 9648 & 16080 & 4179 & 12537 & 20894 \\
\hline & $-10 \%$ & 2765 & 8295 & 13824 & 2961 & 8883 & 14805 & 3047 & 9140 & 15234 & 3959 & 11877 & 19795 \\
\hline
\end{tabular}


Table D-55: Maximum Installed Cost per Controller Unit Supporting the Retrofit from Case 4 to Case 18 to Achieve Payback Periods of 1, 3 and 5 Years as Functions of Different Utility Rates in Climate Zones 4B, 4C, 5A, and 5B

\begin{tabular}{|c|c|c|c|c|c|c|c|c|c|c|c|c|c|}
\hline \multirow{2}{*}{ Building Type } & \multirow{2}{*}{$\begin{array}{c}\text { Utility } \\
\text { Rate } \\
\text { Change } \\
\end{array}$} & \multicolumn{3}{|c|}{ 4B_Albuquerque } & \multicolumn{3}{|c|}{ 4C_Seattle } & \multicolumn{3}{|c|}{ 5A_Chicago } & \multicolumn{3}{|c|}{ 5B_Boulder } \\
\hline & & 1 year & 3 years & 5 years & 1 year & 3 years & 5 years & 1 year & 3 years & 5 years & 1 year & 3 years & 5 years \\
\hline \multirow{5}{*}{ Small Office } & 0 & 176 & 529 & 881 & 150 & 451 & 752 & 213 & 639 & 1065 & 204 & 611 & 1018 \\
\hline & $5 \%$ & 185 & 555 & 925 & 158 & 474 & 789 & 224 & 671 & 1119 & 214 & 641 & 1069 \\
\hline & $10 \%$ & 194 & 582 & 969 & 165 & 496 & 827 & 234 & 703 & 1172 & 224 & 672 & 1120 \\
\hline & $-5 \%$ & 167 & 502 & 837 & 143 & 428 & 714 & 202 & 607 & 1012 & 193 & 580 & 967 \\
\hline & $-10 \%$ & 159 & 476 & 793 & 135 & 406 & 677 & 192 & 575 & 959 & 183 & 550 & 916 \\
\hline \multirow{5}{*}{$\begin{array}{l}\text { Standalone } \\
\text { Retail }\end{array}$} & 0 & 1717 & 5151 & 8585 & 1915 & 5745 & 9576 & 2590 & 7771 & 12951 & 2102 & 6307 & 10512 \\
\hline & $5 \%$ & 1803 & 5408 & 9014 & 2011 & 6033 & 10054 & 2720 & 8159 & 13599 & 2207 & 6622 & 11037 \\
\hline & $10 \%$ & 1889 & 5666 & 9443 & 2107 & 6320 & 10533 & 2849 & 8548 & 14246 & 2313 & 6938 & 11563 \\
\hline & $-5 \%$ & 1631 & 4893 & 8155 & 1819 & 5458 & 9097 & 2461 & 7382 & 12303 & 1997 & 5992 & 9986 \\
\hline & $-10 \%$ & 1545 & 4636 & 7726 & 1724 & 5171 & 8618 & 2331 & 6994 & 11656 & 1892 & 5676 & 9461 \\
\hline \multirow{5}{*}{ Strip Mall } & 0 & 656 & 1967 & 3278 & 765 & 2296 & 3827 & 1021 & 3063 & 5105 & 813 & 2438 & 4063 \\
\hline & $5 \%$ & 688 & 2065 & 3442 & 804 & 2411 & 4019 & 1072 & 3216 & 5360 & 853 & 2559 & 4266 \\
\hline & $10 \%$ & 721 & 2164 & 3606 & 842 & 2526 & 4210 & 1123 & 3369 & 5616 & 894 & 2681 & 4469 \\
\hline & $-5 \%$ & 623 & 1869 & 3114 & 727 & 2182 & 3636 & 970 & 2910 & 4850 & 772 & 2316 & 3860 \\
\hline & $-10 \%$ & 590 & 1770 & 2950 & 689 & 2067 & 3445 & 919 & 2757 & 4595 & 731 & 2194 & 3656 \\
\hline \multirow{5}{*}{ Supermarket } & 0 & 3106 & 9318 & 15531 & 2535 & 7604 & 12673 & 3905 & 11716 & 19527 & 3542 & 10627 & 17712 \\
\hline & $5 \%$ & 3261 & 9784 & 16307 & 2661 & 7984 & 13307 & 4101 & 12302 & 20504 & 3720 & 11159 & 18598 \\
\hline & $10 \%$ & 3417 & 10250 & 17084 & 2788 & 8364 & 13941 & 4296 & 12888 & 21480 & 3897 & 11690 & 19484 \\
\hline & $-5 \%$ & 2951 & 8852 & 14754 & 2408 & 7224 & 12040 & 3710 & 11131 & 18551 & 3365 & 10096 & 16827 \\
\hline & $-10 \%$ & 2796 & 8387 & 13978 & 2281 & 6844 & 11406 & 3515 & 10545 & 17574 & 3188 & 9565 & 15941 \\
\hline
\end{tabular}


Table D-56: Maximum Installed Cost per Controller Unit Supporting the Retrofit from Case 4 to Case 18 to Achieve Payback Periods of 1, 3 and 5 Years as Functions of Different Utility Rates in Climate Zones 6A, 6B, 7 and 8

\begin{tabular}{|c|c|c|c|c|c|c|c|c|c|c|c|c|c|}
\hline \multirow{2}{*}{ Building Type } & \multirow{2}{*}{$\begin{array}{c}\text { Utility } \\
\text { Rate } \\
\text { Change } \\
\end{array}$} & \multicolumn{3}{|c|}{ 6A_Minneapolis } & \multicolumn{3}{|c|}{ 6B_Helena } & \multicolumn{3}{|c|}{ 7A_Duluth } & \multicolumn{3}{|c|}{ 8A_Fairbanks } \\
\hline & & 1 year & 3 years & 5 years & 1 year & 3 years & 5 years & 1 year & 3 years & 5 years & 1 year & 3 years & 5 years \\
\hline \multirow{5}{*}{ Small Office } & 0 & 211 & 634 & 1056 & 213 & 638 & 1064 & 220 & 660 & 1100 & 422 & 1265 & 2108 \\
\hline & $5 \%$ & 222 & 665 & 1109 & 223 & 670 & 1117 & 231 & 693 & 1155 & 443 & 1328 & 2213 \\
\hline & $10 \%$ & 232 & 697 & 1162 & 234 & 702 & 1170 & 242 & 726 & 1210 & 464 & 1391 & 2318 \\
\hline & $-5 \%$ & 201 & 602 & 1003 & 202 & 606 & 1011 & 209 & 627 & 1045 & 400 & 1201 & 2002 \\
\hline & $-10 \%$ & 190 & 570 & 950 & 191 & 574 & 957 & 198 & 594 & 990 & 379 & 1138 & 1897 \\
\hline \multirow{5}{*}{$\begin{array}{l}\text { Standalone } \\
\text { Retail }\end{array}$} & 0 & 2551 & 7653 & 12756 & 2624 & 7872 & 13120 & 2824 & 8471 & 14118 & 5346 & 16037 & 26729 \\
\hline & $5 \%$ & 2679 & 8036 & 13393 & 2755 & 8265 & 13776 & 2965 & 8895 & 14824 & 5613 & 16839 & 28065 \\
\hline & $10 \%$ & 2806 & 8419 & 14031 & 2886 & 8659 & 14432 & 3106 & 9318 & 15530 & 5880 & 17641 & 29401 \\
\hline & $-5 \%$ & 2424 & 7271 & 12118 & 2493 & 7478 & 12464 & 2682 & 8047 & 13412 & 5078 & 15235 & 25392 \\
\hline & $-10 \%$ & 2296 & 6888 & 11480 & 2362 & 7085 & 11808 & 2541 & 7624 & 12706 & 4811 & 14433 & 24056 \\
\hline \multirow{5}{*}{ Strip Mall } & 0 & 999 & 2998 & 4997 & 1034 & 3103 & 5171 & 1106 & 3318 & 5531 & 2037 & 6111 & 10185 \\
\hline & $5 \%$ & 1049 & 3148 & 5247 & 1086 & 3258 & 5430 & 1161 & 3484 & 5807 & 2139 & 6417 & 10695 \\
\hline & $10 \%$ & 1099 & 3298 & 5497 & 1138 & 3413 & 5688 & 1217 & 3650 & 6084 & 2241 & 6722 & 11204 \\
\hline & $-5 \%$ & 949 & 2848 & 4747 & 983 & 2948 & 4913 & 1051 & 3153 & 5254 & 1935 & 5806 & 9676 \\
\hline & $-10 \%$ & 899 & 2698 & 4497 & 931 & 2792 & 4654 & 996 & 2987 & 4978 & 1833 & 5500 & 9167 \\
\hline \multirow{5}{*}{ Supermarket } & 0 & 3900 & 11699 & 19498 & 3763 & 11289 & 18815 & 3942 & 11827 & 19712 & 7767 & 23302 & 38837 \\
\hline & $5 \%$ & 4095 & 12284 & 20473 & 3951 & 11854 & 19756 & 4140 & 12419 & 20698 & 8156 & 24467 & 40779 \\
\hline & $10 \%$ & 4290 & 12869 & 21448 & 4139 & 12418 & 20697 & 4337 & 13010 & 21683 & 8544 & 25632 & 42721 \\
\hline & $-5 \%$ & 3705 & 11114 & 18523 & 3575 & 10725 & 17874 & 3745 & 11236 & 18727 & 7379 & 22137 & 36895 \\
\hline & $-10 \%$ & 3510 & 10529 & 17548 & 3387 & 10160 & 16934 & 3548 & 10645 & 17741 & 6991 & 20972 & 34953 \\
\hline
\end{tabular}


Table D-57: Maximum Installed Cost per Controller Unit Supporting the Retrofit from Case 1 to Case 22 to Achieve Payback Periods of 1, 3 and 5 Years as Functions of Different Utility Rates in Climate Zones 1A, 2A, 2B, and 3A

\begin{tabular}{|c|c|c|c|c|c|c|c|c|c|c|c|c|c|}
\hline \multirow{2}{*}{$\begin{array}{l}\text { Building } \\
\text { Type }\end{array}$} & \multirow{2}{*}{$\begin{array}{c}\text { Utility } \\
\text { Rate } \\
\text { Change }\end{array}$} & \multicolumn{3}{|c|}{ Miami-1A } & \multicolumn{3}{|c|}{ Houston-2A } & \multicolumn{3}{|c|}{ Phoenix-2B } & \multicolumn{3}{|c|}{ Atlanta-3A } \\
\hline & & 1 year & 3 years & 5 years & 1 year & 3 years & 5 years & 1 year & 3 years & 5 years & 1 year & 3 years & 5 years \\
\hline \multirow{5}{*}{ Small Office } & 0 & 355 & 1065 & 1774 & 301 & 904 & 1506 & 319 & 958 & 1597 & 271 & 814 & 1357 \\
\hline & $5 \%$ & 373 & 1118 & 1863 & 316 & 949 & 1581 & 335 & 1006 & 1677 & 285 & 855 & 1425 \\
\hline & $10 \%$ & 390 & 1171 & 1952 & 331 & 994 & 1657 & 351 & 1054 & 1757 & 299 & 896 & 1493 \\
\hline & $-5 \%$ & 337 & 1011 & 1686 & 286 & 858 & 1431 & 303 & 910 & 1517 & 258 & 774 & 1290 \\
\hline & $-10 \%$ & 319 & 958 & 1597 & 271 & 813 & 1355 & 288 & 863 & 1438 & 244 & 733 & 1222 \\
\hline \multirow{5}{*}{$\begin{array}{l}\text { Stand-alone } \\
\text { Retail }\end{array}$} & 0 & 2613 & 7840 & 13066 & 2349 & 7046 & 11744 & 2490 & 7470 & 12450 & 2382 & 7147 & 11911 \\
\hline & $5 \%$ & 2744 & 8232 & 13720 & 2466 & 7399 & 12331 & 2614 & 7843 & 13072 & 2501 & 7504 & 12506 \\
\hline & $10 \%$ & 2875 & 8624 & 14373 & 2584 & 7751 & 12918 & 2739 & 8217 & 13695 & 2620 & 7861 & 13102 \\
\hline & $-5 \%$ & 2483 & 7448 & 12413 & 2231 & 6694 & 11157 & 2365 & 7096 & 11827 & 2263 & 6789 & 11315 \\
\hline & $-10 \%$ & 2352 & 7056 & 11760 & 2114 & 6342 & 10569 & 2241 & 6723 & 11205 & 2144 & 6432 & 10720 \\
\hline \multirow{5}{*}{ Strip Mall } & 0 & 1181 & 3542 & 5904 & 953 & 2859 & 4765 & 990 & 2969 & 4948 & 957 & 2871 & 4785 \\
\hline & $5 \%$ & 1240 & 3719 & 6199 & 1001 & 3002 & 5003 & 1039 & 3117 & 5195 & 1005 & 3015 & 5024 \\
\hline & $10 \%$ & 1299 & 3896 & 6494 & 1048 & 3145 & 5241 & 1089 & 3266 & 5443 & 1053 & 3158 & 5264 \\
\hline & $-5 \%$ & 1122 & 3365 & 5608 & 905 & 2716 & 4527 & 940 & 2820 & 4700 & 909 & 2728 & 4546 \\
\hline & $-10 \%$ & 1063 & 3188 & 5313 & 858 & 2573 & 4288 & 891 & 2672 & 4453 & 861 & 2584 & 4307 \\
\hline \multirow{5}{*}{ Supermarket } & 0 & 2983 & 8949 & 14914 & 3582 & 10747 & 17911 & 3379 & 10137 & 16896 & 3657 & 10972 & 18287 \\
\hline & $5 \%$ & 3132 & 9396 & 15660 & 3761 & 11284 & 18807 & 3548 & 10644 & 17740 & 3840 & 11521 & 19202 \\
\hline & $10 \%$ & 3281 & 9843 & 16406 & 3941 & 11822 & 19703 & 3717 & 11151 & 18585 & 4023 & 12070 & 20116 \\
\hline & $-5 \%$ & 2834 & 8501 & 14169 & 3403 & 10209 & 17016 & 3210 & 9631 & 16051 & 3475 & 10424 & 17373 \\
\hline & $-10 \%$ & 2685 & 8054 & 13423 & 3224 & 9672 & 16120 & 3041 & 9124 & 15206 & 3292 & 9875 & 16459 \\
\hline
\end{tabular}


Table D-58: Maximum Installed Cost per Controller Unit Supporting the Retrofit from Case 1 to Case 22 to Achieve Payback Periods of 1, 3 and 5 Years as Functions of Different Utility Rates in Climate Zones 3B, 3C and 4A

\begin{tabular}{|c|c|c|c|c|c|c|c|c|c|c|c|c|c|}
\hline \multirow{2}{*}{$\begin{array}{l}\text { Building } \\
\text { Type }\end{array}$} & \multirow{2}{*}{$\begin{array}{c}\text { Utility } \\
\text { Rate } \\
\text { Change }\end{array}$} & \multicolumn{3}{|c|}{ Los Angeles-3B } & \multicolumn{3}{|c|}{ Las Vegas-3B } & \multicolumn{3}{|c|}{ San Francisco-3C } & \multicolumn{3}{|c|}{ Baltimore-4A } \\
\hline & & 1 year & 3 years & 5 years & 1 year & 3 years & 5 years & 1 year & 3 years & 5 years & 1 year & 3 years & 5 years \\
\hline \multirow{5}{*}{$\begin{array}{l}\text { Small } \\
\text { Office }\end{array}$} & 0 & 441 & 1322 & 2203 & 286 & 857 & 1428 & 315 & 944 & 1573 & 317 & 950 & 1583 \\
\hline & $5 \%$ & 463 & 1388 & 2313 & 300 & 900 & 1500 & 330 & 991 & 1652 & 332 & 997 & 1662 \\
\hline & $10 \%$ & 485 & 1454 & 2424 & 314 & 943 & 1571 & 346 & 1038 & 1731 & 348 & 1045 & 1741 \\
\hline & $-5 \%$ & 419 & 1256 & 2093 & 271 & 814 & 1357 & 299 & 897 & 1495 & 301 & 902 & 1504 \\
\hline & $-10 \%$ & 397 & 1190 & 1983 & 257 & 771 & 1286 & 283 & 850 & 1416 & 285 & 855 & 1425 \\
\hline \multirow{5}{*}{$\begin{array}{c}\text { Stand-alone } \\
\text { Retail }\end{array}$} & 0 & 2508 & 7523 & 12539 & 2260 & 6781 & 11302 & 2143 & 6428 & 10713 & 2959 & 8876 & 14793 \\
\hline & $5 \%$ & 2633 & 7899 & 13166 & 2374 & 7121 & 11868 & 2250 & 6749 & 11249 & 3107 & 9320 & 15533 \\
\hline & $10 \%$ & 2759 & 8276 & 13793 & 2487 & 7460 & 12433 & 2357 & 7071 & 11785 & 3254 & 9763 & 16272 \\
\hline & $-5 \%$ & 2382 & 7147 & 11912 & 2147 & 6442 & 10737 & 2036 & 6107 & 10178 & 2811 & 8432 & 14053 \\
\hline & $-10 \%$ & 2257 & 6771 & 11285 & 2034 & 6103 & 10172 & 1928 & 5785 & 9642 & 2663 & 7988 & 13314 \\
\hline \multirow{5}{*}{ Strip Mall } & 0 & 1130 & 3389 & 5648 & 927 & 2782 & 4637 & 902 & 2705 & 4509 & 1168 & 3503 & 5838 \\
\hline & $5 \%$ & 1186 & 3558 & 5931 & 974 & 2921 & 4868 & 947 & 2841 & 4734 & 1226 & 3678 & 6130 \\
\hline & $10 \%$ & 1243 & 3728 & 6213 & 1020 & 3060 & 5100 & 992 & 2976 & 4960 & 1284 & 3853 & 6422 \\
\hline & $-5 \%$ & 1073 & 3219 & 5366 & 881 & 2643 & 4405 & 857 & 2570 & 4283 & 1109 & 3328 & 5546 \\
\hline & $-10 \%$ & 1017 & 3050 & 5083 & 835 & 2504 & 4173 & 812 & 2435 & 4058 & 1051 & 3153 & 5255 \\
\hline \multirow{5}{*}{ Supermarket } & 0 & 3583 & 10749 & 17915 & 3647 & 10940 & 18233 & 3631 & 10894 & 18157 & 4738 & 14213 & 23688 \\
\hline & $5 \%$ & 3762 & 11286 & 18811 & 3829 & 11487 & 19144 & 3813 & 11439 & 19065 & 4974 & 14923 & 24872 \\
\hline & $10 \%$ & 3941 & 11824 & 19706 & 4011 & 12034 & 20056 & 3995 & 11984 & 19973 & 5211 & 15634 & 26057 \\
\hline & $-5 \%$ & 3404 & 10211 & 17019 & 3464 & 10393 & 17321 & 3450 & 10350 & 17249 & 4501 & 13502 & 22504 \\
\hline & $-10 \%$ & 3225 & 9674 & 16123 & 3282 & 9846 & 16410 & 3268 & 9805 & 16341 & 4264 & 12791 & 21319 \\
\hline
\end{tabular}


Table D-59: Maximum Installed Cost per Controller Unit Supporting the Retrofit from Case 1 to Case 22 to Achieve Payback Periods of 1, 3 and 5 Years as Functions of Different Utility Rates in Climate Zones 4B, 4C, 5A, and 5B

\begin{tabular}{|c|c|c|c|c|c|c|c|c|c|c|c|c|c|}
\hline \multirow{2}{*}{$\begin{array}{l}\text { Building } \\
\text { Type }\end{array}$} & \multirow{2}{*}{$\begin{array}{c}\text { Utility } \\
\text { Rate } \\
\text { Change }\end{array}$} & \multicolumn{3}{|c|}{ Albuquerque-4B } & \multicolumn{3}{|c|}{ Seattle-4C } & \multicolumn{3}{|c|}{ Chicago-5A } & \multicolumn{3}{|c|}{ Boulder-5B } \\
\hline & & 1 year & 3 years & 5 years & 1 year & 3 years & 5 years & 1 year & 3 years & 5 years & 1 year & 3 years & 5 years \\
\hline \multirow{5}{*}{ Small Office } & 0 & 236 & 709 & 1181 & 185 & 554 & 923 & 261 & 784 & 1307 & 255 & 766 & 1276 \\
\hline & $5 \%$ & 248 & 744 & 1240 & 194 & 581 & 969 & 275 & 824 & 1373 & 268 & 804 & 1340 \\
\hline & $10 \%$ & 260 & 780 & 1299 & 203 & 609 & 1015 & 288 & 863 & 1438 & 281 & 842 & 1404 \\
\hline & $-5 \%$ & 224 & 673 & 1122 & 175 & 526 & 877 & 248 & 745 & 1242 & 242 & 727 & 1212 \\
\hline & $-10 \%$ & 213 & 638 & 1063 & 166 & 498 & 831 & 235 & 706 & 1177 & 230 & 689 & 1149 \\
\hline \multirow{5}{*}{$\begin{array}{c}\text { Stand-alone } \\
\text { Retail }\end{array}$} & 0 & 1966 & 5898 & 9830 & 2004 & 6011 & 10019 & 2823 & 8469 & 14114 & 2308 & 6925 & 11541 \\
\hline & $5 \%$ & 2064 & 6193 & 10322 & 2104 & 6312 & 10520 & 2964 & 8892 & 14820 & 2424 & 7271 & 12118 \\
\hline & $10 \%$ & 2163 & 6488 & 10813 & 2204 & 6612 & 11021 & 3105 & 9316 & 15526 & 2539 & 7617 & 12695 \\
\hline & $-5 \%$ & 1868 & 5603 & 9339 & 1904 & 5711 & 9518 & 2682 & 8045 & 13409 & 2193 & 6578 & 10964 \\
\hline & $-10 \%$ & 1769 & 5308 & 8847 & 1803 & 5410 & 9017 & 2541 & 7622 & 12703 & 2077 & 6232 & 10387 \\
\hline \multirow{5}{*}{ Strip Mall } & 0 & 763 & 2290 & 3817 & 813 & 2439 & 4065 & 1123 & 3369 & 5614 & 909 & 2728 & 4547 \\
\hline & $5 \%$ & 801 & 2404 & 4007 & 854 & 2561 & 4268 & 1179 & 3537 & 5895 & 955 & 2865 & 4775 \\
\hline & $10 \%$ & 840 & 2519 & 4198 & 894 & 2683 & 4472 & 1235 & 3705 & 6176 & 1000 & 3001 & 5002 \\
\hline & $-5 \%$ & 725 & 2175 & 3626 & 772 & 2317 & 3862 & 1067 & 3200 & 5334 & 864 & 2592 & 4320 \\
\hline & $-10 \%$ & 687 & 2061 & 3435 & 732 & 2195 & 3659 & 1011 & 3032 & 5053 & 819 & 2456 & 4093 \\
\hline \multirow{5}{*}{ Supermarket } & 0 & 3394 & 10183 & 16972 & 2681 & 8044 & 13406 & 4187 & 12560 & 20933 & 3808 & 11423 & 19038 \\
\hline & $5 \%$ & 3564 & 10692 & 17821 & 2815 & 8446 & 14076 & 4396 & 13188 & 21980 & 3998 & 11994 & 19990 \\
\hline & $10 \%$ & 3734 & 11202 & 18669 & 2949 & 8848 & 14747 & 4605 & 13816 & 23027 & 4188 & 12565 & 20942 \\
\hline & $-5 \%$ & 3225 & 9674 & 16123 & 2547 & 7642 & 12736 & 3977 & 11932 & 19887 & 3617 & 10852 & 18086 \\
\hline & $-10 \%$ & 3055 & 9165 & 15275 & 2413 & 7239 & 12066 & 3768 & 11304 & 18840 & 3427 & 10281 & 17134 \\
\hline
\end{tabular}


Table D-60: Maximum Installed Cost per Controller Unit Supporting the Retrofit from Case 1 to Case 22 to Achieve Payback Periods of 1, 3 and 5 Years as Functions of Different Utility Rates in Climate Zones 6A, 6B, 7 and 8

\begin{tabular}{|c|c|c|c|c|c|c|c|c|c|c|c|c|c|}
\hline \multirow{2}{*}{$\begin{array}{l}\text { Building } \\
\text { Type }\end{array}$} & \multirow{2}{*}{$\begin{array}{c}\text { Utility } \\
\text { Rate } \\
\text { Change }\end{array}$} & \multicolumn{3}{|c|}{ Minneapolis-6A } & \multicolumn{3}{|c|}{ Helena-6B } & \multicolumn{3}{|c|}{ Duluth-7 } & \multicolumn{3}{|c|}{ Fairbanks-8 } \\
\hline & & 1 year & 3 years & 5 years & 1 year & 3 years & 5 years & 1 year & 3 years & 5 years & 1 year & 3 years & 5 years \\
\hline \multirow{5}{*}{ Small Office } & 0 & 258 & 773 & 1289 & 254 & 763 & 1271 & 253 & 759 & 1266 & 479 & 1436 & 2393 \\
\hline & $5 \%$ & 271 & 812 & 1353 & 267 & 801 & 1335 & 266 & 797 & 1329 & 503 & 1508 & 2513 \\
\hline & $10 \%$ & 284 & 851 & 1418 & 280 & 839 & 1398 & 278 & 835 & 1392 & 526 & 1579 & 2632 \\
\hline & $-5 \%$ & 245 & 735 & 1224 & 242 & 725 & 1208 & 240 & 721 & 1202 & 455 & 1364 & 2273 \\
\hline & $-10 \%$ & 232 & 696 & 1160 & 229 & 686 & 1144 & 228 & 683 & 1139 & 431 & 1292 & 2154 \\
\hline \multirow{5}{*}{$\begin{array}{c}\text { Stand-alone } \\
\text { Retail }\end{array}$} & 0 & 2773 & 8320 & 13866 & 2801 & 8404 & 14007 & 2955 & 8864 & 14773 & 5945 & 17834 & 29724 \\
\hline & $5 \%$ & 2912 & 8736 & 14559 & 2941 & 8824 & 14707 & 3102 & 9307 & 15512 & 6242 & 18726 & 31210 \\
\hline & $10 \%$ & 3051 & 9152 & 15253 & 3082 & 9245 & 15408 & 3250 & 9750 & 16251 & 6539 & 19618 & 32696 \\
\hline & $-5 \%$ & 2635 & 7904 & 13173 & 2661 & 7984 & 13307 & 2807 & 8421 & 14035 & 5647 & 16942 & 28237 \\
\hline & $-10 \%$ & 2496 & 7488 & 12479 & 2521 & 7564 & 12606 & 2659 & 7978 & 13296 & 5350 & 16051 & 26751 \\
\hline \multirow{5}{*}{ Strip Mall } & 0 & 1106 & 3319 & 5532 & 1130 & 3391 & 5652 & 1188 & 3564 & 5940 & 2341 & 7024 & 11707 \\
\hline & $5 \%$ & 1162 & 3485 & 5809 & 1187 & 3561 & 5935 & 1247 & 3742 & 6237 & 2458 & 7375 & 12292 \\
\hline & $10 \%$ & 1217 & 3651 & 6085 & 1243 & 3730 & 6217 & 1307 & 3921 & 6534 & 2576 & 7727 & 12878 \\
\hline & $-5 \%$ & 1051 & 3153 & 5255 & 1074 & 3222 & 5369 & 1129 & 3386 & 5643 & 2224 & 6673 & 11122 \\
\hline & $-10 \%$ & 996 & 2987 & 4979 & 1017 & 3052 & 5087 & 1069 & 3208 & 5346 & 2107 & 6322 & 10536 \\
\hline \multirow{5}{*}{ Supermarket } & 0 & 4217 & 12650 & 21083 & 4103 & 12308 & 20513 & 4244 & 12732 & 21221 & 8703 & 26109 & 43514 \\
\hline & $5 \%$ & 4427 & 13282 & 22137 & 4308 & 12923 & 21539 & 4456 & 13369 & 22282 & 9138 & 27414 & 45690 \\
\hline & $10 \%$ & 4638 & 13915 & 23191 & 4513 & 13539 & 22565 & 4669 & 14006 & 23343 & 9573 & 28719 & 47866 \\
\hline & $-5 \%$ & 4006 & 12017 & 20029 & 3898 & 11693 & 19488 & 4032 & 12096 & 20160 & 8268 & 24803 & 41338 \\
\hline & $-10 \%$ & 3795 & 11385 & 18974 & 3692 & 11077 & 18462 & 3820 & 11459 & 19099 & 7833 & 23498 & 39163 \\
\hline
\end{tabular}




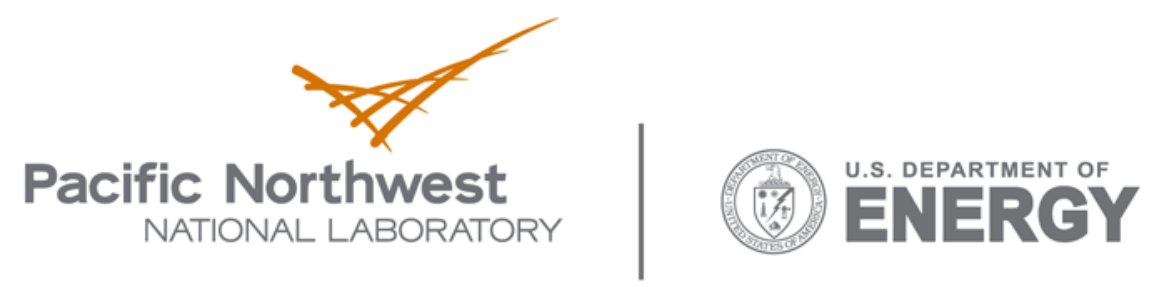

902 Battelle Boulevard

P.O. Box 999

Richland, WA 99352

1-888-375-PNNL (7665)

www.pnl.gov 